SUSANNE WINTER

\title{
Von illusionärer Wirklichkeit und wahrer Illusion
}

\author{
Zu Carlo Gozzis Fiabe teatrali
}

$$
\overline{\underline{\underline{\underline{b}}}}
$$

ANALECTA ROMANICA HEFT 73

VITTORIO KLOSTERMANN - FRANKFURT AM MAIN 


\section{ANALECTA ROMANICA}

BEGRÜNDET VON FRITZ SCHALK

FORTGEFÜHRT VON WIDO HEMPEL, FRANK-RUTGER HAUSMANN UND HARRO STAMMERJOHANN HERAUSGEGEBEN

VON MECHTHILD ALBERT

UND FRANZ LEBSANFT

unter Mitwirkung von

Gaetano Berruto (Torino), Steven Dworkin (Ann Arbor, Michigan),

Peter Fröhlicher (Zürich), Martin-Dietrich Gleßgen (Zürich), Thomas Klinkert (Mannbeim), Georges Kleiber (Strasbourg), Peter Kuon (Salzburg), Patricia Oster-Stierle (Saarbrücken), Heinz Werner (Bochum)

HEFT 73

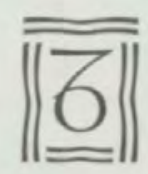

VITTORIO KLOSTERMANN · FRANKFURT AM MAIN 
SUSANNE WINTER

\title{
Von illusionärer Wirklichkeit und wahrer Illusion
}

\author{
Zu Carlo Gozzis Fiabe teatrali
}

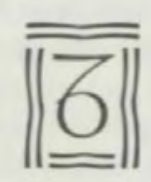

VITTORIO KLOSTERMANN · FRANKFURT AM MAIN 


\section{Gedruckt mit Unterstützung des Fonds zur Förderung der wissenschaftlichen Forschung.}

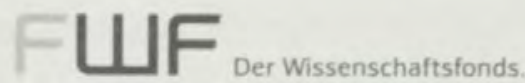

Bibliografische Information der Deutschen Nationalbibliothek

Die Deutsche Nationalbibliothek verzeichnet diese Publikation in der Deutschen Nationalbibliografie; detaillierte bibliografische Daten sind im Internet über bttp://dnb.d-nb.de abrufbar.

(1) Vittorio Klostermann GmbH - Frankfurt am Main 2007

Alle Rechte vorbehalten, insbesondere die des Nachdrucks und der Übersetzung.

Ohne Genehmigung des Verlages ist es nicht gestattet, dieses Werk oder Teile in einem photomechanischen oder sonstigen Reproduktionsverfahren oder unter

Verwendung elektronischer Systeme zu verarbeiten, zu vervielfältigen und zu verbreiten.

Gedruckt auf alterungsbeständigem Papier $\otimes 1509706$

Satz: post scriptum, Emmendingen/Hinterzarten

Druck: Hubert \& Co., Göttingen

Printed in Germany

ISSN 0569-986X

ISBN 978-3-465-03509-1 
INHALT

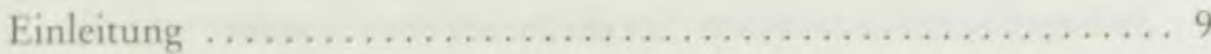

1 KONTROVERSEN UND KONTRASTE ........... 17

1.1 Ein polemisches Debüt $\ldots \ldots \ldots \ldots \ldots \ldots \ldots \ldots \ldots \ldots$

Der etwas andere Almanach - Gesellschafts- und Literatursatire -

Goldoni und Chiari als Duellanten

1.2 Theater-Streit-Kultur ...................... 30

Konfrontation zwischen Goldoni und Chiari-Griselini im Kreuzfeuer der Kritik - Konkurrenz auf der Bühne, Polemik in Texten

1.3 Pamphletistische Literaturbetriebsamkeit . . . . . . . . . . . . 39

Gozzi und Goldoni in polemischem Dialog - Chiari als Konkurrent

Goldonis und Kontrahent Gozzis - Gozzis Polemik gegen Bettinelli-

Goldoni-Satire im Kurzepos

1.4 Das komische Theater vor dem Richterstuhl ... . . . . . . . . . 54

Die Accademia Granellesca - Allegorischer Angriff auf Goldonis

Theater - Gründe und Grundzüge der Polemik Gozzis - Ein

Kompendium der Kontroverse

2 DIE FIABE TEATRALI - KONSTITUENTEN

UND STRUKTUREN $\ldots \ldots \ldots \ldots \ldots \ldots \ldots \ldots \ldots \ldots \ldots$

2.1 L'amore delle tre melarance - Scherz, Satire, Ironie und tiefere

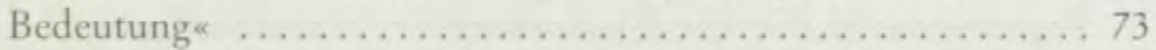

Die Märchen-Komponente - Die Commedia dell'arte-Komponente -

Die satirisch-parodistische Komponente-Dramaturgisches

Kräftespiel - Das Publikum - Theater-Spiel

2.2 Kontexte, Paratexte ............................. 99

Le spose riacquistate und Gedichte - Neue Allianzen -

La Marfisa bizzarra - Satire-Varianten

2.3 Die Fiaba teatrale - Konstitution einer neuen dramatischen

Gattung ............................. 116

Die dramaturgische Modellierung von Märchen und Masken als

Kontrast - Märchenhandlung und Märchenfiguren - Maskenfiguren

- Kontraststrukturen 
2.4 Märchen als Konstituente der Fiabe teatrali

Dramatisierung des Märchens - Inhaltliche und strukturelle

Kongruenzen zwischen narrativer und dramatischer Form -

Theatralisierung der Märchenfiguren

2.5 Commedia dell'arte als Konstituente der Fiabe teatrali . . . . . 143

Zu Begriff und Geschichte der Commedia dell'arte - Aspekte

der Improvisation - Charakteristika und Funktion der Masken -

Doppelte Rollenhaftigkeit - Venedig-Bezug der Masken -

Ironie, Satire, Parodic

2.6 Die Verflechtung der Kontraste . . . . . . . . . . . . . . 168

Maskencharakteristika im Märchenambiente - Märchenillusion, theatrale und nicht-theatrale Wirklichkeit-Masken- und Märchen-

figuren in der theatralen Wirklichkeit - Verkleidung, Verstellung,

Verwandlung - Gegenräume - Vom Märchentext

zum Theatertext

2.7 Masken und Märchen, Lachen und Weinen .............. . 194

Strukturelle Parallelen der Konstituenten Märchen und

Masken - Zum Verhältnis von Ernst und Komik -

Wirkungsintention Lachen und Weinen

3 DIE FIABE TEATRALI IM ITALIENISCHEN

THEATERKONTEXT $\ldots \ldots \ldots \ldots \ldots \ldots \ldots \ldots \ldots \ldots .211$

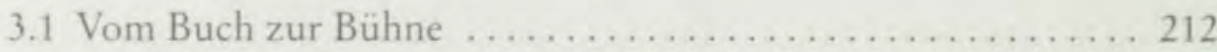

Literarische Reformversuche in der ersten Hälfte des

18. Jahrhunderts - Problematische Commedia dell'arte

Exkurs: Die venezianische Theaterszene ............. 224

3.2 Von alten und neuen Theaterformen auf der Bühne ........ 231

Wegweiser zu einer neuen guten Komödie. Goldonis *Prefazione* -

Wegweisendes Metatheater: Il teatro comico - Alternative Wege.

Gozzis Plädoyer für die Commedia dell'arte

3.3 Die Problematik der Nachahmung ............... 250

Nachahmung und Kopie - Nachahmung und Transformation -

Nachahmung und moralischer Anspruch

3.4 Von der Wahrheit der Illusion in den Fiabe teatrali ... . . . . . 268

Distanz zur Wirklichkeit - Bühnen-Capriccio - Kraft der Einbildung

- Theatrale Wirklichkeit und Imagination

3.5 Indirektheit und Allegorie $\ldots \ldots \ldots \ldots \ldots \ldots \ldots \ldots \ldots \ldots$ 
4.1 Identität und Metamorphose, Wahrheit und Täuschung . . . . 290 Verwandlung als Identitätsverlust - Verwandlung und Verstellung als Täuschung - Verstellung zur Wahrheitsfindung - Identitätswechsel und Rollenspiel

4.2 Liebe als Passion mit Variationen .................. 307 Exzessive und vernünftige Liebe - Varianten der Liebe

4.3 Die Macht des Schicksals ..................... 316 Fremdbestimmung und Schicksalsabhängigkeit - Aspekte des Übernatürlichen

4.4 Ein philosophisches Märchen ... . . . . . . . . . . 327 Ein philosophisches Prinzip und seine Erprobung - Erstarrung und Verwandlung - Konfrontation mit dem Wunderbaren

Literaturverzeichnis . . . . . . . . . . . . . . . . . . 341

Verzeichnis der Werke Carlo Goldonis ................ 355

Verzeichnis der Werke Carlo Gozzis . . . . . . . . . . . 356

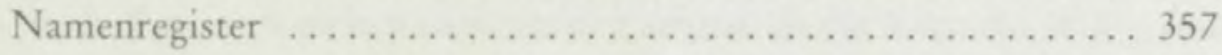





\section{EINLEITUNG}

Fischer. Ich muß wenigstens gestehn, daß ich nie an Hexen oder Gespenster habe glauben können, viel weniger an den gestiefelten Kater.

Schlosser. Es ist das Zeitalter für diese Phantome nicht mehr.

Ludwig Tieck, Der gestiefelte Kater, Prolog

In Tiecks Kindermärchen über das Theater hat das Publikum im Parterre die Zeichen der Zeit offensichtlich verstanden. Hexen und Gespenster, das Ubernatürliche, Geister und Dämonen fielen im Zeitalter der Aufklärung als Ausgeburten menschlicher Phantasie unter das Verdikt der Vernunft und waren auch auf der Bühne nicht mehr gelitten. Als Bodenständig-Vernünftige sind Fischer und Schlosser müber solchen Aberglauben weg*, denn ^die Aufklärung hat ihre gehörigen Früchte getragen*, weshalb sie sich nicht wenig erstaunt zeigen, als der Kater die Bühne doch betritt und entgegen jeder >vernünftigen Illusion* mit Gottlieb spricht. Solche *Unwahrscheinlichkeiten * und *verfluchte Unnatürlichkeiten* widersprechen dem "guten Geschmack und schicken sich nicht für ein Theater, das die w wirkliche Welt ${ }^{1}$ vorstellen soll. Was das ironisch gezeichnete Publikum in Tiecks Gestiefeltem Kater (1797) Ende des 18. Jahrhunderts als aufgeklärten Erwartungshorizont an das Theater heranträgt, setzte Goldoni fast ein halbes Jahrhundert zuvor als Reformprojekt ebenfalls in metatheatralischer Gestalt in Szene. In Il teatro comico (1750) werden die Tradition der Commedia dell'arte verabschiedet, die neue Charakterkomödie mit ihrer Nähe zur Wirklichkeit propagiert und die Wechselwirkungen des guten Geschmacks und der Tugendhaftigkeit bei Publikum, Schauspielern und in den Theaterstücken betont. Damit konkretisieren sich die zu Anfang des Jahrhunderts einsetzenden theoretischen wie vereinzelt auch praktischen Bemühungen, das italienische Theater nach dem vielbeschworenen Niedergang im Seicento zu erneuern, in einem Reformvorhaben, das ganz auf die Bühnenpraxis ausgerichtet

Ludwig Tieck, Der gestiefelte Kater. Ein Kindermärchen in drei Akten mit Zwischenspielen, einem Prologe und Epiloge, Stuttgart, Reclam 1984. Die Zitate sind dem Prolog, dem ersten Akt und dem Anfang des zweiten Aktes entnommen. 
ist und in bisher nicht gekanntem Umfang die pragmatische Dimension des Theaters einbezieht. In der Zielsetzung Goldonis, die sgute Komödie $\alpha^{2}$ im Repertoire des Sprechtheaters durchzusetzen und langfristig zu etablieren, laufen zwei Impulse zusammen, von denen der eine das europaweit wirkende Denken der Aufklärung, der andere national italienischer Natur ist und die Ablösung eines Theatersystems und einer schauspielerischen Darstellungsweise betrifft. Die Erziehung zum guten Geschmack, die Nähe des Dargestellten zur Erfahrungswelt des Publikums, eine größtmögliche Wirklichkeitstreue und Wahrheit des Geschehens und der Charaktere und nicht zuletzt der Anspruch auf moralische Wirksamkeit sind Elemente einer Theatertheorie, wie sie weit über Italien hinaus für die Aufklärung kennzeichnend ist. Dagegen resultieren die Bemühungen um die Ablösung der improvisierten Komödien durch ausformulierte Stücke, die Abschaffung der Maskenrollen und der schauspielerischen Tradition der Commedia dell'arte aus dem Streben nach Überwindung einer spezifisch italienischen Konstellation, nämlich der Diskrepanz zwischen dem erfolgreichen, aber im literarisch-kulturellen Wertekanon nicht verankerten professionellen, öffentlich-kommerziellen Theater der Commedia dell'arte-Truppen und der literarisch anerkannten, aber aufführungspraktisch vernachlässigbaren sogenannten gelehrten Komödie. In Goldonis Charakterkomödien sollten die Publikumswirksamkeit der Commedia dell'arte und die Literarizität der »commedia crudita* eine Verbindung eingehen, die der Komödie wieder zu Ansehen verhilft.

In dieser Situation des Umbruchs, die maßgeblich von Goldoni geprägt ist, erwächst dem Reformprojekt Ende der fünfziger Jahre Widerstand in Form satirisch-polemischer Texte aus der Feder Carlo Gozzis und ein regelrechter Gegenentwurf in Gestalt der Fiabe teatrali. Damit wird Venedig, die Theaterstadt par excellence, zum Kristallisationspunkt zweier völlig unterschiedlicher Konzeptionen von Theater, die weit mehr als lokale und momentane Bedeutung haben, indem sie modellbildend wirken und sich als untergründige Linien durch die folgenden Jahrhunderte ziehen. Gozzis Kritik entzündet sich hauptsächlich an der Vertreibung der Masken, der detaillierten Nachahmung der Wirklichkeit sowie der postulierten Nützlichkeit des Theaters, und er betont im Gegenzug die Theatralität der Commedia dell'arte-Tradition, die Fiktionalität des Theaters und seine unterhaltende Funktion. Mit L'amore delle tre melarance, seinem ersten Theaterstück, trägt Gozzi die Kontroverse $176 \mathrm{r}$ auf die Bühne; innerhalb von fünf Jahren folgen weitere neun Fiabe teatrali, in denen mit

2. -La buona commedia*; Goldoni, I, 716. Zur Zirierweise siehe Kap. 1, Anm. 9. 
einer Ausnahme, L'augellino belverde, keine explizite Polemik mehr betrieben wird. Als dezidierter Gegenentwurf zu Goldonis Komödien und zum aufklärerischen Drama beruhen sie auf den Grundkonstituenten des Märchens und der Masken der Commedia dell'arte, sind voller *Unwahrscheinlichkeiten * und *verfluchter Unnatürlichkeiten « und konterkarieren alle Tendenzen zum Wahrscheinlichen, Natürlichen und Vernünftigen. Im Unterschied zu Goldonis beharrlich verfolgtem Reformprojekt - als solches erscheint es zumindest in Vorworten und Memoiren -, erwecken die Fiabe teatrali den Eindruck sporadischer, einem bizarren Geist entsprungener vergnüglicher Experimente - eine Sicht, die in Gozzis polemischen Texten und seinen Memoiren scheinbar ihre Bestätigung findet. Unter diesem Blickwinkel sind die Fiabe teatrali kaum mehr als eine lästige Provokation auf dem Weg zur Etablierung einer nationalen italienischen Komödic und ein vergeblicher Versuch, den unaufhaltsamen Fortschritt aufklärerischen Denkens im allgemeinen wie hinsichtlich des Theaters zu bremsen. ${ }^{3}$ Diese Ansicht ist vor allem dort verwurzelt, wo Goldoni als eine Art Nationalheld erscheint, dem es nicht nur gelungen ist, die italienische Komödie auf das Niveau der französischen zu führen beziehungsweise diese zu übertreffen, sondern darüber hinaus mit seinem Komödienschaffen die nationale Einigung zu befördern. Neben einem Autor solcher Statur kann kaum ein anderer bestehen, und folgerichtig wird Gozzi zum einen mit Attributen wie »aristokratisch «, sreaktionär $\propto$, -reizbar* oder "ungebildet * versehen, die ihn von vornherein sowohl als Autor im Jahrhundert der Aufklärung als auch persönlich diskreditieren, zum anderen wird die rege Rezeption seiner Fiabe teatrali vor allem in der deutschen Romantik bedenkenlos zum Mißverständnis erklärt. ${ }^{4}$

1. Ein besonders drastisches Beispiel aus neuerer Zeit findet sich bei Wolfgang Theile in nBella cosa è il regnar sopra i cervellic, Zu Carlo Gozzis Theaterstreit mit Goldoni=, in: Romanusche Forscbungen 102, 1990, S. 274-286, hier S. 284 (jetzt in: W. Theile, Carlo Goldoni. Gesammelte Aufsätze 1972-2002, Hg. Irmgard Scharold, Essen, Die Blaue Eule 2002, S. 149-162, hier S. 160), der Gozzi als =Demagogen* bezeichnet, sder die Automatik des Märchens und eines fabulōsen Rechrssystems sowie die leicht aufzuruhrenden Instinkte der Menschen zur antiaufklärerischen Propaganda mißbrauchte*.

- Für die beiden erstgenannten Attribute sind die Belege Legion, für die beiden letzteren seien beispielhaft Enrico Mattioda angefuhrt, der in Il dilettante sper mestiere*, Francesco Albergati Capacelli commediografo, Bologna, Mulino 1993, S. 61, uber Gozzis Verhaltnis zu Albergati schreibt, =Il facilmente irritabile Carlo Gozzi s'infuria per questo cambiamento d'opinione e cerca di infangare l'immagine di Albergati*, sowie Paolo Bosisio, der im Anschluß an Giuseppe Ortolani in Carlo Gozzi e Goldoni. Una polemica letteraria con versi inediti e rari, Firenze, Olschki 1979, S. 78, feststellt: =Mancò infatti a Carlo una completa istruzione e persino la conoscenza del latino: la famiglia, infatti non aveva i mezzi per mantenerlo in collegio ed egli fu affidato a due sacerdoti genovesi che ben poco fecero per dirozzarlo. * Bereits bei Virgilio Brocehi, $=$ La polemica 
Ohne Goldonis Verdienste um die italienische Komödie schmälern zu wollen, bedarf es sicher eines weniger vorurteilsbelasteten Blickes auf Gozzi wie auf Goldoni, um zu einer ausgeglichenen Beurteilung ihres Werkes zu gelangen. Allerdings sind die meisten kritischen Texte Gozzis zum Theater - nimmt man sie wörtlich - dazu angetan, die Etikettierungen des notorischen Antigoldonianers und Antiaufklärers eher zu bestätigen als zu widerlegen. Um der unbefriedigenden Alternative zu entgehen, diese Texte zu ignorieren oder den gängigen Gemeinplätzen von Gozzi als Neider Goldonis und unverbesserlichem Reaktionär zu folgen, ist ein genauerer Blick auf ihren Kontext wie auf ihre Eigenart vonnöten. Dabei wird erkennbar, daß die polemisch geführte Kontroverse keineswegs eine singuläre, dem bizarren Temperament Gozzis geschuldete ist, sondern in einem Kontext pamphletärer Dispute in einer kulturell interessierten Öfentlichkeit steht. Zudem ist festzuhalten, daß in Italien eine argumentative theoretische Diskussion, die der französischen vergleichbar wäre, nicht stattfindet und die Auseinandersetzung mit den literarisch-kulturellen Tendenzen der Zeit sowie mit einer trivialisierten aufklärerischen Ideologie meist schlaglichtartig und schlagwortartig erfolgt. In zäher Beharrlichkeit hält denn auch Gozzi seine Positionen über vierzig Jahre hinweg von den frühen polemischen Texten bis zur zweiten Werkausgabe (I $80 \mathrm{I}-1805)$ aufrecht oder modifiziert sie nur geringfügig, und man täte ihm gewiß keinen Gefallen, seine konservative, bewahrende Haltung zu leugnen und ihn für die aufklärerische Orthodoxie zu vereinnahmen.

Bemerkenswert sind jedoch einige Charakteristika der Texte, die bislang kaum Beachtung fanden. Zum einen stehen sie in einer langen, literarisch legitimierten satirisch-polemischen Tradition, zum anderen relativiert eine latente Ironie und Selbstironie die Schärfe der Angriffe, und nicht zuletzt macht sich Gozzi eine aufklärerische Strategie zueigen, um gegen die Aufklärung anzuschreiben: die Texte beruhen auf einer polaren Denkform, geben sich kompromißlos und operieren polemisch mit Begriffen und Gegenbegriffen. Darüber hinaus sind insbesondere im Hinblick auf die Theaterstücke weitere Eigenheiten wie der Rekurs auf konkrete textliche Äußerungen der Opponenten, die Refunktionalisierung traditioneller Textsorten und eine der scharfen Polemik innewohnende Übertreibung und Polarisierung der Positionen von Bedeutung.

a teatron, in: Rivista d'Italia, Mai 1907, S. 723-742, hier S. 740, findet sich die Ansicht, die Rezeption Gozzis in der Romantik beruhe auf einem Fehlurteil; s. auch P. Bosisio, op. cit., S. to: -certo si trattò di uno di quegli abbagli che i Romantici presero spesso e un po' dovunque.. 
Nimmt man in bezug auf das Theater Abschied von der gängigen Vorstellung, Goldoni stelle in seinen Komödien soziale und politische Strukturen in Frage, ${ }^{5}$ wirken auch Gozzis Märchenstücke weniger mreaktionär $*$, und es treten strukturelle, ästhetische und poetologische Aspekte in den Vordergrund. So fällt auf, daß die Mach-Art der Fiabe teatrali in Zusammenhang steht mit den polemisch-kritischen Texten. Bezeichnenderweise gehen die extreme Polarisierung und bewußte Kontrastierung inhaltlicher Standpunkte in diesen Texten als strukturelles Signum in Gozzis Theater ein, das in den Fiabe teatrali noch prägnanter ist als in den späteren sogenannten spanischen Tragikomödien. ${ }^{6}$ Die Originalität der Fiabe teatrali ergibt sich sowohl aus der Wahl von Märchen- und Maskenelementen als Konstituenten der neuen Gattung als auch aus der Kontraststruktur, und es gilt die Konstituenten wie die Strukturen der neuartigen Stücke näher zu bestimmen. In den Fiabe teatrali gehen Märchen und Masken eine ungewöhnliche Verbindung ein, die maßgeblich ist für die Kontraste, die sich unter anderem auf den Ebenen der drama-

4. Vgl. vor allem die wegweisenden Untersuchungen Franco Fidos und Giorgio Padoans zu Goldomi. Für die Anfänge einer neueren Kritik, die Gozzis Frabe teatrali nicht am -fortschrittlichen-, -realistischen- Theater Goldonis mißt, stehen u. a. die Namen Jean Starobinski und Alberto Beniscelli, dessen Studien zu Gozzis Theater 1986 als Buch publiziert wurden. Während in jüngerer Zeit maBgebliche Artikel von Carmelo Alberti und Piermario Vescovo erschienen, sind monographische Darstellungen von Gozzis Werk bis heute eine Seltenheit, doch zeichnet sich im Jubilăumsjahr 2006 eine Veränderung ab mit Javier Gutiérrez Carou, Carlo Gozzi. La vita. Le opere. La critica. Con un inedito componimento in veneziano, Venezia, Supernova 2006, Anna Scannapieco, Carlo Gozzi: la scena del libro, Venezia, Marsilio zoo6, und Mariagabriella Cambiaghi $(\mathrm{Hg})$, Studi gozziani, Milano, CUEM 2006. Problematisch ist die schwierige Zugänglichkeit von Gozzis Texten, von denen mit wenigen Ausnahmen keine modernen Editionen vorliegen. So sind Z B. im Bereich des Theaters die 20 Tragikomödien nach spanischen Vorlagen nahezu völlig in Vergessenheit geraten. Selbst für die Fiabe teatralt fehlt bislang eine Ausgabe, die sämtliche Stúcke mit den zugehörigen Vorworten enthält. $\mathrm{Zu}$ vielversprechenden Initiativen in dieser Hinsicht s. Anna Scannapieco, $=$ Su Goldoni e Gozzi: cantieri aperti, tra ieri e domani-, in: Verf. (Hg.), Il mondo e le sue favole. Sviluppi europei del teatro di Goldoni e di Gozzi/ Inszenierte Wirklicbkeit und Illusion. Zur europaischen Rezeption von Goldonis und Gozzis Theater, Roma, Edizioni di storia e letteratura 2006, S, 259-275. Im deutschsprachigen Raum ist das Forschungsinteresse für Gozzi wie überhaupt für die italienische Literatur des 18. Jahrhunderts - mit Ausnahme Goldonis - nicht sehr ausgeprägt. Nur zur deutschen Gozzi-Rezeption liegen zwei Arbeiten vor: Helmut Feldmann, Die Fiabe Carlo Gozzis. Die Entstehung einer Gattung und ihre Transposition in das System der deutschen Romantik, Köln, Wien, Böhlau 1971; Rita Unfer Lukoschik, Der erste destsche Gozzi. Untersuchungen zu der Rezeption Carlo Gozzis in der deutschen Spätaufklärung, Frankfurt am Main, Lang 1993.

4 Im Hinblick auf die 20 Tragikomódien wäre in einer eigenen Untersuchung zu kJären, inwieweit sich das in den Fiabe teatrali ausgebildete * System * in den späteren Stücken verändert, wobei der enge intertextuelle Bezug zu den spanischen Stücken sicher weniger Spielraum läßt als der losere zu den Märchen in den Fiabe teatrali. 
tischen Codes, der Figurenkonstellation, der Sprache und des Stils bis hin zum intendierten wirkungsästhetischen Gegensatz des Lachens und des Weinens manifestieren. Über die an sich wirklichkeitsfernen Komponenten des Märchens und der Masken hinaus markieren die Selektion und die solchermaßen artifizielle Montage präexistenten Materials die Distanz zur Alltagswirklichkeit in unübersehbarer Weise.

Damit widersetzen sich die Fiabe teatrali sowohl der Absicht, die Wirklichkeit auf der Bühne abzubilden, als auch dem Versuch, das auf der Bühne Dargestellte unmittelbar auf die alltägliche Wirklichkeit zu beziehen, und erteilen der Nachahmungs- und Widerspiegelungsfunktion des Theaters eine deutliche Absage. Vielmehr führen sie nachdrücklich eine theatrale Wirklichkeit vor Augen, eine Realität sui generis, in der die Aufmerksamkeit auf die Beziehung der Elemente untereinander gelenkt wird und eine Rückbindung an die nicht-theatrale Wirklichkeit nur in indirekter Weise erfolgen kann. Unter einem theatertheoretischen Blickwinkel erweist sich diese offensichtliche Konstruktion von Wirklichkeit im Theater als theaterspezifisch und modern. Wo immer die Theatralität des Theaters in den Vordergrund rückt, treten Gozzis Fiabe teatrali ins Blickfeld; so Anfang des 20. Jahrhunderts in den Überlegungen Meyerholds und in Inszenierungen Vachtangovs, Max Reinhardts und Jacques Copeaus, später unter anderem bei Giorgio Strehler und Benno Besson.

Auch im Hinblick auf den scheinbar antiaufklärerischen Impetus der Fiabe teatrali zeigt sich die Bedeutsamkeit der amimetischen Verbindung von Märchen- und Maskenelementen in einer kontrastiven Struktur: Sie erlaubt es, mittelbar Aspekte ins Spiel zu bringen, die in der diskursiven Diskussion verborgen bleiben. Wenn die märchenhafte Illusion auf der Bühne den Zuschauern zeitweilig zur Wirklichkeit wird und wahr erscheint, wie Gozzi dies fordert, und in dieser theatralen Wirklichkeit Wahrheiten aufzuscheinen vermögen, die sonst verhüllt sind, wirft dies ein Licht auf die Problematik der Erkenntnis von Wirklichkeit und Wahrheit. Die scharfe Trennung zwischen wahrhafter und vermeintlicher Erkenntnis wird unsicher und das Rationalitätspostulat in Frage gestellt. Mittels der Kontraststrukturen wird entgegen universalistischer, nivellierender Denkweisen zum einen auf die Vielfalt und Unterschiedlichkeit von Wahrnehmungsmöglichkeiten hingedeutet, zum anderen auf ihre Unvereinbarkeit. Der Vernunftbetontheit setzt Gozzi die Fähigkeit zur Illusionierung und die Einbildungskraft entgegen, der Unterwerfung unter unmittelbar Vorfindliches die geheimnisvolle Präsenz des Wunderbaren. Mit dieser indirekten Offenlegung problematischer Vereinseitigungen leistet Gozzi selbst gewissermaßen ein Stück Aufklärungsarbeit in theatralischem Gewand. 
In dieser Perspektive gelesen, erscheint es weniger verwunderlich, daß die Fiabe teatrali bei Tieck, Schiller, E.T. A. Hoffmann und anderen ihre Spuren hinterlassen haben, daß Goethe neben Shakespeare und Schiller Gozzi als einen der Autoren nennt, mit denen er das Repertoire des weimarischen Theaters sgeistiger zu erheben suchte $^{7}$ und A. W. Schlegel Gozzi »ungeachtet des großen Abstandes, mit den ausländischen Meistern im romantischen Drama $\alpha$, das heißt mit Shakespeare und Calderón, vergleicht. ${ }^{8}$ Nimmt man die Bedeutungshaltigkeit der Struktur, den Konstruktcharakter und die Selbstbezüglichkeit der Stücke sowie die indirekte Mitteilungsweise in den Blick, wird die Wirkungsmächtigkeit von Gozzis Fiabe teatrali erkennbar, die weit über die deutsche Romantik hinausreicht.

Die Arbeit wurde dankenswerterweise durch ein Charlotte-Bühler-Stipendium des FWF und ein Stipendium des Deutschen Studienzentrums in Venedig e.V. gefördert. Ein herzlicher Dank ergeht darüber hinaus an Peter Kuon, der sie in der Nähe und aus der Ferne begleitet hat.

Johann Wolfgang Goethe, "Campagne in Frankreich «, in: Werke, Hamburger Ausgabe, Bd. 10, München, Deutscher Taschenbuch Verlag 1982, S. 350: -Diese lebendige, sich im Zirkel herumtreibende Masse [d. h. Stücke aktueller Autoren, die sfür den Tag « produzierten] suchte man mit Shakespeare, Gozzi und Schiller geistiger zu erheben *

8 August Wilhelm Schlegel, -Vorlesungen über dramatische Kunst und Literatur. Erster Teils, in: ders, Kritische Schriften und Briefe, Bd. s, Hg. Edgar Lohner, Stuttgart u. a., Kohlhammer 1966, S. 249. 

KONTROVERSEN UND KONTRASTE

Ans Licht einer breiteren Öffentlichkeit trat Carlo Gozzi (1720-1806) 1757 mit La tartana degl'influssi per l'anno bisestile 1756. 'Dieser Almanach für das Schaltjahr 1756 erschien nicht nur anonym mit der falschen Ortsangabe Paris, sondern bezeichnenderweise auch zu einem Zeitpunkt, als das Jahr bereits abgelaufen war. Er gibt den Tenor an, der sämtliche vor oder zeitgleich mit den ersten Theaterstücken entstandenen Texte Gozzis charakterisiert. Durchzogen von ironischen, polemischen und satirischburlesken Untertönen greifen diese in Form von Sonetten und Capitoli, Dialogen, Briefen und Kommentaren, Kurzepen und Epen in eine lebhafte Diskussion um literarische und gesellschaftliche Entwicklungen ein. Teils handgeschrieben, teils in meist kleinen Auflagen gedruckt, teils anonym, teils mit fingiertem Verlagsort, ohne Erscheinungsjahr oder Angabe des Druckers zirkulierten sie und hielten das Interesse am literarischen Leben wach. Sie sind keineswegs nur einem einsamen, reizbar-angriffslustigen Geist entsprungen, ${ }^{2}$ sondern schreiben sich in eine Kultur der von Autoren, Journalisten und gebildeten Laien geführten halböffentlichen Literatur- und Gesellschaftskritik mit ausgeprägt dialogischem Charakter ein, die in der ersten Hälfte des 18 . Jahrhunderts in vielen europäischen

1. Folgt man Vittorio Malamanis Bibliographie der Texte Gozzis in Ernesto Masis Ausgabe der Frabe (2 Bde., Bologna, Zanichelli 1884), so hat Gozzi ab 1736 einzelne Gelegenheitsgedichte in sogenannten raccolse, Festschriften zu besonderen Anlässen wie Hochzeiten, Jubiläen etc., veroffentlicht; s. a. Fabio Soldinis Aufstellung der »Opere a stampa: 1736-1805* in Carlo Gozzi, Lettere, Hg. Fabio Soldini, Venezia, Regione del Veneto, Marsilio 2004, S. 39-72. Zu einer Veränderung der Werkchronologie könnte ein Fund F. Soldinis führen, der ca. 9.500 handschriftliche Blatter umfaßt, dic größtenteils Carlo Gozzi zuzuschreiben sind. Ab Herbst 2006 ist der $\rightarrow$ Fondo Gozzi- in der Biblioteca Nazionale Marciana in Venedig zugänglich. Der Katalog zur Ausstellung, in der der -Fondo Gozzi* der Offentlichkeit vorgestellt wurde, enthält micht nur einschlägige Beiträge, sondern auch ein detailliertes Verzeichnis der Sammlung: Carlo Gozzi 1720-1806. Stravaganze sceniche, letterarie battaglie, Hg. Fabio Soldini, Venezia, Marsilio 2006.

2 Bereits 1886 scheint diese Art der Auscinandersetzung auf Unverständnis zu stoßen, wenn z. B. V. Malamani in La satira del costume a Venezia nel secolo XVIII, Torino, Napoli, Roux e Favale 1886, S. 58-59, ein vernichtendes Urteil uber Gozzis satirischpolemische Texte spricht. Ähnliche Bewertungen finden sich noch 100 Jahre später, wie etwa bei Norbert Jonard, der in La vie quotidienne a Venise au XVIIle siecle, Paris, Hachette 1965, S. I $\$ 2$, schreibt; sces pamphlets vengeurs écrits avec l'aigreur et la hargne d'un homme qui se sent menacé dans sa sécurité.a 
Ländern zu beobachten ist und um die Jahrhundertmitte in Venedig besonders virulent wurde. ${ }^{3}$

Mit der Herausbildung eines »großen $<$ Publikums $\star^{4}$ verändert sich die Form der literarischen Auseinandersetzung auch in Italien grundlegend, indem das "Interpretationsmonopol $\alpha^{5}$ der Autoritäten zunehmend einer diffusen Diskussionskultur weicht. Umfassende, auf Vollständigkeit hin angelegte Abhandlungen wie etwa Ludovico Antonio Muratoris Della perfetta poesia italiana (1706) und Gian Vincenzo Gravinas Della ragion poetica (1708), die im Kontext der Arcadia und ihrer dezidierten Distanzierung vom Seicento auf eine allgemeine Erneuerung der italienischen Literatur zielen, wie auch spezifisch auf die Tragödie gerichtete Werke, z. B. Pier Jacopo Martellos Della tragedia antica e moderna (I7I4), Gravinas Trattato della tragedia (1715) oder Pietro Calepios Paragone della poesia tragica d'Italia con quella di Francia (1732), und noch Scipione Maffeis De' teatri antichi e moderni von $1754^{6}$ sind der gelehrten Tradition verpflichtet und behandeln grundsätzliche poetologische und ästhetische Fragestellungen.

Neben diese abstrahierend-gelehrten Formen treten mehr und mehr ad hoc verfaßte Texte, die zum Teil in kürzesten Zeiträumen auf die aktuelle literarische Produktion reagieren. Anstelle großer Entwürfe geht die Tendenz zu kürzeren, leichter und schneller rezipierbaren Texten. Entspre-

3. Vgl, dazu Jürgen Habermas, Strukturwandel der Offentlichkeit, mit einem Vorwort zur Neuauflage 1990, Frankfurt am Main, Suhrkamp 2001, v. a. das Kapitel sInstitutionen der Öffentlichkeit *. J. Habermas geht v.a, von der franzôsischen, englischen und deutschen Situation aus, die sich in vielem von der italienischen und insbesondere der venezianischen unterscheider. Nicht nur hinsichtlich der politischen und gesellschaftlichen Struktur bestehen grundlegende Differenzen, sondern auch im Blick auf das kulturelle Leben, verfügte Venedig doch seit langem z. B. über mehrere öffentliche Theater. Nichtsdestoweniger lassen sich einige Grundzüge auch auf Venedig ubertragen wie z. B. die Art des *gesellschaftlichen Verkehrs [...], der nicht etwa die Gleichheit des Status voraussetzt, sondern von diesem überhaupt absicht * (S. 97), „ die Problematisierung von Bereichen, die bislang nicht als fragwürdig galten ( Unabgeschlossenheit des Publikums (5.98). Was die Tischgesellschaften, Salons und Kaffechäuser in Deutschland, Frankreich und England waren, sind in Venedig die Cafés, sridotti< und scasini $\kappa$, in denen sich das Publikum nach den Theateraufführungen traf und diskutierte, und hier wie dort knüpfen die zahllosen Pamphlete an diese Gespräche an und werden ihrerseits von diesen aufgenommen.

4 Ebd., S. 99; J. Habermas versteht dieses s diffuse Publikum, das sich im Zuge der Kommerzialisierung des kulturellen Verkehrs bildet *, als neine neue soziale Kategorie *.

5 Ebd., S. 97.

6. Maffeis De' teatri antichie moderni entstand als Antwort auf die lateinische Schrift De spectaculis theatralibus (1752) des Dominikanerpaters Daniele Concina, der das Theater generell als unmoralisch verurteilte. Unter Heranziehung sämtlicher Autoritāten, u. a. Aristoteles', Platons und der Kirchenväter, weist Maffei in scholastischer Weise den Angriff Concinas zurück. 
chend einer auf unmittelbare Wirkung ausgerichteten Strategie wird das allgemein gültige, normative Konzept durch Stellungnahmen zu konkreten Anlässen abgelöst. In solchen nicht mehr systematisch argumentativ, sondern polemisch geführten Kontroversen erscheinen die Positionen allerdings häufig vergröbert und überzeichnet. In besonders ausgeprägter Weise ist dies bei Carlo Gozzis Texten der Fall, so daß sie schnell in den Verdacht geraten, nur das aggressiv-zerstörerische Potential der Satire und Polemik zur Wirkung zu bringen. Indes lassen sich konstruktive Elemente indirekt erschließen ${ }^{7}$ und gemeinsame Charakteristika erkennen, die in engem Zusammenhang mit den Fiabe teatrali stehen und für diese in inhaltlicher wie in struktureller Hinsicht von Bedeutung sind.

\subsection{Ein polemisches Debüt}

La tartana degl'influssi per l'anno bisestile 1756 , im folgenden kurz La tartana genannt, steht am Beginn einer literarisch-kulturellen Polemik, die vor allem zwischen Carlo Gozzi, Carlo Goldoni und Pietro Chiari und in besonderer Intensität bis zum Anfang der sechziger Jahre geführt werden sollte, aber auch danach nicht verstummte. In rascher Abfolge verfaßte Gozzi Texte unterschiedlichster Art, die zum Teil unveröffentlicht blieben, zum Teil einzeln, in Sammelpublikationen oder später in seinen Werkausgaben erschienen. ${ }^{8}$ Nicht alle zeitigten dieselben vehemen-

7 So erscheint der z B. von Paolo Bosisio erhobene Vorwurf, Gozzi betreibe eine "mera demolizione verbale e sovvente verbosa dell'avversario. Mancano $[\ldots]$ la capacità e l'intenzione stessa di proporre soluzioni alternative« angesichts der polemischen Form der Auseinandersetzung kaum angemessen. P. Bosisio, Carlo Gozzi e Goldoni, op. cit., S. 49.

- La tartana, Canti due del ratto delle fanciulle castellane (dies sind die beiden ersten Gesänge des 1819 postum veröffentlichten kollektiven Versepos Le spose riacquistate von Gozzi, Daniele Farsetti und Sebastiano Crotta) und ein großer Teil der satirisch-polemischen Gedichte wurden von Gozzi in Band VIII (1774) der 8-bändigen ColombaniEdition aufgenommen; im letzten Band der Zanardi-Ausgabe (Opere edite ed inedite non teatrali, Bd. I, Venezia 1805) erschien La tartana ein weiteres Mal, daneben die bislang unveröffentlichten Texte La scrittura contestativa al taglio della Tartana und Il reatro comico all'Osteria del Pellegrino. Dieser seltene Band war der Mehrzahl der Gozzi-Forscher bis in die heutige Zeit unbekannt. Ebenfalls in Unkenntnis des ZanardiBandes nahm Vito Pandolfi eine teilweise Veroffentlichung der Texte anhand der Manuskripte in La commedia dell'arte, Bd. 4, Firenze, Sansoni 1958, vor. In Einzelausgaben liegen Parere o siat lettera scritta da un'amico del Friali, ad un'amico di Venezia sopra il. poemetto intitolato Le Raccolte, con la risposta dell' amico di Venezia all'amico del Friult, Venezis 1758 und I sudori d'Imeneo, Venezia 1759 vor. 1979 erschien P. Bosisios bereits erwähnte umfangliche Publikation unveröffentlicht gebliebener Atti Granelleschi sowie eine Zusammenstellung von gegen Goldoni gerichteten Gedichten Gozzis.

Zur Zitierweise der Werke Carlo Gozzis: Die Angaben zu den in die Colombani-Edi- 
ten Reaktionen wie La tartana, doch ist, vor allem in bezug auf die umfangreicheren Texte, ein Wechselspiel von Rede und Gegenrede deutlich erkennbar. La tartana, der Ausgangspunkt und "Stein des Anstoßes* in der langen Reihe der polemischen Texte enhält im Kern bereits grundlegende Aspekte der Auseinandersetzung, auf die Gozzi wie auch seine Kontrahenten immer wieder rekurrieren.

\section{Der etwas andere Almanach}

In La tartana bedient sich Gozzi der Form eines traditionellen venezianischen Almanachs. ${ }^{9}$ Gegliedert nach den vier Jahreszeiten, bietet er für jeden Monat Vorhersagen zu den unterschiedlichsten Bereichen des gesellschaftlichen und kulturellen Lebens: "Degli Scrittori , „De' Predicatori $\propto$, "Della Fiera, detta la Sensa “, "Dell'andare a Padova $\propto$, "Dell' andare la sera al fresco $\approx$ etc. Allerdings wird diese Form, über den angeblichen Erscheinungsort Paris und das verspätete Erscheinungsdatum hinaus, durch die mehrfach gebrochene Urheberschaft fiktionalisiert. Aus der ersten Widmung an den venezianischen Adligen Daniele Farsetti geht hervor, daß es der beste Freund des inzwischen verschiedenen Autors der Tartana ist, der Farsetti als Mäzen um die Publikation des Textes angeht, um so einem Wunsch des Verstorbenen nachzukommen. Zum Verhängnis war diesem Autor seine übergroße Liebe zu den "scrittori Toscani« geworden - dal cinquecento in là, e quanto più erano antichi, più volea loro del bene $(\mathrm{Col}$. VIII, 19) - und das daraus resultierende Entsetzen

tion aufgenommenen Werken verweisen auf Band und Seite in folgender Form: Col. I, I; die Theaterstücke werden nach der Colombani-Edition zitiert, es erfolgen jedoch keine Band-und Seiten-, sondern Akt-und Szenen-Angaben (z. B. III, 2), um das Auffinden in modernen Ausgaben zu erleichtern. Für dic im ersten Band der Opere edite ed inedite non teatrali bei Zanardi publizierten Texte (weitere Bände erschienen nicht) wurde die Abkürzung Zan. XV gewählt, um Verwechslungen mit dem ersten Band der ZanardiEdition der Opere edite ed inedite vorzubeugen.

" Das Modell, slo Schieson*, wird in Gozzis Text selbst genannt und mit folgender Anmerkung versehen: $>$ Appellasi lo Schiesone certo Stampatore di Trevigi, che scrive ogni anno un suo Lunario in versi.* (Col. VIII, 20) Auch Goldoni war Jahre zuvor der Mode gefolgt und hatte einen solchen Almanach verfaßt, der jedoch nicht erhalten ist. In den Mémoires berichtet er: $*$ Je fis vraiment un Almanach qui fut imprimé, qui fut goûté, et qui fut applaudi. Je lui donnai pour titre: l'Expérience du passé Astrologue de l'avenir, Almanach critique pour l'année 1732. Il y avoit un discours général sur l'année, et quatre discours sur les quatre saisons en tersets, entrelassés à la manière de Dante, contenant des critiques sur les mours du siecle, et il y avoit, pour chaque jour de l'année, un pronostic qui renfermoit une plaisanterie, ou une critique, ou une pointe. (Goldoni, I, 1 1 1; Texte Goldonis werden zitiert nach Carlo Goldoni, Tutte le opere, Hg. Giuseppe Ortolani, ${ }_{14}$ Bde., Milano, Mondadori 1935-56, unter Angabe des Bandes und der Seitenzahl). 
angesichts der Umtriebe der modernen Autoren. Melancholisch in sein Zimmerchen zurückgezogen, hatte er La tartana gleichsam als sein Testament niedergeschrieben und war daraufhin verschieden, sco' nomi di Luigi Pulci, di Franco Sacchetti e del Burchiello, suoi carissimi, in sulle labbra $(\mathrm{Col}$. VIII, 20), nicht ohne vorher inständig darum gebeten zu haben, von einem Epitaph in versi martelliani ${ }^{10}$ verschont zu bleiben, das ihn noch einmal tausend Tode sterben lassen würde.

Damit ist sogleich der ironisch-polemische Ton angeschlagen, der den gesamten Text kennzeichnet. Ein übriges tut die eingefügte Notiz des Druckers »all'inimico lettore $\propto$ mit dem Hinweis, daß der Leser ja nicht glauben solle, nun jedes Jahr eine neue Tartana zu erhalten, denn schließlich seien die Vorhersagen, die in der vorliegenden gemacht würden, für alle zukünftigen Jahrhunderte gültig - dank der seherischen Gaben des Verfassers. Wie im Capitolo "Sopra all'anno zu lesen ist, entspringen diese jedoch nicht wie üblich astronomischen Kenntnissen, sondern $* s$ 'io vo' il futuro indovinare, / Guardo il passato e non commetto errore; / Non m'occorre i Pianeti bilanciare. // Premessa quest'idea, mi dice il core: / Dominator di questo bisestile / Sarà la Fame, il Debito, e l'Amore, « (Col. VIII, 30). Wenn sich die Probleme der Zukunft solchermaßen aus der Vergangenheit ergeben, wird der Sinn eines jahresspezifischen Almanachs natürlich fragwürdig, was sich bereits in der Diskrepanz zwischen Datierung und Erscheinungsdatum der Tartana andeutet. Dennoch folgt La tartana nach einigen einleitenden Texten zumindest formal dem Modell. Unübersehbar ist jedoch, daß Gozzi den traditionellen Sinn der bekannten Textform unterläuft und ihr eine neue Funktion zuschreibt. Der volkstümliche Almanach, der zum Vergnügen seiner Leser ironische Zeitkritik übt, verwandelt sich in ein satirisches Pamphlet gegen gesellschaftliche Auswüchse und den Literaturbetrieb der Zeit.

Auf das bereits erwähnte Anfangscapitolo *Sopra all'anno* folgen in vier Sequenzen, beginnend mit dem Winter, jeweils ein allgemeines Capitolo zur Jahreszeit sowie drei Gedichte in ottava rima zu den zugehörigen Monaten. Diesen legt Gozzi mehr oder weniger dunkle Verse des Florentiner Dichters Burchiello zugrunde, die im Sinne von Prophezeiungen in meist abstruser Weise auf den zeitgenössischen venezianischen Kontext

10 - Versi martelliani* sind nach ihrem Erfinder Pier Jacopo Martello benannte Vierzehnsilbler. In Martellos Abhandlung Del verso tragico (1709) wird in Anlehnung an den franzosischen Alexandriner dieser neue 14 -silbige Vers proklamiert, der durch seine Länge cinen adāquateren Gefühlsausdruck erlaube und durch den Reim einen angenehmen Eindruck mache. Die sogenannten versi martelliani wurden bald zur Modeerscheinung, die besonders Chiari und darn auch Goldoni in ihren Theaterstücken beförderten. 
hin gedeutet werden, ${ }^{11}$ wobei die Interpretationsleistung explizit erwähnt wird: »Ma a voler dipanar questa matassa, / Bisogna nel midollo andar cercando; / Si sa, che il senso d'una profezia / Non è facile intender qual si sia.« (Col. VIII, 34). So ergibt sich beispielsweise aus Burchiellos Weissagung *Veglia la Luna, quando il Sol s'abbassa» folgende Bedeutung:

Però il Burchiello per il Sole intese

Gli Scrittor buoni, e saggi, al parer mio;

Gli Scrittoracci per la Luna prese,

Che ammorbano la terra, mi cred'io.

Oggi quel Sol non esce più in palese,

Temo, che di star chiotto sia botio;

Veglia la Luna, e ci domina, e regge,

Se non si desta il Sole a darci legge.

(Col. VIII, 35)

Und im unmittelbaren Anschluß wird auch weiteren Versen Burchiellos ein aktueller Sinn abgewonnen:

E quando disse: :Parliam de' mosconi,

Che trassinando merda si fan d'oro";

Come faremo le interpretazioni,

Sennon che intese dirci di coloro,

Ch' e' torchi inondan di composizioni,

Alle quai corron, com' e' putti al toro,

Le genti, e lascian per fogli ducati,

Onde son grassi, e detti letterati?

(Col. VIII, 35)

Die beiden Beispiele machen deutlich, wie willkürlich und aberwitzig diese Art der Deutung ist, doch überrascht immer wieder die interpretatorische Phantasie, mit der aus dem Zusammenhang gerissenen Versen ein ihnen fremder Sinn abgetrotzt wird. ${ }^{12}$ Je ernsthafter diese philologische

18 Domenico di Giovanni, genannt Burchiello (1404-1449), gilt als besonders schwer verständlicher Dichter. Seine schwankhaft geprägte, überwiegend narrativ-deskriptive Dichtung, deren charakteristische Form das sonetto caudato ist, zeichnet sich durch ausgefallene Wortkombinationen und überraschende Wendungen aus, die willkürlich und absurd wirken und eine parodistische Intention hinsichtlich der literarischen Kultur der Zeit aufweisen. Die überraschende, ganz unkonventionelle Deutung von Burchiellos Versen als Weissagungen wird von Gozzi in einer ironischen Anmerkung gerechufertigt: - Il Burchiello, Fiorentino, fu Poeta, e fece canzoni, e Sonetti sfoggiati, come dice un suo frontispizio. Nessuno intese i suoi scritti, perchè nessuno seppe, ch'egli abbia scritto, come Profeta. A me sembra, che non abbia preso un granchio lo scrittore della Tartana, considerandolo tale. Leggasi questo suo libretto, e ciascheduno sí chiarirà..* (Col. VIII, 34).

12 So zum Beispiel in den Prophezeiungen für den Monat August, $n$ Delle sagre «; Mai non si vide al Profeta Burchiello / Tanto furor, quanto a dir dell'Agosto, / Perché vedeva alle Sagre un bordello, / E più ch'Orazion, frittelle, e mosto; / Femmine, c putti con poco 
Arbeit betrieben wird, um so mehr tritt die Ironie zutage. Hier geht es weder darum, Burchiellos Versen gerecht zu werden, noch die angeblichen Prophezeiungen an der Realität zu messen, sondern sie polemisch-satirischen Zwecken dienstbar zu machen. Durch den Kunstgriff, Burchiello $\mathrm{zu}$ zitieren und scheinbar zu interpretieren, wird die Polemik jedoch literarisch legitimiert.

\section{Gesellschafts- und Literatursatire}

Zielscheibe des Spotts sind nicht nur die modernen Schriftsteller im allgemeinen und insbesondere drei namentlich genannte, Orazio Arrighi Landini, Pietro Chiari und Carlo Goldoni, sondern auch Geistliche und Juristen sowie die Sitten, Lebens- und Umgangsformen von Gozzis venezianischen Zeitgenossen. Es werden die Sittenlosigkeit, Gefallsucht und Geldgier der Geistlichen und die falsche Frömmigkeit der Kirchgănger angeprangert, die Streitsucht der Venezianer und die hinterlistige Profitgier der Juristen, die Flut von Festen und Jahrmärkten, die die Frauen dazu verleiten, ihrer Eitelkeit zu frönen und sich männlichen Blicken zur Schau zu stellen, das übertriebene Modebewußtsein, die Unziemlichkeit abendlicher Vergnügungen und der Cicisbeismo sowie die verschwenderischen Wochenendausflüge und Sommeraufenthalte auf dem Land. Seinen Höhepunkt erreicht das Zerrbild in der Prophezeiung für den Monat Oktober, die mit Dell'uccellare e delle cacce $($ Col. VIII, 64-65) überschrieben ist. Gingen früher sil cittadino e il cavaliere « gemeinsam auf die Jagd, um Vögel oder Wild zu erlegen, so sind sich nun die Herren zu fein dazu und überlassen das Geschäft den Bauern. Sie dagegen sitzen "co' ducati in mano « zu Hause und machen stattdessen Jagd auf leibliche Genüsse, auf Frauen und auf das Glück im Spiel.

Nimmt diese in der langen Tradition satirischer Texte stehende Thematik quantitativ auch den weitaus größten Raum ein, zollte ihr die Kritik doch kaum Beachtung. Vielmehr wird La tartana meist auf die Polemik gegen Carlo Goldoni und Pietro Chiari reduziert. ${ }^{13}$ Diese ist zwar unver-

cervello, / E ciò, che in que' due versi egli ha nascosto: / -Zucche marine, chiocciole, lumache, / Ranocchic, topi, e berte senza brache. // Vidi un migliajo di corbi, e salsiece, / Disse, per non dir cose men che oneste, / =Mescolate con lor ben cento micce, * /V'aggiunse, per non dir donne immodeste, - (Col. VIII, 55).

13 Z. B. P. Bosisio, Carlo Gozzi e Goldoni, op. cit., Giuseppe Petronio im Vorwort zu La tartana in der von ihm besorgten Werkausgabe Gozzis (Opere. Teatro e polemiche teatrali, Milano, Rizzoli 1962, S. 973) und in neuerer Zeit z. B. Gérard Luciani in seinem Beitrag "Carlo Gozzi o la ricerca di un rimovamento del teatro comicos, in: Carmelo Alberti (Hg.), Carlo Gozzi, scrittore di teatro, Roma, Bulzoni 1996, S. 13-32. 
kennbar, vehement und prägnant durch die leicht entschlüsselbaren Anspielungen, aber sie ist Teil eines breiter angelegten Angriffs auf den Literaturbetrieb der Zeit und steht bewußt im Kontext der allgemeinen Zeitund Sittenkritik. Mit diesem Text schaltet sich Gozzi in eine bereits ein Jahrzehnt währende öffentliche Auseinandersetzung zwischen Goldoni und Chiari sowie ihren jeweiligen Anhängern ein, und die Provokation ist wohl kalkuliert: «Or anch'io vo' compor questa leggenda, / Che non sia certo un'opra di gigante; / Ma avverà forse, che il mondo s'accenda, / E se ne faccia un disputar galante $\propto$ (Col. VIII, 28).

Auffällig ist die Konzentration der literarischen Thematik am Anfang und am Ende der Tartana sowie in den Jahreszeiten-Capitoli. Eine grundlegende Dichotomie, die zu den Konstanten Gozzischer Polemik zählen wird, bestimmt den Text von Anfang an: diejenige von sscrittori buoni

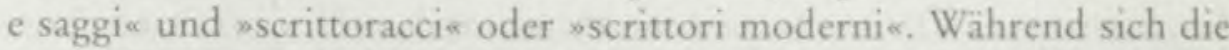
guten, klugen - wie der fiktive Autor der Tartana - durch die respektvolle Liebe zu den alten Meistern auszeichnen und einem "stil netto, e purgato / $\mathrm{Da}^{\prime}$ gergoni lombardi, o venezianiผ (Col. VIII, 2I) verpflichtet sind, geht den modernen jegliche Art von Bildung und Respekt vor der Tradition ab, *di saper non c'è semenza* (Col. VIII, 24). Dies führt nicht nur zu Nachlässigkeiten in stilistischer Hinsicht, sondern auch zu einer allgemeinen Oberflächlichkeit, die sowohl der Massenproduktion von Texten entgegenkommt als auch modischen Phänomenen wie etwa dem Gebrauch der versi martelliani Vorschub leistet.

Neben dieser allgemein gehaltenen literarischen Polemik stehen in $\mathrm{La}$ tartana Texte, in denen, wie im Falle Arrighi Landinis, Namen direkt genannt, solche, in denen für die Zeitgenossen leicht dechiffrierbare Antonomasien verwendet werden („Originale oder »dottor « für Goldoni, *Saccheggio für Chiari),${ }^{14}$ und solche, die zwar im Allgemeinen bleiben, jedoch konkrete Hintergründe haben. Bemerkenswert ist, daß die beiden einzigen Texte, die sich direkt auf Goldoni und Chiari beziehen, nicht im Mittelpunkt der Tartana stehen, sondern jeweils am Rand, unter den zahlreichen Prätexten sowie als Abschluß. Dagegen ergießt sich der Spott über Landini mehrfach in den Jahreszeiten-Capitoli. So ergibt sich im Hinblick auf die Literatur-Polemik eine nahezu symmetrische Struktur. ${ }^{15}$

14 Im Falle Goldonis spielt Gozzi mit sOriginales auf dessen Betonung der Originalität der Reformbestrebungen und die weitgehende Ausblendung von vorgängigen theoretischen und praktischen Erneuerungsversuchen und mit ndottor " auf dessen juristische Ausbildung an. "Saccheggio verweist auf Chiaris Wiederverwendung literarischer Versatzstücke und insbesondere auf die offensichdiche Imitation Goldonischer Stücke.

15 Im letzten -Prätext $\alpha$ und im Schlußgedicht wird auf Goldoni und Chiari verwiesen, in den ersten drei und den letzten zwei Texten des eigentlichen Almanachs stehen allge- 
Im Mittelpunkt des Frühlings-Capitolo steht Landinis der arkadischen Tradition verpflichtete, bukolisch-petrarkisierende Lyrik:

Qualcun direbbe di questa stagione:

Ecco Zeffiro, l'erbe, e i fiorellini,

E l'usignuol colla zolfa al macchione,

E simil coserelle da bambini,

Che forse al secol d'oro s'apprezzavano,

Or dan mattana infino a' contadini.

Allora gli uccelletti s'ascoltavano

Volentier sulle frasche, or grassi, e cotti

Più volentier dallo schidion si cavano.

(Col. VIII, 42)

Ihre Fortsetzung findet die Polemik gegen diese Art von käuflicher Gelegenheitsdichtung,${ }^{16}$ die in plagiatorischer Weise literarische Versatzstücke montiert, im Sommer-Capitolo, in dem ein Text desselben Autors in der Manier eines kombinierten aufklärerischen Lehr- und Liebesgedichts aufgegriffen und zerlegt wird, sowie im Herbst-Capitolo, das die Beliebigkeit und Banalität der Themenwahl bloßstellt. ${ }^{17}$

meinere literarische und theatralische Aspekte im Vordergrund, und die drei in regelmäBigen Abständen aufeinanderfolgenden Capitoli im Inneren des Gesamttextes richten sich gegen den jeweils namentlich genannten Arrighi Landini.

is Daß Landinis Opus käuflich zu erwerben ist, wird nicht nur im Capitolo selbst, sondern auch in einer Anmerkung betont.

17 Absichtsvoll werden in den Anmerkungen einige besonders pädagogisch-didaktisch ausgerichtete Verse zitiert: $\bullet$ E insolenti chiamar gl'insetti ardisci? $* ;$ Diversi son, candida irene, i beni, / Che dal sudore il corpo uman ricava = (Col. VIII, so).

Die Frage, warum unter den zahlreichen Poeten der Zeit gerade Arrighi Landini zur Zielscheibe der Angriffe wurde, scheint bisher nicht gestellt worden zu sein. Eine Antwort konnte zum einen darin liegen, daß er in Venedig lebte und eine gewisse Reputation genoß (darauf deutet der Eintrag in Giovanni Maria Mazzucchellis Gli scrittori d'Ttalia, Brescia, Bossini 1753-63, hin), was die Effektivität der Polemik sicherte. Zum anderen war er vehementer Parteigänger Goldonis und hatte sich auf dem Höhepunkt der Auseinandersetzungen zwischen Goldoni und Chiari im Jahr 1754 öffentlich auf dessen Seite gestellt. Vgl, das von C. Alberti aufgestellte Inhaltsverzeichnis zum MS Composizioni uscite su i Teatri, Commedie, e Poeti nell'Anno MDCCLIV in Venezia; C. Alberti, - Gare e contrasti tra due -poeti comici* negli anni $1753-1756 \%$, in: C. Alberti; Ginette Herry (Hgg.), Tra libro e scena. Carlo Goldoni, Venezia, Il Cardo 1996, S. 61-101, hier S. $92-98$. Als konkreter und aktueller Anlaß für Gozzis offentliche Nennung des Namens diente mit größter Wahrscheinlichkeit die venezianische Aufführung von Goldonis La villeggiatura im Karneval 1756, dem Entstehungsjahr der Tartana. Als Dank Goldonis an seinen Anhànger Landini wird in der ersten Szene des ersten Aktes Landinis eben im Druck erschienenes Gedicht La Prinavera. Poema in versi martelLiani explizit erwähnt und gelobt als ein Werk, an dem es nichts zu kritisieren gebe. Offensichtlich hat sich Gozzi durch diese Art offener Schmeichelei zu einem Gegenschlag herausgefordert gefühlt. 
Ein Spektakel besonderer Art wird in den Oktaven $>\mathrm{A}^{\prime}$ lettori $\alpha$ evoziert: *Dove fan loro imprese i ciurmatori, / Vedestù mai, Lettore, in sulla piazza, / Due Fantaccini far gli schermitori, / In mezzo a innumerabil turba pazza? (Col. VIII, 26). „La piazza «, die venezianische Piazza San Marco, ist Schauplatz eines grotesken Duells zwischen zwei Kontrahenten, die sich auf der einen Seite durch Unwissenheit, eine gewisse Geschicklichkeit, einen guten Instinkt und den Vorsatz auszeichnen, sich nie geschlagen zu geben, auf der anderen ebenfalls durch Unwissenheit, aber auch durch Betrügereien. Statt mit dem Degen zu fechten, schlagen sie, die Augen weit aufgerissen, mit Knüppeln aufeinander ein und brüllen sich an, Cosi l'ajuta a comparir feroce / Poco saper, temeritade, e voce. $*$ Der eine mit Namen Originale und der andere, Saccheggio genannt, scharen täglich eine beträchtliche Zahl von Anhängern um sich, und das Stadtgespräch dreht sich nur noch darum, welcher der beiden der bessere ist. Bald teilt der Zwist nicht nur die Stadt in zwei Parteien, sondern selbst innerhalb der Familien tobt der Streit, Nelle case ifratelli contendevano, / Le mogli co' mariti facean peggio, / In ogni loco acerba è la tenzone, / Tutto è scompiglio, tutto è dissensione. * (Col, VIII, 27). Ganze vier Oktaven lang wird diese erbitterte Auseinandersetzung zwischen den Parteigängern von Originale und Saccheggio zum Thema gemacht und die Unmöglichkeit aufgezeigt, sich einer Parteinahme zu entziehen. Nicht nur Originale und Saccheggio selbst sind die Objekte des Spotts, sondern auch ihre Anhänger, die nicht vernünftig argumentieren, sondern sich fanatisch auf eine Seite schlagen. Doch hat dies für die beiden Progatonisten ganz erfreuliche Folgen: „Così tenendo il popolo in puntiglio, / Traean que due ciurmanti un buon guadagnox, was sie allerdings bedauerlicherweise zur Überheblichkeit verführt hat: »andavano intuonando: / Io son Gradasso; io sono il Conte Orlando* (Col. VIII, 28)..$^{18}$

Diese theatralisch-burleske Schilderung des unaufhörlichen Duells zwischen Originale und Saccheggio und der Fanatisierung ihrer Anhänger richtete sich, für die Zeitgenossen unverkennbar, gegen die beiden derzeitigen Konkurrenten und Protagonisten der venezianischen Theaterszene, Carlo Goldoni und Pietro Chiari. Seit Jahren standen sie im Rampenlicht der Offentlichkeit und bemühten sich um die Gunst des Publikums, 1749, ein Jahr nachdem Chiari seine Arbeit als Bühnenautor der Truppe Giu-

18 Zur zunehmenden Relevanz des Publikums hinsichtlich des literarischen und theatralischen Lebens in Venedig vgl. Cesare de Michelis, =La scoperta del pubblico*, in: ders., Letterati e lettori nel Settecento veneziano, Firenze, Olschki 1979, S. 7-35. 
seppe Imers am Theater San Samuele aufgenommen hatte und Goldoni für Girolamo Medebachs Truppe an Sant'Angelo schrieb, war anläßlich der Aufführung von Chiaris La scuola delle vedove, einer Parodie von Goldonis Vedova scaltra, eine offene Kontroverse ausgebrochen, ${ }^{19}$ die in der Saison $1753 / 54$ einen neuen Höhepunkt erreicht und bis zum Erscheinen der Tartana kaum an Vehemenz eingebüßt hatte. Erwies sich ein neues Stück auf der einen Bühne als Erfolg, vergingen oft nur wenige Wochen, bis die Konkurrenz mit einer ähnlichen Produktion aufwartete und das Publikum damit abzuziehen versuchte. Daß dabei allgemein Chiari als der Imitator und Plagiator galt, macht der Name *Saccheggio $*$ deutlich. Unter solchen, maßgeblich von ökonomischen Überlegungen bestimmten Bedingungen wuchs der Druck auf die Autoren, möglichst rasch wirkungsvolle Stücke zu produzieren. Darauf spielt La tartana, ohne konkrete Namen zu nennen, mehrfach an. So in der bereits zitierten Strophe aus *Degli scrittori* oder in den Prophezeiungen für den Monat Februar, »Delle commedie

"E' piove forte, e l'oche hanno gran setea, Cosi il Profeta nostro ha scritto un giorno.

Per la gran pioggia, so che prenderete

Quel mar di Commedie, che vanno attorno.

Per l'oche, la gran folla intenderete,

Che ognor ne vuol di nuove, ond'io ritorno

Al Burchiel mio, che in un verso ci spiana:

-Cervellin d'oche, e gran teschi d'alfana.*

(Col. VIII, 36)

Im selben Gedicht wird noch einmal darauf hingewiesen, daß dieses Meer von Komödien nur ofredda mercanzia $\propto$ ist und hauptsächlich *per il danaio * entsteht. Das letzte Monatsgedicht fordert die Autoren gar auf, bei sich abzeichnendem Publikumsschwund im Theater doch einfach den Verkaufsgegenstand zu wechseln: „Venderan storia, o vero Strologia, / D'altra matera diverran mercanti* (Col. VIII, 70). Der Autor als Kaufmann, der mit seiner Ware möglichst großen Profit erzielen will, kann der Herstellung der Produkte selbstverständlich nur mehr begrenzte Aufmerksamkeit und Zeit widmen, "Dicon: La Commedia dev'esser piena, / E vada il fatto poi come si sia; « (Col. VIII, 37). Als Folge der merkantilistischen Einstellung entstehen heterogene Machwerke, die schnell aus

13 Auf Chiaris Komódie reagierte Goldoni mit der Veröffentlichung des Prologo apologetico alla commedia intitolata La vedova scaltra contro le criticbe contenute nella commedia intitolata La scuola delle vedove. Wie Goldoni in seinen Memoiren berichtet, wurde umgehend ein Auffuhrungsverbot für Chiaris Stück erteilt (Goldoni, I, 263). 
alten Stücken zusammengeflickt und durch ganz unnatürliche, übertriebene-aber wirkungsvolle - Verhaltensweisen der Figuren charakterisiert sind. »Il costume o dev'esser un bordello, / $\mathrm{O}$ in tutto una virtù, che non si trova * (ebd.). In dieser auf den Erfolg und damit aufs Geld ausgerichteten, moralische Maßstäbe unterordnenden Haltung ${ }^{20}$ unterscheiden sich die Schriftsteller allerdings in nichts von anderen Berufsgruppen, die $\mathrm{La}$ tartana ebenfalls satirisch präsentiert: den Geistlichen, die predigen, was gefällt, um eine volle Kirche zu haben, oder den Advokaten, die vertreten, was ihre Klientel wünscht.

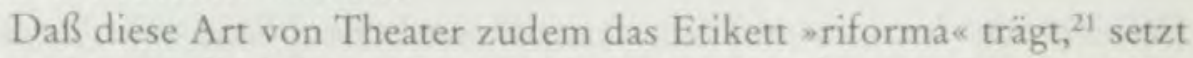
dem Ganzen die Spitze auf: "Ciò, che natura non ha mai sognato, / Caratteracci, genti affascinate, / Omelie, paragon da buon mercato, / Sentenze vecchie in versi rigonfiate / A dritto, a torto, ed argomenti in torma / Oggi han dato a' Teatri la riforma (ebd.). Das Theater dieser selbsternannten »riformatori« und »novi Molier $\propto$ hat allerdings, folgt man der Dezember-Prophezeiung mit dem Titel "Sopra il ritorno del Sacchi, Truffaldino «, seinen Zenit bereits überschritten. Von der Rückkehr Antonio Sacchis, einem der berühmtesten Truffaldino-Darsteller der Zeit, der mit seiner Truppe von Venedig aus eine mehrjährige Tournée in Portugal unternommen hatte, erhoffte man sich neue Impulse, um die Langeweile zu vertreiben, die sich inzwischen bei den Zuschauern angesichts der Goldoni- und Chiari-Stücke breitgemacht hat: »Già pe' Teatri la gente sbaviglia, / Sonneferando ne' palchetti cova, / Fiacca, e dimessa è quella meraviglia, / Che udiasi un dì per la riforma nuova e (Col. VIII, 68). Der zeitweilige Erfolg der »opre, dette regolate e pure« sei nur der Beeinflussung des Publikums durch die Kenner und Gelehrten zu ver-

20 In der Widmung *All'erudito raccoglitore dell'opere sue " des zweiten Bandes seiner italienischen und lateinischen Gedichte und Prosawerke gibt Chiari selbst diese Einstellung unumwunden zu: vle occasioni di verseggiare mi nascono tutto giorno tra piedi senza cercarle. [...] Io sono il primo a conoscere il poco loro valore, e a confessarle forse men degne di tante altre compagne loro, a cui son esse vicine; [...] Chi compra, o vende, come si suol dire, all'ingrosso, non può far scelta del meglio»; Pietro Chiari, Poesie e prose italiane e latine, Bd. 2, Venezia, Pasinelli 1761, S. $13-14$.

Der entscheidende Aspekt in Gozzis Polemik ist die Verbindung von Geld, Massenproduktion und nachlassender moralischer Integrität bei gleichzeitigem Anspruch, eine s moralische Komödie zu schaffen. Die Reduzierung des Angriffs auf eine stypisch adlige* Kritik gegenüber dem kaufmännischen Interesse eines Bürgerlichen und dem Beruf des Schriftstellers greift zu kurz; vgl. Kapitel 3, Anm. 56 im Exkurs zur venezianischen Theaterszene.

21 Goldoni wie Chiari beanspruchen für sich, die Reform der italienischen Komödie eingeleitet zu haben; siehe z. B. Goldonis Vorwort zur Bettinelli-Edition von 1750 sowie die Vorworte zu einzelnen Komödien und Chiaris "Osservazioni criticher zu Il poeta comico. 
danken, denn schließlich wolle niemand als der Dumme dastehen, wenn diese die Vorzüge des Neuen lobten. Nun aber soll endlich das gelangweilte Gähnen wieder einem befreiten Lachen Platz machen, sollen Späße und Phantasie die Bühne beleben, »Non siam per sostener tue commedie, / Che non vogliamo controversia, o intrico; / Ci bastan tue facezie, e fantasie, / E t'accettiam per maggior nostro amico.* (Col. VIII, 69). Daß diese letzte »Profezia del Burchiello $\propto$ für den Monat Dezember eine der wenigen wirklichen Vorbersagen in der Tartana ist, in der nicht nur ein Burchiello-Text für die Deutung der Gegenwart herangezogen wird, sondern tatsächlich die Zukunft ins Spiel kommt, verleiht ihr besondere Relevanz. Damit eröffnet sich eine Perspektive, die von Anfang an für Gozzis eigene Theaterstücke von Belang sein wird: die Einbeziehung der Tradition der Commedia dell'arte.

Wenn das letzte sonetto caudato "Al libraio venditore della Tartana* empfiehlt, La tartana einfach als ein Werk Chiaris oder Goldonis auszugeben und zu behaupten, sie sei in versi martelliani geschrieben, damit sie nicht zum Ladenhüter werde, sondern vielmehr * un [sic] stormo d'eruditi veneziani« angerannt käme, "Che scuotendo le mani / Diran: Grand'uom! gran verso! gran sentenza! « (Col. VIII, 70 ), unterstreicht dies noch einmal, daß weniger die Autoren selbst als vielmehr ihre Anhängerschaft Zielscheibe des Spotts ist. Sich blind und oberflächlich einem Trend anzuschließen, ist das Bedenkliche, sei es im Bereich der Literatur, der Mode oder der Moral.

Die enge Verbindung von satirischer Gesellschaftskritik und Literaturkritik in La tartana kann jedoch nicht darüber hinweg täuschen, daß sich die beiden Stoßrichtungen trotz mancher Gemeinsamkeiten durch unterschiedliche Qualitäten auszeichnen. So liegen beiden grundsätzliche Aspekte wie eine um sich greifende Oberflächlichkeit oder der zunehmende Einfluß des Geldes in moralisch sensiblen Bereichen zugrunde, und beide sind spezifisch im Sinne einer Ausrichtung auf den venezianischen Kontext. ${ }^{22}$ Während jedoch die Texte allgemeinerer Gesellschaftskritik wie - Della Fiera, detta la Sensa $<$, ,Dell'andare a Padova $\alpha$, sDell'andare la sera al fresco $\approx$, Dell'uccellare, e delle cacce $\propto$, "Delle Sagre $\propto$ und selbst die Berufsgruppensatiren gegen Schriftsteller, Geistliche und Advokaten in einer

22 Dies wird bereits in der Notiz = Lo stampatore all'inimico lettore e deutlich, in der Interessenten für einen Tageskalender an die Verkaufer auf der Rialtobrücke verwiesen werden, aber auch durch zahlreiche Hinweise auf venezianische Bräuche und Feste sowie den Schauplatz des Originale-Saccheggio-Kampfes, =la piazza«, d. h. den Markusplatz, die einzige venezianische spiazza (andere Platze werden mit -campo* bezeichnet). 
langen Tradition stehen ${ }^{23}$ und keine konkreten Namen aufweisen, sind die Widmung an die Leser, in der das Originale-Saccheggio-Duell dargestellt wird, und vor allem die Jahreszeiten-Capitoli, in denen der Name Arrighi Landinis mehrfach auftaucht, in ihrer Personenbezogenheit zielgerichteter. Dennoch handelt es sich, vor allem in bezug auf Goldoni und Chiari, nicht um eine persönliche Satire, verstanden als direkter Angriff auf die Privatperson, sondern um eine Attacke auf die maßgeblichen Repräsentanten des venezianischen Theaterbetriebs. Trotzdem konnte es kaum ausbleiben, daß eine weitere Voraussage schnell Wirklichkeit werden sollte,

Sovvengavi che questa è la Tartana;

Deh non s'arrosti per cosa triviale

Quella vostra scienza sovrumana.

Darannovi di scritti uno spedale da farne controversia, e apologia, Il celebre Dottor tale, o cotale,

L'msigne Abbate, o il mal, che Dio vi dia.

(Col. VIII, 33-34)

In den folgenden Jahren entstand tatsächlich eine Flut von Texten, in denen sich der *celebre Dottor * Goldoni, der minsigne Abbate* Chiari und Gozzi gegenseitig angriffen, verteidigten, rechtfertigten. Der direkte Schlagabtausch dauerte an, bis Goldoni und Chiari 1762 Venedig den Rücken kehrten.

\subsection{Theater-Streit-Kultur}

Diese Kontroverse zwischen Gozzi, Goldoni und Chiari, in die am Rande auch andere Autoren wie zum Beispiel Saverio Bettinelli involviert waren, steht, wie bereits angedeutet, keineswegs isoliert. Vielmehr erscheint sie als Fortsetzung einer in Venedig seit Jahren währenden Diskussion, die sich um das Theater, genauer um die Komödie drehte und deren Protagonisten, wie folgende Skizze zeigt, Carlo Goldoni, Pietro Chiari und Francesco Griselini waren. Nicht nur auf der Bühne, sondern auch in Vorworten, Versepisteln und Gedichten nahmen die Autoren und ihre jeweiligen Anhänger meist in polemisch-ironischer Weise Stellung zu aktuellen Stücken, zu deren Handlung, Personen und Sprache. ${ }^{24}$ Erst vor

23. Als Vorbilder gelten Gozzi Ariost und Boileau, von dem er 12 Satiren übersetzt und mit Anmerkungen versehen hat. Im Settecento stehen Namen wie Martello, Marcello, Becelli u. a. für die fortdauernde Tradition der Satire.

24 Bemerkenswert ist, daß die von Goldoni angestrebte Nobilitierung der Komödie offensichtlich keinerlei Auswirkung auf die rhetorische Form der poetologischen Ausein- 
diesem Hintergrund treten einerseits eine gewisse Selbstverständlichkeit von Gozzis Eingreifen und andererseits die Besonderheiten seiner Parteinahme zutage.

Daß sich die Diskussion vor allem in Venedig und an den Komödien entzündete, ist symptomatisch. Zum einen spielte das Theater eine entscheidende Rolle im sozialen und kulturellen Leben Venedigs, der Theaterstadt par excellence, so daß das Interesse einer breiten Offentlichkeit gegeben war. ${ }^{25} \mathrm{Zum}$ anderen konnte man es sich erlauben, über die Aufführungen oder die Texte der Komödien ohne den traditionell gelehrten Ballast der Tragödiendebatten zu urteilen und sich auf das immer relevanter werdende Kriterium des »buon gusto $\approx$ zu berufen, das zum Gemeinplatz wurde und zur Rechtfertigung der eigenen Meinung diente.

\section{Goldoni-Chiari-Querelen}

Der Beginn der offenen, von Gozzi in La tartana gebrandmarkten Auseinandersetzung zwischen Goldoni und Chiari läßt sich auf das Jahr 1749 datieren. Seit einiger Zeit war die Konkurrenz zwischen den Sprechbühnen in Venedig aus ökonomischen Gründen härter geworden und der Wettstreit um die Publikumsgunst intensiver. Chiari, seit 1747 in Venedig und an den Teatri Grimani als Bühnenautor engagiert, präsentierte im Oktober 1749 am Theater San Samuele eine Komödie mit dem Titel La scuola delle vedove, die ganz offensichtlich eine Parodie von Goldonis La vedova scaltra war, deren Premiere Ende 1748 am Theater Sant'Angelo stattgefunden hatte. ${ }^{26}$ Dieser Provokation begegnete Goldoni mit der Ver-

andersetzung hatte. Während Geschichte und Poetik der Tragödie dem genus sublime entsprechend in gelehrten Traktaten abgehandelt wurden, fand die Diskussion um die Komödie hauptsächlich in Para- und Gebrauchstexten statt.

is Vgl. Kap. 3, Exkurs: Die venezianische Theaterszene.

26 Chiaris erste Jahre in Venedig sind nur spärlich belegt, so daß nicht nur das genaue $\mathrm{Da}_{3}$ tum seiner Ankunft in Venedig unsicher ist, sondern auch die ersten an San Samuele aufgefuhrten Stücke L'avventuriere alla moda und La scuola delle vedove unauffindbar sind; vgl. C. Alberti, - Introduzionee zu ders. ( $\mathrm{Hg}$.), Pietro Chiari e il teatro europeo del Settecento, Verona, Neri Pozza 1986, S. 1 T-36, hier S. 14-16. Tatsächlich enthält keine der mehrbändigen Ausgaben von Chiaris Komödien eines der beiden Stücke, noch liegen sie in venezianischen Bibliotheken als Einzelausgaben vor. Demgegenüber sind im Ausstellungskatalog I teatri pubblici di Venezia (secoli XVII-XVIII), Hg. Ludovico Zorzi u. a., Venezia 1971, unter den Nummern 215 und 216 sowohl L'avventuriere alla moda als auch $L$ a scuola delle vedove verzeichnet; unklar bleibt, um welche Art von Dokument es sich handelt (Handzettel, Besetzungszettel, Titelblatt einer Druckausgabe); die unter 215 angegebene Ausgabe von Chiaris Komödien enthält L'avventuriere alla moda nicht. 
offentlichung des Prologo apologetico alla commedia intitolata La vedova scaltra contro le critiche contenute nella commedia intitolata La scuola delle vedove, einem Dialog zwischen Prudenzio, »riformatore de' teatri $\propto$, und Polisseno, "poeta «, ${ }^{27}$ in dem der Autor der Scuola delle vedove nicht nur des Plagiats angeklagt wird, sondern Polisseno Punkt für Punkt die augenscheinlich in Chiaris Stück enthaltenen Vorwürfe hinsichtlich der Wahrscheinlichkeit, der Nachahmung und literarischer Regeln widerlegt. Prudenzio bleibt das letzte Wort im Gespräch: •Il Signor Polisseno è partito, ed io pure me ne anderò. Veramente, s'egli si scalda un poco, lo compatisco. Ha egli il merito d'aver introdotto il buon gusto delle Commedie, ed ora lo vorrebbono gettar a terra. Ma non sarà, non sarà; a Venezia gli vogliono bene; a Venezia si fa Giustizia. Critiche? Foco di paglia, foco di paglia. ${ }^{28}$ Diese Einschätzung oder Hoffnung Goldonis entsprach jedoch nicht der Realität, denn zum einen wurden zunächst weitere Aufführungen der beiden Komödien durch die venezianische Regierung untersagt und zugleich die Vorlage neuer Stücke vor dem Magistrato della Bestemmia dekretiert, ${ }^{29}$ zum anderen sollte sich das venezianische Theaterpublikum in sgoldonistik und *chiaristik spalten und die Konkurrenz stimulieren. So könnte die Konfrontation mit Chiari auch als Anregung für Goldonis intensive Reflexion über sein Reformvorhaben und die dafür so entscheidenden Texte aus dem Jahr 1750 , die metatheatralische Komödie Il teatro comico sowie das ausführliche Vorwort zur Erstausgabe seiner Komödien bei Bettinelli, gedient haben. Das Vorwort zur 1751 aufgeführten Prosakomödie L'incognita macht allerdings deutlich, daß Goldoni im Hinblick auf den Publikumserfolg zu weitgehenden Konzessionen bereit war. L'incognita, so schreibt Goldoni, sei eine »commedia romanzesca«, die er aufgrund des großen Publikumserfolgs ähnlicher Stücke von Chiari verfaßt habe, obwohl er diese Art von Komödien an sich nicht gutheißen könne. Dieses Bekenntnis belegt, daß es nicht nur

Bereits vor der Affäre um La scuola delle vedove könnte ein Schmähgedicht Goldonis oder eines seiner Anhänger anläßlich der Aufführung von Chiaris L'avventuriere alla moda im Oktober 1749 als Auslöser der Polemik gewirkt haben. Siehe Goldoni, XIII, 945, Sonetto del Goldoni all'abate Chiari und Ortolanis Kommentar. Die Erwähnung dieses Gedichtes wird allerdings in der Goldoni-Forschung sorgsam vermieden, wohl um Chiari den ersten Stoß im Duell zuschreiben zu können.

27. Polisseno Fegejo ist Goldonis arkadischer Name, Prudenzio ist der *capocomico « von Sant'Angelo, Girolamo Medebach.

28 Goldoni, II, 4 I 4 .

29 Während Goldoni in seinen Memoiren nur vom Aufführungsverbot für Chiaris Stück spricht, stimmt die Sekundärliteratur darin überein, daß dieses beide Komödien betraf; z. B. Iteatri pubblici di Venezia, op. cit., S. 119 , oder Roberto Tessari, Teatro espettacolo nel Settecento, 2. Aufl., Roma, Laterza 1997, S. 73. 
Chiari war, der Goldoni imitierte, sondern auch Goldoni auf Chiarische Manier das Publikum an sich zu ziehen versuchte. ${ }^{30}$

\section{Griselini im Kreuzfener der Kritik}

Kurz unterbrochen wurde das $*$ Duell $\propto$ Goldoni-Chiari durch eine Polemik, die Francesco Griselini 1752 mit der Aufführung von $\mathrm{Il}$ marito dissoluto $^{31}$ am Theater San Luca auslöste. Stein des Anstoßes war vor allem eine Szene, in der sich Pantalone, im Personenverzeichnis als »mercante onorato* bezeichnet, als Philosoph und Autor einer Komödie mit dem Titel »Il marito dissoluto* geriert. ${ }^{32}$ Die Kritik entzündete sich nicht nur an der Unwahrscheinlichkeit, daß Pantalone als einfacher Kaufmann fähig ist, eine Komödie zu schreiben ${ }^{33}$ sondern auch am dramaturgischen

$10 \mathrm{Zu}$ L'incognita schreibt Goldoni: QQuesta Commedia che ora pubblico colle stampe, diversa è forse da tutte le altre mie. Ella è romanzesca, fatta per me non per inclinazione ch'io avessi ad un tal genere di teatrale componimento, che anzi ne son nemico, ma per un mero capriccio, in una certa occasione che a farlo mi ha stimolato. Alcune Commedie di cal carattere esposte furono sulle Scene da un valoroso soggetto ch'io tanto venero, quanto egli me dispreaza ed insulta. Fortunate riuscirono tali composizioni, da un noto Romanzo onninamente estratte, e quantunque condannassi io dentro di me medesimo la massima di nuovamente sulle nostre Scene introdurle, l'esito m'invaghi di darne una io pure al Popolo, che del sorprendente qualche volta s'appaga. * (Goldoni, III, 795) Ob Goldonis Incognita tatsächlich als Parodie auf Chiaris Trilogie L'orfano perseguitato, L'orfano ramingo und L'orfano riconosciuto ( $175 \mathrm{i}$ ) nach Fieldings Roman Tom Jones gedacht war, wie Alberto Beniscelli in soldoni nello specchio di Gozzi: divergenze e incontri tra drammaturgia e scenau, in: Elena Sala Di Felice; Laura Sannia Nowē (Hgg.), La cultura fra Sei e Settecento, Modena, Mucchi 1994, S. 197-210, hier S. 209, in einer Anmerkung schreibt, kann aufgrund dieses Vorworts, das vielmehr eine publikumswirksame Imitation nahelegt, bezweifelt werden, wenn auch das Stück heute noch so unwahrscheinlich und ubertrieben wirkt. Daß Fieldings Roman erst 1749 erschienen war, wirft ein besonderes Licht auf die Geschwindigkeit der Umarbeitung Chiaris.

Auch Gozzi weist in einem Gedicht darauf hin, daß Goldoni Chiari imitiert (Col. VIII, 200) und nicht nur umgekehrt.

11 Francesco Griselini, $1 /$ marito dissoluto, Commedia di carattere, Venezia, Bassaglia 1752.

12 Pantalone spricht der Tradition der Figur gemäß dialektal gefärbt. Als Philosophierender vertritt er eine popularisierte aufklärerische Position: =Tutti i homeni xe formai coll'istessa Architettura, $\mathrm{e}$ turti i agisse coll'istesso meccanismo per via d'un spirito libero, e immortal, dal qual depende l'armonia dei moti della nostra macchina; la percezion, e'l modo de paragonar, e meggio sviluppar le idee. No la creda, no, che l'educazion, la nobiltà del nascer, e le ricchezze condusa all'acquisto delle scienze; anzi ghe dirò, che l'educazion istessa alle volte rovina, e mette fren ai svoli, che poderave far i spidi spesso i xe quei oggetti, che svia dalla bona strada. El solo genio, el desprezzo della fadiga, e la continua reflession xe le cose, che mena al saver: e queste se pol trovar ugualmente nei poveri, e nei ricchi; in quei della più alta, e della più bassa estrazion.* (II, 15).

3s Dieser Kritikpunkt wird in der Komodie selbst vorweggenommen, wenn Flaminia zu Pantalone sagt, *Non avrei mai stimato, che un Mercante potesse aspirare al conseguimento di cognizioni tanto sublimi (II, 15 ). 
Aufbau, innerhalb dessen diese Szene als unmotivierter Fremdkörper erscheint, sowie an den Äußerungen Pantalones selbst, der implizit Kritik übt an der von Goldoni propagierten Beobachtung der Umgebung als Grundlage für das Schreiben von Komödien. ${ }^{34}$ Eine anonyme Schrift folgte der anderen: »Conferenze tra un cavaliere e l'autore delle lettere critiche mit dem Titel Della commedia italiana wurden mit Osservazioni contro-critiche beantwortet, die wiederum eine Lettera apologetica dell'autore delle Lettere critiche scritta in risposta all'illustrissimo Signore N.N. sopra il libretto intitolato Osservazioni contro-critiche di Antonio Bianchi sopra un trattato della Commedia italiana dell'antedetto autore zeitigten. ${ }^{35}$ Ohne näher auf den Inhalt der Schriften einzugehen, wird sichtbar, daß das Theater, und vor allem die Komödie, in Venedig Anlaß waren, heftige Debatten zu führen und sich öffentlich, wenn auch anonym, zu äußern. Daß die Texte größtenteils gedruckt wurden, bezeugt, daß das Interesse daran groß und seitens der Verleger mit einem lukrativen Geschäft zu rechnen war.

\section{Konkurrenz selbsternannter Theaterreformer und ihrer Anhänger}

Nach dieser kurzen Episode richtete sich das Augenmerk bis zum Erscheinen von Gozzis Tartana 1757 wieder auf Goldoni und Chiari. Mit dem Wechsel Goldonis an das Theater San Luca und der daraus sich ergebenden Nachfolge Chiaris an Sant'Angelo flammte die Konkurrenz erneut auf, so daß die Jahre $1753 / 54$ einen neuerlichen Höhepunkt markieren. Daß Chiaris Erfolg in Venedig zunahm und seine Position stabiler wurde, ist nicht nur an den steigenden Zuschauerzahlen abzulesen, ${ }^{36}$ sondern auch

34 Als amoderner - Autor hat Pantalone seine Komödie nämlich in 14 Tagen - in deutlichem Anklang an Goldonis Äußerungen im Vorwort zur Bettinelli-Edition von 1750-auf der Basis der Beobachtung seiner Umgebung geschrieben, ohne sich an irgendwelchen Modellen zu orientieren. Nun liest er zum Vergleich Molière, sper veder la gran defferenza, e per scovrir quanto se pol far con un longo studio, e quanto colle forze della natura ajutae dall'osservazion $\alpha$, und muß feststellen: = Infinitamente xe diverso el pensar de quell'Auttor [sic] immortal del mio basso, e meschin. Mi son come una Talpa, che no vede, in fazza a un'Argo, che ghà mille occhi. « Auf den Einwand Flaminias, dies sage er nur aus Selbstbescheidenheit, antwortet er: $\gg$ No; ghe parlo con verità; so conoscerme assae. Se tutti fusse come mi, val' a dir manco giudici parziali de quel, che i produsse; molti no tiorave per scriver mai più la penna in man. Ma basta; lassemo sto descorso, che podaria ferir qualcun. * (II, is).

35 Ausführlicher dazu siche Giuseppe Ortolani, Settecento. Per una lettura dell'Abate Chiari. Studi e note, Venezia, Fondazione Cini 1905, S. 464.

36 So wurde beispielsweise Il filosofo veneztano $175418 \mathrm{Mal}$ wiederholt, wie Chiari in 
daran, daß 1754 seine Komödie $I l$ poeta comico aufgeführt wurde, die als theatralisches Manifest ein bewußtes Gegenstück zu Goldonis Teatro comico (1750) darstellt. Chiaris Anliegen angesichts der laufenden kontroversen Diskussionen um das Theater war, sdi cangiare in cattedra di poesia comica le pubbliche Scene, onde tutto ad un tratto illuminare i ciechi, convincere gli increduli, e dar l'armi in mano alle persone giudiziose, e discrete da sostenere le proprie opinioni, e combattere le altrui stravaganze. $\alpha^{37}$ Analog zu Goldoni, der von seiner 1750 aufgeführten metatheatralischen Komödie Il teatro comico sagt, "piuttosto che una Commedia, Prefazione può dirsi alle mie Commedie«, bezeichnet Chiari Il poeta comico als .Commedia preliminare ${ }^{38}$ und meint damit den poetologischen Anspruch des Stücks, der hier exemplarisch, im Vorgriff auf kommende Komödien zur Darstellung kommt. Daß nicht nur die Konkurrenz das Geschäft belebt, sondern auch Kritik den Geist anstachelt, geht aus einem zu Beginn der Saison 1754 rezitierten allegorischen Prolog Chiaris hervor, in dem Venezia, Prologo und Commedia auftreten und Venezia dem Kritisierten und von Neid Verfolgten ewigen Ruhm verspricht. ${ }^{39}$

Auch die zahlreichen Ähnlichkeiten in der Wahl der Titel bei Goldoni und Chiari sind ein Indiz dafür, daß keineswegs eine heimliche Nachahmung des Gegenspielers intendiert war, sondern ein offener Wettbewerb stattfand. So standen sich auf den venezianischen Spielplänen eine Pamela (1750) und eine Pamela maritata (1753) gegenüber, ein Moliere (1751) und ein Moliere marito geloso (1753), eine Sposa persiana (1753) und eine Schiava chinese (1753), ein Filosofo inglese (1754) und ein Filosofo viniziano (1754), ein Terenzio (1754) und ein Marco Accio Plauto (1755), ${ }^{40}$ aber auch Goldoni zögerte nicht, Titel Chiaris zu varïeren oder

den =Osservazioni- zu diesem Stück selbst schreibt; Pietro Chiari, Commedie in versi, 10 Bde., Venezia $1756-1762$, hier Bd. IV.

37 Commedie in versi, Bd, III, S. 6. Die ironischen Anspiclungen auf Goldoni sind in diesem Stück unübersehbar, so z. B, wenn von smondo e reatro* (II, 4 ), von den Masken (III, 4) oder den Plagiatsvorwürfen anläßlich des Filosofo viniziano die Rede ist. In Konkurrenz zu Goldonis Reformprojekt insistiert auch der Protagonist Zanetto auf seiner Intention, sdi riformar la scenau (III, 4).

18 Goldoni, II, ro45; Chiari, Commedie in versi, Bd. III, S. 5.

39 Venezia: >Per farsi in sulle Scene d'eternita ben degni, / La più pungente critica suol aguzzar gl'ingegni. / Soffrite pur, soffrite questi odj memorandi. / Che invidiati io voglio quelli, che voglio grandi. / Cogli Autor suoi la satira perir quà giù sen deve, / Che la fa disonora, non già chi la riceve. Chiari, Raccolta di prolog bi in versi alle sue commedie recitate in Venezia e altrove, cominciando dall' anno 1753 , Venezia, Pasinelli 1754, XVI.

6. Jeweils der erste Titel ist von Goldoni, der zweite von Chiari; vgl. auch die Liste der Stucke Chiaris und ihrer Referenztexte in Armando Marchi, $\rightarrow$ Il mercato dell'immaginario*, in: C. Alberti (Hg.), Pietro Chiari e il teatro europeo del Settecento, op. cit, S. $77-113$, hier S. 85 . Was die Datierung betrifft, folge ich bei Goldoni den Angaben in Ortolanis Aus- 
zu übernehmen, wie zum Beispiel 1751 mit L'avventuriere onorato und noch 1760 mit Pamela maritata.

Anlaß zur Imitation gaben die unterschiedlichsten Aspekte; einmal war es das "romanzesco $\propto,{ }^{41}$ ein andermal die versi martelliani oder der venezianische Dialekt, der Exotismus oder ein Modewort wie nfilosofo», und nicht immer stand ein analoger Titel auch für eine Übereinstimmung in der Handlung. Die Parallelität der Premieren von Goldonis Sposa persiana und Chiaris Schiava chinese im Herbst 1753 sowie des Filosofo inglese und des Filosofo viniziano im Karneval 1754 zeigen die Engführung des Wettstreits an. Der überwältigende Erfolg von La sposa persiana mit 34 Wiederholungen ${ }^{42}$ animierte Chiari, sich daran nicht nur mit einer exotischen Komödie zu messen, sondern gleich mit zwei, wie er im Vorwort zur Ausgabe der Commedie in versi schreibt:

Lo strepito che fece in quell'anno medesimo la Sposa Persiana del Sig. Dottor Goldoni m'invogliò di metter a gara su' teatri nostri la gran novità de' costumi Chinesi, che del pari eccitasse la curiosità del Pubblico, e ne meritasse gli applausi. Le speranze mie non caddero a quella volta deluse. La mia Schiava Chinese cosi ben si sostiene contro il torrente della malignità, e dell'invidia, che mi die corraggio a produrre una seconda Commedia del colore medesimo, la quale viene ad essere la seconda compresa nel volume presente. Questa seconda Commedia è intitolata Le Sorelle Chinesi, perocchè non fa ella che seguitare la prima, e ne ripiglia l'intreccio, dove pareva in essa finito. [...] e superò di gran lunga la Sorella, e compagna sua nella strepitosa accoglienza, che le fece il pubblico allora in due fazioni diviso, e nelle fazioni sue ostinato, e caldissimo, ${ }^{43}$

Diese direkte Konfrontation auf der Bühne wurde von den beiden Anhängerschaften mit einer Flut von Pamphleten begleitet und geschürt. ${ }^{44}$

gabe, während bei Chiari in Commedie in versi davon auszugehen ist, daß er =more veneto: datiert, das heißt: das neue Jahr beginnt erst im März, so daß beispielsweise -carnovale $1753 \alpha$ in der üblichen Zeitrechnung dem Jahr 1754 entspricht.

4) Im Vorwort zu L'incognita beschreibt Goldoni dieses Romanhafte einer Komödie wie folgt: *ideandomi una favola romanzesca, tessei con tale immagine la presente Commedia, la quale è di tanti fatti, di tanti accidenti ripiena, che potrebbe servir di sommario per un romanzetto di quattro tomi almeno. [...] è una Commedia romanzesca, perché nel giro di poche ore una moltitudine di accidenti comprende inaspettati e strani, e talor sorprendenti; tuttavolta però studiato ho di condurli in maniera tale, che non abbiano a dirsi impossibili o inverisimili, ma solo da una estraordinaria combinazione diretti.(Goldoni, III, 795-796).

12 Im allgemeinen werden bereits acht bis zehn Wiederholungen als Erfolg verbucht.

4 Pietro Chiari, Commedie in versi, Bd. X, S. 4-5. Chiaris Charakterisierung der beiden Parteien als *ostinato e caldissimo* bestätigt Gozzis satirische Darstellung in La tartana.

4. Vgl. das bereits erwähnte Manuskript Amedeo Svajers, Composizioni uscite su i Teatri, Commedie, e Poeti nell'Anno MDCCLIV in Venezia; dazu C. Alberti, »Gare e contrasti tra due spoeti comici $\alpha$ negli anni $1753-1756 \%$, op, cit., und Kapitel VII, - La rivalità con 1'abate Chiari-, in: C. Alberti, Goldoni, Roma, Salerno 2004, S. $215-232$. 
Zunāchst griff der venezianische Dialektdichter Giorgio Baffo Goldonis Filosofo inglese in einer satirischen Versepistel in versi martelliani an. Er kritisierte, daß es in diesem Stück nichts zu lernen gäbe, die Charaktere keinerlei »verità < besäßen und es sich nicht um eine Komödie, sondern vielmehr um eine sdesertazion handle. $^{45}$ Goldoni antwortete auf diese Vorwürfe mit einem Gedicht, das in der Art der Tenzonen kunstvoll die Reime Baffos aufnimmt: » Responderò in succinto, se farlo m'è permesso, // Co le so stesse rime, e col so metro istesso. « Darauf reagierte nicht nur Baffo mit einem weiteren Gedicht, sondern auch Gasparo Gozzi, der Goldonis Komödie verteidigte. Wie diese sind zahlreiche andere, im selben Kontext stehende Texte in venezianischem Dialekt verfaßt, womit sich die lokale, sehr spezifische Ausrichtung nicht nur in inhaltlicher, sondern auch in sprachlicher Hinsicht manifestiert.

Neben der Polemik um Goldoni, die in Baffos Gedichten auch seinen Rivalen Chiari streift, zirkulierten diverse Schriften, die explizit gegen Chiari gerichtet waren oder zu dessen Verteidigung dienten. ${ }^{46}$ So findet sich in den 1755 erschienenen Censure miscellanee sopra la commedia mit einer Lettera anonima, die sachliche Irrtümer in Chiaris La Marianna o L'orfana riconosciuta und seinen chinesischen Stücken anprangert, nicht nur eine generelle Kritik sämtlicher Stücke Chiaris, sondern auch eine höchst ironische Reaktion auf dessen Dichterkrönung im Jahr 1754. Fast unvermeidlich nimmt sich noch aus heutiger Sicht die ironische Reaktion auf ein Büchlein aus, das den Titel Della vera poesia teatrale. Epistole poetiche di alcuni letterati modanesi dirette al Signor Abate Pietro Chiari colle risposte del medesimo ${ }^{47}$ trägt und offensichtlich anläßlich der Krönung Chiaris zum Hofpoeten durch Francesco III., Herzog von Modena, erschienen war. Auf die elf enkomiastischen Versepisteln aus der Hand hochgestellter Verehrer Chiaris folgt jeweils eine Antwort des Geehrten, der das Lob huldvoll entgegennimmt. Daß die Lobredner mit Superlativen nicht gerade sparsam umgehen, wird bereits in der ersten Epistel deutlich:

Tu vai de i Greci sommi, Tu de' Latini al paro,

E de gl'Itali antichi Cigno animoso, e raro.

Tu superi gl'Ispani, Tu superi gl'Inglesi

Moderni, e prischi; ah il soffrano, Tu superi i Franzesi.

45 Zit. nach Goldoni, XIII, $201 \mathrm{ff}$.

46. Die im folgenden angefuhrten anonymen und meist undatierten Texte befinden sich in der Bibliothek der Casa di Carlo Goldoni in Venedig.

9. Die fast 9o-seitige Festschrift trägt folgende Angaben: In Modana, Eredi di Bartolomeo Soliani, imprimatur Die 30. Augusti 1754. 
Tu a gli Europei calenti campo novello apristi,

Nuovo Comico Mondo Tu, CHIARI, discopristi,

Con l'esempio mostrando larga in se stessa, estensa

$\mathrm{La}$ Poesia divina quasi infinita immensa. ${ }^{48}$

In den Censure miscellanee schließt also an einen "Congresso di Parnaso", in dem das Loblied auf die neuen Dichter gesungen wird, ein "Discorso fatto dalla commedia $\propto$ an, der der Verwunderung darüber Ausdruck gibt, daß nun einem Dichter so hohes Lob gezollt werde, der doch im Schlamm der Hippokrene steckengeblieben und nicht einmal bis zum Saum des Helikon vorgedrungen sei. Dieses Bild wiederum korrespondiert unübersehbar mit La vera commedia von Midonte Priamideo [i.e. Pietro Verri], einer deutlichen Parteinahme für Goldoni, in der Chiaris Forderung, eine Komödie müsse in Versen geschrieben sein, lächerlich gemacht wird. ${ }^{49}$ Ein weiterer anonymer Text mit dem Titel L'asino in cattedra lehnt sich seinerseits an die erwähnte Lettera anonima an, was durch zahlreiche wörtliche Zitate offenbar wird, und kehrt diese ironisch um. Auf Verris La vera commedia reagierte Chiari maliziös mit der Widmung seines Werkes La filosofia per tutti. Lettere scientifiche in versi martelliani $(1756)$ an $*$ Midonte Priamideo Milanese. Pastor arcade di Roma ${ }_{0}{ }^{50}$ Verse aus La vera commedia aufnehmend, schreibt er in der Widmung: „Cerca, perch'io l'impari, nè invano or m'affatichi, / Chi fosse mai Poeta senza imitar gli antichi« und führt im Vorwort aus, daß er auch für seine Filosofia per tutti von anderen Philosophen profitiert habe, "Tanto non mi vergogno d'imitare, e ricopiare il buono dove lo trovo*.

So entstand ein kaum noch zu entwirrendes Geflecht von Texten, die teils in ironischer, teils in ernster Weise mit Goldonis und Chiaris Theater oder untereinander abrechnen und manchmal nicht nur einem ernstzunehmenden Kritikbedürfnis entsprungen zu sein scheinen, sondern auch der Lust am polemischen Schreiben. ${ }^{51}$ Nur auf diesem bewegten Hinter-

48 Das exponierte Reimwort sestensa* ist nicht nur Teil der Synonymenreihung "larga in se stessaa, ,infinita immensa", sondern spielt auch auf das Haus Este an, das sich dem Theater und Chiari gegenüber so wohlwollend zeigt.

49 "Mormori pur Poeta in Ippocrene immerso, / Ch'esser non pù̀ Commedia, se non è fatta in versi-. Zu Goldoni schreibt Verri: -Goldoni la Commedia di bei costumi madre / Risveglia, e mille grazie scherzan con lei leggiadre. * Midonte Priamideo, La vera commedia, s, n.t.

Wie aus ciner Verlagswerbung auf der letzten Seite der 3 Bände der Poesie e prose italiane e latine Chiaris von $176 \mathrm{t}$ hervorgeht, antwortete dieser selbst in einem $n$ Dispaccio di ser Ticucculia a chi scrisse il Congresso di Parnasso * auf die anonyme Polemik. Der Text scheint allerdings verschollen zu sein.

so Pietro Chiari, La filosofia per tutti, Venezia, Pasinelli 1756; Widmung und Vorwort ohne Seitenzahlung.

51. Interessant ist in diesem Zusammenhang, daß persönliche Freundschaften nicht zwangs- 
grund sind Carlo Gozzis Tartana und alle weiteren polemischen Texte angemessen zu verstehen.

\subsection{Pamphletistische Literaturbetriebsamkeit}

Mit dem Erscheinen von Gozzis Tartana beginnt sich in mehrfacher Hinsicht eine Veränderung in der Auseinandersetzung abzuzeichnen. Zum einen tritt mit Gozzi nicht ein Anhänger eines der beiden bisherigen Kontrahenten zu seiner Verteidigung auf den Plan, sondern ein ironischkritischer Beobachter, der aus einer gewissen Distanz sowohl die beiden -Duellanten $\alpha$ als auch ihr Publikum ins Visier nimmt. Zum anderen weitet sich der Schauplatz von der Theaterbühne auf andere Räume aus, so daß die Debatte um das Theater nicht mehr isoliert, sondern als ein Aspekt einer umfassenderen Problematik erscheint. Als weiteres Charakteristikum und wohl als Folge dieser Ausweitung über den Bereich des Theaters hinaus, läßt sich bei den hauptsächlich Betroffenen Goldoni und Chiari eine Verlagerung der Kontroverse von der Bühne und den Paratexten der edierten Stücke zu Gedichten und Prosatexten feststellen. Mit wenigen Ausnahmen ist - in seltenen Fällen mit Hilfe des Erscheinungsdatums, meist eher aufgrund indirekter textinterner Hinweise - die ungefähre Abfolge der Texte bis 1761 rekonstruierbar. ${ }^{52}$ Sie soll im folgenden in groben

Tāufig eine entsprechende Parteinahme zur Folge haben mussen. So erklärt beispielsweise Ferdinando Toderini, daß er in der Polemik gegen Giorgio Baffo auftreten, ihm im übrigen aber immer freundschaftlich verbunden sein werde. Vgl. C. Alberti, •Gare e contrasti tra due spoeti comici* ncgli anni 1753-1756*, op. cit, S. 70 .

12 Uber Malamanis Bibliographie hinaus haben v. a. Bianca Peruzzi in einer unveroffentlichten Tesi di laurea (Padova, 1969/70) und P. Bosisio in Carlo Gozzi e Goldoni eine chronologische Ordnung der vielfach undatierten polemischen Texte vorgenommen, wobei allerdings das enge Ineinandergreifen der Texte von mindestens drei Autoren (Gozzi, Goldoni, Chiari; daneben z. B. Bettinelli, Bordoni) nicht deutlich wird. Zudem wurde mancher Hinweis auf die Abfolge in Gozzis eigenen Texten und in den Anmerkungen Ortolanis in Goldoni, XIII übersehen. Ein besonderes Problem hinsichtlich der Datierung stellen die in Col. VIII aufgenommenen Gedichte Gozzis dar, deren genaue Entstehungszeit nur in seltenen Fällen zu erschließen ist. Hilfreich ist in mancher Hinsicht Gozzis eigene Darstellung der Entwieklung der Polemik in Discorso, notizie, verita, e riflessi, iquali, per esser frivolezze, non saranno letti, e perciò non annojeranno i lettori (Col. VIII, 243-259), die sich aufgrund intertextueller Befunde als weitgehend korrekt erweist.

Obwohl Gozzi selbst den Beginn der Kontroverse auf das Erscheinen von La tartana datiert und weder von Gozzi noch von den Mitgliedern der Accademia Granellesca (s. Kap. 1.4) Texte vorliegen, die auf eine öffentlichkeitswirksame Polemik gegen Goldoni vor 1757 schließen lassen, wird immer wieder versucht, die Auseinandersetzungen bereits früher anzusetzen. So bestätigt P. Bosisio einerseits, daß es keine Goldoni-kritischen Granelleschi-Texte vor 1757 gebe, will den Beginn der Polemik jedoch um etwa 
Zügen vorgestellt werden, wobei einerseits direkten textuellen Referenzen besondere Aufmerksamkeit gewidmet wird, andererseits denjenigen Texten, die über die Goldoni-Chiari-Gozzi-Triade hinausweisen. Dieser chronologisch orientierten Übersicht, die auch das Bild Gozzis in den Augen der anderen nachzeichnet, folgt eine Zusammenfassung der inhaltlichen Schwerpunkte von Gozzis Position, die als Ausgangspunkt für die Diskussion seines Theaters dient.

\section{Gozzi und Goldoni in polemischem Dialog}

\section{Auf Gozzis Tartana reagierte Goldoni unmittelbar mit einem Capitolo an den *illustrissimo Signor Avvocato Giuseppe Alcaini* zu Sebastiano}

14 Jahre vordatieren (Carlo Gozzi e Goldoni, op. cit., S. 22-23), Begründet wird dies mit einer Außerung Goldonis in seinen Memoiren, in der er von scenseurs rigides de mes productions* schreibt, die aufgetaucht seien, nachdem er angefangen habe, seine Komödien ganz auszuschreiben. Da dies ab 1743 der Fall war, ist für Bosisio dieses Jahr maßgeblich. In zwei Komödien und einem Verstext aus den Jahren 1750, 1754 und 1755 meint er Anspielungen auf Gozzi und die Granelleschi zu erkennen. Ginette Herry nimmt in $=1756-1758$ : Venezia a teatro ossia Carlo Gozzi prima di Carlo Gozzir, in: C. Alberti (Hg.), Carlo Gozzi, scrittore di teatro, op. cit., S. 33-82, Bosisios These auf und versucht sie mit einigen wenigen weiteren Texten zu stützen. Sie geht so weit, sogar das Zirkulieren einer handschriftlichen Fassung von La tartana im Jahr 1755 für möglich zu halten. Eine solche Spekulation übersieht allerdings, daß zumindest die DezemberProphezeiungen, in denen von einer baldigen Rückkehr Sacchis die Rede ist, eindeutig dagegen sprechen.

Eine Rückdatierung des Beginns der Polemik läßr sich m. E. anhand der wenigen Texte Goldonis und den in ihnen enthaltenen unspezifischen Anspielungen nicht begründen. Sollte man dennoch daran festhalten, daß Goldoni bestimmte Personen damit treffen wollte, wäre zu überprüfen, ob sich die Anspielungen nicht vielmehr gegen Gasparo Gozzi oder Pietro Chiari richten. Gasparo Gozzi veröffentlichte 1750 den ersten Band der Lettere diverse und spricht dort nicht nur über die Nachahmung der Alten und über den Stil, sondern auch über literarische Massenproduktion und ähnliches. Wenn Goldoni in Il cavaliere di buon gusto Gasparo Gozzis Briefe dennoch lobt, könnte dies taktische Gründe gehabt haben. Chiari außert sich im 3. Band der Lettere scelte di varie materie piacevoli, critiche, ed erudite, 3 Bde., Venezia, Pasinelli 1750-52, in Anspielungen auf Komödien Goldonis kritisch zum Nicht-Einhalten der Einheiten und zur Unwahrscheinlichkeit der Ereignisse. Wenn Chiari diesen Kriterien auch in vielen seiner eigenen Stücke keinerlei Bedeutung beimißt, so können die Außerungen doch in polemischer Absicht als spuristisch « interpretiert werden. Was die Karikatur der $\mathrm{Pu}$ risten und Anhänger der Crusca betrifft, könnte man Goldoni mit gutem Recht auch in die allgemeine Tradition der Literatur- und Literatensatire einreihen, die in Venedig besonders lebendig war, vgl. Giulio Natali, Il Settecento, Storia letteraria d'Italia, Bd. I, 6. Aufl., Milano, Vallardi 1964, S. $4^{82}$.

Wie auch immer sich die Situation nach Auffinden der Manuskripte Gozzis darstellen wird, erscheint mir die Tatsache entscheidend, daß ab 1757 ein dichtes Geflecht von Texten entsteht, die zahillose intertextuelle Bezüge untereinander aufweisen, und so von einer vollig neuen Qualităt von Polemik gesprochen werden kann. 
Veniers Amtsantritt als Prokurator an San Marco..$^{53}$ Nach der anfänglichen Klage darüber, daß alle Welt von ihm, Goldoni, Dramen und Gedichte wolle und er daher keine Zeit mehr habe, sie gut zu machen, nimmt er sich doch des geforderten Gedichts an und rechnet in diesem Zusammenhang mit La tartana ab:

Formar desio dell'argomento al paro

Carmi sonori, ed imitar vorrei

Il Chiabrera, il Petrarca, il Bembo e il Caro.

Ma se mai del Burchiello i versi miei

Volessero seguir la foggia strana,

Contro la musa mia bestemmierei.

Ho veduto stampata una Tartana

Piena di versi rancidi sciapiti,

Versi da spaventare una befana.

Versi dal saggio imitator conditi

Col sale acuto della maldicenza,

Pieni di falsi sentimenti arditi.

$\mathrm{Ma}$ conceder si può questa licenza

A chi in collera va colla fortuna,

Che per lui non ha molta compiacenza.

Chi dice mal senza ragione alcuna,

Chi non prova gli assunti e gli argomenti.

Fa come il cane che abbaia alla luna.

Seiner Wut auf die satirischen Verse in La tartana gibt Goldoni im weiteren Verlauf der Terzinen beredten Ausdruck: ${ }^{\circ}$ Fremo di rabbia, ed ho me stesso a sdegno, / Strapazzato veggendo il mio lavoro / In un mestier di si scabroso impegno. « Was Goldoni La tartana vorwirft, ist die BurchielloImitation, die »versi rancidi sciapitiء hervorbringt, sowie die mangelnde Beweisführung für die vorgebrachte Kritik. Während sich diese Aspekte im Rahmen des inhaltlichen Bereichs bewegen, bringt Goldoni mit der Unterstellung, daß das Schicksal dem Verfasser der Tartana nicht gerade hold sei und sich "maldicenza* wie "falsi sentimenti arditi daraus erklärten, eine persönliche Sphäre ins Spiel, die in La tartana unberührt geblieben war. Gerade dieses Hinübergleiten von der allgemeinen in die persönliche Satire wird Gozzi Goldoni immer wieder vorhalten und mit satirischer Schärfe beantworten.

Ein zweiter, ebenfalls 1758 erschienener Text Goldonis führt die Verteidigung gegen La tartana und die Gegenattacke auf Gozzi fort. Wie das Capitolo an Alcaini ist La tavola rotonda eines der unzähligen $\mathrm{Ge}-$ legenheitsgedichte, die anläßlich bedeutender privater, doch in die Öffentlichkeit getragener Ereignisse wie Geburtstage, Hochzeiten, Jubiläen,

3) Goldoni, XIII, $44^{8}-453$; erschienen 1758 , geschrieben wohl noch 1757 . 
Klostereintritte etc. von unterschiedlichster Seite produziert und in sogenannten raccolte, kleinen Festschriften, veröffentlicht wurden; so auch La tavola rotonda, "Poemetto giocoso in occasione de' felicissimi sponsali fra Sua Eccellenza il sig. Pietro Contarini e Sua Eccellenza la signora Maria Venier $\propto$ in Oktaven. ${ }^{54}$ Darin wird das Lob auf das Hochzeitspaar größtenteils ausländischen, an einem *runden Tisch» sitzenden Gästen in den Mund gelegt, was nicht nur eine komische Nationalitätentypologie ermöglicht, sondern auch die Charakterisierung einzelner Personen. Nach einer allgemeinen Einleitung, die die Topoi der Auseinandersetzung zwischen Goldoni und Chiari aufnimmt, ${ }^{55}$ äußern sich die verschiedenen Gäste aus Frankreich, Spanien, Deutschland, Asien, England und Italien über das Hochzeitspaar. Unter den Italienern aus dem Friaul, aus Rom, Venedig, Turin befindet sich auch einer aus der Lombardei, der sich hauptsächlich durch seine Vorliebe für die toskanische Sprache sowie die Dichter Petrarca, Dante, Berni und Burchiello auszeichnet. Als Goldoni im Gedicht von seinem noblen römischen Freund, der ihn zu dieser Runde eingeladen hat, aufgefordert wird, das offizielle Hochzeitsgedicht zu verfassen, steht der Lombarde auf und erhebt seine Einwände:
Un Lombardo che affetta esser cruscante,
Col riso in bocca e col veleno in petto,
Ergesi intorno in aria di pedante.
E favella cosi senza rispetto:
Vada prima studiar Petrarca e Dante
Chi vuol fare canzona ovver sonetto;
E chi vuol schiccherar brillanti ${ }^{56}$ ottave,
Abbia dal Berni o dal Burchiel la chiave.

Und er fährt fort, den auserwählten Dichter, der scogli occhi ardenti, / Pieno di gioja e di dolcezza il petto « dem Auftrag seines Freundes nachkommen wollte, zu kritisieren:

54 Goldoni, XIII, 472-485. Interessant ist die Beurteilung dieser Gedichte Goldonis durch Ortolani, der ansonsten nicht mit Lob für Goldoni spart; über La tavola rotonda urteilt er zum Beispiel: snessun valore letterario ha il presente poemetto, noioso a leggersie (Goldoni, XIII, 1006). Zur Mode der raccolte s. u.

55 So zum Beispiel Goldonis Betonung des svero- ( - Debole è il mio cantar, ma canto il veros; -Delle genti pingendo il ver costume $)$ und seine Praferenz fur =caratteri originali< und doch zugleich suniversali* (-Che bel quadro per me bizzarro e nuovo / Di caratteri veri e originali! / Li studio attento e di raccor mi provo / All'usato esercizio i materiali / Per esporli, non già, com'io li trovo, / Ma con l'arte di farli universali; / Sicché in scena si vegga il vizio espresso, / Ma nessun possa dire: Io son quel desso.*). Damit sichert sich Goldoni wohlweislich schon im vorhinein gegen den Vorwurf der persönlichen Satire ab.

* Immer wieder spottet Gozzi daraufhin über dieses Lieblingswort Goldonis, Zan. XV, ז80, Col. VIII, 189. 
Questi (soggiunse) che da voi si loda, Zeppi di barbarismi ha i scritti suoi. Il plauso, il grido, l'aiutar con froda Finor gli amici ad usurpar tra voi. Faccia baldoria pur, gongoli e goda, Abbia uno stuol di mecenati eroi, Vanti l'opre tradotte in più d'un suolo: Basto i suoi carmi a scorbacchiare io solo.

Mi chiedete ragion perch'io lo faccia? In bronzi, in marmi, la ragion si scriva. Basta che opra qualunque a me non piaccia, Perch'io creder la deggia opra cattiva. Ah mi scrosciano l'ossa, e mi si agghiaccia Il sangue ed ogni parte sensitiva, Quando a vanvera leggo e all'impazzata Il suo Esopo, il Te Deum, la Mascherata. ${ }^{5}$ ?

Daraufhin erklärt jeder der Anwesenden in seinem Idiom den Lombarden für verrüickt:

C'est un fou, c'est un fou, disse il Francese; Lustich star, lustich star, disse il Germano; Splin chiamò l'entusiasmo il saggio Inglese; L'è mat, saugneli in chel, disse il Furlano; Disse chiel è Guascon, il Piemontese; Esto es piccaro, disse il grave Ispano.

Il Persiano dicea: Star mamalucco.

E il Venezian: Vardè che omo de stucco.

Gipfel der Unverschämtheit des Lombarden ist sein Abgang: "Si levò dalla mensa, e rabbuffato / Partì il pedante, e non ci disse addio. « Gänzlich überlegen jedoch reagiert der Beschuldigte selbst, "Signori miei, perdono / Volentieri l'insulto a me dovuto «. Er gibt offen zu: »il so che buon scrittor non sono, / E che ai fonti miglior non ho bevuto a, doch betont er sogleich, daß er trotzdem viel Erfolg habe. Zudem unterscheidet er deutlich zwischen dramatischer und lyrischer Sprache, wobei er sich in ersterer jedem verständlich machen könne, sich zweiterer hingegen kaum gewachsen fühle. Dieses Lavieren zwischen topischer Selbstbescheidenheit und ostentativer Präsentation des eigenen Erfolgs charakterisiert

57 Die erwähnten Texte Esopo, Te Deum und Mascherata sind Gelegenheitsgedichte Goldonis. Wahrend sich in den beiden letzteren, 1756 und im Januar 1758 erschienen, keine direkten Angriffe ausmachen lassen, enthält Esopo alla grata (1755) entsprechende Hinweise, die allerdings teils in den Kontext der Kontroverse mit Chiari einzuordnen sind (z. B. zur Verwendung der versi martelliami), teils sehr allgemein bleiben, wo sie sich z. B. gegen ein puristisches Stilideal wenden. 
nicht nur dieses Gedicht, sondern auch zahlreiche andere, die keinen Bezug zu Gozzis Tartana aufweisen. Gozzi wird vor allem den Vers *Vanti l'opre tradotte in più d'un suolo* mehrfach ironisch zitieren, um die falsche Selbstbescheidenheit Goldonis zu brandmarken. La tavola rotonda intensiviert die im Capitolo sich abzeichnende persönliche Satire, indem die Person selbst auftritt und mit ihrem Verhalten dem Spott der anderen preisgegeben wird. Ein Pedant, der allenthalben nur darauf achtet, daß die Sprache toskanisch rein ist und das Wörterbuch der Crusca als einzigen Maßstab anlegt, der um des Kritisierens willen kritisiert und sich dazu noch gegen allen Anstand aufführt, hat in der Gesellschaft der fröhlichen, gutmütigen Lobredner keinen Platz. Daß mit diesem *Lombardo* Gozzi gemeint sein soll, erscheint zwar zunächst etwas verwunderlich, da dieser ja nicht aus der Lombardei stammt, sondern Venezianer ist, doch verweist die Darstellung der Figur im Gedicht unzweifelhaft auf den Autor der Tartana. ${ }^{58}$ Darüber hinaus soll Goldoni, wie im Vorwort zu Gozzis Scrittura contestativa al taglio della Tartana, der Antwort auf die beiden Goldoni-Texte, berichtet wird, unter seinen Freunden verbreitet haben, daß es sich um eine Satire auf Gozzi handle.

Diesem direkten Angriff auf seine Person begegnete Gozzi prompt mit einem Text, den er im Vorwort zwar als zweiten Band der Tartana bezeichnet, der jedoch im Gegensatz zu La tartana allein gegen Goldoni gerichtet ist und diesen - Goldonis Verfahren in La tavola rotonda imitierend - persönlich auftreten läßt. Damit spitzt sich die allgemeine $\mathrm{Ge}$ sellschafts-und Literatursatire zu einer sehr spezifisch ausgerichteten Polemik zu. Aus dem Vorwort des fiktiven Herausgebers, »a' lettori dagli occhi aperti«, geht eindeutig hervor, daß nicht nur Goldonis Capitolo, sondern auch La tavola rotonda bereits vorlagen. ${ }^{39}$ Analog zur mehr-

58 Diesen erbärmlichen Pedanten wahrheitsgemäß als Venezianer darzustellen, hätte einer stillschweigenden Konvention widersprochen, die in den meisten Texten venezianischer Autoren der Zeit eingehalten wird: ob in Gedichten oder in Theaterstücken, wo immer ein Venezianer auftaucht, ist er eine ganz und gar positive, vorbildliche Figur. Damit wird nicht nur dem Publikum geschmeichelt, sondern auch die kollektive Identităt dieser besonderen Stadt gestärkt.

In der Scrittura contestativa erläutert Gozzi, „C'introdusse poi un certo suo Lomdardo [sic] cotto, e sciocco sprezzatore del Fegejo, in uno scorcio di buffoncello col Burchiel sulle labbra, sperando cosi di far ridere i suoi parziali, e di vincere per questo modo il campo: e peggio ancora che ha avuta faccia di sostenere esserci nella persona di quel suo Lombardaccio lo spirito dello scrittore della Tartana (Zan. XV, 7x).

59 Wenn die Scrittura contestativa al taglio della Tartana im Untertitel auch das Jahr 1757 und wie La tartana als Erscheinungsort Paris trägt, so ist docb mit großer Sicherheit anzunehmen, daß dieser Text ebenfalls 1758 in Venedig erscheinen hätte sollen. Dies geht auch aus einer Anmerkung Gozzis zu Il teatro comico all'Osteria del Pellegrino hervor (Zan. XV, 188). Goldoni bemühte sich jedoch um ein Publikationsverbot, so daß die Scrittura contestativa erstmals 1805 im letzten Band der Zanardi-Ausgabe gedruckt 
fachen Brechung der Autorschaft in La tartana, wird auch die Scrittura contestativa von einem Herausgeber präsentiert, der sich als Freund Polisseno Fegejos, d. h. Goldonis, ausgibt. Dieser habe in seiner Wut über La tartana völlig unnötigerweise »una rugginosa spadaccia di piombo spuntata " gezückt und ein Capitolo verfaßt, "che è una pura villania senza grazia, senza sale, senza dottrina alcuna $\propto$ (Zan. XV, 70 ), mit dem er zu ihm gekommen sei, um ihn vor der Veröffentlichung um Rat zu fragen. Seine gutgemeinten Änderungsvorschläge mißachtend, habe Fegejo das erbärmliche Produkt drucken lassen, woraufhin er, der Herausgeber, zur Rechenschaft gezogen worden sei, warum er Fegejo von dieser Dummheit nicht abgehalten habe. Um weiteren Vorwürfen zu entgehen, lege er nun seine glücklicherweise erhaltenen Kommentare und Korrekturen der Öffentlichkeit vor. Doch nicht genug damit, Fegejo habe auch noch $\mathrm{La}$ tavola rotonda veroffentlicht, in der er den Autor der Tartana in der Figur eines verrückten »Lombardo « verspotte. Wenn er sich nun auch mit der Scrittura contestativa den Zorn und $\mathrm{Haß}$ der *goldonisti* zuziehen werde, so wolle er diesen doch noch sagen, $>$ che il dimostrar minor furore per il Fegejo fia cosa sana, perocchè farà diminuire due terzi, e forse più il prezzo delle chiavi de' palchetti, che ha posto mezzo in rovina un numero grande di famiglie (Zan. XV, 72). Diese hinterlistig-ironische Anspielung auf die Öffentlichkeitswirkung des Schlagabtauschs insinuiert, daß die hohen Eintrittspreise des Theaters, die sich aus der Konkurrenz mit Chiari ergaben, nicht mehr zu halten wären, hätte Goldoni nicht die Gelegenheit ergriffen, nach einem Abflauen der Kontroverse mit Chiari eine neue Front aufzubauen. Zugleich wird wie in La tartana die Anhängerschaft Goldonis verhöhnt, die sich fanatisch auf seine Seite schlägt, ohne sich in literarischen Dingen überhaupt auszukennen. Auf dieses Vorwort und eine absichtsvoll an einen stadtbekannten venezianischen Bettler gerichtete Widmung, die nicht nur einen Vers aus Goldonis Capitolo aufnimmt, ${ }^{60}$ sondern bewußt mit dessen Widmungen der Thea-

vorlag. Sowohl P. Bosisio, Carlo Gozzi e Goldoni, op. cit, als auch B. Peruzzi (tesi di laurea), op. cit., ordnen die Scrittura contestativa vor Goldonis La tavola rotonda ein, wohl in Anlehnung an Gozzis Discorso, notizie, verita, e riflessi in Col. VIII, 243, und in Unkenntnis des fiktionsinternen Vorworts. Wäre die Datierung P. Bosisios und B. Peruzzis zutreffend, würde dies bedeuten, daß der erste Text der Scrituera contestativa, - L'editore a' lettori dagli occhi apertie, nachträglich verändert oder gar später hinzugefügt worden wäre. Ebenso unbeachtet blieb bisher eine merkwürdige inhaltliche Überschneidung der beiden Teile $=$ Scrittura di risposta und -Composizione fegejana contestativa al taglio della Tartana*, in denen dieselben Strophen aus Goldonis Capitolo einer ironischen Interpretation unterzogen werden.

w In Discorso, notizie, verita, e riflessi, dem zusammenfassenden Rückblick auf die Polemik mit Goldoni und Chiari, schreibt Gozzi: -Per ribattere la sua [i.e. Goldoni] bassa 
terstücke an einflußreiche Persönlichkeiten kontrastiert, folgen entsprechend der narrativen Ankündigung im Vorwort drei Hauptteile: Zunächst ein fingierter Brief Goldonis an seinen Freund mit der Bitte um Korrekturen, weil er gerade völlig mit Aufträgen überlastet sei und keine Zeit dafür habe ("Lettera fegejana $\propto) ;{ }^{61}$ dann die $"$ Scrittura di risposta« an den "Amico quanto fratello «, in der der Freund mit Fegejo hart ins Gericht geht und ihm unter Beteuerung ihrer unzerbrechlichen Freundschaft anhand einiger Auszüge aus La tartana beweist, daß die Kritik sehr wohl berechtigt sei. Schließlich präsentiert er unter dem Titel »Composizione fegejana contestativa al taglio della Tartana* eine präzise stilistische und inhaltliche Analyse des Capitolo, die gekrönt wird durch eine alternative Fassung des Gedichts und die Bitte an Goldonis Freunde, ihn doch nicht weiter mit derartigen literarischen Aufträgen zu belästigen.

Wie La tartana nimmt die Scrittura contestativa ihren Ausgang von vorgängigen Texten, und beide können als Prototyp einer maliziös ironischen Interpretationskunst gelten. Die Vorgehensweise jedoch ist unterschiedlich. Burchiellos Verse werden in den Dienst einer Satire auf gegenwärtige Mißstände gestellt, die so literarisch abgesichert erscheint. Gozzi spielt mit der Offenheit der ihres Kontexts entledigten Worte und bewegt sich fortwährend auf der Grenze zwischen Deutung und Mißdeutung. Er bindet Vergangenheit und Gegenwart zusammen, reaktualisiert Altes und macht es für das Heute fruchtbar, kurz: er imitiert Burchiello nicht, sondern rezipiert ihn in phantasievoll-kreativer Weise. Zugleich unterminiert er die Textsorte "Almanach «, denn in La tartana wird weniger die $\mathrm{Zu}$ kunft vorausgesagt, als vielmehr die Tragfähigkeit der »Prophezeiungen* der Vergangenheit für die Gegenwart erprobt. So zeigt sich in La tartana unter dem Deckmantel eines zukunftsweisenden Kalenders die Relevanz der Vergangenheit für die Gegenwart - ein, wie sich zeigen wird, grundlegender Aspekt in Gozzis Denken.

Mit der Scrittura contestativa tritt Gozzi demonstrativ dem von Goldoni im Capitolo erhobenen Vorwurf entgegen, „Chi dice mal senza

proposizione, ch'io era m collera colla fortuna, dedicai quest'Opuscolo a Pietro Carati, conosciuto nostro cencioso Cittadino, che cercava elemosina. La Dedicatoria era scritta in versi sciolti, e conteneva di que 'ratti, ch'io credo sali.* (Col. VIII, 245).

41 In diesem Brief werden nicht nur die wichtigsten Aspekte der Kritik Gozzis Fegejo selbst in den Mund gelegt, sondern zugleich der juristische Stil des Advokaten Goldoni parodiert. Fegejo bezeichnet La tartana als *mal ideato tentativo* auf den *merito incomprensibile letterario di me povero Fegejo, riformatore del Teatro Italiano, scrittore impuntabile in purgata lingua Toscana d'ogni genere di versi, e di composizioni, poeta esimio sperimentato, ed approbato per una involuta esorbitanza d'opere toscane replicatamente stampate in Venezia, in Fiorenza, a Bologna, a Pesaro, a Treviso, a Bergamo, e a Bassano con licenza de' superiori- (Zan, $\mathrm{XV}, 78)$. 
ragione alcuna, / Chi non prova gli assunti e gli argomenti, / Fa come il cane che abbaia alla luna. ${ }^{62}$ Dies ist ihm Anlaß genug, sich wiederum der Form der Textinterpretation zu bedienen, doch reichert er diese argumentativ mit scharfer Kritik an, belegt und beweist und kehrt so tatsächlich seine interpretatorische Strategie um. Statt das Potential des vorliegenden Textes geistreich-positiv auszuschöpfen, bestimmt die Intention der Demontage den fast unerschöpflichen Einfallsreichtum des Interpreten. Zwar wird der Aspekt der Kontiguität von Vergangenheit und Gegenwart weitergeführt, doch beschränkt er sich auf den inhaltlichen Bereich und bleibt ohne Konsequenzen für die Textgestaltung. Die beißende Ironie der Scrittura contestativa und der Hauptvorwurf, Goldoni habe sich vom Erfolg dazu verführen lassen, sich für einen großen Schriftsteller Italiens zu halten und seine Werke als vorbildliche vielfach in Druck zu geben, obwohl die Sprache keinerlei traditionellen literarischen Maßstäben genüge und er nie an die von ihm mißachteten Größen der dramatischen Literatur heranreichen werde, ließen es Goldoni wohl geraten scheinen, sich um ein Publikationsverbot zu bemühen. ${ }^{63}$

\section{Chiari im Blickfeld}

Damit waren neue Fronten in der venezianischen Literaturszene geschaffen, die jedoch die Spannungen zwischen Goldoni und Chiari keineswegs aufhoben, und dies aus guten Gründen. Attackierte Gozzi Goldoni auch aufs heftigste, beschränkte sich die Auseinandersetzung doch zunächst auf den literarisch-textgebundenen Bereich, während das szenische Terrain unberührt blieb. Dagegen konkurrierten Goldoni und Chiari weiterhin um ausverkaufte Häuser und volle Kassen. So findet die Polemik zwischen Goldoni und Chiari beispielsweise in Il festino d'Amore ihre Fortsetzung, einem Gedicht Chiaris, das bemerkenswerterweise zum selben Anlaß entstand wie Goldonis Tavola rotonda. Darin werden sowohl La tavola rotonda und das Capitolo als auch Gozzis Tartana ironisch anzitiert, doch steht eindeutig Goldoni als Zielscheibe des Spotts im Mittelpunkt, während Gozzi eine geringere Rolle spielt. ${ }^{64}$ Goldoni wiederum

2. Goldoni, XIII, 450 .

63 Davon berichtet Gozzi ebenfalls in Discorso, notizie, verita, e riflessi, Col. VIII, 245246.

* Pietro Chiari, Il festzno d'Amore, Per le solenni nozze di S. E. la N. D. Maria Venier, con S. E. il N. H. Pietro Contarini. Ottave dell'abate Pietro Chiari, Poeta di S. A. il Sig. Duca di Modana, s.n.t. Chiari macht sich in seinem allegorischen Gedicht nicht nur über die sturba straniera* lustig, die sich =quasi a rotonda tavola imbandita* (XVII) sieht und 
hatte bereits 1755 in der Komödie $I$ malcontenti die Figur Grisologo als offene Satire auf Chiari konzipiert, was zu einem Aufführungsverbot in Venedig geführt hatte. 1758 erschien dieses Stück leicht umgearbeitet im Druck in der Pitteri-Edition, wobei noch immer zahlreiche Spitzen gegen Chiari erhalten sind, ${ }^{65}$ die dieser in Il festino d'Amore prompt pariert.

Während derartige polemische Bezugnahmen auf Texte oder die Person des Konkurrenten bei Goldoni und Chiari nur noch vereinzelt auftreten, läßt Gozzi keine Gelegenheit aus, auf die aktuelle Entwicklung zu reagieren. Nach La scrittura contestativa al taglio della Tartana geht Gozzi sowohl in zahlreichen kleineren Gedichten gegen Goldoni und Chiari an ${ }^{66}$ als auch in einem allegorischen Gedicht mit dem Titel $I$ sudori d'Imeneo, das 1759 anonym zur Hochzeit von Sebastiano Mocenigo und Chiara Zeno erschien. I sudori d'Imeneo erzählt von Hymenaios' Z wist mit Cupido, der statt Liebe Haß zwischen den Eheleuten sät und Hymenaios' Suche nach einem Paar, das ausnahmsweise unter der Obhut Amors lebt. Als sein Blick auf Venedig fällt, bleibt er dort hängen, sImeneo al finestrin lieto galluzza, / E dice: Io son nel golfo de' perfetti! $\alpha,{ }^{67}$ und er entscheidet sich für das Paar Mocenigo/Zeno. Ein Hinweis darauf, welches Chaos Cupido auch in Komödien anrichte, zwei Oktaven, die Ignorantia an ihrem Lieblingsort, dem Theater, vorstellen und einige Spitzen gegen die Dichterlinge, die nur darauf warten, daß sie etwas in einer raccolta unterbringen können, genügen, um Goldoni und Chiari als Zielscheibe der Allegorie auszumachen. Und tatsächlich rächt sich Chiari unmittelbar in einem weiteren Gelegenheitsgedicht für die Anspielungen in I sudori

auf Inspiration wartet, sondern auch darüber, daß nun so schnell wie möglich Verse geschmiedet werden musssen: -Si fanno i versi, come far si ponno: / Ci voglion mesi, e a me s'accorda un'ora: / Dell'estro mio non son padrone, e donno / Onde far da cicala ai di festivi / Tosto che dica alcun: su canta e scrivi. (1.I) Die intertextuelle Referenz zu Goldonis Capitolo ist unübersehbar. Dort heißt es; - L'illustre casa a verseggiar t'invita: / Lascia, lascia ogni studio in abbandono; / Se tu lo neghi, il cavalier s'irrita. // [...] I] commando mi onora, io lo confesso, / Ma la fretta mi cruccia e mi flagella.* (Goldoni, $\mathrm{X} 11 \mathrm{I}, 449)$.

Auf Gozzis Tartana und die darin enthaltenen Seitenhiebe auf die Schriftstellerei als Broterwerb bezichen sich zweifelsohne die Verse, in denen beteuert wird, daß ein wahrer Dichter niemals für Geld schreibe - mit der Einschränkung allerdings, daß ihn die Umstände doch dazu zwingen könnten: - Son mordaci follie, sono menzogne: / Loro scriver non fa l'alme onorate. / Sia forza o genio dell'età presente, / Gloria de' Vati, è di cantar per niente, = (IV).

is So z. B. gegen seine angeblich universelle Bildung $(I, 8)$, gegen seinen überladenen Stil und die krude Gattungsmischung in seinen Stücken (II, 7), gegen holprige versi martelliami, venezianischen Pseudo-Dialekt und historische Inkongruenzen (III, 9); Goldoni, III, rors-1099.

4h. Vgl. Col. VII, z B. $>$ Fegejo delle satire si rides oder s Fegejo è insuperbito-.

67. Carlo Gozzi, I sudori d'Imeneo, Venezia, Zatta 1759, 3 I (Strophenzählung). 
d'Imeneo. ${ }^{68}$ Sehr viel deutlicher wird Gozzis Satire dort, wo er Goldonis Verfahren aus La tavola rotonda aufgreift und diesen in personam auftreten läßt. Apoll hat nämlich beschlossen, alle Poeten, die etwas zu den Hochzeits-raccolte beitragen wollen, vor seinen Richterstuhl zu zitieren.

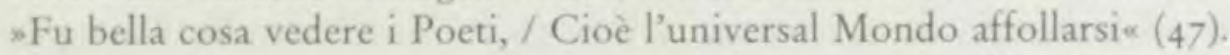
Aus dieser Masse taucht einer auf, der sichtlich von sich selbst überzeugt ist und nicht zögert, Apoll anzusprechen:

Apollo, crederai, perchè mi vedi

Grassotto, e basso, io giunga il sezzo, e lento,

lo so, che la ragion di ciò mi chiedi.

Sappi, che alquanto poco ben mi sento.

Poi m' hanno trattenuto addietro, credi,

Mille a' quali è palese il mio talento,

E de' miei versi eternamente han fame

Principi, Duchi, Cavalieri, e Dame. (s9)

Auf seine Entschuldigung hin, leider nicht besser gedichtet zu haben ( $*$ Mi sopraggiunse un catarro, e una scesa, / E un'emicrania ; 60), beginnt er zu rezitieren, wird jedoch sofort von Apoll unterbrochen: «Signor, Febo gridava, e' mi vien caldo, / Veggo il tuo libro ha di pagine un mondo. / Io non patisco un compor si ribaldo «, worauf der Dicke antwortet, *Che modo è questo? zitto, sta un po saldo, / Questo Poema da ognun mi distingue, / E ci son dentro dieci madrilingue. $\times(6 \mathrm{r})$ So macht Gozzi in wenigen Versen Goldonis Massenproduktion, sein ständiges Selbstlob und die Sprachmischung in seinen Texten lächerlich.

\section{Gozzis Polemik gegen Bettinelli}

I sudori d'Imeneo ist eine eher lau ausgefallene Reaktion auf La tavola rotonda, doch erschöpft sich das Gedicht nicht in den neuerlichen Angriffen auf Goldonis wie Chiaris poetische Produkte, sondern nimmt auch eine Debatte über die Mode der Gedichtsammlungen zu festlichen Anlässen, der raccolte, auf, in die Gozzi bereits ein Jahr zuvor mit Parere o sia lettera scritta da un'amico del Friuli, ad un'amico di Venezia sopra il poemetto intitolato Le Raccolte, con la risposta dell'amico di Venezia

68 Pietro Chiari, La mascherata degli dei, Venezia, Coleti 1759, Canto primo, XLVIXLVIII. Chiari fordert den Autor der Sudori d'Imeneo auf, ihn doch nicht mit allen anderen in einen Topf zu werfen, $\gg$ Perché fanno amendue peggio che male, / Quando un corsar l'altro corsaro assales, und betont, daß er nicht sla Burchiellesca sua sferza sonora a fürchte, denn die kônne er auch nachmachen, $=\mathrm{Ma}$ nol fo, perchè legge è di creanza / Di parlar, e vestir sempre all'usanza.* 
all'amico del Friuli eingegriffen hatte. Die Autoren dieses 1758 anonym erschienenen Werkes sind laut Gozzi Marco Forcellini, Natale delle Laste und er selbst, der gebeten wurde, der ernsthaften Kritik des Parere eine scherzhaftere Antwort hinzuzufügen. ${ }^{69}$ Beide Texte, Parere o sia lettera... wie I sudori d'Imeneo, richten sich gegen Saverio Bettinellis Kurzepos Le raccolte, das bereits in zwei Editionen von 1751 und 1752 vorlag und 1758 in Venedig in einer dritten Auflage gedruckt wurde. Zudem machte Bettinelli Anfang dieses Jahres mit den Lettere virgiliane von sich reden, so daß eine Stellungnahme doppelt motiviert war. ${ }^{70}$ Sowohl Le raccolte als auch die Lettere virgiliane sind Pamphlete, in denen Bettinelli gegen die Mode der raccolte, gegen die platte Imitation und das leichtfertige Verseschmieden angeht. In Le raccolte folgen auf das Vorwort, in dem bereits sämtliche Proömialtopoi ironisiert werden, vier Gesänge in Oktaven, die vom Versuch Cacoetes, der neuen Göttin der Verseschmiede, erzählen, mit Hilfe ihrer dichtenden Heerscharen Apolls Parnaß zu erobern. Obwohl sie zuletzt ihre raccolte als Waffen einsetzen, ist ihnen kein endgültiger Erfolg beschieden. Bettinelli scheut sich nicht, Dichter der Vergangenheit wie auch Zeitgenossen beim Namen zu nennen und mit ihnen ins Gericht zu gehen. Wie im Parere sogleich festgestellt wird, handelt es sich bei Bettinellis Raccolte um eine schlechte Imitation Ariosts und Boileaus. ${ }^{71}$ Analog zum zweiten der Lettere virgiliane, in denen am

a Vgl. Carlo Gozzi, Memorie inutili della vita di Carlo Gozzi scritte da lui medesimo e pubblicate per umiltà, Hg. Giuseppe Prezzolini, 2 Bde., Bari, Laterza 1910, Bd. I, S. 200 (im folgenden abgekürzt als Mem. mit Band-und Seitenangabe dieser Ausgabe). In der -Cronologia* seiner Fiabe-Ausgabe (Carlo Gozzi, Fiabe teatrali, Hg. Paolo Bosisio, Roma, Bulzoni r984) charakterisiert P. Bosisio das Parere unzutreffend als *operetta satirica ancora rivolta contro il Chiari e il Goldoni, composta sullo spunto fornito dal poemetto Le Raccolte di Saverio Bettinelli (S. 95). Der Text wendet sich eindeutig gegen Bettinelli.

70 Zu den verschiedenen Editionen der Raccolte wie der Lettere virgiliane siche V.E. AIfieris Nachwort zu Saverio Bettinelli, Lettere virgiliane e inglesie altri scritti critici, $\mathrm{Hg}$. Vittorio Enzo Alfieri, Bari, Laterza 1930, S. 299-304.

Zur Mode der raccolte siehe u. a. Francesco Colagrosso, Un'usanza letteraria in gran voga nel Settecento, Firenze, Le Monnier 1908; W. Theodor Elwert, -Venedigs literarische Bedeutung. Ein bibliographischer Versucha, in: Archiv fur Kulturgeschichte 36, 3, 1954, S. 261-300, hier S. 299-300, Pino Fasano, L'utile e il bello. Le transizioni delle forme letterarie alle soglie dell'era borghese, 2. Aufl., Napoli, Liguori 1996, S. 3 Iff. Die Sammelbände, deren Beiträge von den Auftraggebern bezahlt wurden, waren unter anderem auch ein Forum für die Vorstellung junger Dichter. Die Kritik an den raccolte scheint im 18 . Jh. genau so üblich zu sein wie die Veröffentlichung der Festschriften selbst. Bereits 1723 beklagt Scipione Maffer in $>$ Istoria del teatro e difesa di esso* ihre weite Verbreitung. Fast paradox erscheint es, daß Bettinellis Raccolte selbst als Hochzeitsgeschenk an Andrea Cornaro entstanden.

71 Weitere Modelle sehen F. Colagrosso (op. cit., S. 80) in Popes The Duncaad und Elvie Guagnini in Swifts Battle of the Books (-Sul Bettinelli Inglesen, in: Ilaria Crotri; Ric- 
Titel von Dantes Divina Commedia Kritik geübt wird, klagen auch die Autoren des Parere über die Unangemessenheit von Le raccolte, denn es gehe weniger um raccolte als um schlechte Dichter. In pedantischer Weise wird so Gesang für Gesang untersucht, Kritik und Lob wechseln einander ab, und Bettinellis Verurteilung von Dantes Sprache wird (aus heutiger Sicht zu Recht) mangelndem historischen Sprachverständnis zugeschrieben. Dieser akademischen Textkritik folgt die von Ironie und Polemik sprühende Antwort des venezianischen Freundes, der sich zunächst wiederum über den Titel mokiert und statt Parere sopra il poemetto intitolato Le Raccolte *Fiche contro all'urlo detto, Le raccolte vorschlägt. Er vermutet, daß der Autor der Raccolte bei der Schlacht auf dem Parnaß selbst von den Büchern getroffen wurde und $x^{\prime}$ col cervello, che gli traballava nel cranio * (27) geschrieben habe. Absichtlich zitiert er Verse, die Bettinelli selbst als Zitat der von Französismen durchsetzten poetischen Sprache verstanden wissen wollte, präsentiert sie ironisch als $*$ versi toscanissimi “ (30) und bedauert allgemein die mangelnde Beherrschung der toskanischen Sprache. Deshalb verordnet er seinem Discipulus, der verbotenerweise die Nase in die Raccolte gesteckt hat, sofort wieder eine Dosis Dante, Cino da Pistoia, Guittone und Guido Cavalcanti, ne tutta la schiera delle antiche fonti soavissime, che ci allattarono. Cosi la intendo, così la voglio, e dovrà per un gran tempo stare con la Crusca nelle maní, e nel mezzo a quegl'intarlati ( 35 ), denn eine perfekte Imitation dieser Dichter würde ihm, auch wenn seine Gedanken irrelevant wären, mit Sicherheit die Achtung der Gelehrten verschaffen.

Dieser ironische Schluß, der das negativ besetzte Schlagwort "cruscante « der Lächerlichkeit preisgibt, scheint weniger auf Le raccolte als vielmehr auf die Lettere virgiliane zu zielen, in denen Vergil aus dem Elysium der Arkadia in Rom über die Untugenden der zeitgenössischen Dichter berichtet und nicht nur die Imitierenden und Plagiatoren kritisiert, sondern auch die imitierten Autoritäten, allen voran Dante, ${ }^{72}$ Die

ciarda Ricorda (Hgg.), Saverio Bettinelli. Un gesuita alla scuola del mondo, Roma, Bulzoni 1998 , S. 149-163, hier S. 163), die jedoch beide ihrerseits Bezüge zu Boileaus Lutrin aufweisen.

73 -A Dante null'altro mancò che buon gusto, e discernimento nell'arte. Ma grande ebbe l'anima, el'ebbe sublime, l'ingegno acuto, e fecondo, la fantasia vivace, e pittoresca, onde gli cadono dalla penna de' versi e de' tratti mirabili,- (Bettinelli, Lettere virgiliane, $\mathrm{Hg}$. Pietro Tommasini-Mattiucci, Città di Castello, Lapi 1913, S. 14). Zu Ariost z. B. schreibt Bettinelli: s'A Ariosto può far de' poeti ed eziandio più regolati di lui. Egli è gran poeta se aleuni canti si tronchino dell'Orlando furioso ch'egli stesso condanna, e tutte le stanze che non contengono fuor che turpi buffonerie, miracoli di Paladini, incanti di Maghi, o sozze imagini [sic] indegne d'uomo bennato.* (ebd. S. 57-58). Ein weiterer Text Gozzis nimmt explizit Bezug auf Bettinellis Lettere virgiliane: $\gg$ Stanze per la vestizione 
pauschale Mißachtung und Abwertung der Tradition und einzelner in Gozzis Augen herausragender Dichter der Vergangenheit scheint der Auslöser für die gegen Bettinelli gerichteten Texte zu sein, deren Vehemenz jedoch insofern erstaunlich ist, als in anderen Bereichen weitgehende Übereinstimmungen zwischen beiden Autoren bestehen. Nicht nur die Zeitkritik, die die Mode, die Redeweisen, den französischen Einfluß oder die literarische Massenproduktion betrifft, sondern auch der polemische Duktus verbinden ihre Texte. Eine tiefer gehende inhaltliche Auseinandersetzung mit Bettinellis Lettere virgiliane kommt allerdings nicht von Carlo Gozzi, sondern von seinem Bruder Gasparo. ${ }^{73}$

\section{Goldoni-Satire im Kurzepos}

Unterdessen zirkulierten in Venedig weiterhin Sonette und andere Gedichte, die die Polemik zwischen Gozzi, Goldoni und Chiari schürten. ${ }^{74}$ Aus der Feder dreier Autoren der Accademia Granellesca entstand ein Text mit dem Titel Le spose riacquistate, ${ }^{75}$ der ein um das Jahr 900 an-

dell'illustriss. signora Vittoria Lavezari nel Monastero del Corpus Dominia (Col. VIII, 276-284). Dort greift er die Geistlichen an, die sich in literarische Angelegenheiten mischen (sowohl Chiari als auch Bettinelli gehören zu diesen), und präzisiert: $m \mathrm{E}$ specialmente stolti sono i Frati, / Che abbandonando la Chiesa, e i Concili / Van negli Elisj a parlar co' Virgilj, *

Im Canto ditirambico de' partigiani del Sacchi Truffaldino (Col. VIII, 164-179) parodiert Gozzi Bettinellis Schlacht um den Parnaß mit den Bemühungen, eines Bergs Polenta Herr zu werden. Unvermittelt bricht er die Beschreibung ab und schließt: $\Rightarrow \mathrm{Ma}$ dove scorro! ad emular col metro / sulla polenta i struggitor di Dante?*.

73 Gasparo Gozzis Difesa di Dante erschien kurz nach Bettinellis Lettere virgiliane; siehe dazu V. E. Alfieris Kommentar in S. Bettinelli, Lettere virgiliane e inglesi, op, cit., S. $300-$ 312.

74 Dazu Gozzi in Discorso, CoL. VIII, 246-247: "I ferri si riscaldarono, e le occasioni di Nozze, di Monacazioni, di giornate solenni, le Poesie, che si costumano, furono campo d'un combattimento poetico, che tenne la Città in movimento, I Sonetti manoscritti andavano in copia girando. « Allein zu vier Gelegenheitsgedichten Goldonis, Poemetto de' riti, Visita delle sette chiese und La settimana santa, Capitolo per Monaca, in denen jeweils mehr oder weniger direkt auf die Kontroverse mit Gozzi angespielt wird, gibt es unmittelbare, durch Titel-oder Wortzitate markierte Reaktionen Gozzis; s. u. a. Oktaven zum feierlichen Gelübde von Foscarina Zeno, Col. VIII, 228-233. Darüber hinaus waren mit Sicherheit zahllose handgeschriebene Texte in Umlauf, die heute verloren sind, so daß die tatsächliche Verbreitung und gesellschaftliche Relevanz der Auseinandersetzung wohl eher unterschätzt werden.

75 Zur Entstehungsgeschichte von Le spose riacquistate s. Gozzi, Discorso, Col. VIII, 8-9. Das Versepos umfaßt sechs Gesänge, von denen die ersten beiden von Carlo Gozzi, die mittleren von Daniele Farsetti und die letzten beiden von Sebastiano Crotta stammen. Gozzi veröffentlichte seine beiden Gesănge erstmals im 8. Band der Colombani-Ausgabe unter dem Titel Il ratto delle fanciulle castellane. Eine Edition des gesamten Epos 
gesiedeltes, legendäres venezianisches Ereignis aufgreift: den Raub der Bräute und der Mitgift durch Piraten während eines großen kollektiven Hochzeitsfestes vor San Pietro di Castello. Das burleske Epos, das in einer dezidiert venezianischen Umgebung spielt, ist wie La tartana geprägt von einer beißenden Satire auf zeitgenössische Untugenden und Mißstände. Erneut wird Vergangenes in die Gegenwart projiziert und mit literarischen wie volkstümlichen Traditionen gespielt. ${ }^{76}$ Was als religiöse Zeremonie gedacht war, wird zum großen Heiratsmarkt, auf dem die Bräute wie Vieh angepriesen und auch noch die häßlichsten an den Mann gebracht werden. Das Nahen der feindlichen Uskoken bleibt unbemerkt, weil die Luft von der *Frittellaja Balecca* rauchgeschwängert ist, so daß die Uskoken die jungen Venezianerinnen zusammenraffen und fliehen können. Die Venezianer, aus den Tavernen kommend, nehmen die Verfolgung auf, obwohl einer meint, die Uskoken seien vom Himmel geschickt, um die Venezianer von ihren untreuen, häßlichen, herzlosen, eingebildeten Weibern zu erlösen. Mit dem zweiten Gesang setzt die Satire auf Goldoni (Pulejo / Fegejo) ein, die sowohl auf die Werke als auch auf den Autor zielt. Zunächst hält eine der geraubten Venezianerinnen eine heroische Rede nach dem Vorbild der Tragikomödien Goldonis, um die Tränen ihrer Leidensgenossinnen zu stillen, und nimmt dann stoisch alle Folter-und Morddrohungen der Uskoken hin, da sie durch ihre häufigen Theaterbesuche abgehärtet ist. Inmitten des Durcheinanders erhebt sich sun'uomo grosso, e piccolino, / Ch'è tra gli Uscocchi mago, ed indovino* (Col. VIII, r I 8) - physiognomisch unverkennbar Goldoni. Neben vielen anderen Berufen war er auch Poeta, "Avea studiato la Natura, e il mondo,

auf der Grundlage zweier Manuskripte nahm D. Pietro Bettio, Vizebibliothekar der Marciana, 1819 vor: Le spose riacquistate. Poema giocoso di Carlo Gozzi, Daniele Farsetti e Sebastiano Crotta con gli argomenti di Gasparo Gozzi, accademici Granelleschi, Venezia, Alvisopoli 18 t9. Zur Datierung gibt es zwei Hinweise im Text; namlich die Rückkehr des Truffaldino Sacchi nach Venedig (Col. VIII, 120) sowic Goldonis Romreise (Canto IV, 153), so daß die Entstehung wohl auf das Jahr 1759 fallte und nicht auf 1761, wie Fabio Soldini in Gasparo Gozzi, Lettere, Parma, Ugo Guando 1999, S. 102425, vermutet. Gozzis Canti unterscheiden sich in den beiden Ausgaben im wesentlichen nur bezüglich der Figurennamen.

Eine enge Verbindung dieses Textes ergibt sich zu Goldonis *Poemetto $L$ La visita delle sette chiese anläßlich der Einkleidung von Teresa Milesi, mit deren Bruder, Marco Milesi, Goldoni befreundet war. Dieser Marco erscheint im 2. Gesang des Ratto delle fanciulle castellane unter dem Namen - Furia * (in Le spose riacquistate unter seinem eigenen Namen Mareo $)$ als treuer Freund des Fegejo: •era un'Uscocco di lui spasimato* (Col. VIII, 121).

76 Zur Bedeutung der Überlagerung von religiösen und politischen Feierlichkeiten und ihrer Inszenierung gerade am Beispiel dieses legendären Ereignisses s. Giorgio Padoan, -Venezia: Mondo e Teatro , in: Manlio Brusatin ( $\mathrm{Hg}$.), Venezia e lo spazio scenico, Venezia, Edizioni -La Biennale di Venezia $=1980$, S. 37-42, hier S. 37-38. 
/ Degli altri libri poco ne sapeva; (Col. VIII, I 19).? Weil sein Stern durch die Rückkehr des Truffaldino Sacchi im Sinken ist, verkauft er seine Seele dem Teufel, um Zauberer zu werden. Unter zahllosen Anspielungen auf Goldonis Komödien, auf seine Geldgier, auf die Granelleschi und $\mathrm{La}$ tartana wird von Pulejos Rettungsaktion für die Uskoken erzählt, die die venezianischen Verfolger ins Verderben stürzen soll. Behindert wird Pulejo dabei durch den Oberteufel Malacoda, der versucht, ihm Angst einzujagen, indem er zunächst in Gestalt eines konkurrierenden Theaterautors (d.i. Chiari) erscheint, dann Verse aus La tartana zitiert und zuletzt als Truffaldino Sacchi auftritt. Dies treibt den Dicken schließlich in die Flucht und macht ihn so rasend, daß er unter seinen Flüchen fast erstickt. Mit der epischen Einkleidung der Satire, die stellenweise dramatische Qualitäten annimmt, stellt Gozzi der Scrittura contestativa, die philologische Muster der Textinterpretation imitiert und parodiert, ein geistreiches Versepos an die Seite, das bereits in manchem auf L'amore delle tre melarance vorausweist. Während Farsetti im dritten und vierten Gesang, eingebettet in den Fortgang der Handlung, die Satire auf Goldoni und sein venezianisches Theaterreform-Projekt weiterführt, versiegt sie in den letzten beiden Canti, die nur noch vom Sieg der Venezianer und einem fürstlichen Festessen auf der Laguneninsel Sant'Erasmo, dem *Gemüsegarten Venedigs«, berichten.

\subsection{Das komische Theater vor dem Richterstuhl}

Ein weiterer entscheidender Text Gozzis in der Polemik mit Goldoni ist Il teatro comico all'Osteria del Pellegrino, tra le mani degli Accademici Granelleschi, ${ }^{78}$ der jedoch wie die Scrittura contestativa unveröffentlicht blieb. Während sich die Scrittura contestativa speziell gegen Goldonis

77 Diese Verse beziehen sich auf Goldonis Vorwort zur Bettinelli-Ausgabe von 1750, in dem er als Grundlage für sein Theaterschaffen nicht vorgängige Texte, sondern die sgran libri, Mondo e Teatro (Goldoni, I, 772) und die Beobachtung der Natur angibt; vgL. Kap. 3.2.

78 Auch über die Datierung dieses Textes bestehen Zweifel. Wahrend P. Bosisio in der Chronologie seiner Fiabe-Ausgabe $175^{8}$ angibt, schlägt A. Beniscelli in $=$ La dilogia di Bettina nelle pagine critiche di Carlo Gozzie, in: Carlo Goldoni, La buona moglie, Genova, Edizioni del Teatro di Genova 1987, S. 48-68, hier S. $65-66$, unter Hinweis auf ein im Manuskript befindliches Motto die Jahre 1760/61 vor. Diese Hyporhese kann durch zwei zusătzliche Indizien im Text bestätigt werden: erstens wird auf ein Lobgedicht Voltaires auf Goldoni angespielt, das im Juli 1760 heiße Diskussionen in La gazzetta veneta ausgelöst hatte und von Gozzi immer wieder in der Polemik angefuhrt wird. Zweitens wird Goldonis Impresario delle Smime erwähnt, der im Dezember 1759 Premiere hatte. Dies spricht für eine Entstehung des Textes im Jahr 1760. 
Capitolo und im allgemeinen gegen dessen Anspruch richtet, ein gefragter Dichter (sbuon poeta, e buon scrittore toscano $;$ Z Zan. XV, 82) und der Erneuerer des italienischen Theaters ( $>$ il gran regolatore, il bravo legislatore, lo incomparabile scrittor di commedie“; Zan. XV, 93) zu sein, zielt Il teatro comico all'Osteria del Pellegrino sehr viel konkreter auf Goldonis Komödien-Produktion und seine angeblichen Neuerungen. In diesem Zusammenhang tauchen jedoch auch wieder Elemente der Zeitund Sittenkritik aus La tartana auf, so daß die Intensivierung der Polemik gegen den Komódienautor Goldoni mit einer erneuten Rückbindung an generelle gesellschaftliche Entwicklungen einhergeht.

\section{Die "Accademia Granellesca"}

Bereits in La tartana und der Scrittura contestativa machen die Vorworte nebenbei deutlich, daß die Position des Autors (bzw. des fiktiven Autors und des fiktiven Herausgebers) nicht die eines Einzelnen ist, sondern repräsentativ für eine ganze Gruppe, ${ }^{79}$ und die Texte Parere o sia lettera wie auch Le spose riacquistate sind wie erwähnt Gemeinschaftsproduktionen. Mit Il teatro comico all'Osteria del Pellegrino, tra le mani degli Accademici Granelleschi steht nun der Name dieses Kollektivs im Titel: • Accademici Granelleschi๔. Die Accademia Granellesca war eine der zahllosen Institutionen dieser Art, die zwar seit dem I6. Jahrhundert existierten, doch gerade in der ersten Hälfte des 18 . Jahrhunderts im Rahmen der Wissensverbreitung und -vulgarisierung einen neuen Aufschwung nahmen. ${ }^{80}$ Die Akademien jeglicher Ausrichtung, literarisch, philosophisch, musikalisch, historisch, ökonomisch, mathematisch, physikalisch, religiös etc., bildeten nicht nur Zentren des geistigen Lebens Italiens, sondern gaben auch wichtige Impulse für den aufkommenden Journalismus. In der Nachfolge der Arcadia, die 1690 in Rom gegründet wurde, entstanden auch in Venedig literarische Akademien wie etwa die Accademia degli

74 In beiden Texten wird die Accademia Granellesca jeweils in einem Vorwort erwähnt; La tartana, =Dello Scrittore della Tartanaะ, Ottave, Col. VIII, zr; Scrittura contestatrua, =L'editore a' lettori dagli occhi aperti *s \& E meno devo aombrare, ora ch'io scorgo l'intiera Accademia de' Granelleschi, la quale in sulla materia di che si tratta è una brigatella brava, e fiera, uscita all'aperto dalla mia parte, armata d'alcuni Sonetti, e versi d'una tempera affatto invincibile dalla poca prosperita del Fegejo. $=$ (Zan. XV, 73 ).

* Vigl. G. Natali, Il Settecento, Bd. I, op. cit., S. 35 ; Brendan Dooley, - Le accademiea, in: Girolamo Arnaldis Manlio Pastore Stocchi (Hgg.), Storia della cultura veneta, s/1, II Settecento, Vicenza, Neri Pozza 1985, S. 77-90; Michele Battagia, Delle Accademie veneziane, Venezia, Picotti 1826 , der allein in Venedig vom 15. Jh. bis zum Erscheinungsdatum des Buches ober 140 Akademien zählt! 
Animosi, die dank Apostolo Zenos Anstrengungen 1698 zur Colonia Arcadica erklärt wurde, die Società Albrizziana, die Planomaci oder eben die Granelleschi. Ziel war die Pflege der italienischen Dichtung, vor allem Dantes, Petrarcas und des Cinquecento, in Form von Editionen und in der eigenen Nachahmung sowie die Beobachtung des zeitgenössischen literarischen Marktes samt Berichterstattung in den Journalen. ${ }^{81}$ Die Accademia Granellesca allerdings scheint sich in manchem von diesen seriösen Bemühungen zu unterscheiden. Zum ersten lassen der Name und das Emblem, eine Waldohreule mit einem Paar Hoden in den Krallen, Zweifel an der Ernsthaftigkeit aufkommen. Zum zweiten deuten auch die Erzählungen über die Gründung der Akademie darauf hin, daß sie als Parodie auf die Feierlichkeit der altehrwürdigen Institutionen und die neuerliche Gründungswelle entstand. ${ }^{82}$ So scheint sich ein Kreis jüngerer, aus besseren Familien stammender Venezianer einen Spaß daraus gemacht zu haben, einen auf der Kanzel erbärmliche Gedichte rezitierenden Priester namens Giuseppe Sacchellari einzuladen, doch einmal zum Treffen der "brigata di giovani dabbene» zu kommen und weitere Kostproben zu geben. Trotz des schallenden Gelächters der Jungen nahm Sacchellari bereitwillig das Angebot an, Fürst der Accademia Granellesca werden und den Ehrentitel eines Arcigranellone tragen zu dürfen. Am 21. Juni

* S. dazu Giannantonio Moschini, Della letteratura veneziana del secolo XVIII fino a' nostri giomi, Venezia, Palese 1806, S. 28 5-290, und M. Battagia, Delle Accademie veneziane, op. cit., S. 68-85. Venedig ist im 18 . Jh. noch eine der wichtigsten Verlagsstädte Italiens, in der zahlreiche Neueditionen Dantes, Petrareas, Pulcis oder Ariosts entsteher.

52 So könnte das Emblem ein parodistisches Pendant zu dem der venerianischen Accademia de' Pellegrini (gegründet 1550 ) sein, das einen Wanderfalken mit Diamanten zwischen den Klauen zeigte (vgl. M. Battagia, Delle Accademie veneztane, op. cit., S. 18), und der Name könnte anagrammatisch vom Namen des Vorsitzenden der Granelleschi, des sogenannten Arcigranellone, G. Sacchellari, inspiriert sein.

Merkwürdigerweise wurde in der Forschung eine solche parodistische Intention nie in Betracht gezogen. Die Beurteilung der Akademie schwankt zwischen der Anerkennung ihrer poesia bernesca und dem Abscheu vor den beleidigenden, trivialen, obszönen Gedichten. Zur Geschichte der Accademia Granellesea siehe Gasparo Gozzis -Lettera* aus den Lettere diverse und Daniele Farsettis Memorie dell'Accademia Granellesca in der Ausgabe der Nuova raccolta di Operette italiane in prosa ed in verso inedite o vare, Bd. 14, Treviso 1795, auf die sich auch Carlo Gozzi immer wieder bezicht. Kurzbiographien der Mitglieder der Accademia Granellesea finden sich in P. Bosisios Carlo Gozzi e Goldoni, op. cit., S. 375-419. 1925 erschien ein Buch mit dem Titel L'Accademia Gozziana von Francesco Pedrina (Milano U. a., Albrichi, Segati \& C.), das die sgiornaliera adunanza letteraria*, von der Gozzi in seinen Memoiren (Mem. I, 34) berichtet, ohne weitere Dokumente zur $\rightarrow$ Accademia Gozziana * macht. Literarische Zirkel dieser Art existierten allenthalben - ohne mit dem Etikett sAccademia versehen zu sein.

Der folgenden Darstellung der Gründungsgeschichte der Accademia Granellesca liegen Farsettis Memorie zugrunde. 
1747 fand die Krönungszeremonie statt, grotesk inszeniert mit Verkleidung, Rezitation, Holztrompetenfanfaren und einem Dichterkranz aus Radicchio, Lattich und Pflaumen, durch die sich der Arcigranellone in höchstem Maße geehrt fühlte. Nachdem das ausgelassene Vergnügen ein paar Jahre gedauert hatte, scheint sich die Akademie auf Vorschlag Gasparo Gozzis ernsteren Dingen, nämlich vor allem der Lektüre Dantes gewidmet zu haben. Offenbar war es dann die Theater-Polemik, die 176 I zur Auflösung der Akademie führte, da sich Meinungsverschiedenheiten unter den Mitgliedern eingestellt hatten und der Arcigranellone gar zum Anhänger Chiaris geworden war.

Entgegen der üblichen Darstellung der Accademici Granelleschi als erbitterter Kämpfer für den Purismus und die toskanische Sprache, läßt diese Geschichte der Akademie erkennen, daß zumindest ihre Ursprünge spielerischer Art waren und dem Vergnügen dienten. Daß sich dies auch zehn Jahre danach nicht grundsätzlich geändert hat, belegt die Einleitung zu Il teatro comico all'Osteria del Pellegrino. Auffällig ist hier wie in anderen Texten Gozzis die Selbstironie, mit der die Rahmenerzählung durchzogen ist.

Im Karneval, bei eisigen Temperaturen, trifft sich die Accademia Granellesca in der Osteria del Pellegrino am Markusplatz. Ihre Mãntel, Hüte und Masken haben die Granelleschi wahllos auf ein verlaustes Bett geworfen und harren nun frierend, auf harten Bänken und wackligen Stühlen sitzend und mit Löffeln auf die leeren Teller trommelnd, des Essens. Zum Zeitvertreib lesen sie ihre Gedichte vor, wle quali sono d'una natura, e d'un'arte molto sottile, e faticosa, apprezzate da dieci nomini dell'Italia tra mille, da dugento rispettata, e dagli altri settecento novanta ascoltata, e intesa come l'Araba. Ecco la minestra, che fumica, le lingue misalate colle ciocche di prezzemolo affogato nel burro, zuccaro, e agrume. Le poesie si stanno.« (Zan. XV, 176). Hier zögert der Erzähler, in der Beschreibung der Mahlzeit fortzufahren, denn *Non è già questa una Commedia della nuova riforma da intrattenere colle scempiaggini $\propto$ (Zan. XV, 173). Erwähnt wird jedoch noch, daß es nach dem Essen »alcune guastadelle di ottimo vin greco* gab, »come che non odiano Pindaro, nè Teocrito i Granelleschi $\alpha$ (ebd.). So sind schon in den ersten Zeilen die sich zu Topoi entwickelnden Hauptaspekte der Polemik erkennbar: die Respektierung der literarischen Tradition durch die Granelleschi, das Unverständnis ihrer Zeitgenossen und die Mißbilligung der *Reform-Komödien $\propto$. 


\section{Allegorischer Angriff auf Goldonis Theater}

Unterbrochen wird die poetisch-kulinarische Szene durch das plötzliche Auftauchen eines Monsters im Getümmel auf dem Markusplatz:

Il corpo era d'uomo, la statura bassa, e grassa, e goffa oltremodo, ${ }^{83}$ le vestimenta erano cangianti, e tenea al gallone la spada. Nuova, e strana cosa era il capo, poichè aveva quattro facce con quattro bocche, quattro nasi, e otto occhi; uno di vista corta, tre cispi, quattro rovesciati, e per tutte quattro bocche ragionava. I discorsi venivano da un cervello solo, e picciolino, come che la zucca fosse assai grande, e tale, che si sarebbe potuta chiamare zuccone. E quanto agli orecchi erano due soli lunghissimi, e pengiglianti. ( $\mathrm{Zan} . \mathrm{XV},{ }_{178}$ )

Schnell versammelt sich eine Menschenmenge um das Monster, das beginnt, mit einem seiner Münder Pantalone, den Dottore, Brighella und Truffaldino nachzuahmen. Nach anfänglicher Begeisterung der Zuschauer verläuft sich jedoch die Menge, so daß das Monster seinen zweiten Mund öffnet und als Celio, Rosaura, Leandro, Clarice einige geläufige Szenen aus dem alltäglichen Leben mimt. Als auch dies niemanden mehr interessiert, fängt es an, in langen Versen heroische Figuren aus fernen Ländern mit fremden Sitten zu evozieren und zuletzt verlegt es sich darauf, Catterina und Maddalena win contrasto per gli amori, e per la gatta (Zan. XV, 179) vorzuführen. Als das Monster auf Einladung der Granelleschi in die Osteria kommt und Solitario ${ }^{84}$ sieht, erbleicht es nnelle labbra di tutte quattro le bocche ( $Z$ an. XV, $180-18 \mathrm{r}$ ) und versucht zu fliehen. Die Granelleschi lassen jedoch kurzerhand die Türen verschließen und zwingen das Monster, ihnen Rede und Antwort zu stehen. Solitario, zum Gesprächspartner des Monsters bestimmt, ${ }^{85}$ wehrt sich zunächst heftig und will diese Aufgabe auf den Botaniker Giovanni Marsili abwälzen, mit der Begründung, daß dieser ja Erfahrung mit Unkraut und giftigen Pflanzen habe. Zuguterletzt bewegen Tränen und Trauer der Granelleschi Solitario doch, den Dialog zu führen. Das Monster stellt sich als s Teatro

83. Wie bereits mehrere 'Textausschnitte zeigten, sind dies die physiognomischen Eigenschaften Goldonis, die Gozzi immer wieder zur satirischen Charakterisierung verwendet. Auch dafür kōnnte der Anlaß in Goldonis Texten selbst liegen, in denen er häufig von seiner eigenen Person und seinen Befindlichkeiten spricht. Dort heißt es z. B.: * Son per natura un pocolin poltrones (Capitolo, Goldoni, XIII, 425), *So ben che di sudor bagnava i panni, / e son carco di ciccia, e carco d'annie (Visita delle sette chiese, Goldoni, $\mathrm{XIII}, \varsigma_{21}$ ), $>$ Ambi il viso grassotto e ritondetto, / Ambi abbiamo una pancia badiale, / I] collo corto, e spazioso il petto- (Goldoni, XIII, 593; dieses Gedicht entstand allerdings erst 1760 ).

84 -Solitario ist Carlo Gozzis Name in der Accademia de' Granelleschi.

85 Es ist der Mäzen der Akademie, Farsetti, der Solitario für das Gespräch auswahlt. Bereits in La tartana fällt Farsetti die Funktion des Herausgebers zu. 
comico dell'Italia* vor und fährt fort: "Io sono figliolo di quel terribile Polisseno Fegejo nuovo Terenzio de' tempi nostri, del Molier dell'Italia, ${ }^{86}$ del riformator delle Commedie, di quel fertilissimo ingegnoso regolato Scrittore, e poeta nell'uno, e nell'altro sesso. (Zan. XV, $182-183$ ). Damit wird offensichtlich, daß die vier Seiten der Maske vier verschiedene Arten von Theater bzw. Komödien repräsentieren, die Goldoni im Laufe seiner venezianischen Karriere erprobt hat: die Commedia dell'arte, Charakterkomödien (commedie di carattere), exotische Komödien (commedie di carattere orientale) und Volkskomödien (commedie popolari). Im folgenden Dialog werden am Beispiel zweier Komödien Goldonis, Il teatro comico und La bona muger (La buona moglie), zahlreiche Aspekte der sogenannten Komödienreform diskutiert. Nicht zufällig fällt die Wahl auf Il teatro comico, ein metatheatralisches Stück, das mittels des Theaters im Theater die Reformbestrebungen anschaulich macht, ${ }^{87}$ und La buona moglie, der Fortsetzung von La putta onorata, die »quasi esempio di cose vere $\alpha$ sind. ${ }^{88}$ Beide Stücke markieren entscheidende Punkte auf dem reformerischen Weg. Wiederum also greift Gozzi Texte Goldonis auf und demontiert sie auf teils ernsthafte, teils ironische Weise. Während er zunächst Goldonis Konzeption des Dichters und Autors anhand der Figur Lelio aus Il teatro comico als unhaltbar entlarvt, stellt er dann bezüglich des Binnenstücks die Frage, was Goldoni eigentlich reformieren wolle, "le Commedie, gl'Intermedj, o i Drammi? \& (Zan. XV, r94) und kommt zum Schluß, daß er keine andere Reform erkennen könne als die, daß nun das ausgeschrieben sei, was vorher auf der Grundlage des scenario improvisiert wurde. Insgesamt macht er deutlich, daß Goldoni vieles von dem, was er in seinem Stück als Teil der Reform proklamiert, selbst nicht einhält, ${ }^{89}$

\$o Terenzio und $/ 1$ Moliere sind die Titel zweier Komödien Goldonis, in denen er sein Selbstbild in Gestalt der berühmten Autoren modelliert.

87 Dazu ausfuhrlich in Kap. 3.2.

48. So Goldoni im Vorwort zu La buona moglie, Goldoni, II, 523 . Diesen Passus zitiert Gozzi selbst im Verlauf von Il zeatro comico all'Osteria del Pellegrino, Zan. XV, 219. Zu Gozzis Kritik s. A. Beniscelli, - La dilogia di Betrina nelle pagine critiche di Carlo Gozzis, op. cit., S. 48-68. Zur Bedeutung von La putta onorata (gewissermaßen dem ersten Teil der Bettina-Komödien) für Goldonis Reformprojekt und zur bewußten $>$ Konstruktion* einer teleologischen Perspektive der Reform, s. Nicola Mangini, =Su due -topoi* dell'autobiografia goldoniana*, in: Franca Angelim ( $\left.\mathrm{Hg}_{+}\right)$, Memorie di Goldoni $e$ memoria del teatro, Roma, Bulzoni 1996, S. 23-34. Daß Gozzi gerade cin Bertina-Stuek wảhlt, zeigt seine Sensibilität fur Goldonis Reform-Strategie.

89 So z. B. hinsichtlich der Einheit der Handlung, des Verhaltnisses von guten und schlechten Charakteren sowie des Allgemeinen und des Besonderen in der Handlung, hinsichtlich der Verwendung von Prosa und Vers im Hinblick aut die Forderung nach Wahrscheinlichkeit und der Obszönitäten, Zweideutigkeiten und Handgreiflichkeiten in den Stucken. 
und daß die Regeln, nach denen er seine Komödien verfasse, vor allem die des Publikumserfolgs und der vollen Kassen seien. Unterbrochen wird dieser Dialog von einer nLezione agli Studenti della Comica Poesia , in der Solitario am Beispiel von La bona muger Goldonis Arbeitsweise vorführt. Laut Teatro comico entsteht ein Stück »a poco a poco dopo un lungo studio, una lunga pratica, ed una continua istancabile osservazione del Teatro, de' costumi, e del genio della nazione (Zan. XV, 203, als Zitate aus Il teatro comico). In ausgesprochen satirischer Weise beschreibt nun Gozzi, wie Goldoni als Spion am offenen Fester sitzend die Unterhaltungen und das Gezänk seiner Nachbarinnen belauscht und sofort niederschreibt, um daraus den 1 . Akt seiner Komödie zu machen. Er scheut keine Mühe, die banalsten Dinge zu kopieren und die "poesia naturale di panche, sedie, tavolex einer Osteria sowie die sparole, che udiva dire alle puttane, a' malviventi, a' gondolieri ${ }^{\prime}(\mathrm{Zan} . \mathrm{XV}, 210)^{90}$ für sein reformiertes Theater fruchtbar zu machen. Dem »studio del mondo $\approx$ folgt die »osservazione del teatro «, die ihn veranlaßt, seine ganzen Niederschriften in Szenen und Akte einzuteilen, sie zu einer »unità dell'azione « zu verbinden und in den Mund von 17 Schauspielern zu legen, weil seine Truppe gerade so viele Mitglieder zählt. So hat Goldoni ungeachtet der schlechten Charaktere im Stück ein Kleinod produziert und ruft fröhlich aus: „Oh divina

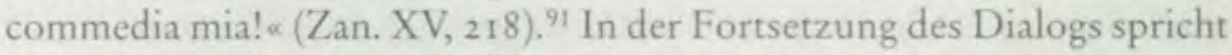
Solitario allerdings ein vernichtendes Urteil über die Komödie:

So benissimo che vai cantando essere poeta della natura, ma sappi che nelle tue minestre c'è solo la natura carnale, e materiale, e non la natura dello spirito elevato, e ammaestrato dalle scienze all'utile delle genti, e alle composizioni sane, regolate, e poetiche, e che se non hai altro fine, che quello dell'intrattenere, non hai regolato il Teatro, nè riformate le Commedie dell'arte. (Zan. XV, 223)

Zuletzt, nachdem alle vier Münder des Monsters nicht mehr wissen, was sie zu ihrer Verteidigung anbringen sollen, zieht das Monster sein Hemd hoch und entblößt, zur größten Verwunderung der Granelleschi, auf seinem Bauch einen fünften Mund, der sich für die vier anderen entschuldigt und gesteht, "che tutto fu fatto per amor mio, e non per altro« (Zan. $\mathrm{XV}, 253)$, worauf das Monster verschwindet. Auf die letzte Befürchtung

90 Im Vorwort zu La putta onorata schreibt Goldoni: - [... ] i Gondolieri di Venezia, i quali furono da me nella presente Commedia imitati con tanta attenzione che più volte mi posi ad ascoltarli, quando quistionavano, sollazzavansi o altre funzioni facevano, per poterli ricopiare nella mia Commedia naturalmente. (Goldoni, II, 42T). Gozzi bezieht sich also auch hier wieder auf einen konkreten Text und eine Formulierung Goldonis.

91 Diese Anspielung auf Dante ist besonders pikant, da Gozzi Goldoni ständig vorwirft, sich nicht mit den Alten auseinanderzusetzen, ja sie nicht cinmal zur Kenntnis zu nehmen. 
Solitarios hin, daß seine Kritik ungehört verhallen und die schlechten als Vorbilder angepriesenen Komödien die Welt in einen »bosco di ladroni, di traditori, di sfrenati, di miscredenti, di lussuriosi« verwandeln werden, gehen die Granelleschi wehklagend auseinander, im selbstironischen Bewußtsein ihrer Märtyrerrolle, schi qua, e chi là a spargere parolette in difesa del buon gusto, e delle purgate scritture, e a scagliare dardi alla corruzione del secolo, e a viso aperto cercando il martirio.* (Zan. XV, 255 ).

•Parolette dieser Art verbreiteten die Granelleschi dann in gedruckter Form in den Atti degli Accademici Granelleschi, deren erste Folge im Dezember 1760 veröffentlicht wurde. Sie enthielten überwiegend burlesksatirische Gedichte, sonetti caudati, capitoli, und canzoni, in deren Mittelpunkt nicht nur Goldoni und Chiari, sondern auch andere Autoren und die Unsitten der Zeit standen. Unübersehbar ist allerdings, daß bis zum Zeitpunkt des Erscheinens der ersten Atti-Folge die Polemik stärker auf Goldoni als auf Chiari zielte. Nach der dritten Lieferung der Atti wurde die Publikation eingestellt, was die Attraktivität der Broschüren sicherlich nur erhöhte. ${ }^{92}$ Die meisten der für die Atti vorgesehenen Gedichte nahm Gozzi 1774 unter der Überschrift »Varie composizioni facete satiriche in den achten Band der Colombani-Ausgabe auf. In inhaltlicher Hinsicht besteht - insbesondere was Goldoni betrifft - eine weitgehende Übereinstimmung mit den bereits vorgestellten längeren Werken. Die Angriffe richten sich vor allem auf die Unangemessenheit der von Goldoni wie Chiari geübten persönlichen Satire, auf die ökonomischen Interessen, die hinter der literarisch-dramatischen Produktion stehen, auf Goldonis Anspruch, der Reformator des italienischen Theaters zu sein und seine Traditionsvergessenheit beziehungsweise -leugnung.

12 Siche dazu ausfuhrlich P. Bosisio, Carlo Gozzi e Goldomi, op. cit, S. 19f. und $27 \mathrm{ff}$, der u.a. in Anlehnung an Gozzis vage Aussagen in seinen Memoiren von einem Publikationsverbot durch den Magistrato dei Riformatori dello Studio di Padooa spricht und dafür *implicazioni ideologiche e politiche * geltend macht, was jedoch angesichts der ganz im Allgemeinen bleibenden Texte nicht überzeugt. Vielmehr ist anzunehmen, daf die Kontroverse Ausmaße anzunehmen begann, die die offentliche Ordnung bedrohten; vgl. Gozzi, Discorso, Col. VIII, 249-250. In seiner großen monographischen, an Detailinformationen reichen Arbeit zu Carlo Gozzi, die in der italienischen Forschung kaum zur Kenntnis genommen wurde, bezweifelt Gérard Luciani, daß es überhaupt ein Publikationsverbot gegeben habe, da er keinerlei diesbezügliche Dokumente bei den Riformatori oder dem Trabuale alla Bestemmia finden konnte und geht von einer freiwilligen Unterbrechung der Publikation der Atti aus (Gérard Luciani, Carlo Gozzi (1720-1806). L'bomme et l'awere, Paris, Champion 1977, S. 185 ). 


\section{Gründe und Grundzüge der Polemik Gozzis}

Immer wieder betont Gozzi, wie lächerlich der Anlaß zu einer Auseinandersetzung war, die in der Zwischenzeit ungeahnte Ausmaße angenommen hatte, $" \mathrm{~A}$ un Medico, Avvocato, ed Assessore / Io dissi un di, che non è buon Poeta; / L'opinione è del Burchiel Profeta; / Andromm'io per sì poco in un savore? « (Col. VIII, 183), und rechtfertigt die Fortführung und Einengung der Polemik auf Texte Goldonis und Chiaris mit deren übertriebener Reaktion auf La tartana. Ihre Antworten bewegten sich in Gozzis Augen nicht im Bereich einer allegorischen Darstellungsweise und litererarisch sanktionierter Modelle der Aggression wie Satire oder Parodie, vielmehr enthielten sie derart persönliche Angriffe, daß eine Gegenreaktion unvermeidlich war. ${ }^{93} *$ Invidioso $*$, maldicenza*, * collerico colla Fortuna «, »versi rancidi sciapiti« und »menzogna « tauchen als Zitate aus Goldonis und Chiaris Gedichten schlagwortartig in Gozzis Texten auf und belegen den unmittelbaren Bezug zwischen Text und Gegentext. Auf einen weiteren moralisch bedenklichen Aspekt der Gelegenheitsdichtung Goldonis und Chiaris weist Gozzi indirekt hin, wenn er mehrfach beteuert, daß La tartana kostenlos in Umlauf gebracht worden sei. ${ }^{94}$ Die beiden Kontrahenten dagegen veröffentlichten ihre Beiträge nicht als selbständige Publikationen, sondern brachten sie in raccolte unter, was ihnen zum einen eine breite Resonanz bei den Geehrten - und diese gehörten meist einflußreichen Familien an -, zum anderen aber auch die Bezahlung ihrer diffamatorischen Gedichte sicherte.

Der Grund dafür, daß Goldoni La tartana nicht einfach in ihrem Anliegen hinnehmen konnte, das sie nach Gozzis Beteuerung verfolgte, nämlich »di dire la verità sopra a' costumi, e agli scrittori del corrente secolo« (Zan. XV, 69), liegt laut Gozzi in seiner mangelnden Souveränität

93 Im Vorwort zu Zan. XV stellt Gozzi den Sachverhalt im Rückblick folgendermaßen dar: -Per aver io detta la innegabile verità in alcuni versi faceti manoseritti, e che furono stampati, e pubblicati contro alla mia aspettazione, che il Goldoni era uno scrittore italiano maccheronico, quel dabben'uomo si è per modo riscaldato il cervello da farlo collegare col Chiari, suo rivale, e con alcuni poetastri suoi partigiani caricandomi di tali fangose e goffe satire, di tali derisioni sgraziate, di tali insidie d'astuzia infelice, che m'obbligarono alla necessità di sfoderare un'arma tagliente e pungente satirica ragionata per porre in fuga le zanzare moleste. (Zan. XV, 8). Wenn hier auch eine Selbstverteidigung Gozzis intendiert ist, machen die Abfolge der polemischen Texte sowie die Veränderungen in der Art der Auseinandersetzung deutlich, daß die traditionelle Darstellung, nach der ein harmloser, friedliebender Goldoni von einem angriffslustigen, eigensinnigen Gozzi herausgefordert wird, nicht haltbar ist. Darauf weist auch Norbert Jonard in einer Anmerkung seiner Ausgabe von Goldonis Mémoires (Paris, Aubier r992, S. 670) hin.

94 So zum Beispiel im Avviso al lettore zur ersten Ausgabe der Atti Granelleschi: »[la] Tartana, che fu certamente donata, e non mai venduta (Col. VIII, 137). 
der Kritik gegenüber. Dieser Vorwurf korrespondiert mit einer Terzine in Goldonis Capitolo, sFremo di rabbia, ed ho me stesso a sdegno, Strapazzato veggendo il mio lavoro / In un mestier di sì scabroso impegno a, 95 auf die sich Gozzi gezielt bezieht. Goldoni, der sich von Anfang an in Venedig das Image eines Theaterreformers gegeben und dem $175^{\circ}$ im manifestartigen Vorwort zu seiner Komödien-Edition bei Bettinelli, in der Komödie Il teatro comico und in zahlreichen Geleitworten und Widmungen beredten Ausdruck verliehen hatte, legte in Gozzis Augen eine Einbildung und Überheblichkeit an den Tag, die die Kritik geradezu herausforderten. "La tua superbia e un volere, che ella sia buona commedia a forza, ci fa increscere i tuoi difettacci; fossi umile non proveresti tale sciagura.* (Zan. XV, r 10).

Unablässig zieht Gozzi in Zweifel, daß Goldoni wahrhaftig ein s riformatorea sei und gibt kurze Hinweise auf die Begründung dieser polemischen Infragestellung. Einerseits existierten bereits vor Goldoni Reformbewegungen, die auf "sane rappresentazioni von opere saggie, $e$ d'ottima poesia “ (Zan. XV, 125 ) zielten, ${ }^{96}$ andererseits wiesen die frühen Stücke Goldonis kaum einen Unterschied zur traditionellen Commedia dell'arte auf, und seine Charakterkomôdien seien nichts als Nachahmungen französischer Vorbilder. Nur unter absichtlicher Vernachlässigung dieser Tatsachen kann sich Goldoni für einen *Moliere novello $\approx$ und *riformator di Teatro* ausgeben. Daß Goldoni seit 1750 mehrere GesamtAusgaben seiner Komödien veranlaßt hat, um so zum einen Maßstäbe zu setzen, zum anderen seinen Ruhm zu verbreiten und damit auch noch Geld zu verdienen, ist besonders ärgerlich, denn mit dem Druck verschafft Goldoni seinen Produkten eine Dignität, die ihnen nach Meinung Gozzis nicht zusteht. ${ }^{97}$ Dabei spielt Gozzi auch auf Goldonis verschiedene Berufe ( $\rightarrow$ medico, avvocato, assessore $)^{\text {) }}$ an und spricht ihm kurzerhand die

5s Goldoni, XIII, 452.

\% Siche dazu Kap. 3.1.

v7 -Ma più d'ogni altra cosa istupisco che tu abbia avuta la temerità di dare alle stampe per esemplari, e per insegnare agli altri l'opere tue con tante prefazioni di fracida boria, $c$ lodi a te stesso. - (Zan. XV, 251).

Ilaria Crotti stellt in ihrem Artikel -Bettinelli e Goldoni, da Venezia alla luna a, in:

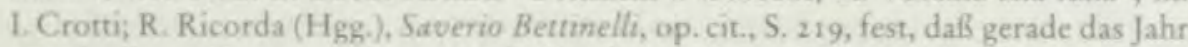
1757 in diesem Zusammenhang entscheidend war: $>$ il " $\$ 7$ risulta tra l'altro l'annata in cui si concludono le edizioni Bettinelli, Paperini, Gavelli, Corciolani, prende avvio la Pitteri, mentre proseguono la napoletana Venaccia ela torinese Fantino e Olzati-, So könnte dies auch einer der Gründe dafür sein, daß Gozzi gerade zu diesem Zeitpunkt mit La tartana an die Offentlichkeit trat und indirekt auf die Diskrepanz zwischen der Seriosität der Editionen und der Lächerlichkeit des Zwists mit Chiari aufmerksam machre. Vgl. z. B. den bereits zitienten Ausschnitt aus der -Lettera fegejana* ( $\mathrm{Zan}, \mathrm{XV}, 78$ ), in dem einige der Editionen aufgezählt werden. 
Qualität eines »buon Poeta* ab. Das Rollengedicht "Canto d'un poeta* (Col. VIII, 238-239), in dem jeder vierte Vers auf »Poeta endet, führt ironisch vor, wie einfach es ist, zum spoeta $\approx$ zu werden. Zugleich wird deutlich, woran sich dies maßgeblich entscheidet: am Umgang mit der Sprache. Dieser Aspekt steht im Kontext der Sprachproblematik und des Konflikts zwischen »antichi $*$ und »moderni*, der das ganze Settecento prägt. Im Gegensatz zu Goldoni ist für Gozzi die Vertrautheit mit Dante, Petrarca und den Dichtern des Quattro- und Cinquecento unabdingbar, und fraglose Priorität kommt für eine ernstzunehmende Dichtung dem spuro toscano $z$ zu, denn "li Fiorentini [sono] li veri Italiani* (Zan. XV, 87). ${ }^{98}$ Diese Position führt zu einer andauernden Polemik gegen Goldonis ^gergone fastidioso, che sa di foro, tien di proclama, e di bando, pute d'appigionasi, esce tra il Lombardo, il Marchigiano, ed altre Città, castella, e villaggi« (Zan. XV, Io9). Während Goldoni immer wieder mit dem Eingeständnis kokettiert, er komme auch ohne das Crusca-Wörterbuch und die Lektüre der Alten aus, ${ }^{99}$ und zugleich auf seinen Erfolg und die Exemplarität seiner Komödien hinweist, wirft Gozzi ihm vor, nicht einmal einen bestimmten Stil zu erkennen, geschweige denn, ihn nachahmen zu können. So macht er sich darüber lustig, daß Goldoni La tartana für eine Burchiello-Imitation halte und fordert ihn auf, doch zu erraten, wen er wirklich imitiert habe. ${ }^{100} \mathrm{Je}$ mehr Goldoni die Überflüssigkeit der Crusca

48 Die Kenntnis der literarischen Tradition wie auch des Toskanischen ist für Gozzi eine Grundvoraussetzung; daß dann je nach Gattung und Stil eines Werkes unterschicdliche Sprachebenen aktualisiert werden, ist selbstverstandlich, wie z. B. die Fiabe teatrali mit ihrem Kontrast zwischen hoher literarischer Sprache und venczianischem Dialckt deutlich machen.

99 So z. B. im Capitolo: $»$ Non ho stil che mi regga e mi governi-, -basse rime alla grand'opra impiego, / Ed io stesso conosco il mio difetto (Goldoni, XIII, 452), in La tavola rotonda: =Desta la veritade il mio pensiero, / Debole è il mio cantar, ma canto il vero.*; "Purtroppo il so che buon scrittor non sono, / E che ai fonti migliori non ho bevuto* (Goldoni, XIII, 472, 480) und in vielen anderen Gedichten. Selbst wenn es sich dabei nicht um ein wirkliches Eingeständnis, sondern um einen exzessiven Gebrauch des Bescheidenheitstopos handeln sollte, würde dessen Wirkung durch das regelmäßig folgende Eigenlob aufgehoben.

Mit seiner Kritik an Goldonis Sprache und anderen Vorwürfe wie z. B. dem, Goldomi schreibe vor allem für Geld oder er nenne sich zu Unrecht ^riformatore , steht Gozzi nicht allein, sie tauchen bereits 1754 in den Composizioni uscite sic i teatri auf.

100 Scritura contestativa, Zan. XV, 95, 98. Auch heute noch werden Gozzis frühe Texte gerne der spoesia burchiellesca* zugeordnet. Zieht man jedoch neben Gozzis Aussage Burchiello-Gedichte und De Robertis Beschreibung der poesia burchiellesca in der Storia della letteratura italiana, Hgg. Emilio Cecchi und Natalino Sapegno, Bd. 3: Il Quattrocento e PAriosto, Milano, Garzanti 1966, S. 427-436, in Betracht, erscheint dies kaum gerechtfertigt. Zutreffender ist dagegen die Bezeichnung poesia bernesca, zu deren beliebtesten Formen sonetto caudato und capitolo sowie karikierende, burleske, obszöne Züge gehören. 
beteuert und demonstrativ den Publikumsgeschmack als Richtschnur in den Vordergrund stellt, um so unverrückbarer beharrt Gozzi auf ihrer Unentbehrlichkeit. Diese bewußte Polarisierung verdeckt meist die differenziertere Meinung Gozzis, nach der sich die Qualität von Dichtung nicht an der äußeren Form und Sprache bemessen kann, sondern vom Inhalt abhängt. Dieser bedarf aber, kurz gesagt, der adäquaten Vermittlung, deren Gelingen wiederum eine weitgehende Beherrschung aller Ausdrucksmöglichkeiten erfordert: $»$ La buona Poesia sta nel pensiero, / Chi non ha lingua, il pensier non esprime. « (Col. VIII, 166). Daher ist das eingehende Studium vorgängiger Literatur unerläßlich und die Auseinandersetzung mit Form und Stil Voraussetzung für jede Art des Schreibens. Goldoni wie Chiari stellen sich jedoch als geborene Dichter dar ${ }^{101}$ und rufen damit Gozzis entschiedene Kritik hervor. Wenn Goldoni sich darauf beruft, daß er eine Sprache spreche, die allen verständlich sei und im $\mathrm{Ca}$ pitolo betont, $n$ Vo cercando le rime e i sentimenti / Dalle oneste persone, e gli scrittori/ Cerco imitar che piacciono alle genti«, interpretiert Gozzi dies als Anbiederung ans Publikum. Und diese praktiziert Goldoni nach Gozzi nicht nur in sprachlicher Hinsicht, sondern auch im Hinblick auf die Machart der Stücke sowie ihren angeblichen moralischen Anspruch.

Wie die vier Gesichter des "Teatro comico* anschaulich machen, wechselt Goldoni je nach Publikumsgeschmack die Sprache, den Stil, die Gattung. Da das venezianische Theaterpublikum äußerst unbeständig ist und stets nach Neuem verlangt, ist Goldoni zu ständigen Veränderungen gezwungen. So entsteht in Gozzis Augen ein unauflösbarer Widerspruch zwischen Goldonis teleologisch ausgerichtetem Reformgedanken und dem angestrebten Publikumserfolg, der sich selbstverständlich auch finanziell auswirkt. Hinzu kommt, daß sowohl die finanziellen Aspekte als auch der Drang zu Novitäten Goldoni zu einem Vielschreiber machen, dem es unmöglich ist, eine gleichbleibende Qualität seiner Werke zu sichern. Wenn nun Goldoni in der vielzitierten $*$ Prefazione $\times$ von 1750 und in den Vorworten zu seinen Komödien immer wieder den Publikumserfolg als Indiz für die Qualität seiner Komödien ins Feld führt, ${ }^{102}$ ist dies in zweifacher Hinsicht zweifelhaft. Zum einen kann ein so rasch wechselnder Publikumsgeschmack kein Qualitätskriterium sein, da sich Qualität zumindest über eine gewisse Zeit beweisen muß, zum anderen

101 Im Vorwort zur Bettinelli-Edition 1750 spricht Goldoni yom *comico genio*, das ihn zum Reformator befahige, bei Chiari findet sich der Satz: -1 Poeti nascono Poeti॰, in: It genio ed i costami del secolo corrente, Venezia, Novelli 1761.

102 In der - Prefazione- heißt es beispielsweise zu Momolo cortigrano: -Piacque essa estremamente, e fu tante volte replicata con istraordinario concorso, che fui allora tentato di crederla perfetta Commedias; Goldoni, I, 768. 
rennt das Publikum in jedes Spektakel, gibt es nur etwas Neues zu sehen. ${ }^{103}$ Der Zulauf der Zuschauer kann demnach wohl deren Gefallen am Stück zeigen, doch niemals als Urteil über die Qualität gewertet werden. Damit trifft Gozzi eine klare Unterscheidung zwischen der Bühnenwirksamkeit und dem gelehrten Qualitätsurteil, das allein die sperfekte Komödie $\alpha$ ausweisen kann.

Bereits 1750 unterstreicht Goldoni seine Bemühungen sper ricondurre sul Teatro Italiano il buon costume e 'I buon gusto della Commedia\&, spricht vom Theater als "scuola dell'onestà* und kombiniert diesen Aspekt mit der Sprachfrage: er habe in seinen Stücken weniger Wert auf die Sprache und dafür mehr auf die Moral gelegt. ${ }^{104}$ Dieser Betonung des moralischen Anspruchs tritt Gozzi energisch entgegen und macht polemisch deutlich, wie wenig vorbildlich sich die Figuren verhalten und wie oft sich Zweideutigkeiten und Anspielungen aus der Commedia dell'arte auch in Goldonis Stücken finden. Zieht man in diesem Kontext die Parodie auf Goldonis Arbeitsweise in Il teatro comico all'Osteria del Pellegrino in Betracht, die sich im wesentlichen mit dem Stichwort »ricopiare « charakterisieren läßt, wird ein Widerspruch zwischen postulierter Vorbildlichkeit und kruder Nachahmung erkennbar, auf dem Gozzis Polemik basiert. Erweisen sich die moralisch zweifelhaften Stücke trotzdem als erfolgreich, so zeigt dies nur, wie verdorben die Zuschauer sind, "sono corrotti i cervelli, ed è corrotta la volontà del popolo« (Zan. XV, $23 \mathrm{I}$ ). Folglich stellt sich die Frage, wie man denn das Theater reformieren könne, wenn man dem schlechten Geschmack eines wankelmütigen Publikums nachlaufe, und Gozzi antwortet: »Un solo rimedio ci scorgo, e sarebbe questo: Di bandire le Commedie dell'arte, e le nuove riforme ugualmente, e chiudere

${ }_{103}$ Dieser Aspekt zicht sich wie ein Topos durch Gozzis Texte; er hat ihn, vor allem in der Scrittura contestativa, zu rhetorischen Kabinettstücken beflügelt. Beispielhaft sei ein polemisches sonetto caudato angeführt, das die Absurditit von Goldonis Argumentation bloßstelle (Col. VIII, $184-185$; $11^{2}$ Abate* ist Chiari):

Dottor, se incontra qualche tua Commedia Non dir per questo, ella sia buona mai, Perché, se incontra una all'Abate assai, Tu di, ch'ella è cattiva, e ch'ella tedia.

E se a qualch'altra il Popol non t'assedia,

Stolto, e ignorante non lo chiamerai, Os'una all'altro casca, non dirai:

Quest'è, perch'ella è una fola, un'inedia.
O tu vuoi, che il concorso sia buon segno,

O l'abbandono un tristo segno sia,

O il popolo a decider non sia degno.

Perdio, Dottor, di qua non fuggi via; Rispondi, e aguzza, quanto vuoi, l'ingegno;

$\mathrm{O}$ tu, o l'Abate, o il Popolo è in follia. Se astratto, $\mathrm{e}$ in balordia

Rispondi: E' sempre buon segno il concorso; Viva il Dottor, l'Abate, il Sacchi, e l'orso.

$104 \mathrm{Vgl}$. Prefazione dell'autore alla prima raccolta delle commedie 1750, Goldoni, 1, 769; Visita delle sette chiese, Goldoni, XIII, 517 ; Esopo alla grata, Goldoni, XIII, 29 a 
i Teatri per tre, o quattro anni per far venire una gran fame al popolo di vedere il Teatro di nuovo aperto.* (Zan. XV, 254).

\section{Ein Kompendium der Kontroverse}

Dieser Ratschlag taucht wenig später noch einmal auf, nämlich in Gozzis Fogli sopra alcune massime del genio e costume del secolo dell'abate Pietro Chiari e contro a' Poeti Nugnez de' nostri tempi aus dem Jahr 1761. Der umfangreiche 'Text ist ein in ein narratives Gewand gekleidetes Pamphlet, das zwar als direkte Reaktion auf Placido Bordonis Nuovo segreto per farsi immortale un poeta nelle Gazzette ( 1760 ) und Chiaris Il genio ed i costumi del secolo corrente (176I) erschien, jedoch gleichsam ein Kompendium der dreijähigen Polemik darstellt. ${ }^{105}$ Mehrfach verweist Gozzi auf seine früher erschienenen Werke La tartana und I sudori d'Imeneo, macht aber auch demonstrativ auf die Scrittura contestativa und Il teatro comico all'Osteria del Pellegrino aufmerksam, die bislang unveröffentlicht geblieben seien, sper servire de' Cavalieri, pregati dai Poeti Nugnez a tor loro la vergogna, e il danno della pubblicazione $\alpha .{ }^{106}$

105 Der Geistliche Placido Bordoni war Anhänger Chiaris, gab $176 \mathrm{r}$ dessen Gedichte in 3 Bänden heraus und trat mit Nuovo segreto offentlich zur Verteidigung Chiaris an. Chiaris Prolog La notte critica hatte einen anonymen Kritiker auf den Plan gerufen, der am 11. Oktober 1760 (Nr. 72 ) in La gazzetta veneta scerti dubbi publizierte. Diese gaben Anlaß zu einer langeren Auseinandersetzung, in deren Verlauf in der Gazzetta veneta eine Reihe von Stellungnahmen und Gegendarstellungen erschienen, auf die auch Carlo Gozzi in den Fogli anspielt. Bordonis anonym erschienene Streitschrift, die als Untertitel-Lettera di N.N. scritta all'Ab. Pietro Chiari sopra li s. Dubbjk trägt, war laut Carlo Gozzi nichts als ein wüster Angriff auf die Granelleschi (s. Mem., I, 34, 225-226). Zwei weitere Pamphlete aus dem Umkreis der Granelleschi gegen Bordonis Nuovo segreto sind Soffolto Planomacos [i.e. Giannantonio Deluca laut einer Anmerkung in La gazzetta veneta, S. 440] Arte senza regole per rendere immortale un poeta fuori delle gazzette e sulle gazzette und anonym erschienene Riflessioni critiche sopr'alcune proposizioni trovate nel libro intitolato Il genio ed i costumi del secolo corrente [...] da un Accademico Planomaco, Venezia, Bassanese 1762. Dieser Text wird von P. Bosisio, Carlo Gozzi e Goldoni, op. cit., S. 4o5, Giuseppe Manzoni zugeschricben, der sowohl der Accademia Granellesca als auch den Planomaci angehörte. Zum Verlauf der Debatte siehe auch die ausführlichen Kommentare Antonio Zardos in Gasparo Gozzi, La gazzetta veneta, $\mathrm{Hg}$. Antonio Zardo, Firenze, Sansoni $1955,299 \mathrm{ff}$.

Wie weit die Kontroverse inzwischen in die Offentlichkeit getragen worden war, ist daran sichtbar, daß nun auch die Journale zu wichtigen Foren werden. Diese Funktion sollte sich im Laufe der kommenden Jahre noch verstärken. 1760/61 war es vor allem die von Gasparo Gozzi herausgegebene Gazzetta veneta, die sich der aktuellen Diskussion öfnete. Wahrend Gasparo Gozzi Goldoni wohlwollend gegenüberstand, sind die Beiträge zu Chiari kritisch bis iromisch.

${ }^{106} \mathrm{Fogli}, 5 \mathrm{t}-52$. Im folgenden werden die Titel abgekürzt als Nuovo segreto (Bordoni), Genio (Chiari) und Fogli (Gozzi). 
*Poeti Nugnez* heißen Goldoni und Chiari in Anlehnung an Lesages Roman Histoire de Gil Blas de Santillane, in dem der Titelheld zu seiner großen Überraschung in Madrid seinen alten Freund Fabrice wieder trifft, der sich, inzwischen zum »poète Nuñez « geworden, als Roman- und Komödienschreiber durchschlägt.

Chiaris Genio ist angeblich eine freie Übersetzung anonymer franzōsischer " filosofiche riflessioni , gibt sich jedoch sehr bald als Beitrag zur laufenden Kontroverse zu erkennen. ${ }^{107}$ Schon im Vorwort nimmt er ausführlich Stellung zum Phänomen der anonymen Publikation. Unverkennbar ist in den Außerungen die Anspielung auf Gozzis Tartana ${ }^{108}$ bis hin zur wörtlichen Anlehnung an Goldonische Gedichte, »Alcuni lo fanno per sola vergogna di comparire ignoranti o maledicenti, e tali sono coloro, che con anonimi libricciuoli attaccano la riputazione altrui $\alpha_{,}{ }^{109}$ Darauf reagiert Gozzi prompt in den Fogli: snon aveva nome del suo Scrittore, ma i pesciolini sapeano ch'ella era di Carlo Gozzi. Se ad alcuno mancasse il saperlo, suonisi la tromba, si raduni il popolo. Sappiasi che la Tartana è di Carlo Gozzi, di Carlo Gozzi, « (Fogli, 26). Etwa die Hälfte der I 5 ×Articoli« von Chiaris Genio richtet sich direkt gegen Gozzi und die Granelleschi, die andere Hälfte weist losere oder keine Bezüge dazu auf. Neben Fragen zur Gattung der Komödie und zur Sprache, die Anlaß sind, die Granelleschi als "gramatici [sic] und »autori malnati $z$ zu beschimpfen, berührt Chiari das Verhältnis von Kritik und Satire und fordert in offensichtlicher Gegenposition zu Gozzi und den Granelleschi, "La Critica, e la Satira esser dovrebbero due nemiche implacabilia. ${ }^{10}$ Dies alles inspi-

107 Unklar ist, ob Chiari sich tatsächlich an einer französischen Vorlage orientierte. G. Luciani ist $m$. E. der einzige, der diese Frage stellt und konstatiert, daß er den franzôsischen Text ndans toute la production du XVIIIème siècle en ce genre de littérature* (Carlo Gozzi, op. cit., S. 178) nicht habe identifizieren können. Im Hinblick auf den Titel könnte La Bruyères Les caractères ou les maerers de ce siècle als Vorbild gedient haben, doch gibt es kaum inhaltliche Entsprechungen. In Gozzis Fogli trifft man auf zwei widersprüchliche Aussagen in bezug auf einen Referenztext. So heißt es cinmal,, $\mathrm{E}$ dovete avvertire, che le parole del Nugnez Maestro non sono dell'anonimo Francese tradotto, e da lui beneficato d'aggiunte- (S. 56 ), ein andermal allerdings: = lo teneva il toccalapis nella destra mano, da una parte il Testo Francese, dall'altra la Traduzionex (S. 60). Es wäre jedoch nicht verwunderlich, wenn Gozzi das Spiel mit einem fiktiven Referenztext für seine Reaktion fruchtbar machen würde.

108 In einer Komödie mit dem Titel Gli amanti in collera, die im Karneval 1760 aufgeführt wurde, Iäßt Chiari einen Dottor Tartana auftreten, der allerdings weniger als Abbild Gozzis denn als polemisch-satirisches Amalgam aus Gozzi und Goldoni erscheint.

109 Genio, 5.

130 Genio, 71 . Interessant und bezeichnend für Chiaris Eklektizismus ist es, daß er andererseits Positionen Gozzis und der Granelleschi aufgreift und zu seinen eigenen macht,

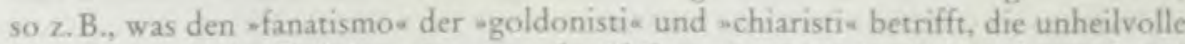
Zurücksetzung der Religion zugunsten der Philosophie oder den übertriebenen Trend zum modischen Luxus. 
rierte Gozzi zu ciner polemischen Abrechnung mit den *Poeti Nugnez «, die er in zwei Anfangs-Sermoni gegen Chiari und Bordoni und acht Fogl vornimmt. Nachdem er sich bei seinen Gegnern sun nome di pedante stitico, di semplice, e vigliacco grammatico, di Goto, e d'Unno, di censore dappoco, di Poeta sciocco, di zucca vuota, e brievemente, d'ignorante, e d'uomo da nulla« (Fogli, 19) gemacht habe, hebt er nun zur Verteidigung seiner Position an. Er läßt die Kontroverse, ausgehend von La tartana, noch einmal Revue passieren, fügt an entsprechenden Stellen Zitate aus Il genio ed i costumi und anderen Texte Chiaris ein, widerlegt sie oder entlarvt ihre inneren Widersprüche. Daß die Verteidigung wie selbstverstầndlich den Angriff impliziert, erstaunt nicht, hält man sich die vorausgehenden Texte Gozzis vor Augen. Unter der Überschrift *Cause, e storia della Tartana stampata a Parigi nel 1757 nennt Gozzi explizit Gründe, die ihn dazu veranlaßt haben, mit La tartana an die Öffentlichkeit zu treten: die Arroganz, mit der die Poeti Nugnez die literarischen Reformbemühungen im 18. Jahrhundert ignorierten, gegen das traditionell in zwei Kategorien - nämlich die Commedia dell'arte-Aufführungen und die Aufführungen literarischer Werke ${ }^{111}$ - geteilte Theaterrepertoire angingen, sich als si migliori Poeti del Mondo* (Fogli, 23) gerierten und mit einer massenhaften Produktion von Theaterstücken, Romanen und kritischen Schriften den Markt überschwemmten. Wie in früheren Texten zeigt sich Gozzi erstaunt darüber, daß La tartana zum Ausgangspunkt einer so intensiven Auseinandersetzung werden sollte, handelt es sich doch bei der noperetta di pochi foglia $(F o g l i, 26)$ um eine ssatira in generale de' $^{\prime}$ costumi $\alpha(F o g l i, 27)$, in der sich von 63 Seiten vielleicht 5 auf Schriftsteller beziehen, und zwar auf ihre literarischen Aktivitäten. Wiederum begründet Gozzi die Fortführung des Streits mit den persönlichen Attacken in den Reaktionen Goldonis und Chiaris, die sie später in salcuni sonettacci molto sgraziati, e vili, e sporchi manoscritti $($ Fogli, 49) auch gegen die übrigen Granelleschi vorbrachten. Inhaltlich steht im Zentrum der Auseinandersetzungen zum einen das Verhältnis zur literarischen Vergangenheit bzw. der Tradition im allgemeinen, zum anderen das von Goldoni und Chiari propagierte »Reformtheater «. Im Namen von Wirklichkeitsnähe und Moralität zielt dieses einerseits auf die Zerstörung der Tradition der Commedia dell'arte, andererseits auf die Ablösung des gelehrten Theaters, was Gozzi vor allem bezüglich der Commedia dell'arte für eine kulturelle Verarmung hält. Der Behauptung Chiaris, sche le scene

II - $[$... ] la materia Teatrale divisa in due parti. L'una ne 'Zanni impossibili a sopprimersi, e necessaria alla malenconia, l'altra in sane, poetiche, regolate, e istruttive composizioni. (Fogli, 24). 
Venete non ebbero Poeti prima dell'Abate Chiari e del Dottor Goldoni « (Fogli, 42), begegnet Gozzi mit der Aufzählung moralisch fragwürdiger Situationen und Inhalte in den neuen Komödien ${ }^{112}$ und verweist auf den unauflösbaren Widerspruch zwischen dem Anspruch auf Exemplarität und dem (auch ökonomisch begründeten) Streben nach Publikumserfolg. Im Hinblick auf die Relevanz der literarischen und sprachlichen Tradition dient Gozzi ein Zitat aus Goldonis Capitolo ${ }^{113}$ als Grundlage für die Darstellung der Position der Poeti Nugnez, die befinden, »che il Burchiello è uno schiffo [sic] Poeta, che il Pulci è un asino, che i libri maestri di lingua sono ridicoli, che chi scrive in purgato Toscano è un buffone, e andate innanzi $;$; che sono cattivi Maestri Dante, Petrarca, Boccaccio, Burchiello, Pulci, Sacchetti, tutti gli autori antichi, tutti i cinquecentisti^ (Fogli, 33). Dieser dezidierten Abwertung und Abwendung von der Tradition steht Gozzis Eintreten für eine profunde Kenntnis der Autoren der Vergangenheit und eine Vertrautheit mit der literarischen Sprache, dem Toskanischen, gegenüber, was ihm von gegnerischer Seite den Vorwurf einbringt, ein "cruscante «, "gramatico und "pedante zu sein. Chiaris Diktum $\gg \mathrm{I}$ poeti nascono poeti $($ Genio, 70 ) veranlaßt Gozzi, seine Vorstellungen vom Umgang mit der Tradition dahingehend zu präzisieren, daß er diesen für die Entwicklung eines eigenen, individuellen Stils für unentbehrlich hält, wie er am Beispiel von Tizian, Tintoretto und anderen ausführt. ${ }^{114}$ Imitation vorgängiger Literatur - nicht etwa eines einzelnen Autors - ist als Stilübung zu verstehen, die es ermöglicht, unterschiedliche Inhalte in verschiedener Weise darzustellen und squella franchezza* verschafft, *con la quale si passa a tentare nuove strade con buon fondamento (Fogli, I18). Die Tradition ist in Gozzis Augen nicht unnötiger Ballast, sondern die Basis, auf der Neues entstehen kann, oè indispensabile per aprirsi una nuova strada co' buoni principj * (Fogli, 124). ${ }^{115}$

112 -Anzi vi facciamo il vantaggio che possiate non nominare quelle tante Commedie, nelle quali faceste porre in iscena le coppette a Truffaldino; e dargli fuoco con la stoppa al diretano. Quelle nelle quali faceste in iscena salassare Silvio, mettendolo spesso in sporche necessita per la pozione che aveva presa. Quelle che faceste battere la Teriaca, e tante altre che vi fruttarono della vergogna, e poca utilità contro alle vostre parole del Genio,* (Fogli, 61-62).

[1] "Ma se mai del Burchiello i versi miei/ Volessero seguir la foggia strana, / Contro la musa mia bestemmierei. // Ho veduta stampata una Tartana / Piena di versi rancidi e sciapiti, / Versi da spaventare una befana. .

114 -Intendo di sapere dai Nugnez perehè Tiziano, Tintoretto, il Bassano, e Paolo Veronese, incominciando il loro studio dall'imitare Giovanni Bellino, il Carpaccio, Felice Bellino, ed altri più antichi Pittori, sieno riusciti sì gran originali Maestri? * (Fogli, IIs).

115 Noch einmal führt Gozzi an dieser Stelle das Beispiel Tizians an, "passato ad essere Originale per la via dell'imitazioner. 
Wie fast alle polemischen Texte Gozzis, und in besonderem Maße La scrittura contestativa und Il teatro comico all'Osteria del Pellegrino, nehmen auch die Fogli sopra alcune massime del genio e costume del secolo dell'abate Pietro Chiari e contro a' Poeti Nugnez de' nostri tempo ihren Ausgang von Texten, die unter exaktem Rückgriff auf Formulierungen und einzelne Begriffe ironisch zitiert, argumentativ widerlegt oder absichtlich gegen den Strich interpretiert werden. ${ }^{116}$ Diese von Gozzi zum Prinzip seiner Auseinandersetzung mit Goldoni, Chiari oder Bettinelli erhobene Textbezogenheit ist ein Verfahren, das zwei unterschiedliche Funktionen erfüllt: zum einen ist es geeignet, in direkter Weise Inkonsistenzen und Widersprüche in den Referenztexten bloßzulegen, zum anderen signalisiert es indirekt die Wichtigkeit der Lektüre vorliegender Texte und ist damit gegen die zeitgenössische Tendenz gerichtet, die Relevanz der literarischen Tradition zu ignorieren oder abzulehnen. Jedes Pamphlet, in dem Gozzi die Auseinandersetzung mit den großen Autoren früherer Jahrhunderte fordert, zeigt zugleich, daß diese nicht bei der bloBen Rezeption oder Imitation stehen bleiben darf, sondern zu einer Reaktualisierung im zeitgenössischen Kontext führen muß. Allein die phantasievolle Vielfalt der Formen, in die Gozzi seine Beiträge kleidet, kann als Beleg für die inspirierende Kraft vorgängiger Texte gelesen werden.

Ein weiterer Aspekt der Kontroverse ist die Polarisierung, die zwar jeder Polemik inhärent ist, jedoch von Gozzi in besonderer Weise kultiviert wird. Nicht nur im Hinblick auf ihre Physiognomie erscheinen Goldoni und Gozzi als die reinsten Gegensätze, "Sappia, ch'egli è un'omaccio grasso, grasso, / E ch'io son magheretto, magheretto* (Col. VIII, I82), sondern auch die Standpunkte hinsichtlich der Sprache, der Moral oder der Konzeption von Dichtung stellt Gozzi in auffäligem Kontrast dar. So steht in grundsätzlicher Weise die Achtung vor der Tradition ihrer Mißachtung gegenüber, das Plädoyer für die Vertrautheit mit der Literatur und der literarischen Sprache der Vergangenheit konstrastiert mit der Überzeugung, Begabung und Beobachtung der Welt und der Natur mach-

116 Selbst cine so beilaufige Tatsache wie Solitarios anfängliche Weigerung in Il teatro comico all'Osteria del Pellegrimo, sich mit dem viergesichtigen Monster zu unterhalten, mit der Begründung, "perché anderà vantando d'essere stato criticate [...], e voi sapete, che un criticato si guadagna nome di uomo di qualche cosa- (Zan. XV, 183), geht auf eine Stelle in Goldonis - Prefazione* von 1750 zurück, wo es heißt: - Le composizioni di niun valore non sono nemmeno oggetto degno di critica Che se alle mie Comedie ne sono state fatte, o se ne faran tuttavia in avvenire, io trarrò quindi un sicuro argomento che degne sieno di osservazione, e però fornite di qualche merito.* (Goldoni, 1, 773) Auch Gedichte, in denen Gozzi beispielsweise Goldonis Liebe zu Schokolade verspottet, basieren auf dessen Versen, - Voi però non temete ... oh cosa vedo! / Ecco dolei, rinfreschi, e cioccolata. 
ten den Schriftsteller aus. Die Abwertung und Verdrängung der Commedia dell'arte beantwortet Gozzi mit einem hohen Lob auf den Truffaldino Sacchi, den moralischen Anspruch der sperfetta Commedia $\alpha^{117}$ Goldonis mit dem demonstrativen Nachweis von Unregelmäßigkeiten und sprachlich wie moralisch Zweifelhaftem.

Im Hinblick auf die Fiabe teatrali ist sowohl die Refunktionalisierung vorgängiger Literatur als auch das Prinzip der Kontrastierung von grundlegender Bedeutung. Untrügliches Kennzeichen der polemischen Texte Gozzis ist darüber hinaus eine permanente Selbstironie, die die Schärfe der Angriffe mildert. Die polemische Kontrastierung bringt eine extreme Gegensätzlichkeit der Positionen mit sich, die auf der einen Seite - der gegnerischen - in die Satire mündet, auf der anderen - der eigenen - in Selbstironie. Als solche muß auch der Schluß der Fogli verstanden werden, in dem von einer dreijährigen Schließung der Theater die Rede ist, "per far venire una gran fame al Popolo di vedere il Teatro di nuovo aperto* (Fogli, 165-166). Diesen Ratschlag gibt Gozzi zu einem Zeitpunkt, als er selbst gerade sein erstes Stück, L'amore delle tre melarance, auf die Bühne gebracht und Triumphe gefeiert hatte.

117 Goldoni, I, 768. 
KONSTITUENTEN UND STRUKTUREN

\author{
2.1 L'amore delle tre melarance - \\ "Scherz, Satire, Ironie und tiefere Bedeutung *
}

Die Aufführung von L'amore delle tre melarance im Januar $176 \mathrm{I}^{1}$ markiert einen entscheidenden Punkt sowohl in Carlo Gozzis literarischer Aktivität als auch im Theaterleben Venedigs. Zum einen ist L'amore delle tre melarance Fortführung und zugleich Höhepunkt der Polemik gegen Goldoni und Chiari, zum anderen emanzipiert sich Gozzi mit diesem Stück von der bisherigen dialogisch-textbezogenen Auseinandersetzung, experimentiert mit neuen Formen und stellt Goldonis und Chiaris Stücken ein Theater eigener Art entgegen, was zu einer unübersehbaren Veränderung der venezianischen Theaterlandschaft führt. Almanache, Gedichte, Kurzepen, Briefe, Dialoge und textkritische Abhandlungen als bisher bevorzugte Textsorten werden in den sechziger Jahren weitgehend abgelöst von der dramatischen Form, in der Gozzi die Polemik weitertreibt und auf der Bühne in Szene setzt. Damit betritt er nicht nur

-Scherz, Satire, fromic und tiefere Bedeutung- ist der Titel eines 1822 entstandenen Lustspiels von Christian Dietrich Grabbe, der die Aspekte von L'amore delle tre melarance treffend bezeichnet.

Zum Termin der Uraufführung von L'amore delle tre melarance gibt es leicht differierende Angaben. Gozzi selbst datiert sic im Vorwort zu $\rightarrow$ Analisi riflessiva della fiaba L'amore delle tre melarance= (Col. I, 75) auf den 25 . Januar 1761, dem folgen z. B. Ernesto Masi in Sulla storia del teatro italiano nel secolo XVIII, Sala Bolognese, Forni r 989 (unveränderter Nachdruck der Ausgabe Florenz 1891), S. 70, G. Luciani in Carlo Gozzi (1720-1806), op. cit., Bd. 1, S. 215 , unter Berufung nicht auf Gozzi selbst, sondern auf die -Notatori Gradenigo *; Gasparo Gozzi schreibt in ciner am Mittwoch, den 27. Januar in La gazzetta veneta erschienenen Rezension, das Stück sei zum ersten Mal am Sonntagabend, und somit am 24, zu sehen gewesen, während Angelo Fabrizi in *Carlo Gozzi e la tradizione popolare: a proposito dell'Amore delle tre melarance «, in: Italianistica 7, 1978, S. 336-345, hier S. 337, ohne nähere Hinweise den 2 r. Januar angibt, P. Bosisio in seiner Ausgabe der Fiabe teatralt einmal den 25.1., dann den 21.1. (S. 97 resp. 113) nennt und Alberto Beniscelli (Carlo Gozzi, Fiabe teatrali, Milano, Garzanti 1994, S. 6) zu Carlo Gozzis Angabe anmerkt: - Da correggersi in 21 gennaio $1761 \propto$.

In der Colombani-Edition finden sich die Fiabe teatrali in folgenden Bänden: Bd. I: Analisi riflessiva della fiaba L'amore delle tre melarance, Il corvo, Turandot, Il re cervo; Bd. II: La donna serpente, La Zobeide, II mostro turchino, I pitocchi fortunati; Bd. III: L'augellino belverde, Il re de' genj. 
das wichtigste Terrain seiner Gegenspieler, die sich beide maßgeblich als Theaterautoren und -reformer verstanden, sondern erreicht auch eine wesentlich breitere Öffentlichkeit als mit handschriftlich zirkulierenden Gedichten oder in kleinen Auflagen gedruckten Traktaten. Auf die Öffentlichkeitswirksamkeit und daraus resultierende ökonomische Aspekte von Theater-Kontroversen macht Gozzi bereits in La tartana ironisch aufmerksam, wenn die beiden Kontrahenten Saccheggio und Originale ihre Fehde sin mezzo a innumerabil turba pazza« (Col. VII, 26) austragen und die ganze Stadt in die unversöhnlichen Lager der *goldonisti und der "chiaristi $\propto$ spalten.

Wie Carlo Gozzis Bruder Gasparo in La gazzetta veneta am 27. Januar $176 \mathrm{I}$ berichtet, wurde L'amore delle tre melarance am Theater San Samuele von der Truppe Sacchi als »commedia a soggetto* ohne Nennung des Autors aufgeführt. ${ }^{2}$ Analog zu zahlreichen anderen im Kontext der Polemik entstandenen Texten, hat Gozzi also auch sein dramatisches Erstlingswerk anonym vorgestellt, was bei einer "commedia a soggetto* nicht überrascht, da es sich um Improvisationstheater in der Tradition der Commedia dell'arte handelt, für das nicht ein Autor, sondern die Schauspielertruppe selbst verantwortlich zeichnet. Eine ausgeschriebene Textvorlage existiert in diesem Falle nicht. Vielmehr blieb die Ausführung auf der Basis eines knapp skizzierten Handlungsablaufs und der schriftlichen Fixierung einiger zentraler Repliken weitgehend den Schauspielern und ihren improvisatorischen Fähigkeiten überlassen. Daß Gozzi die Aufführung von L'amore delle tre melarance der Truppe Antonio Sacchis anvertraute, ist nicht verwunderlich, galt diese doch als eine der ersten ihrer Art, und schon 1757 schließt La tartana mit der Hoffnung, der weltberühmte Truffaldino Sacchi möge nach Venedig zurückkehren und das Publikum vor den Machwerken Goldonis und Chiaris, „quest'opre, dette regolate, e pure (Col. VIII, 68), retten.

Solchen angeblich regelmäßigen und moralisch unbedenklichen Stükken stellt Gozzi mit L'amore delle tre melarance aber nicht tatsächlich in dieser Hinsicht untadelige gegenüber, wie man aufgrund der bisherigen Polemik vermuten könnte. Das Image des traditionsgläubigen, puristischen Pedanten widerlegend, orientiert er sich nicht etwa am Modell der literarischen Komödien des Cinquecento und präsentiert keine sittsame, sämtlichen Einheiten der Zeit, des Ortes und der Handlung gehorchende,

2 Gasparo Gozzi, La gazzetra veneta, op.cit, S. 467: schi compose la commedia non si sa, ma viene attribuita a diversi autori-. Zu Spekulationen der Zeitgenossen über den möglichen Autors. Alberto Beniscelli, La finzione del frabesco. Studi sul teatro di Carlo Gozzi, Casale Monferrato, Marietti 1986, S. 61. 
in reinstem Toskanisch verfaßste Komödie, sondern ein hinreißendes Spektakel, das, wie im folgenden zu zeigen ist, gegen alle zeittypischen Tendenzen eine bunte Mischung aus Märchenspiel, Commedia dell'arte, Parodie und beißender Ironie in sich vereinigt.

Diese sstravaganza scenica* oder sfanciullaggine* (Mem. I, 34 und 23I), wie Gozzi selbst im topischen Gestus der Selbstbescheidenheit und in bewußtem Kontrast zu Goldonis und Chiaris Betonung ihrer schriftstellerischen Leistungen schreibt, war ein durchschlagender Publikumserfolg, der die von Gozzi in seinen Memoiren angedeuteten Befürchtungen der Granelleschi bei einer Vorablektüre gründlich widerlegte:

Composto e letto da me il mio strano apparecchio a' nostri dotti accademici granelleschi, benché le loro risa sulla letrura mi facessero un buon pronostico, essi medesimi però nel fine mi sconsigliarono, anzi mi pregarono a non esporre quella fanciullaggine, adducendo che sarebbe fischiata e che poteva pregiudicare il decoro accademico con tanto onore sino a quel punto sostenuto. (Mem. I, $230-231)$

Den ironischen Hinweis auf die Ehre der Akademiemitglieder, die durch das kindisch-kindliche Stück angegriffen werden könnte, pariert Gozzi mit dem Argument, *che conveniva assalire l'intero pubblico sul teatro per cagionare una scossa di diversione $($ Mem. I, 231). Dies erreichte die Aufführung offensichtlich, denn das Stück wurde sogleich sieben Mal wiederholt, obwohl sich die Karneval-Spielsaison bereits ihrem Ende zuneigte. Eine so positive Publikumsresonanz auf sein erstes Theaterstück animierte Gozzi, der Truppe Sacchi weitere zu liefern und damit den sichtbaren Beweis anzutreten, daß nicht nur Goldoni und Chiari das Theaterpublikum der Stadt anzulocken vermochten, sondern auch Märchenstücke zu Publikumsmagneten werden konnten.

L'amore delle tre melarance, als *commedia a soggetto , das heißt als weitgehend improvisiertes Stück konzipiert, für das den Schauspielern nur eine Handlungsskizze und einige ausgeschriebene Dialoge vorlagen, wurde von Gozzi auch für seine Werkausgabe 1772 nicht als vollständiger dramatischer Text ausgearbeitet. Es erscheint dort, mehr als to Jahre nach der ersten Aufführung, im Rahmen einer ausführlichen, kommentierten Inhaltsangabe unter dem Titel ^Analisi riflessiva della fiaba L'amore delle tre melarance. Rappresentazione divisa in tre atti $\alpha$. Diese ungewöhnliche Präsentation eines Theaterstückes kann nicht nur als bewußter Übergang von den bisherigen Formen der Polemik zur dramatischen Gattung verstanden werden, sie eröffnet Gozzi auch die Gelegenheit, seinen polemischen Intentionen deutlich Ausdruck zu verleihen und näher auf die 
szenische Realisierung sowie auf die Publikumsreaktionen einzugehen. Wenngleich der Duktus der Analisi riflessiva weniger der einer abgeklärten retrospektiven Darstellung als der einer Streitschrift ist und daher eine Rhetorik der Vergröberung, der Verzerrung und des Extrems vorherrscht, sind insbesondere die Außerungen zur Wirkung der Aufführung auf die Zuschauer und zu den parodistisch-polemischen Aspekten im Hinblick auf grundlegende ästhetische Positionen Gozzis von weitreichendem Interesse. Gozzi selbst weist darauf hin, daß konkrete Anspielungen auf die Kontroverse mit Goldoni und Chiari im Jahr 1772 nicht mehr aktuell waren und, so ist zu vermuten, auch nicht mehr verstanden wurden, was entsprechende Erklärungen in der Gesamtausgabe notwendig machte, ${ }^{3}$ doch scheint in den Einzelheiten und Kleinigkeiten Grundsätzliches auf, das auch für die Konzeption der folgenden Fiabe teatrali bestimmend wirkt.

Im Prolog, den Gozzi in seiner ursprünglichen Form in achtzeiligen ottava rima-Strophen der Analisi riflessiva voranstellt, ${ }^{4}$ thematisiert ein junger Bote in direkter Publikumsansprache unverblümt den Publikums-

3. Interessant ist die Bemerkung Gozzis im Vorwort, Lamore delle tre melarance sei in den folgenden Jahren sspogliata delle caricate censure a' due accennati Poetis aufgeführt worden, mperch'era mancata la circostanza, e il proposito* (Col. I, 76). So wird aus der scaricata parodia buffonesca sull'opere de' Signori Chiari, e Goldoni* (Col. I, 75) ein Marchenstück wie alle folgenden Fiabe teatrah, in denen, wie zu zeigen ist, das polemische Anliegen nicht mehr in direkter, sondern in indirekter Weise fortgefürt wird. Damit ist die Attraktivitat von L'amore delle tre melarance auch als bloßes Theaterspektakel ohne parodistischen Hintergrund belegt, und es bestätigt sich die Interpretation des Stückes als Scharnier zwischen den polemischen Texten der ersten Jahre und den dramatischen Werken der folgenden.

2001 wurde Edoardo Sanguinetis Version von s-Lamore delle tre melarance* als stravestimento fiabesco dal canovaccio di Carlo Gozzi* im Rahmen der Theater-Biennale in Venedig und in Genua unter der Regie von Benno Besson uraufgeführn. Die sprachlich überaus kunstvolle Fassung in versi martelluan erwies sich in Bessons das Theatralische des Theaters betonenden Inszenierung auch in heutiger Zeit als großer Publikumserfolg. $\mathrm{V}$ gl. Edoardo Sanguineti, L'amore delle tre melarance, un travestimento fiabesco dal canovaccio di Carlo Gozzi, Teatro di Genova, Genova, il nuovo melangolo 2001; darin auch: Verf., sUn cosi frivolo principioe L'amore delle tre melarance di Carlo Gozzis, S. $15-28$.

Daß der retrospektive Blick Gozzis in der Analist riflessiva nicht in allem die ursprüngliche Situation wiedergibt, machen zum Beispiel Hinweise auf Goldonis Baruffe chiozzotte deutlich, die erst ein Jahr nach L'amore delle tre melarance, nämlich im Januar 1762 uraufgeführt wurden, im nachhinein aber zur Begründung und Veranschaulichung polemischer Intentionen herangezogen werden.

+ Der Prolog lag bei der Uraufführung gedruckt vor, wie dies für Prologe häufig der Fall war, wurde jedoch wohl irrtumlich Gasparo Gozzi zugeschrieben, vgl. A. Beniscelli, La finzione del fiabesco, op. cit., S. 61, und Piermario Vescovo, sLo specchio e la lentee, in: Ilaria Crotti; Ricciarda Ricorda (Hgg.), Gasparo Gozzi. Il Lavoro di un intellettuale nel Settecento veneziano, Padova, Antenore r989, S. 388-412, hier S. 403. 
schwund der letzten Zeit und beklagt den geschmacklichen Wankelmut. Habe das Publikum vor kurzem noch den Schauspielern zugejubelt, die der Tradition der Commedia dell'arte verpflichtet sind, entziehe es diesen nun seine Gunst, was sich, wie er hinzufügt, unmittelbar auf ihr Wohlbefinden auswirke, denn »dov"è maggior folla / Si beve meglio, e il ventre si satolla " (Col. I, 77). Auf diesen handfesten, materiellen Aspekten des Theaterbetriebs insistiert der Prolog und nimmt damit einen wichtigen Punkt der Polemik gegen Goldoni auf. Während dieser in seinen Vorworten immer wieder äußert, ein starker Publikumszulauf sei ein Zeichen für die Qualität seiner Stücke, betont Gozzi demonstrativ den Zusammenhang von Publikumserfolg und finanziellem Nutzen für die Truppe. Die Anspielungen auf die Konkurrenz zwischen dem Improvisationstheater und den Aufführungen, die auf Papierbergen und Tintenmeeren der Theaterschriftsteller basieren, münden in einen impliziten ironischen Verweis auf Goldoni: "e se talento non abbiamo in dono, / Basta, che piaccia a voi, perchè sia buono.^ (Col. I, 78). Um die Publikumsgunst zurückzugewinnen, werden *commedie nuove, / Cose grandi, e non mai rappresentate " (Col. 1,78$)$ angekündigt, die Altes in ganz neuer Form erstehen lassen: -D'inaspettati casi vederete / In questa sera un'abbondanza grande, / Maraviglie, che udite aver potete, / Ma non vedute dalle nostre bande. (Col. I, 79).5 Nur vom Hören, nicht vom Sehen war den Zuschauern bekannt, was sie mit dem Titel L'amore delle tre melarance verbanden: nicht ein Theaterstück, sondern ein Märchen. Und so beschwören die letzten Verse des Prologs eine Situation herauf, die dem gesamten Publikum gleichermaßen vertraut war, $»$ Fate conto, mie vite, mie colonne, / D'essere al foco colle vostre Nonne.* (Col. I, 79).

Was das Publikum nun zu sehen und zu hören bekam, war ein fulminantes Spiel, in dem der Prinz Tartaglia, mit Melancholie geschlagen, unter größten Anstrengungen nach zehn Jahren zum ersten Mal wieder zum Lachen gebracht werden soll. Nach vielen vergeblichen Versuchen wird mit Hilfe des Zauberers Celio Truffaldino, die Inkarnation des Komischen, an

5 Ahnlich plakativ wirbt Anton Francesco Grazzinis (genannt II Lasca) * Canto di Zanni e di Magnifichi $\alpha$ für Commedia dell'arte-Vorstellungen. Daß Gozzi die burleske und satirische Dichtung des Cinquecento und speziell die des Lasca kannte, belegen seine Anmerkungen zum Canto ditirambico de" partigiani del Sacchi Truffaldino aus demselben Jahr 1761 sowie Bemerkungen und ein Zitat in Ragionamento ingenuo (Col. I, 20-2r). Für den Prolog hat v. a. folgende Strophe als Referenz gedient: -Commedie nuove abbiam composte in guisa / Che quando recitar le sentirete, / Morrete delle risa, / Tanto son belle, e facete; / E dopo ancor vedrete / Una danza ballar sopra la scena, Di varj, e nuovi giuochi, tutta piena.* (Tuttri Trionfi, Mascherate, o Canti carnascialeschi andati per Firenze dal tempo del Magnifico Lorenzo de' Medici fino all' anno 1559. Cosmopoli, Passerio 1750, S. 499-50r) 
den Hof geholt, doch versagen auch seine Künste. Zuguterletzt entlockt der ungeschickte Sturz einer Alten dem Prinzen das langersehnte Lachen, als er diese, die Beine zum Himmel gestreckt, auf dem Boden liegen sieht. Zwar ist nun der Prinz von seiner Krankheit geheilt, doch hat das Lachen böse Folgen, denn hinter der alten Frau verbirgt sich die Fee Morgana. Als Beschützerin der Prinzessin Clarice und des ersten Ministers Leandro, die mit Tartaglias Tod spekuliert hatten, um als Paar den Thron besteigen zu können, verdammt sie Tartaglia im Gegenzug zur Liebe zu den drei Orangen. Angesichts des heftigen Verlangens, das Tartaglia sogleich erfaßt, macht er sich mit Truffaldino auf die Suche nach den drei Orangen, die sich seiner Erinnerung an die Erzählungen seiner Großmutter nach unter der Obhut der zaubermächtigen Riesin Creonta befinden. Mit Hilfe Farfarellos, eines von Celio zu Hilfe gerufenen Teufels, und seines Blasebalgs erreichen sie in Windeseile das Schloß Creontas. Dort sind vier Gefahren zu bestehen, für deren Überwindung der Zauberer Celio jeweils das rechte Mittel weiß. Ist das rostige Tor mit Zauberschmalz geölt, der ausgehungerte Hund mit Brot gefüttert, der Bäckersfrau statt ihrer Brüste eine Bürste zur Reinigung des Ofens gereicht und das halbverfaulte Brunnenseil getrocknet, können die drei Orangen aus Creontas Schloß entwendet werden. Truffaldino, mit den drei Orangen vom Teufel zurückgeblasen, von Hunger und Durst geplagt, entschließt sich, eine der Früchte zu öffnen, und siehe da, es entsteigt ihr ein ganz in Weiß gehülltes Mädchen, das, reicht man ihr nichts zu trinken, sterben wird. Truffaldino öffnet in seiner Verzweiflung die zweite Orange, doch auch ihr entsteigt ein Mädchen, das um etwas zu trinken bittet. Noch bevor sich Truffaldino hinter die dritte Orange machen kann, sterben die beiden. Glücklicherweise trifft nun Tartaglia ein, der sich an die Mahnung Celios erinnert, die Orangen nur in Wassernähe zu öffnen. So kann er das dritte Orangenmädchen retten und die vor Schönheit strahlende Ninetta zu seiner Frau machen. Um ihr Prinzessinnengewänder zu holen, verläßt Tartaglia sie. Mittlerweile hat jedoch Morgana einen Plan ausgeheckt, Clarice und Leandro doch noch auf den Thron zu verhelfen: die Mohrin Smeraldina verwandelt Ninetta mit Hilfe einer Zaubernadel in eine Taube und setzt sich an ihre Stelle. An den Hof zurückgekehrt, soll auch Tartaglia in ein Tier verwandelt werden, und der Weg für Clarice und Leandro wăre frei. Als Tartaglia mit den Kleidern und dem ganzen Hofstaat zurückkommt, erkennt er zwar seine Ninetta nicht wieder, sieht sich jedoch gezwungen, die falsche Prinzessin mit an den Hof zu nehmen. Dort ist inzwischen dem Koch Truffaldino dreimal das Fleisch für das Hochzeitsmahl angebrannt, weil eine Taube ihn mit einem Zauberspruch in Schlaf versenkt hat. Beim vierten Mal erwischt Truffaldino das Tier und fühlt die Zau- 
bernadel. Kaum ist sie entfernt, steht Ninetta vor ihm. Als Tartaglia die Küche betritt, findet er seine wahre Geliebte dort, und der königlichen Hochzeit steht nichts mehr im Wege. Die Mohrin Smeraldina wird zum Tod auf dem Scheiterhaufen verurteilt, Clarice und Leandro die Verbannung angedroht.

Provokativ harmlos bezeichnet Gozzi L'amore delle tre melarance als sfavola fanciullesca a, $n$ favola trivialea, smirabile novità puerile* oder ^fanfaluca misteriosa (Col. I, 75, 88, 100, 113 ), um darüber hinwegzutäuschen, wie komplex das Stück ist, in das Komponenten aus unterschiedlichsten Bereichen einfließen: Über seinen Titel als Märchen ausgewiesen, wird es nun auf der Theaterbühne einem Publikum vorgeführt, das über Figuren lacht, die es aus der *commedia all'improvviso" kennt und sich über Anspielungen auf die Zeitgenossen Chiari und Goldoni amüsiert. Auf welche Weise Gozzi in L'amore delle tre melarance Märchen, Commedia dell'arte und Parodie kombiniert, soll im folgenden deutlich werden.

\section{Die Märchen-Komponente}

Titel wie Prolog stellen das Märchen in den Vordergrund, und tatsächlich sind Handlung, Figuren und sprachliche Formeln weitgehend märchenhaft geprägt. ${ }^{6}$ Schwierigkeiten und ihre Bewältigung bestimmen den Handlungsverlauf, Verwünschungen, Verbote und die Überwindung von Gefahren und Hindernissen mit übernatürlicher Hilfe sind elementare Bestandteile. Formelhafte Verse und die mehrfache Wiederholung bestimmter Situationen folgen dem Märchenschema. Typische Figuren wie König, Prinz, Prinzessin, Fee und Zauberer bevölkern eine Welt, in der wunderbare Verwandlungen von Feen in alte Weiber, von Orangen in Mädchen, von Menschen in Tiere sowie sprechende Tore, Seile und Hunde nicht verwundern. Endlose Entfernungen werden spielend überwunden, und am Schluß steht die Hochzeit des Prinzenpaars.

Die Handlung, so schreibt Gozzi, sè tratto dalla più vile tra le fole, che si narrano a' ragazzi๔ (Col. I, 80), doch gibt er keine präzise Quelle an, während Gasparo Gozzi in seiner Rezension Basiles 1634-36 erschienene Märchensammlung Lo cunto de li cunti overo Lo trattenemiento de peccerille nennt: $:$ L'argomento d'essa è tratto dallo Cunto delli Cunti, capriccioso e raro libro scritto in lingua napoletana, che contiene tutte le

6 Zu den Charakteristika vgl. Max Lüthi, Märchen, bearbeitet von Heinz Rölleke, 9. durchgeschene und ergänzte Auflage, Sturtgart, Metzler 1996. 
fiabe narrate dalle vecchierelle ai fanciulli. $\alpha^{7}$ Nachdem dies lange Zeit unhinterfragt geblieben war, wurde inzwischen von Angelo Fabrizi nachgewiesen, daß sich Gozzi nicht an I tre cedri, der literarischen Variante des Märchens in Basiles Sammlung orientiert, sondern die mündliche Tradition des nördlichen Italien aufgegriffen hat. ${ }^{8}$ So erklären sich die in der Analisi riflessiva auffallend häufig wiederkehrenden Hinweise auf das Erzählen und Hören durch die Wahl der nicht-literarischen Form des Märchens. Wo beispielsweise von den unüberwindlichen Gefahren beim Schloß Creontas die Rede ist, heißt es bei Gozzi: »erano que', che si narrano a' bambini con questa fola " (Col. I, 96), Bäckersfrau, Seil, Hund, Tor und Creonta sprechen "puntualissim[i] col testo della Favola fanciullesca" (Col. I, 98), und die Orangenmädchen folgen ebenfalls dem wohlbekannten Text, wfedel seguace del testo della favola, diceva tosto: Dammi da bere, ahi lassa! Presto moro, idol mio, / moro di sete, ahi misera! Presto crudele. Oh Dio!« (Col. I, 103). Mit diesem oralen Märchenprätext geht Gozzi sehr frei um, ergänzt ihn um Episoden und Rollen, die nicht aus diesem Märchen stammen, sondern dramatischen oder polemischen Erfordernissen gehorchen. So führt Gozzi als zusätzliche Figuren die königliche Nichte Clarice, den ersten Minister Leandro sowie die Zauberriesin Creonta ein, deren Name an Pulcis Morgante erinnert, stellt der Fee Morgana, die auf Boiardos Orlando innamorato verweist, den Zauberer Celio entgegen und versieht beide mit ein paar Teufelchen aus Dantes Divina Commedia. ${ }^{9}$ Bei der Hinzufügung dieser mit dem Märchenkontext kompatiblen Figuren bleibt es jedoch nicht, denn Gozzi nimmt gerade im Bereich der dramatis personae entscheidende Erweiterungen und Umgestaltungen vor.

Gasparo Gozzi, La gazzetta veneta, op, cit., S. 467 .

A. Fabrizi, op. cit.

- Der Teufel Farfarello wird von Celio zu Hilfe gerufen, der Dämon Draghi(g)nazzo steht auf Morganas Seite. Beide Teufel werden in Dantes Inferno im 2r. Gesang erwähnt. Sicher nicht zufällig ist, daß dieser Gesang einen Bezug zu Venedig aufweist. Als Vergleich für den siedenden Höllenpfuhl werden nämlich die Pechpfannen in Venedigs Arsenal herangezogen - ein intertextuelles Spiel, das im szenischen Klamauk wohl eher untergegangen sein dürfte.

Farfarello taucht auch in Pulcis Morgante auf und gehört so zudem in den Kontext des heroisch-komischen Ritterepos, einem weiteren Bezugspunkt Gozzis, dem auch die Namen Morgana und Creonta zuzurechnen sind.

Zur parodistischen Funktion von Farfarello und Draghinazzo im Kontext der Goldoniund Chiari-Polemik siehe unten. 


\section{Die Commedia dell'arte-Komponente}

Bewegen sich die genannten Veränderungen noch innerhalb des Rahmens der dramatisierten narrativen Gattung, wird dieser ganz offensichtlich durchbrochen mit den Figuren Tartaglia, Pantalone, Brighella und Truffaldino, den vier Masken der Commedia dell'arte. ${ }^{10}$ Diese genuinen Theaterfiguren, die das Theatralische par excellence verkörpern, vermischen sich auf unterschiedliche Art mit der Märchenwelt. Sie verschmelzen mit ihr in paradoxer Weise wie im Fall Tartaglias, der Maske und Märchenprinz zugleich verkörpert, sie betreten sie in identischer Funktion wie Truffaldino, der in der Commedia dell'arte wie im Märchenstück als Diener auftritt, oder sie werden wie Pantalone und Brighella neu eingeführt. Durch ihre typischen Masken und Kostüme, durch Gestik, Mimik, Sprache und die lazzill erweisen sie sich unverkennbar als Elemente aus der Welt des improvisierten komischen Theaters. Ihrem Spiel, das sich durch einen ausgeprägten Improvisationscharakter, durch virtuose Sprach-und Körper-Akrobatik, durch Übertreibungen und Gags auszeichnet, war das Lachen des Publikums gewiß, und gerade die Truppe Sacchis vereinte Maskenschauspieler, die dies in unübertrefflicher Weise beherrschten. ${ }^{12}$ Wie schwer ein solches theatralisches Ereignis in Worte zu fassen ist, betont Gozzi in der Beschreibung der Szene, in der Tartaglia just in dem Moment eintrifft, als die beiden Orangenmädchen Truffaldino unter den Händen wegsterben:

Truffaldino piangeva, parlava loro con tenerezza. Stabiliva di tagliar la terza Melarancia per aiutarle. Era per tagliarla, quando usciva

15. Ein Charakteristikum der Commedia dell'arte, auf das in Kap, 2,5 näher eingegangen wird, sind die sogenannten *maschere", zwei (in seltenen Fällen auch drei) Alte (vecchi) und zwei Dienerfiguren (zanmi), die unter regional unterschiedlichen Namen figurieren.

II Ursprunglich bezeichnet dieser Terminus Scherzhaftes $\mathrm{v}$ a. der beiden zanni in Sprache, Gestik, Handlung.

12. Sowohl Gozzi als auch Goldoni rühmen in Memoiren und Vorworten das damals weithin geschätzte Können der Maskendarsteller Sacchi, Derbes/Darbes, Fiorilli, Zannoni; z. B. Gozzi, in Mem. I, 221; - [...] le valenti maschere meritamente amate dal pubblico, Sacchi, Fiorilli, Zannoni e Derbes, che divertivano i Grandi ed il popolos; Goldoni, in -Prefazioni dell'edizione Pasquali«: -Antonio Sacchi, celebre Arlecchino, il migliore Arlecchino d'Italia, che recitando col nome di Truffaldino unisce alle grazie del suo personaggio tutto il talento necessario ad un bravo Comico, e dice le cose le più brillanti e le più spiritose del mondo- (Goldoni, I, S. 736) und -Cesare Darbes, celebre Pantalone [...]* (Goldoni, I, S. 752). Auch Giuseppe Baretti hebt in Les Italiens, ou Maurs et coutumes d'Italie. Ouvrage traduit de l'Anglais de M. Baretty, Genève 1773, S. $78-79$ [Account of the Manners and Customs of Italy, London 1768 ] Sacchi und Fiorili [sic] lobend hervor. Zitiert wird die französische Übersetzung von Barettis ursprünglich englisch geschriebenem Werk, da diese in Venedig verbreitet war und auch Gozzi vorlag. 
Tartaglia furioso, che lo minacciava. Truffaldino spaventato fuggiva abbandonando la Melarancia.

Gli stupori, i riflessi, che faceva questo grottesco Principe sui gusci delle due Melarance tagliate, e sopra a' due cadaveri delle giovinette, non sono dicibili.

Le maschere facete della Commedia all'improvviso in una circostanza simile a questa fanno delle scene di spropositi tanto graziosi, di scorcj, e di lazzi tanto piacevoli, che nè sono esprimibili dall'inchiostro, nè superabili da' Poeti. (Col. I, ros)

Wenn eine Improvisationsszene dieser Art zwanzig Minuten dauern konnte ( $\$$ Tal scena durava un terzo d'ora con le risa continuate degli ascoltatori*, Col. I, 86), zeigt dies, welchen Stellenwert Gozzi der Improvisation einräumt - in bewußtem Gegensatz zu Goldoni, der seit Jahren bemüht war, Masken und Improvisation zurückzudrängen. Seine programmatische Ächtung der *commedia all'improvviso* erwidert Gozzi allerdings nicht mit einer generellen Rehabilitierung, vielmehr greift et einzelne wirkungsvolle Elemente auf und integriert sie in einen neuen Kontext. Märchen und Masken gehen dabei eine Symbiose ein, in der sich narrative und dramatische Komponenten gegenseitig befruchten. Steht das Märchen für die Illusion, das Wunderbare und die Spannung, so verkörpern die Masken das Spielerische und das Drastische. Wie jede neue Verbindung bringt auch diese im Hinblick auf die einzelnen Bestandteile unübersehbare Veränderungen mit sich.

Insbesondere dringt das Komische der Masken in das Märchen ein. Der ideale Märchenprinz in Gestalt Tartaglias büßt nicht nur äußerlich an Schönheit und Würde ein, sondern wird von der abstrakten Figur zur greifbaren, körperbetonten Gestalt. Die Maske, behaftet mit ihrem typischen Stottern, behält dieses sprachliche Charakteristikum auch in ihrer Rolle als Prinz bei, und sie läßt jede königliche Majestät vermissen, als Truffaldino den Prinzen untersucht, um die Ursachen für seine Melancholie festzustellen: Ampullen, Fläschchen, Salbendosen und Spucknäpfe stehen am Krankenbett, der Patient klagt, hustet, ächzt und spuckt. Der Diener, der im Märchen mit dem Prinzen auszieht, um die Orangen zu erbeuten, ist nun Truffaldino, "persona benemerita nel far ridere, e ri-

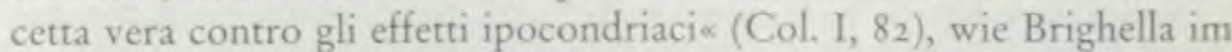
Stück selbst bemerkt. Damit wird die blasse Nebenfigur des Märchens aufgewertet zu einer maßgeblich am Erfolg des Theaterstücks beteiligten Rolle, ist doch Truffaldino neben Brighella einer der beiden zanni der Commedia dell'arte, die in besonderer Weise durch Körperlichkeit und Komik charakterisiert sind. So nimmt es auch nicht Wunder, daß Truffaldino vor Durst und Hunger die Orangen öffnet, denn die Befriedigung körperlicher Bedürfnisse bestimmt die Maske wesentlich. Daß Gozzi mit solchen Stereotypen in L'amore delle tre melarance einen spielerischen 
Umgang pflegt, wird deutlich, wenn er in ironischer Umkehrung der typischen Züge Truffaldino am Ende zum königlichen Koch macht, der sich nicht listig selbst bedient, um seine Lebensgeister zu stärken, sondern den Hochzeitsschmaus der andern zubereitet, wobei ihn dann der Schlaf übermannt.

Diese Verschränkung von komischer und Märchen-Ebene setzt sich fort bis zu Figuren, die nicht von Maskendarstellern interpretiert werden, wie zum Beispiel König Silvio, Vater des Prinzen Tartaglia. In ganz unkōniglicher Weise muß dieser nicht nur Brighella Rede und Antwort stehen, ob nicht etwa ein gewisses Leiden, das er sich in seiner Jugend zugezogen und an seinen Sohn vererbt haben könnte, die Ursache von Tartaglias Melancholie sei oder vielleicht der Prinz aus Scham eine anstreckende Krankheit verheimliche, sondern er betritt am Ende des Stücks auch noch selbst die Küche, um nach dem Hochzeitsbraten zu sehen, und scheut sich nicht, das glückliche Brautpaar kurzfristig in eine Besenkammer einzusperren. Wie Gozzi selbst schreibt, entstand auf diese Weise »una rappresentazion teatrale ignuda affatto di parti serie, e interamente caricata di buffonesco in tutti i personaggix (Col. I, 75). Während der Handlungsverlauf in weiten Teilen der mündlichen Tradition des Märchens von den drei Orangen folgt, die zwei Erzählstränge aneinanderfügt - die Suche nach den Orangen und die Hinauszögerung des glücklichen Endes mittels der Substitution Ninettas durch die Mohrin Smeraldina -, unterliegen die Märchenfiguren weitgehenden Veränderungen und werden zu komischen Theaterfiguren, szenisch wirkungsvollen Handlungsträgern, die das per se handlungsorientierte Märchen dramaturgisch bereichern. Beide Komponenten, Masken und Märchen, waren dem zeitgenössischen venezianischen Publikum wohl vertraut, und Gozzi konnte nicht nur auf den positiven Wiedererkennungseffekt und das entsprechende Wohlgefallen beim Publikum zählen, sondern auch auf die unterschiedliche Wirkung der Ingredienzen: Wundern und Staunen angesichts der märchenhaften Illusion, Lachen und Vergnügen angesichts der komischen Figuren.

\section{Die satirisch-parodistische Komponente}

Daß den Masken seit jeher auch ein satirisch-parodistisches Potential innewohnt, kam Gozzi für den dritten Aspekt des Stücks, die Polemik gegen Chiari und Goldoni, entgegen. ${ }^{13}$ Zielscheibe von Gozzis Angriffen ist

13 Die Improvisation der Commedia dell'arte erlaubte traditionell vor allem den Masken sprachliche, gestische und mimische Formen von Satire und Parodie, die sich durch 
auf allgemeinster Ebene wie in La tartana der Konkurrenzkampf, der hier zwischen der Fee Morgana und dem zu diesem Zweck neu eingeführten Zauberer Celio ausgetragen wird. Konkreter sind es dann auch die Handlungsführung, die Gestaltung der Figuren, Stil und Sprache in bestimmten Stücken, die ins Lächerliche gezogen werden. Wie das Antagonisten-Paar Morgana / Celio zeigt, fungieren in L'amore delle tre melarance nicht nur die Masken der Commedia dell'arte als Träger der Parodie, vielmehr werden auch andere Figuren sowie Sprache, Stil und die Handlung selbst in diesem Sinne funktionalisiert, so daß sämtliche Komponenten des Stücks, in variabler Weise eingesetzt, zur Parodie beitragen.

Sprache und Stil des Theaters von Chiari und Goldoni sind gewissermaßen der Auslöser für Gozzis Stück, denn Truffaldinos Untersuchungen des melancholischen Prinzen Tartaglia ergeben, daß die Ursache des Leidens in unverdaulichen versi martelliani liegt. Was die besten Arzte des Landes nicht hatten herausfinden können, riecht Truffaldino schon am Atem des Prinzen, und der Auswurf bestätigt die Diagnose: » raccolto lo sputo, lo esaminava; trovava delle rime fracide, e puzzolentix (Col. I, 86). Die modischen versi martelliani, Vierzehnsilbler nach dem Vorbild des französischen Alexandriners, vorzugsweise von Chiari, aber auch von Goldoni verwendet, sind also der wahre Grund des hypochondrischen Verhaltens von Tartaglia. ${ }^{14}$ Und schlimmer noch, Leandro berichtet, daß Morgana ihm zudem Briefchen in versi martelliani gegeben habe, die er Tartaglia in den Brei mische, damit dieser vollends an den weffetti ipocondriaci $\left(\mathrm{Col} . \mathrm{I}, \mathrm{8}_{3}\right.$ ) zugrundegehe, so daß er mit Clarice endlich den Thron besteigen könne. Auch Truffaldino, den Helfer in der Not, der Tartaglia zum Lachen bringen und ihn wieder hoffähig machen soll, will Leandro auf diese Weise aus der Welt schaffen, doch meldet Clarice Zweifel an der Wirksamkeit des Rezepts an, das höchstens wie Opium wirke, und schlägt stattdessen effektivere Mittel wie Arsen oder Schüsse aus der Büchse vor. Bei diesen Anspielungen, die zweifelsohne Lacherfolge waren, beläßt es Gozzi nicht, sondern setzt die versi martelliani selbst in parodistischer Weise ein, indem er die allen bekannten Märchenformeln, die Klagen der Orangenmädchen sowie die Sprüche Creontas und ihrer Zauberdinge, in eben diese Versart kleidet. Das Publikum wird nicht nur von der ungewohnten Form der gewohnten Formeln überrascht gewesen sein, sondern

ihren ephemeren Charakter der Zensur entzogen; siehe dazu Kenneth Richards, Laura Richards, The Commedia dell'Arte. A Documentary History, Oxford, Blackwell 1990, S. 195-

14 Bereits in La tartana polemisiert Gozzi gegen die pathogene Wirkung der neuen Komödien, wenn das Publikum klagt: =Questi dottor ci opprimeano i cardiaci; / Eravam farti tutti ipocondriaci. (Col. VIII, 69). 
auch den komischen Kontrast zwischen der Gestelztheit der vorformulierten gereimten Verse und der sprachlichen Improvisation wahrgenommen haben. Hatten der Prolog ${ }^{15}$ wie auch die anfänglichen Diskussionen der Figuren um die Verse in ihrer komischen Übertreibung die Aufmerksamkeit des Publikums einmal geweckt, konnten ihm die versi martelliani im Stück selbst kaum noch entgehen.

Ein Beispiel für parodistische Sprachkritik * in L'amore delle tre melarance betrifft die Mohrin Smeraldina, die laut Analisi riflessiva anfangs als Morganas Dienerin und Botin ein italianisiertes Türkisch spricht, was sich ändert, als sie nach der Verwandlung Ninettas in eine Taube an deren Stelle auf den Prinzen wartet, um von ihm als Braut an den Hof geführt zu werden..$^{16} n$ Non parlava più Turco italianizzato $\alpha$, schreibt Gozzi, - Morgana le aveva fatto entrar nella lingua un Diavolo toscano*, und er fügt hinzu, =Sfidava turti i Poeti nel ragionare correttamente« (Col. I, 106). Über die allgemeine Anspielung auf die Diskussion um eine adaquate Sprache und Bühnensprache hinaus, könnte sich hier der konkrete Hinweis auf einen Höhepunkt der Kontroverse zwischen Goldoni und Chiari im Jahr 1754 verbergen. Im Streit um Goldonis La vedova scaltra und Chiaris Scuola delle vedove spielte die Sprache einiger aus fremden Nationen stammender Figuren eine gewichtige Rolle. ${ }^{17}$ Die Frage, ob dem Publikum dieser Zwist noch im Bewußtsein war, ist wohl eher zu verneinen, doch mit großer Sicherheit erinnerten sich die Betroffenen.

Auch die Gestaltung der Figuren, der scaratteria, in Chiaris und Goldonis Stücken wird in L'amore delle tre melarance lächerlich gemacht, und dies auf genuin parodistische Weise, indem Gozzi das auf die Spitze treibt, was Chiari und Goldoni als *normal * zu gelten scheint. Das Krude, Derbe, Plumpe fast sämtlicher Figuren in L'amore delle tre

15 -E bestic, e porte, ed uccelli udirete / Parlare in versi, e meritar ghirlande, / E forse i versi saran Martelliani, / Acciò battiate volentier le mani.- (Col. I, 79).

15. Diese Szene ist besonders grotesk, da Smeraldina zwar Ninettas Platz eingenommen, jedoch ihre dunkle Hautfarbe behalten hat. So komme Tartaglia zurück und findet eine -schwarze Ninetta* vor, dic er dann trotz seiner Bedenken gezwungenermaßen heiraten muß. Obwohl es Morgana ja ein leichtes gewesen wäre, Smeraldina weiß zu zaubern, vermeidet Gozzi diesen srealistischen * Zug, um die komische Wirkung zu erhöhen.

1) Siche dazu Goldonis Prologo apologetico alla commedia mtitolata La vedovia scaltra (Goldoni, II, 409-411), in der Goldoni sich für das perfekte Italienisch des Engländers Milord Runebif, des Franzosen Monsieur Le Blau und des Spaniers Don Alvaro de Castiglia rechtfertigt, während Chiari seinen Spanier ein mit italienischen Einsprengseln vermischtes Spanisch sprechen läßt. Als Hauptgrund für sein Vorgehen führt Goldoni die Verstandlichkeit an; auf das Argument der Wahrscheinlichkeit entgegnet er *la lingua non fa la Commedia, ma il caratteres. Damit setze Goldoni seine Forderung nach dem *vero* und snaturales zugunsten der Publikumswirkung außer Kraft und bietet eine willkommene Angriffsflàche für polemische Kritik; vgl. Kap. I.2. 
melarance richtet sich gegen Goldonis »commedie popolari« wie Il campiello, Le massere und Le baruffe chiozzotte, in denen nicht nur Figuren und Handlung, sondern auch die Sprache volkstümlich-alltäglich sind. ${ }^{18}$ Zieht man Goldonis Vorwort zu Il campiello in der Pitteri-Edition von $175^{8}$ heran, so finden sich dort expressis verbis die von Gozzi kritisch vermerkten Charakteristika: L'azione di questa Commedia è semplicissima, l'intreccio è di poco impegno, e la peripezia non è interessantex, und weiter »è scritta coi termini più ricercati del basso rango e colle frasi ordinarissime della plebe, e verte sopra i costumi di cotal gente.$^{19}$ Für seine polemischen Zwecke braucht Gozzi also nur Goldonis eigene Worte zu wiederholen. Über die bloße Parodie des Niedrigen, Gewöhnlichen hinaus zielt Gozzi auf einen entscheidenden Aspekt goldonischer Ästhetik. Daß Il campiello trotz aller Einfachheit und Trivialität erfolgreich war, schreibt Goldoni nämlich wie so oft der wverità di costume“ zu. Wenn Gozzi nun dieses Ordinäre, ausgesucht Niedrige in L'amore delle tre melarance in einen völlig neuen, wirklichkeitsfernen, märchenhaften Kontext stellt und das Stück an Erfolg Il campiello dennoch in nichts nachsteht, demonstriert er auf indirekte Weise, daß der Publikumszuspruch wohl kaum der »verità di costume« zu verdanken ist und führt so Goldonis Argumentation ad absurdum. ${ }^{20}$

Sehr viel direkter ist die Chiari-Parodie: Clarice, von Gozzi neu in die Märchenhandlung eingeführt, ist eine derart übertrieben gezeichnete, von Ehrgeiz und Machtbesessenheit getriebene Figur, »una Principessa di carattere strano, bizzarro, e risoluto* (Col. I, 83), wie man sie laut Gozzi noch nie zuvor auf der Bühne gesehen hat. Sie überschüttet

18 In der Analisi riflessiva heißt es: $\rightarrow$ Nella scelta di questo primo argomento, ch'è tratto dalla più vile tra le fole, che si narrano a' ragazzi, e nella bassezza de' dialoghi, e della condotta, e de' caratteri, palesemente con artifizio avviliti, pretesi di porre scherzevolmente in ridicolo Il Campiello, Le Massere, Le baruffe Chiozzotte, e molte altre plebee, e trivialissime opere del Signor Goldoni.* (Col. I, 80).

19 Die gesamte Passage lautet: $=$ Lazione di questa Commedia è semplicissima, l'intreccio è di poco impegno, e la peripezia non è interessante; ma ad onta di tutto ciò, ella è stata fortunatissima sulle scene in Venezia non solo, ma con mia sorpresa in Milano fu cosi bene accolta, che si è replicata tre volte a richiesta quasi comune. La mia maraviglia fu grande, perché ella è scritta coi termini più ricercati del basso rango e colle frasi ordinarissime della plebe, e verte sopra i costumi di cotal gente, onde non mi credeva che fuori delle nostre lagune potesse essere intesa, $\mathrm{e}$ cosi bene goduta. Ma in essa vi è una tal verità di costume, che quantunque travestito con termini particolari di questa Nazione, si conosce comunque da tutti.* (Goldoni, VI, 175).

20 Im Vorwort zur Pasquali-Edition der Baruffe chiozzotte (1774) spielt Goldoni auf Gozzis Kritik an (der erste Band der Colombani-Ausgabe, der die Analisi riflessiva enthält, war 1772 erschienen) und rechtfertigt die Wahl des niederen Sujets damit, >che la natura e l'esempio mi hanno consigliato a tentarlo, e la riuscita delle prime Commedie mi ha autorizzato a produrre le altre.* (Goldoni, VIII, I29). 
Leandro, ihren zukünftigen Mann und König, nicht nur mit Vorwürfen wegen des viel zu langsamen Dahinsiechens von Tartaglia und schlägt, wie bereits erwähnt, zur Beseitigung Truffaldinos Mittel mit sofortiger Wirkung vor, sondern läßt Leandro auch noch schwören, daß er ihr nach der Heirat das Kommando über die Armee überlassen wird, denn, so argumentiert sie, selbst bei einer Niederlage könne sie dank ihrer weiblichen Reize den feindlichen Hauptmann immer noch verführen und ihm dann ein Messer in den Bauch stoßen. Ausdrücklich nennt Gozzi Chiaris Stücke als leuchtende Vorbilder für eine so exzentrische Figurenzeichnung: x Ringrazio il Signor Chiari, che $m$ 'ha dati varj specchi nelle sue Opere per far una parodia caricata di caratteri. * (Col. I, 83). Daß es nicht unüblich war, Figuren in Konflikten schnell zum Messer oder anderen gefährlichen Gegenständen greifen zu lassen, zeigen zahlreiche Stücke Goldonis und Chiaris, wie zum Beispiel Goldonis Bottega del caffe und La Pamela, in denen Männer ihre Frauen, Herren ihre Diener und adlige Damen vermeintlich aus niedrigem Stand kommende Dienerinnen umzubringen drohen, ${ }^{21}$ oder Chiaris Marianna und La madre tradita. ${ }^{22}$ Während die Uraufführung von Marianna, einer Komödie, in der Vater und Sohn als Rivalen handgreiflich um Marianna kämpfen, schon etwa

24 Gerade diesen beiden Komödien Goldonis widmet sich Giuseppe Baretti in seiner Zeitschnift La frusta letteraria (1763-65) ausführlich. Die kritisch-satirische Peitsche trifft Goldoni und Chiari besonders hart, wobei in der Besprechung von La bottega del caffe und Pamela unter anderem auch dieser Punkt beruhhrt und mit einer für das Blatt typischen beißenden Ironie die Unwahrscheinlichkeit solcher Handlungsweisen bervorgehoben wird. Zu Pamela schreibt Baretti: "Sono tutti caratteri falsi e ridicoli. Milorde è un innamorato mezzo gonzo e mezzo bestiale. Come gonzo, ammira Pamela che, secondo l'uso delle contadine, vuol piuttosto far a' pugni che cedere. Bisogna esser gonzo per credere questa virtù il non plus ultra della perfezione muliebre. Come bestiale poi, maltratta i suoi servitori, vuol ammazzare un povero vecchio suo maggiordomo, scorgendolo innamorato della sua dea, e tratta la sua stessa sorella, che è una gran dama, come un facchinaccio tratterebbe un altro facchinaccio. La miledi è uno di qué caratteri dameschi che non esistono altrove fuorché nelle commedie goldoniane: voglio dire che è una dama, la quale non solamente vuole dar degli schiaffi a Pamela, ma la vuole brutalmente strozzare con le sue mani, cacciarle uno stiletto nel cuore, ed in sostanza farla morire per insegnare alle dame il modo di vendicarsi, quando i loro nobili fratelli pensano a sposare delle cameriere. Che bella dama! - (Giuseppe Baretti, La frusta letterarad, Hg. Luigi Piccioni, Bd. 2, Bari, Laterza 1932, S. 39-40).

22 Den Hinweis, daß sich Gozzi speziell auf $L a$ madre tradita beziche, gibt auch Bosisio in seiner Ausgabe der Fiabe teatrali und stützt sich wohl auf folgende Verse aus Gozzis La Marfisa bizzarra, IV, 46 (Col. VII, 110). Daß das Motiv jedoch nicht nur dort auftritt, sondern weiter verbreitet war, machen die oben erwähnten Titel deutlich.

Edalle Madri tradite dir posso,

Ch'apprendano ifaneiul, se ben si guarda,

A maledire i morti, e i testamenti,

A beffeggiar le Madri, ed i parenti.
E contro il Padre a por mano alla spada, Corrergli addosso per farlo morire, A ingannar, a tradir qual sia la strada, Imparano i fanciul, se il ver vuoi dire. 
ein Jahrzehnt zurücklag, ist La madre tradita ein aktuelles Stück, das im Karneval 1760 Premiere hatte und dem Publikum präsent gewesen sein dürfte. Wenn in L'amore delle tre melarance Tartaglias Entschluß, sich auf die Suche nach den drei Orangen zu machen, auf den Widerstand des königlichen Vaters stößt und Tartaglia daraufhin in wüste Drohungen ausbricht, so war die Parodie auf Chiaris Szene, in der Aladino das Schwert gegen seinen Vater Nerestano zückt, sicher nicht zu übersehen. Laut Analisi riflessiva machte der Köníg das Publikum zudem in einer Bemerkung explizit darauf aufmerksam: Rifletteva, che il poco rispetto del figliuolo nasceva dall'esempio delle nuove Commediex, und Gozzi kommentiert: $\$ S$ 'era veduto in una Commedia del Signor Chiari un figliuolo sguainar la spada per ammazzar il proprio Padre. Di esempj consimili abbondavano le Commedie d'allora, censurate da questa inetta favola.* (Col. I, 91). Metatheatralische Äußerungen dieser Art sind in der Analisi riflessiva kein Einzelfall, doch bleibt offen, was tatsächlich auf der Bühne ausgesprochen wurde. Bei der weiten Reise Tartaglias und Truffaldinos zu Creontas Schloß ist ihnen der von ihrem Gönner Celio gerufene Teufel Farfarello behilflich, der sie mit einem Blasebalg zweitausend Meilen weit befördert. Ohne Not wird nicht nur diese beträchliche Entfernung eingeführt, sondern auch in drei aufeinanderfolgenden Szenen ein zweimaliger Ortswechsel - von Creontas Schloß zum königlichen Hof und von dort zurück zum Schloß -, den Gozzi selbstironisch kommentiert, "Qual'irregolarità! (Col. I, 97), wobei es wiederum Chiari ist, den die Polemik trifft: Nelle sue Rappresentazioni, tratte dall'Eneide, egli faceva fare a' suoi 'Trojani nel giro d'una scenica azione de' viaggi grandissimi, senza il mio Diavolo con mantice.* (Col. I, 95). Ergänzend weist Gozzi auf ein zweites, heute verschollenes Stück hin, Ezelino, tiranno di Padova, in dem zwischen zwei aufeinanderfolgenden Szenen mehr als 30 Meilen zurückgelegt, eine Stadt eingenommen und sämtliche Gegner getötet werden. Wie La madre tradita standen auch die Aeneis-Bearbeitungen kurz vor oder zeitgleich mit L'amore delle tre melarance auf dem Spielplan, ${ }^{23}$ so daß die Aktualität der Polemik außer Zweifel steht und ihre Wirksamkeit nicht minder, denn Gozzi konnte damit rechnen, daß sein Publikum auch die konkurrierenden Theater besuchte und sich um so mehr an den Seitenhieben freute. Auf die trivialen Themen und banalen Inhalte der zeitgenössischen Stücke wird ebenfalls verwiesen, wenn Pantalone am Anfang des zweiten Akts ausführlichst Tartaglias Zustand nach dem Fluch

23 Chiari selbst gibt in Band VIII seiner Commedie in verst (Venezia, Bettinelli 176r) für Navigazione d'Enea dopo la rovina di Troja den Herbst 1760 , für Enea nel Lazio den Januar 1761 als Erstaufführungstermine an. 
Morganas darlegt und lange über dessen Wunsch reflektiert, vom Vater ein Paar Eisenschuhe für die lange Reise zu bekommen, den er, Pantalone, dem Vater vortragen müsse. Zum Schluß, beim Hochzeitsfest, kulminiert die Parodie, wenn zunächst Pantalone in die Küche kommt, um vom Zorn des Königs zu berichten, daß die Suppe, das Siedfleisch und die Leber nun gegessen seien und der Braten noch immer auf sich warten lasse, und wenig später der König höchstpersönlich in der Küche erscheint, sil quale con Monarchesca gravità, e collo scettro alla mano minacciava Truffaldino per la tardanza dell'arrosto, e per la vergogna, che sofferiva un suo pari coi convitati. * (Col. I, 112 ).

Die Ebene dieser gezielten satirisch-polemischen Anspielungen auf aktuelle Stücke und laufende literarische Debatten wird überlagert durch die karikaturistische Darstellung der beiden maßgeblichen venezianischen Theaterautoren. In Gestalt der Fee Morgana alias Chiari und des Zauberers Celio alias Goldoni inszeniert Gozzi als Fortführung des Duells auf dem Markusplatz in La tartana ihren Konkurrenzkampf nun auf der Bühne. ${ }^{24}$ Das Antagonisten-Paar versucht nach Kräften, die Interessen der Gegenseite zu untergraben und seine Zauberkünste einzusetzen, um den Einfluß des anderen zu minimieren. Der Höhepunkt der grotesken Auseinandersetzung ist erreicht, wenn Morgana und Celio zusammentreffen und sich in versi martelliani wüst beschimpfen. Dabei befleißigt sich Morgana eines pindarischen Pathos, dunkler Sprache und einer komplizierten Syntax, während Celio sich eines trockenen, hölzernen Stils bedient, so daß die Repliken stilistisch heftig miteinander kontrastieren. Gozzi gibt die Episode in der Analisi riflessiva in ihrer ursprünglichen Form wieder und kommentiert:

Il primo [d. h. Goldoni] aveva fatto un tempo l'Avvocato nel foro Veneto. La sua maniera di scrivere sentiva dello stile delle scritture, che si accostumano dagli Avvocati in quel rispettabile Foro. Il Signor Chiari si vantava d'uno stile pindarico, e sublime; $\mathrm{ma}$, sia detto con sopportazione, non ci fu nessun gonfio, e irragionevole scrittore seicentista, che superasse i suoi smoderati trascorsi. (Col. I, 108)

24 Warum der erganzte Zauberer den Namen Celio trägt, wird von Gozzi nicht thematisiert. Denkbar ware, daß Gozzi durch Luigi Riccobonis Histoire du théatre italien (t728) inspiriert wurde, die Pietro Cotta, genannt Celio, dem Lehrer Riccobonis, gewidmet ist. Celio strebte (ăhnlich wie Goldoni) eine Umerziehung des Publikums durch Ubersetzungen und die Aufführung nicht improvisierter Stücke an. Ein weiterer Bezug ließe sich zu Giulio Cesare Becellis Komödie I falsi letterati (1740) herstellen, in der im Kontext einer Debatte zwischen santichi und smoderni ein $*$ Celio filosofo erseheint. Darüber hinaus tritt in Goldonis Komodie Il vecchio bizzarro (1754) ein Celio auf, der allerdings in nichts Goldoni gleicht. Der Name Celio könnte jedoch von Gozzi in perfider Weise gewählt worden sein, um damit an den größten Mißerfolg Goldonis in Venedig zu erinnern, den dieser mit besagter Komodie erlitten hatte. 
Morgana und Celio gehören als Fee und Zauberer zu den Figuren der Märchenwelt, doch schreibt Gozzi ihnen eine weitere Funktion zu, die ihre antagonistische Ausrichtung akzentuiert: Morgana und Celio sind Kartenspieler. Als solche haben sie auf bestimmte Karten gesetzt und damit verloren oder gewonnen. Die enge Beziehung zwischen Spieler und Karte, die sich somit einstellt, wird in L'amore delle tre melarance zum Protektionsverhältnis. Die Fee Morgana protegiert den falschen ersten Minister Leandro, »Cavallo di Coppe (Col. I, 82), und ist König Silvio feindlich gesinnt sper aver perduti molti de' suoi tesori sul ritratto di quel Re" (Col. I, 83). Dagegen steht Celio der Zauberer auf der Seite des Königs, $\gg$ Re di Coppe $\propto($ Col. I, 81 $){ }^{25}$ Silvio wie Leandro tragen nach Gozzis Vorstellungen Kostüme, die den auf den Spielkarten abgebildeten Kleidern entsprechen, so daß sie auf der Bühne leicht zu identifizieren sind. Mit dieser zusätzlichen, übergreifenden Ebene spielt Gozzi nicht nur auf einen in Venedig grassierenden Zeitvertreib, das Glücksspiel, an, ${ }^{26}$ sondern unterstreicht auch den Spielcharakter von L'amore delle tre melarance: Kartenspiel, Theaterspiel und Rollenspiel überlagern sich, ohne daß eine strikte Trennung der Ebenen möglich wäre. ${ }^{27}$ Über die strukturellen und dramaturgischen Implikationen hinaus drängt sich im Kontext der Polemik Gozzis gegen Chiaris und Goldonis kommerzielle Interessen im Li-

25 Beide Karten gehören zu einem neapolitanischen Kartenspiel, das auch in Venedig verbreitet war.

26. Zur Mode und zu den verschiedenen Arten des Glükspiels im Venedig des 18. Jahrhunderts siehe Giovanni Battista Magrini, I tempi, la vita e gli scritti di Carlo Gozzi aggiuntevi le sue annotazioni inedite alla Marfisa Bizzarra, Benevento, De Gennaro 188 , S. $13^{-15}$, sowie allgemein G. Natali, Il Settecento, op. cit, Bd. I, S. 68 , der Venedig in dieser Hinsicht besonders hervorhebt. In den 7oer Jahren harte die Spielleidenschaft derartige Ausmaße angenommen, daß das berühmte Ridotto vom Magistrat offiziell geschlossen wurde.

Goldoni plädiert in seinen Memoiren für Mäßigung, jedoch keinesfalls fur ein Verbot des Spiels: -Les petits jeux paroissent devenus nécessaires; on ne peut pas passer une soiree sans rien faire; après la nouvelle du jour, après la critique de son prochain et même de ses amis, de toute nécessité il faut jouer.* (Goldoni, I, 547). Auch Chiari äußert sich ausführlich zu Glucksspiel und Lotto in den Lettere scelte. Welchen Stellenwert das Spiel als Thema einnahm, machen nicht nur Goldonis Komödien Il giuocatore und La bottega del caffe deutlich, in denen die negativen persönlichen und gesellschaftlichen Auswirkungen unmäßiger Spielleidenschaft vorgefuhrt werden, sondern beispielsweise auch Parinis Giomo. Zu Spiel und Spielleidenschaft bei Goldoni siehe das Kapitel sLa poetica del gioco fra vraisemblance e vérité «, in: Franco Fido, Guida a Goldoni. Teatro e società nel Settecento, Torino, Einaudi 1977.

27 Das Spiel wie die improvisierte Komödie und die Maskenrollen unterliegen Regeln und Kodifikationen, die Rahmen und Ablauf des Spiels abstecken. Diese vorgegebene Ordnung jedoch wirkt stimulierend auf die Phantasie und vermittelt so den Eindruck von Freiheit und Improvisation. Auf diese Ambiguitat wird im Zusammenhang der Commedia dell'arte naher cinzugehen sein. 
teraturbetrieb auch inhaltlich eine Parallele zum Glücksspiel auf: Theater wie Glücksspiel sollten dem Vergnügen dienen und nicht ökonomischen Interessen, die aus Spielern unvermeidlich Gegner machen.

\section{Dramaturgisches Kräftespiel}

In seinem Theaterstück setzt Gozzi die Parteibildung im Spiel in eine Reihe oppositiver Strukturen um, die sich in dramaturgischer Hinsicht als sehr fruchtbar erweisen. So bilden sich am Hof, ausgehend von den Protektionsverhältnissen Morgana/Leandro und Celio/Silvio zwei rivalisierende Personengruppen, die beide unverhohlen am Thron interessiert sind: zu Leandro halten sich Clarice und Brighella, zu Silvio der Prinz Tartaglia und Pantalone. Die Dreiergruppen, bestehend aus zwei Adligen und einer Maskenfigur, sind symmetrisch angelegt. Aus dieser Konstellation entsteht jedoch noch kein dramatischer Konflikt. Erst als Truffaldino auftaucht, kommt die Handlung in Gang. Von Celio als Gegenmaßnahme zu Morganas Martelliani-Rezept geschickt, soll er den hypochondrischen Tartaglia heilen, ${ }^{28}$ denn das Übel, verursacht durch Morgana, in Anspielung auf Chiaris pathetisch-larmoyante Stücke als $*$ Regina dell'ipocondria (Col. I, 87) bezeichnet, bedarf einer Radikalkur, die nur dem Prototyp der komischen Maskenfiguren anvertraut werden kann.

Die Funktion Truffaldinos als dramatisch wirksame Kraft beschränkt sich nicht auf diesen Anfang, er fungiert auch im zweiten Handlungsstrang als Auslöser, indem er die Orangen offnet, und am Ende tritt er als Retter auf, der Ninetta von ihrer Taubengestalt befreit. Genau besehen, ist es allerdings nicht Truffaldino selbst, der Tartaglia zum Lachen bringt und damit heilt, sondern es ist Morgana, die sich als alte Frau verkleidet hat. Sie, die Truffaldinos heilsame Wirkung unterbinden wollte, wird selbst zum Objekt des Lachens. Beim Anblick ihres Sturzes, bei dem sie rücklings auf dem Boden liegend die Beine in die Luft streckt, entlädt sich Truffaldinos Lachen. Diese gleichermaßen unabsichtliche wie indiskrete Umkehrung normaler Verhältnisse stellt die durch die Melancholie des Prinzen gestörte

In der Analisi riflessiva weist Gozzi selbst auf eine gewisse Inkonsistenz hin, die sich aus dem Zusammenspiel von Celio und Truffaldino ergibt. Ist Celio Goldoni und Truffaldino die Inkarnation des Komischen in der Commedia dell'arte, so dürfte Celio nicht ausgerechnet eine Maskenfigur schicken, da Goldoni ja gerade die Abschaffung der Masken betreibt. Gozzi rechtfertigt die Ungereimtheit mit dem Spielcharakter von L'amore delle tre melarance und erklärt, daß das höchst polemische Stück durch derartige Funktionsdoppelungen der Figuren und Überlagerung der Ebenen weniger angreifbar sei. 
Ordnung wieder her. Zugleich ist sie jedoch der Anlaß für die Verwünschungen Morganas, die die Labilität der wiederhergestellten Ordnung sogleich deutlich machen. Dieses Oszillieren zwischen erreichter und gestörter Ordnung setzt sich in den beiden folgenden Akten fort, und immer ist Truffaldino mittel- oder unmittelbar beteiligt. Entscheidend ist, daß Truffaldino der gewichtigste Part im dramatischen Geschehen zugedacht ist. ${ }^{29}$ Während die anderen Masken neue Rollen spielen, Tartaglia den Prinzen, Pantalone den Vertrauten des Königs, oder wie Brighella als Diener Leandros im Hintergrund bleiben, tritt Truffaldino in L'amore delle tre melarance als das auf, was er an sich ist, als "persona benemerita nel far ridere (Col. I, 82) - und als solche ist er nicht nur Tartaglia nützlich, sondern auch dem Publikum. Truffaldino steht direkt, mittels seiner typisch komischen Masken-Charakteristika, und indirekt, über seine strukturelle Funktion, für den komischen Charme und die Wirksamkeit der Commedia dell'arte-Masken. Zu diesem figuralen Plädoyer für die Commedia dell'arte-Tradition kommen zahlreiche autoreflexive Äußerungen von Figuren, die die gängigen Komödien parodistisch ab-oder die »commedia all'improvviso $\approx$ aufwerten. So fehlt es nicht an ironischen Hinweisen auf mangelnden Respekt der Kinder gegen ihre Eltern in den neuen Komödien, auf tränenreich-larmoyante Episoden in versi martelliani, auf die fatale Wirkung eben dieser Verse oder die epidemieartige Verbreitung poetischer Fähigkeiten, die auch vor der Bäckersfrau, dem Hund, dem Tor, dem Seil bei Creontas Schloß nicht halt macht. Besonders deutlich wird der metatheatralische Aspekt in L'amore delle tre melarance in einer Diskussion zwischen Clarice, Leandro und Brighella, der sich nach Clarices und Leandros Thronbesteigung den Posten eines Zeremonienmeisters am Hof erhofft. Als "sopraintendente a' Regii spettacoli (Col. I, 92) will er, die Maskenfigur, in erster Linie improvisierte Komödien mit Masken, "opportuna a divertire un popolo con innocenza. ${ }^{30}$ Clarice und Leandro lehnen dies ab, »non volevano goffe buffonate, fracidumi indecenti in

29. In - Ironie et mélancolie (I): Le théâtre de Carlo Gozzi * und •(II): La Princesse Brambilla de E.T.A. Hoffmann*, in: Critique 22, 1966, S. 291-308 und $438-457$, geht Jean Starobinski jeweils auch auf die wichtige Rolle Truffaldinos in Liamore delle tre melarance ein, hat jedoch vor allem das Märchen im Blick, so daß Truffaldino nicht als Element der Commedia dell'arte-Komponente der Fube teatrali und in seiner traditionellen Funktion als handlungstreibende Kraft wahrgenommen wird, sondern Shakespeares Clowns verwandt scheint und damit einer Tradition nahestehend, nqui attribue au bouffon, au clown, les fonctions ambiguês d'un fauteur de désordre et d'un sauveur, d'un auxiliaire surnaturel qui ignore la véritable portée de ses actes,* (S. 307).

10 Das Argument, die ncommedia all'improvviso biete dem Publikum cin harmloses Vergnügen und sei daher für öffentliche Theater geeignet, zieht sich durch sämtliche argumentativen Texte Gozzis; vgl. Kap. 3.2. 
un secolo illuminato, und machen sich dagegen für tragisch-pathetische Stücke und Charakterkomödien stark: „Clarice voleva Rappresentazioni tragiche, con de' personaggi, che si gettassero dalle finestre, dalle torri, senza rompersi il collo, e simili accidenti mirabili: Idest Opere del Signor Chiari. Leandro voleva Commedie di caratteri: Idest Opere del Signor Goldoni. «(Col. I, 92) Die Szene endet mit einer pathetischen Rede Brighellas, in der er die Sacchi-Truppe, ohne sie zu nennen, zutiefst bedauert, da sie ihr Publikum verloren habe, das sie doch so lange Zeit aufs beste unterhalten habe. Diese Bezugnahme Brighellas auf die eigene Situation scheint das Publikum sehr wohl verstanden und mit Applaus quittiert zu haben: Entrava con applauso di quel Pubblico, che aveva ottimamente inteso il vero senso del suo discorso. (Col. I, 93).

\section{Das Publikum}

Ein letzter wichtiger Aspekt ist die Reaktion des Publikums. Die Form der nachträglichen narrativen Darstellung von L'amore delle tre melarance bietet die seltene Gelegenheit, die pragmatische Dimension des Theaters einzubeziehen. Die Beschreibung der Kommunikation zwischen Bühne und Zuschauerraum in der Analisi riflessiva - in mehr als zehnjährigem Abstand von der Uraufführung - wird selbstverständlich durch apologetische Intentionen mitbestimmt, doch läßt sich die von Gozzi angestrebte Wirkung seines ersten Bühnenstücks gut erkennen. Wie publikumsgerichtet das Theater dieser Zeit war, machen die oft separat zur Aufführung gedruckten Prologe und der »commiato ", die Schlußverse mit direkter Ansprache der Zuschauer und der Bitte um Applaus, sehr deutlich. Diesem Muster folgt auch Gozzi, doch stehen gerade die letzten Worte des Stücks wiederum unter ironischen Vorzeichen, wenn das Publikum nicht nur um Applaus gebeten wird, sondern auch darum, sich bei den Journalisten für eine positive Kritik von L'amore delle tre melarance einzusetzen. ${ }^{31}$ Die

31 - Non lasciava di terminare la favola col consueto finale, che sa a memoria ogni ragazzo: di nozze, di rape in composta, di sorci pelati, e gatti scorticati ec. e siccome i Signori Gazzettieri di quel tempo facevano elogi sterminati sui loro fogli ad ogni Opera nuova. che veniva rappresentata del Signor Goldoni, non si ommetteva una calda raccomandazione all'Uditorio, perch'egli volesse farsi intercessore co' Signori Gazzetticri in vantaggio della buona fama di questa fanfaluca misteriosa.- (Col. 1, 113).

Der formelhafte Schluß beendet auch die folgenden Fiabe teatrali Il corvo und Il re cervo. Aufgrund des Nebentextes, der die Formel in $/ l$ corvo einleitet, ist anzunehmen, daß sie auf eine traditionelle mündliche Märchenschlußformel zurückgeht: *chiude la Rappresentazione con le seguenti parole, colle quali sogliono le vecchiarelle chiudere le Fole a' fanciulli, che le ascoltano* (Col, I, 21x). 
lebhafte Reaktion des Publikums auf das Geschehen auf der Bühne illustriert Gozzis Hinweis auf den Aufruhr, den der parodistisch-provokante Dialog zwischen der Fee Morgana und dem Zauberer Celio hervorgerufen hat. Gozzi selbst nennt die Szene wla più ardita di questa scherzevole parodia* und schildert den Effekt bei "goldonisti und "chiaristi so: "I due partiti delli Signori Chiari, e Goldoni, ch'erano nel Teatro, e che s'avvidero del tratto mordace, fecero ogni prova per porre in un tumulto di sdegno l'Uditorio, ma tutti gli sforzi furono vani.* (Col. I, 107-108). Daß solche Szenen zum Stadtgespräch wurden und die Attraktivität der Aufführung noch steigerten, ist leicht vorstellbar.

Auf zwei Aspekte geht Gozzi mehrfach ein: die Reaktionen des Publikums auf die Improvisationsszenen der Masken sowie auf das Märchenhaft-Wunderbare. Daß vor allem die Szenen mit Tartaglia und Truffaldino große Lacherfolge waren, wird ausdrücklich erwähnt. Zweimal spricht Gozzi zudem von "questi due personaggi sempre facetissimi (Col. I, 9o, 96) und bezieht damit unverkennbar eine Gegenposition zu Goldonis und Chiaris Ablehnung und Abwertung des improvisierten Theaters, die in Clarices und Leandros Reaktion auf Brighella zum Ausdruck kommt. Wie selbstverständlich das Lachen angesichts des Spiels der Masken und besonders Truffaldinos ist, geht aus einer rhetorischen Frage hervor, die Gozzi im Zusammenhang der Küchen-Szene mit Truffaldino und der Taube auf die lakonische Bemerkung vi suoi lazzi erano facetissimi« hin stellt: "Si chieda all'Uditorio, il perchè questa scena piacesse estremamente* (Col. I, 111 ).

Daneben ist es die Wirkung des Märchenhaft-Wunderbaren, auf die Gozzi aufmerksam macht. Ausführlich kommentiert er die Szene am Zauberschloß Creontas. "Ebbi occasione di conoscere, all'apritura di questa scena con degli oggetti affatto ridicoli, la gran forza, che ha 'l mirabile sull'umanità , und er fügt hinzu, stenevano tutto il Teatro in un silenzio, e in un'attenzione nulla minor di quella, ch'ebbero le migliori scene dell'Opere de' nostri due Poeti, (Col. I, 97, 98). Damit ist für Gozzi nicht nur erwiesen, daß das Wunderbare noch immer eine große Faszination auf die Menschheit auszuüben vermag, sondern auch, daß sich die Aufmerksamkeit des Publikums eben so gut auf die Darstellung von unverkennbar Erfundenem wie von angeblich Nachgeahmtem richten kann. In ironischer Anspielung auf Goldonis und Chiaris ständige Suche nach neuen Sujets sowie auf Goldonis Beteuerung, die Welt auf der Bühne exakt abzubilden, schreibt Gozzi: ngli Uditori informati sino da loro primi anni dalle balie, e dalle Nonne loro degli accidenti di questa fola, erano immersi profondamente nella materia, e impegnati strettamente cogli animi nell'ardita novità di vederli esattamente rappresentati 
sopra un Teatro.* (Col. I, 106-107). Daß sich die erwachsenen Zuschauer von vertrauten Kindermärchen fesseln lassen, verweist auf das paradoxe Zusammenwirken von Altbekanntem und Neuem, das in der Analisi riflessiva immer wieder angesprochen wird. Altbekannt ist die Geschichte in ihrem Verlauf bis hin zu den sprachlichen Formeln, neu die Gestaltung und Inszenierung. Auch die phantastischsten, unwahrscheinlichsten Szenen rufen nicht etwa ein spöttisch-überlegenes Lächeln hervor, sondern nehmen das Publikum gefangen, wie die folgende Episode zeigt. Nachdem Truffaldino und Tartaglia die Gefahren vor dem Schloß gemeistert haben und Tartaglia glücklicher Besitzer der drei Orangen ist, folgt unter Aufbietung aller bühnentechnischen Möglichkeiten ( si sentiva il tremuoto, s'udivano gran tuoni «, Col. I, 98) Creontas Dialog mit den ihr untreu gewordenen Schutzobjekten. Wiederum betont Gozzi die Wirksamkeit der Szene und unterstreicht dies, indem er seine eigene Reaktion beschreibt: «L'Uditorio era contentissimo di quella mirabile novità puerile, ed io confesso, che rideva di me medesimo, sentendo l'animo a forza umiliato a godere di quelle immagini fanciullesche, che mi rimettevano nel tempo della mia infanzia.* (Col. I, Ioo). Die bewußte retrospektive Wahrnehmung der unübersehbaren Diskrepanz zwischen dem Kindlich-Kindischen der Szene und der unwillkürlichen Hingabe an die Vorstellung (in beiderlei Sinn: an die Imagination wie an die Darstellung auf der Bühne), des Mißverhältnisses von Ursache und Wirkung, kann nur zu einem selbstironischen Lachen führen, das die Unmittelbarkeit des Eindrucks verdeutlicht. Neben das Lachen über die Figuren tritt also das Gefesseltsein durch die Handlung, neben den distanzierten Blick das Eintauchen in das Bühnengeschehen. Diese doppelte Wirkung erzielt Gozzi mit einem "mirabile misto col ridicolo (Col. I, 106), das er in L'amore delle tre melarance zum ersten Mal erprobt.

Der Erfolg der Aufführungen war überwältigend, und er zeigte, daß es neben Goldoni und Chiari Raum für eine andere Art von Theater gab, ${ }^{12}$ in dem sich Elemente unterschiedlichster Provenienz zu einem neuen Ganzen verbinden, das sich weder in der Parodie noch im Märchen noch in der Commedia dell'arte erschöpft. Vielmehr ist es gerade die Kombination und Verflechtung der Einzelkomponenten, aus denen etwas unverwechselbar Neues entsteht, das sich deutlich von allen zeitgenössischen dramatischen Formen abhebt. Im Kontext der Polemik als parodistischer Angriff auf Goldonis und Chiaris Theater konzipiert, nutzt Gozzi

12 - Non fu mia colpa. Il cortese Pubblico volle replicata molte sere alla fila questa parodia fantastica. Il concorso fu grande. La Truppa del Sacchi cominciò a respirare dall’ oppressione* (Col. I, t13), schreibt Gozzi. 
alle Möglichkeiten, auf verschiedenen Ebenen die Kontrahenten selbst, ihre Konkurrenz sowie Einzelheiten ihrer Stücke lächerlich zu machen, doch geht er weit über diese direkte Art der Parodie hinaus. L'amore delle tre melarance ist bereits in Form und Struktur polemisch, basiert das Stück doch auf zwei Komponenten, die beide den zeitgenössischen Tendenzen entgegenstehen und dem ausdrücklichen Verdikt Goldonis unterliegen. Sowohl die Commedia dell'arte mit ihren Masken als auch das Märchenhaft-Wunderbare, nicht Wahrscheinliche, werden im Rahmen des Reformprogramms dezidiert abgelehnt. Indem Gozzi gerade alte, traditionsreiche Genera für sein Theaterstück erfolgreich fruchtbar macht, provoziert er nicht nur bewußt, sondern widerlegt indirekt auch das Argument, die Sucht des Publikums nach dem ganz Neuen zwinge die Autoren, das Alte hinter sich zu lassen. ${ }^{33}$ Beide, das Märchen wie die improvisierte Komödie, erfreuten sich seit Jahrhunderten und noch immer des regen Interesses breiter Schichten und konnten als Beleg dafür gelten, daß weder die Vertreibung der Masken von der Bühne noch des Wunderbaren aus den Büchern bisher gelungen war; ganz im Gegenteil potenzierte ihre spielerische Verflechtung in L'amore delle tre melarance das Vergnügen des Publikums.

L'amore delle tre melarance zielt nicht, wie oft behauptet wurde, auf eine Wiederbelebung der dank Goldoni nahezu eliminierten Commedia dell'arte, sondern ist ein zukunftsweisendes Projekt, eine neue dramatische Form, die Gozzi w fiaba teatrale a nennt, wobei der Name deutlich auf die beiden konstitutiven Komponenten hinweist, das Märchenhafte und das Theatralische. Die neue Gattung ist weder Märchen noch Commedia dell'arte, sondern eben ffiaba teatrale $\star$ und setzt sich aus charakteristischen Elementen sowohl der narrativen wie auch der dramatischen Form zusammen, wobei sich diese überlagern und ergänzen, so daß spezifische Strukturen entstehen, in denen die Einzelkomponenten eine neue Funktion erfüllen.

\section{Theater-Spiel}

Zunächst steht in L'amore delle tre melarance das Parodistisch-Polemische im Vordergrund. Die bewußte Übertreibung im Hinblick auf die Unwahrscheinlichkeit der Handlung, die Exzentrizität der Figuren und die Artifizialität der Sprache zielt vor allem auf das Theater Chiaris und

3) Darin gleicht das erste Theaterstück den vorausgegangenen polemischen Texten, die ebenfalls hãufig alte Textsorten neu funktionalisieren. 
Goldonis. Wie Gozzi unterstreicht, bedarf es dieser karikierenden Gestaltung, um den gewünschten Effekt zu erzielen, "Si rifletta, che, se le parodie non danno nella caricatura, non hanno giammai l'intento, che si desidera, e s'usi indulgenza ad un capriccio, che nacque da un'animo puramente allegro, e scherzevole, ma amicissimo nell'essenziale de' Signori Chiari, e Goldoni, (Col. I, 108). „Caricatura «, mesagerazione «, simproprietá $\alpha^{34}$ sind die Termini, die die parodistische Verrückung benennen und zugleich die Distanz zur Wirklichkeit markieren. Der betont wirklichkeitsferne, unwahrscheinliche Charakter des Stücks macht die Kluft zwischen theatralischem Ereignis und Realität überdeutlich und hebt den spielerischen, kapriziösen Aspekt der Fiaba teatrale hervor. Nicht Personen stehen auf der Bühne, sondern Typen aus der Commedia dell'arte und schematisierte Märchengestalten, grob umrissen und marionettenhaft geführt. Das freie Spiel der Phantasie bewegt die Figuren in Menschen-, Masken-oder Tiergestalt in Schloß- und Wüsten-Räumen, so daß sich ein bewußter, nicht zu übersehender Gegensatz zum "stile familiare, naturale e facile ergibt, der in Goldonis Teatro comico proklamiert wird, »per non distaccar[si] dal verisimile $(\amalg, 2)$. Doch nicht nur das Bühnengeschehen wird von der Imagination bestimmt, auch der Zuschauerraum unterliegt ihrer Suggestion. Das Publikum taucht für kurze Zeit in die fiktive Welt ein, vergißst sich und wird zum Kind, das gebannt den Erzählungen der Großmutter lauscht. Die Realität scheint aufgehoben im Spiel, der Sinneseindruck überwältigt die Vernunft.

Dieser momentane Sieg der Illusion über die Wirklichkeit führt jedoch nicht zur Evasion, denn kaum hat sich die Illusion eingestellt, löst sie sich auch schon wieder auf, indem sie parodistisch rückgebunden wird an die Realität, genauer an das zeitgenössische Theater. Die metatheatralischen Einsprengsel zielen sowohl auf konkrete Charakteristika bestimmter Autoren und ihrer Stücke als auch auf die theatralische Täuschung selbst. Sehr deutlich tritt das Spiel mit der Illusion zutage, wenn es beispielsweise heißt, "Pantalone non credeva tal maraviglia (Col. I, 112), als Truffaldino ihm erzählt, daß er wegen einer sprechenden Taube in der Küche eingeschlafen sei. In dieser Hinsicht besonders aufschlußreich ist die Szene, in der der Zauberer Celio den Teufel Farfarello ruft

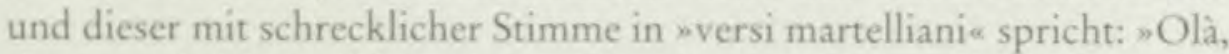
chi qua mi chiama dal centro orrido, ed atro? / Sei tu Mago da vero, o

4. Siche z. B. Col. 1, 108, 91, 111. Immer wieder betont Gozzi in der Analisi riflessiva die bewußte parodistische Vergröberung: - La parodia non girava, che sulle bassezze, e trivialità d'alcune opere, e sull'avvilimento di alcuni caratteri de' due Poeti. Un'eccessiva mendicità, improprietai, e bassezza formavano la parodia. - (Col. I, 1 10-1rit). 
Mago da Teatro? / Se da Teatro sei, non è mestieri [sic] il dirti, / Che sono un'anticaglia Diavoli, Maghi, e Spiriti. « Als Celio in Prosa antwortet, er sei ein wirklicher Zauberer, erwidert Farfarello: „Or ben, sia chi tu voglia; se da Teatro sei, / In versi martelliani almen parlar mi dei.x (Col. I, 93). Über die Anspielungen auf die Debatte über die Verwendung von Prosa, Vers und versi martelliani hinaus, wird hier die Problematik eines Wahrheits- und Wirklichkeitsanspruches im Theater berührt. L'amore delle tre melarance gibt darauf provisorisch eine originelle Antwort: im Zusammenspiel betont wirklichkeitsferner Elemente aus dem Märchen und der Commedia dell'arte entsteht ein höchst illusionäres Spektakel, das jedoch durch seine parodistische Intention demonstrativ auf die Wirklichkeit zurückweist und so indirekt die Wahrheit über die aktuelle Theaterlandschaft enthüllt.

Retrospektiv schreibt Gozzi den Anlaß, die bisher schriftlich ausgetragene Polemik nun auf die Bühne zu verlagern, zum einen der Abqualifizierung seiner Gedichte und Traktate als Produkte eines eingefleischten Puristen und Pedanten zu, zum anderen dem Wunsch, Goldonis Behauptung zu widerlegen, der Publikumserfolg sei ein Kriterium für die Qualität der Stücke.

Ma forse perché cento consimili mie composizioni d'argomenti scherzevolmente ed efficacemente trattati, con le quali fui invero un martirio a quel buon uomo, erano pur chiamate tuttavia con disprezzo da lui e da' suoi partigiani eco della di lui voce, frivole e non curabili maldicenze uscite dall'animo d'un uomo torbido, invidioso e cattivo, e perché egli citava sempre ostinatamente il concorso popolare per autenticità del merito delle sue teatrali produzioni, espressi un giorno, senza rimordimento del mio cuore, che il concorso in un teatro non decideva che le opere sceniche sue fossero buone, e che io m'impegnava di cagionar maggior concorso delle sue orditure colla fiaba dell' Amore alle tre melaranze, racconto delle nonne a' lor nipotini, ridotta a scenica rappresentazione. (Mem. I, 230$)^{35}$

Aus diesem letztgenannten Anstoß läßt sich auch die bewußte Degradierung von L'amore delle tre melarance als sinetta favola“, »diavoleria*, »puerilità oder "fanfaluca misteriosa $\propto$ in Gozzis Analisi riflessiva erklären. Je unbedeutender, verrückter, kindischer das Stück sich gibt, desto unzutreffender erweist sich Goldonis Korrelation von Publikumserfolg

35 Diese Erklärung folgt auf das in Kap. $\mathrm{r}$ bereits angeführte Gedicht *Dottor, se incontra qualche tua commedia* (Col. VIII, $184-185$ ), das die Widersprüchlichkeit von Goldonis Position ironisiert, der zwar den Publikumszulauf bei seinen Stücken für ein Qualitätskriterium hält, nicht jedoch bei Chiari, und andererseits das Publikum Ignoranten schimpft, wenn es bei einer seiner eigenen Komódien ausbleibt, wahrend er im Falle Chiaris daraus die schlechte Qualitāt des Stückes ableitet. 
und Qualität, denn >Il cortese Pubblico volle replicata molte sere alla fila questa parodia fantastica. Il concorso fu grande, “ (Col. I, 113). Wesentlicher als dieser punktuelle Aspekt ist jedoch die Eroberung eines neuen Raums der Auseinandersetzung, in dem nicht nur polemisch kritisiert, sondern zugleich mit wirkungsvollen Formen experimentiert wird. Wieviel attraktiver und effektiver - sowohl in kurz-als auch in langfristiger Perspektive - die szenische Gestaltung der Polemik war, ${ }^{36}$ macht ein Blick auf Texte deutlich, die zwar heute wie zu Gozzis Zeiten deutlich weniger Publikumsresonanz erzielen, doch als Kontext relevant sind, in dem die ersten Fiabe teatrali enstehen.

\subsection{Kontexte, Paratexte}

$\mathrm{Zu}$ den Texten, die in unmittelbarem zeitlichen und inhaltlichen $\mathrm{Zu}-$ sammenhang mit L'amore delle tre melarance stehen, zählen sowohl Gedichte, die ab Dezember 1760 für die Veröffentlichung in den Atti granelleschi vorgesehen waren, als auch das Kurzepos Le spose riacquistate und das Epos La Marfisa bizzarra. So vielfältig die Textsorten, die Gozzi wählt, auch sein mögen, die direkte Polemik gegen Goldoni und Chiari bleibt sich im wesentlichen gleich und ist hauptsächlich auf das nicht inhaltlich, sondern ökonomisch motivierte Konkurrenzverhältnis gerichtet, auf die von beiden propagierten Reformbestrebungen, die auf die Verdrängung der $*$ commedia all'improvviso* und die Etablierung angeblich regelmäßiger, moralisch einwandfreier Stücke zielen sowie auf den Nützlichkeitsanspruch, unter dem das Theater bzw. die Literatur stehen. In unterschiedlicher Ausprägung und Akzentuierung finden sich diese Aspekte in kurzen wie umfangreichen Texten Gozzis um 1760, wobei L'amore delle tre melarance als Theaterstück zweifelsohne den Höhepunkt markiert und zugleich eine Veränderung der polemischen Auseinandersetzung signalisiert.

36. Goldoni hatte, wie in Kap. 1.3 erwahnt, durch Beziehungen zu einflußreichen Persônlichkeiten erwirke, daß bereits einige fruhe polemische Texte Gozzis unveröffentlicht blieben; mit der Publikation der Atti granelleschi und der Auffuhrung von L'amore delle tre melarance im Jahr 1761 war dann ein Hōhepunkr der Kontroverse erreicht. Was die langfristige Wirkung von Lamore delle tre melarance betrifft, so sei hier nur an Meyerhold oder an Prokofjew und die 1921 uraufgeführte Oper Die Liebe zu den drei Orangen erinnert. 


\section{Le spose riacquistater und Gedichte}

In mehrfacher Hinsicht weist das vom Autorenkollektiv Carlo Gozzi, Daniele Farsetti und Sebastiano Crotta um 1760 verfaßte Kurzepos Le spose riacquistate ${ }^{37}$ auf L'amore delle tre melarance voraus. Im zweiten der beiden aus der Feder Gozzis stammenden Gesänge, die er unter dem Titel Il ratto delle fanciulle castellane separat veröffentlichte, tritt nicht nur Goldoni-Pulejo bereits als »mago, ed indovino« (Col. VIII, I I 8) auf, auch steht ihm ein Teufel hilfreich zur Seite, so daß er unter anderem den Zauberberg mit Namen »monte dall'oro« wie im Flug erreicht. Im vierten Gesang führt Farsetti eine tatkräftige Zauberin ein, die sich gegen Pulejo stellt und gar den Teufel auf ihre Seite zieht. Damit ist zum einen das antagonistische, im Übernatürlich-Märchenhaften angesiedelte Paar Celio/Morgana in groben Zügen vorgezeichnet, zum anderen die Helferrolle von Teufeln skizziert. Auch der Truffaldino Sacchi spielt eine nicht unbedeutende Rolle in Gozzis Gesängen, denn Sacchis Publikumserfolg ist der Grund für Pulejos Entscheidung, Zauberer zu werden, um sich so - fern von der Bühne - seinen Lebensunterhalt zu verdienen. Als der Teufel Malacoda, von Pulejo zu Hilfe gerufen, sich zuerst in Chiari, dann in Sacchi verwandelt, um Pulejo zum Narren zu halten, flieht dieser in panischer Angst, unfähig, Wahres von Eingebildetem zu unterscheiden und sich im rechten Moment der Illusion bewußt zu werden - ein ironischer Hinweis Gozzis auf die Problematik des Verhältnisses von Wahrheit und Fiktion in bezug auf Goldonis wiederholte Beteuerungen, die Wirklichkeit auf der Bühne abzubilden.

Ben si ricorda, che nella scienza

Di chiamar gente al Teatro l'ha vinto,

E che l'avea ridotto all'astinenza,

$\mathrm{E}$ a fare il Mago per il vitto spinto;

Or di nuovo sel vede alla presenza,

Non si ricorda, ch'egli è un Sacchi finto

Tanta è la rabbia, e il livor, che lo rode,

Che fugge, e il ver più non vede, e non ode.

(Col. VIII, I3I)

Sind es in Il ratto delle fanciulle castellane hauptsächlich die Figuren, Figuren-Konstellationen und poetologisch-ästhetische Aspekte, die die Bezugspunkte zwischen Epos und Theaterstück bilden, rücken der Canto ditirambico de' partigiani del Sacchi Truffaldino und andere Gedichte das Problem der Commedia dell'arte und des Umbruchs schauspieltech-

37 $\mathrm{Zu}$ Entstehungsgeschichte und Datierung des Textes siehe Kap. 1.3. 
nischer Traditionen in den Mittelpunkt. Der im selben Jahr wie L'amore delle tre melarance entstandene Hymnus auf den berühmten Truffaldino Sacchi ist zugleich eine Invektive gegen Goldonis und Chiaris Umgang mit der Commedia dell'arte. Motive des Dezember-Gedichts aus La tartana aufnehmend und anstelle der Burchiello-Verse Zitate aus Anton Francesco Grazzinis Canti carnascialeschi ${ }^{38}$ einstreuend, legt Gozzi den Anhängern Sacchis das Lob seiner Improvisationskunst in den Mund: "Sacchi innocente, / Di nostra mente / Consolazione, / Tato, e mignone, / Tu con le pure / Caricature, / E con gl'imbrogli, / Quando tu il vuogli, / E con gli amori, / E co' furori, / Le gelosie, / Le braverie, / Senza osceni allettamenti, / Imposture, adulazioni, / Vinci tutte le invenzioni / De' Poeti prepotenti๔ (Col, VIII, r69-170). Eines der am häufigsten gebrauchten Wörter dieses Textes ist srisa $\propto$, das freie, befreite Lachen, das Sacchis Improvisation hervorbringt. Der Unschuld der Sacchischen Späße stehen die Laster gegenüber, die die angeblichen Reformer auf die Bühne bringen, der daraus resultierenden $»$ malinconia $\propto$ des Publikums der heilsame Trost des Lachens. In allegorischer Überformung sieht das Publikum diese Konstellation in L'amore delle tre melarance auf der Bühne in Gestalt des melancholischen Tartaglia und des komischen Truffaldino. Über Sacchi hinaus werden im Dithyrambus die übrigen Mitglieder der Truppe sowie zwei bekannte, bereits verstorbene Commedia-dell'arteSchauspieler, Vitalba und Rodrigo, namentlich genannt und in das Loblied auf die am Teatro San Samuele gepflegte Improvisationskunst einbezogen, während Schauspielern der Theater San Giovanni Grisostomo und San Salvatore, den Spielstätten Chiaris und Goldonis, eine deutliche Abfuhr erteilt wird. ${ }^{39}$

Daß nun neben den Autoren auch die Schauspieler ins Kreuzfeuer der Polemik geraten, ist zum einen darauf zurückzuführen, daß die Truppen generell aufs engste mit den Autoren verbunden waren, die auf vertraglicher Basis für sie schrieben, zum anderen darauf, daß Goldoni die nprima Donna* seiner Kompagnie, Caterina Bresciani, genannt Ircana, ${ }^{40}$

38. Siehe oben Anm. 5.

39 Diesen persônlichen Angriff thematisiert Gozzi in einem nachfolgenden Schweifsonett in ironischer Weise. Auf seine Bitte an die Schauspieler, ihm doch wieder die Hand zu reichen, erklärt er, seine Invektiven im Ditrambo hätten ja nur eine positive Wirkung. denn die absehbare "vendetta * Goldonis und Chiaris, =co' lor versi, e prosea (Col. VIII, $18 \mathrm{t}$ ), brächte der Truppe mehr Zuschauer und also mehr Geld ein.

42. Fur Caterina Bresciani hatte Goldoni die Rolle der Ircana in La sposa persiana geschrieben. Den überwältigenden Erfolg dieser orientalisehen Tragikomödie ( 34 Aufführungen allein in der Herbst-Saison 1753) schreibt Goldoni in seinen Memoiren nicht dem Exotismus, sondern der Schauspiclerin Bresciani zu, die seitdem ihren Rollennamen trug: "Je dois les agréments que me procura cette Piece à Madame Bresciani, qui jouoit 
zum Abschluß der Karneval-Saison 176r ein complimento in venezianischem Dialekt rezitieren ließ, in dem direkt auf die Aufführung von Gozzis erstem Bühnenstück und die drohende Konkurrenz Bezug genommen wird. Mit Blick auf L'amore delle tre melarance beklagt sich Ircana, daß es böse Zungen gebe, die die Schauspieler und vor allem den *Poeta « beleidigten und verleumdeten, was diesen sehr zu Herzen gehe. Doch wolle sie darauf nicht weiter reagieren, denn $* A$ longo andar ga più rason chi tase" (Col. VIII, 14I). Allerdings erhofft sie sich vom venezianischen Publikum Gerechtigkeit und das heißt, Treue zu diesem Theater und seiner Truppe.

Tanto del vostro amor, tanto me fido,

Veneziani cortesi, e de bon cuor,

Che nell'anno, che vien, spero, e confido

Egual prosperità, se no maggior.

Avvilirne i vorria, ma me ne rido.

Ghe vol altro, che Fiabe, a farse onor,

E Maghi, e Strighe, e Satire, e schiamazzi:

Le vol esser Commedie, e no strapazzi.

(Col. VIII, r4o)

Am 7. Februar 1761 erschien dieser Epilog in der Gazzetta veneta, die inzwischen nicht mehr Gasparo Gozzi, sondern kurioserweise Pietro Chiari führte. ${ }^{41}$ Als unmittelbare Reaktion darauf sollte die März-Ausgabe der Atti granelleschi zwei Texte Carlo Gozzis enthalten, von denen der erste jedoch nach der Einstellung der Publikation der Atti unveröffentlicht blieb, der zweite, die direkte Antwort auf Ircana, von Gozzi in

le rổle d'Hircana; ététait pour elle que je l'avois imaginẻe et travaillée. [...] Cette Actrice qui ajoutoit à son esprit et à son intelligence les agrémens d'une voix sonore et d'une prononciation charmante, fit tant d'impression dans cette heureuse Comédie, qu'on ne la nomma depuis que par le nom d'Hircana. (Goldoni, I, 326).

4 Carlo Gozzi druckte den Text Goldonis unter der Uberschrift >Addio, composto dal Signor Goldoni, e recitato dalla Comica Bresciani nel Teatro di S. Salvatore a Venezia* in Band VIII der Colombani-Edition ab, um damit den notwendigen Hintergrund für seine $>$ Risposta $<$ zu schaffen.

$\mathrm{Zu}$ Chiaris Gazzetta veneta siehe Ricciarda Ricorda, = La Gazzetta veneta di Pietro Chiarie, in: Elena Sala Di Felice; Laura Sannia Nowé (Hgg.), La cultura fra Sei e Settecento, Modena, Mucchi r994, S. 8 5-114.

Die zweite Nummer der Gazzetta veneta yom 11. Februar 1761 enthielt den *Addio* der Sacchi-Truppe, in dem es heißt * Fra poco andran neglette, andranno disusate / Le Maschere, che furo per ridere inventate. / Non vi sarà chi in esse più si voglia erudire; / Ed un Piacer d'Italia dovrà con lor perire! / Non sono, non son queste, (che che talun diranne) / Degl'Itali Teatri le mal nate tiranne; / Sono nostre ingegnose del riso eccitatrici, / Che non escludon l'altre Commedie più felici.* Unverkennbar ist nicht nur die Kritik an der Vertreibung der Masken von der Bühne, sondern am Ende auch das Werben für eine Pluralitat der Komödienformen. 
seine Gesamtausgabe übernommen wurde. ${ }^{42}$ Unter dem Titel $»$ Risposta data dal Pubblico alla Signora Bresciani Comica, da me scritta* spricht Gozzi, ebenfalls in venezianischem Dialekt, der Schauspielerin diplomatisch seine Anerkennung aus, polemisiert aber heftig gegen Goldoni und seine geschriebenen Stücke, die die Schauspieler nicht nur viel Geld kosten, sondern zudem zur »corruzion d'un Popolo* (Col. VIII, 142) beitragen. Es wird insinuiert, Goldoni habe Ircana für den Schlag gegen Gozzi instrumentalisiert, und das Publikum fordert sie auf, Goldoni doch zu beruhigen. "Savemo, che le Fiabe sulla scena / A un Poeta no basta a far onor; / Ma per sie zorni avemo fatto piena, / E nu femo l'onor, e el desonor. / Diseghe, che no l'abbia tanta pena, / Perché el palesa quel, che el ga in tel cuor, / E alfin el perderà cervello, e polpe, / Volendose sforzar a far da volpe. (Col. VIII, 143 ).

\section{Neue Allianzen}

Während Gozzi durch die Aufführung von L'amore delle tre melarance nun im Rampenlicht einer Öffentlichkeit stand, die weit größer war als diejenige, die sich für Sonette, Traktate, fingierte Briefe oder Kurzepen interessierte, bahnte sich hinter den Kulissen eine unerwartete Koalitionsbildung an. Verdankten La tartana, Le spose riacquistate und insbesondere L'amore delle tre melarance dem Antagonismus zwischen Goldoni und Chiari wesentliche Impulse, war bereits in der zweiten Nummer von Chiaris Gazzetta veneta ein Gedicht zu lesen, in dem die beiden Namen friedlich nebeneinander standen: "Gentil Goldoni, valoroso Chiari / E gli altri quanti siete tutti v'amo: / Deh! non mi siate in favorire avari / Che Fratelli ugualmente ognun vi chiamo. / Ch'io non cerco spiaceri, o sali amari / Nè l'un dell'altro disgustato io bramo a; unterzeichnet ist das Gedicht mit *Vostra Umiliss. Serva e cordiale Amica La Veneta Gazzetta $\alpha{ }^{4}{ }^{43}$ In der nächsten Nummer wurde Chiari deutlicher. Quasi als Anekdote wird über die brüderliche Versöhnung zwischen dem Abate Chiari und dem Dottor Goldoni berichtet und der Hintergrund beleuchtet. Das Ver-

42 Der erste Text, der nun bei P. Bosisio, Carlo Gozzi e Goldoni, op. cit., S. 206-208, abgedruckt ist, war als complimento der Sacchi-Truppe vorgesehen, wurde jedoch offensichtlich durch einen anderen Epilog ersetzt. Gozzi nimmt darin sowohl Bezug auf die zitierten Verse der Bresciani als auch zum wiederholten Male auf Goldonis Korrelation von Qualität und Publikumserfolg cines Stückes. -Sappiam, che delle Melarance i casi / Non fanno ad un Poeta grand'onore. / Ma se voi li godeste, persuasi, / Da voi nasce l'onore, e il disonore, / Or qui sarei per replicarvi quasi / De' novelli Molier il batticuore: / Le vostre care man sono un tesoro / Per far Poeti, e coronar d'alloro,-

4) La gazzetta veneta, Nr. 2, 11.2.176r. 
hältnis wird beschönigt, der Konkurrenzkampf heruntergespielt und das Verdienst der beiden Reformer gewürdigt. ${ }^{44}$ Auf einen kleinen Hinweis, daß die Konkurrenz jederzeit wieder aufflammen könne, folgt in einer für Chiari bezeichnenden Übertreibung die verschleierte Begründung für die überraschende Koalition der bisherigen Gegner: »Ne tempi famosi dell'ultimo Triunvirato Romano, in perfetta amistà riuniti, si videro Marco Antonio ed Augusto a solo fine d'opprimere un terzo, e di disfarsi di Lepido che contrario trovarono a loro disegni, ed indegno affatto d'essere loro competitore e rivale. « Unter dem Druck des Erfolgs von

4t La gazzetta veneta, Nr. 3, 18.2,1761. Da der Text schwer zugänglich ist, seien die relevanten Passagen hier vollständig wiedergegeben:

*Fra le novelle che allettar ponno i curiosi, ed interessare ancora le persone di spirito abbiasi il primo luogo quella, che corre da più giorni addietro, e somministrando ampla materia di piacevoli ragionamenti alle pubbliche, e private adunanze merita da me pure in questo luogo le mie riflessioni. I due Comici Poeti che da tanti anni addietro si dividono, e si contrastano infra di loro il favore di questa eruditissima Dominante, scordando improvvisamente l'emulazione antica, sono divenuti per modo amici, che si vedono passeggiar insieme le Pubbliche Piazze, seder insieme nelle Botteghe più frequentate, e visitarsi scambievolmente come se tra di loro passasse la più invecchiata amicizia. Un Fenomeno è questo per verità che si reputa più strano, e meraviglioso delle Comete. Tutti ne parlano, aleuni ne dubitano, pochi l'intendono, e non manca ancora chi faccia sopra di lui degli infausti presaggi, che quel Fenomeno appunto sarà egli sul nostro cielo di corta durata. Per quanto io nè giudico questa novella amicizia tra l'Abate Chiari, ed il Dottor Goldoni non può sembrare una meraviglia, se non agli occhi di coloro, che gli hanno sempre riputati nimici. Tra loro non è mai corsa a viva voce una parola sola che potesse dirsi una offesa. Non v'ha chi li abbia sentiti parlare l'uno dell'altro, se non in termini di moderazione, e di stima. Se nelle Commedie loro ebbe luogo sopra le Scene qualche censura, non oltrepassò questa i limiti dell'onesto, e persuasi entrambi del pari che il dare, e il ricevere vanno ordinariamente indivisi; al dare e al ricevere, si mostrarono meno sensibili, che al vedere non curato il nome loro, o male ricompensate le loro fatiche. [...] Quella che parea contrarietà e nimicizia, non era che emulazione lodevole, per aver più seguaci alle loro bandiere, per far più soldi ne' Teatri loro, e più romore nel Mondo. La novità d'un Poeta animoso, che la riforma tentava delle Scene Italiane decadute pur troppo dal Greco e Latino splendore antico, non fece da principio, che rivolgere in lui solo le maraviglie di tutti, quasi fosse meritamente un portento. Dalle meraviglie ne nacque I'Universale curiosità; e questa suol esser madre mai sempre del più raffinato sapere. Riscosse dalla meraviglia le menti più rozze, e dalla curiosità ravvivate, passarono d'un salto a riputarsi capaci d'ogni decisione piu malagevole. Non v'ha chi non ami l'opinione sua a segno di crederla indubitabile. [...] Quante contrarietà di pareri non doveano però risvegliarsi in una vasta Metropoli, comparendo sulle Scene un secondo Poeta novello, niente meno coraggioso del primo, che seco lui osava dividere la gloria della intrapresa riforma. Altri per contrarie disposizioni dell'animo, altri per diversità di gusto in materie Poetiche, ed altri finalmente per semplice voglia di contraddire, cominciarono a volersi distinguere col metter in dubbio le altrui decisioni. Ecco allora dividersi in due il partito quasi Universale d'un solo. Ecco da questi due partiti discordi nascer le gare, dalla gara l'altercazione, dall'altercazione il puntiglio, e dal puntiglio la presunzione assai cieca di voler ad ogni costo depresso il partito contrario e il partito suo vincitore.* 
L'amore delle tre melarance versucht Chiari, mit Goldoni gemeinsame Sache zu machen, um so des neuen Bühnenkonkurrenten besser Herr zu werden. Was jedoch zunächst wie eine Versöhnung erscheint und als solche in die Literaturgeschichte einging, entpuppt sich bei genauerem Hinsehen als Mythos. Zum einen konkurrieren Goldoni und Chiari auf der Bühne noch um $1760 / 61$ wie ehedem mit Stücken, die sich nun aus der griechischen Mythologie speisen und teilweise sogar dieselben Titel tragen. ${ }^{45}$ Zum anderen sind in einer im April 1761 , also wenige Wochen nach Erscheinen von Chiaris Versöhnungsartikel herausgegebenen raccolta*Anacreontica* der beiden Autoren enthalten, in denen zwar Chiari die Verbrüderung beschwört, der leise Spott Goldonis über Chiari jedoch unüberhörbar ist. ${ }^{46}$ Gozzi selbst scheint dem strategischen Zug Chiaris von vornherein keine Bedeutung beigemessen zu haben, jedenfalls bleibt eine explizite Reaktion aus.

\section{La Marfisa bizzarra}

Neben den kurzen, auf die aktuelle Situation bezogenen Texten entsteht in diesen Monaten ein satirisch-burleskes Epos mit dem Titel La Marfisa bizzarra, das jedoch erst im Rahmen der Colombani-Edition 1772 vollständig zur Veröffentlichung kommt. Im Vorwort, unter der selbstironischen Überschrift *Prefazione scritta tra 'l dubbio, che sia necessaria, e'l dubbio, che sia inconcludente «, erklärt Gozzi, daß zehn Gesänge

45 Die Serie der Aufführungen mythologischer Stücke beginnt im Herbst 1759 mit Chiaris Elena rapita, auf die in kurzen Abständen La rovina di Troja, Navigazione d'Enea dopo la rovina di Troja und Enea nel Lazio (Januar $176 \mathrm{1}$ ) folgen. Im Karneval 1760 prasentiert Goldoni Enea nel Lazio in unmittelbarer Konkurrenz zu Chiaris Navigazione d'Enea. Dieser rächt sich dafür, indem er in der folgenden Spielzeit ein Stück mit demselben Titel auf die Bühne bringt.

46. Die Festschrift erschien anläßlich der Einkleidung der Nobildonna Contarina Balbi bei Bettinelli in Venedig. Chiari deutet unter dem Motto -Tutto si cangia* auf die Versöhnung mit Goldoni hin und fährt unter Hinweis auf den sich ständig verändernden Publikumsgeschmack fort: -Il vol d'un Aquila / Non par fatica, / E il passo esaltasi / D'una formica / Senza riflettere / Qual sia miglior. // Al buono, e al meglio / Volti del paro / Sentiamo applaudersi / Dal Volgo ignaro / Quello, ehe costane / Meno sudor.* (XL1) * Oh dura, e misera / Sorte de Vati / Da instabil genio / Pur condennati / Che instabil abbiano / Stile, e pensier. - (XIII) Darauf antwortet Goldoni: >Ma deh perdonami / S'eguale al merto / L'onor non recoti / D'illustre Serto, / S'io non ti celebro / Vate immortal // Poichè la Critica / Tacciar potria / Che ad arte uniscaci / Scaltra Talia / Con vicendevole / Talento equal. a (XI.IV) =Si, Tu sei l'Aquila; / Io la Formica. / Tu voli all'apice / Senza fatica; / Mia Musa ai Cardini / Salir non sà // Prodigio sembrami / Piú d'una volta, / Che in me si tolleri / Natura incolta, / Ed è Giustizia, / Che a Te si $f_{a}=(X L V)$ 
des spoema faceto $\propto$ bereits aus dem Jahr $176 \mathrm{I}$ stammen, ${ }^{47}$ ihn jedoch das Gerede um die Marfisa und die Versuche, das Epos als "Schlüsselroman« zu lesen und die Modelle für die Figuren ausfindig zu machen, bewogen hätten, die Arbeit abzubrechen. Er legt dann jedoch offen, daß zwei Figuren des Epos tatsächlich satirische Portraits zeitgenössischer Autoren seien, streitet aber andere direkte Bezüge ab. "Paleserò, s'è necessario, che Marco, e Matteo dal Pian di San Michele, due Paladini, che si vedono dipinti nel Poema, rappresentano due scrittori, che in quella stagione s'erano dichiarati coll'alleanza d'alcuni altri scrittorelli, con soverchia animosità contro a' buoni scrittori antichi, e contro chi difendeva l'invulnerabile fama di quelli.« (Col. VII, i I). ${ }^{48}$ In den "Annotazioni $\propto$ zu La Marfisa bizzarra wird allerdings eine weitere Figur enthüllt, nämlich der Autor selbst: „Non si cela che sotto il nome del Paladino Dodone dalla Mazza è figurato l'autore, del poema della Marfisa a ${ }^{49}$ Dodon dalla Mazza, in Pulcis Morgante ein Begleiter Rinaldos, ist in Gozzis Epos einer der wenigen Aufrechten, die sich gegen den allgemeinen Sittenverfall stellen. In ausgesprochen selbstironischer Weise mehrfach "Dodone il Santo" ge-

47 -Dieci canti di questo libro furono da me seritti sette anni or saranno, vale a dire l'anno $1761 *$ (Col. VII, 10). Auszüge aus einigen Gesängen finden sich gedruckt schon in den 1761 erschienenen Fogli sopra alcune massime del genio e costume del secolo. Aus Gozzis Vorwort von $177^{2}$ ergibt sich, daß das Epos mit seinen zwölf Gesängen, der Widmung und dem Vorwort 1768 fertiggestellt war. Gozzi erläutert im Vorwort, daß es Parinis Mattino und Mezzogiomo waren, die ihn veranlaften, La Marfisa bizzarra wieder aufzunchmen und zu vollenden. -Due Poemetti usciti alla stampa da poco tempo in verso sciolto, l'uno intitolato, il Mattino, l'altro il Mezzogiorno, che mi lasciano con ingordigia desiderare La sera, risvegliarono in me la brama di dar fine all'imprigionata Marfisa bizzarra. « (Col. VII, 13).

Zur Entstehungsgeschichte und einer kritischen Edition des Textes s. Marta Vanore, -Per l'edizione critica de La Marfisa Bizzarra di Carlo Gozzi", in: Quaderni Veneti 39,2004, S. $29-63$.

48 1883 veroffentlichte G. B. Magrini in seiner Monographie I tempi, la vita e gli scritti di Carlo Gozzi, op. cit., erstmals ein Manuskript unter dem Titel - Annotazioni alla Marfisa bizzarras, in dem Gozzi offensichtlich nicht mehr verständliche Anspielungen klären wollte. Die Erlauterung zur ersten Strophe nennt denn auch die Namen Goldonis und Chiaris explizit: = Uno scopo, tra i molti altri dell'autore della Marfisa, Accademico Granellesco sotto il nome del Solitario, fu di prendere di mira i cattivi serittori, che in quella stagione in Venezia sviavano le menti dalla coltura, e particolarmente il Goldoni ed il Chiari, scrittori di commedie, di romanzi, di prose, e di poetiche composizioni in ogni genere e metro infelicissime. Si troveranno nel poema della Marfisa buon numero di squarci di censura e dileggio, diretti a' cattivi scrittori del tempo in cui fu composto; nè si nega che nel mezzo agl'infiniti caratteri presi in generale che campeggiano nel poema, sotto i due nomi de' Paladini Marco e Matteo dal pian di San Michele, sono figurati particolarmente il Chiari cil Goldoni, maggiori nimici arrabbiati degli Accademici Granelleschi accennati. (S.277).

Die Namen $>$ Marco e Matteo dal pian di san Michelea sind nicht von Gozzi erfunden, sondern aus Ariosts Orlando furioso (XVIII, 10) übernommen.

43 G. B. Magrini, I tempi, la vita e gli scritti di Carlo Gozzi, op. cit, S. 280. 
nannt, weiß dieser aber auch sehr wohl von den Querelen der anderen, den Mißständen und dem allgemeinen Chaos zu profitieren. Analog zu La tartana erschöpft sich La Marfisa bizzarra nicht in der literarischen Satire, sondern zeichnet ein satirisch-ironisches Bild der zeitgenössischen Gesellschaft insgesamt und nimmt einige auffällige Phänomene näher ins Visier. ${ }^{50}$ So sind es nicht die Attacken gegen den Literaturbetrieb der Zeit, die im Vordergrund stehen und den Tenor des Epos bestimmen, sondern die karikierende Darstellung der Paladine in ihren politischen und klerikalen Funktionen. ${ }^{51}$ In einer Vorbemerkung zu den *Annotazioni schreibt Gozzi, der Autor habe die Figuren Boiardos und Ariosts nur dazu gebraucht, "per coprire d'una veste allegorica un piccolo abbozzo del prospetto de' costumi, della morale de' giorni suoi e dei caratteri in generale de' suoi compatrioti, riformati da' scrittori perniziosi, e dalla scienza del nostro secolo detto illuminato. $\alpha^{52}$ Rinaldo wird zum Weiberheld, der gerne spielt, trinkt, Schnaps, Tabak und Wein schmuggelt, Astolfo ist nach neuer Art und Sitte Modeschöpfer in Paris und Erfinder des Cicisbeismo, Guottibuossi und Gualtiero werden, weil sie ein wenig Griechisch und Latein können, Priester, aber auch Kuppler, Bradamante, "la qual rimodernato avea il cervello $\alpha$ (Col. VII, 43), kämpft nicht mehr,

\$ Ein direkter Bezug zu La tartana ergibt sich durch eine Anspielung auf Arrighi Landini (Col. VII, 272-274). Offensichtlich hatte dieser auf die Angriffe in La tartana reagiert, was Gozzi zu einer kleinen Revanche veranlaßte.

31 Allein die Lektüre dieses satirisch-burlesken Epos müßte genūgen, um den Topos zu widerlegen, Gozzi als Adliger (Gozzi trägt zwar den Titel eines sconte der Terraferma, gehort jedoch nicht dem venezianischen Patriziat an, wie irrtum lich immer wieder behauptet wird; darauf weist schon Ernesto Masi in *Carlo Gozzi e le sue fiabe teatraliq, in: ders, Sulla storia del teatro italiano nel secolo XVIII, op. cit., S. 1-202, hier S. It, hin) habe den Adel gegen aufklärerisch inspirierte und insbesondere gegen Goldonis Angriffe verteidigt. Die Adelssatire in La Marfisa bizzarra wie in einigen Theaterstukken zeigt deutlich, daß Gozzi diese gesellschaftliche Gruppe keineswegs schonte. Vielmehr wird zu klaren sein, welche Form der Kritik er für angemessen bzw. unangemessen halt, wobei sich unter diesem Gesichtspunkt Gozzis Behandlung des Adels in nichts von der anderer Zielgruppen unterscheidet.

32 G. B. Magrini, I tempi, la vita e gli scritti di Carlo Gozzi, op. cit., S. 276.

Gozzi erwähnt hier nur Boiardo und Ariost, wenngleich auch Pulcis Morgante sowic andere Epen desselben Stoffkreises zu seinen Vorlagen zählten; siehe dazu G. Luciani, Carla Gozzi, op. cit., S. 1015-1017. Alberto Beniscelli weist in =Introduzione a Carlo Gozzi: La Marfisa bizzarma, tra pamphlet e teatros, in: La rassegna della letteratura italiana 83, 1979, S. 225-244, auf =una esplicita scelta saccademicace Gozzis hin, sper il solo fatto di cercare le soluzioni espressive dentro un materiale prefabbricato (S.231) und stellt weitgehende Úbereinstimmungen zwischen Bernis Rifacimento des Boiardoschen Orlando innamorato und Gozzis Marfisa fest, wobei er Gozzis Text einen pamphlethaften Charakter attestiert. Dabei bleibt allerdings unberücksichtigt, daßi sich Gozzi des vorgegebenen Materials - analog zu zahlreichen früher entstandenen Texten - vor allem in polemischer Absicht bedient, um die Traditionslosigkeit zeitgenōssischer Autoren bloßzustellen. 
sondern sorgt als Hausfrau für das tägliche Brot und spart eifrig im Hinblick auf die Zukunft der Kinder, Marfisa, die gerne Ballerina, Sängerin oder Schauspielerin geworden wäre, gibt ihr Geld mit vollen Händen für Kleider, Schmuck und Romanneuerscheinungen aus, wobei sie an den kapriziösen Charakter Clarices in L'amore delle tre melarance erinnert, Filinor ist ein durchtriebener Adliger und sfilosofo , Giulia di Scozia Dichterin, "Incolta con un po' di affettazione (Col. VII, I46). Allein Orlando behält Haltung und steht für die gute alte Zeit, »in ver manteneva il suo grado, / Ed i nuovi costumi biasimava (Col. VII, 38). Mittels dieses Figurenarsenals brandmarkt Gozzi die Verflechtung von Religion und Politik, Schmuggel und Geldschieberei, Hypokrisie und Spielsucht, Cicisbeismo und Modeversessenheit.

Wie in den meisten seiner polemischen Texte bedient sich Gozzi auch hier bedeutender Texte und Namen der literarischen Tradition, die er neu funktionalisiert. Die Verteidigung der *buoni scrittori antichi und ihrer winvulnerabile fama* besteht nicht in sklavischer Imitation und blinder Verteidigung, sondern in ihrer Aneignung in Form einer kreativen Rezeption wie in Fogli sopra alcune massime del genio e costume del secolo dell'abate Pietro Chiari e contro a' Poeti Nugnez de' nostri tempi deutlich zum Ausdruck kommt. ${ }^{53}$ Mit Hilfe der burlesk-satirischen Funktionalisierung des heroisch-komischen Epos zielt Gozzi auf die aktuelle soziale, politische und kulturelle Situation. ${ }^{54}$ Daher wäre eine eventuelle Kritik der Gelehrten an den Anachronismen in La Marfisa unangebracht,

53 Vgl. Kap. 1.4.

54 Wahrend das Komisch-Parodistische in Pulcis Morgante, Boiardos Orlando innamorato und Ariosts Orlando furioso, folgt man Klaus W. Hempfers Argumentation in seinem Artikel s Textkonstitution und Rezeption: Zum dominant komisch-parodistischen Charakter von Pulcis Morgante, Boiardos Orlando Innamorato und Ariosts Orlando Furioso*, in: Romanistisches Jabrbuch 27,1976, S. 77-99, auf die rhetorisch-poetische Tradition, Stil- und Gattungsaspckte zielt, literarische Normensysteme gegeneinander ausspielt und Strukturen parodiert, geht es Gozzi nicht um das Epos als Gattung. Vielmehr greift er die Form im polemischen Kontext auf und spielt mit der Diskrepanz zwischen traditioneller Idealität epischer Helden und Handlungsweisen und satirisch verzerrter Darstellung des gegenwartigen Lebens. Dabei dienen ihm, wie er - wiederum selbstironisch - schreibt, die sfatterelli cavati dal mio Turpino* als spretesti a porre in circostanze le Dame, i Cavalieri, l'arme, e gli amori, e dalla circostanza pullula quella satira sul costume, alla quale chiedo la benedizione dal Cielo.* (Col. VII, 14). Wenn Ulrich Schulz-Buschhaus in =Parinis Giomo und das Epos im Settecento*, in: Susanne Knaller; Edith Mara (Hgg.), Das Epos in der Romania, Tübingen, Narr 1986, S. 357372 , hier S. 361, bezüglich La Marfisa bizzarra von der nstrukturellen Problematik der asthetisch eher mißgluckten Schrift $\approx$ spricht, sin der sich Epos und Satire oft gegenseitig im Weg stehen*, so übergeht er die polemische Intention Gozzis, die darin besteht, den Verächtern der > buoni scrittori $\approx$ zu zeigen, daß die Beschäftigung mit vorgangiger Literatur direkt in die Gegenwart fuhren und aus vermeintlich verstaubten Texten eine beißende, überaus aktuelle Satire werden kann. 
wie Gozzi in der *Prefazione* vorbeugend betont, denn diese Anachronismen sind es gerade, die den komischen Kontrast unterstreichen. So trinken die Paladine Kaffee und Schokolade, geben Pamphlete in Druck und beten zu Heiligen, die erst geboren werden müssen. Als spoema giocoso [...] d'uno stile scopertamente famigliare (Col. VII, 14) führt es in besonders drastischer Weise die Diskrepanz zwischen ursprünglicher epischer Nobilität und nunmehriger Dekadenz vor Augen. Die Gründe für den allgemeinen Verfall nennt Turpin: "Ma la vera ragion, per quel, ch'io sento, / Della rivoluzion del secol nostro, / E il costume novel, l'ozio, gli amori, / E la vita epicuria, e gli scrittori.* (Col. VII, 246). Diese letzteren, die in Gestalt von Marco und Matteo auftreten, werden maßgeblich für den derzeitigen Zustand verantwortlich gemacht, denn ihre Leser und Zuschauer, denen sie in den Vorworten ihre Romane und Theaterstücke als nistruttivi, [...] filosofici, e vaghi per le Dame (Col. VII, I I 2) anpreisen, lernen folgerichtig für ihr eigenes Leben daraus und ahmen nach, was sie sehen und lesen. Auf diese Weise erfahren sie von Überfällen auf heilige Jungfrauen, von Mädchen in männlicher Verkleidung, sehen Türken mit einer Schar Frauen, die zu allem bereit sind, und Eunuchen, die die Sklavinnen mit Grobheiten delektieren, und nehmen dies alles als Lebensanleitung und Richtschnur für sich selbst. ${ }^{55}$ Welche Folgen diese wörtlich verstandene Nutzanwendung der Literatur oder ein oberflächlicher Literaturkonsum haben können, macht La Marfisa bizzarra in polemischer Zuspitzung überdeutlich: „I Paladini leggeano i frontispizj, / E qua, e là di volo sei parole, / Poi commetteano mille malefizj / Intuonando: Il tal libro così vuole. / Se v'era alcuno, ch'abborisse [sic] i vizj, / E dicesse: Non dessi, e non si puole; / Gridavan: Chi se' tu, c'hai tanto ardire, / I Paladini di Francia di smentire? $\approx(\mathrm{Col}, \mathrm{VII}, 23)$. Fatal ist, daß selbst Karl der Große der Anziehungskraft der neuen Literatur erliegt und so ein ausgesprochen schlechtes Beispiel gibt:

Chiari wie Goldoni machen immer wieder den Topos vom Theater als Schule geltend und weisen auf den Erziehungseffekt des Theaters bzw. des Romans hin; siehe dazu ausführlich Kap. 3.2. Diese utilitaristische Rechrfertigung von Literatur und Theater greift Gozzi polemisch auf und verzerrt sie ins Groteske wie etwa im to. Gesang, wo Marfisa auf der Suche nach Rezepten für ihre Flucht aus dem Kloster Chiaris Romane heranzicht. Nachdem das Modell aus La bella pellegrina versagt, holt sie sich Rat in La filosofessa italiana, was tatsachlich zum Erfolg führt, und auch ihre weitere - Lebensgeschichte verlauft ganz nach den Mustern der unwahrscheinlichen Begebenheiten und Peripetien in Chiaris Romanen, was Gozzi so kommentiert: - No che non v'è ne' romanzi del Chiari / Sorpresa a quella di Marfisa eguale. = (Col. VII, 333). Alle von Gozzi angeführten Beispiele fragwürdigen und eben nicht nachahmenswerten Verhaltens sind Theaterstúcken Goldonis und Romanen Chiaris entnommen, die meist explizit mit Titel genannt werden. 
Ma più di tutti dà cattivo esempio

A lasciar correr certe Commedie,

E certi Romanzacci, e il compor empio,

Carloman, presso al novissimo die,

Che con la bocca aperta, vecchio, e scempio

Ascolta, come fosser litanie,

Anzi le cose più nefande apprezza,

E poi travolge gli occhi di dolcezza.

(Col. VII, II $_{3}$ )

Die gegen den Literatur- und Theaterbetrieb gerichteten satirisch-polemischen Partien nehmen im gesamten Epos nur begrenzten Raum ein, während die $176 \mathrm{I}$ in Fogli sopra alcune massime del genio e costume del secolo vorab veröffentlichten Oktaven, wie in diesem Kontext nicht anders zu erwarten, den Akzent eindeutig auf die literarischen Aspekte legen. Mehr als in vorausgehenden Texten steht neben Goldoni Chiari hier im Blickfeld, wobei Gozzi seine Romane in den Vordergrund rückt, so daß sich für die Polemik zwei Zielscheiben bieten, das Theater (Matteo-Goldoni) und der Roman (Marco-Chiari). Auch die Flut schlechter bis mittelmäßiger Gedichte in den raccolte wird mit Spott bedacht, und Marco und Matteo trifft der Vorwurf, diese als Forum für Angriffe auf Dodone mißbraucht und über Vorsprachen an einflußreicher Stelle dessen öffentliche Antwort verhindert zu haben. Während Dodone darüber leicht hinweggehen kann, da auch er Verbündete hat, läßt er sich die Kritik an der literarischen Produktion Marcos und Matteos nicht nehmen: »Marco, e Matteo va tenendo nel dua, / E ride sempre della lor malizia, / Dicendo: Io vo' del bene a tuttidua, / E non intendo partir l'amicizia, / Ma dir sin che avrò fiato, e sarò morto, / Che nelle lor scritture hanno un gran torto. \& (Col. VII, 172). Wie in früheren Texten macht sich Gozzi über die literarische Massenproduktion lustig, die er auf die Finanznot der Autoren zurückführt, »s'eran dati alla poetic'arte, / Per guadagnarsi il vitto in qualche parte* (Col. VII, 35). Ein besonders krasses Beispiel ist Matteo, der dafür wirbt, seine s I-bändige Werkausgabe, die bald erscheinen soll, zu subskribieren und für jeden Band einen halben Scudo im voraus zu zahlen. »E vero, soggiugnea, che replicate / De' miei divini scritti l'edizioni, / [...] / Ma son poi tanto rare, e ricercate, / Che in bella carta, e buone correzioni, / $\mathrm{E}$ con figure in rame, indispensabili / Son per le biblioteche memorabili,« (Col. VII, 272). Dieses kommerzielle Denken ist Gozzi, ökonomische Zwänge des Literaturbetriebs hellsichtig durchschauend, zutiefst suspekt, da es in seinen Augen nur dazu führen kann, Gängiges, Publikumswirksames in möglichst großen Mengen zu produzieren. Gefährlich wird dies dann, wenn die Texte mit den Termini sistruttivo oder * filosofico « beworben werden, mit dieser Produktion 
also die Forderung nach Exemplarität verbunden ist. ${ }^{56} \mathrm{Um}$ den Publikumsgeschmack zu befriedigen, füllen Untreue, Verrat, familiäre Händel, kurz Trivialitäten des Alltags die Seiten, ${ }^{57}$ und trotz der meist guten Wendung zum Schluß steht das Negative im Vordergrund, das Leser oder Zuschauer weit mehr in Bann zieht als ein tugendreiches Ende. So widersprechen sich der postulierte didaktische Nützlichkeitsanspruch und die tatsächliche Wirkung, und die Literatur macht sich mitverantwortlich für bedenkliche gesellschaftliche Entwicklungen. In satirischer Prägnanz faßt Gozzi den Sachverhalt folgendermaßen zusammen:

lo non iscopro in questi nuovi fogli, $\mathrm{E}$ in queste farse, dette oggi esemplari,

Che debolezze, e mal condotti imbrogli, Caratteracci arditi, e truffe, e bari, E tradimenti a' Mariti, e alle Mogli; Poi sermon lunghi per porre i ripari, Ma il vizio alletta, e la predica stanca, Onde il mal cresce, e il buon costume manca.

(Col. VII, 39)

\section{Satire-Varianten}

Von der Publikation des ersten größeren Textes Gozzis 1757 bis zu $L a$ Marfisa bizzarra sind Chiari und Goldoni stets präsent, als Hauptfiguren, wie in La tartana als Saccheggio und Originale, in L'amore delle tre melarance als Fata Morgana und Celio Mago, in La Marfisa bizzarra als Marco e Matteo dal pian di San Michele, oder implizit über ihre Werke. Als exponierte Kontrahenten im venezianischen Literatur- und Theaterbetrieb stehen Chiari und Goldoni im Mittelpunkt der literarischen Öffentlichkeit der Stadt, so daß jeder Angriff auf sie fast zwangsläufig eine

56 Auch A. Beniscelli weist in "Introduzione a Carlo Gozziø, op. cit., S. 238-240, darauf hin, daß Gozzis Satire auf die smercificazione borghese della letteratura ziele, die die Schriftsteller, Rezipienten, Impresarï und Verleger in ein Verhältnis der scollaborazione-corruzione bringe. Gozzis Position ist allerdings nicht allein auf eine *moralità antica e immobilen zurückzuführen, sondern beruht auf der Aufdeckung des Widerspruchs zwischen angestrebtem Publikumserfolg, Mimesis-Konzeption und Nützlichkeitsaspekt in der Literatur; vgl. ausführlicher dazu Kap. 3.3.

37. Wie in L'amore delle tre melarance wird für solche trivialen Verirrungen Chiaris La madre tradita angefuhrt, in der ein Sohn seinen Vater bedroht, Goldonis Impresario delle Smirne wird als scuola lasciva = bezeichnet, in der man sla lussuria, i lazzi, ed il languire (Col. VII, 1 to) lernen könne, und Chiaris Roman La filosofessa italiana steht als Beispiel für unmoralisches Verhalten von Frauen, die, bereits schwanger, ahnungslose Herzöge ehelichen. 
Gegenreaktion zeitigt, und sei es aus publizistischen Gründen. Gozzis Polemik geht, wie gezeigt, mit wenigen Ausnahmen von konkreten Texten Goldonis oder Chiaris aus und macht deren Unhaltbarkeit direkt oder indirekt deutlich, indem sie Inkonsistenzen enthüllt oder auf Widersprüche zwischen argumentativen Begleittexten und literarischen Werken verweist. Die Angriffe zielen, wie Gozzi stereotyp beteuert, nicht auf die Person Goldonis oder Chiaris, sondern auf den Schriftsteller und seine Werke. Nicht umsonst nennt er sie immer wieder «amico $\propto$, bezeichnet sie aber im selben Atemzug als »peste della Poesia«, was zunächst höchst befremdlich und eher ironisch erscheinen mag, doch unterscheidet er damit zwischen persönlichem Bereich und offizieller Funktion der Person. ${ }^{58}$ Im Falle Chiaris und Goldonis ist es nicht wie bei Franceseo Griselinis Marito dissoluto ein spezielles Stück, eine Komödie, an der sich ein literarischer Streit entzündet, sondern es sind umfassendere Tendenzen der literarischen und theatralischen Entwicklung, die zur Debatte stehen. Nicht nur darin, sondern auch in der Form unterscheiden sich Gozzis polemische Texte wesentlich von denen der Griselini-Auseinandersetzung sowie denen seiner Kontrahenten.

Gozzi sieht sich in einer jahrhundertealten satirisch-burlesken Tradition, die mit den Namen Pulci, Burchiello, Berni und Ariost verbunden ist, und greift deren kleinere und größere Formen wie sonetto caudato, capitolo oder das heroisch-komische Epos auf, um sie mit aktuellen Inhalten zu füllen. Die kreative, spielerische Rezeption dieser Formen und die intertextuellen Bezüge sind nicht nur ein Hinweis auf die Entstehung von Texten aus Texten, sondern zugleich eine indirekte Polemik gegen die betonte Traditionslosigkeit der modernen Schriftsteller, den Wahrheitsanspruch, den sie für ihre Texte geltend machen, und die Beteue-

58 Das sonetto cardato hat Gozzi in den 8. Band der Colombani-Ausgabe aufgenommen (Col. VIII, 2 ro):

Dottore, e Abate, s'io v'ho travagliato nel poetico vostro lavorio,

Siete in error, se giudicate, ch'io $\checkmark$ 'habbia per odio, o invidia tanagliato.

Vi sono amico, e vi son sempre stato, Ognun di voi fratello è in Cristo, e mio, E v'abbraccio, e vi bacio, ma perdio Avete il secol guasto, e rovinato.

Però, s'io spargo alcuni miei sudori Per unguento alla rogna, che appiccate, Non ammettete il popolo a romori. Inventate, scrivete, diluviate, Procurate concorso, e protettori, Trombe, ed ombrelli alle follie, che fate. Farò inchin, sberrettate,

Predicherovvi santi per la via, Ma sempre peste della Poesia.

Wie in Kap. 1.3 ausgeführt, reagiert Gozzi auf die persönliche Satire Goldonis in La tavola rotonda in ahnlicher Weise in der Scrittura contestativa. Als persōnliche Satire können auch die auf physiognomische Eigenheiten zielenden Gedichte gewertet werden, in denen Gozzi jedoch oft sein eigenes verzerrtes Bild dem Goldonis kontrastiv gegenüberstellt, wie z. B. - "grasso* und -magheretto* (Col, VIII, 182). 
rung, zum Nutzen des Publikums die Realität auf der Bühne abzubilden. Während andere Literatur- oder Theatersatiren des I8. Jahrhunderts, von denen Pier Jacopo Martellos Verssatiren, Benedetto Marcellos Il teatro alla moda, Giulio Cesare Becellis I falsi letterati oder Parinis Terzinen „Il teatro zu den bekanntesten zählen, meist Einzelstücke sind, ist die Permanenz der Thematik und die Vielfalt der Formen bei Gozzi auffällig. Als bewege er sich auf einem Experimentierfeld der literarischen Auseinandersetzung, ergreift er immer neue Möglichkeiten, eine Öffentlichkeit literarisch und kulturell Interessierter anzusprechen.

Daß Gozzi sich mit Polemik und Satire unweigerlich dem Vorwurf aussetzte, aus Bosheit, Neid und Niedertracht zu schreiben, machen bereits die ersten Reaktionen Goldonis und Chiaris deutlich. In Chiaris Il genio e i costumi del secolo corrente ist diese Anschuldigung besonders virulent. Er verurteilt die anonyme Veröffentlichung von Texten und mutmaßt, "alcuni lo fanno per sola vergogna di comparire ignoranti o maledicenti«. Uberdies sei die Zahl der "libri criticati per invidia e per odio* weitaus größer als die der zu Recht kritisierten. In gewohnt selbstgefälliger Überheblichkeit stellt er klar, daß ihn dies jedoch nicht berühre: „Incapace, qual esser deve ogni uomo d'onore, d'invidiare la gloria altrui, mi consola, che sia invidiata la mia ${ }^{59}$ Im Artikel Riflessioni sopra la critica* attackiert er die Granelleschi, und damit vor allem Gozzi, in schärfster Weise, wirft ihnen vor, sich in den soli confini della gramatica [sic] * zu

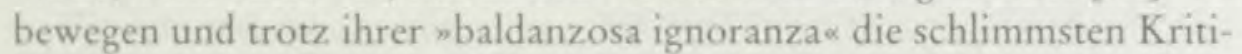
ker zu sein. Kaum hat er ihnen unterstellt, die Kritik falle dort am ungerechtesten aus, wo man kritisiere, was man selbst auch mache, beschuldigt er sie, nur zu kritisieren und selbst nichts zu produzieren. ${ }^{60}$ Der entscheidende Aspekt des Problems findet sich am Ende des langen $*$ Articolo $:$ * La Critica, e la Satira esser dovrebbero due nemiche implacabili, e sono oggidi divenute sorelle , doch eine Differenzierung zwischen Kritik und Satire bleibt aus. Vielmehr verwischt Chiari sogleich wieder den Unterschied, wenn er sich fragt, A fronte della Critica, e della Satira, torna gli puù conto di difendersi, o di tacere? $\alpha^{61} \mathrm{Daß}$ es Chiari hier nicht um die sich abzeichnenden Anfänge einer "modernen * Literaturkritik in den Gazetten und Journalen ging, sondern allein um eine Achtung der satirischen

39 P. Chiari, Il genio ed i costami del secolo corrente, op. cit., S. s und 9.

No s s critica divien maldicenza, ed invidia, quando si biasima negli altri ciò, che facciamo noi stessie, dagegen: =I poeti nascono Poeti, ed il criticare però le Opere loro non è cosi facile come sel fingono i soli Gramatici, che nulla scrivono mai, e pensano di poter ragionare di tutzo,* (ebd., S, 69, 70). Eine solch widersprüchliche, inkonsistente Argumentation charakterisiert einen großen Teil seiner Texte.

(4) Ebd., S. 71 . 
Invektiven Gozzis und der Granelleschi, ist unübersehbar. Wie allerdings eine Satire ohne Kritik aussehen könnte, darüber schweigt Chiari. Daß die Satire ein genuin kritisches Genre ist, dürfte auch ihm klar gewesen sein, die Frage ist jedoch, worauf sie zielt und in welche Form man sie kleidet. In den Fogli antwortet Gozzi direkt auf Chiari, indem er zum einen der sogenannten "satira insofferibile, der "maldicenza scellerata* die ssatira in generale de' costumi* gegenüberstellt (Fogli, 27), zum anderen Lucilius, Horaz, Juvenal, Boileau und Dante anführt, die die Tradition und Relevanz der Gattung belegen. In diesem Zusammenhang weist Gozzi immer wieder auf den Unterschied zwischen den "fangose e goffe satire " (Zan. XV, 8) der anderen und seinen eigenen hin, die er »scherzevoli oder »urbanamente satirici, faceti, e ragionevoli« (Col. VIII, 258 ) nennt. ${ }^{62} \mathrm{Im}$ Gegensatz zur plumpen Diskreditierung der ersteren steht die »satira urbana « unter einer "humanen Verpflichtung « und verlangt in Anlehnung an Quintilian Bildung und Überlegenheit, die sich nicht am Unglück anderer laben.$^{63}$ So verstanden, ist die Satire nicht Verunglimpfung der Kontrahenten, sondern indirektes Aufzeigen von bedenklichen

62 In Discorso, notizie, verita, e riflessi (Col. VIII, 258) nimmt Gozzi Goldonis und Chiaris Argument, jede Kritik habe wenigstens den Vorteil, den Kritisierten als kritisierenswert auszuzeichnen, halb ironisch, halb ernsthaft auf und verweist auf die lange Geschichte literarischer Kontroversen, die eine ganz andere Qualität aufweisen, als die zeitgenössischen Kritiken sie zu erreichen vermögen.

-Il pubblicar de' Sonetti urbanamente satirici, faceti, e ragionevoli, non fa, che far noto, che quella persona, contro alla quale sono scritti, fu un ingegno, che ha meritato l'occupazione d'un'altro ingegno.

Se i Sonetti satirici a stampa di Matteo Franco contro Luigi Pulci, del Pulci contro al Franco, di Alfonso de' Pazzi contro Benedetto Varchi, di Annibal Caro contro Lodovico Castelvetro, e di tanti altri scrittori, non scemano già la fama, ma la ristabiliscono tanto agli agenti, quanto a' pazienti, il Signor Goldoni, da me lodato in quanto è dovere, e i suoi partigiani, non dovranno accusarmi per quella picciola porzione di satirette scherzevoli, ch'io pubblico in vantaggio dell'immortalità del nostro nazionale.

$\mathrm{O}$ le mie satirette hanno qualche merito di colto linguaggio, di grazia, d'eleganza, di facilità, e di sali, o non hanno nessun merito. Se l'hanno, giovano all'immortalità dell'oggetto, che comprendono; se non l'hanno, cadono nell'obblivione, come i goffi, sgraziati, e ignoranti ragli tanto di biasmo, quanto di lode, de' Foglivolantisti, e Giornalisti odierni dell'Adria, e non fanno nè bene nè male,

6) Siehe dazu ausführlich Gert Ueding, „Rhetorik des Lächerlichen«, in: Lothar Fietz; Joerg O. Fichte; Hans-Werner Ludwig (Hgg.), Semiotik, Rhetorik und Soziologie des Lachens. Vergleichende Studien zum Funktionswandel des Lachens vom Mittelalter zur Gegenwart, Tübingen, Niemeyer 1996, S. 21-36, hier v.a. S. 30-31.

Wie nah sich Gozzi an Quintilians Argumentation in der Institutio oratoria hält, wird auch deutlich, wenn man seine Kontrastierung von aufgeregter Reaktion der ChiariAnhänger und den sanften, milden Affekten der anderen in Betracht zieht, sowie seine ausdrückliche Betonung, daß La tartana zwar auch gegen Schriftsteller gerichtet sei, aber dies nur auf ein paar Seiten, "[che] non biasimano però la loro nascita, le loro azioni, i loro costumia (Fogli, S, 27). 
Entwicklungen und Mißständen. Die literarisch sanktionierte Form der urbanen Satire ermōglicht in Gozzis Augen scharfe Zeitkritik ohne zu verletzen - eine Position, die zur festen Topik »metasatirischer Rede gehört und auf die Legitimation aggressiven Schreibens zielt. ${ }^{64}$ In diesem Sinne legitim versteht Gozzi seine direkte Polemik, die von La tartana bis zu L'amore delle tre melarance reicht.

Nach vier Jahren satirisch-polemischen Engagements in einer facettenreichen Vielzahl an Textformen führte Gozzi die Kontroverse auf der Bühne fort, wo sie an Raffinesse und angesichts des Stellenwertes des Theaters in der venezianischen Gesellschaft an Relevanz gewann. Indem Gozzi nun Stücke schrieb, wurde er zum direkten Konkurrenten der Kontrahenten Chiari und Goldoni - jedoch nicht durch Imitation und Plagiat, sondern durch ein Theater, das bewußt und provozierend andersartig ist. In polemischer Intention ist das erste Stück als $»$ commedia a soggetto in der Tradition des Improvisationstheaters konzipiert, räumt den Masken wesentliche Partien ein, trägt einen Märchentitel und ist geprägt durch Übertreibung, Parodie und Polarisierung. Selbstironische Einwürfe in der Analisi riflessiva weisen auf das Spielerische der Kritik hin, das im wörtlichen Sinne vorgeführt wird. Auf Vergnügen, nicht Belehrung, auf spielerische Enthüllung der Mängel und Probleme, nicht auf gelehrte Demonstration zielt L'amore delle tre melarance, so daß der wohl kalkulierte Publikumserfolg nicht auf sich warten ließ.65

Wenn Gozzi die zwischen 1757 und 1761 entstandenen Texte im Nachhinein als "gradini $\propto$ bezeichnet, $\nsim$ che mi condussero a ordire de' capricci scenici $\alpha$ (Mem. I, 228), unterstreicht dies, daß die erste Fiaba teatrale Kontinuität und Höhepunkt zugleich darstellt, denn die Polemik erscheint hier in einer Form, die in die Zukunft weist. Implizierte bereits bisher der Rückgriff Gozzis auf tradierte literarische Formen eine allgemeine Kritik an der demonstrativen Abwendung und Verleugnung der zeitgenössischen »modernen* Autoren von Vorgängigem, stellt Gozzi nun in Zusammenarbeit mit Sacchi ein Stück auf die Bühne, das nicht nur in provokanter Weise Altbekanntes, dem Zeitgeist Verdächtiges wie

it S. dazu Christoph Deupmanns grundlegende Studie Furor satincusc, Verhandlangen über literarische Aggression im 17. und 18. Jahrbundert, Tübingen, Niemeyer 2002, die den Zusammenhängen von Aggressionstabu und Legitimationsmodellen in den Bereichen Jura, Medizin, Didaktik, Psychologie, Theologie und vor allem in der Literatur nachgeht.

is In seinen Memoiren berichtet Gozzi: - La novita d'una tal fola inaspettata, ridotta ad azione teatrale, che non lasciava d'essere una parodia arditissima sull opere del Goldoni e del Chiari, né vuota di senso allegorico, ha cagionata un'allegra rivoluzione strepitosa $e$ una diversione cosi grande nel pubblico, che i due poeti videro come in uno specthio la lor decenza.* (Mem. I, 231). 
Märchen und Commedia dell'arte präsentiert, sondern die Anstrengungen der selbsternannten riformatori $\propto$ des Theaters bewußt und offensichtlich konterkariert. Das polemische Potential der woriginale stravaganza scenica" (Mem. I, 231) liegt demnach sowohl im Inhalt als auch in Struktur und Form. Der erfolgreiche Entwurf der Fiaba teatrale L'amore delle tre melarance markiert den Übergang von der direkten, dialogisch geführten Auseinandersetzung mit Chiari und Goldoni zu einer indirekten, in der Material, Form und Struktur zu den entscheidenden Trägern der polemischen Intentionen werden und sich die Fiaba teatrale als neue Gattung etabliert.

\subsection{Die Fiaba teatrale - Konstitution einer neuen dramatischen Gattung}

Innerhalb von fünf Jahren, zwischen 1761 und 1765 , entstehen weitere neun Märchenstücke, in denen Gozzi mit der bereits für L'amore delle tre melarance konstitutiven Form experimentiert. In diesem Zeitraum tritt die offene, textgebundene Auseinandersetzung mit Goldoni und Chiari mehr und mehr in den Hintergrund. Auf die Effektivität und unmittelbare Wirkung des Theaters sowie die Wandlungsfähigkeit des Publikumsgeschmacks setzend, stellt Gozzi dem Repertoire der Theater San Luca und Sant'Angelo, an denen Goldoni respektive Chiari als Theaterschriftsteller verpflichtet waren, eine Reihe von Aufführungen entgegen, die den Erfolg des ersten Stücks fortschreiben und eine Verschiebung des Publikumsinteresses zugunsten der Fiabe teatrali bewirken. ${ }^{66}$ Daß Gozzi seine Stücke im Gegensatz zu Goldoni und Chiari erst ein Jahrzehnt nach der Entstehung in der Gesamtausgabe von $1772-74$ veröffentlicht und sich damit der Möglichkeit beraubt, in Vorworten und Begleittexten die neue Gattung zu erklären, abzugrenzen und zu verteidigen, unterstreicht nicht nur das Vertrauen in die Überzeugungskraft der Darstellung auf der Bühne, sondern auch den zunächst eher akzidentellen Charakter seiner Theaterproduktion. ${ }^{6}$ ?

66 Nach dem Publikumsschwund, den Goldoni beispielsweise bei der Villeggiatura-Trilogie im Herbst 1761 hinnehmen mußte, kam Sior Todero Brontolon im Januar 1762 auf to Aufführungen, Le baruffe chiozzotte auf 9 . Gozzis zur selben Zeit aufgeführte Fiabe teatrali $I l$ corvo und $I l$ re cervo erreichten jeweils 16 Aufführungen, wobei letzteres Stück in direkter Konkurrenz zu Sior Todero Brontolon stand. Dagegen wurde Turandot, ebenfalls im Januar 1762 uraufgeführt, nur 7 Mal gespielt.

67 Als L'amore delle tre melarance zum ersten Mal aufgeführt wurde, war Gozzi bereits 40 Jahre alt. 
Generell unterscheiden sich, wie angedeutet, die folgenden Fiabe teatrali von der ersten durch die Reduktion des polemischen Elements. Wenn sich Gozzi auch zugute hält, in seiner scherzhaften Parodie auf die maßgeblichen Komödienautoren der Zeit keine Namen zu nennen, ${ }^{68}$ so war doch für das Publikum offensichtlich, gegen wen sich die Attacke richtete. Der allmähliche Verzicht auf eine direkte, an konkreten Einzelaspekten orientierte Polemik und auf die turbulente Vorführung lächerlich-grotesker Figuren, Situationen und Handlungen lenkt die Aufmerksamkeit auf die verbleibenden Konstituenten, das Märchen und die Commedia dell'arte sowie auf ihr Zusammenspiel. Deutlich ist eine zunehmende Konturierung dieser Grundkomponenten zu erkennen, die in unmittelbarem Zusammenhang mit der Klärung ihres Verhältnisses untereinander steht.

Gozzi selbst nimmt in einem späten, von ihm auf den 20. April 1801 datierten Text mit dem Titel La più lunga lettera di risposta che sia stata scritta, inviata da Carlo Gozzi ad un Poeta teatrale italiano de' nostri giorni eine Charakterisierung und Gruppierung der Fiabe teatrali vor, die drei maßgebliche Spielarten erkennen läßt. ${ }^{69}$ Demnach zeichnen sich L'amore delle tre melarance und die beiden unmittelbar folgenden Stücke $I l$ corvo ( $176 \mathrm{r}$ ) und $I l$ re cervo $(1762)$ durch $\times$ alcune maraviglie magiche di trasformazioni a aus, woraufhin Gozzi mit Turandot (1762) und später mit I pitocchi fortunati (1764) zwei Stücke schreibt, die angeblich ganz ohne Wunder und Verwandlungen auskommen und ihren Erfolg - laut Kritikern - allein den vier Masken verdanken. Dagegen sind es in La donna serpente (1762), La Zobeide (1763), Il mostro turchino (1764), L'augellino belverde $(1765)$ und Zeim, Re dei genj $(1765)^{70}$ nicht allein die Maskenfiguren, die das Publikum faszinieren, sondern mindestens eben so sehr die aufwendige Ausstattung. Die Relation von Märchenelementen und Masken steht also im Vordergrund der Klassifizierung. Nun ist freilich

6. Dies geht aus La paù lunga lettera che sza stata scritta [...] hervor, wo er von L'amore delle tre melarance als *una mia poetica scherzevole pittura allegorica di que' due Scrittori dominatori, e senza però nominarliк spricht (Zan. XIV, 95).

69 Vgl. La più lunga lettera, Zan. XIV, 32-34.

Die Einteilung beruht laut Gozzi auf Vorwürfen von Kritikern, die den Publikumserfolg der Fiabe teatrali einmal dem Marchenhaften und den Metamorphosen, cin andermal den Masken zuschrieben und die Stücke damit diskreditieren wollten; dem trat Gozzi mit jeweils neuen Varianten entgegen, die zeigen sollten, daß es weder allein das Marchenhafte noch allein die Masken waren, die das Publikum anzogen.

70 In La pix lunga lettera verwendet Gozzi diesen Titel, der der Zanardi-Ausgabe entspricht, während das Stück in der Colombani-Edition II re de' genj heißt; identisch ist bei beiden Ausgaben der Zusatz no sia / ossia La serva fedele-, wobei dieser zweigliedrige Titel in seinem ersten Teil das Märchenhafte akzentuiert, während der zweite ein typischer Komodien- oder Librettotitel ist. 
zu bedenken, daß es sich bei »Märchen $\star$ und *Masken « um zwei ganz unterschiedliche Begrifflichkeiten handelt. Ist das Märchen eine ×Erzähl-

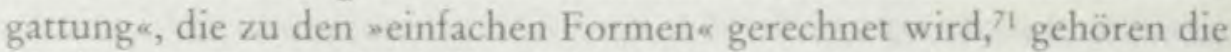
Masken zur Commedia dell'arte, die keineswegs eine literarische Gattung, sondern eine spezifische szenische Aufführungsform darstellt. ${ }^{2}$ So ist zunächst zu fragen, in welcher Weise diese Komponenten in den Fiabe teatrali nach L'amore delle tre melarance auftreten und wie sie kombiniert und funktionalisiert werden. Unter hauptsächlicher Bezugnahme auf $I l$ corvo und $I l$ re cervo sollen im folgenden die strukturellen Aspekte der neuen Gattung aufgezeigt werden.

Während die erste Fiaba teatrale nur in Form eines $»$ kritischen Berichts* über die Aufführung vorliegt, sind alle folgenden Stücke dialogisch ausformuliert - mit Ausnahme weniger improvisierter Passagen der Masken, die zwar den Inhalt des Monologs oder Dialogs vorgeben, die sprachliche Gestaltung jedoch den Schauspielern überlassen. Die dramaturgischen Strukturen zeichnen sich in diesen vollständig ausgeschriebenen Texten naturgemäß deutlicher $\mathrm{ab}$ als in der stark auktorial gefärbten Nacherzählung von L'amore delle tre melarance. Mit Il corvo und Il re cervo treten die Charakteristika der Fiaba teatrale klar zutage, so daß am Beispiel dieser beiden ersten dramatischen Texte Gozzis die wesentlichen strukturellen Züge der neuen Gattung exemplarisch sichtbar werden. Zudem existieren sowohl für $I l$ corvo als auch für $I l$ re cervo Vorstufen des publizierten Textes, die es im Falle von Il corvo erlauben, den Prozeß von einem ersten narrativen Entwurf bis zum endgüligen dramatischen Text nachzuvollziehen, im Falle von $I l$ re cervo, verschiedene Fassungen des dramatischen Textes zu vergleichen ${ }^{73}$ und damit wichtige Aspekte der endgültigen Form zu erkennen.

$7 \mathrm{Vgl}$. M. Lüthi, Märchen, op. cit., S. 1, und André Jolles, Einfacbe Formen. Legende, Sage, Mythe, Rätsel, Spruch, Kasus, Memorabile, Märchen, Witz, 6. Aufl., Tubingen, Niemeyer 1982 .

72 Siche unten Kap, 2.5.

73 Die Autographe liegen in der Biblioteca Nazionale Marciana in Venedig in zwei Kodizes, die zum einen eine narrative Fassung, in der Terminologie der Commedia dell'arteTradition ossatura genannt, sowie zwei dramatische Vorläuferversionen von II corvo, zum anderen zwei recht unterschiedliche dramatische Entwürfe von $I l$ re cervo enthalten. Beide wurden erstaunlich spät, nämlich erst in den letzten Jahren, teilweise bzw, vollständig publiziert und ausgewertet. Des weiteren befinden sich seit 1932 vier Kodizes in Venedig, die weitgehend den ersten vier Banden der Colombani-Edition entsprechen. Seit Herbst 2006 ist der umfangreiche $*$ Fondo Gozzi- der Offentlichkeit zugänglich.

Im Gegensatz zu einem canovaccio diente die erhaltene narrative Fassung von $I l$ corvo nie als Spielvorlage, sondern quasi als bereits in Akte und Szenen gegliederte Inhaltsangabe und architektonische Basis für eine schriftliche dramatische Ausarbeitung. Zum Problem der Terminologie und den zahlreichen terminologischen Irrtumern bezüglich 


\section{Die dramaturgische Modellierung von Märchen und Masken als Kontrast}

Wie L'amore delle tre melarance basiert auch $I l$ corvo auf einem Märchen, das sich in Basiles Lo cunto de li cunti findet. ${ }^{74}$ Auf ihm beruht das Handlungsgerüst des Stücks, jedoch enthält bereits die ossatura als Handlungsentwurf, der die Grundlage für eine spätere Ausarbeitung bildet, bedeutende Veränderungen, die das dramatische Element des narrativen Textes verstärken. Gozzis Entwurf setzt bei der Schiffslandung Jennaros mit Angela in Frattombrosa ein und reicht die lange Vorgeschichte in einem Dialog zwischen diesen beiden Figuren nach: Jennaro erklärt der unglücklichen Angela, Prinzessin von Damaskus, daß er sie seinem Bruder Millo, dem König von Frattombrosa, zuliebe entführt habe, der sich, seit er einen

der vorliegenden autographen Texte siehe den wegweisenden Artikel von Laura Ricco. -Goldoni, Chiari, Gozzi fra scritto e non scritto*, in: Problemi di critica goldoniana VI, Ravenna, Longo t999, S. 7-67, hier v. a. S. 18-23, jetzt in: Laura Riccò, Parebbe un romanzor. Polemiche editoriali e linguaggi teatrali ai tempi di Goldoni, Chiar, Gozzi, Roma, Bulzoni 2000, S. 147-215; dort findet sich im Anhang auch die ossatura von Il corvo, S. $272-284$, die erstmals 1957 von Jean-Michel Massa unter dem Titel -Un canevas inèdit de Carlo Gozzic in: Revue des études italiennes 4, 1957, S. 219-229, verôffentlichr wurde; ein zweites Mal erschien der Entwurf in Elvira Garbero Zorzi, -Intorno ai manoscritti di Carlo Gozzi-, in: Chigtana 31, 1976, S. 233-246. Erst A. Beniscelli nahm im 4. Kapitel seines Buches La finzione del frabesco, op. cit., eine Interpretation der verschicdenen Fassungen vor. In =Gli autografi di Re Cervo*, in: $A C M E$, Annali della Facoltà di lettere e Filosofia dell'Università deggli Studi di Milano, 36, 1, 1983, S. 61-146, legt. P. Bosisio die Erstfassungen von $I l$ re cervo vor und vergleicht sie.

24 -Il corvos ist das 9. Marchen des 4. Tages in Giambattista Basiles Lo cunto de li cunti. Hg, Michele Rak, Milano, Garzanti 1986, S, $814-835$. Warum Gozzi gerade dieses Märchen gewahlt hat, wird nirgends thematisiert. Es gibt jedoch wie im Falle der Wahl der Namen des Teufels Farfarello und des Dämons Draghi(g)nazzo in L'amore delle tre melarance cinen Hinweis im Prätext. Wie der 21. Gesang von Dantes Inferno weist auch das Märchen - Il corvo- einen Bezug zu Venedig auf. Als Iennariello auszieht, um für seinen Bruder die ersehnte Frau zu suchen, heiBt es: oE, fatta subito armare una grande nave piena di mercanzie, vestito da mercante salpò alla volta di Venezia, specchio dell'Tralia, casa di uomini virtuosi, libro mastro delle meraviglie dell' Arte e della Natura, dove si fece dare un salvacondotto per passare a Levante e fece vela alla volta

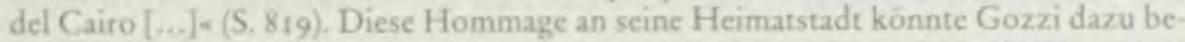
wogen haben, sich gerade für =Il corvo* zu entscheiden und zu sehen, ob einer seiner Zeitgenossen das intertextuelle Spicl durchschaute.

Möglicherweise geht auch II corvo wie Liamore delle rre melarance auf die mundliche Tradition des Marchens zurück. Darauf weist Edoardo Sanguineti in =La donna serpente come fiaba <, in: Carlo Gozzi, La donna serpente, Genova, Edizioni del Teatro di Genova 1979, 5. 13-24, hier S. 22, unter Bezugnahme auf eine unveröffentlichte Arbeit Pasquale Mottoleses hin. Gozzi selbst allerdings bezicht sich im Vorwort zu II corvo auf Basile: * Tal fola si narra a' fanciulli, ed io ho tratto l'argomento di questa da un libro Napoletano, intitolato; Lo cunto delle cunte: trattenemiento per le piccierille [sic]. (Col. 1, 1 18). Bis heute liegt keine weitere Untersuchung zu diesem Problem vor. 
frisch getöteten Raben auf einem Marmorstein gesehen habe, nach einer Frau mit weißer Haut, roten Lippen und tiefschwarzem Haar verzehre und darüber melancholisch geworden sei. Angela zeigt Verständnis, rügt jedoch Jennaros Listanwendung und kündigt die Rache ihres Vaters, des mächtigen Zauberers Norando, an. Tatsächlich wird Jennaro wenig später prophezeit, daß die für seinen Bruder vorgesehenen Geschenke, ein Falke und ein Roß, diesem Unglück brächten und, liege Millo bei Angela, beide von einem Drachen verschlungen würden. Übergebe Jennaro die Geschenke jedoch nicht oder offenbare er das Geheimnis, solle Jennaro selbst zu Marmor werden.

\section{Märchenhandlung und Märchenfiguren}

Gozzis Umstellung und Umgewichtung der Vorgeschichte und der Ereignisse, die sich in Frattombrosa abspielen, zeigen die sichere Hand des Theaterautors, der sowohl die Handlung auf den unlösbaren inneren Konflikt Jennaros zwischen seinem Wissen um die Verwünschungen und der verzweifelten Bemühung, diese zu vereiteln zuspitzt, als auch spektakuläre Szenen, in denen ein Falke, ein Pferd und ein Drache auf der Bühne erscheinen, in den Mittelpunkt rückt. Daß Jennaro den Falken und das Roß tötet, kaum hat Millo sie in der Hand, und in der ersten Nacht mit einem Schwert in Millos Schlafgemach entdeckt wird, muß am Hof höchstes Mißtrauen wecken, doch kann Jennaro, daraufhin von seinem Bruder zum Tod verurteilt, selbst dann nicht sprechen, will er nicht zur Marmorstatue werden. Auch das Ende verdichtet Gozzi bereits in der ossatura. So vergeht bei Basile ein Jahr, nachdem sich Iennariello zuguterletzt doch noch entschlossen hat zu reden und folglich zu Marmor wird, bis der Vater Liviellas ${ }^{75}$ (in Gozzis ossatura Angela, in den dramatischen Entwürfen bis zum endgültigen Text Armilla) Jennariellos Rückverwandlung in Aussicht stellt, unter der Bedingung, die beiden Zwillingssöhne Liviellas und Milluccios zu opfern. Dagegen ist es bei Gozzi Angelas eigenes Blut, das die Statue wieder zum Leben erwecken kann. ${ }^{76}$ Damit rafft

75 A. Beniscelli spricht in La finzione del fiabesco, op. cit., S. 76 ff., von $*$ Luciella 4 , meint jedoch Liviella. Auch nennt er versehentlich den Zauberer in II re cervo, der ursprünglich Guzarat(t)e hieß (vgl. P. Bosisio, Gli autografi «, op. cit.), >Durindarte «, während er korrekt $\gg$ Durandarte $*$ geschrieben wird.

76. Am Ende des 2. Aktes det ossatura findet sich noch ein Relikt aus der Märchenfassung. wenn Gozzi anmerkt: "Angela sia una giovane vedova ch'abia [sic] un figlioletto d'anni tre e questo serva per restituire la statua in uomo. * (E. Garbero Zorzi, op. cit., S. 242.). In Akt IV, Szene s desselben Textes ist es dann jedoch Angela, die sich selbst für Jennano opfert. 
Gozzi die Handlung nicht nur zeitlich, sondern er verzichtet auch auf zwei Figuren, die Kinder, die zum einen dramaturgisch nicht notwendig sind und deren Opferung zum anderen den Publikumsgeschmack auf eine harte Probe stellen würde. ${ }^{77}$ Gozzis Corvo folgt weitgehend dem Märchen, was die Hauptfiguren, den Handlungsgang, den Handlungsort und märchenhafte Mechanismen wie das durch das Farbenspiel des blutenden Raben auf dem weißen Stein geweckte Verlangen nach einer schönen Frau, die dreifache Prophezeiung verbunden mit dem Schweigegebot und die Metamorphosen betrifft. Allerdings konzentriert Gozzi das Geschehen auf seine handlungsintensiven, bühnenwirksamen Momente und erreicht so nebenbei, und ganz im Gegensatz zu L'amore delle tre melarance, die Einhaltung der Einheiten von Zeit und Ort. $I /$ corvo ist jedoch nicht nur ein für die Bühne eingerichtetes Märchen, vielmehr nimmt Gozzi Veränderungen vor, die signifikant sind für die neue Gattung der Fiaba teatrale. Bereits vom Märchen zur ossatura lassen sich Abweichungen erkennen, die dann in konsequenter Weise weitergeführt werden bis zum endgültigen Theatertext. Dabei betrifft die Umgestaltung zum einen märcheninterne Komponenten, zum anderen werden märchenfremde Elemente neu eingeführt.

Innerhalb des Märchenkontexts greift Gozzi am deutlichsten bei der Figur des Zauberers ein. Dieser trägt im Märchen keinen Namen, wird nur als ngran vecchione bezeichnet, und tritt erst ganz am Ende als Helfer auf, als Jennaro von seinem steinernen Dasein erlöst werden soll. Gozzi dagegen gibt ihm nicht nur einen Namen, zuerst Celio, dann Norando (wohl um keine Zweifel am Unterschied zu Celio alias Goldoni in L'amore delle tre melarance aufkommen zu lassen), sondern er steigert auch seine Präsenz von Entwurf zu Entwurf. Ist es - im Gegensatz zum Märchen, in dem ein Taubenpaar Jennaro das Schreckliche verkündet - in der ossatura Celio selbst, der den Fluch ausspricht, der auf dem Falken, dem Pferd und der Hochzeitsnacht liegt und Jennaro zugleich das Redeverbot erteilt, greift Gozzi in den Dramatisierungen auf das Märchenmotiv zurück, behält jedoch den Auftritt Norandos bei und doppelt so das Märchenhafte: zunächst erscheinen die Tauben, Botinnen Norandos, als Künderinnen des bevorstehenden Unglücks, dann taucht Norando selbst auf einem Meeresungetüm auf - nicht in der nichtssagenden Gestalt eines Greises, sondern als *vecchio venerabile, e fiero in vista, con vesti ricche all'Orientale $\propto(I, 7)$. Nachdem Jennaro am Ende des 2. Aktes dem Bruder

Was Gozzi offensichtlich in der zweiten Fiaba teatrale noch nicht wagt, mutet er ein Jahr später den Zuschauern in La donna serpente zu, wenn die Kinder Rezia und Bedredino ins Feuer geworfen werden. 
die Geschenke überreicht, jedoch, um das drohende Unheil zu verhindern, den Falken sogleich getötet und dem Pferd die Beine abgehauen hat, taucht im 3. Akt Norando auf, um sich über diese Brutalitäten Jennaros zu beklagen. Im 4. Akt ruft Jennaro selbst Norando, um sich in selbstloser Bruderliebe zu vergewissern, daß seine Versteinerung wenigstens für Millo ein Ende des Elends mit sich bringe. Norando aber bleibt unerbittlich bis zum letzten Akt. Als Millo trauernd vor Jennaros Marmorstatue steht, gibt Norando sich jenem zu erkennen und teilt ihm mit, daß das Blut Armillas, wie Angela bereits im ersten dialogischen Entwurf heißt, Jennaro ins Leben zurückrufen könne. In den beiden Schlußszenen steht Norando ganz im Mittelpunkt: durch seine Macht verwandelt sich nicht nur Jennaro; auch Armilla, seine Tochter, die sich für Jennaro geopfert hat, erweckt Norando, nachdem sich alle Prophezeiungen erfüllt haben, wieder zum Leben, und am Ende verzeiht er Armilla, Jennaro und Millo großmütig.

Aufgrund dieser Veränderungen taucht die Gestalt des Zauberers an allen entscheidenden Punkten der Handlung auf, und es besteht kein Zweifel, daß sie es ist, die das Geschehen wesentlich bestimmt. Auf Meeresungetümen oder durch die Wände betritt sie die Bühne, ihrer ständigen unsichtbaren Präsenz ist sich vor allem Jennaro sicher, $\gg \mathrm{Ma}$ tu, Norando, / Crudel Norando, che invisibil certo / Mi sei d'intorno* (IV, 5). Norando ist es, der den Meeressturm entfachte, in dem das Schiff Jennaros mit Armilla fast untergegangen wäre, er ist es, der Jennaro den prächtigen Falken und das schöne Pferd als todbringende Geschenke für den Bruder zuführte, er gebietet über zwei sprechende Tauben, reitet ein Meerestier und schickt den Drachen. In seiner Macht steht es, Jennaro in eine Statue zu verwandeln und ihn sowie die tote Armilla wieder ins Leben zurückzurufen. Die Märchenfigur des Zauberers rückt in Il corvo weit in den Vordergrund, versehen mit ihren typischen Funktionen: sie verflucht, verzaubert und greift zuletzt mit ihren magischen Kräften rettend ein. So wird die Funktion der zaubermächtigen Gestalt Norandos verstärkt, das Übernatürliche betont und die märchenhafte Atmosphäre im Theaterstück hervorgehoben.

Es überrascht daher nicht, wenn Gozzi im Vorwort zur Ausgabe von 1772 auf die Figur Norandos besonders hinweist: »In Norando, negromante di questa Fola, scorgerà il mio Lettore in qual'aspetto nobile, e differente da tutti gli altri goffi Maghi delle consuete Commedie dell'arte, io abbia voluto porre i negromanti, ch'entrano nelle mie Fiabe.* (Col. I, I20-12I). Im Gegensatz zu diesen lächerlichen Zauberern der Commedia dell'arte, die unvermittelt immer dann auftauchen, wenn eine Figur verwandelt werden soll, um die Liebesverwicklungen weiter zu kompli- 
zieren, und nach getaner Arbeit wieder von der Bühne verschwinden, hat Norando in I/ corvo die Funktion des Spielemachers, der die Faden in der Hand hält. ${ }^{78}$

\section{Maskenfiguren}

Zu den vier handlungstragenden Figuren aus dem Märchen, König Millo, Prinzessin Armilla, Prinz Jennaro und Norando, treten in $\mathrm{Il}$ corvo weitere dramatis personae, die nicht aus dem Märchen kommen, sondern aus der Commedia dell'arte: Brighella, Truffaldino, Pantalone und Tartaglia sowie Smeraldina. Während Smeraldina in ihrer traditionellen Rolle als Kammerfrau Armillas, der Prinzessin von Damaskus erscheint, stellen die Masken nicht nur sich selbst dar, sondern nehmen jeweils eine Rolle als Figur im Märchenkontext ein: Brighella und Truffaldino sind Jäger des Königs Millo, Tartaglia ist königlicher Ratgeber und Pantalone Admiral der königlichen Flotte. Keine dieser Figuren findet sich in Basiles Version, sieht man von einem kurzen Hinweis auf einige Kammerdiener ab.

Bercits in der ossatura treten Truffaldino und Brighella an Scharnierstellen zwischen den Akten auf, was Gozzi ungeachtet leicht veränderter Szeneneinteilungen im endgültigen Text beibehält. So eröffnen die beiden Masken den 2. und den 5. Akt, und Truffaldino beschließt den dritten mit Pantalone und Tartaglia. Während Truffaldino und Brighella im 2. Akt zudem die 4. Szene gestalten, streicht Gozzi den in der ossatura für den 4. Akt vorgesehenen Parallelauftritt. Damit ist der 2, Akt im besonderen geprägt durch die Präsenz von Maskenfiguren und Improvisation, was nicht bedeutet, daß diese Verbindung zwangsläufig wäre. Der endgültige Text nämlich weist den vier mit festgelegten Masken und Kostümen ausgestatteten Figuren unterschiedliche dramatische Ausprägungen zu. Für Truffaldino und Brighella ist ausnahmslos das improvisatorische Spiel vorgesehen, wobei sie ihre Repliken selbst gestalten, allerdings auf der Grundlage recht präziser Angaben Gozzis, die häufig bereits Hinweise

$n$ Zu den Zauberergestalten und Märchenelementen in der Commedia dell'arte siehe Kap. 2.7.

An manchen Punkten in Il corvo wird allerdings deutlich, daß Norando nicht autonom handelt, sondern selbst von einer unbestimmten, höheren Macht abhängig ist - cine zusätzliche Ebene, die im Märchen selbstverstandlich fehlt. Norando wurde námlich einstmals prophezeit, daß seine Tochter entführt und daraus viel Unheil entstehen würde. Erst als sich diese Prophezeiung erfüllt hat, ist Norando wieder frei, -menschlich * zu handeln: = Or posso esser umano* (V,8). Auf diese nicht gerade märchenhafte Abhàngigkeit eines Zauberers von anderen Schicksalsmāchten wird im Zusammenhang der Frage nach dem Handlungsspielraum der Figuren näher einzugehen sein; vgl. Kap. 4.3. 
zur szenischen Darstellung und maskentypischen lazzi enthalten. ${ }^{79}$ Pantalone wie Tartaglia dagegen sprechen meist exakt vorgegebenen Text, stimmen jedoch ausnahmsweise in der letzten Szene des 3. Aktes in die Improvisation Truffaldinos und Brighellas ein. Während die Szenen Truffaldinos und Brighellas ganz im Zeichen des Komischen stehen, stellen Pantalone und Tartaglia als Admiral und königlicher Ratgeber ernstere Varianten der Maske dar, die als Figuren enger in die Märchenhandlung eingebunden sind und daher weniger $*$ Improvisationsspielraum $\alpha$ genießen.

Festzuhalten ist zunächst, daß in Il corvo zu den vier Märchenfiguren vier Maskenfiguren treten und so eine neue dramaturgische Ordnung entsteht, die eine klare Symmetrie erkennen läßt. Im Gegensatz zu L'amore delle tre melarance ist die Trennlinie zwischen Märchen- und Maskenfiguren eindeutig, da keine Maskenfigur zur Märchenfigur wird noch umgekehrt, wie etwa im Falle Tartaglias in L'amore delle tre melarance. Die beiden Figurengruppen unterscheiden sich jedoch nicht nur in generischer Hinsicht voneinander, sondern auch in inhaltlicher, ethnischer und sprachlicher. Während Jennaro, Armilla, Millo und Norando aufs engste mit märchentypischen Situationen und Ereignissen verbunden sind, stehen die Masken am Rande des märchenhaften Geschehens, sind weder selbst direkt betroffen, noch greifen sie handelnd ein. Anders als Jennaro, Millo und Armilla, deren Herkommen und Situation märchenhaft fern und unbestimmt bleibt, sind die Masken trotz ihrer Universalität traditionell konkret verortet. Dies wird in Il corvo besonders im Fall Pantalones deutlich. Schon in der zweiten Szene des Stücks kommt im Dialog mit Jennaro über die glücklich überstandenen Gefahren auf See die Sprache auf Pantalones Herkunft:

Jen. Pantalone, io mi credei perduto a cosi orribile burrasca.

Pant. Come! Sala da che paese sia mi?

Jen. Si, dalla Giudeca [sic] di Venezia; me l'avrete detto mille volte.

Pant. Mo dassenazzo, che, dove ghe xe Zuechini, no pericola bastimenti. Ho imparà a mie spese. Do pieleghi, e un trabaccolo ho rotto da Malamocco a Zara per imparar el mestier.

79 So beginnt etwa die Eröffnungsszene des 2. Aktes, in der Truffaldino den Kônig wecken will, sich jedoch unsicher ist, ob es bereits neun geschlagen hat oder nicht, folgendermaßen ( $I$ l re cervo, $1 \mathrm{I}, \mathrm{I})$ :

Truf. Esce adagio per non destar il Re. Parlerà basso; darà qualche cenno del misero stato, in cui si trova il Re, dopo aver ucciso il maledetto Corvo. Non bisogna impacciarsi con corvi. Satira allusiva. Descrive la grassezza, e'l buon stato del Re prima, la magrezza, e'l pessimo stato dopo il corvicidio. È divenuto pazzo dopo la maladizione del brutto Orco. Replica le parole, che suol dir Millo, quando è preso dalla sua smania. 
Als Maske der Commedia dell'arte ist Pantalone herkömmlich Venezianer, doch weist er in $I l$ corvo nicht nur an exponierter Stelle explizit darauf hin, sondern bestimmt den Ort zudem genauer: er kommt von der Giudecca und hat, wie so viele dort, die Seefahrt erlernt, um Handel zu treiben. Den Ausgangs- und den Zielpunkt dieser Reisen nennt Pantalone ebenso wie die beiden typisch venezianischen Handelsschiffe (pielego, trabaccolo), mit denen er während seiner Lehrzeit Schiffbruch erlitt. Mit diesen exakten geographischen und technischen Angaben schafft Gozzi einen Verweis auf die Wirklichkeit, der betont mit der märchenhaften Vagheit kontrastiert - und dies umso stärker beim ursprünglichen Publikum des Stückes, dem venezianischen, das die Diskrepanz zwischen Wohlbekanntem und Märchenhaft-Entferntem noch deutlicher wahrgenommen haben dürfte. Dies gilt auch für die Sprache: während Gozzi die Märchenfiguren in artifiziellen Versen reden läßt, sprechen die Masken sämtlich in Prosa und manche, wie hier Pantalone, sogar im Dialekt, der keineswegs geglättet, sondern vielmehr in seiner Farbigkeit betont wird.

\section{Kontraststrukturen}

Das neue dramaturgische System Gozzis, das in Il corvo erstmals klar zutage tritt, basiert also maßgeblich auf Kontrasten, die durch eine bewußte Auswahl, Akzentuierung und Neuzusammenstellung von Einzelelementen aus bestehenden Formen entstehen. Die Grundstruktur bildet das Gegenüber von Märchenfiguren und Masken der Commedia dell'arte, aus dem sich alle weiteren Gegensätze ergeben. Für den Zuschauer sichtbar unterschiedlich sind die Figuren zunächst in ihrem Äußeren: die einen sind unmaskiert, die anderen tragen die traditionellen Masken, die einen sind reich gekleidet, sall'orientale«, die anderen haben ihre maskentypischen oder andere einfache Kostüme an ${ }^{80}$ Beginnt das Spiel, wird deutlich, daß die einen in wohlgesetzten Versen reden, die anderen dagegen in Prosa und teils im Dialekt, daß diese ihren Text improvisieren und in Szene setzen, während jene den vorgegebenen, rhetorisch ausgefeilten deklamieren. Hinzu kommt die unterschiedliche geographische und soziale Herkunft der zwei Figurengruppen. Stammen die einen aus den märchenhaften Königshãusern von Damaskus und Frattombrosa, sind die

5. In Il corvo fehlen nahere Angaben zu den Kostumen von Pantalone und Tartaglia, wahrend Truffaldino und somit wahrscheinlich auch Brighella als Jäger (-da cacciatore*, II, 1 ) gekleidet sind. 
anderen aus Italien, aus Venedig (Pantalone) oder Neapel (Tartaglia), und üben Berufe aus wie Admiral, Minister oder Jäger. Während schließlich die einen den Zauberkräften unterliegen, sind die anderen davon nicht betroffen.

Diese klare, oppositive, auf der Symmetrie von jeweils vier miteinander kontrastierenden Figuren beruhende Struktur wird durch zwei zusätzliche Figuren angereichert, die eine Zwischenstellung einnehmen. Leandro wird als Partner des Ministers Tartaglia eingeführt, Smeraldina als Kammerfrau von Armilla. Smeraldina kommt in dieser Rolle eine wichtige Funktion zu: als maskenlose Dienerinnen-Figur der Commedia dell'arte nähert sie sich dem Kreis des Märchenhaften an und läßt alles Komisch-Derbe hinter sich. Sie tritt nicht zusammen mit den Masken auf, sie spricht nicht in Prosa, sondern in Versen und erweist sich im Laufe der Handlung als ins Märchenhafte Eingeweihte. Bereits in der dritten Szene des I. Aktes deutet Smeraldina in einem a parte an, daß sie mehr weiß als alle anderen: $\gg$ Ah che del ratto i crudi vaticinj / Che chiusi ho in sen, s'avvereranno alfine. * Erst im 4 . Akt enthüllt sie die Prophezeiungen, deren Zeugin sie wurde, als Norando bei der Geburt seiner Tochter Armilla nach deren Schicksal forschte. Damit gehört Smeraldina zwar noch nicht der Märchensphäre an, da sie nicht unmittelbar vom Orakelspruch betroffen ist, doch ist sie Hüterin eines Geheimnisses, das das ganze Stück erst motiviert. Diese Figur, die einerseits im Märchen Basiles nicht existiert und andererseits dem Kontext der Commedia dell'arte enthoben ist, transzendiert die Kontraststruktur und kann als Indiz dafür gelten, daß Gozzis Fiabe teatrali zwar eine klar definierte Struktur zugrundeliegt, diese jedoch nicht schematisch befolgt, sondern spielerisch umgesetzt und so jeweils neu mit Bedeutung angereichert werden kann.

Nur zweieinhalb Monate nach $I l$ corvo, am 5 . Januar 1762 , kam die dritte Fiaba teatrale, Il re cervo, zur Aufführung. ${ }^{81}$ Programmatisch legt Gozzi auch hier die Kontraststruktur zugrunde, die als Signum der neuen Gattung gelten kann. Während die vier Maskenfiguren wie in allen Fiabe

81 Gozzi reiht Il re cervo im ersten Band der Colombani-Edition an vierter Stelle nach Turandot ein und bestatigt dies durch das Vorwort: il Re Cervo, che fu la quarta mia Fola, e che successe alla Turandot * (Col. I, 326), gibt aber als Aufführungsdaten für Il re cervo den s. Januar 1761 (more veneto, das heißt 1762) und für Turandot den 22. Januar 1762 an. In der späteren Zanardi-Ausgabe folgt $I l$ re cervo chronologisch korrekt auf Il corvo, doch sorgt das Vorwort wiederum für Verwirrung. Einmal spricht Gozzi vom großen Publikumserfolg der zwei vorausgehenden Fiabe teatrali, dann jedoch bezeichnet er $I I$ re cervo als scin zweites Märchenstück, was wohl so zu interpretieren ist, daß er im ersten Fall L'amore delle tre melarance zu den Fiabe teatrali zählt, im zweiten jedoch erst Il corvo als scchte Fiaba teatrale wertet. 
teatrali dieselben bleiben, dient nun nicht mehr Basile bzw, die mündliche italienische Tradition als Märchenquelle, sondern die orientalische. Il re cervo geht, wie alle folgenden Märchenstücke, mit Ausnahme von L'augellino belverde, auf Erzählungen aus den Anfang des 18. Jahrhunderts in Frankreich entstandenen Sammlungen Les mille et une nuits, Les mille et un jours und Les mille et un quart-d'beure zurück, wobei häufig Kontaminationen vorgenommen werden. ${ }^{82}$ So auch in $1 \mathrm{l}$ re cervo: der erste Handlungsstrang, die Wahl einer ehrlichen und treuen Frau mit Hilfe einer Zauberbüste, ist der *Histoire des quatre sultanes de Citor" aus Les mille et un quart-d'beure entnommen, der zweite um das Geheimnis der Verwandlung in andere Körper der $»$ Histoire du Prince Fadlallah fils de Bin-Ortoc, Roy de Mouzel $\propto$ aus Les mille et un jours. Gozzi verbindet diese beiden Stränge zu einem dramaturgisch schlüssigen Ganzen, in dem die Handlung wiederum von einer übergeordneten Figur mit magischen Kräften beherrscht wird, die dieses Mal nicht nur wie in $\mathrm{Il}$ corvo ausgearbeitet, sondern neu eingeführt wird. Indirekt sind beide Handlungsstränge durch diesen Zauberer namens Durandarte motiviert, denn er vertraut Deramo, dem König von Serendippo, zwei Geheimnisse, »due secreti magici, due portenti, due maraviglie» (Col. I, 332), an, die jeweils einen Handlungsstrang beherrschen. Zum einen schenkt er ihm zwei Büsten, deren eine jede Lüge und Unwahrheit durch ein Lächeln anzeigt, zum anderen gibt er ihm einen Zauberspruch, der es ermöglicht, sich in einen anderen, toten Körper zu verwandeln. Aus diesen beiden Geheimnissen entsteht eine chronologisch und kausal geordnete Handlungsfolge. Im ersten Akt wählt Deramo mit Hilfe der Zauberbüste aus zahlreichen Bewerberinnen eine Frau, im zweiten und dritten droht er diese samt des Thrones zu verlieren, weil sich Tartaglia den Zauberspruch erschlichen und in seine Gestalt verwandelt hat, während er selbst zunächst als Hirsch, dann als ärmlicher Greis ums Überleben kämpft. ${ }^{83}$ Neben der übergeordneten Zauberergestalt Durandarte, die zunächst in Form eines Papageis auf die Bühne kommt und erst am Ende ihre wahre Identität preisgibt, ist es die Maske Tartaglia, mittels derer Gozzi weitere

12. Teils nennt Gozzi die Märchentitel und -sammlungen in Vorworten oder anderen Texten selbst, teils auch nicht wie im Fall von $/ /$ re cervo. Der Hinweis auf die beiden Referenztexte findet sich wohl erstmals bei G. Luciani, Carlo Gozzi, op. cit., S. 513

83 Hinsichtlich dieser Verwandlungen weisen die drei Fassungen, die als Manuskripte vorliegen, zahlreiche Varianten auf. Siehe dazu und zu weiteren, in unserem Zusammenhang nicht wesentlichen Unterschieden zwischen den Manuskripten den bereits angefuhrten Artikel von P. Bosisio, sGli autografi di Re cervo", op, cit, dessen Ergebnisse in *Dal copione alla stampa. La vicenda testuale di Re cervoe, in: Carlo Gozzi, Re cervo, Teatro di Genova, Genova, Marietti 1991, S. 29-35, noch einmal zusammengefalit werden, sowie A. Beniscelli, La finzione del fiabesco, op, cit, S. 87-92. 
handlungsinterne Verknüpfungen kausaler Art schafft. Tartaglia ist nicht nur beleidigt, daß es nicht seine Tochter Clarice ist, die zur Königin gewählt wird, sondern er liebt darüber hinaus ausgerechnet diejenige, auf die Deramos Wahl fällt, nämlich Pantalones Tochter Angela. Daß er sich das Geheimnis der Verwandlung erschleicht und so an die Stelle des Königs Deramo tritt, ist also zweifach motiviert.

Während in $I l$ corvo sämtliche Maskenfiguren neu zu den im Märchen vorkommenden Gestalten hinzutreten, ersetzt Gozzi in Il re cervo den bösen Derwisch, der in der »Histoire du Prince Fadlallah fils de Bin-Ortoc, Roy de Mouzel $\propto$ in die Gestalt des Königs schlüpft, durch die Maskenfigur Tartaglia, der als untreuer erster Minister seinen König hintergeht. Hingegen sind Pantalone als zweiter Minister, Brighella als Küchenchef und Truffaldino als Vogler von Gozzi ergänzt. Im Gegensatz zu ihrer Rolle in Il corvo ist Smeraldina als Schwester Brighellas hier deutlich dem Commedia dell'arte-Personal zugeordnet. Trotz mancher Verschiebungen basiert die Grundstruktur auch in $I l$ re cervo auf dem Kontrast zwischen märchenhaften Figuren und solchen, deren Wurzeln in der Commedia dell'arte liegen. Und wiederum stehen sich Szenen gegenüber, die gãnzlich ausformuliert sind und solche, die, zumindest in der Wortwahl, weitgehend der schauspielerischen Improvisation der Masken überlassen werden. ${ }^{84}$ Zudem kontrastieren wie im zweiten Stück rhetorisch durchgeformte Verse mit italienischer oder venezianischer Prosa.

Mit $I l$ corvo und $I l$ re cervo hat Gozzi ein snuovo genere franco, audace, e smoderato con artifizio (Col. I, 125 ) geschaffen, in dem sich die turbulente Überlagerung und vielfache Kreuzung von Elementen aus Märchen, Commedia dell'arte, Parodie und Theaterpolemik in L'amore delle tre melarance klärt und zu einer durchsichtigen kontrastiven Struktur entwickelt, deren Grundkonstituenten dem Märchen und der Commedia dell'arte entstammen. Zu präzisieren ist nun, welche Aspekte und Komponenten des Märchens und der Commedia dell'arte für die neue Verbindung auf der Bühne jeweils relevant sind, welchen Veränderungen sie unterliegen und wie ihre Relation näher zu bestimmen ist.

* Wahrend Pantalone keine einzige Improvisationsszene zugewiesen wird, stehen Smeraldina zweimal und sogar Leandro einmal zusammen mit Truffaldino auf der Bühne und improvisieren ebentalls. Dies entspringt der Notwendigkeit einer schnellen, adãquaten Reaktion auf Truffaldinos Einfalle. 


\subsection{Märchen als Konstituente der Fiabe teatrali}

Es fällt auf, daß Gozzi für seine Werke häufig auf Vorgängiges zurückgreift, vorzugsweise auf Formen und Gattungen, die in der literarischen Debatte der Zeit umstritten sind oder überwiegend mit Geringschätzung behandelt werden. So auch bei den Fiabe teatrali, für die er im Gegensatz zu den polemischen Texten nicht als elitär geltende Formen v. a. des Cinquecento wählt, sondern volkstümlich-populäre, das Märchen und die Commedia dell'arte, die im 18 . Jahrhundert zwar auch unter dem Verdikt der Kritiker und Theoretiker stehen, sich aber dennoch des Interesses eines breiten Publikums erfreuen.

Nachdem im 16. und 17. Jahrhundert in Italien mit Giovan Francesco Straparolas Le piacevoli notti (Venedig 1550 und 1553$)^{85}$ und Giambattista Basiles Lo cunto de li cunti (posthum Neapel I634/36) zwei für die Geschichte des Märchens entscheidende Sammlungen erschienen waren, auf die noch Pompeo Sarnellis Posilecheata (Neapel 1684 ) folgte, dominierten Ende des 17. und Anfang des 18. Jahrhunderts französische Märcheneditionen. Zunächst veröffentlichten Charles Perrault und Mme d'Aulnoy Märchenbücher, in denen sowohl Volksmärchen als auch eigene Erfindungen vereint waren, um 1700 entstand dann eine Flut sogenannter Feenmärchen aus der Feder meist adliger Autorinnen. Einen überwältigenden Erfolg erzielte Les mille et une nuits en françois (Paris, $1704-1717$ ), eine Sammlung orientalischer Märchen, erstmals von Jean Antoine Galland aus dem Arabischen übersetzt. Animiert durch die starke Resonanz, brachten François Pétis de la Croix $1710-12$ Les mille et un jours. Contes persans, traduits en français ${ }^{86}$ und wenig später Thomas-Simon Gueullette Les mille et un quart-d'heure. Contes tartares $(1712 / 1715)$ heraus. Als Krönung dieser Märchenleidenschaft kann das $1785-89$ erschienene 4 I-bändige Cabinet de fées gelten.

ss Vgl. Calvinos Himweis auf die italienische * Vorreiterrollee im Zusammenhang mit dem Märchen und insbesondere auf Venedig: -1 grandi libri di fiabe italiani, si sa, sono nati in anticipo sugli altri. Già a metä del secolo XV1, a Venezia, nelle Piacevoli Notti di Straparola, la novella cede il campo alla sua più anziana e rustica sorella, la fiaba di meraviglie e d'incantesimi, con un ritorno d'immaginazione tra gotica e orientale alla Carpaccio, e un'incrinatura dialettale allo stampo della prosa boccaceesca. [...] E nel Settecento, di nuovo a Venezia, ma stavolta con sufficienza e ostentazione di concedersi a un gioco, l'astioso e supercilioso Carlo Gozzi fa calcare alle fiabe le tavole del palcoscenico, tra le maschere dell'Artea, in: Italo Calvino, Sulla fiaba, Milano, Mondadori 1996, S. 31.

36. Zur Rolle des haufig als Mitautor angegebenen Lesage s, Paul Sebags ausführliche Einfuhrung zu François Pétis de la Croix, Les mille et un jours, contes persans, $\mathrm{Hg}$. Paul Scbag, Paris, Christian Bourgois Editeur 1980, S. 7-31, hier 5. 16-17. 
Im Kontext dieser Märchenmode, die kaum in das Jahrhundert der Aufklärung zu passen scheint und doch so viel über die Divergenz zwischen proklamierten Zielen und tatsächlicher Situation verrät, steht Gozzis Wahl des Märchens als eine der Grundkonstituenten seiner Fiabe teatrali. So kann er sich zum einen der Aufmerksamkeit seiner gebildeteren Zeitgenossen für ein umstrittenes Genre sicher sein, zum anderen kann er weitgehend die allgemeine Bekanntheit der Texte voraussetzen, was wiederum die Neugier auf ihre szenische Bearbeitung erhöht. Im Wettbewerb um die Gunst des venezianischen Theaterpublikums dürften solche Überlegungen nicht unwesentlich gewesen sein. Betrachtet man allerdings die Auswahl der Märchentexte, die Gozzi für seine Theaterstücke trifft, wird deutlich, daß er gerade nicht der französischen Mode der Feenmärchen folgt, sondern die italienischen und orientalischen Sammlungen bevorzugt. Das an den höfisch-ständischen Rahmen gebundene Feenmärchen, in dem es *um die Applikation märchenhafter Elemente (oder Funktionen im Sinne von Wladimir Propp) auf die - spiegelbildlich zur Realität verstandene - höfische Gesellschaft $\alpha^{87}$ geht, ist nicht nur zu sehr soziologisch und national geprägt, sondern auch zu literarisch im Sinne einer Artifizialität, die sich im ironischen oder parodistischen Spiel mit dem Märchenhaften äußert. Geeigneter als Matrix für das neue Genre erweisen sich die unspezifischeren italienischen Märchen sowie die exotisch-orientalischen. Sie beziehen sich nicht auf eine konkrete Realität, die es auf dem Umweg über das Märchen zu enthüllen gilt, sondern machen »die märchenhaften Mechanismen im Leben schlechthin $\kappa^{88}$ sichtbar. Ihre "Ernsthaftigkeit *, die absieht von allem Spielerischen, Selbstironischen und im Gegensatz zum Verweischarakter der Feenmärchen die Autonomie der Märchenwelt garantiert, verleiht ihnen eine Allgemeinheit, die sie nicht nur universeller macht, sondern auch in bestimmter Weise funktionalisierbar. In dieser zeit- und ortlosen Allgemeinheit, wenn auch manchmal eingefärbt mit vagen exotischen Tönen, sind sie in Gozzis neuer Gattung auch mit anderen Elementen leichter kombinierbar.

87 Friedrich Wolfzettel, - Der verzerrte Spiegel der höfischen Welt: Überlegungen zum historischen Standort des französischen Feenmarrchens am Ende des 17. Jahrhunderts und im frühen 18. Jahrhundert", in: Sebastian Neumeister ( $\mathrm{Hg}_{\mathrm{g}}$ ), Frahaufklarung, München, Fink 1994 , S. $241-286$, hier S. 245 .

88 Ebd. 


\section{Dramatisierung des Märchens}

Wenn nun das Märchen zum Theaterstück oder genauer zu einer maßgeblichen Komponente der Fiabe teatrali wird, so bleiben zweifellos wesentliche Merkmale der narrativen Gattung erhalten, doch bringt die Transformation in eine dramatische Form zwangsläufig auch Veränderungen des Ausgangsmaterials mit sich. Nicht zuletzt fällt die in allen von Gozzi herangezogenen Märchensammlungen (Basile, Sarnelli, Galland, Pétis de $\mathrm{La}$ Croix und Gueullette) vorhandene Rahmenerzählung weg, die die einzelnen Geschichten in einen größeren narrativen Kontext stellt und untereinander verbindet; erhalten bleibt dagegen in einigen Fällen der Titel der Erzählungen. ${ }^{89}$

\section{Inhaltliche und strukturelle Kongruenzen zwischen narrativer und dramatischer Form}

Wie zuletzt Holger Korthals ausführlich dargestellt hat, sind das Drama - als dramatischer Text, nicht als Theateraufführung - und die Erzählung in theoretischer Hinsicht skeine weit auseinanderliegenden Pole in einer Gattungstrias Lyrik-Epik-Dramatik, sondern zwei eng verwandte -Proto-Gattungen $*$ der literarischen Geschehensdarstellung $\alpha$, die beide auf den Geschehenselementen Akteure, Schauplätze, Ereignisse basieren. ${ }^{90} \mathrm{Da}$ dem Drama im allgemeinen ein narrativer Nukleus zugrundeliegt, ${ }^{91}$ ist die Dramatisierung von Erzählungen einer der häufigsten Gattungswechsel in der traditionellen Trias Lyrik-Epik-Dramatik, unter den auch Gozzis Stücke fallen, läßt man die Besonderheit der Masken einstweilen außer acht. Diesem »normalen* Gattungswechsel von der Erzählung zum Drama geht in Les mille et un jours interessanterweise einer in umgekehrter Richtung voraus, wie im Vorwort zu lesen ist, das Gozzi zweifellos bekannt war. Dort stellt François Pétis de la Croix sein

5v Darauf weist Gozzi im Vorwort zu $1 /$ corvo hin: "ho voluto conservare il solo titolo, e alcune circostanze note delle medesime.* (Col. I, 119). Bei den Fiabe teatrali, die auf orientalischen Märchen basieren, wählt Gozzi statt der langen, wenig aussagekrättigen Uberschriften (s. Histoire du Prince Fadlallah etc.) sprechende Titel, die denen der italienischen Sammlungen ähneln, wie z. B. Il re cervo, La donna serpente.

90 Holger Korthals, Zuzischen Drama und Erzäblung. Ein Beitrag zur Theorie geschebensdarstellender Literatw, Berlin, Erich Schmidt Verlag 2003, S. 12.

7 Dies ist deutlich sichtbar Z, B, an der Arbeitsweise Gozzis, der mit der ossatura (s,o.) eine narrative Grundlage für die folgende dramatische Ausarbeitung legt. Auch die argomenti, die den scenari der Commedie dell'arte bei Flaminio Scala vorangehen, sind die narrative Grundlage der szenischen Darstellung. 
Werk als Übersetzung eines Buches mit dem Titel Hazâr Yek Roûz aus der Feder des mit ihm befreundeten Derwischs Moclès vor und berichtet über die Vorlage folgendes: »Moclés [sic] étant encore fort jeune, s'avisa de traduire en Persan des Comedies Indiennes qui ont été traduites en toutes les Langues Orientales. [...] Mais le Traducteur Persan pour donner à son Ouvrage un air original, mit ces Comedies en Contes, qu'il appella Hezaryek-Rouz, c'est-à-dire Mille \& un Jour. $\star^{92}$ Am Beginn der komplexen Texttradierung hätten demnach also dramatische Texte gestanden, die vom Derwisch Moclès in persische Prosa übertragen und von Pétis de la Croix ins Französische übersetzt wurden, so daß Gozzis Fiabe teatrali tatsächlich einer Wiederherstellung der ursprünglichen Form gleichkämen. Wenn sich inzwischen auch erwiesen hat, daß Pétis de la Croix' Darstellung erfunden ist, ${ }^{93}$ wirft dies ein Licht auf den unkomplizierten Umgang mit Texten und Textgattungen, wobei das Märchen, wie sich zeigen wird, für einen Wechsel ins Dramatische besonders geeignet ist. ${ }^{94}$

Folgt man dem in der Märchenforschung gängigen, von Antti Aarne geschaffenen und von Stith Thompson bearbeiteten Typensystem, ergibt sich, daß Gozzi für seine Stücke hauptsächlich zu den Zauber- und Wundermärchen innerhalb der »eigentlichen Märchen $\alpha^{95}$ greift, die unterschiedliche wunderbare Faktoren aufweisen wie verzauberte Ehepartner, übernatürliche Gegner, Aufgaben, Helfer, Gegenstände etc. In Il corvo, La Zobeide und Il re de' genj wird das Geschehen durch Zauberer bzw. Gestalten mit magischen Kräften bestimmt, in $1 l$ mostro turchino durch ein Ungeheuer, in $\mathrm{Il}$ re cervo durch eine Zauberbüste und einen Zauberspruch, in La donna serpente durch einen übernatürlichen Ehepartner, Cherestani, Tochter eines Sterblichen und einer Fee. Turandot und I pitocchi fortunati, signude affatto di meraviglie, e di trasformazioni (Zan. XIV, 33), wären dagegen zu den novellenartigen Märchen zu zählen, die nach Max Lüthi »ohne weiteres als Novelle oder romanartige Geschichte bezeichnet werden [könnten] «, jedoch durch sihr Handlungsfeld, ihr Personal (Könige, Prinzessinnen), ihre wirklichkeitsferne Stilisierung « als Märchen erscheinen. Analog zum Märchen sind auch die Fiabe teatrali mit Begriffen wie Zauber, Wunder, Übernatürliches verbunden. ${ }^{96}$ Die-

92 Les mille et un jour [sic]. Contes persans, traduits en français par M. Pétis de L.a Croix, Bd. $t$, Paris, Vve Riccur 1710, unpaginiert.

9) Diesen Beweis tritt P. Sebag im Vorwort zu seiner Ausgabe von Les mille et un jours, op. cit., S. 12-16, an.

94 In $n$ La donna serpente come fiabas, op. cit., S. 13, spricht E. Sanguineti vom Märchen als einer -struttura miniteatrale«, die mit Gozzis Fuabe teatrali =uno spazio e una strutrura predestinate- gewinne.

95 S. M. Lüthi, Märchen, op. cit., S. 16-19.

\%. Vgl. ebd., S, 2-3. 
ser Charakter des bewußt Wirklichkeitsfernen, Fiktiven wird von Gozzi hinsichtlich der Märchenkonstituente in allen Fiabe teatrali beibehalten - daß es an anderer Stelle wiederum eben so bewußt durchbrochen wird, zeigt die Analyse der Commedia dell'arte-Komponenten. Über das allgemeine Charakteristikum der Wirklichkeitsferne hinaus übernimmt Gozzi in den Fiabe teatrali im wesentlichen den Handlungsverlauf des Märchens bzw. der Märchen, die jeweils als Basis fungieren, das königliche Personal, magische Objekte oder Personen, Verwandlungen, Zaubersprüche, Prophezeiungen, fest geprägte Schlüsse, ${ }^{97}$ formelhafte Verse, die Dreizahl der Repetition von Formeln und Handlungssituationen. Typisch märchenhaft hinsichtlich der Handlung ist beispielsweise die Ausgangslage in Il corvo, Turandot und La donna serpente, die jeweils durch einen Mangel gekennzeichnet ist, wobei die Situationen weitgehend der Beschreibung Vladimir Propps entsprechen: $»$ La prise de conscience du manque peut se produire de la façon suivante: l'objet du manque peut se faire connaître malgré lui, en se montrant un instant, en laissant derrière lui une trace éclatante, ou en apparaissant au héros sous l'aspect d'une certaine image. $e^{98}$ Jennaro geht in $I l$ corvo für seinen Bruder Millo auf die Suche nach einer Frau, die so weiß wie der Marmor, so schwarz wie der Rabe und so rot wie sein Blut ist, das dieser auf dem marmornen Stein vergossen hat, Calaf sieht zufällig Turandots Portrait, entbrennt in Liebe zu ihr und sucht sie trotz aller Warnungen und Cherestani erscheint Farruscad in La donna serpente als weiße Hirschkuh, der er nachjagt, bis er die schöne Prinzessin findet.

Ein weiteres marrchentypisches Charakteristikum kommt in den Fiabe teatrali zum Tragen: die Begegnung mit dem Wunderbaren, mit dem Zauber geschieht ohne Erschütterung und Überraschung. Als Jennaro in $I l$ corvo $(\mathrm{I}, 6)$ zwei Tauben sprechen hört, zôgert er nur einen Moment und verfolgt dann mit Interesse, was sie reden:

Jen. Come! Dove son io? qual portento

È questo? Due Colombe, che favellano?

Che favellan di me? S'ascolti, e taccia.

Die Erscheinung Norandos auf einem Meeresungetüm in der folgenden Szene wird in Jennaros Replik nicht einmal mehr thematisiert. Eben so fraglos nehmen die übrigen Figuren Jennaros Verwandlung in eine Mar-

L'amore delle tre melarance endet mit solch ciner Formel, die auch $I l$ corvo und Il re cervo abschließt: $\rightarrow$ Non lasciava di terminare la favola col consueto finale, che sa a memoria ogni ragazzo; di nozze, di rape in composta, di sorci pelati, e gatti scorticati ec.(Col. I, 1 13 3).

98. Vladimir Propp, Morphologie du conte, Paris, Seuil r970, S. 93. 
morstatue sowie seine Rückverwandlung und die Auferweckung Armillas am Ende des Stücks hin. Im Hinblick auf die Reaktion der Figuren auf das Übernatürliche ergeben sich allerdings Unterschiede zwischen den Märchen- und den Maskenfiguren, auf die später ausführlich eingegangen wird. Festzuhalten bleibt, daß die aus dem Märchenprätext in die Fiabe teatrali übernommenen und vom eigentlichen Märchengeschehen betroffenen Figuren keinerlei Erstaunen zeigen angesichts dessen, was sie an Wunderbarem *erleben $\%$.

Gerade dieses selbstverständliche Miteinander von Wirklichkeitsnahem und Wirklichkeitsfernem ist es, das das Märchenhafte vom Phantastischen unterscheidet. Für Tzvetan Todorov wird das Phantastische genau im Moment der Unschlüssigkeit, des Zögerns sowohl der Figuren eines Textes als auch seiner Leser angesichts eines Geschehnisses faßbar. Die Ambiguität des Status eines Ereignisses, die Frage, ob es der Realität oder dem Traum, der Wahrheit oder einer Illusion zuzurechnen ist, macht das Phantastische aus. ${ }^{99}$ Im Märchen dagegen ruft das Übernatürliche keine besondere Reaktion hervor, weder bei den Figuren noch beim Leser. Demnach ist das Wunderbare des Märchens nicht durch eine bestimmte Haltung gegenüber den erzählten Ereignissen charakterisiert, sondern durch die Natur der Ereignisse selbst. Diese gehorchen so ganz anderen Gesetzen als denen der normalen Welt, daß ein Zögern über ihre Zugehörigkeit zu *Realität « und *Wahrheit * gar nicht erst aufkommt. Sie werden im Märchen, hat man sich einmal auf diese andere Welt eingelas-

99 In Introduction a la littérature fantastique, Paris, Seuil 1970, S. 37-38, definiert Tzve$\tan$ Todorov drei Bedingungen für das Phantastische: "D'abord, il faut que le texte oblige le lecteur à considérer le monde des personnages comme un monde de personnes vivantes et à hésiter entre une explication naturelle et une explication surnaturelle des événements évoqués. Ensuite, cette hésitation peut être ressentie également par un personnage; ainsi le rôle de lecteur est pour ainsi dire confié à un personnage et dans le même temps l'hésitation se trouve représentée, elle devient un des thèmes de l'ceuvre; [...]. Enfin il importe que le lecteur adopte une certaine attitude à l'égard du texte: il refusera aussi bien l'interprétation allégorique que l'interprétation spoétiqué, *

Dieser Definitionsversuch stieß immer wieder auf Kritik, da das Phantastische so-zum einen auf den Moment des Zögerns reduziert erscheint, zum anderen zu sehr von ciner psychischen Reaktion abhängig gemacht wird; vgl. z. B. Jean-Luc Steinmetz, La littérature fantastique, Paris, PUF 1990. Rosalba Campra schlāgt in =1l fantastico: una isotopia della trasgressione , in: Strumenti critici 45, 2, 1981, S. 199-231, eine Definition des Phantastischen vor, die vom Begriff der Grenze ausgeht: *Appare quindi come preliminare al fantastico, in questo senso, la nozione di frontiera, di limite non valicabile per l'essere umano. Una volta stabilita l'esistenza di due statuti di realtà, l'attuazione del fantastico consiste nella trasgressione di questo limite, per cui il fantastico si configura come azione (S. 204). Diese Betonung der Grenzüberschreitung unterstreicht den Unterschied zum Märchen, in dem gerade nicht zwei getrennte Bereiche erscheinen, sondern eine Homogenität von Realitätsnäherem und-fernerem dargestellt wird. 
sen, von den Figuren wie vom Leser als normal, natürlich und keineswegs beunruhigend angenommen. ${ }^{100}$

Dies unbedingte Einlassen auf die Märchenwelt ist es auch, das Gozzi immer wieder von seinen Zuschauern fordert. Es setzt eine kindliche Unvoreingenommenheit und Naivität voraus, die Gozzi bei der Aufführung von L'amore delle tre melarance demonstrativ überrascht an sich selbst entdeckt: L'Uditorio era contentissimo di quella mirabil novità puerile, ed io confesso, che rideva di me medesimo, sentendo l'animo a forza umiliato a godere di quelle immagini fanciullesche, che mi rimettevano nel tempo della mia infanzia. (Col. I, IOO). Eine derartige momentane Überwältigung durch die sgran forza, che ha 'l mirabile sull'umanità (Col. I, 97) zeigt, daß das Märchenhaft-Wunderbare die Zuhörer und Zuschauer noch immer in seinen Bann zu ziehen vermag. ${ }^{101}$ Die Frage nach der Wahrscheinlichkeit der Ereignisse spielt dabei nicht die geringste Rolle, sie ist durch die Wahl der Gattung Märchen selbst obsolet, denn "das Wunderbare ist in dieser Form nicht wunderbar, sondern selbstverständlich $\alpha,{ }^{102}$

Daß die Transposition so charakteristischer Aspekte einer narrativen Gattung auf die Bühne glücken konnte, liegt in strukturellen und formalen Eigenschaften des Märchens, die eine dramatische Gestaltung wesentlich begünstigen. Dazu zählen seine geringe erzählerische Ausdehnung, seine Handlungsbetontheit, sein klarer Bau und die Ausgliederung in mehrere Episoden. ${ }^{103} \mathrm{Im}$ Vordergrund der Märchenerzählung steht das Fortschreiten der Handlung beziehungsweise des Geschehens, wogegen ausführlichere Beschreibungen und Schilderungen von Landschaften, Gegenständen, Figuren selten sind. Ins Licht wird hauptsächlich das gerückt, was den Helden oder die Heldin direkt betrifft. Damit sind für eine märchentextnahe Bühnenfassung wichtige Kriterien erfüllt.

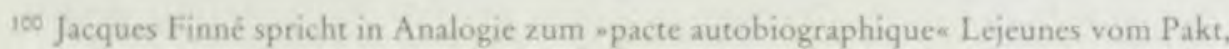
den Leser und Autor beim Marchen schließen. Dieser Pakt besteht in der Suspendierung der Frage nach der Wahrscheinlichkeit des märchenhaften Geschehens und dem zeitweiligen Einlassen auf die Marrchenwelt mit ihren eigenen Gesetzen. "Somme toute, la grande opposition entre conte de fées et conte fantastique vient du fait que, dans le premier, lecteur et auteur s'unissent par un pacte, alors que, dans le second, l'auteur doit imposer son fantastique au lecteur, * (La littérature fantastique. Essai sur l'organisation surnaturelle, Bruxelles, Editions de I'Université de Bruxelles 1980, S. 21 ).

$101 \mathrm{Zu}$ Gozzis Verständnis der Einbildungskraft als anthropologische Grundkonstante, die zwar zurückgedrängt, aber nicht verdrāngt werden kann, siehe v. a. Kap. 3.4. Unter pragmatischem Blickwinkel wird Gozzis Position durch das Publikumsinteresse bestàtigt, das sich unmittelbar in den Aufführungszahlen niederschlägt, die bei den Fiabe teatrali zwischen 7 und 19 liegen.

102 A. Jolles, op. cit., S. 243.

$103 \mathrm{Vgl}$. M. Lüthi, Märchen, op. cit., S. 3 und 25-32. 
In der dramatischen Umsetzung wird das Beschreibende üblicherweise vermieden, der Akzent liegt auf der Handlung, die sich sowohl im Dialog als auch in der szenischen Aktion manifestiert, und die Konzentration auf wenige Figuren wie auch die Klarheit des Handlungsablaufs kommen dem Theater eben so entgegen, wobei insbesondere eine episodische Struktur bereits eine sinnvolle Einteilung in Akte und Szenen nahelegen kann. So lassen sich etwa der Zweier- oder Dreierrhythmus, in dem sich zahlreiche Märchenhandlungen entfalten, unschwer in eine dramatische Gliederung umsetzen, womit die traditionelle Formelhaftigkeit des Ablaufs im Märchen ihr Pendant fände im schematisierten Dramenaufbau. Unter dieser Perspektive könnte hinsichtlich der Handlung das »allgemeinste Schema, das dem europäischen Volksmärchen zugrunde liegt , $^{104}$ nämlich Schwierigkeiten und ihre Bewältigung auch für die Komödie gelten. Wenn dieses Schema auch den Nachteil hat, sehr allgemein und daher wenig aussagekräftig zu sein, bleibt doch festzuhalten, daß eine problematische Ausgangslage und ihre positive Bewältigung, die zu einem glücklichen Ende führt, für das Märchen wie für die Komödie charakteristisch sind.

Schließlich korrespondiert auch die Darstellungsweise von Personen und Dingen im Märchen mit derjenigen in einer spezifischen Art von Theater. Nicht individuell gezeichnet, sondern geradezu entindividualisiert, sind die Märchenhelden keine Persönlichkeiten, aber auch kein Typus, sondern eine allgemeine Figur. Haupt- wie Nebenfiguren tragen häufig nicht einmal einen Namen, sondern nur Funktionsbezeichnungen wie König, Prinzessin, Stiefmutter etc., Gefühle, Stimmungen, Absichten spielen für den Handlungsfortgang keine Rolle. ${ }^{105}$ Sowohl in der gelehrten Komödie, der "commedia erudita*, als auch in der improvisierten, der "commedia all'improvviso«, begegnet man überwiegend solchen nicht-individualisierten Figuren - daneben, vor allem in der scommedia all'improvviso «, natürlich auch Typen wie den Masken. Treten Märchenfiguren auf die Bühne, so bedarf es daher, was ihre Modellierung angeht, in diesem Kontext kaum eines größeren Eingriffs. Allerdings muß den Märchenfiguren eine Stimme verliehen werden, wobei die dialogische Form des Theaters im Vergleich mit der auktorial-narrativen Form des Märchens eine spezifische sprachlich-stilistische Gestaltung der Repliken der einzelnen Figuren bedingt, die in den Fiabe teatrali maßgeblich von der Kontraststruktur bestimmt ist.

104 Ebd., S, 25 .

105 Vgl. V. Propp, op, cit., S. 92, -Notons que d'une façon générale, les sentiments et les intentions des personnages n'agissent en aucun cas sur le déroulement de l'action.* 
Daß, wie sich hier andeutet, Märchen und Theaterstücke bei genügend weitgehender Abstraktion vergleichbare Kompositions- beziehungsweise Strukturgesetze aufweisen, hat in theoretischer Hinsicht die Weiterführung von Vladimir Propps Arbeit zum Märchen durch Étienne Souriau und Algirdas J. Greimas gezeigt. ${ }^{106}$ Wären Gozzis Fiabe teatrali tatsächlich nur dramatisierte Märchen und nicht eine ganz neue Gattung, stellten sie in geradezu idealer Weise Analyseobjekte für Greimas' auf Propps Märchenmorphologie aufbauendem Aktantenschema dar. Wie die folgende kurze Skizzierung der Modelle zeigt, lenken diese zwar die Aufmerksamkeit auf Strukturähnlichkeiten zwischen der einfachen Form des Märchens und einer vereinfachten dramatischen Textur - womit sich Gozzis Wahl des Märchens als eine Konstituente seiner neuen dramatischen Gattung von einem strukturellen Gesichtspunkt aus als sinnvoll und adäquat erweist -, doch sind die Modelle in dieser Form nicht geeignet, die Spezifika Gozzischer Fiabe teatrali zu erfassen. ${ }^{107}$ In der Morphologie des Märchens hat Propp die unbedingte Priorität des Handlungsverlaufs vor den Figuren und der Handlungsweise postuliert. ${ }^{108}$ Eine bestimmte, von Propp systematisierte Figurenkonstellation ist jedoch Voraussetzung für das märchentypische Funktionieren der Handlung. Als konstante Elemente der Märchen unterscheidet Propp eine begrenzte Anzahl möglicher Funktionen (3 $\mathrm{I}$ ) der Figuren, das heißt Handlungseinheiten, die jeweils aufeinander folgen, jedoch im Einzelfall nicht alle vorhanden sein müssen. Dazu zählen z. B. Entfernung, Verbot, Übertretung, Schädigung, Emp-

156 Etienne Souriau, Les deux cent mille situations dramatiques, Paris, Flammarion 1950: Algirdas Julien Greimas, z. B. Sémantique structurale, Paris, Larousse 1966. In *Marchen und Marchenroman , in: Poetica 6, 1974 , S, $129-179$, wendet Ilse Nolring-Hauff Propps Modell auf die narrative Großform des Artusromans an, womit deutlich wird, daß das Schema grundlegend, doch zugleich so allgemein ist, daß es zusätzlicher Kriterien bedarf, damit eine Analyse aussagekräftig wird.

1071976 versuchte Ludovico Zorzi in -Struttura $\rightarrow$ Fortuna della fiaba gozzianae, in: Chigiana 31, $11,1976,5.25-40$, eine Darstellung der Figurenkonstellation von L'amore delle tre melarance auf der Basis von Propps Modell. Dabei reduziert er das Stück auf eine - contaminazione tra la morfologia della fiaba e la morfologia della commedia dell'Arte* (S. 36), die jedoch der Komplexität der Überlagerung, des Ineinandergreifens und vor allem des Kontrastes verschiedenster Ebenen nicht gerecht wird.

Daß eine sinnvolle Anwendung von Greimas' Aktanten- und Propps bzw. Bremonds Funktionenmodell im Bereich des Theaters notwendig eine Adaption und Modifikation bedingt, macht Anne Ubersfeld in Lire le thèatre 1, durchgeschene Neuauflage, Paris, Belin 1996, deutlich. Sie sieht im Aktantenmodell zunächst einmal den Vorteil darin, daß es erlaubt =de faire l'économie d'analyses aussi confuses que la classique analyse psychologiquer des personnages et aussi aléatoires que la tout aussi classique rdramaturgie du texte de thêâtre* (S. 45), das heißt, gängige Analysemethoden zu überwinden.

108 V. Propp, Morphologie du conte, op. cit., S. zo: $=$ Dans l'étude du conte, la question de savoir ce que font les personnages est seule importante; qui fait quelque chose et comment il le fait, sont des questions qui ne se posent qu'accessoirement. $\alpha$ 
fang eines Zaubermittels, Kampf, Sieg etc. Die Anzahl der im Märchen auftretenden Figuren gibt er mit sieben an: Aussender, Held, Prinzessin, Gegenspieler, Schenker, Helfer, falscher Held. Greimas begrenzt die Zahl der Träger fundamentaler Handlungsfunktionen dagegen auf sechs und benennt die "Aktanten $\approx$ in abstrakterer Weise mit Subjekt, Objekt, Sender, Empfänger, Adjuvant und Opponent. Damit läßt sich folgendes elementare Handlungsschema konstruieren: der Sender (eine Kraft oder ein Wesen) schickt das Subjekt im Hinblick auf einen Empfänger (der konkret oder abstrakt sein kann) auf die Suche nach einem Objekt; dabei hat das Subjekt sowohl Verbündete oder Helfer als auch Gegner.

Wendet man dieses Modell beispielsweise auf die Fiaba teatrale Il corvo an, lassen sich die Aktantenpositionen folgendermaßen besetzen: der Sender ist Millo, der Empfänger ebenfalls, das Subjekt ist Jennaro, das Objekt Armilla, der Opponent Norando, der Adjuvant Pantalone. Auch einige von Propps Funktionen wie Entfernung, Verbot, Schädigung, Kampf und letztlich der Sieg sind gegeben. Damit sind der grobe Handlungsverlauf und die Hauptfiguren erfaßt, doch wird weder der grundlegende Unterschied zwischen der narrativen und der dramatischen Form deutlich, noch die Differenzierung der Figuren über ihre Funktionen hinaus. So bleibt Entscheidendes verborgen wie das spezifisch Theatralische der Fiabe teatrali, die für die neue Gattung konstitutive Kombination divergenter Materialien aus Märchen und Commedia dell'arte sowie die Kontraststruktur.

Das Theatralische von Gozzis Stücken resultiert nicht nur aus dem betont Spielerischen der Masken, vor allem Truffaldinos und Brighellas, sondern zu einem guten Teil auch aus der Märchenkonstituente. Auf dem Theater manifestiert sich das Spektakuläre hauptsächlich im Visuellen, einem Bereich, der auch für das Märchen wesentlich ist, denn Formen, Farben, Licht, besondere Gestalten spielen im märchenhaften Stil eine entscheidende Rolle, wogegen das Akustische zurücktritt. Die Visualitât des Märchens eignet sich also bestens, sind die entsprechenden bühnentechnischen Voraussetzungen gegeben, für eine Übertragung auf die Bühne. Erscheinungen, Verwandlungen, sprechende Tiere oder Dinge, die im Märchen gang und gäbe sind, zeigt Gozzi auch in seinen Stücken. Die märchenhaften Elemente verwandelt er in einen regelrechten $* B$ Buhnenzauber ", was ihm allerdings den Vorwurf einbringt, das Publikum vor allem mit dem "mirabile delle apparizioni, e delle trasformazioni $\propto$ (Col. I, 215) zu begeistern. ${ }^{109}$

109 Im Nebentext gibt Gozzi detaillierte Hinweise zur Realisierung soleher Verwandlungsszenen, um die Illusion môglichst nicht zu stören. Auf die Diskrepanz zwischen dieser 
Zusammenfassend kann man also im Hinblick auf die Präsenz von Zauber, Wunder, Übernatürlichem, auf Handlungsablauf und Figurenarsenal, die Bedeutung des Visuellen und die Formelhaftigkeit eine weitgehende Korrespondenz der Märchencharakteristika in der narrativen und in Gozzis dramatischer Gattung konstatieren. Veränderungen innerhalb der Märchenkomponente betreffen vor allem den Bereich der Figuren, die im Märchen allgemein gehalten, weder individuell gezeichnet, noch streng typisiert sind. Als solche allgemeinen Figuren treten sie auch in den dramatischen Kontext ein, doch werden sie nicht mehr narrativ vorgestellt, sondern konstituieren sich im Dialog. Über ihre Spache gewinnen sie ein eigenes Profil, das es näher zu bestimmen gilt.

\section{Theatralisierung der Märchenfiguren}

Im Rahmen der Flaba teatrale werden die Märchenfiguren in Kontrast zu den komischen Masken zu »ernsten * Rollen. Schon dies ist eine entscheidende dramaturgisch bedingte Modifikation, denn es ist ja gerade typisch für Märchenfiguren, daß sie nicht mit den Begriffen komisch, tragisch, lustig oder ernst zu fassen sind, sondern vielmehr jenseits dieser Kategorien stehen. Die Auswahl der Märchenstoffe trifft Gozzi so, daß die Hauptfiguren immer königlichen Geschlechts sind und damit der traditionellen Rollenzuschreibung für shohe«, »ernste « Figuren entsprechen. Regelkonform und zugleich mit der Prosa der Masken kontrastierend ist auch die Versform ihrer Sprache. Die endecasillabi sind wohlgesetzt, wie schon Jennaros erster Dialog mit Armilla in Il corvo zeigt:

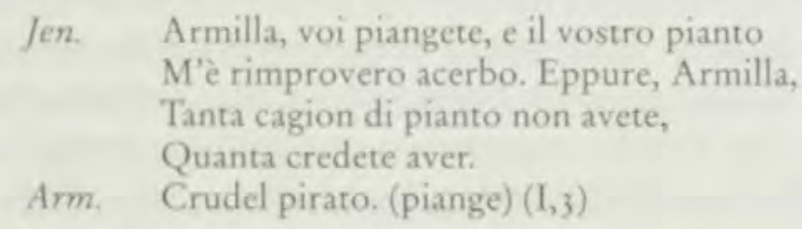

Der Rhythmus, die Zäsur im zweiten Vers und rhetorische Figuren wie Inversionen, die zweimalige Apostrophe, die wiederholte Verwendung der figura etymologica und die Alliteration, die Jennaros letzten mit Armillas erstem Vers verbindet (credete/crudel), machen deutlich, daß die Sprache der Märchenfiguren eine bewußt gehobene ist. Nur in seltenen Fällen sprechen die Märchenfiguren in Prosa oder a soggetto, wenn sie

demonstrativen Illusionswahrung und eben so deutlichen Illusionsbrechungen an anderer Stellen wird in Kap. 3.4 und 3.5 näher eingegangen. 
mit Masken zusammentreffen. In mehreren Szenen des ersten Akts von Il corvo wird das Gespräch Jennaros mit Pantalone in Prosa geführt, was mit der großen Vertrautheit Pantalones und Jennaros von Kindheit an erklärbar ist. Sobald Jennaro jedoch die Prophezeiungen Norandos vernommen hat und gewissermaßen ganz vom Märchenhaften vereinnahmt ist, spricht er nur noch in Versen. ${ }^{110}$ Diese nehmen bisweilen geradezu heroisch-pathetischen Charakter an, wenn Armilla etwa ausruft Oh Dio! Tiranno / Solo con me vuoi rimaner? T'intendo. / Prima morrò .... $(\mathrm{I}, 3)$ oder Jennaro Pantalones Fluchtvorschlag zurückweist, „Una fuga improvvisa inaspettata / Reo mi farebbe, ed innocente io sono. / Innocente morrò $(\mathrm{IV}, 7)$. Gefühlsbetonte Dialoge ergeben sich vor allem zwischen Armilla und Jennaro: nicht zu Ende geführte Sätze und Fragen, Ausrufe und unzählige Male die Anweisung *(piange) « machen die Ausweglosigkeit der Situation und die Betroffenheit Armillas, die Jennaros Schicksal ahnt, unüberhörbar. Aber auch Millo zeigt seine Rührung angesichts der Verwandlung des Bruders in eine Marmorstatue:

Mil. Soldati, amici, popoli, lasciatemi:

Qui bramo di morir, piangendo sempre.

Non mi si rechi mai cibo, o conforto.

Qui vo morir. Da quest'afflitta salma

tra sospir caldi, e lagrime sanguigne

Esca lo spirto mio.

(siede al fianco della statua, e abbraccia le ginocchia di quella) Dolce fratello,

Innocente fratel, chi mi tha tolto? $(\mathrm{V}, 3)$

Zahlreiche *a parte disperato " „ con amorevolezza , *da se con furore "a parte affannoso* unterstreichen die bewußt pathetisch-tragische $\mathrm{Ge}$ staltung der Märchenfiguren. Da typische Elemente der Märchenhandlung wie die negative Ausgangslage in Form von Verbot, Verwünschung, Mangel, Entfernung oder Bewährungsproben und Prüfungen durch die Rede der Figuren selbst vermittelt werden, kann sich in dieser Rede angesichts der problematischen Situation eine subjektive Betroffenheit manifestieren, die in Verzweiflung mündet, wenn kein Ausweg sichtbar ist. Was im Märchen in wenigen Sätzen lakonisch zur Kenntnis gebracht wird, nimmt in der Fiaba teatrale dramatische Züge an. Die Situationen, in

110 Wenn Gozzi umgekehrt Masken in Versen reden läßt wie z. B. Truffaldino in Il corvo, III, 7, oder Brighella mit Smeraldina in II mostro turchino, III, 2, so tut er dies nur in parodistischer Absicht, die er im Vorwort zu Il corvo klar zu erkennen gibt (s, u.). Dagegen sind $a$-soggetto-Partien ernster Marchenfiguren (z. B. in Laugellino belverde oder I pitocchi fortunati) auf die Notwendigkeit eines schnellen Reagierens auf Truffaldinos Improvisation zurückzuführen. 
die insbesondere die Protagonisten durch Verbote, Vorhersagungen oder Verwünschungen gestellt sind, lösen bei diesen innere Konflikte aus, die ihren Ausdruck in wortreichen, rhetorisch brillanten Monologen oder Dialogen finden. Die Fraglosigkeit und Selbstverständlichkeit des Geschehens im Märchen wird damit angetastet, doch unterbleibt sowohl eine Infragestellung der Abhängigkeit von übernatürlichen Mächten durch die Figuren als auch eine psychologisch differenzierte Handlungsweise, die ihnen Individualität verleihen würde. Vielmehr werden sie innerhalb des märchenhaft ablaufenden Geschehens zu Trägern großer Gefühle. Diese sind, wie Gozzi immer wieder betont, unentbehrlich für sein Theater auch im Hinblick auf die Kontraststruktur. * Una circostanza di fortissima passione « muß dem Komischen, Lächerlichen gegenüberstehen, damit die Spannung beim Publikum erhalten bleibt, und dies ist nicht zu erreichen ssenza colori rettorici, gradi di apparecchio, ed eloquenza pittrice artifiziosax (Col. I, 120). Die affektgeladene, rhetorische Sprache der Märchenprotagonisten entspricht den zum Äußersten getriebenen Gefühlen und Handlungen, wobei Sprache wie Verhalten gleichermaßen stilisiert sind. Einen Höhepunkt in dieser Hinsicht stellen zwei Szenen am Ende von $I l$ corvo dar, in denen Armilla sich entschließt, gemäß der Forderung ihres Vaters Norando ( $₫$ Ahi padre iniquo! / La mia morte tu brami! Or P'averai.*), ihr Blut für Jennaro zu geben: *Io ti consacro / Me stesso, e '1 sangue mio. $\propto(\mathrm{V}, 5)$. Jennaro, der wieder lebendig wird, begreift nicht sofort, warum Armilla verwundet vor ihm liegt und schwört dem Täter Rache. In wenigen Worten erklärt Armilla ihr Selbstopfer, bittet Jennaro um ein Angedenken in Dankbarkeit, $»$ Gratitudine sol nella memoria / Serba per me, se 'l merto", und stirbt vor den Augen des verzweifelten Jennaro. So formt Gozzi in Il corvo wie in den andern Fiabe teatrali die blutlosen Märchenfiguren zu höchst dramatischen Gestalten, die, ist die märchenhafte Handlung einmal in Gang gekommen, maßgeblich durch ihre Gefühle bestimmt sind.

Damit ergeben sich für die dramatische Gestaltung der Märchenkonstituente vor allem im Bereich der Figuren Parallelen zur Tragikomödie, die auch in anderer Hinsicht Ähnlichkeiten mit den Fiabe teatrali aufweist. Sind nicht-historische Stoffe, die Orientierung an narrativen Vorlagen, ernste Themen wie die Gefährdung des Lebens oder Lebensglücks der Protagonisten, das gute Ende, der hohe Stand der Hauptpersonen und das Vorkommen niederer Personen gemeinsame Charakteristika allgemeiner Art, erweist sich im spezielleren die Zeichnung der Figuren in Tragikomödie und Fiabe teatrali als weitgehend identisch. Hier wie dort stehen die leidenschaftlichen Gefühle und die heroische Haltung der königlichen (in der Tragikomödie auch adligen) Protagonisten in außergewöhnlichen 
Situationen im Vordergrund, ohne daß die Figuren psychologisch ausgearbeitet und der Motivation der Gefühle nähere Beachtung geschenkt würden. ${ }^{111}$ Die Figuren erfüllen vielmehr Funktionen in einem Geschehensablauf, der sich durch Extremsituationen auszeichnet, wobei das visuell Spektakuläre und eine gesteigerte Rhetorik auf die Imagination und die emotionale Betroffenheit der Zuschauer abzielen. ${ }^{112}$ Im Hinblick auf den Geschehensablauf bestehen allerdings entscheidende Unterschiede zwischen der Tragikomödie und den Fiabe teatrali. Während es in den Tragikomödien Menschen sind, oft ein Vater, ein Rivale oder eine Rivalin, die dem Glück der Protagonisten entgegenstehen, ergibt sich die Gefährdung in den Fiabe teatrali aus der übernatürlichen Sphäre durch Zauberer, magische Gegenstände, Prophezeiungen etc. Ist der dramatische Konflikt in der intrigen- und peripetienreichen Tragikomödie meist innerhalb des Kreises der dramatis personae durch Täuschung, angedrohten Selbstmord, Tod oder Mord lösbar, ${ }^{113}$ sind die Märchenfiguren dagegen von den Gesetzen der Märchenwelt bestimmt und in ihrer Handlungsfreiheit eingeschränkt. Auch in dramaturgischer Perspektive ist die Differenz zwischen Tragikomödie und Fiabe teatrali nicht zu übersehen: die Mischung des Personenstandes und des Tragischen mit dem Komischen in vielen Tragikomödien weist keine Kontraststruktur auf, die für die Fiabe teatrali so typisch ist. Festzuhalten bleibt jedoch eine gemeinsame stendance à frapper la sensibilité et l'imagination des spectateurs, une prédilection pour les violences de la passion ou l'héroísme chevaleresque ${ }^{11+}$ die offensichtlich weder im 17 . noch im 18 . Jahrhundert ihre Wirkung auf das

111 Vgl. Roger Guichemerre, La tragi-comédie, Paris, PUF 1981, S. 102:-Le public du temps cherchait plus dans les tragi-comédies la diversité des incidents et une agréable ssuspensione que des analyses fouillées des états d'âme ou des motivations profondes des héros. Cela explique qu'il y ait peu de scaractères dans ce genre de pièces, et que les personnages soient généralement des stypes assez sommaires, ou encore des semplois, auxquels leur fonction dans l'intrigue confêre les mêmes traits conventionnels.*

112 R. Guichemerres Charakterisierung der Rhetorik und der Wirkungsästherik der französischen Tragikomödie des 17. Jahrhundert trifft in hohem Maße auch auf die Märchenkonstituente der Fiabe teatrali zu: $\gg$ C'est en effet une véritable rhétorique passionnelle, si l'on peut dire, qu'urilisent les auteurs de tragi-comédies, rhétorique qui exprime les sentiments exaltés des personnages et cherche à faire partager au public leurs ardeurs, leurs violences, leurs douleurs. Ce langage qui ne craint ni l'outrance ni la surcharge pour mieux entrainer ou émouvoir l'auditoire, emploie avec prédilection un certain nombre de tropes et de figures de style - métaphores, hyperboles, antithèses - tandis que reviennent constamment quelques formes d'écriture théâtrale - monologues douloureux et stances lyriques a (ebd., S. r98).

133 Nur vereinzelt wird in den Tragikomodien auf Magisches, Ubernatürliches zurückgegriffen, das dann in sporadischer Weise Verwandlungen u. a. zeitigt, vgl. R. Guichemerre, op. cit., S. 189 .

$1 i 4$ Ebd., S. 9. 
Publikum verfehlt haben. Mehr als 10 Jahre nach der Uraufführung von Il corvo bemerkt Gozzi, daß er aus einem sargomento inetto, falso, e puerile, trattato con arte, apparecchio, ed eleganza* ein Stück gemacht habe, mit dem es ihm gelungen sei, $\gg[$ di] impegnar gli animi, ridurli ad ascoltare con serietà, e commoverli sino al grado delle lagrime* (Col. I, I I 8). Damit ist die Reaktion der Zuschauer im Theater eine gänzlich andere als die der Zuhörer eines Märchens. Genau so wenig wie das Märchen mit den Kategorien komisch, tragisch, lustig, ernst zu fassen ist, so wenig lacht oder weint der Zuhörer oder Leser; höchstens empfindet er Genugtuung über den guten Ausgang. ${ }^{15}$ Die Fiabe teatrali dagegen zielen, was die Märchenkonstituente anbelangt, bewußt auf Mitgefühl und -leiden.

\subsection{Commedia dell'arte als Konstituente der, Fiabe teatrali}

Als Antidot gegen die starken Gefühle der Märchenfiguren wirken die vier Masken der Commedia dell'arte, die in Gozzis Stücken die traditionellen Namen Tartaglia, Pantalone, Truffaldino und Brighella tragen und sich auf der Bühne durch typische Masken und Kostüme augenfällig von den Märchenfiguren abheben. Analog zum Märchen übernimmt Gozzi auch aus dem komplexen Phänomen Commedia dell'arte einzelne Komponenten und integriert diese in den neuen Kontext der sfiaba teatrale «. Auf dem Hintergrund einer skizzenhaften Darstellung der Charakteristika und der Geschichte der Commedia dell'arte wird die selektive, kombinatorische Vorgehensweise sichtbar, die, wie Gozzi immer wieder betont, etwas ganz Neues, "un nuovo genere di rappresentazioni Teatralis, ${ }^{116}$ hervorbringt.

\section{$\mathrm{Zu}$ Begriff und Geschichte der Commedia dell'arte}

Wie problematisch eine Beschreibung der Commedia dell'arte ist, mag aus folgender Äußerung Fernando Tavianis hervorgehen: •Molti credono che la Commedia dell'Arte sia una tradizione italiana, e che il suo segreto

Iis A. Jolles nennt als Reaktion - Befriedigung * (-Wenn nun aber Personen und Begebenheiten des Märchens auch nicht den Eindruck des eigentlich Moralischen machen, so kann man doch nicht leugnen, daß sie eine Befriedigung gewahren ${ }^{\text {) }}$ ) und fuhrt diese darauf zurück, $\Rightarrow$ daß es in diesen Erzahlungen so zugeht, wie es unserem Empfinden nach in der Welt zugehen müßte (op. cit., S. 239).

116. Prefazione zu Il corvo, Col. I, 124. 
sia l'improvvisazione. [...] La storia della Commedia dell'Arte è forse la storia del suo mito e nient'altro $*{ }^{117}$ Wenn dem tatsächlich so sein sollte, hatten die venezianischen Theaterdebatten des 18 . Jahrhunderts neben der über Paris und die Comédiens italiens erfolgten Rezeption der Commedia dell'arte sicher keinen geringen Anteil an der Entstehung dieses Mythos. Einer der ersten, wenn nicht überhaupt der erste Beleg für den Terminus *ommedie dell'artex findet sich bei Goldoni, in Il teatro comico (1750), ${ }^{118}$ dem programmatisch metatheatralischen Stück. Dort stellt Placida, die "prima Donna , die alten $\nsim$ commedie dell'arte $\alpha$ der $*$ commedia di carattere« neuen Stils gegenüber:

Se facciamo le commedie dell'arte, vogliamo star bene. Il mondo è annoiato di veder sempre le cose istesse, di sentir sempre le parole medesime, e gli uditori sanno cosa deve dir l'Arlecchino, prima ch'egli apra la bocca. Per me vi protesto, signor Orazio, che in pochissime commedie antiche reciterò; sono invaghita del nuovo stile, e questo solo mi piace: dimani a sera reciterò, perché, se la commedia non è di carattere, è almeno condotta bene e si sentono ben maneggiati gli affetti. $(\mathrm{I}, 2)$

Scheint hier der Begriff zur Bezeichnung eines dramatischen Genus zu dienen, setzt in der übernächsten Szene eine Replik Toninos, der die Rolle des Pantalone spielt, einen anderen Akzent:

Caro sior Orazio, buttemo le burle da banda, e parlemo sul sodo. Le commedie de carattere le ha buttà sottosora el nostro mistier. Un povero commediante, che ha fatto el so studio segondo l'arte, e che ha fatto l'uso de dir all'improvviso ben o mal quel che vien, trovandose in necessità de studiar e de dover dir el premedità, se el gh'ha reputazion, bisogna che el ghe pensa, bisogna che el se sfadiga a studiar $[\ldots](I, 4)$

Mit "studio segondo l'arte u und "dir all'improvviso charakterisiert Tonino die Schauspieltechnik und stellt sie dem Studium und Sprechen eines vorgegebenen Textes gegenüber, während eine Anmerkung Goldonis im 3. Akt eine weitere Bedeutungsvariante ins Spiel bringt: dort bezeichnet Goldoni die von Lelio im Stück als »anticaglie « abqualifizierten Titel $L a$ statua, Il finto principe und Madama Pataffia als "commedie delle peggiori dell'arte $\propto(I I, 9)$ und meint damit einen Teil des Repertoires der professionellen Schauspieltruppen, das Stücke unterschiedlicher Art umfaßt und über Generationen tradiert wird. ${ }^{119}$ Daß Giuseppe Baretti in seiner

II) So Fernando Taviani in einer bahnbrechenden Studie zur Commedia dell'arte: Fernando Taviano, Mirella Schino, Il segreto della Commedia dell'Arte, Firenze, Usher 1982, S. 295 .

$118 \mathrm{Vgl}$. F. Taviani, op, cit., S. 435 .

119 Piermario Vescovo stellt in seinem Artikel = La riforma nella tradizionen, in: Carmelo Alberti; Gilberto Pizzamiglio (Hgg.), Carlo Goldoni 1793-1993, Venezia, Regione del 
Rezension von Il teatro comico in La frusta letteraria Goldonis Gegenüberstellung von scommedie dell'arte* und scommedia di carattere" polemisch aufgreift, wobei er scommedia di carattere* typographisch hervorhebt und zum Terminus "commedie dell'arte" ergänzend hinzufügt scom'egli le chiama «, ${ }^{120} \mathrm{kann}$ als weiterer Beleg für die semantische Unschärfe des Begriffs in der zeitgenōssischen Terminologie gewertet werden. Der Übergang von der pluralischen Verwendung zum Singular ncommedia dell'arte im Sinne eines dramatischen Genus oder eines Phānomens wurde maßgeblich durch Texte Carlo Gozzis eingeleitet. ${ }^{124}$

Grundlegend für das Phänomen Commedia dell'arte in historischer Hinsicht ist das Auftauchen professioneller Schauspieltruppen, die nicht nur zum Vergnügen - dem eigenen und dem der Zuschauer - in besonderem Rahmen zu Festzeiten auftraten, sondern das Theaterspielen zum Beruf machten. Bereits Anfang des 16. Jahrhunderts existierten solche organisierten Truppen, die sich aus zwei Sphären zusammensetzten, der des Straßentheaters der *ciarlatani und *saltimbanchi und der des höfischen Theaters. Die neue Organisationsform brachte zum einen einen sozialen Aufstieg der Gaukler und Jahrmarktschreier mit sich, zum anderen profitierte sie vom Wissen und Können des höfischen Theaterspiels. ${ }^{122}$ Eine wichtige Rolle spielten in diesem Zusammenhang die Frauen, die in diesen Truppen arbeiteten und weitgehend über deren Erfolg entschieden. Sie gelten als Kulturträgerinnen und machten vor allem in den sechziger Jahren von sich reden wie zuvor die meretrices honestae. In der zweiten Jahrhunderthalfte traten so renommierte Kompanien wie die Gelosi, Confidenti, Accesi, Fideli hervor, die sowohl im höfischen Rahmen als auch außerhalb agierten. Beispielhaft sei die Aufführung von Tassos Aminta 1573 durch die Gelosi genannt, die in ganz Norditalien sowie an

Veneto, 1995, S, 137-155, hier S. 140-142, die Bedeutung im Sinne eines Teils des Repertoires in den Vordergrund.

182 Giuseppe Baretti, La frasta letteraria, Hg. Luigi Picconi, Bd. 3, Bari, Laterza 1932, S. 316.

124 Vgl. Piermario Vescovo, *.La più lunga lettera di risposta che sia stata scritta ..... Riflessioni sull'ultimo Gozzik, in: Bodo Guthmuller, Wolfgang Osthoff (Hgg.), Carlo Gozzi. Letteratura e musica, Roma, Bulzoni 1997, S. $119-140$, hier S. $122 \mathrm{ff}$. Wenn sich bei Goldoni auch wie z. B. im Vorwort zu Band XII der Pasquali-Ausgabe neben der hàufigen Verwendung der pluralischen die Singular-Form findet, ist tatsächlich weniger ein dramatisches Genus als ein Element des Repertoires gemeint: - Entrato dunque e preso posto in Arena, vidi che si rappresentava in quel giomo una Commedia dell'Arte, nella quale aveva molto a faticar l'Arlecehino.* (Goldoni, L, 707).

12 Vgl. K. Richards, L. Richards, op. cit, S. 35 ff, und F. Taviani, M. Schino, op. cit, S. 359 : -Il teatro delle compagnie dell'Arte apri, insomma, per la prima volta un carale fra il mondo chiuso degli spettacoli di strada $e$ il mondo della cultura e degli spertacoli non subalternics. 
zahlreichen europäischen Höfen spielten. Allein diese Tatsache spricht gegen die hartnäckig sich haltende Vorstellung, die Commedia dell'arte sei volkstümlich, populär und als Theater besonders für niedere Bevölkerungsschichten konzipiert. Was die Aufführungsorte außerhalb der Höfe betrifft, ${ }^{123}$ betont Fernando Taviani, daß Aufführungen nicht auf freien Plätzen, sondern in Sälen stattfanden, während Kenneth und Laura Richards auch Straßen und Plätze als Aufführungsorte nennen, zugleich jedoch erwähnen, daß geschlossene Räume den kommerziellen Interessen der Truppen insofern entgegenkamen, als dort kontrolliert Eintrittskarten verkauft werden konnten. Daß das Theater nun käuflich war, damit neue Publikumsschichten erschlossen wurden und das Gesetz von Nachfrage und Angebot galt, sind Hauptaspekte der Commedia dell'arte, die aus heutiger Perspektive oft unterbewertet sind, während Improvisation und Maskenfiguren - zwei fundamentalen Aspekten des $\$$ Mythos $*$ Commedia dell'arte - zu viel Gewicht beigemessen wird. Nicht nur stellten die Maskenfiguren ursprünglich einen Teil des ausgeglichenen dramaturgischen Gesamtgefüges dar, ohne es zu dominieren, auch wechselten die Schauspieler die Rollen, so daß die gängige Identifikation von Darsteller und Rolle, von Schauspieler und Maske ebenfalls in den Bereich des Mythos zu verweisen ist, ${ }^{124}$ der sich hauptsächlich auf spätere ikonographische Darstellungen gründet, während zeitgenössische schriftliche Quellen den Masken wenig Beachtung schenken.

Ähnlich problematisch ist die Vorstellung der Commedia dell'arte als Improvisationstheater, wenn der Begriff der Improvisation nicht näher geklärt wird. ${ }^{125}$ Je nach Blickwinkel steht die Freiheit der schauspieleri-

12s Nach Roberto Tessari, Commedia dell'arte: la maschera e l'ombra, Milano, Mursia 1981, S. 65, mieteten zunächst die Schauspieler, die sich bewußt von den Gauklern unterscheiden wollten, fur ihre Darbietungen in den Städten Zimmer oder Säle; an die Höfe kamen sie selbstverständlich erst, wenn sie über ein gewisses Renommee verfügten.

It4 Vgl. F. Taviani, M. Schino, op. cit., S. 350: *Fisso, per noi, sempre in una stessa maschera, l'attore dell'Are era invece visto dai contemporanei sotto il segno di Proteo, il dio delle infinite trasformazioni.

123 Der deutsche Terminus oStegreiftheater verleitet noch mehr zur Annahme, die Aufführung entstehe ad hoc aus der Laune der Schauspieler. Noch 1992 schreibt Bernhard Greiner in Die Komödie, Tübingen, Francke 1992, S. 70: - Es gibt nur einen glühenden Augenblick der hier und jetzt mit höchster Lust sich präsentierenden Körper - in Pantomime, Akrobatik, Tanz, Stimme - und das Hier und Jetzt der witzigen Rede in der schlagfertigen Replik, dem unerwarteten Wortspiel, und schon folgt der nächste Augenblick, wieder tendenziell ganz für sich, vom vorherigen oder folgenden kaum etwas wissend..

Schon Gozzi weist in *Appendice al Ragionamento ingenuo del Tomo primo* im 4. Band der Colombani-Ausgabe darauf hin, daß nicht der Handlungsverlauf improvisiert sei, sondern die Dialoge: $\rightarrow$ Spero, che mi sarà concesso, che la Commedia improvvisa stia negl'improvvisi dialoghi, che la tessono, e non in una improvvisa orditura. [...] Chi 
schen Gestaltung im Vordergrund oder aber die Gebundenheit an »generici und szibaldoni $\alpha$, die den Schauspielern ein Repertoire an Repliken, Dialogen, Scherzen, literarischen Zitaten boten, das diese jeweils neu einsetzen, kombinieren und variieren konnten. Entscheidend für den Improvisationsbegriff ist zunächst sicher nicht die Virtuosität des Einzelnen, sondern das dramaturgische Vermögen der ganzen Truppe. Nicht umsonst wird in diesem Zusammenhang von *teatro degli attori ${ }^{2}$, vom Schauspielertheater, gesprochen, das nicht einem geschriebenen Text mit vorgegebenen Rollen folgte, sondern sich auf der Basis von Handlungsschemata ${ }^{126}$ entfaltete, die in den Truppen ebenso über Generationen tradiert wurden wie die szenische Technik und das dramaturgische Wissen eines jeden Schauspielers, die diese Art der Aufführung erforderten. Fernando Taviani charakterisiert dieses Theater als steatro della parola parlata contrapposto alla parola scritta: sia perché esso trasmette quasi sempre oralmente la composizione dei suoi spettacoli, sia perché all'interno degli spettacoli gli attori, indipendenti dagli scrittori per quanto riguarda la dicitura, possono potenziare tutti quegli aspetti, a cominciare dal plurilinguismo, che difficilmente vengono sfruttati dagli scrittori ${ }^{127}$

vedesse il soggetto, che serve di guida a que' valenti Comici per far la Commedia ogni sera, posto a un lumicino per comodo di tutta la Truppa, direbbe tosto, che la Commedia è all'improvviso, e stupirebbe, che colla traccia di alcuni cenni compresi da un foglio, dieci, o dodici persone si espongano al Pubblico coraggiosamente a tessere uno spettacolo di dialoghi, che dura tre ore, che tiene sempre allegro l'Uditorio, e che conduce l'argomento proposto al suo fine. - (Col. IV, 34 ). Für weniger versierte Schauspieler existierten die "generici-, die Gozzi, wie er in seinen Memoiren schreibt, für die Truppe Sacchi überarbeitete: *Non so dire [...] quante migliaia di fogli abbia empiuti di soliloqui, di disperazioni, di minacce, di rimproveri, di preghiere, di correzioni paterne e d'altri discorsi ch'entrano a proposito nelle scene delle commedie improvvisate e che i comici chiamano senerici, necessari agli attori ed alle attrici non pratici di quell'arte per riscuotere degli applausi* (Mem. I, 25s).

126 Solche Handlungsskizzierungen werden als =scenario-, *canovaccio* oder =soggettobezeichnet und von Andrea Perrucci in seinem Traktat über die darstellende Kunst von 1699 folgendermaßen beschrieben: - Il Soggetto non è altro, che una tessitura delle Scene sopra un Argomento formato, dove in compendio si accenna un' azzione [sic], che deve dirsi, e farsi dal Recitante all'improvviso, distinguendosi per atti, e per scenes, in: Andrea Perrucci, Dell'arte rappresentativa premeditata ed all'improvviso, $\mathrm{Hg}$. Anton Giulio Bragaglia, Firenze, Sansoni antiquariato 1961, S. 256.

ID F. Taviani, M. Schino, op. cit., S. $371-372$.

Vito Pandolfi spricht in seiner ausführlichen Studie und Dokumentation vom historischen Interesse an der sautonomia dell'arte dello spettacolos, die an der Commedia dell'arte festgemacht werden kŏnne und lehnt in diesem Zusammenhang eine stilistische Untersuchung, die sich nur auf ascenaris, d. h. Handlungsskizzen, stutzen kann, mit folgender Begrùndung ab: >ma questa, che finora è stata considerata la fonte principale, mi sembra in realtà la più indiretta, e la più povera di reali contributi, non potendo certo quei sommari schemi di vicende offrire una sia pur limitata visione dello spettacolo che ne risultava. * V. Pandolfi, La Commedia dell'Arte, op. cit., Bd. 3, S. 1 L. 
Was das Repertoire der Truppen angeht, unterschied sich dies nicht wesentlich von dem akademischer Dilettanten: Es umfaßte Komödien, Tragödien, Tragikomödien, Farcen, Schäferspiele, Intermezzi, die je nach Nachfrage und Marktlage angeboten wurden. Die Handlungsverläufe orientierten sich, was die Komödien betrifft, vielfach an Plautus und Terenz sowie an geschriebenen Stücken zeitgenössischer Autoren oder beruhten auf einer Modifikation beziehungsweise Kombination vorliegender Texte. 128

Trifft diese Skizzierung des Phänomens Commedia dell'arte vor allem für das 16. und noch den Anfang des 17. Jahrhunderts zu, so ergibt sich für das I8. Jahrhundert ein anderes Bild, wobei häufig tatsächliche Veränderungen und tradierte Vorurteile kaum mehr zu unterscheiden sind. Bereits im 17. Jahrhundert setzen die Auseinandersetzungen um die Commedia dell'arte ein, ${ }^{129}$ die noch im 18 . Jahrhundert Gegnern und Befürwortern Argumente für ihre jeweilige Position an die Hand geben werden und in ihrer diskursiven Zuspitzung einzelner Aspekte der Entstehung des Mythos Commedia dell'arte Vorschub leisten sollten. In Luigi Riccobonis Histoire $d u$ thêatre italien von 1728 findet sich neben einem Abriß über die Geschichte der Commedia dell'arte eine Darstellung ihrer Charakteristika, die als weitgehend repräsentativ für die zeitgenössische italienische Meinung gelten darf: Die Commedia dell'arte entstand in der Zeit eines Geschmacksverfalls, sie entbehrt einer klaren dramatischen Struktur sowie jeden moralischen Anspruchs und ist Zeugnis eines übertriebenen schauspielerischen Ehrgeizes. ${ }^{130}$ Solche und ähnliche abwertende Urteile ziehen sich durch die Mehrzahl der poetologischen Texte des I8. Jahrhunderts, durch Theatergeschichten und Vorworte zu gedruckten Stükken und finden in Goldonis Teatro comico einen beredten Ausdruck auf der Bühne selbst.

128 In Appendice al Ragtonamento beschreibt Gozzi das Repertoire der Sacchi-Truppe und weist darauf hin, daß viele Komödien von Terenz, Plautus und Porta im spanischen und italienischen Theater als ausgeschriebene längst vergessen sind, während sie als Vorlagen für *commedie all'improvviso* weiterleben (Col. IV, 46-47).

129 Dazu ausführlicher in Kap. 3.

130 Luigi Riccoboni, Histoire du theiatre italien, op. cit, S. 46-47 und S. 74-75: - Le Siècle seizième fini, vers l'an 1620 , les belles lettres tomberent beaucoup en Italie. Dans cette décadence c'eût été un grand miracle que le Thêâtre fût conservé dans sa regularité, [...] les Monstres qui avoient succedé à la Tragedie n'en portoient point le nom glorieux [...]. On les fit en Prose \& en trois Actes. LArlequin \& tous les autres Acteurs masqués y furent introduits, pour achever de gàter notre Théätre Tragique. La Comedie écrite de son côté ceda la place à la Comedie Impromptu qui resta de nouveau la seule Maitresse du Champ de Bataille. $\propto$ Plus de Comedies nouvelles qui réveillassent la curiosité des honnêtes gens, mais des farces le plus souvent remplies de sotises énormes, ces Comediens ignorans qui n'avoient ni esprit, ni talent, ni mours, n'avoient d'autres recours qu'à la source intarissable des polissonneries.a 
Carlo Gozzi dagegen schreibt nicht nur einen Dithyrambus auf den berühmtesten Truffaldino-Darsteller der Zeit, Antonio Sacchi, sondern greift auch in seinen Fiabe teatrali Elemente der Commedia dell'arte auf und setzt diese entgegen Goldonis explizitem Verdikt bewußt ein. Legt man als einen der wichtigsten Aspekte der Commedia dell'arte das NichtVorhandensein eines ausgeschriebenen Textes und damit die schauspielerische Improvisationsleistung zugrunde, steht Gozzis erstes Theaterstück, L'amore delle tre melarance, unzweifelhaft in dieser Tradition - analog zu Goldonis frühen Stücken, die erst später zur Veröffentlichung in den Gesamtausgaben als geschriebener Text ausgearbeitet wurden, wie aus den Vorworten der Pasquali-Ausgabe hervorgeht. ${ }^{131}$ Die nachträglich verfaßte Analisi riflessiva der ersten Fiaba teatrale Gozzis sowie Außerungen in den Memorie inutili ${ }^{132}$ legen nahe, daß für die Aufführungen ein sscenario existierte, das den Schauspielern als Arbeitsgrundlage diente, den Handlungsgang skizzierte sowie möglicherweise bestimmte Dialogpartien verzeichnete, die nicht improvisiert werden sollten, wie etwa die Verwünschungen Morganas im Stile Chiaris oder die Parodie der Martelliani-Verse. Alle folgenden Stücke hingegen lagen der Truppe als geschriebene dialogische Texte vor, die der Improvisation nur noch wenig Raum lassen und diese grundsätzlich auf die Masken beschränken. Die von Gozzi in allen Fiabe teatrali beibehaltenen Maskenfiguren sprechen nun teils vorgegebenen Text, teils improvisieren sie, wobei entsprechende Passagen lediglich Anweisungen für den Dialog bzw. Monolog, die Gestik und Mimik enthalten, wie ein Auszug aus Il re cervo (II, 13 ) zeigt, in dem Truffaldino den Papagei fängt:

Esce con una rete in collo, e varj attrecci attinenti all'uccellatura. Esamina il luogo, lo trova opportuno a tendere insidie a' volatili. Vede il cervo morto, l'esamina, scopre, ch'egli ha la macchia bianca sulla fronte, si ricorda la taglia posta dal Re, fa de' trasporti di gioja sopra 'I buon principio dell'uccellatura. Tende la sua rete, discorrendo indispettito del torto fattogli da Smeraldina. Rammemora i regali, che le ha fatti di uccelli. Protesta di non voler più guardarla. Parla con voce bassa per non sturbare l'uccellagione. Tesa la rete, si ritira da una parte. Suona varj zuffoletti da uccellatore per richiamo di uccelli, ne suona di caricati, e proporzionati al suo carattere. Scopre il pappagallo, ch'è 'I Mago Durandarte, ivi lasciato da Ci-

in Siehe zum Obergang von ungeschricbenem zu aufgeschriebenem Theater und den Eigenheiten der gedruckten Ausgaben die ausfuhrliche Studie von L. Riccó, =Goldoni, Chiari, Gozzi fra scritto e non scritton, op. cit., S. 7-67.

$132 \mathrm{Vgl}$. Carlo Gozzi. Mem. 1, 230 und 264, wo Gozzi die erste Fiaba als -il mio strano apparecchio und sordita parodia d'abbozzo comico allegorico * bezcichnet. 
golotti. Mostra avidità di prenderlo nella rete. Fischia con caricatura, s'affanna. II pappagallo entra volontario nella rete.

Wenn diese Art der Notierung dem Schauspieler auch relativ viel Freiheit läßt, ist es doch ein grundsätzlich anderes Vorgehen als in der Commedia dell'arte. Während dort das szenische Spiel und der Dialog aller Akteure auf der Grundlage einer Handlungsskizze erwächst, sprechen in Gozzis Fiabe teatrali die Schauspieler einen vom Autor wörtlich vorgegebenen Text, in den sich die a-soggetto-Partien einfügen müssen, wobei nicht nur auf sprachlich folgerichtige Übergänge zu achten ist, sondern auch auf inhaltliche Aspekte, die unter Umständen für den vorausgehenden oder folgenden vorformulierten Text relevant sind. Im Vorwort zu Il corvo geht Gozzi auf die Problematik eines solchen Verfahrens ein und unterstreicht die Diskrepanz zwischen schriftlicher Fixierung und Improvisationsgabe der Maskenschauspieler:

Si troverà, ch'ella [i.e. la Fiaba teatrale] è scritta parte in versi, parte in prosa, e ch'ell'ha alcune scenette disegnate col solo argomento, e coll'intenzione.

Chiunque vorrà prestar assistenza alla Truppa Sacchi, e sostener le maschere, e la Commedia improvvisa dell'arte, farà ciò, che feci io, o prenderà un granchio.

Il Signor Chiari ha voluto far parlare in versi le maschere; ha fatto lor dire delle gran freddure, e, facendo corbellar quelle, ha fatto corbellare se stesso. La scena settima nell'atto terzo del Corvo è una picciola parodia su questo proposito.

Nessuno potrà scrivere la parte d'un Truffaldino in prosa, non che in versi, e il Sacchi è uno di quegli eccellenti Truffaldini da eseguir l'intenzione, scritta da un Poeta in una scena improvvisa, in modo da superar ogni Poeta, che volesse scriverla. (Col. I, 121-122)

Offensichtlich handelt es sich hier um ein zweifaches Problem: zunächst um die Integration improvisierter Passagen in einen ausgeschriebenen Text, der der Aufführung zugrunde liegt, sodann um die Möglichkeit der Überlieferung improvisierter Passagen. Sollen die Stücke publiziert und dauerhaft als Text einer Leserschaft zugänglich gemacht werden, ist die schriftliche Form unumgänglich, auch wenn sie weder imstande ist, das szenische Spiel exakt vorzugeben noch es adäquat wiederzugeben.

Damit sind zwei wesentliche Charakteristika der Commedia dell'arte, nämlich das der Oralität - sowohl im Hinblick auf die Tradierung des Repertoires als auch auf die szenische Technik aller Schauspieler -, und das der schauspielerischen Autonomie nicht mehr gegeben. Aus Gozzis Vorwort geht deutlich hervor, daß der Schauspieler, und sei er ein so exzellenter Maskendarsteller wie Sacchi, der Intention des Autors zu folgen und diese möglichst weitgehend zu erfüllen hat. Von einem *Schauspielertheater* oder »Schauspieler-Autor $\alpha$ kann nicht mehr die Rede sein, vielmehr ist es ein Autorentheater, das allerdings im Hinblick auf eine be- 
stimmte Truppe mit Masken konzipiert ist und damit unübersehbar auf die Tradition der Commedia dell'arte verweist. Sowohl Goldoni als auch Chiari und Gozzi produzierten über Jahre hinweg für jeweils eine Kompanie, die fest an ein Theater gebunden war und deren Schauspieler mit ihren Stärken und Schwächen sie bestens kannten. ${ }^{133}$ Das Repertoire setzte sich aus der Commedia dell'arte-Tradition, Stücken zeitgenössischer italienischer Autoren sowie Übersetzungen vor allem aus dem Franzôsischen zusammen, wobei das Publikum ersteres besonders schätzte, ${ }^{14}$ Aus dieser Situation erklärt sich die Präsenz der Masken auch in den frühen Stücken Goldonis und Chiaris, die dabei das Talent und die Tradition der Schauspieler, die Anziehungskraft dieser Partien beim Publikum sowie den ökonomischen Aspekt im Auge hatten. Wie aus Gozzis Vorwort zu Il corvo hervorgeht, ging Chiari, um die Masken in geschriebene Stücke einzubinden, so weit, sie in Versen sprechen zu lassen, was zwangsläufig zu einem grotesken Verhältnis zwischen den typisierten Eigenschaften der Figur und ihren neuen sprachlichen Charakteristika

139 Goldoni wie Gozzi erwahnen die Tatsache, da 6 sie die Rollen den Schauspielern auf den Leib schreiben, in Vorworten bzw. Memoiren. Goldoni schreibt z. B. im Vorwort zum 11. Band der Pasquali-Ausgabe: stutte le opere teatrali che ho poi composte, le ho scritte per quelle persone ch'io conosecva, col carattere sotto gli ocehi di quegli Attori che dovevano rappresentarle, e ciò, cred 'io, ha molto contribuito alla buona riuscita de' miei componimenti- (Goldoni, 1, 694), Gozzi in seinen Memoiren: sin un breve giro di tempo studiai e penetrai filosoficamente tanto bene gli spiriti e i caratteri de' mici soldati che turte le parti da me scritte ne' miei capricci poetici teatrali, composte con la mira all'anima de' miei personaggi e a quelli addossate, erano esposte sul teatro per modo che sembrava che uscissero da' loro propri cuori naturalmente, e perciò piacevano doppiamente* (Mem. I, 249). In der Fortsetzung des Textes weist er darauf hin, daf Goldoni ebensó gearbeitet habe. Zur Bedeutung einzelner Schauspieler für die Fiabe teatrali vgl. Franco Vazzoler, -Un napoletano a Venezia: Agostino Fiorilli (Tartaglia) fra Sacchi e Gozzie, in: C. Alberto (Hg.), Carlo Gozzi, scrittore di teatro, op. cit., S. 151-169. Bemerkenswert ist, daß einige wichtige Mitglieder der Truppe Sacchi, für die Gozzi die Fiabe teatrali schrieb, bereits in der Kompanie (Compagnia Imer) gearbeitet hatten, bei der Goldoni und Chiari in den Jahren zuvor als Stuckeschreiber angestellt gewesen waren, so daß die fruhen venezianischen Stücke Goldonis, Chiaris und Gozzis von nahezu denselben Schauspielern aufgeführt wurden.

134 Ein wertvolles Dokument, das Einblick in das Repertoire des Teatro di San Luca gibt, ist der $=$ Squarzo degli utili del teatro per le recite relative degli Autunni e Carnovali

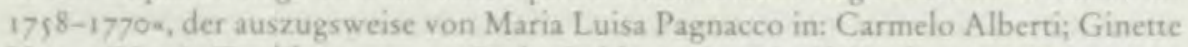
Herry (Hgg.), Tra libro e scena. Carlo Goldoni, Venezia, Il Cardo 1996, S. 103-119. veröffentlicht wurde.

Goldoni berichtet im Vorwort zum 13. Band der Pasquali-Ausgabe über das Commedia dell'arte-Repertoire der Truppe an San Luca; -il solo Cicisbeo sconsolato [von Giovan Battista Fagiuoli] era stato addottato dai Comici fra le Commedie dell'Arte, ma sfigurato, e ridotto alla foggia de' loro pasticci, come fatto avevano della Sorella del Porta, dei Menechmi di Plauto, del Convitato di pietra e di molte altre, che non conoscevano de' loro Aurori che il titolo.s (Goldoni, I, S, 716). 
führen mußte. ${ }^{135}$ Einige Jahre nach diesen wenig glücklichen Versuchen, als Chiari und Goldoni im Namen eines sreformierten Theaters $*$ bereits ganz auf die Masken verzichteten, betraten sie in Gozzis Stücken die Bühne wieder. Nicht, daß sie verschwunden gewesen wären - im Commedia dell'arte-Repertoire agierten sie selbstverständlich weiter, doch aus den geschriebenen Stücken hatte Goldoni sie nachdrücklich verbannt.

\section{Charakteristika und Funktion der Masken}

Wenn Gozzi - zunächst polemisch in L'amore delle tre melarance, dann aber in allen folgenden, ausgeschriebenen Fiabe teatrali wie selbstverständlich - Maskenfiguren der Commedia dell'arte unter die dramatis personae mischt, so stellt sich zum einen die Frage nach ihren Charakteristika in diesem neuen Kontext, zum anderen die nach ihrer Funktion.

Festzuhalten ist, daß Gozzi in den Fiabe teatrali immer dieselben vier Masken auftreten lässt: Tartaglia, Pantalone, Truffaldino und Brighella, wobei die Reihenfolge ihrer Nennung von Stück zu Stück varïiert. Diese Konstanz der Masken steht in engem Zusammenhang mit der Besetzung der Truppe Sacchi, die über entsprechend geeignete, auf diese Rollen spezialisierte Schauspieler verfügte, ${ }^{136}$ wobei die Vierzahl, untergliedert in die paarweise Anordnung Tartaglia/Pantalone und Truffaldino/Brighella, für den strukturellen Aspekt der Fiabe teatrali wesentlich ist. Einen ausgesprochenen Kontrast zu den aus dem Märchenkontext kommenden Figuren bilden die Masken hinsichtlich dramaturgischer und sprachlicher Charakteristika, die sie bereits in der Commedia dell'arte auszeichnen. In dramaturgischer Hinsicht verkörpern sie - vor allem in der Gestalt Truffaldinos - das eigentlich Theatralisch-Spielerische, in sprachlicher tragen sie durch ihren Dialekt oder andere Eigenheiten wesentlich zum »plurilinguismo bei. Wenn, wie in der Analisi riflessiva beschrieben, eine Improvisationsszene Truffaldinos 20 Minuten dauern konnte, unterstreicht dies das bewußt eingesetzte spielerisch-virtuose Moment. Offenbar hatte sich

135 Die Komödie, auf die Gozzi anspielt, ist L'inganno amoroso, uraufgeführt in der Saison $1754 / 55$, in der nicht nur die venezianische Figur Zanetto, sondern auch Arlecchino in gereimten martellianischen Versen sprechen. Zur poetologischen Auseinandersetzung um die Masken und die Commedia dell'arte siehe Kap. 3.I.

136 Vgl. Carlo Gozzi, Mem. I, 245 ; - Antonio Sacchi, Agostino Fiorilli, Atanagio Zannoni, Cesare Derbes erano le quattro maschere: Truffaldino, Tartaglia, Brighella e Pantalone; rutti attori eccellenti nella lor professione. La perizia nell'arte, la prontezza, la grazia, la fertilitá, i lazzi, i sali, le arguzie, la naturalezza e molta filosofia erano le loro doti.* Es fallt auf, daß der Dottore bei Gozzi nirgends auftaucht und konsequent alternative Namen für Truffaldino wie Arlecchino oder Pulcinella vermieden werden. 
gegenüber den Anfängen der Commedia dell'arte eine Verschiebung des ursprünglich ausgeglichenen Verhältnisses zwischen Maskenfiguren und nicht maskierten zugunsten der Masken ergeben, deren improvisatorisches Spiel bereits im 17. Jahrhundert sichtlich breiteren Raum einnahm ${ }^{137}$ und damit auch die Identifikation von Schauspieler und dargestellter Maskenfigur begünstigte. Die dramaturgisch sinnvoll eingebetteten lazzi entwickelten sich mehr und mehr zu kleinen Bravourstücken der Masken, die den Handlungsrahmen sprengten und gewissermaßen zu eigenständigen "Einlagen * wurden. ${ }^{138}$ Was die Sprache anbelangt, unterscheiden sich die Masken in der Commedia dell'arte von den übrigen parti durch Eigenheiten unterschiedlicher Art. Ublicherweise setzte sich das Figurenspektrum aus den Paaren der innamorati, der vecchi und der zanni sowie dem capitan, der vecchia und weiteren variablen Personen zusammen, wobei die Namen der Figuren regional variieren. ${ }^{139}$ Während das Liebespaar stets korrektes toskanisches Italienisch spricht, kommen der stotternde Tartaglia aus dem neapolitanischen Kontext, der Dottore oder Graziano aus der Universitätsstadt Bologna und Magnifico oder Pantalone aus Venedig. Sind diese Figuren sprachlich jeweils regional oder durch ein besonderes Merkmal wie das Stottern festgelegt, richtet sich der Dialekt der beiden zanni, Dienerfiguren mit wichtiger dramaturgischer Funktion, meist nach dem Aufführungsort: sie sprechen -Milanese, Bergamasco, Napolitano, o Siciliano, ed altre maniere ", wie Perrucci schreibt. ${ }^{140}$

Indem Gozzi in den Fiabe teatrali Tartaglia, Pantalone, Truffaldino und Brighella auftreten läßt, wählt er bewußt dramaturgisch wie auch

137 In einem nicht datierten Text des Schauspielers Pier Maria Cecchini (1563-1645) zur Commedia dell'arte (abgedruckt in: V. Pandolfi, La commedia dell'arte, op. cit., Bd. 4, 5. 78-90) findet sich zu den "parti ridicole a folgende Bemerkung: - le quali parti quantunque dilettino, molte volte perô rompono il filo della Comedia, e fanno cosi le lor digressioni dimenticare il soggetto all'ascoltante $[\ldots]=($ S. 88).

$138 \mathrm{Vgl}$. Marco De Marinis, Capire al teatro. Lineamenti di una nuova teatrologia, Roma, Bulzoni 1999, S. 132, Anm: sda azione molto complessa, >burla ben integrata nella drammaturgia dello spettacolo comico (come, ad esempio, negli scenari di Flaminio Scala), il lazzo (che - giova ricordarlo - come termine compare per la prima volta solo con Basilio Locatelli, intorno al 1620 ) si trasforma, con il tempo, in una micro-azione spesso slegata dalle strutture generali e quindi con effetto centrifugo rispetto ad esse. \&

109 Goldoni notiert im Vorwort zum 13. Band der Pasquali-Ausgabe die Zusammensetzung der Compagnia Imer zur Zeit, als er für diese zu schreiben begann (1734). Danach bestand die Truppe, die das Teatro San Samuele bespielte aus $\mathrm{t}_{3}$ Schauspielerinnen und Schauspielern: primo amoroso di titolo, primo, secondo, terzo amoroso, prima donna (2fach besetzt), seconda, terza donna, servetta, primo vecchio (Pantalone), secondo vecchio (Dottore), primo zanni (Brighella), secondo zanni (Arlecchino). (Vgl. Goldoni, I, $712-716)$.

14 Vgl. A. Perrucci, Dell'arte rappresentativa premeditata ed allimprovosso, op. cit., S. 215 . 
sprachlich stark markierte Figuren und macht damit wichtige Elemente der Commedia dell'arte-Tradition für sein Theater fruchtbar: das der szenischen, sprachlichen wie körperlichen, Improvisation wie das der sprachlichen Differenzierung, die bereits in der antiken Komödie für komische Effekte sorgte.

\section{Doppelte Rollenhaftigkeit}

$\mathrm{Zu}$ diesen aus der Tradition übernommenen Charakteristika tritt bei Gozzi eine Besonderheit der Maskenfiguren: Die Masken sind in den Fiabe teatrali nicht nur sie selbst als Tartaglia, Pantalone, Truffaldino, Brighella, wie sie traditionell als Alte, vecchi, und Diener, zanni, auftreten, sondern Gozzi weist ihnen zudem eine Rolle im Gefüge der dramatis personae der Märchenhandlung zu, die von Stück zu Stück varïert. Nur in der ersten Fiaba teatrale, L'amore delle tre melarance, betritt Truffaldino als Truffaldino die Bühne, in den folgenden ist er königlicher Jäger (Il corvo, La donna serpente), Aufseher über die Eunuchen (Turandot), Vogler (Il re cervo), Bettler (I pitocchi fortunati), Wurstmacher (L'augellino belverde), Kerkermeister (Il re de'genj) und zweimal Diener königlicher Personen (Zobeide, Il mostro turchino). Auch Brighella taucht nur dreimal in der Dienerrolle auf (L'amore delle tre melarance, La donna serpente, Zobeide) und ist sonst Jäger ( $I l$ corvo), Küchenchef (Il re cervo), Aufseher (Turandot, Il mostro turchino, Ilre de' genj), Bettler (I pitocchi fortunati) und nicht zuletzt Poet (L'augellino belverde). Tartaglia übernimmt auffallend häufig die Rolle eines Ministers - meist eines schlechten, bösen - und avanciert vom Erbprinzen in L'amore delle tre melarance zum König von Monterotondo in L'augellino belverde. ${ }^{141}$ Pantalone schließlich ist ebenfalls sowohl Minister ( $I l$ re cervo, Zobeide, Il mostro turchino, L'augellino belverde, Il re de'genj) - ausschließlich ein guter, treuer - als auch Admiral (Il corvo), königlicher Sekretâr (Turandot), Onkel des Königs (La donna serpente) und Bettler (I pitocchi fortunati). Während hinsichtlich der Partien, die Truffaldino und Brighella in den Fiabe teatrali spielen, noch ein - wenn auch loser - Zusammenhang mit ihrer Tradition als Dienergestalten niederer Herkunft hergestellt werden kann, nehmen Tartaglia und Pantalone ganz neue Rollen ein, die mit ihrer ursprünglichen Funktion als komische Alte, die sich durch eine für

141 L'augellino belverde ist eine Art Fortsetzung von L'amore delle tre melarance, in der dieselben Figuren wieder auftauchen und die Geschichte fortgeschrieben wird; vgl. Kap. $4 \cdot 4$. 
ihr Alter unpassende Verliebtheit, durch Geiz, übertriebenes Mißtrauen oder andere Laster der Lächerlichkeit preisgeben, ${ }^{142}$ kaum noch in Verbindung zu bringen sind. Als Minister, Admiral, Sekretär und ähnliches stehen sie den hohen, meist königlichen Personen hierarchisch nahe, während Truffaldino und Brighella in ihren *Märchenrollen $\propto$ sozial deutlich niedriger positioniert sind. Analog zur Tradition der Commedia dell'arte nehmen sie zuvorderst die "parti ridicole" ein und sorgen vor allem in den a-soggetto-Szenen durch ihr Verhalten, ihre Sprache und ihre Gestik - die Masken verhindern ein differenziertes Mienenspiel - für das Lachen des Publikums. Schreibt Perrucci in seinem Traktat vor allem dem ersten Diener oder zanni die dramaturgische Funktion zu, die Handlung voranzutreiben, ${ }^{143}$ erfüllen Brighella und Truffaldino diese Aufgabe in Gozzis Fiabe teatrali nur sporadisch. Einzig in L'amore delle tre melarance fungiert Truffaldino tatsächlich noch als Handlungsmotor, wobei die Rolle bezeichnenderweise metatheatralisch überwölbt ist und Truffaldino explizit als slustige Figur* ("persona benemerita nel far ridere «) eingeführt wird. In den folgenden Stücken übernehmen überwiegend andere, nämlich märchenhafte Instanzen, die dramaturgische Funktion als Handlungsmovens.

Die besondere doppelte Rollenhaftigkeit der Masken, hauptsächlich Pantalones und Tartaglias, in Kombination mit ihren sprachlichen Eigenheiten ist ein Spezifikum der Fiabe teatrali, das zwei Beispiele näher beleuchten sollen. Während die dialektale Sprache Pantalones im Text als solche gedruckt erscheint, ist das traditionelle Stottern Tartaglias nicht notiert. Daß für Gozzi jedoch dieses sprachliche Charakteristikum der Maske, welche Rolle auch immer sie in einer Fiaba teatrale bekleiden mag, selbstverständlich ist, wird in Il re cervo deutlich, wo das Stottern Tartaglias einen wichtigen Aspekt hinsichtlich der Entwicklung der Handlung darstellt und explizit thematisiert wird. Tartaglia, der sich als erster Minister hinterlistig die Möglichkeit erschleicht, in die Gestalt des Königs

142 Vgl. A. Perrucci, op, cit, S. $194:-$ Or perche le parti de' Veechi sogliono essere per lo più ridicole per essere innamorati, e la vecchiaia quando cade in questo errore è derisibile; come anche per esser avari, tenaci, sospetti, e viziosi, quindi è ch'a diversi linguaggi si sono attribuite le parti di Padri. Pantalone allerdings nimmt eine Sonderstellung ein, da er hinsichtlich der Sprache, d. h. des Dialekts, zwar zu den eparti ridicole* zählt, in der Funktion als Berater und im sozialen Status eines Städters oder zumindest eines Kaufmanns jedoch sparte graves ist, wie Pier Maria Cecchini in Frutt delle moderne comedie et avisi a chi le recita (Padova 1628) betont (Teilabdruck in V. Pandolfi, La commedia dell'arte, op. cit., Bd. 4, S. 100): s L a parte del vecehio sotto habito, \& come [sic; i. e. nome] di Pantalone, è sempre parte graue, ma vien però mescolata frà le ridicoli per la lingua, \& vestimento.*

145 A. Perrucci, op. cit., S. 21 5: =Il suo officio sarà tirar l'intrigo, ed imbrogliare le Carre 
Deramo zu schlüpfen und an seine Stelle zu treten - als Herrscher wie als Liebhaber Angelas -, fürchtet, bei ansonsten geglückter Verwandlung sein Stottern nicht los zu werden und reflektiert darüber:

Oh maraviglia! [...] Entro nel corpo del Re; $e$, creduto Deramo, vado in possesso del Regno, e piú d'Angela mia, che adoro. Ma quando sarò in questo corpo, chi sa, se conserverò il difetto, di tartagliare? Non vorrei essere conosciuto. Diavolo! sarebbe un brutto imbroglio. Ma, quando sono Re, di che temere? Non perdiamo più tempo. $(I I, 7)$

Nachdem die Metamorphose gelungen ist und Tartaglia sin forma di Deramo e erscheint, bestätigt sich im folgenden Monolog Tartaglias Befürchtung: $\bowtie$ Resti Deramo nella sua miseria. (tartaglierá) Oh maledetta imperfezione di lingua, ancora mi perseguiti? $\propto(I I, 8)$. Selbstverständlich fällt auch der Umgebung Deramos neben den ungewohnt rauhen Umgangsformen des falschen Königs das befremdliche Stottern auf, was Pantalone mehrfach a parte kommentiert mit $*$ Mi son sbasio! l'è deventà un can. No lo conosso più. L'ha cambià infin la ose, e el se intartagia, che el

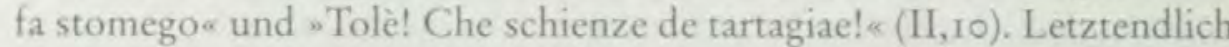
ist es freilich nicht das Stottern, das ihn entlarvt, sondern der Zauberer Durandarte, doch machen die Szenen deutlich, in welcher Weise Gozzi traditionelle Charakteristika dramaturgisch fruchtbar macht und durch Selbst- und Fremdkommentare der Figuren im Stück thematisiert. Das Stottern an sich ist kein Grund, der Maske Tartaglia nicht eine Ministerrolle zuzuschreiben, noch dient es als untrügliches Kennzeichen der Figur, das sie innerhalb des fiktionalen Rahmens als maskierte unmittelbar demaskieren würde, vielmehr gibt es Anlaß zu selbstreflexiven Äußerungen und zu entsprechenden Reaktionen einer anderen Maskenfigur, nämlich Pantalones. Wenn in allen anderen Fiabe teatrali Tartaglia Minister- oder ähnliche Rollen spielt und in diesen mit Sicherheit ebenfalls stottert, ohne daß dies von den Mitagierenden explizit angemerkt würde, ist davon auszugehen, daß das Stottern als Unzulänglichkeit, verstärkt durch die Diskrepanz zwischen sprachlichem Defekt und sozialer Stellung, vor allem zur Belustigung des Publikums beitrug.

Als zweites Beispiel für die Besonderheit der doppelten Rollenhaftigkeit der Masken in sprachlicher Hinsicht seien Pantalone und die beiden zanni angeführt. Pantalone, als Maske traditionell Venezianer, spricht in allen Stücken Gozzis venezianisch, sei er Admiral in Frattombrosa, Minister in Samandal oder Bettler in Samarkand. Daß dies innerhalb des Spiels keine Verwunderung erregt noch eines Kommentars wert ist, mag merkwürdig anmuten und ist nur mit der betont fiktionalen Anlage der Fiabe teatrali erklärbar. Die Frage nach der Wahrscheinlichkeit, 

immer dasselbe Venezianisch spricht, ist eben so irrelevant wie die nach der Wahrscheinlichkeit des Eingreifens von Zauberern und anderen übernatürlichen Kräften in das Geschehen. Innerhalb der theatralen Wirklichkeit bleibt beides - gemäß dem Märchenschema - als gegebene Tatsache unhinterfragt. Mag es aus Gründen der Tradition noch als "natürlich" erscheinen, daß Pantalone als venezianische Maske den autochthonen Dialekt benutzt, ist man einigermaßen überrascht, daß offensichtlich auch Truffaldino und Brighella in orientalischer Märchenumgebung venezianisch sprechen. Zwar ist bei den zahlreichen Improvisationsszenen, für die Gozzi den zu sprechenden Text nicht ausformuliert, sondern nur inhaltlich skizziert, nicht zu erkennen, welche Sprache, welchen Dialekt Brighella und Truffaldino sprechen, doch lassen einige wenige wortlich vorgegebene Passagen den Schluß zu, daß die beiden zanni sich nicht ihres bergamaskischen Heimatdialekts, sondern eben auch des Venezianischen bedienen, und dies, obwohl in mehreren Fiabe teatrali ausdrücklich zur Sprache kommt, daß sie aus Bergamo stammen. ${ }^{144}$ Erstaunlich ist weniger die Tatsache, daß die beiden Masken venezianisch sprechen, als vielmehr die Divergenz zwischen dem aus der Tradition der Commedia dell'arte übernommenen Ort der Abstammung der Masken und ihrem Dialekt, der wohl wie manches andere Merkmal der Figuren auch auf Gozzis genaue Kenntnis der Fähigkeiten seiner Darsteller zurückzuführen ist. ${ }^{145}$

14 So z. B. in I pitoccbi fortunati, wo Brighella seine Geschichte erzählt: >I casi mici? Ghe li desvolzo in tun momento. Mi son un Bergamasco, che ha scomenzà a servir per mozzo de stalla. El primo guadagno, che ho avù, xe sta una scalzada d'un cavallo, che m'ha scavezzà una gamba in do tocchie etc. Daß Brighella nicht nur venezianisch spricht, sondern sich auch in spezifisch venezianischen Brauchen und Einrichtungen auskennt, macht eine Äußerung hinsichtlich der Häßlichkeit seiner Tochter deutlich, in der er auf eine sbocca della verità am Palazzo Ducale anspielt. - La xe struppia da tutte do le gambe; la ga un muso, che la par una denonzia secreta; una gobba, che ghe sormonta sora la testa* etc. $(1,8)$. In der darauffolgenden Szene, 1,9 , spricht auch Truffaldino in einem kurzen ausformulierten Monolog venezianisch, während mit I, 10 eine Szene a soggetto folgt, in der Truffaldino auf seine bergamaskische Herkunft verweist, zweifelsohne jedoch weiterhin venezianisch redet, $>$ Se per sorte Apollino, e Belfagor gli abbiano detto, che ha notne Truffaldino, e ch'è Bergamasco?e.

Fur wertvolle Hinweise zum Venezianischen danke ich Daria Perocco.

145 In Goldonis Komödie Il bugiardo, die 17 so uraufgeführt wurde, sprechen in der Druckfassung Pantalone, Brighella und Arlecchino ebenfalls cin - allerdings stark geglattetes - Venezianisch, jedoch ist der Ort der Handlung Venedig und somit der Dialekt *wahrscheinlich* und gerechtertigt, Gozzi weist im Vorwort zu $1 l$ corvo auf den Dialekt Pantalones und Brighellas hin (Truffaldino wird nicht erwähnt) und polemisiert im gleichen Atemzug gegen Goldonis Praxis, in den Editionen seiner Stücke den Dialekt entweder zu eliminieren oder durch Anmerkungen zu erläutern: *Non giudicandole [scil. le Teatrali opere] degne di passare i monti, o i mari per farsi leggere dagli esteri, non pratici del dialetro Veneziano, necessario al mio Pantalone, e al mio Brighella, non 
Die Flexibilität der zanni-Partien hinsichtlich ihrer Herkunft, die aus Perruccis oben zitierter Beschreibung hervorgeht, hätte es Gozzi sicherlich erlaubt, sie als Venezianer zu bezeichnen, was er jedoch konsequent vermeidet. Umso auffälliger ist ihre Sprache und darüber hinaus ihre immer wieder aufscheinende Vertrautheit mit Venedig. Inmitten einer in unbestimmter Ferne angesiedelten Handlung hört das venezianische Publikum sein eigenes Idiom also von drei Masken auf der Bühne - im übrigen eine Sprache, die unterschiedslos von allen Venezianern, ob Doge oder Gondoliere, gesprochen wird ${ }^{146}$ und als identifikatorisches Element betrachtet werden kann, wobei diese Identifikation zugleich unterminiert wird durch die Diskrepanz von Ort und Sprache, so daß den Masken in sprachlicher Hinsicht eine illusionsstörende Funktion zukommt.

\section{Venedig-Bezug der Masken}

In ähnlicher Weise ambivalent ist der häufige explizite Venedig-Bezug in der Maskenrede - ein weiteres Merkmal der Fiabe teatrali Gozzis. Auffällig sind die Hinweise auf Venedig insofern, als sie in einem exotischmärchenhaften Ambiente erfolgen, sei es das erfundene Frattombrosa in Il corvo, sei es das chinesische Peking (Turandot), das georgische Tiflis (La donna serpente) oder das usbekische Samarkand (I pitocchi fortunati), und offensichtlich einer handlungsimmanenten Motivation entbehren. Dies macht den Kontrast zwischen wirklichkeitsfernem Märchengeschehen und schlaglichtartiger, detailhafter Rückbindung an eine dem Publikum vertraute Realität in den Maskenpartien umso deutlicher. An den entlegensten Orten bringen die laut Nebentext häufig in orientalische Kostüme gekleideten Masken ohne zu zögern venezianische Örtlichkeiten, Gegebenheiten, Ereignisse und stadtbekannte Personen ins Spiel und

perderò il tempo a far delle postille alle parti di que' due personaggi, spiegando, verbigrazia, che osello vuol dire uccello, o che aseo vuol dire aceto ec. Siccome providamente ha fatto il Signor Goldoni nelle stampe dell'opere sue in considerabile benefizio degli stranieri, * (Col, 1, 123).

146 Irrtümlich wird das Venezianische in Gozzis Fiabe teatrali immer wieder als volkstümliches Element gewertet, wie z. B. von G. Luciani, Carlo Gozzi, op. cit., S. 557 , der behauptet: sle dialecte employé par les Masques est la =langue du commun ", d'un Tiers-Etat pris globalement, sans nuances internes, sans diversifications psychologiques, sans contenu réellement vécua. Ohne näher auf Einzelheiten des von Gozzi schriftlich verwendeten Dialekts einzugehen, ist unbestreitbar, daß zur Zeit Gozzis - wie auch davor und danach - das Venezianische von allen gleichermaßen gesprochen wurde und keinesfalls als schichtenspezifisches Charakteristikum, populär oder gar minderwertig* gelten kann. 
erwāhnen zugleich ihre Herkunft aus Venedig, Bergamo und Neapel, den traditionellen Ursprungsorten der Masken. Nur in seltenen Fällen wird diese Inkongruenz von Ort der Handlung, Abstammung und Wissen um Veneziana (allein bei Pantalone decken sich die letzten beiden Aspekte) explizit aufgelöst durch eine *vernünftigee Erklärung wie beispielsweise in Turandot, wo Pantalone nebenbei bemerkt, daß ihn das Schicksal von Venedig an den chinesischen Hof verschlagen habe: „Prima che le mie desgrazie me facesse abbandonar el mio paese, e che la mia fortuna me innalzasse senza merito all'onor de secretario de Vostra Maestà, no aveva altra cognizion della China, se no che la fusse una polvere bonissima per la freve terzana $(\mathrm{II}, 2)$. In allen anderen Stücken bleibt eine Erklärung der Präsenz der Masken an den orientalischen Höfen aus, die Situation wird sowohl von Seiten der Masken als auch der Märchenfiguren als gegeben vorausgesetzt und - wie im Falle des Dialekts - nicht weiter hinterfragt. Ob Truffaldino und Brighella nun aus Bergamo, Tartaglia aus Neapel und Pantalone aus Venedig kommen, macht hinsichtlich der venezianischen Einsprengsel kaum einen Unterschied: ungeachtet ihrer ausdrücklich genannten oder stillschweigend als bekannt vorausgesetzten Herkunft verweisen alle vier immer wieder auf Venedig. Stadtbekannte Gestalten wie u. a. "Chiara matta* (Il re cervo), sel strolego Cingarelloe (Turandot), - la scimia del Padoanello* ( $I l$ mostro turchino) werden evoziert, Orte, von *Caorle, Mazorbo, Portobuffolè $($ Il mostro turchino) bis zur $*$ Bragola $*$ und *calle de' Corli (L'augellino belverde), und typische Feste wic die Regata storica (L'augellino belverde) genannt und venezianische Lieder gesungen ( $I$ l mostro turchino und $I /$ re de' genj). ${ }^{147}$ Immer wieder verbindet Gozzi die Hinweise auf Venedig mit aktuellen ironisch-kritischen Einwürfen, die die Maskenrede seit jeher auszeichnen, da die Improvisation traditionell Gelegenheit bietet, über das Bühnengeschehen hinaus direkt auf die Wirklichkeit zu verweisen. Wenn beispielsweise Pantalone in Il re cervo anläßlich der Nachricht von der Hochzeit des Königs Deramo mit seiner Tochter Angela ankündigt: $\nsim$ Vado a dar parte con quattro righe a mio fradello Boldo a Venezia delle mie esaltazion. Si ben che sta novità anderà su madama la gazzetta, nonostante vogio scriver una madama lettera, e metterla a madama la posta« $(1,13)$, wußte das venezianische Publikum, daß Gozzi sich über Chiari mokiert, was später beim Druck in einer Anmerkung erläutert werden mußte: »Alludesi alla gazzetta, che scriveva in quel tempo il Signor Abate Chiari, appellandola

16 In der gedruckten Ausgabe der Fiabe teatrali versieht Gozzi die meisten dieser Veneziana mit erklärenden Fußnoten. 
madama la gazzetta. ${ }^{148}$ Auch zur venezianischen Mode fallen in $I l$ re cervo sowie in I pitocchi fortunati Bemerkungen, deren komische Wirkung vor allem im ersten Stück durch einen verfremdenden Blick von außen erhöht wird. Brighella, wie Smeraldina in orientalischem Kostüm, "Smeraldina avrà un gran ventaglio, de' gran fiori, e pennacchi in caricatura « $(I, 4)$, hätte es vorgezogen, seine Schwester salla Veneziana, con un bel tegnon, e con un mantiglion negligente* gekleidet zu sehen, worauf diese antwortet: Oh che matto! Io ci scommetto, che, se vado a Venezia vestita in questa forma, fo innamorare tutti $\mathrm{i}$ Veneziani di buon gusto, e che i Berrettini rubano dieci mode da questi miei abbigliamenti, e vuotano in tre giorni le borse a tutte le donne Veneziane.* Das Argument Smeraldinas aufgreifend, erwidert Brighella: »Mo sicuro. La novità piase, e per questo se ti fussi comparsa avanti al Re de Serendippo alla Veneziana, ti faressi qualche colpo colla novità. « Dieses ironische Spiel mit der Fiktion, in dem die venezianische Realität als das exotisch Neue erscheint und das Orientalische als das Gewöhnliche, macht die Relativität der Standpunkte und die daraus resultierende unterschiedliche Wahrnehmungsweise auf komische Weise deutlich. ${ }^{149}$

$1+8$ Immer wieder ist nach Chiaris Übernahme der Gazzetta veneta in der Zeitschrift selbst von - Madarma la Gazzetta = die Rede, sei es in direkter Ansprache eines fingierten Lesers an das Journal, sei es als Selbstbezeichnung. Der erste Beleg findet sich in der Ausgabe vom 18. März 1761: - Io son debitore a Madama la Gazzetta [...] «. Parodistisch fügt Gozzi das unsinnige Epitheton beliebigen anderen Wörtern bei.

In Fogli sopra alcune massime .... (S. 39-40) erwähnt Gozzi Chiaris Neverung ebenfalls: - Allora il Nugnez che facea i visacci alla Gazzetta si pose a scrivere la Gazzetta, ma per rimediare poi a quel titolo plebeo di Gazzetta, egli l'ha nobilitata chiamandola: Madama la Gazzetta.

199 Eine weitere Variante der Venedig-Bezüge bilden solche, die als mehr oder weniger offensichtliche captatio benevolentiae und Hommage an Venedig interpretiert werden können. Bereits erwāhnt wurden die verborgenen intertextuellen Bezüge in L'amore delle tre melarance und $I l$ corvo zu Passagen in Dantes s Inferno* und Basiles *Il corvo*, die sich auf Venedig beziehen (siehe oben Anm, 9 und 74) und eine solche - wenn auch nur Literaturkennern verständliche - Ehrbezeugung darstellen. Dazu zahlen darüber hinaus sehr unterschiedliche Phänomene wie einzelne Außerungen in der Art ssemo nati civilmente a Venezia, che semo onesti $\propto(I l$ re cervo, 1,3 ), oder Pantalones Reaktion auf Altoums Verzweiflung angesichts der Unerbittlichkeit Turandots, „Cara Maestà, no saveria che consegio darghe. In tei nostri paesi no se zura de sta sorte de legge. No se fa de sta qualità de editri. No ghe esempio, che i Prencipi se innamora de un retrattin, a segno de perder la testa per l'original, e no nasce putte, che odia i omeni, come la Prencipessa Turandot, so fia " (Tirrandot, II, 2), wie auch in derselben Fiaba teatrale die Umgestaltung eines der drei Rätsel gegenüber der Marchenvorlage. Sind dort die Sonne, das Meer und das Jahr zu erraten, ersetzt Gozzi das Meer-Ràtsel durch folgendes, das quasi als Höhepunkt an dritter Stelle steht:

Dimmi, qual sia quella terribil fera

Quadrupede, ed alata, che pitosa

Ama chi l'ama, e co' nimici è altera.

Che tremar fece il mondo, e che orgogliosa 
Weitreichender noch als die vorteilhafte Zeichnung Angelas, der Tochter des Venezianers Pantalone, die sich im übrigen in I pitocchi fortunati wiederholt, wo König Usbec die wunderschöne, unbescholtene Angela am Ende ebenfalls heiratet und auf den Thron führt, ist die fast durchgängig positive Eigen- und Fremdcharakterisierung Pantalones als außergewöhnlich guter und tugendhafter Mensch. Vor allem in Il corvo erscheint Pantalone als vorbildlicher Admiral, dessen Güte, Treue und Umsicht in krassem Gegensatz zu Tartaglias Verhalten stehen, wobei gerade in diesem Stück seine Herkunft von der Giudecca stark hervorgehoben wird. Kaum hat er zusammen mit Prinz Jennaro Armilla, Prinzessin von Damaskus, in einer abenteuerlichen Fahrt über das Meer nach Frattombrosa gebracht und damit den sehnlichsten Wunsch Millos, des Königs und Bruders Jennaros, erfüllt, begegnet ihm am Strand ein Jäger auf einem edlen Pferd, einen wunderschönen Falken in der Hand. Pantalone versäumt es nicht, die beiden herrlichen Tiere für Jennaro zu kaufen, der sie wiederum seinem Bruder Millo zu schenken gedenkt. Auf Jennaros Frage "Quanto vi costarono? a antwortet Pantalone:

Quel che ho volesto; gnente; tre bezzi; sie milioni de zecchini. No ho mai da esser paron mi, dopo tante beneficenze, che ho recevesto, de mostrar una piccola gratitudine? Le xe vostre; vogio che le recevè; no vogio che me le paghè; come ve comandava da piccolo, vogio poder comandarve anca da grando qualche volta. $(\mathrm{I}, \mathrm{s})$

Als Jennaro insistiert, erwidert er: „Mo via, sier pissotto, andè a dormir no me mortifichè (a parte) Ho speso dusento zecchini, e se avesse anca speso un'occhio, averia gusto, prima perchè sto putto xe le mie viscere, e po per far veder, che anca alla Zuecca ghe xe dei Ceseri, dei Pompei, e dei Gofredi $\alpha$, tritt ab, und Jennaro schließt den Dialog mit Veramente buon vecchio, ottimo core, / Carattere invidiabile. Io dovrei / Esser felice;

Vive, $e$ trionfa ancor. Le robuste anche

Sopra l'istabil mar ferme riposa;

Indi col petto, e le feroci branche

Preme immenso terren. D'esser felice

Ombra in terra, ed in mar mai non son stanche

L'ali di questa nuova altra fenice. (II,5)

Die richrige Antwort Calafs lautet *Fera beata, / Sei dell'Adria il Leon feroce, $\mathrm{e}$ giusto*, der venezianische Lowe also. In deutlicherer und direkterer Weise kann der Heimatstadt kaum gehuldigt werden. Doch auch in den beiden Turandot vorausgebenden Frabe teatrali gibe es eindeutige Ehrenhezeugungen für Venedig: in /l re cervo findet der König Deramo nach langer Suche mit Hilfe det Zauberbüste, die Lügen und Unehrlichkeit durch ihr Lachen enthült, endlich eine ehrliche Frau, nämlich Angela, die Tochter Pantalones, sveneta donna- $(1,12)$. Durch das ganze Stück hindurch erweist sie sich, auch in Extremsituationen, als gute, zuverlassige, treue Gattin, die der Liebe Deramos würdig ist, als =virtuosa donnae (III, ro). 
[...] $\ldots$. Pantalone wird zum einzigen Vertrauten Jennaros, dem er sich in seiner verzweifelten Situation anvertraut, die es ihm nicht erlaubt, seine Unschuld zu enthüllen, und wiederum ist das Lob Pantalones verbunden mit dem Hinweis auf seine Heimat: "Ah, caro amico, vecchio benemerito, / Esempio raro d'ogni servo, onore / Di quell'alma città, che vi produsse * $(\mathrm{III}, 4)$. Die ausdrückliche Venedig-Hommage mittels Pantalone geht einher mit einer unübersehbaren Veränderung der Figur, sowohl gegenüber der traditionellen Rolle des vecchio als auch der des venezianischen Kaufmanns in Goldonis Komödien. ${ }^{150}$ Gozzi setzt letzterem, immer darauf bedacht, sein Geld zusammenzuhalten und zu vermehren, in $I l$ corvo einen freigebigen, aufopferungsbereiten Pantalone entgegen, dessen Tugenden gepaart sind mit einer Portion gesunden Menschenverstandes, die die Figur vor übertriebener Moralität bewahrt. Diese neue, positive Gestaltung Pantalones, der nun explizit wie implizit als Medium für das Venedig-Lob dienen kann, ist in $I l$ corvo besonders evident, zieht sich jedoch durch alle weiteren Fiabe teatrali bis zu Il re de' genj, der letzten, in der Pantalone als s virtuoso Vecchio di Patria Veneziano « $(I I, 6)$ bezeichnet wird. Wie Goldoni Pantalone, einen der beiden Alten (vecchi) in den "commedie dell'arte", in seinen Komödien zum venezianischen Kaufmann umgestaltet, so nimmt Gozzi seinerseits in den Fiabe teatrali eine Veränderung an der Maske vor. In seiner Funktion als königlicher Erzieher, Berater oder Minister repräsentiert Gozzis Pantalone weder eine Generation im sozialen Gefüge, noch verweist er auf einen konkreten sozialen Stand, sondern ist den realen gesellschaftlichen Verhältnissen eben so fern wie die übrigen Personen der Handlung, sowohl Masken als auch Märchenfiguren. Die traditionelle venezianische Herkunft der Maske machen Goldoni wie Gozzi für ihre Zwecke fruchtbar, der eine, indem er sie zum Vertreter des venezianischen Kaufmannsmilieus macht, der andere, indem er ihr positive charakterliche Eigenschaften verleiht und damit seiner Vaterstadt die Reverenz erweist. ${ }^{151}$

$199 \mathrm{VgL}$. Goldoni: Figurasi un uomo di buona fede, facile a lasciarsi ingannare, ed è quasi sempre nelle Commedie dell'Arte lo scopo delle furberie del Brighella, delle impertinenze dell'Arlecchino, e della derisione degli Amorosi. Tale è il povero Pantalone nelle Commedie a soggetto; ma io nelle Commedie mie di carattere ho reso la riputazione a questo buon personaggio, che rappresenta un onesto Mercante della mia Nazione.a (Goldoni, 1, 7rs).

151 Wenn Gozzis Gestaltung der Pantalone-Maske als Abweichung von einem Modell dargestellt wird, wie dies immer wieder der Fall ist (vgl. z. B. H. Feldmann, Die Fiabe Carlo Gozzis, op.cit., S. 75-76; Arnaldo Momo, La carriera delle maschere nel teatro di Goldoni, Chiari, Gozzi, Venezia, Marsilio 1992, v. a. S. 301), wird nicht deutlich, daß dieses >Modell- des venezianischen Kaufmanns auf Goldoni zurückgeht, also quasi zeitgleich mit Gozzis Version entstand und modellhaften Charakter erst in der Rezeption gewann. F. Fido weist in Guida a Goldoni, op. cit., im übrigen im ersten Kapitel darauf 
Generell ist das Lob der Stadt auf den venezianischen Bühnen der Zeit gängige Praxis, wie die noch erhaltenen Prologe Chiaris und Goldonis zeigen, ${ }^{152}$ doch fällt auf, daß Gozzi die enkomiastischen Einsprengsel in der Maskenrede verankert und in das Bühnengeschehen integriert. Wie schnell allerdings bei Gozzi ein Venedig-Kompliment in Zeitsatire umschlagen kann, zeigt die Antwort Pantalones auf Tartaglias wohlgemeinte Bitte in L'angellino belverde, ihm als König Nachhilfeunterricht im Liebesdiskurs zu geben: sinsegnami due parole graziose di quelle tue veneziane da dirle «: $:$ Grazie della carica. Maestae. A Venezia se fa l'amor alla francese, o all'inglese; su sto merito no so più gnente. (III, 7$)$.

Über diese vielfaltige verbale Vergegenwärtigung Venedigs auf der Bühne hinaus, setzt Gozzi auch visuelle Verweise ein, wenn beispielsweise in Il re cervo und L'augellino belverde der Geschichtenerzähler Cigolotti auftritt - nicht in personam, sondern einmal als Figur, die den Prolog spricht, das andere Mal als Statue. Dem Vorwort zu Il re cervo ist nicht nur einiges über Cigolotti zu entnehmen, sondern auch über die Darstellung dieser Figur auf der Bühne und die Reaktion des Publikums.

Questo [prologo] era d'un vecchio, appellato Cigolotti, notissimo in Venezia, d'una grottesca figura, solito formare de' rigoletti nella Piazza di S. Marco, e a narrare al popolo le maraviglie degli antichi Romanzi, e de' Negromanti, con una voce molto grossa, una goffa gravità, e un miscuglio di spropositi infiniti, nel suo linguaggio, ch'egli affettava toscano.

Atanagio Zanoni, che sostiene con rara abilità il personaggio del Brighella tra le Maschere nella Truppa Sacchi, rappresentava cotesto vecchio con quella perfetta

hin, daß Goldonis Kaufmann hauptsächlich im familiären Ambiente auftritt, so daß fraglich ist, ob auf diesem Hintergrund davon gesprochen werden kann, daß Gozzi (im Gegensatz zu Goldoni) Pantalone *ideologisch unschädlich = macht (Feldmann, op. cit.) oder ihn aus der aktiven Politik ausschließt (Momo, op. cit.).

152 Vgl. Pietro Chiaris Raccolta di prologhi in versi alle sue Commedie recitate in Venezia e altrove, op. cit., und die in Ortolanis Goldoni-Ausgabe unter dem Titel *Introduzione alle recite.... in verschiedenen Bầnden aufgenommenen Texte. Solche Prologe und Epiloge wurden zu Beginn und am Ende der Spielzeit sowie bei Gastspielen meist von der - prima Donna* rezitiert und enthielten Komplimente an die Stadt, die Regierung, das Publikum, wie aus folgenden Äußerungen Goldonis hervorgeht: sI Comici, la prima sera che si presentano sopra un Teatro per loro nuovo, o che ricompariscono sopra di uno in eui stati sieno altre volte, sogliono fare un complimento all'Udienza, ed è la prima Donna ch'è incaricata ordinariamente di quest'ufficio.* (Goldoni, I, 726). -Avvezzo il Popolo a veder sempre sortire la prima Donna a recitare quel Complimento, che sapevano tutti a memoria, riusci una sorpresa piacevole il vedere tutta la Compagnia in semicircolo e sentir cose nuove, $e$ in vari metri e con varie invenzioni sentir gli elogi della Città, del Governo e degli ordini vari delle persone.* (Goldoni, I, 728). Auch Gozzi schricb solche Texte, die sich nun im Fondo Gozzi finden. *Non so dire qual numero di sprologhic, qual numero di saddio in versi, da recitarsi al pubblico le prime e le ultime sere del corso delle rappresentazioni loro, abbi scritti per le prime attrici pro tempore* (Mem. I, 255). 
imitazione nel vestito, nella voce, negl'intercalari, nel gesto, e nella positura, che suol far sempre ne' Teatri un grand' effetto, con indicibile applauso. (Col. I, $327-328)^{153}$

Cigolotti ist nicht der einzige, der in L'augellino belverde als Statue im Theater erscheint, zu ihm gesellen sich Cappello, ebenfalls nnovellatore della piazza", wie das Personenverzeichnis angibt, sowie „Rioba e compagni, statue del Campo de' Mori di Veneziae. ${ }^{154}$ Auch in dieses Stück strömte das Publikum, um zu sehen, »se le statue, rese ambulanti, e favellatrici, somigliavano a' loro simulacrix, wie Gozzi im Vorwort schreibt (Col. III, 12-13).

Auf der Bühne Vertrautes wiederzufinden, jedoch in anderem Kontext und durch die Rampe auf Distanz gebracht, weckt offensichtlich das Vergnügen der Zuschauer. Bekannte Namen, Orte, Gegebenheiten, die immer wieder in der Maskenrede auftauchen und das entrückte Märchengeschehen durchsetzen, schaffen eine Brücke zwischen Bühne und Zuschauerraum, zwischen Fiktion und Wirklichkeit. Es entsteht ein augenzwinkerndes Einverständnis, in dem die unbestimmte Ferne des Märchens momentan aufgehoben scheint im gemeinsamen Wissen des Publikums und der Masken um alles Venezianische, doch zugleich wirkt das Bekannte in der doppelt sunnatürlichen* Umgebung - der Bühne wie dem Märchenambiente - verfremdet. Es lädt nicht zur einfachen Identifikation ein und bietet kein dekoratives Lokalkolorit, sondern es holt die Zuschauer immer wieder aus der Evasion zurück und bewirkt ein Oszillieren zwischen dem Wiedererkennen des Vertrauten und dem Bewußtsein seiner komischen Verfremdung auf der Bühne. Zugleich wird das märchenhaft Ferne und Unbestimmte durch die Anspielungen an die venezianische Wirklichkeit rückgebunden und so eine mögliche Korrelation von Erfahrungswelt der Zuschauer und dargestellter Märchenwelt angedeutet.

15. Goldoni hatte sich von diesen Gestalten, die die Piazzetta bevölkerten, bereits 1735 fur das Teatro San Samuele zu einem Intermezzo mit dem Titel La birba inspirieren lassen: - Trattenendomi di quando in quando nella Piazza San Marco, in quella parte che dicesi la Piazzetta, e veggendo ed attentamente osservando quella prodigiosa quantità di vagabondi, che cantando, suonando o elemosinando, vivono del soave mestier della birba, mi venne in mente di trar da coloro il soggetto di un Intermezzo giocoso; e mi riusci a maraviglia, * (Goldoni, I, 719-720).

134 In einer Anmerkung erläutert Gozzi, $>$ Cosi sta scritto a' piè d'una delle statue nel campo de' Mori a Venezia.< (III, 15$)$. Die Statuen, an Hauswànden angebracht, sind bis heute auf dem Campo de' Mori zu sehen, ihre Herkunft und Bedeutung ist ungewiß. 
Neben den Hinweisen auf Venedig ist die Maskenrede in den Fiabe teatrali durch zahlreiche ironische, satirische und parodistische Anspielungen auf die zeitgenössische Welt des Theaters, der Oper und der Literatur charakterisiert. Dominierte dieser Aspekt in L'amore delle tre melarance das gesamte Stück, sind entsprechende explizite Außerungen in den folgenden Fiabe teatrali seltener und werden ausschließlich den Masken anvertraut, wobei die Literatursatire zunächst überwiegend auf konkrete Stücke oder Autoren wie Chiari und Goldoni zielt, im folgenden jedoch zusehends allgemeiner wird. Beispielsweise parodiert Gozzi in seinem zweiten Theaterstück, Il corvo, Chiaris Versuch, die Masken in Versen reden zu lassen, indem Truffaldino den von Tartaglia und Pantalone dringend erwarteten Bericht über die vorgefallenen Ereignisse in übertrieben ernster Pose in gestelzten Elfsilblern vortrāgt und dies folgendermaßen einleitet: nchiederà in grazia di non esser interrotto, perchè un Poeta gli ha data in iscritto la narrazione in versi, acciò possa farsi dell'onore, e che spera di averla a memoria* (III, 7$)$. Zwischendurch wischt er sich den Schweiß von der Stirn und endet schließlich in Prosa: $>$ Truf. Dice di essere stanco di parlare in versi, che teme di annojarli, non essendo cosa propria al suo personaggio il ragionare in versi; che terminerà in prosa.* Mit diesen Feststellungen der Maske über ihre eigenen Fähigkeiten und Charakteristika im Beisein von Brighella und Tartaglia demonstriert Gozzi in der Art einer mise en abyme vor den Augen der Zuschauer die Unmöglichkeit und Unangemessenheit, den Masken eine ungewohnte Redeweise aufzudrängen, die nicht nur das Publikum, nämlich Brighella und Tartaglia auf der Bühne und die Zuschauer im Saal, auf eine Geduldsprobe stellt, sondern auch den Schauspieler in Bedrängnis bringt, der es gewohnt ist zu improvisieren oder zumindest in Prosa zu sprechen.

Im selben Stück gibt es eine weitere Improvisationsszene, in der Truffaldino und Brighella das ihnen eigene, typisch Maskenhafte betonen, eine allgemeine Anspielung auf Schauspieler einflechten und demonstrativ übertrieben ein moralisch verwerfliches Verhalten vorführen. Angesichts der Probleme am Hof von Millo halten sie es für angebracht, diesen zu verlassen:

Brighella è avaro. Trova troncate le vie di utilizzare per la mestizia introdotta; dunque l'uomo d'abilità deve abbandonarla. Truffaldino è un parasito. Trova la cucina inoperosa, tronche le vie de' stravizzi, dunque l'uomo di abilità deve abbandonarla. Eglino sono due personaggi fatti per far ridere. La Corte è ridotta seria, e malinconica sino nella Servetta; eglino non ci stanno piú a proposito. Brighella: che ivi stanno, come fioretti in mare, pesci in prato ec. Truffaldino: 
anzi come formaggio in una libreria ec. Brighella: anzi com'acqua in tavola d'un Tedesco ec. Truffaldino: anzi come Comici in un Teatro poco frequentato ec. Dopo un dialogo, che satiricamente dimostri due servi cattivi, che non sentono gratitudine de' benefizj ricevuti, ma abbandonano i loro padroni caduti in miseria, giudicando, che cosi deva fare l'uomo di spirito, per cercar miglior fortuna altrove, entrano. $(\mathrm{V}, \mathrm{I})$

Truffaldino und Brighella ãußern und verhalten sich nicht nur gemäß ihren traditionellen Charakteristika, sie weisen auch ausdrücklich auf ihre Funktion als komische Figuren hin, führen im Wettstreit der Vergleiche Schauspieler im Theater an und präsentieren zudem eine Parodie auf die Rolle des bösen Dieners. So entsteht ein komplexes Referenzgeflecht, in dem die Masken auf ihre Rolle als Masken, auf die Situation als Schauspieler, auf ihre Rolle als Dienergestalten und auf den aktuellen gesellschaftlichen Entwurf des suomo di spirito * verweisen. Daraus ergibt sich eine Vielschichtigkeit der Masken, auf die unter dem Aspekt der Identität noch näher einzugehen ist.

In L'augellino belverde, der vorletzten Fiaba teatrale Gozzis, die als Fortsetzung von L'amore delle tre melarance nach Ablauf von etwa 20 Jahren konzipiert ist, nimmt die Literatur- bzw. Literatensatire vor allem in der Person Brighellas, der als Dichter, Hellseher und angeblicher Liebhaber der Königinmutter Tartagliona auftritt, folgerichtig wieder breiten Raum ein. Bereits in der ersten Szene gibt Brighella in ekstatischer Verzükkung Verse zum besten, die den begeisterten Pantalone zur Bemerkung veranlassen, "el fa versi, che i xe da raccolta per nozze* $(\mathrm{I}, \mathrm{I})$, was nicht nur ein Licht auf die Beschränktheit Pantalones wirft, der die üblichen Sammlungen von mehr oder minder gelungenen Gelegenheitsgedichten zur Hochzeit für hohe Poesie hält, ${ }^{155}$ sondern eben auch auf Brighellas Verse, deren Qualität tatsächlich höchstens amateurhaft zu nennen ist:

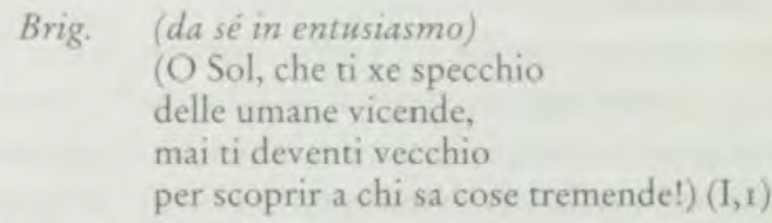

Nachdem Pantalone sein von Anspielungen auf die literarischen Diskussionen der Zeit geprägtes Lob ( Sior Strolego caro, se' un Poeta felice, no se' imitator, no affettè la lingua toscana; le vostre xe cose, e no parole ${ }^{156}$ )

155 Zur Debatte um die raccolte siehe Kap. 1.3.

156 Vgl. Kap. I zu Imitation, toskanischer Sprache bzw. Crusca und dem Schlagwort -cose e non parolee, das in vulgarisierender Weise die res-verba-Thematik der aufklärerischen Diskussion aufnimmt; siehe dazu auch Klaus Semsch, Abstand von der Rhetorik. Struk- 
beendet hat, schwindet bei Brighella die Inspiration, und er sucht $\mathrm{Zu}$ flucht in der nächsten Metzgerei: *Ma oimè, va mancando l'entusiasmo celeste; [...] Vedo vicina una bottega de Luganegher. Reparemo con do soldi de sguazzetto la debolezza, che sol lassar l'estro divin, el furor Poetico. « Petrarca- und Berni-Zitate schmücken Brighellas poetische Ergüsse im Angesicht der Königin Tartagliona, die er nur bedichtet, um ihr Erbe zu erschleichen, was ihm am Ende der Fiaba teatrale als Strafe die Verwandlung in einen Esel einbringt. Diese drastische Maßnahme bildet den Höhepunkt der Literatursatire, der auf Seiten der Märchenfiguren eine Philosophiesatire gegenübersteht.

Auch in Il re de' genj finden sich zahlreiche literarische Seitenhiebe mittels der Masken. Tartaglia und Brighella, die als Gesandte des Königshauses vor der schwarzhäutigen Amazone Canzema und ihrer Waffenträgerin Smeraldina auftreten, um ein Friedensangebot zu unterbreiten, befleißigen sich einer ausgesprochen rhetorischen Sprache, deren Form in krassem Gegensatz zur Niedrigkeit der Vergleiche, der Metaphern und des Vokabulars steht. Sie reden nicht wie üblich in Prosa, sondern in Versen, wobei Brighella Tartaglia den Vortritt läßt, angeblich aufgrund des Grades und des Alters, in Wahrheit jedoch, weil Smeraldina es auf ihn abgesehen hat und er angesichts ihrer Gegenwart seine Beredtsamkeit schwinden fühlt ("Con quella sorte de morose presenti no ga eloquenzaa):

Tart. Quando la causa manca, anche l'effetto

Doverebbe cessar. L'esperienza,

Magnifica Regina, fa vedere,

Che, passata la cassia, verbigrazia,

I molesti pruriti hanno il lor fine. (III, 3)

Leise, an Brighella gewandt, schließt Tartaglia selbstironisch seine Rede: "Ah Brighella? potea parlar/meglio Demostene? Spero bene. « Demonstrativ die Nutzlosigkeit leerer Rhetorik und falscher Beredsamkeit vorführend, bleibt der gewünschte Erfolg der Rede aus, und die beiden können von Glück sagen, daß Canzema, um nicht als grausam zu gelten, darauf verzichtet, Tartaglia und Brighella - dem Muster des contrappasso folgend - die Zunge ausreißen zu lassen. Stattdessen fordert sie Smeraldina auf, dafür zu sorgen, daß ihnen Nase und Ohren abgeschnitten werden. Angesichts dieser verzweifelten Situation bittet Tartaglia Brighella, von der Zuneigung Smeraldinas zu profitieren, Liebe zu heucheln und sie so von ihrem Vorhaben abzubringen, doch lehnt Brighella ab: „Son un Cesare de 
costanza; no me avvilisso a adular una donna. No l'amo, e per l'interesse de do strazze de recchie, e d'un'onza de naso, no tradisso, e no lusingo le putte, per le quali no go inclinazion.« (III, 4$)$. Diese ins Extrem getriebene heroische und moralische Haltung parodiert zum einen einen opernhaften Heroismus, zum anderen ex negativo die von Gozzi immer wieder angeprangerte laxe Moral in den Komödien der Zeit. Nachdem allerdings Smeraldina den Hufschmied und Tierarzt (maniscalco) auffordert, zur Tat zu schreiten, besinnt sich Brighella eines besseren, $*$ Bisogna abbandonar l'eroismo in pressa, e sfodrar la retorica subito qua «, nähert sich Smeraldina und beginnt in Tragödenmanier in gedrechselten Versen zu reden:

Smeraldina, scherzai. Questo è quel naso,

Che un di ti piacque, e questo è quel sembiante,

Che a' tuoi benigni sguardi

Più caro non sarà senza il suo naso.

Smer. (con tragico sussiego)

Passò quel tempo, Enea. Se quel tuo core

Non potei posseder, (commossa) il naso almeno

Presso di me, nelle mie man restando,

Utile mi sarà qualche momento. (III,4)

Wie bei Tartaglia ist es auch hier die Diskrepanz zwischen Redeform und -inhalt, die die rhetorischen Bemühungen lä́cherlich macht; kommt auf der Bühne der entsprechende Tonfall, die Gestik und Mimik hinzu - letzteres mehr bei Smeraldina als bei Tartaglia, dessen Gesichtsausdruck durch die Maske bestimmt ist - sowie vermutlich das Wissen des Publikums um die parodistische Nachahmung bestimmter Schauspieler in anderen Theatern oder in anderen Stücken, war die komische Wirkung solcher Szenen sicher unwiderstehlich und ein kaum zu überbietender Kontrast zu den unmittelbar vorausgehenden oder nachfolgenden pathetisch-tragischen der Märchenhandlung.

\subsection{Die Verflechtung der Kontraste}

Wie die bisher beschriebenen Charakteristika der Masken in den Kontext einer Fiaba teatrale integriert sind, welche Funktion sie übernehmen und in welchem dramaturgischen Verhältnis Masken- und Märchenkonstituente zueinander stehen, soll im folgenden exemplarisch an La donna serpente gezeigt werden, da in diesem Stück zum einen der Kontrast zwischen Märchensphäre und Maskenambiente besonders ausgeprägt ist, zum anderen die Masken durch Anzahl, Ort und Länge ihrer Auftritte ein deutliches Gegengewicht zu den Märchenfiguren bilden. 
In der *fiaba teatrale tragicomica La donna serpente, die im georgischen Tiflis und Umgebung spielt, stehen Farruscad, der König von Tiflis, und die Fee Cherestanì im Mittelpunkt der Märchenhandlung. Vor acht Jahren war Farruscad auf der Jagd einer schneeweißen, reich gezierten Hirschkuh begegnet, die bei der Verfolgung in einem Fluß verschwand. Farruscad, Pantalone und zuletzt auch Truffaldino waren ihr nachgestürzt und fanden sich unversehens in einem herrlichen Palast wieder. Farruscad heiratete Cherestani, die neun Monate später zwei bildschöne Kinder, Bedredin und Rezia gebar. Einen Wermutstropfen gab es allerdings im höchsten Glück: die rätselhafte Prophezeiung der Prinzessin an ihren Gemahl:

Non ricercar chi sia. Verrà '1 momento,

Che saprai tutto. Lamorosa smania

Di te mi piace, ed abbi forte il core

Per sofferir le più tremende cose.

Oime: pur troppo giugnerà l'atroce

Punto per me, per te, dolce mio sposo. $(1,2)$

Von Neugier geplagt, hatte Farruscad vor drei Tagen einen Schreibtisch der Prinzessin aufgebrochen in der Hoffnung, dort etwas zu finden, was über ihre Herkunft Aufschluß geben könnte, doch wurde er von Cherestani auf frischer Tat ertappt. Sie war daraufhin mit beiden Kindern, dem Gefolge und dem gesamten Palast verschwunden, während Farruscad, Pantalone und Truffaldino in einer Wüste zurückgeblieben waren. Dort treffen sie zufällig auf Brighella, Tartaglia und den treuen Minister Togrul, die sich nach achtjähriger Abwesenheit des Prinzen vom Hof in Tiflis mit Hilfe des Zauberers Geonca auf die Suche nach dem Vermißten gemacht hatten. Pantalone und Togrul, der von Elend und Bedrängnis in Tiflis berichtet, versuchen, Farruscad von seinen sehnsuchtsvollen Gedanken an Cherestani abzubringen und ihn für sein Reich zurückzugewinnen, doch erscheint Cherestani Farruscad im Traum, spricht von einem Wiedersehen und nimmt Farruscad das Versprechen ab, sie, was auch immer sie tue, nicht zu verfluchen. Unter Blitz und Donner erscheinen die Kinder Bedredin und Rezia, gefolgt von ihrer Mutter, die beide zum Entsetzen der Umstehenden ins Feuer wirft und Farruscad befiehlt, nach Tiflis zurückzukehren. Dort verteidigen mit letzten Kräften Canzade, die Schwester Farruscads, und Smeraldina das Reich gegen den Mohrenkönig Morgone und warten auf eine lebensrettende Nahrungsmittellieferung des Ministers Badur. Cherestanì hat jedoch die durch den Verräter Badur vergifteten Lebensmittel vernichtet, so daß Badur mit leeren Händen an den Hof kommt, den Überfall durch Cherestanì beklagt und Farruscad 
im Anblick seiner verhungernden Untertanen Cherestanì nichtsahnend verflucht. Cherestanì erscheint, enthüllt die Wahrheit über Badur, über ihre eigene Herkunft und ihr Schicksal. Als Fee in heftiger Liebe zu Farruscad entbrannt, hatte sie den Feenkönig gebeten, sterblich zu werden, was dieser nur unter der Bedingung zugestehen wollte, daß Farruscad acht Jahre lang nicht nach ihrer Herkunft fragen und sie am letzten Tag, an dem sie schreckliche Dinge zu tun gezwungen sei, nicht verfluchen dürfe; andernfalls müsse Cherestanì 200 Jahre lang ihr Dasein als Schlange fristen. In Farruscads Angesicht verwandelt sich Cherestanì nun in das schreckliche Tier. Während in Tiflis der entscheidende Kampf gegen Morgone vor der Tür steht, der dank Cherestanis nochmaligem Eingreifen erfolgreich bestanden wird, versucht Farruscad verzweifelt, Cherestanì zurückzugewinnen. Die Fee Farzana, die Farruscad ins Verderben stürzen will, um ihre Schwester Cherestanì endgültig ins Feenreich zurückzuführen, setzt ihn, seines Scheiterns sicher, drei gefährlichen Situationen aus, die Farruscad jedoch mit Hilfe des Zauberers Geonca besteht. Als letzte Prüfung gibt er nach langem Zögern einem Schlangenungeheuer cinen Kuß, worauf sich dieses in Cherestanì verwandelt.

\section{Maskencharakteristika im Märchenambiente}

Dieses kurze Resümee täuscht aufgrund seiner Handlungsorientiertheit über die starke Präsenz der Masken in La donna serpente hinweg. Pantalone als »ajo di Farruscad «, Erzieher des Königs Farruscad, Truffaldino als Jäger, Tartaglia als niederer Minister Farruscads und Brighella als Diener des königstreuen Wesirs Togrul dominieren nicht nur die erste Hälfte des ersten Aktes, sondern auch den Anfang der beiden folgenden. Einer expositorischen ersten Szene, in der sich die Feen Farzana und Zemina darüber unterhalten, daß morgen der Tag gekommen sei, an dem sich entscheide, ob Cherestani sterblich werde und sie sie damit endgültig an ihren Gemahl Farruscad verlören, folgt eine lange Szene a soggetto zwischen Truffaldino und Brighella. Damit wird ein erster deutlicher Kontrast geschaffen, der sich auf verschiedenen Ebenen manifestiert. Den beiden weiblichen Märchengestalten stehen die männlichen Masken gegenüber, den Unsterblichen die Sterblichen, dem vorgegebenen Text die Improvisation, den rhetorisch geformten Versen der Feen ${ }^{157}$ die dialektale Prosa Truffaldinos und Brighellas.

157 Die endecasillabi, in denen Farzana ihre Feenschwester Zemina daran erinnert, unter welch harten Bedingungen ihr König Demogorgone Cherestani in die Sterblichkeit 
Während die erste Szene im mbosco corto e spiclt, das heißt in einem Wald-Bühnenbild, das nur wenig in die Tiefe geht, um im hinteren Bühnenteil bereits das folgende Bild vorbereiten zu können, befinden sich die beiden Masken in der zweiten Szene in einer schrecklichen Fels- und Stein-Wüste, wo sie sich zufälig getroffen haben und im Dialog a soggetto die Exposition fortführen, wobei zum einen typische Maskencharakteristika in Sprache, Verhalten und Funktion sichtbar werden, zum anderen indirekt auch poetologisch-ästhetische Aspekte hinsichtlich des Umgangs mit Illusion, Fiktion und Wahrheit berührt werden.

Maskentypisches erscheint in Truffaldinos Erzählung der Vor-Geschichte, das heißt der Begegnung und Heirat Farruscads mit Cherestani und der Ubertretung des Frageverbots, die laut Anweisung Gozzis in der Art eines Märchens vorzutragen ist: sTruff. Si pianta, com'uno, che narra una Fola ad un fanciullo, usando spesso la formula: e cusi, sior mio benedetto ec « $(\mathrm{I}, 2)$. Truffaldinos Erzählung ist geprägt von Wort- und Phrasenwiederholungen wie »e corri, e corri, e cammina, c cammina ec. , der repetitiven Märchenformel »e cusi, sior mio benedetto , oder s la più bella cosa, che si possa vedere con due occhi ec. «, die im Text kursiv erscheinen, und den Fortgang der Geschichte als Ostinato begleiten. Sie sind nicht nur Zeichen der Alltagssprache der seinfachen « Maskenfigur, sondern zugleich komisches Element, das den märchenhaften Bericht durchdringt. Der pragmatische Charakter und die derbe Sprache der Masken kommt bei Tartaglias Auftritt in der vierten Szene zum Vorschein, wenn Tartaglia angesichts des vor Überraschung fast in Ohnmacht fallenden Pantalone sagt, >Signor Togrul, il vecchio crepa, e ancora non ci ha detto, dove sia il Principe. Pantalone, narraci, dov'è 'I Principe Farruscad, e poi mori in pace $(I, 4)$ oder kurz darauf, *Mo di, dov'è, dov'è, vecchio flemmatico, non ci seccare, $\propto$

Ebenfalls komisch wirken die typischen Eigenschaften der Maske im Märchenambiente, die im Laufe der Erzählung ans Licht treten, wie etwa die feige Zurückhaltung, sich auf der Jagd nach der schönen Hirschkuh

entlassen will, sind durch Inversionen, Hyperbata und Parallelismen charakterisiert: -Non ti ricorda, / Quante Demogorgone opre in dimani / Vuol che Cherestani crude, e inaudite / In apparenza a Farruscad suo faccia? / Che condannata I'ha a tener occulto /L'esser suo per ott'anni, e 'I fatal giomo, / E a non scoprir dell'opre sue gli arcani? / Credimi pure: no, diman non passa, / Che sarà maladetta dal suo sposo, / Che rimarrà nostra compagna.ะ (I,I)

Demogorgone wird schon in Boiardos Orlando innamorato als Herrscher über die Feen erwähnt und in seiner Grausamkeit beschrieben: -Sopra ogni fata è quel Demogorgone $f$ (Non so se mai lo odisti racontare) / E iudica tra loro e fa ragione, / E quello piace a lui, può di lor fare. / La notte se cavalca ad un montone, / Travarca la montagne e passa it mare / E strigie e fate e fantasime vane / Batte con serpi vive ogni dimane.e (II, 13, 27). 
nach Farruscad und Pantalone in den Fluß zu stürzen, die Truffaldino erst aufgibt, als er einen gedeckten Tisch im Wasser zu erkennen meint. Die Sorge um die eigene Haut, von der die offensichtliche Feigheit herrührt, der Pantalones Treue und Geringschätzung seines eigenen Lebens gegenüberstehen, und die Wichtigkeit leiblicher Bedürfnisse wie des Essens stellen typische Maskenmerkmale dar, die Gozzi aus der Tradition übernimmt und auf die Spitze treibt, denkt man an das Magenpflaster aus der Hand des Zauberers Geonca, "posto sulla bocca dello stomaco $(\mathrm{I}, 2)$, das Brighella wie Togrul und Tartaglia erlaubt, zwei Monate lang ohne Hunger und Durst nach ihrem König zu suchen. Daß Hunger und Durst dann am Ende nicht etwa mit Geld aus der Hand eines Herrn am Tisch eines Gasthauses gestillt werden, sondern aus dem Nichts eine üppige Tafel auftaucht, ist charakteristisch für Gozzis Kombination von Masken- und Märchenelementen, die so eine neue Funktion erhalten. ${ }^{158}$ Einerseits wird das Tischlein-deck-dich-Märchenmotiv in den Bereich der konkreten, typisierten körperlichen Bedürfnisse der Masken gezogen, andererseits scheint diesen nur noch auf märchenhafte Art beizukommen zu sein. Auf diese Weise findet eine in den Handlungsverlauf integrierte verfremdende Verflechtung der Masken- und der Märchenkomponenten statt, die auf der Bühne nicht reflektiert wird, auf Zuschauer und Leser jedoch komisch wirkt.

Einen komischen Effekt erzielen auch die präzisen Angaben, die die pragmatisch sveranlagten" Masken zu den märchenhaft-wunderbaren Dingen machen. So klagt Tartaglia, der für die lange Reise mit Brighella und Togrul durch den Monte Olimpo ebenfalls mit einem Magenpflaster ausgestattet war: „Ei, ei, Pantalone; e mangiare? Oh bella! Mi lasciano quì col cerotto sullo stomaco. Questo aveva la virtù di tener sazj due mesi. Sono passati cinquantanove giorni, e cinque ore; per poche ore potrò ancora resistere, ma poi cascherò morto. « Die Erwähnung der genauen Wirkungszeit in numerischer Exaktheit erinnert an Brighellas Angabe der präzisen Zahl der Stufen, die durch den Monte Olimpo in die Wüste geführt haben: "che avevano fatti quaranta milioni, settemila, dugento, e quattro scaglioni, e ch'erano giunti in quel deserto* $(\mathrm{I}, 2)$, bei der die komische Wirkung ebenfalls auf der Diskrepanz zwischen Erfundenem und übertrieben exakter Beschreibung beruht. Eine Steigerung erfährt diese in Tartaglias Fortführung seiner Überlegungen zum Magenpflaster, in denen er auf die Notwendigkeit und Nützlichkeit eines solchen in vielen Fällen hinweist:

15* Gozzi spielt diese Kombination bereits in L'amore delle tre melarance aus, wo Truffaldinos Durst den Tod zweier Orangenprinzessinnen verursacht und die dritte nur knapp demselben Schicksal entrinnt. 
Bella virtủ è però quella di questo cerotto! A quante povere genti sarebbe necessario! I Padri giugnerebbero col cerotto in scarsella, troverebbero le loro famiglie affamate a piangere, $e$ taffete, un pezzo di cerotto sullo stomaco a tutti; rimedierebbero a quella miseria, in cui sono abbandonati. A quanti Comici, a quanti Poeti sarebbe una manna! Oh se 'I Masgomieri avesse questo cerotto, sarebbe certo più fortuna, che col suo balsamo greco, e col suo taccomacco del Cavalier Burri per le sciatiche, e per l'inappetenza, e l'indigestione. $(I, 4)$

Das beilăufige Einfließen sozialer Realität, die Bemerkung zu Schauspielern und Dichtern, das heißt der Hinweis auf die eigene Situation, sowie die Nennung eines in Venedig stadtbekannten Scharlatans ${ }^{159}$ im Zusammenhang mit dem Zauberpflaster sind charakteristisch für die Maskenrede bei Gozzi, der so die traditionell in der Improvisation gegebene Möglichkeit aufgreift, über das Bühnengeschehen hinaus auf die Wirklichkeit zu verweisen und die Masken damit betraut, in ironischer, parodistischer oder satirischer Weise auf aktuelle gesellschaftliche, Theater- und Literatur-Debatten anzuspielen und immer wieder Venezianisches ins Spiel $\mathrm{zu}$ bringen. In einer Improvisationsszene mit Truffaldino und Brighella zu Anfang des zweiten Aktes finden sich dieselben Aspekte in gleicher Reihenfolge wieder: Die stereotypen Äußerungen der Masken zum Essen und Trinken, das am Abend in ungeahnter Quantität und Qualität aus dem Nichts aufgetaucht war, münden in Truffaldinos Bemerkung, $\gg$ che in quel deserto si stava assai meglio, che nelle Città (II,I), und es folgt »una satira sui disturbi, e sui costumi delle città, massime sulla corte, e spezialmente sulla penosa vita de' servi “, in der der Topos des locus amoenus und der Stadt-Land-Opposition der arkadischen Poesie von Truffaldino und Brighella in parodistischer Weise auf die Befriedigung körperlicher Bedürfnisse und auf das Dienerleben übertragen werden. Der Hinweis Truffaldinos auf das beschwerliche Dienerdasein an den Höfen, der von Brighella aufgenommen und ausgeführt wird, dient als Ausgangspunkt für eine sich unmittelbar anschließende, ausführliche Unterhaltung der beiden Masken über Dienerrollen in Komödien:

Truff. adduceva il gran disturbo de' servi nelle commedie, che piacevano a' padroni, e a' servi no. A lui piaceva l'Arlecchino, a' padroni no. Lo faceva ridere; i padroni dicevano, che il ridere delle buffonate di quel personaggio era una scioccheria. Se dovesse ficcarsi degli aghi nelle natiche per non ridere a ció, che lo faceva ridere. Brig. che certo quello era un gran disturbo. Che quando le maschere dicevano nella commedia delle cose, che lo facevano ridere, conveniva per

159 Masgomieri bzw, Masgumieri, sein griechischer Balsam und seine Sälbchen tauchen auch im 9. Gesang der Marfisa bizzarra auf, wo Gozzi in einer Anmerkung erlãutert: -Il Masgumieri fu ciurmatore notissimo- (Col. VII, La Marfisa bizzarra, IX, 63). 
la vergogna, ch'egli ridesse sotto al tabarro. Truff. ch'egli aveva vedure moltissime Dame, e moltissimi Cavalieri ridere senza vergognarsi; che tuttavia è contento d'esser partito da un mondo, che sosteneva un'incomoda serietà in apparenza, e in sostanza era assai ridicolo. Quella solitudine gli piaceva ec. $(\mathrm{I}, \mathrm{I})$

Die Anspielung auf die zeitgenössische Diskussion über die Masken der Commedia dell'arte ist deutlich. Als komische Masken über den Effekt von Masken auf der Bühne räsonierend, weisen Truffaldino und Brighella einerseits auf das unmittelbar Komische Arlecchinos hin, das bei Unvoreingenommenheit unwillkürlich ein Lachen hervorruft, und entlarven andererseits die strategische Behauptung, daß höhere soziale Schichten ( Dame und (Cavalieri $*$ ) auf solch niedere Komik nicht mit Lachen reagierten, als heuchlerisch. ${ }^{160}$ Mit einem letzten Seitenhieb gegen den falschen Schein der höfischen Welt, sei diese nun die fiktionsinterne oder eine reale außerhalb des Theaters, endet die satirische Einlage, und Brighella und Truffaldino wenden sich wieder den Gedanken ans Essen zu, wobei es Gozzi nicht versäumt, auch noch Venedig zu erwähnen: ^Brig. voleva una merenda polita con salse ec. Truff. voleva una merenda da veneto cortigiano ec.«. Ein solches Ineinandergreifen von Selbstreflexivität, Ironie, parodistischen und satirischen Bemerkungen ist bezeichnend für zahlreiche Maskenszenen in den Fiabe teatrali, die so einen Kontrapunkt zur in sich geschlossenen höfischen Märchenwelt bilden, die sich selbst ernst nimmt und nicht über sich nachdenkt.

\section{Märchenillusion, theatrale und nicht-theatrale Wirklichkeit}

Bemerkenswert erscheint der Umgang mit der Illusion bzw, der Illusionsbrechung in den beiden Expositions-Szenen. Wird im allgemeinen den zanni die Möglichkeit der Illusionsbrechung zugeschrieben, die ihre improvisierten Passagen nutzen können, um aus der Fiktion auszubrechen, gegebenenfalls Aktuelles einzubeziehen und sich direkt ans Publikum zu wenden, fällt diese Funktion in La donna serpente eben nicht den Masken, sondern den Feen zu. Am Ende ihres Dialoges verweisen sie selbstreflexiv auf ihre Aufgabe als Schauspielerinnen bzw, als Truppe, das Publikum zu amüsieren und ihre »Geldgeber $\approx$ nicht etwa zu langweilen:

Farz. Andiam; che non è onesto il recar tedio

Al mondo aspettator d'opre inaudite,

E sopratutto, con gli arcani nostri

tho Vgl. Kap. 3.7. 


\section{Convien non recar noja a chi ci ascolta, Poichè d'essi'l miglior saria perduto. \\ Zem. Oh Ciel, pria d'annojar chi èl nostro bene, \\ Con Farruscad Cherestani perisca. $(I, 1)$}

Einigermaßen gewagt mutet es an, so die erste Szene einer Fiaba teatrale zu beenden, die sich eben unter Zuhilfenahme eines Feenreiches und zeitlicher Dimensionen, die sich über Jahrhunderte erstrecken, eines Zauberers und angekündigter Metamorphosen von Feen in Menschen und Menschen in Tiere zu entwickeln beginnt. Dagegen verbleiben Truffaldino und Brighella in ihrem Dialog auf der fiktionalen Ebene, wenngleich Brighella diese im Hinblick auf ihre Wahrscheinlichkeit in Frage stellt. Wie wenig Truffaldino bereit ist, auf $\gg$ realistische , svernünftige $*$ Einwürfe Brighellas einzugehen, zeigt seine Reaktion auf dessen Feststellung, daß die Hirschkuh sicher ertrunken sei, wenn man sie im Fluß nicht mehr gefunden habe: $*$ No, che non interrompa una narrativa di somma importanza. E così, sior mio benedetto ec. $(1,2)$. Die Ablehnung des Einwurfs ist deutlich und wird unterstrichen durch die Aufnahme der Märchenformel, die unmittelbar zurückführt in die Erzählung der Geschehnisse, die Truffaldino selbst immer wieder kommentiert ( $\$$ Sempre arcani, sempre cose secrete $\star$, Oh maraviglia $*$ ), ohne an ihrem Wirklichkeitscharakter zu zweifeln. Brighella hingegen mag den Schilderungen kaum Glauben schenken ( $\mathrm{fa}$ degli stupori della narrazione: non presta fede $\alpha$ ), läßt aber nach Truffaldinos Beteuerungen die Sache auf sich beruhen und beginnt, seine eigene Geschichte zu erzählen, die um nichts wahrscheinlicher ist, ${ }^{161}$ jedoch unhinterfragt bleibt. Damit verhält sich Truffaldino gemäß dem üblichen Rezeptionsmodus des Märchens, der ein stillschweigendes Einvernehmen zwischen Erzähler und Zuhörer vorsieht, das das Kriterium der Wahrscheinlichkeit außer Kraft setzt. Dagegen durchbricht Brighella angesichts der Erzählung Truffaldinos, der in Haltung, Gestik und Sprache explizit als Märchenerzähler auftritt, die Konvention. Bereits in den ersten beiden Szenen fällt damit ein Schlaglicht auf Formen des Umgangs mit dem Unwahrscheinlichen, sowohl was die Darstellung als auch was seine Aufnahme betrifft. Möglichst spannend und kurzweilig müssen die sopre inaudite sein, wie die Feen zu verstehen geben, und die Zuschauer und -hồrer tun gut daran, sich wie Truffaldino darauf einzulassen und nicht wie Brighella in unangemessener Weise Zweifel anzumelden.

161 Brighella, Tartaglia und Togrul haben sich auf Empfehlung des Zauberers Geonca zum Olymp begeben, von wo sie uber viele Stufen in ein tiefes. Loch absteigend endlich in der Wuste ankamen. 
Im weiteren Verlauf des Stücks treten die Feen nicht mehr aus der märchenhaften Handlung heraus, und es bleibt allein den Masken überlassen, einen Kontrast zu den ganz ins märchenhafte Geschehen involvierten Protagonisten zu bilden. Die Masken stehen allerdings nicht außerhalb der Märchenhandlung, sondern vielmehr am Rand, doch erlaubt ihnen diese Position, das Märchengeschehen aus einer gewissen Distanz zu sehen, zu kommentieren, zu reflektieren und durch Digressionen zu unterbrechen. In einer langen dritten Szene, die auf die Improvisation Truffaldinos und Brighellas folgt, fällt Pantalone diese Aufgabe zu. Während Prinz Farruscad sich in Liebe zur verschwundenen Cherestani verzehrt, sich ihre liebliche Gestalt vor Augen ruft und seine Neugier verflucht, die zum Verlust der Geliebten sowie der beiden Kinder Rezia und Bedredin geführt hat, fordert Pantalone ihn auf, diese Liebe zu vergessen, und erwidert den von Farruscad in petrarkistischer Manier vorgebrachten Katalog der märchenhaften Schönheit Cherestanis in bernesker Umkehrung: der *alma grande, generosa, altera, / Della più bella Principessa* stellt er die »striga maledetta gegenüber, und wünscht sich den Zauberring Angelicas herbei, der Ruggiero die Augen über Alcina geöffnet hat, um auch Farruscad von seinem Irrtum zu überzeugen. Dieser geht jedoch in keiner Weise auf Pantalones drastische Einwürfe ein, sondern fährt unbeirrt fort:
Far. (in trasporto da una parte)
Belle chiome, ove siete? io v'ho perdute.
Pant. (dall'altra parte dopo averlo udito) Zucca pelada maledetta, con quattro cavelli canui sulla coppa, e forsi con della tegna, scoverzite per carità.
Far. (come sopra)
Occhi, stelle brillanti; ahi dove siete?
Pant. (come sopra) Occhi infossai, come quelli del cavallo del Gonella, pieni de sgargagi, copai, lasseve veder.
Far. Bocca, rubini ardenti, bianche perle, Più non vi rivedrò! chi mi v'ha tolto?
Pant. Zenzive paonazze, con quattro schienze marze; lavri scaffai, bocca de seppa col negro, in to tanta malora lassete veder. $(1,3)$

Eine solche groteske Gegenüberstellung von stereotypen Schönheitsund phantasievoll bildhaften Häßlichkeitsmerkmalen, in der ein märchenhaft-petrarkistischer und ein bernesker Diskurs zusammenstoßen, kann kaum als Dialog im eigentlichen Sinn bezeichnet werden, da es an keinem Punkt zu einem Informationsaustausch zwischen Farruscad und Pantalone kommt. Stattdessen werden zwei monologartige Partien ineinandergeschachtelt, deren Kontrastwirkung durch die im Nebentext festgehaltene Position der beiden Schauspieler auf der rechten und der linken Seite der Bühne visuell verstärkt wird. Auch von einer wirklichkeitsnahen 
Relativierung der Märchenperspektive durch die Maskenfigur kann nicht die Rede sein, denn Pantalone vertritt keineswegs eine nrealistische $\propto$ Position, die den märchenhaften Superlativ korrigeren könnte, sondern eine eben so extreme, stilisierte wie der Prinz. Vielmehr wird der komische Kontrast zwischen zwei konträren Sichtweisen unterstrichen, die innerhalb des märchenhaften Rahmens denselben Wirklichkeitsstatus beanspruchen, sich aber für das Publikum durch die Stilisierung und Polarisierung als gleichermaßen realitätsfern enthüllen. Zugleich wirft diese Szene ein Licht auf die Frage nach dem Wahrheitsstatus literarischer Diskurse eine Frage, die auch die Fortührung des Dialogs bestimmt. Um den Prinzen zur Vernunft zu bringen, erzählt Pantalone nun als Exemplum ein Märchen aus Les mille et un jours, das als Digression die Geschichte des Königs Ruzvanschad und der Prinzessin Schéhéristani unterbricht, auf der die Handlung von La donna serpente beruht. Pantalone schließt seine Erzählung von der Hexe Dilnovaz, die sich 300-jährig in die Gestalt der 20-jährigen Gemahlin des Königs von Tibet verwandelt und so den König betrogen hat, mit den Worten „Questi xe fatti de verità, Altezza, no le xe miga fiabe da contar ai puttelli ", worauf Farruscad unmittelbar reagiert und eine sehr pragmatische Frage stellt, "Come può darsi, / Che vecchia sia Cherestani, mia sposa, / S'ella mi fu feconda di due figli? « Was Pantalone als wahre Fakten bezeichnet und das Publikum, entgegen Pantalones Behauptung, eindeutig als Märchen identifiziert, wird von Farruscad ernst genommen, auf seine eigene Situation übertragen und ruft bei ihm eine berechtigte Frage sowie eine Selbstanklage wegen seiner Neugier und seines Ungehorsams hervor. Das Geständnis »Fui disubbidiente $*$ wiederum nimmt Pantalone zum Anlaß, sich über das Frageverbot Cherestanis zu mokieren, darauf hinzuweisen, daß es doch selbstverständlich sei, die Wahrheit über die eigene Frau erfahren zu wollen. Die Aufforderung an Farruscad, in sein Reich zurückzukehren und dort nach dem rechten zu sehen, lehnt dieser schließlich ab: sIo morrò, prima / D'abbandonar queste contrade, il giuro. / Sognai già di veder l'amata sposa; / Parmi d'averla innanzi", so daß Pantalone resigniert in Selbstmitleid verfällt, Oh povero Pantalon! Mo la vada, dove che la vol, che per adesso mi no go più fià de seguitarla. * Drei ganz unterschiedliche Redeweisen Pantalones vermögen es nicht, Farruscad vom Gedanken an Cherestani ab- und «zur Vernunft * zu bringen, weder die literarisch markierte des Antipetrarkismus, noch die volkstümliche des Märchens, noch die der Maske Pantalone eigentlich angemessene, nämlich die alläglich pragmatische.

Bemerkenswert ist allerdings, daß es ausgerechnet das Märchen ist, das, setzt man - wie Pantalone dies fordert - seine Wahrheit voraus, bei Farruscad eine Reaktion hervorruft, die man als vernünftig bezeichnen 
könnte. Nachdem in der vorausgehenden zweiten Szene durch Truffaldino darauf hingewiesen wurde, wie ein Märchen angemessen zu rezipieren sei, scheint in dieser dritten Szene für einen kurzen Moment seine heilsame Wirksamkeit beim Zuhörer aufzuscheinen, wenn Farruscad anfängt nachzudenken, sich eigene Gedanken zu machen. Zieht man dies sowie die Variabilität der Ausdrucksweise Pantalones in Betracht, wird deutlich, daß Gozzi in den langen Maskenszenen weit über die Belustigung des Publikums durch komische Effekte hinausgeht und über die Masken auch poetologisch-ästhetische Aspekte vermittelt.

Eine ganz außergewöhnliche improvisierte Maskenszene mit Truffaldino und Brighella findet sich im dritten Akt, an dessen Anfang die kriegerischen Auseinandersetzungen in Tiflis stehen: aus dem Bühnengeschehen heraustretend, berichtet Truffaldino marktschreierisch über die Ereignisse, die in den letzten Stunden in Tiflis vorgefallen sind, über die Schlacht und den wundersamen Sieg von 400 getreuen Soldaten über das 2 Millionen-Mann-Heer des Mohrenkönig Morgone, über Verwundete und Tote und vieles mehr, und bietet dem Publikum einen schriftlichen Bericht für nun soldo a an, in dem es all das nachlesen könne. Auf die Frage Brighellas, wie denn etwas gedruckt sein könne, das noch nicht einmal eine Stunde zurückliege, antwortet Truffaldino, sche gli scrittori, e gli stampatori, quando si tratta di guadagnare, sono saette" (III, 5 ). Der Spitze gegen Schriftsteller und Drucker folgt eine weitere gegen die Venezianer, wenn Truffaldino auf Brighellas Vorschlag, nach Venedig zu gehen und die Berichte dort zu verkaufen, meint, »che per venderle a Venezia converrebbe aggiungere alla relazione trenta volte il doppio di successi. \& Im Vorwort zu La donna serpente geht Gozzi ausführlich auf diese Szene ein und erläutert sowohl den venezianischen Hintergrund als auch die praktischen Überlegungen, die zu dieser Lösung führten, die schauspielerische Ausführung auf der Bühne und die Reaktion des Publikums:

La scena quinta dell'atto terzo di questa Fiaba è una di quelle invenzioni, dette triviali inezie dai ridicoli serj scrittori di fogli, e d'inette, e goffe satire.

Essendo questa rappresentazione pienissima di prodigi, per risparmio di tempo, e di spesa alla Truppa comica, e per non obbligarla alla dimostrazione col fatto di molti avvenimenti mirabili, ma necessarj da sapersi dall'Uditorio, feci uscire il Truffaldino imitator di que' mascalzoni laceri, che vendono le relazioni a stampa per la Città, accennando il contenuto in compendio di quelle con de' spropositi. Il Sacchi Truffaldino uscendo con un tabarro corto, e lacero, un cappello tignoso, e un gran mazzo di relazioni a stampa, gridava, ad imitazione di que' birbanti, accennando in compendio il contenuto della relazione, dichiarando i successi accaduri, ed eccitando il popolo a comperar il foglio per un soldo.

Tal scena inaspettata, ch'egli faceva con molta grazia, e verità, e con una di quelle imitazioni sempre fortunate, spezialmente nel Teatro, cagionava un'intero tu- 
multo, e continuati scoppj di risa nell 'uditorio, e si scagliavano da' palchetti a quel personaggio confezioni, e danari per avere la relazione. (Col. II, I3-I4)

Ahnlich wie im Falle Cigolottis in Il re cervo wird hier ein Stück dem zeitgenössischen Publikum bestens vertrauter venezianischer Realität auf der Bühne nachgestellt und in einen neuen Kontext integriert. Hier wie dort bleibt angesichts des Zusammenspiels von Wiedererkennen und Verfremdung der Erfolg beim Publikum nicht aus. Daß diese Szene nicht nur Elemente der Wirklichkeit auf die Bühne bringt, sondern auch umgekehrt die Bühnenwirklichkeit auf die Realität wirkt, geht aus der Fortführung der $\approx$ Prefazione* Gozzis hervor:

Giunto agli orecchi de' venditori delle relazioni il successo di questa scena, si unirono, e posti alla porta del Teatro con un gran fardello de' loro già disutili, e muffati fogli, che nulla avevano a fare colla rappresentazione, all'uscire dell'Uditorio, si posero a gridare con quanta voce avevano la relazione de' gran casi avvenuti nella Donna serpente. Nel bujo della notte venderono un numero infinito di que' fogli, ingannando il popolo, e se n'andarono all 'osteria a far de' brindisi al Sacchi, e a far nascere di que' pubblici discorsi, che sono favorevolissimi ad una Comica Truppa. (Col. II, 14-15)

Diese Episode wirft nicht nur ein Licht auf die von Gozzi genau kalkulierte Publikumswirksamkeit seiner Fiabe teatrali, sondern auch auf die Flexibilität der Maskendarsteller, die es erlaubt, derartige Nachahmungen zu komischen Kabinettstücken zu erheben. Umso größer ist der Kontrast zu den unmittelbar folgenden Szenen, in denen die Stimme des Zauberers Geonca den in Tiflis Zurückgebliebenen berichtet, daß eine feindliche Fee Farruscad in den Tod führen wolle und sie auffordert, ihrem Prinzen nachzueilen und ihm zu helfen. Die Szene schließt mit einem Ariost-Zitat Truffaldinos und seinem Werbegeschrei: Chi va lontan dalla sua patria, vede / Cose, da quel, che si credea, lontane. / Nuova, autintica, e distinta relazion, che ve descrive, e ve dichiara ec. (entra gridando la relazione). (III,8), ${ }^{162}$

\section{Masken- und Märchenfiguren in der theatralen Wirklichkeit}

In den Anfangsszenen von La donna serpente treten nicht nur die Maskencharakteristika deutlich hervor, sondern auch Verhaltensunterschiede von Masken- und Märchenfiguren, die sich insbesondere hinsichtlich Pragmatik und Idealismus, Körperhaftigkeit und Körperlosigkeit, Er-

162 Ariost, Orlando furioso, VII, 1 ; auf denselben Gesang wurde auch in vorausgehenden Szenen in Anspielungen auf die Alcina-Episoden Bezug genommen. 
staunen und Selbstverständlichkeit angesichts märchenhafter Ereignisse manifestieren. In der bereits erwähnten Szene mit Pantalone und Farruscad steht dem völlig vom Märchengeschehen gefangengenommenen Farruscad ein Pantalone gegenüber, der ihn in die "Wirklichkeit $\alpha$, das heißt an seinen Hof in Tiflis, zurückholen will. Farruscad allerdings ist keinem wie auch immer gearteten Versuch zugänglich, ihn von seinen Gedanken an Cherestani abzubringen. Die Absorption der Protagonisten durch die Märchenhandlung, ihr völliges Involviertsein in die Märchenwelt im Gegensatz zur distanzierteren Haltung der Masken, die meist von pragmatischen Gesichtspunkten bestimmt ist, zeigt sich auch in der fünften Szene des ersten Aktes. Tartaglia, der sich auf Pantalones Anraten versteckt hat, um den Prinzen später zusammen mit Brighella und Togrul zu überraschen, sieht Farruscad unverhofft nahen, vertieft in seine Klage über den Verlust Cherestanis und der Kinder. Einem Impuls folgend, will Tartaglia ihm entgegeneilen und ihn umarmen, erinnert sich aber des Befehls Pantalones und kehrt in sein Versteck zurück, aus dem er Farruscad weiter beobachtet und plötzlich einen reich gedeckten Tisch entdeckt. Dieser war auf die Anrufung Cherestanis durch Farruscad erschienen, der jedoch bei seinem Anblick verzweifelt ausruft:
No che cibo non prendo. Io vo' morire
D'inedia, e di dolor. Qual tirannia
Eे questa, di voler, che in vita io resti,
Perch'io mora d'angoscia ogni momento,
E non morendo mille morti io soffra? $(\mathrm{I}, 5)$

Tartaglia dagegen fühlt sich sofort vom Hunger überwältigt ( $s$ mi sento morire di fame $\alpha)$ und nähert sich heimlich dem Tisch. Als eine Stimme ertönt, „Farruscad, cibo prendi, e ti nodrisci «, flieht Tartaglia erschrocken, kann es jedoch nicht lassen, einen zweiten Versuch zu unternehmen, der ebenfalls scheitert, da der Tisch eben so unvermittelt wie er aufgetaucht war auch wieder verschwindet. Während Farruscad ganz der Trauer um den Verlust seiner geliebten Frau anheimgefallen ist, am liebsten stürbe und das Essen als qualvolle lebensverlängernde Maßnahme versteht, treibt der Hunger, die Lust am Essen Tartaglia unverzüglich an den Tisch - offensichtlicher ist der Kontrast zwischen quasi körper- und bedürfnisloser, sich in Liebe und Trauer verzehrender Märchengestalt und von körperlichen Bedürfnissen dominierter Maske kaum zu gestalten; ein Kontrast, der sich auch sprachlich manifestiert. Farruscads oben zitierte Verse basieren auf der Antithese von Sterben und Leben und dem Paradoxon, im Leben tausend Tode zu sterben, die kunstvoll durch Parallelismen (syntaktisch und semantisch: $*$ morire / D'inedia, e di dolor $\propto-»$ mora 
d'angosciac; syntaktisch: sin vita io resti - - mille morti io soffra «, semantisch dagegen antithetisch), Antithesen, Paradoxon ("che in vita io resti, / Perch'io mora d'angoscia «) und Oxymoron (»non morendo mille morti io soffrac) gestaltet sind. Tartaglias Replik bildet das Gegenstück in Prosa: *Quella mensa non c'era. Chi l'ha portata? Mi sento morire di fame. Se potessi di nascosto prendere qualche cibo $;$; der metaphorischen Rede stehen praktische Überlegungen und den rhetorischen Feinheiten eine alltägliche Redewendung mit dem Wort »morire» gegenüber, und Farruscads "No che cibo non prendo * kehrt sich in Tartaglias *Se potessi di nascosto prendere qualche cibo um.

Auch in anderer Hinsicht ergibt sich ein bedeutender Verhaltensunterschied: Als Märchenfigur nimmt Farruscad das plötzliche Auftauchen des Tisches wie auch die Stimme als selbstverständlich hin, während Tartaglia sich zunächst über den Tissch wundert, dann über die Stimme erschrickt, "(spaventato) Che voce è questa! Dove diavolo m'hanno lasciato? «, und zuletzt, als der Tisch verschwindet, entsetzt flüchtet. Eine ähnliche Reaktion zeigen Tartaglia und Pantalone in der zweiten Szene des zweiten Aktes auf die Ereignisse der Nacht: Ein Erdbeben, tintenfarbener Regen, Eulengeheul und Hundegebell haben sie in tiefen Schrecken versetzt Truffaldino und Brighella dagegen haben dank des guten Essens und des hervorragenden Weines von alledem kaum etwas bemerkt. Die Sonne, die blutrot aufgeht, verdorrte Bäume, versetzte Berge und purpurrote Bäche sind weitere Unglückszeichen, die sie zur Flucht veranlassen würden, wären sie nicht, wie sie selbst versichern, ihrem Prinzen treu. Daß dieser sich in der folgenden Szene nicht über derartige Ereignisse wundert, sondern sie als "natürliche Erfüllung der Prophezeiungen Cherestanis versteht und daraufhin die Bewahrheitung weiterer schrecklicher Vorhersagen befürchtet, ergibt sich folgerichtig aus seinem bereits im ersten Akt sichtbaren Verhältnis zum Übernatürlichen, das bei ihm keinerlei Befremden hervorruft. Angesichts dieser Nicht-Reaktion der Märchenfigur auf das Außergewöhnliche bricht die Maske Pantalone in Tränen

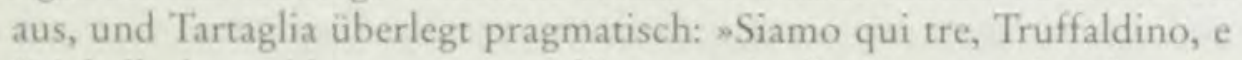
Brighella doverebbero essere qui d'intorno. In cinque potressimo legarlo, e portarlo via. « $(\mathrm{II}, 3)$. Was im Märchen gang und gäbe ist, die Selbstverständlichkeit des Wunderbaren, erscheint den Masken problematisch. Sie zweifeln nicht an den ins Groteske gesteigerten swunderbaren « Naturphänomenen, sondern verzweifeln an Farruscad, der auf alle diese Zeichen nicht reagiert. 


\section{Verkleidung, Verstellung, Verwandlung}

Auf die durch die Masken bestimmten Anfangsszenen des ersten Aktes, in denen die Vorgeschichte erzählt und ihre Folgen an Farruscad vorgeführt werden, folgen Szenen, in denen das Märchenhafte mehr und mehr in den Vordergrund tritt und vor den Augen der Zuschauer sichtbar wird. Der Übergang zur Märchenwelt ist durch zwei Parallelszenen markiert, in denen die Thematik von Sein und Schein aufleuchtet. Gleichsam als Rezeptionssignal an die Zuschauer werden Farruscads Unsicherheit über den Status des von ihm Gesehenen und mögliche Deutungen vorgeführt. In diesen Parallelszenen unternehmen Pantalone und Togrul einen letzten Versuch, Farruscad von Cherestani ab- und zur Vernunft zu bringen, indem sie zum Mittel der Verkleidung greifen: Pantalone erscheint Farruscad als Priester Checsaja, Togrul als sein Vater Atalmuc. Nicht nur Farruscad, sondern auch das Publikum glauben, den Priester Checsaja und den Vater vor sich zu haben; "si avverte, che 'I Pantalone accomodato da sacerdote non dovrà avere nessun segno, per cui gli spettatori possano riconoscerlo* (II,7), schreibt Gozzi im Nebentext, und für die nächste Szene gilt dasselbe. Der vermeintliche Checsaja versucht noch einmal, Cherestani als »sozza maga $\propto$, novella Circe barbara, iniqua $\approx$ zu diskreditieren, erklärt, die Bäume und Steine, die Farruscad um sich sehe, seien von der Hexe verwandelte Menschen ${ }^{163}$ und droht Farruscad, daß auch er binnen kurzem zu einem Drachen werde. In seiner Verzweiflung bittet Farruscad Checsaja um Rat, worauf dieser ihn auffordert, Frau und Kinder zu vergessen und ihm unverzüglich nach Tiflis zu folgen. Bei Farruscads Worten $* \mathrm{Si}$, sacro lume, / Ti seguirò; ma qui 'l mio cor rimane... / Mi raccomando a te « fällt die Priesterverkleidung von Pantalone ab, ohne daß dieser selbst es bemerkte. Vor dem Publikum und dem überraschten Farruscad entlarvt, setzt er als Priester seine Rede fort, bis Farruscad ihn scharf rügt und wegschickt. Die letzten Repliken Pantalones und Farruscads weisen auf Cherestanì als Urheberin dieser Rückverwandlung hin und verdeutlichen noch einmal die divergierenden Positionen:

Pant. (guardandosi intorno) Oime!.. Oime! Ah, che l'ho dito, che co tutti i bei secreti no lo despettolevimo più da sta striga scarabazza. (entra fuggendo)

Far. (in trasporto)

Cherestani, tu m'ami ancora, e vuoi,

Ch'io quì t'attenda ... Ma che vidi mai!

Qual meraviglia! $(\mathrm{I}, 7)$

${ }_{163}$ Deutlich sind hier die Anklānge an die Alcina-Episoden im VI. und VII. Gesang des Orlando furioso. 
Unmittelbar, mit einer Wortwiederholung und Fortführung des unvollstāndigen Verses, schließt die folgende Szene an, in der Togrul als Atalmue Farruscad erklärt, welch verheerende Folgen sein selbstvergessenes Verhalten für das Reich hatten und haben:

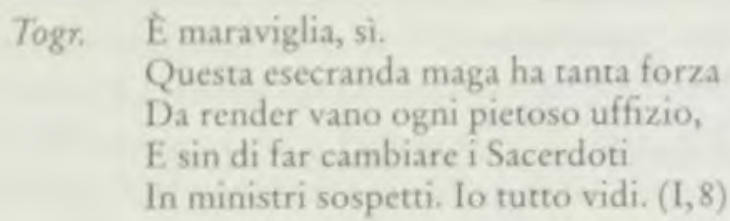

Mit diesen Versen kehrt Togrul die Sichtweise des in der vorausgegangenen Szene Geschehenen um: nicht Pantalones betrügerische Verkleidung wurde von Cherestani entlarvt und der Priester in Pantalone rückverwandelt, sondern sie ließ den Priester in den Augen Farruscads als Pantalone erscheinen: Sappi, figlio, / Che colui, che a te parve Pantalone, / Checsaja è, il Sacerdote. Non t'abbagli / Il cambiamento suo, la fuga sua, / Ch'opra della tua maga è quanto apparve.a $(\mathrm{I}, 8)$. Diese Worte aus dem Mund des vermeintlichen Vaters rufen bei Farruscad eine Unsicherheit über das wahre Verhältnis von Sein und Schein hervor, die ihn erneut an Cherestani zweifeln läßt. Als er zudem erfährt, daß vor ihm nicht sein Vater, sondern dessen Geist steht, da der Vater vor acht Jahren aus Kummer über die Abwesenheit des Sohnes gestorben ist, findet er sich bereit, von Cherestani zu lassen und dem väterlichen Geist zu folgen. Wiederum fällt in diesem Moment die Gestalt Atalmucs von Togrul ab, und Farruscad sieht sich zum zweiten Mal getäuscht und ent-täuscht. Togrul jedoch flüchtet nicht wie Pantalone, sondern mahnt den Prinzen, angesichts von Atalmucs Tod, der Bedrohung des Reiches durch den Mohrenkönig Morgone und der jammervollen Lage des Volkes, sich endlich von den Fesseln Cherestanis zu befreien und in sein Reich zurückzukehren, das er im letzten Moment mit Hilfe des Zauberers Geonca noch retten könne.

In einem Monolog gibt Farruscad seiner inneren Zerrissenheit beredten Ausdruck; $\bowtie$ Oh qual tormento ...! / Oh qual mente agitata! $\ltimes$, ringt sich aber zu einer Entscheidung zugunsten seines Reiches durch. Im Begriff zu gehen, fühlt er jedoch eine merkwürdige Müdigkeit über sich hereinbrechen, die er nicht zu deuten weiß: s L'inaspettato ... prodigioso sonno ... $/$ Qualcosa vuol da me. (s'addormenta) $\times(I, 9)$. Als er wieder erwacht, hat sich die Bühne in einen Garten mit einem herrlichen Palast verwandelt, den er als den Cherestanis wiedererkennt. Tatsächlich erscheint auch Cherestanì, und die Szene entwickelt sich zum dramatischen Höhepunkt des ersten Aktes, indem sie Farruscad ihre brennende Liebe und die Unausweichlichkeit ihres Handelns erklärt: 


\begin{abstract}
Ah, Farruscad,
Tu m'amasti, io ti amai; so, quanto io t'amo,

So quanto grande è 'l mio dolor, ch'io sono

Cagion di tante stragi. Ma le stelle,

Il destin mio crudel così comanda.

Sforzata sono a comparir tiranna

Per eccesso d'amor. Son condannata

A farmi sospettar maga, deforme,

Sotto a finte bellezze, e tutto è amore,

E'l più fervido amor, che a te mi stringe. (piange) $(\mathrm{I}, 10)$
\end{abstract}

Zugleich weist sie auf die Unmôglichkeit hin, ihm ihre Identität preiszugeben, und macht seine Neugier für ihrer beider Unglück verantwortlich. Am nächsten Tag, so prophezeit sie, werde sich ihr Schicksal erfüllen, da Farruscad angesichts dessen, was geschehen werde, nicht umhin könne, sie zu verfluchen:

\author{
Sò, che non hai \\ Tanta costanza in cor da sofferire \\ Quanto nascer vedrai nel vicin giorno; \\ E perirà, Cherestani, tua sposa. \\ Sorgerà 'I nuovo sol sanguigno in vista, \\ L'aere fia tetro, tremerà "1 terreno, \\ Questo non fia per Farruscad più asilo, \\ Egli saprà, chi sono; indi pentito \\ Piangerà la miseria della sposa \\ Inutilmente, e solo mio fia 'I danno. (piange) ( $(1,10)$
}

Die Liebe zu Farruscad, die Furcht vor dem ihr vorhergesagten Schicksal und das Wissen um die Unvermeidbarkeit des Kommenden verleihen Cherestanì tragische Züge. In einer bis zum äußersten angespannten $\mathrm{Ge}$ fühlslage schwört Farruscad schließlich, seine Gemahlin -komme, was da wolle - nicht zu verfluchen, womit die unabdingbare Voraussetzung zur Erfüllung der Vorhersage gegeben ist und das Schicksal beziehungsweise das Stück seinen Lauf nehmen kann.

\title{
Gegenräume
}

Im zweiten Akt entwickelt sich die Handlung in rascher Folge, wobei sowohl der Handlungsstrang Farruscad-Cherestani fortgeführt als auch das Geschehen in Tiflis ins Blickfeld gerückt wird. Allerdings beginnt auch der zweite Akt mit Szenen, in denen Masken allein oder mit anderen Personen zusammen auftreten, so daß die am Ende des ersten Aktes aufgebaute Spannung zunächst unterbrochen wird. Die beiden bereits erwähn- 
ten einleitenden a-soggetto-Szenen mit Brighella und Truffaldino bzw. Pantalone und Tartaglia, die das merkwürdige Geschehen der Nacht reflektieren, sowie die dritte, in der Farruscad die dunklen Prophezeiungen Cherestanis vor Togrul wiederholt, bereiten den sichtbaren Einbruch der Märchensphäre vor. Im Beisein aller, auch der Masken Pantalone und Tartaglia, betreten nach Blitz und Donnerschlag die beiden Kinder Bedredin und Rezia die Bühne und kündigen die baldige Ankunft ihrer Mutter an. Böses ahnend versuchen Pantalone und Tartaglia, mit den beiden Kindern zu fliehen, doch erscheint die königliche Cherestanì mit Gefolge auf der Bühne und gebietet ihnen Einhalt: sFermatevi. Non puossi a' grand'arcani / Della nascita lor tor que' due figli. * (II,5). Noch einmal weist sie unter Tränen auf die Unausweichlichkeit ihres Handelns hin, "Anime mie... ciò, che non voglio ... voglio / Deggio voler ... ciò, che voler non posso... / Piango per voi ... per me ... pel padre vostro , und fordert Farruscad auf, alles, was er nun sehen wird, zu erdulden ohne nachzufragen, * Soffri tutto. / Credi, ch'io sia tiranna a me medesma / Più, che non sono a te*. Die Redeweise Cherestanis ist geprägt von emotionaler Betroffenheit, die sich sowohl in den abgerissenen Sätzen äußert als auch im Weinen, s(gli abbraccia, e bacia piangendo) $\propto$, und von tiefer Zerrissenheit angesichts des ihr vorgeschriebenen Handelns, rhetorisch verdeutlicht in Paradoxa und Antithesen. Als sie die Kinder von Soldaten in ein loderndes Feuer werfen läßt, äußert Farruscad nur ein Wort, „Crudel «, und verstummt vor Cherestanis Befehl, mit allen Umstehenden nach Tiflis zurückzukehren.

Tiflis repräsentiert einen Gegen-Raum zu dem von Cherestani beherrschten. Dort geht es um Krieg, Politik und Lebensmittellieferungen. Auch das Paar Canzade und Togrul bildet einen offensichtlichen Gegensatz zu Cherestani und Farruscad. Canzades und Togruls Liebe ist »vernünftig « und zielt auf eine geordnete Führung des Reiches in Abwesenheit Farruscads, ihre Trennung ist pragmatisch bestimmt - Togrul geht auf die Suche nach Farruscad, Canzade verteidigt mit letzten Kräften die Stadt -, und ihr Wiedersehen geht unter in der Vorbereitung der ausschlaggebenden letzten Schlacht gegen den Mohrenkönig Morgone. In dieser Gegenwelt verflucht Farruscad Cherestani, weil sie die vermeintlich rettende Lieferung von Nahrungsmitteln vernichtet hat:

\footnotetext{
Sia maladetto il punto, in cui ti vidi,

Ti maladico, infernal maga infame.

Ti maladico si .... Ma inutil sfogo

Ê questo al mio dolor di maladirti. (II, II)
}

Damit erfüllt sich die Vorhersage, und Cherestanì verwandelt sich in eine Schlange. Diese Szene bietet noch einmal Gelegenheit, beim Auftritt Che- 
restanis mit Blitz und Donner und bei ihrer Verwandlung in das Ungeheuer das Märchenhafte zu betonen und zugleich mit allen rhetorischen Mitteln Cherestanis Verzweiflung über ihr Schicksal sprachlich deutlich zu machen. In ihrem Monolog, der durch Ausrufe, abgebrochene Sätze und unmittelbare Rücknahme von eben Gesagtem charakterisiert ist, deutet sie eine letzte Hoffnung an, Farruscad könne sie doch noch retten:

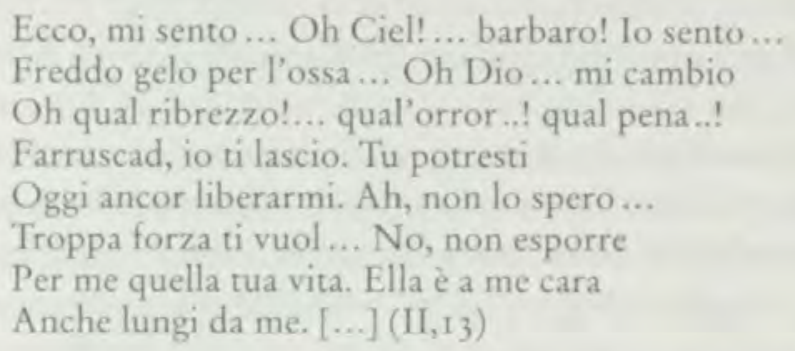

Fest entschlossen, das ihm Mögliche zu tun, scheut Farruscad nicht vor den gefährlichen Aufgaben zurück, die ihm die Fee Farzana stellt. Diese, seines Scheiterns sicher, hat nicht mit dem Eingreifen Geoncas gerechnet, der Farruscad zur Seite steht, um ihn vor dem sicheren Verderben zu retten. Nun stehen sich zwei übernatürliche Mächte gegenüber, denen Farruscad ausgeliefert ist - die eine führt ihn in die Gefahr, die andere heraus. Jeweils im rechten Moment ertönt Geoncas Stimme und nennt das richtige Mittel, den Gegner, zuerst einen wilden Stier, dann einen schwertbewaffneten Riesen zu besiegen. So besteht der märchenhaft furchtlose Farruscad, der das Außergewöhnliche als Selbstverständliches annimmt, die ersten beiden Gefahren. Die dritte und letzte Aufgabe, die nicht Mut erfordert, sondern ein Höchstmaß an Selbstüberwindung, besteht darin, eine hinter einem Grab verborgene häßliche Schlange zu küssen. Auch dies meistert Farruscad im letzten Moment mit Geoncas Hilfe, so daß der Bann gebrochen ist und die Fiaba teatrale abrupt endet, indem Cherestani als reich gekleidete Königin vor Farruscad erscheint und so die gerade aus Tiflis Herbeigeeilten ein glückliches Paar antreffen, das zusammen mit Tartaglia und Pantalone in das Reich Eldorado zurückkehren wird, Canzade mit Togrul als Regenten in Tiflis einsetzt, Truffaldino Smeraldina und Brighella eine andere Frau sowie reiche Gaben verspricht.

Zusammenfassend läßt sich für La donna serpente konstatieren, daß die Masken zwar hinsichtlich ihrer Bühnenpräsenz eine wichtige Rolle spielen, für die Entwicklung der Handlung jedoch kaum eine Bedeutung haben. In 20 von insgesamt 39 Szenen stehen Masken auf der Bühne, wobei sich ausgedehnte Improvisationsszenen am Anfang des ersten und zweiten sowie innerhalb des dritten Aktes mit ausgeschriebenen Maskensze- 
nen und Auftritten von Masken zusammen mit anderen Personen abwechseln. Truffaldino und Brighella erscheinen ausnahmslos gemeinsam und spielen - außer in drei kurzen Szenen - a soggetto. Auch Pantalone und Tartaglia treten meist zu zweit auf, wobei ihre Partien, abgesehen von zwei bzw. drei Improvisationen, ausgeschrieben sind. Häufig sind sie in Kombination mit Märchenfiguren, vor allem mit Farruscad, zu sehen und treffen, zwar nicht alleine, aber in personenreichen Szenen, auch mit Cherestanì zusammen, während Truffaldino und Brighella als Jäger und Diener nur in der Schlußszene, die komödientypisch alle Personen auf der Bühne vereint, in Cherestanis Umkreis auftreten. Keine der vier Masken fungiert als Handlungsmovens, vielmehr dienen ihre Auftritte im ersten Akt zunächst der expositorischen Rückschau auf die Ereignisse der vergangenen acht Jahre sowie der narrativen Vergegenwärtigung und der Veranschaulichung des aktuellen Zustandes von Farruscad. ${ }^{164}$ In Parallelführung beginnt auch der zweite Akt mit einer Rückschau der Masken, allerdings nur auf die vergangene Nacht, an die sich die Auftritte Bedredins, Rezias und Cherestanis anschließen, die wiederum in die „Gegenwart « des Märchengeschehens führen. Im dritten Akt, der in Tiflis spielt, treten sowohl Tartaglia als auch und vor allem Truffaldino in der fünften Szene als Berichterstatter auf und überbrücken so sprachlich die zeitlichen und örtlichen Distanzen. In diesen narrativ berichtenden Passagen der Masken bringt Gozzi alle traditionellen Merkmale der Maskenrede wie Vielsprachigkeit (Dialekt, Stottern, improvisiertes und vorgegebenes Sprechen), Sprachwitz, eingeflochtene literarische Zitate und Sprichwörter, ironisch-polemische Anspielungen auf Aktuelles ${ }^{165}$ sowie ihre typischen Eigenschaften und ihre körperlich-gestische Beweglichkeit zur Geltung, aus denen die komische Wirkung solcher Szenen resultiert. Vor allem die Improvisationsszenen mit Truffaldino und Brighella bilden einen extremen Kontrast zu den Szenen, in denen die Märchenhandlung dargestellt wird, und werfen ein besonderes Licht auf die märchenhaf-

${ }^{\text {tht }}$ Erstaunlich ist, daß ausgerechnet die Masken, deren Handlungs- und Spielbetontheit immer wieder hervorgehoben wird, am Anfang hauptsächlich in erzählender Funktion erseheinen, doch erreicht Gozzi durch das Einsetzen der sprachlichen und gestischen Möglichkeiten der Masken eine Auflockerung der expositorisch narrativen Passagen, die nicht in allen Fiabe teatralt gleichermafen gelungen ist wie in La donna serpente.

165 Vgl. Roberto Tessari, =Il testo e l'assenza. Carlo Gozzi e la Commedia dell'artee, in: Carlo Gozzi, La donna serpente, op. cit., S. 54, 56. Tessari nennt in diesem Zusammenhang auch sappelli diretri al pubblicos, was jedoch interessanterweise nicht zutrifft. Dic Masken sprechen das Publikum nie in direkter Weise an, so daß die Spielebene nicht verlassen wird. Nur im scongedo-, den letzten Versen der Stücke, wendet sich in den Fiabe teatrali traditionsgemäß meist cine Schauspielerin, seltener ein Schauspieler an das Publikum mit der Bitte um Applaus. 
ten Begebenheiten, von denen die Masken nicht direkt betroffen, in die sie aber doch involviert sind, sei es durch märchenhaft bewerkstelligte Ortswechsel oder magische Ereignisse wie das unvermittelte Auftauchen eines gedeckten Tisches, die Verwandlung des Essens in Schlangen und ähnliches. Einzig Pantalone greift in einer Szene handelnd in das Märchengeschehen ein, wenn er in Gestalt des Priesters Checsaja auftritt, doch läßt Gozzi diesen Versuch demonstrativ scheitern, während es Togrul in der Parallelszene immerhin gelingt, in Farruscad die Einsicht in die Notwendigkeit der Rückkehr nach Tiflis zu wecken. Damit wird selbst auf der Bühne deutlich, daß der Einfluß der Masken als handlungstreibende Kraft erloschen ist.

Die erzählende Darstellung des Märchengeschehens durch die Masken, die durch Übertreibung und Wahrhaftigkeitsbeteuerungen das Märchenhafte umso unwahrscheinlicher erscheinen läßt, schafft eine gewisse ironische Distanz des Zuschauers zum Erzählten, die jedoch insofern begrenzt ist, als die Masken nicht aus der theatralen Wirklichkeit heraustreten und weder a parte noch ad spectatores sprechen, sondern als Figuren der Märchenhandlung dialogisch kommunizieren, das selbst Erlebte weitergeben und nicht distanziert darauf verweisen. Die traditionellen Charakteristika der Masken prägen die Perzeption und Darstellung des Geschehens allerdings in einer Weise, die sich stark von der der anderen Personen unterscheidet, seien diese auch wie etwa Togrul und Canzade hinsichtlich der Märchenhandlung ebenso peripher. Ihr Verhältnis zum MärchenhaftWunderbaren gleicht dem Farruscads und zeichnet sich durch eine Selbstverständlichkeit aus, die jede Thematisierung von vornherein unterbindet. Konsequenterweise ist es daher Brighella, der beispielsweise von der wundersamen Reise durch den Monte Olimpo und vom Magenpflaster erzählt, während Togrul dies an keiner Stelle erwähnt. Zwischenrufe der Masken wie »oh maraviglia «, "sempre arcani «, "sempre cose secrete $\alpha$ etc. zeigen zwar eine Verwunderung angesichts der Ereignisse, doch kommt es nicht zur entscheidenden Infragestellung, so daß die Masken sich gewissermaßen auf der Grenze des Märchen-Spiels bewegen, diese jedoch nicht überschreiten. Eine Ausnahme bildet freilich Truffaldino in der fünften Szene in Akt III, in der er dem Publikum den Bericht über die Kampfeshandlungen bei Tiflis anpreist. Zwar tritt er hier, die svenditori delle relazioni in Venedig in Kleidung und Verhalten imitierend, ganz offensichtlich aus dem Märchenspiel heraus, doch nicht, um es zu kommentieren, in Frage zu stellen oder aufzuheben. Es wird kurz unterbrochen, dem Publikum werden - in typisch maskenhafter Übertreibung - wichtige Ereignisse der Nebenhandlung mitgeteilt, die auf der Bühne nicht darstellbar, doch zum Verständnis der folgenden Szenen unentbehrlich 
sind, worauf der Auftritt Pantalones und Tartaglias in der nächsten Szene in die Handlung zurückführt. Der Einfall Gozzis, Truffaldino in Gestalt der venezianischen Verkäufer von Sensationsnachrichten auftreten zu lassen, dient nicht nur dem Amüsement des Publikums, sondern verleiht dem märchenhaften Geschehen auch einen Anschein von vertrauter Realität, indem es nicht nur verbal, sondern auch szenisch sichtbar an die nicht-theatrale Wirklichkeit rückgebunden wird.

Während der Anfang aller drei Akte durch die starke Präsenz der Masken und Improvisationsszenen geprägt ist, die sich im dritten Akt etwas weiter zur Mitte verschieben, ist jeweils die zweite Hälfte der Akte von ausgesprochen märchenhaft-wunderbarem Charakter. So entsteht eine Dramaturgie des Kontrasts, die im Rahmen eines Aktes dem betont Komischen das Ernsthaft-Pathetische gegenüberstellt, wobei jeder Akt mit einem entscheidenden Element der Märchenhandlung endet, auf das dann wieder die Maskenszenen des nächsten Aktes folgen. ${ }^{166}$ Vor Beginn der dargestellten Handlung liegt das Verbot, nach der Identität Cherestanis zu forschen, das Farruscad, wie Truffaldino erzählt $(I, 2)$, vor drei Tagen, sozusagen am Ende der Vorgeschichte, übertreten hat. Am Ende des ersten Aktes steht der Schwur Farruscads, Cherestani nicht zu verwünschen, was auch immer sie tut, am Ende des zweiten die Verwünschung und die prophezeite Verwandlung Cherestanis in eine Schlange, am Ende des dritten die Wiedergutmachung der Übertretung der Verbote und die Rückverwandlung der Schlange in Cherestani. ${ }^{167}$ Die Spannung, die sich so am Ende der Akte durch Tabus, Verbote, Prophezeiungen aufbaut, wird am Anfang des Folgeaktes durch die Masken zeitweilig suspendiert, so daß sich eine durch die Unmittelbarkeit der Darstellung in den eigentlichen Märchenszenen hervorgerufene Betroffenheit der Zuschauer mit einer distanzierteren Haltung bei den Maskenszenen abwechseln.

1to Im Vergleich zu anderen Fiabe teatrali, in denen Maskenszenen ganz pragmatisch zur Überbrückung und Ablenkung bei Bühnenbildwechseln eingesetzt werden, tritt in $\mathrm{La}$ donna serpente die Rücksicht auf bühnentechnische Probleme in den Hintergrund, und es dominiert die formbewußte Anlage.

162. Im Programmbeft zur Aufführung von Gozzis La donna serpente in Genua t979 weist Eduardo Sanguineti auf diese deutliche Strukturierung der Akte mittels entscheidender Etappen der Märchenhandlung hin, läßt jedoch die im nachsten Akt unmittelbar folgenden Maskenszenen und damit die offensichtliche Kontraststruktur außer acht. Vgl E. Sanguineti, - La donna serpente come fiaba*, op, cit., S. 20 . 


\section{Vom Märchentext zum Theatertext}

Wie gezielt Gozzi die Märchenelemente dramaturgisch einsetzt, macht ein Blick auf die »Histoire du roi Ruzvanschad et de la princesse Schéhéristani« aus Les mille et un jours deutlich, auf die La donna serpente rekurriert. ${ }^{168}$ Gozzi folgt im wesentlichen dem Handlungsverlauf des Märchens, greift jedoch an entscheidenden Punkten verändernd ein, um die szenische Wirksamkeit zu erhöhen. Das Märchen ist durch eine räumliche Zweiteilung in das Genienreich und den chinesischen Hof sowie eine inhaltliche Dreiteiligkeit strukturiert, die sich in eine erste Phase der Begegnung zwischen dem jungen chinesischen König Ruzvanschad und Schéhéristani, der Tochter des Königs der Genien, in eine zweite der vorübergehenden Trennung mit anschließendem Wiedersehen und eine dritte der definitiven Trennung mit überraschender Wiedervereinigung gliedert. Am Ende der ersten Phase steht ein Treueversprechen, am Ende der zweiten die Übertretung des Verbots, Schéhéristani wegen ihres Verhaltens zu tadeln, am Schluß des Märchens die glückliche Wendung. Die erste Phase der Trennung, die sich durch den Tod des Genienkönigs und die notwendige Rückkehr Schéhéristanis auf die Insel Schéhéristan ergibt, zerfällt in bezug auf Ruzvanschad in eine Zeit der Melancholie und eine Zeit der Reise. Die zweite, sehr viel längere und endgültig scheinende, ist allein durch die Melancholie geprägt, der Ruzvanschad verfällt, nachdem er erfährt, daß seine Vorwürfe an Schéhéristani, ihren Sohn ins Feuer geworfen, die Tochter einer Hündin anvertraut und die Lebensmittellieferung eines Ministers vergiftet zu haben, nicht gerechtfertigt waren. Auch Gozzis Fiaba teatrale weist eine solche Dreiergliederung auf, äußerlich sichtbar an den drei Akten, doch folgt Gozzi dem Märchen nicht in allen Punkten, sondern eliminiert, kondensiert die langen Zeiträume, ${ }^{169}$ ergänzt und variiert, bis eine dramaturgisch wirkungsvolle Struktur entsteht. Anders als im Märchen spielt bereits in der hauptsächlich von den Masken vorgetragenen Vorgeschichte, die der ersten und einem Teil der zweiten

is Das Märchen war in Venedig bereirs Jahre zuvor Vorlage für ein Bühnenwerk, das allerdings als damals beliebtes Genre der Tragödienparodie mit Gozzis Fiabe teatrale nur entfernte stoffliche Ähnlichkeiten hat. In Zaccaria Valaressos Rutzvanscad il Giovine. Arcisopratragichissima Tragedia elaborata ad uso del buon gusto de' Grecheggianti Compositori da Cattuffio Panchianio Bubulco Arcade, erschienen 1724 in Venedig, wird im Prolog auch Kerestani erwähnt, sde' Genj alta Nipote, s'uni contro il divieto ad uom terreno, come ne fano al Mondo Le Novelle Persian eterna feder.

169 Die erste Trennung dauert ein Jahr, die zweite zehn, nach deren Ablauf Schéhéristani mit den Kindern zu dem ihr treu gebliebenen Ruzvanschad zurückkehrt und sie glücklich zu viert leben, bis nach dem Tod Ruzvanschads und Schéhéristanis ihr Sohn König von China und ihre Tochter Regentin der Insel Schéhéristan werden. 
Marchenepisode entspricht, ein Tabu und der Bruch des Tabus eine entscheidende Rolle: Farruscads Neugier, mehr über Cherestani zu erfahren, wurde ihm zum Verhängnis und hat ihn in die Situation gebracht, die nun auf der Bühne dargestellt und entwickelt wird und am Ende des ersten Aktes in den Schwur Farruscads mündet, Cherestani nicht zu verfluchen, was auch immer sie tut. Der zweite Akt endet - analog zum Märchen - mit dem Bruch des Schwurs und Cherestanis Verwandlung in eine Schlange, der dritte ist den Aufgaben gewidmet, die Farruscad bestehen muß, um Cherestanì zurückzugewinnen, und führt in ein für das Märchen wie die Komödie gattungstypisches happy end. Das Treueversprechen, die weite Reise und die jahrelange Melancholie Ruzvanschads als narrative Elemente, die nicht bühnengerecht umgesetzt werden können, streicht Gozzi beziehungsweise ersetzt und ergänzt sie durch Anleihen aus anderen Märchen wie im Fall des Identitätstabus - ein Motiv, das in Märchen, Mythen und Legenden gleichermaßen zu finden ist -, der Verwandlung Cherestanis in eine Schlange und der spektakulären Bewältigung von drei Aufgaben im dritten Akt, ${ }^{170}$ die zum einen geeignet sind, Spannung zu erzeugen, zum anderen der visuellen Komponente eines Schauspiels Rechnung tragen. In dieser Hinsicht ist auch die Wahl der Handlungsorte in der Fiaba teatrale interessant: Farruscad ist nicht wie Ruzvanschad König von China, sondern von Tiflis, was unschwer damit zu erklären ist, daß Gozzi nach Turandot, der sfiaba chinese teatrale tragicomica «, den Ort der Handlung im nächsten Märchenstück aus Gründen der Abwechslung in eine andere ferne Gegend verlegt. Neben dem Palast im georgischen Tiflis stellt die Bühne in zahlreichen Szenen eine schreckliche, steinig-felsige Wüste dar, sowie am Ende des ersten Aktes den herrlichen Palast Cherestanis und im dritten Akt eine ländliche Gegend mit Bergen im Hintergrund und einem Grab, dem die Ungeheuer entsteigen. Effektvoll wechseln so Szenen in offenen und geschlossenen, abweisenden und anziehenden Räumen ab. Statt der lieblichen Symphonie, die im Märchen beim Anblick von Schéhéristanis Palast ertönt, begleiten Donner, Blitz und Erdbeben das Erscheinen Cherestanis, wie Gozzi überhaupt in $\mathrm{La}$ donna serpente die visuellen und akustischen Möglichkeiten der Bühnentechnik in hohem Maße nutzt.

Den tiefergreifenden Veränderungen in der Handlung wie der Übertretung des Verbots, nach Cherestanis Identität zu forschen, und der Einführung der drei Aufgaben am Ende stehen überraschend viele detailge-

170 Diese Szenen verweisen mehr auf cinen epischen Kontext als auf cinen märchenhaften, wobei direkte intertextuelle Bezūge zu Boiardos Orlando innamorato bestehen; vgl. die entsprechende Anmerkung in A. Beniscellis Ausgabe der Fabe teatrali, op. cit., S. 283. 
treue Übernahmen aus der Vorlage gegenüber, die zum Teil im Hinblick auf die Schaffung von Kontrasten und Parallelen akzentuiert werden. Bis hin zu Formulierungen folgt Gozzi dem Märchen: so sind die von Pantalone wiedergegebenen rätselhaften Worte Cherestanis ( di Re, pur non son quella./ Son Prencipessa, e pur non son chi sono", I,3) direkt dem Märchen entnommen, wenn es dort auch nicht Schéhéristani ist, die sie spricht, sondern die Protagonistin einer Binnenerzählung, sla princesse des Naïmans $\propto$, we suis fille et femme de roi, et cependant je ne suis point ce que je dis. Je suis princesse, et ne suis point ce que je suis $\alpha .{ }^{171}$ Auch Cherestanis an Farruscad gerichtete Mahnung, sie nicht zu verwünschen und nicht nach den Gründen zu fragen für das, was sie tut, gleicht dem Märchen weitgehend: „Non aver brama / Di saper la ragion di quanto vedi; / Non la chieder giammai. Credi; ogni cosa / Nascerà con ragion.* $(\mathrm{I}, \mathrm{I} O)$. Was hier positiv formuliert ist ("nascerà con ragion*), findet sich in Les mille et un jours in negativer Form: »Les génies ne font jamais rien mal à propos. Si quelquefois vous me voyez faire des actions qui ne vous paraissent pas raisonnables, dites en vous-même: elle n'agit pas ainsi sans raison. ${ }^{172}$ Auf besonders ingeniöse Weise löst Gozzi, wie bereits erwähnt, das Problem, von Verlauf und Ergebnis der Schlacht zwischen der Armee Tiflis' und dem Heer des Mohrenkönigs Morgone zu berichten. Während das Märchen in wenigen Zeilen den blutigen Sieg der Chinesen mit Hilfe Schéhéristanis und der Geister erzählt, läßt Gozzi Truffaldino auf der Bühne den gedruckten Kriegsbericht anpreisen, dessen Übertreibungen erstaunlicherweise nur geringfügig vom Märchen abweichen. ${ }^{173}$ An inhaltlichen Einzelheiten, die Gozzi übernimmt, wären etwa der Gegensatz von gutem und schlechtem Minister zu nennen, die bösen Vorahnungen Muézins wie Pantalones bei der ersten Begegnung mit Schéhéristani/Cherestanì und ihre Befürchtung, daß Zauberei im Spiel ist und sie es mit einer Hexe zu tun haben, es jedenfalls nicht mit rechten Dingen zugeht. ${ }^{174}$ Der Ortswechsel zwischen dem Reich Schéhéristanis/

171 * Histoire du roi Ruzvanschad et de la princesse Schéhéristanié, in: François Pétis de la Croix, Les mille et un jours, op. cit., S, 83. Zur Identitatsproblematik s. Kap. 4.I.

172 Ebd., S, ror.

73 Dort heißt es, ebd., S. tos: - Au milieu de la nuit, cette princesse avec tous les génies de sa suite se mit à la tẽte des Chinois, et fondit sur les Mogols, qui voulurent d'abord faire quelque résistance; mais ils furent tous renversés. Les génies et les Chínois en firent un si horrible carnage, qu'à peine le roi des Mogols, qui commandait en personne, put-il se sauver. Le lendemain, quand le jour vint à paraïtre, on vit toute la plaine jonchée de corps morts, et Ruzvanschad fut d'autant plus content de cette victoire qu'clle ne lui coûta que quelques soldats."

174 Muézin spricht von senchantement , bezeichnet Schéhéristani als =effroyable magicienne* (S. 82) und vergleicht sie mit der in der Binnenerzählung vorkommenden Dil- 
Cherestanis und den übrigen Schauplätzen wird im Märchen wie in der Fiaba teatrale von Geistern bzw. vom Wind bewerkstelligt, und hier wie dort ist es der Tod des Vaters der Fee, der diese in ihr Reich zurückruft. In La donna serpente erhält dieser Tod ein Pendant im Tod von Farruscads Vater, so daß sich die beiden Protagonisten Cherestanì und Farruscad an einem bestimmten Punkt in derselben Situation befinden, nämlich an die Stelle ihres Vaters treten zu müssen. Gozzi behält auch die Zweisträngigkeit der Erzählung bei, die die Liebesgeschichte mit dem politisch-kriegerischen Schicksal des chinesischen Reiches verbindet, und baut sie noch aus, indem er Farruscad eine Schwester gibt, die nach dem Tod des Vaters in seiner Abwesenheit in Tiflis den Thron bekleidet und durch den Angriff des schrecklichen Mohrenkönigs Morgone persönlich in Gefahr ist. Zudem führt Gozzi Togrul ein, beziehungsweise spaltet Muézin, den treuen Minister Ruzvanschads, der ihn sowohl bei der ersten Begegnung mit Schéhéristani begleitet als auch in seinen melancholischen Phasen die Amtsgeschäfte führt, in zwei Figuren, nämlich Pantalone und Togrul. Pantalone gewinnt als stetiger Begleiter Farruscads und gegenüber Muézin deutlich an Profil, sowohl durch seine maskenhaften Verhaltensweisen als auch durch eine stärkere Kontrastierung mit Farruscad. Togrul dagegen, der in und für Tiflis sein Bestes tut, Canzade liebt und sie am Ende zur Frau erhält, bleibt eine ähnlich blasse Nebenfigur wie Muézin im Mârchen. Mit Canzade und Togrul hat Gozzi ein komplementäres und zugleich kontrastierendes Paar zu Cherestanì und Farruscad geschaffen, das die Zweisträngigkeit und Zweiweltlichkeit unterstreicht.

Mit den Veränderungen und Eingriffen Gozzis im Hinblick auf eine wirkungsvolle dramaturgische Struktur, der zeitlichen Raffung, der Akzentuierung von Kontraststrukturen, der Zuspitzung auf Entscheidungsmomente, der emotionalen Aufladung konfliktuöser Situationen und der Ergänzung um effektvolle Szenen mit Verwandlungen, Riesen und Ungeheuern, geht eine unübersehbare Verschiebung des Akzents in inhaltlieher wie in wirkungsästhetischer Hinsicht vom Märchen zur Fiaba teatrale einher. Die Art des Umgangs mit dem Märchen gleicht der mit der Commedia dell'arte: Für seine Fiabe teatrali wählt Gozzi charakteristische Grundzüge, die er etwa in bezug auf Verbote, Prophezeiungen und das Eingreifen übernatürlicher Mächte teilweise noch verstärkt, greift einzelne Komponenten heraus und fügt neue, typische Bestandteile aus

nouaze (S. 99), wie dies auch Pantalone in seiner abschreckenden Beispiclgeschichte in $\mathrm{L}_{3}$ tut- =Striga-/-strega* nennt sie mehrfach nicht nur Pantalone, sondern auch Tartaglia. 
dem gesamten Märchen-Repertoire hinzu. Diese eklektische Behandlung des Märchens erlaubt es auch, Elemente anderer Textgattungen einzubringen, wie zum Beispiel im dritten Akt von La donna serpente. Anstelle der 1ojährigen Melancholie Ruzvanschads im Märchen stehen bei Gozzi drei Aufgaben, die Farruscad zu bewältigen hat, um Cherestanì zurückzugewinnen und sie von ihrem Schlangendasein zu erlösen. Während die Dreizahl als Charakteristikum auf das Märchen verweist, sind die Aufgaben selbst eher denen eines Helden in einem Ritterepos vergleichbar, wobei es wie des öfteren in den Fiabe teatrali Boiardos Orlando innamorato ist, der Gozzi als intertextuelle Referenz dient. ${ }^{175}$ Anders als die Masken und das Märchen ist allerdings das heroisch-komische Epos keine Konstituente der Fiabe teatrali, doch verweisen die sporadischen Bezüge auf eine literarische Gattung, deren Fiktionalität eben so offensichtlich ist wie die des Märchens. Im Unterschied zum Epos dienen die Aufgaben, die Farruscad bewältigen muss, nicht dazu, seinen Mut und seine Stärke zu demonstrieren, sondern führen seine Abhängigkeit von übernatürlichen Mächten vor Augen. Sein Handeln ist gleichermaßen fremdbestimmt wie das Cherestanis. Vorhersagen, Orakelsprüche, auferlegte Bedingungen motivieren das Verhalten der Märchenfiguren und rufen innere Konflikte hervor, die in einer leidenschaftlichen Rhetorik ihren Ausdruck finden und das Publikum in einer Weise involvieren, die dem Märchen fremd ist.

\subsection{Masken und Märchen, Lachen und Weinen}

Daß Märchen und Masken die Grundkonstituenten der Fiabe teatrali sind, ist wohl kein Zufall, sondern von Gozzi in mehrfacher Hinsicht absichtsvoll gewählt. Er greift damit zwei im I8. Jahrhundert vieldiskutierte und umstrittene Phänomene auf und macht seinen unkonventionellen Standpunkt in Form eines neuen dramatischen Genres anschaulich. In der Kombination von Märchen- und Commedia dell'arte-Elementen nutzt Gozzi formale und strukturelle Ähnlichkeiten und macht Konvergenzen und Divergenzen für seine Intentionen fruchtbar. Mit Märchen und Masken wendet er sich gegen ein Theater, das sich als Abbildung der Wirklichkeit versteht und in möglichst großer zeitlicher wie örtlicher Nähe zum Publikum bewegt. Märchen und Masken stehen in den Fiabe teatrali

$175 \mathrm{Vgl}$. Matteo Maria Boiardo, Orlando innamorato, im ersten Buch Canto XXIV, im zweiten Buch die Canri IV und XXVI. Wie mehrfach erwähnt, gibt es an anderer Stelle auch Bezüge zu Ariosts Orlando furioso und Pulcis Morgante. 
für einen indirekten Bezug zur Wirklichkeit, für eine Zeit- und Ortlosigkeit, ${ }^{176}$ für eine Allgemeinheit und universelle Gültigkeit, die sie zu Trägern einer anderen Wahrheit eigener Art machen - das Märchen mehr in handlungsbezogener, die Masken eher in ontologischer Hinsicht.

\section{Strukturelle Parallelen der Konstituenten Märchen und Masken}

Gemeinsamkeiten struktureller Art eröffnen die Möglichkeit, Elemente aus Märchen und Commedia dell'arte zu kombinieren, zu verflechten und so die Wirkung noch zu steigern. Beide, Märchen wie Commedia dell'arte, sind handlungsbetont, bei beiden basieren Handlungsverlauf sowic Figurenkonstellation auf typischen Mustern, die jeweils neu zusammengestellt und variiert werden, so daß sich beide einerseits durch eine gewisse Monotonie, andererseits aber durch eine große Vielfalt auszeichnen. ${ }^{177}$ Nach Vladimir Propp ist die Zahl der Handlungsträger im Märchen auf sieben begrenzt, wobei für die Übergänge und Verbindungen zwischen den Funktionen unentbehrliche Figuren hinzutreten können, und interessanterweise verfügen auch die improvisierten Stücke mit den Paaren der innamorati, der vecchi, der zanni und der einzelstehenden

176 Die Herkunft der Commedia dell'arte-Masken aus bestimmten italienischen Orten spielt seit langem nur noch eine akzidentelle Rolle, die das komische Potential vor al$\mathrm{lem}$ im Hinblick auf die Vielsprachigkeit erhöht, aber nicht als Verweis auf eine geographische oder ethnographische Wirklichkeit wirkt. Während die Masken als Elemente der *commedie dell'arte im 18 . Jahrhundert *ortlos * sind, haben die scommedie all'improvvisos, wie aus den scenari ersichtlich wird, hingegen meist einen realen Handlungsort wie vor allem Neapel, Florenz, Bologna, Livorno, Mailand, Venedig.

Gilt das Kriterium der Zeit- und Ortosigkeit für Märchen und Masken unter einer generellen Perspektive, ist zugleich hinzuweisen auf die Rückbindung an die Realität in den Fiabe teatralt, die sich in bezug auf die Masken wie gezeigt in Anspielungen auf venezianische Charakteristika, auf literarische Debatten u. ä. manifestiert, im Hinblick auf das Märchen, wie noch auszufuhren ist, durch eine allegorische Funktionalisierung.

I7) Vgl. I. Calvino, der als sproprietà più segretae des Märchens sla sua infinita varietà ed infinita ripetizione" nennt; op. cit., S. 37. V. Propp hat in Morphologie du conte 31 sogenannte *Funktionen* ausgemacht, innerhalb derer sich die Handlung bewegt, und er konstatiert: -Nous pouvons dire en anticipant que les fonctions sont extrèmement peu nombreuses, alors que les personnages sont extrêmement nombreux. C'est ce qui explique le double aspect du conte merveilleux: d'une part, son extraordinaire diversité, son pittoresque haut en couleur, et d'autre part, son uniformité non moins extraordinaire, sa monotonie.- (Op. cit., S. 3o).

Im Hinblick auf die Improvisation der Commedia dell'arte-Truppen besteht dieselbe Ambivalenz von Monotonie und Diversifikation, sowohl was die Handlungsschemata als auch was die Masken und die allabendliche schauspielerische Neuschōpfung anbelangt. 
servetta über einen Grundstock von sieben Personen, der je nach Bedarf erweitert werden kann. In beiden Fällen sind diese Personen nicht individuell gezeichnet und psychologisch vertieft, sondern stellen entweder allgemeine Figuren dar oder wie im Fall der Alten und der Diener der Commedia dell'arte typisierte Figuren, die sich schon durch die Masken als solche ausweisen. Märchen wie Commedia dell'arte sind durch Kontraste charakterisiert, die sich auf diversen Ebenen manifestieren; im Märchen scheiden sich die Figuren in gute und böse, schöne und häßliche, vornehme und niedrige etc., in diesseitige und einer Über- oder Unterwelt angehörige, ${ }^{178}$ in der Commedia dell'arte finden sich die Kontraste nicht nur auf Figurenebene zwischen Jungen und Alten, Dienern und Herren, Verliebten und Nicht-Verliebten, sondern auch formal stehen sich "lingua und Dialekt gegenüber, Masken und nicht maskierte Schauspieler, Komik und Ernst und in dramaturgischer Hinsicht handlungstreibende und -retardierende Kräfte sowie zwei Tempi der Rezitation und Improvisation. ${ }^{179}$ Weiterhin fallen im Märchen wie in der Commedia dell'arte, vor allem bei den Masken, Formeln verschiedenster Art und Wiederholungen auf, festgeprägte Anfänge und Schlüsse, ${ }^{180}$ Wiederholungen wörtlicher Rede in der Wiedergabe durch Dritte, Wortwiederholungen und Wiederholung von Handlungsmomenten meist im Dreierrhythmus; in ihrer gliedernden Wirkung sind solche Redundanzen in der Informationsvergabe wichtige Orientierungshilfen für den Zuhörer beim mündlichen Vortrag, der ja für das Märchen wie für die Commedia dell'arte die ursprüngliche Darbietungsform darstellt.

Dieser Überblick macht deutlich, daß die Kombination von Märchenund Commedia dell'arte-Elementen in den Fiabe teatrali auf strukturellen und formalen Gemeinsamkeiten gründet, die die Vereinbarkeit der beiden Formen gewährleisten. Anders als die zahlreichen Dramatisierungen narrativer Texte im 18 . Jahrhundert, die sowohl in Frankreich als auch in Italien in Mode waren und in Venedig mit Goldonis und Chiaris Bühnenadaptionen von Romanen Richardsons, Fieldings, Marivaux' und Mar-

$178 \mathrm{Vgl}$. M. Lüthi, op. cit., S. 28.

i79 Für die Commedia dell'arte des 16 , und 77 . Jahrhunderts fordert M. De Marinis: -bisogna cominciare a pensare la loro recitazione come interamente regolata da una vera e propria logica di contrasti e delle opposizioni estreme e violenti und setze dem scodice elegante* den *codice energico* entgegen; op. cit., S. 145 und 149.

${ }^{180}$ So im Märchen z. B. die Einleitungsformel ses war einmal a, die Schlußformel sund wenn sie nicht gestorben sind, dann leben sie noch heute «, am Ende der Theaterstücke der s congedo «, eine Schlußformel, die die Zuschauer mit der Bitte um Applaus direkt anspricht. Die Märchen- wie die Bühnenschlußformel fuhren den Zuhörer bzw. Zuschauer aus der Fiktion in die Wirklichkeit zurück und machen so die temporäre Aufhebung der Wirklichkeit und ihrer Gesetze rückwirkend noch eirmal deutlich. 
montels in den fünfziger Jahre einen Höhepunkt erreichten, ${ }^{181}$ setzen die Fiabe teatrali nicht die Tradition der Intrigen- und Charakterkomödien unter Ausnutzung szenischer Effekte fort, sondern konstituieren eine neue dramatische Gattung, deren narrative Komponente weitgehende Affinitäten zum dramatischen Bestandteil aufweist.

Immer wieder wird darauf hingewiesen, daß Märchen und Commedia dell'arte in Gozzis Fiabe teatrali nicht zum ersten Mal miteinander in Berührung kommen, sondern bereits in den scenari der Commedia dell'arte das Märchen eine Rolle spielt. ${ }^{182}$ Betrachtet man allerdings die wenigen scenari, die erhalten sind, genauer, finden sich dort zwar gelegentlich Märchenelemente, doch ist der Unterschied zu den Fiabe teatrali fundamental. Dies sollen die Inhaltsangaben zweier Improvisationsstücke verdeutlichen, die in Flaminio Scalas Teatro delle favole rappresentative von $161 \mathrm{I}$, einer der wichtigsten Sammlungen der Commedia dell'arte-Tradition, als "argomento “ jeweils den eigentlichen scenari vorangehen.

181 Zum französischen Kontext vgl. Cerstin Bauer-Funke, -Dramaturgische Kreativität. Theaterdichter des $x 8$. Jahrhunders dramatisieren *contes moraux * von Jean-François Marmontele, in: Kreativitä, Hg. Perry Reisewitz, Bonn, Romanistischer Verlag 1997, 5. $23-34$.

Fur Venedig seien beispielhaft einige Titel genannt: Chiaris Trilogie Lorfano perseguttato, L'orfano ramingo, L'orfano riconosciuto geht auf Fieldings Tom Jones zurück, La Marianna o saa l'orfana und La Marianna o sta l'orfana riconoscauta auf Marivaux' Vie de Marianne, La bella pellegrina auf einen eigenen Roman gleichen Titels, Goldonis Pamela und Pamela maritata auf Richardsons Pamela, or Virtue rewarded und Il cavaliere di spirito auf Marmontels Le scrupule.

162 P. Vescovo macht in - Per una lettura non evasiva delle Fiabe. Preliminariø, in: C. Alberti $(\mathrm{Hg})$, Carlo Gozzi scrittore di teatro, op, cit, S. $171-213$, in einer Anmerkung (S. 177) darauf aufmerksam, daß bereits Francesco Albergati Capacelli Gozzis Fiabe (nach anfanglicher Begeisterung) verächtlich in cine Reihe mit den ncommedie dell'arte con magie« stellt. Wie aus dem bereits erwähnten * Squarzo degli utili- des Theaters San Luca hervorgeht, waren auch zur Zeit Goldonis und Gozzis noch solche Stücke mit Titeln wie Clarice maga, Serva maga oder Dama Demonio im Repertoire.

Unter den 51 in einem in der Biblioteca del Museo Correr in Venedig liegenden Manuskript zusammengetragenen und inzwischen veröffentlichten scenari aus dem 17 . Jahrhundert finden sich nur zwei, in denen ein $=$ mago* (Amphitrioni di Plauto) bzw. ein -negromante mit =spiriti< (Zanni finto morto) auftreten; Gli scenari Correr. La commedia dell'arte a Venezia, Hg. Carmelo Alberti, Roma, Bulzoni 1996. Wenn auch nicht unbedingt davon ausgegangen werden kann, daß dies für scenari-Sammlungen repräsentativ ist, wirtt es doch cin bezeichnendes Licht auf die Haufigkeit derartiger Stücke.

Neben den scenari wird auch das théätre de la foire immer wieder als Bezugspunkt für das Märchenhafte und die Kombination von Märchen und Masken genannt. Die spièces forainese von Lesage und D'Orneval unterscheiden sich jedoch insofern grundlegend von Gozzis Fiabe teatrali, als sie durch kurze, prägnante Dialoge in Prosa und zwischengeschobene airs gekennzeichnet sind und somit dem dramatisch-musikalischen Genre angehören. Darüber hinaus fehlt die für die Fiabe teatrali typische Kontraststruktur mit allen strukturellen und semantischen Konsequenzen. Zum théatre de la foire s. Andrea Grewe, Monde renwersé - Théätre renversé, Lesage und das Théâtre de la Foire, Bonn, Romanistischer Verlag 1989. 
Flavio finto negromante. Comedia

Argomento

Fu in Pesaro un giovine di mediocre fortuna, il quale amava una fanciulla, figlia d'un Pantalone, ricco mercante, uomo più tosto scemo che astuto, se bene l'astuto e lo scaltro faceva. S'avvide il giovane (che Flavio si nomava) esser cosa impossibile l'aver la detta giovane per moglie, per esser ella figlia unica, e da molti, per le sue ricchezze, desiderata e richiesta; pure, facendo forza a se medemo et alla fortuna, col fingersi Negromante e facendo varie e diverse burle, acquistò la detta giovane per moglie, con grazia del padre e di tutti i suoi parenti.

\section{L'arbore incantato. Pastorale}

Argomento

Ergasto, vecchio pastor d'Erimanto, si trova aver una figliuola, nomata Fillide, la quale s'innamora d'un pastor d'Arcadia, chiamato Sireno, che in quel tempo era esule di quelle selve. Riamava il giovane la ninfa, ma, richiamato in un subito dal padre, fu costretto partire, con promissione di ritornar in brevissimo tempo a riveder l'amata ninfa. Avvenne che un zio del detto pastore, quale era Mago et incantatore, lo fece uscir del senno, acciò ch'egli non partisse e più dell'amata Fillide non si ricordasse; la quale, non vedendo ritornare l'amante suo, dal padre se ne fugge, conducendosi in Arcadia sotto nome di Lisio pastorello, e per accidente ella diviene forsennata, et il pastore ritorna in pristino. Finalmente, dopo molti avvenimenti, per mezzo d'un'altra ninfa, creduta morta, e con l'arte del Mago, divengono tutti contenti. ${ }^{183}$

Beiden scenari, der Komödie wie der Pastorale, liegen nicht etwa bestimmte Märchen zugrunde wie bei Gozzi, sondern sie basieren auf typischen, traditionellen Komödienstoffen und -handlungen, auf Liebesverwicklungen mit glücklicher Auflösung, ${ }^{184}$ während die Märchenelemente nur akzidentellen Charakter haben. Beide Male trägt der Zauberer, sei er *fingiert « oder »echt«, dazu bei, daß das gute Ende zustandekommt, das auf normalem Wege offensichtlich nicht (mehr) zu erreichen ist, doch ist sein Wirken nicht märchenhaft, sondern eher pragmatisch bestimmt. In Flavio finto negromante stellt sich der vorgebliche Zauberer den anderen Personen jeweils als solcher vor und verspricht Hilfe, ordnet Verkleidun-

183 Faminio Scala, Il teatro delle favole rappresentative, $\mathrm{Hg}$. Ferruccio Marotti, Bd. 2, Milano, Il Polifilo 1976, S. 283 und 507.

184 Vito Pandolf beschreibt den modellhaften Aufbau der Komödien-scenari Scalas folgendermaßen: »giovani che si amano, contrasti con i vecchi, fauste nozze finali, spesso qualche peripezia, e quasi sempre spiritus movens dell'intrigo il servo o i servi (variante moderna degli schiavi plautini). Le varianti sul tema possono essere molteplici.* (V. Pandolfi, -Gli scenari dell'arte*, in: La commedia dell'arte, op. cit., Bd. 5, S. 207). Interessant ist, daß die *argomenti \&ei Flaminio Scala den Handlungsgang meist angeben, ohne die typischen komischen Figuren wie Arlecchino zu erwăhnen, obwohl diese in den Komödien selbstverständlich zu den Personen des Stücks gehôren. 
gen und andere Maßnahmen an und löst so letztendlich die Verstrickungen. Auch im pastoralen Ambiente von L'arbore incantato stehen Liebesverwicklungen diverser Art im Mittelpunkt; erwiderte beziehungsweise unerwiderte Liebe, Geschlechtertausch, die Auferstehung Totgeglaubter, die Verwandlung einer Nymphe in einen Baum und Arlecchinos in einen Kranich und deren (unmotivierte) Rückverwandlung prägen den verwirrenden Handlungsverlauf, an dessen Ende das Eingeständnis Sabinos, des Zauberers, steht, daß alles sein Werk war, sper far succedere cosi lieto fine $\alpha .{ }^{185}$ In scenari anderer Sammlungen ${ }^{186}$ treten gleichfalls Zauberer auf, oft in Begleitung von Geistern, bei Basilio Locatelli ausgestattet mit einem Zauberstab, die die übrigen Personen verwandeln, in Pflanzen, Tiere oder andere Personen, ihnen Zaubertränke und -speisen reichen, die zur Umkehr des Begehrens führen, Liebe in $\mathrm{Haß}$ und $\mathrm{Haß}$ in Liebe verkehren oder die Erinnerung auslöschen und so auf vielfältige Weise Verwicklungen und Verstrickungen provozieren, die sich am Ende durch neuerliche Eingriffe des Zauberers klären. An märchenhaften Elementen finden sich also hauptsächlich die Gestalt des Zauberers sowie die von ihm bewirkten Verwandlungen, wobei sich grob zwei Typen von scenart mit Märchenelementen unterscheiden lassen: im einen treten diese nur am Rande in zufalliger Weise als unerwartete Helfer aus einer Notlage auf und erfüllen eine Deus-ex-machina-Funktion, im anderen bekleiden die Zauberer eine Art Spielleiterfunktion, wobei die übrigen Figuren ihnen völlig ausgeliefert sind. Sie verstärken die Liebesverwirrungen durch Zauberei und effektvolle Verwandlungen, was hie und da zwar den Widerstand der Betroffenen gegen den *mago* weckt, meist jedoch in einer allgemeinen Versöhnung endet und nur in Ausnahmefällen zur Vernichtung des Zauberers führt. ${ }^{187}$ Entscheidende Aspekte des Märchens, die Gozzi für die Fiabe teatrali nutzt, spielen in den scenari der *commedie dell'arte keine Rolle: das allgemeine Schema von Schwierigkeiten und ihrer Bewältigung, die durch Mangel oder Notlage gekennzeichnete Ausgangslage, der Handlungsverlauf auf der Basis typischer Module, ein Held/eine Heldin als Hauptträger der Handlung und die funktional erfaßbare Figurenkonstellation, Kontraststrukturen, Formelhaftigkeit und nicht zuletzt eine Atmosphäre des Übernatürlichen, Wunderbaren ${ }^{188}$ sind nicht entscheidend für Struktur und Inhalt der "commedie dell'arte con magie $\alpha$. Sie folgen vielmehr traditionellen dramatischen Mustern, die mit

185 Flaminio Scala, op. cit., S, s 15 .

186 Z. B. V. Pandolfi, -Gli scenari dell'artea, op. cit., S. 213 ff.; Ferdinando Neri, Scenari delle maschere in Arcadia, Città di Castello, Lapi 1913; Gli scenari Correr, op. cit.

ist So z. B. in der Pastoralkomödie La nave, in F. Neri, op. cit., S. 69 ff.

$188 \mathrm{Vgl}$. M. Luthi, op. cit., und V. Propp, op. cit. 
einzelnen märchenhaften Elementen angereichert werden. Gozzis Fiabe teatrali dagegen weisen wie gezeigt einen Großteil der genannten Charakteristika auf und unterscheiden sich dadurch fundamental von den Commedia dell'arte-Stücken, daß das Märchen zu einer Grundkonstituente wird, narrative und dramatische Strukturen aufs engste verquickt sind und in einer Art ars combinatoria Elemente aus verschiedenen Bereichen unter Nutzung ihres formalen, semantischen und konnotativen Potentials zusammengeführt werden. ${ }^{189}$

Die als grundlegend beschriebene Kontraststruktur der Fiabe teatralt, die sich im Hinblick auf die Konstituenten Märchen und Masken, auf die Figurenkonstellation, auf die Sprache und das Verhalten der Personen manifestiert, steht als Charakteristikum sowohl zum Märchen als auch zur Commedia dell'arte in Bezug, wobei sich die Commedia dell'arte gegenüber dem Märchen durch die Vielfalt und Prägnanz der Kontraste auszeichnet und somit als struktureller Ausgangspunkt für die Fiabe teatrali fungiert. Nicht alle genannten Kontraste sind jedoch ausschließlich für die Commedia dell'arte charakteristisch, sondern kennzeichnen als gattungstypische Merkmale der Komödie (wie zum Beispiel Komik/Ernst, Diener/Herr, handlungstreibende/-retardierende Kräfte) auch die ^commedia erudita«, doch bleibt die Feststellung, daß die Commedia dell'arte in besonderer Weise auf Kontraststrukturen beruht. Letzten Endes sind diese auf zwei ganz unterschiedliche Darstellungsmodi zurückzuführen, die in den improvisierten Komödien zusammenwirken: dem ernsten Spiel der sinnamorati und dem komischen der Masken. Gozzis Fiabe teatrali spielen diese beiden Komponenten formal, inhaltlich und darstellerisch in extremer Weise aus.

\section{Zum Verhältnis von Ernst und Komik}

Um zu einer näheren Bestimmung der Funktion und des Verhältnisses von Ernst und Komik in den Fiabe teatrali zu gelangen, werden im folgenden Rainer Warnings Überlegungen zu einer Pragmasemiotik der Komödie ${ }^{190}$ herangezogen, auf deren Folie das Charakteristische der Fiabe

189 In Commedia dell'arte: La maschera e l'ombra, op. cit., spricht R. Tessari in bezug auf die *generici $\alpha$ und die scanovacci $\alpha$ mehrfach von *meccanismo combinatorio*, *montaggi , $_{\text {ricombinazione meccanica }}(\mathrm{S} .87,88,94)$, um das Funktionieren der scommedie dell'arte* zu beschreiben. Bei Gozzi ist die Zahl der Komponenten größer, die untereinander kombimiert werden, so daß die Komplexität des Ganzen wächst.

190 Rainer Warning, =Elemente einer Pragmasemiotik der Komódie-, in: Wolfgang Preisendanz; Rainer Warning (Hgg.), Das Komiscbe (Poetik und Hermeneutik VII), Munchen, 
teatrali deutlich auszumachen ist. Nach R. Warning konstituiert sich die Handlung der Komödie generell auf zwei Ebenen: der Ebene der umfassenden Komödienhandlung, die er nach E. v. Hartmann als wanderweitige Handlung ${ }^{19}$ bezeichnet, und der der eigentlich komischen Handlungen. Die Relation dieser beiden Konstitutionsebenen stellt den Hauptaspekt der Untersuchung in inhaltlicher Hinsicht dar. Ausgehend von der Feststellung, daß die komisch scheiternde Handlung keine einmalige ist, sondern ein sich episodisch wiederholendes, nichtiges Ereignis und somit die *komische inventio offensichtlich über die Ausschöpfung paradigmatisierter ridicula zu beschreiben ist $\times,{ }^{192}$ ergibt sich für das Ausspielen der Paradigmen komischer Handlung die Notwendigkeit einer anderweitigen Handlung, die die komischen Handlungen veranlaßt, trägt und zum Abschluß bringt. Dabei reicht das Spektrum der Interaktion zwischen dem Paradigma komischer Konflikte und der großen syntagmatischen Organisation der Komödie in der anderweitigen Handlung von einer reinen Ermöglichungsstruktur komischen Gegensinns über dessen prozeßhafte Aufhebung bis hin zu seiner latenten Verunmöglichung. ${ }^{193}$ In einem dominant paradigmatischen Strukturtyp hat die anderweitige Handlung als Ermöglichungsstruktur komischen Gegensinns dreierlei zu leisten: "Sie muß zunächst den Widerstand aufbieten, an dem sich der komische Charakter abarbeitet. Sie muß sodann dieses episodische Scheitern überführen in ein endgültiges, und sie muß schließlich dieses endgültige Scheitern so gestalten, daß eine Reintegration des Gescheiterten gleichwohl möglich bleibt, « ${ }^{194}$ Unter diesen Bedingungen wird die anderweitige Handlung zu einer Art Norm- oder Regelebene, von der sich der komische Charak-

Fink 1976, S. 279-333. v.a. Kap. 1 -Einleitunge und Kap. 2 "Die Inhaltsebene*, Wenn der Begriff *anderweitige Handlungs auch nicht überzeugend ist, da er zu sehr Sekundäres, Unwesentliches konnotiert, wird er hier als für R. Warnings Darstellung wichtiger Terminus beibehalten.

191 Ebd., S. 286.

192 Ebd., S. 289. In diesem Zusammenhang streift R. Warning die Commedia dell'arte und konstatiert: -Die sogenannte Improvisation aktualisiert in Wahrheit vorgegebene Paradigmen, als deren allgemeinstes die canavacci [sic], die stereotypen Handlungsschemata anzusehen sind. . (\$. 288). Die Angaben in den canovacci entsprechen jedoch überwicgend dem, was $\mathrm{R}$. Warning als umfassende oder anderweitige Handlung bezeichnet, wobei zu bedenken ist, daß canovacci für die ganze Gattungspalette der Commedia dell'arte (Komōdie, Pastorale, Tragikomödie, Tragödie) vorlagen. Auch lassen sich die von ihm erwähnten Tiraden, Monologe, Dialoge ete. aus Andrea Perruccis Dell'arte rappresentativa, op. cit., nicht generell unter der Rubrik thesaurierte ridicula subsummieren, da auch fur die sparti serie- solche sogenannten *generici* erstellt wurden.

191 Ebd., S. 298.

194 Ebd., S. 291. 
ter abhebt, eine Folie für das tolle Treiben der Unvernunft $\alpha .{ }^{145}$ Neben solcher Charakterkomik existiert die »sogenannte Situationskomik «, die die "sogenannte Intrigenkomödie ${ }^{196}$ kennzeichnet, bei der es durch die Massierung von Hindernissen zu einer Infragestellung des Kausalitätsprinzips in der Handlung kommt. Mit diesem Paradigma ergibt sich nach R. Warning die Möglichkeit, »den komischen Charakter von der Verantwortlichkeit für seine Fehlhandlungen zu entlasten $\alpha .{ }^{197}$ Ein Abbau der in beiden Typen vorliegenden Polarisierung in der Aktantenstruktur liegt bei einem Komödientyp vor, der sich durch eine »reduzierte Paradigmatik« auszeichnet. In diesem Fall entfaltet die Komödienhandlung selbst den komischen Konflikt, und die paradigmatische Opposition ist nicht mehr die von Vernunft und komischer Unvernunft, sondern ein Konflikt rivalisierender Normen.

Ganz offensichtlich ist für Gozzis Fiabe teatrali die Existenz zweier Konstitutionsebenen und die Interaktion zwischen einer *anderweitigen Handlung « und dem Paradigma der komischen Handlungen gegeben, wobei die Märchenhandlung die anderweitige Handlung bildet und das Paradigma der komischen Handlungen von den Masken eingelöst wird. Wenn diese Doppelstruktur auch vorhanden ist, so lassen sich die Fiabe teatrali doch weder der einen (Charakterkomik) noch der anderen (Situationskomik) Ausprägung dominanter Paradigmatik zuordnen, geschweige denn einem Komödientyp reduzierter Paradigmatik, der sich durch den Abbau der Polarisierung von komischen Figuren und anderweitiger Handlung auszeichnet. ${ }^{198}$ In den Fiabe teatrali wird das Komi-

195 Ebd., S. 292.

Auch K. Stierle setzt in - Komik der Handlung, Komik der Sprachhandlung, Komik der Komödieฯ, op. cit., den Zielpunkt der Komödie dort an, wo ndie Wiederherstellung vernünftiger Zustände, einer geordneten kulturellen Welt * erreicht ist, und betrachtet die * Perspektive vernünftigen Handelns a als konstitutives Element der Komödie; * Die Gegenseite des Vernünftigen, mit der sich der Zuschauer identifiziert, ist in der Komödie schon mitenthalten * (S, 260). Wie R. Warning stehen auch K. Stierle bei dieser Feststellung vor allem Komödien Molières vor Augen. Was die Identifikation des Zuschauers mit der Partei der Vernünftigen betrifft, ist wohl eher der skeptischen Position R. Warnings (vgl. op. cit., S. 292) zuzustimmen.

196 Ebd., S. 293. Das zwei Mal gebrauchte Attribut deutet auf ein terminologisches Unbehagen hin, das jedoch nicht thematisiert wird.

197 Ebd., S. 294.

198 Daß R. Warning seine Überlegungen hauptsächlich an franzôsischen Modellen (Molière, Beaumarchais, Marivaux) entwickelt und das Subjekt der komischen Handlung, den komischen Charakter, in den Mittelpunkt stellt, wirft die Frage nach der Gültigkeit für andere Komödientypen wie beispielsweise den der Commedia dell'arte oder Goldonis auf. Die Commedia dell'arte bildet nicht nur aufgrund der Masken einen Spezialfall, für den die *Reintegration des Gescheiterten " schon äußerlich nicht zu leisten ist, sondern 
sche der Masken nicht durch die anderweitige Handlung erst ermöglicht, sondern ist quasi vorgegeben durch die Charakteristika der Masken, die sich in allen Stücken gleichermaßen und in gleicher Weise zeigen; sie sind weder komische Charaktere im Sinne Molières noch treten sie als Intrigierende in den Mittelpunkt des Geschehens, wie dies etwa bei Beaumarchais oder im italienischen Umfeld in der Commedia dell'arte der Fall ist, wo die zanni Intrigen spinnen und eine handlungstreibende Aufgabe erfüllen. Das Komische der Masken beruht vielmehr auf typisierten sprachlichen, gestischen und charakterlichen Merkmalen, die sich durch relative Zeit- und Ortlosigkeit sowie einen hohen Grad an Allgemeinheit auszeichnen und punktuell wirksam werden. Selbstverständlich bestehen die Frabe teatrali nicht bloß aus einer Reihung komischer Maskenszenen, wie dies sam Pol eindeutig dominierender Paradigmatik « beispielsweise bei Aristophanes der Fall ist, sondern weisen eine kausal durchkonstruierte Handlung auf, die »als eine anderweitige dem komischen Paradigma unterlegt wird $\alpha .{ }^{199}$ Das Verhältnis von anderweitiger Handlung und komischem Paradigma ist in den Fiabe teatrali ein besonderes: Die gleichsam autonome Komik der Masken entbindet die anderweitige Handlung von ihrer Funktion als Ermöglichungsstruktur in semantischer Hinsicht und erlaubt die Aufhebung der binären Strukturierung in der Opposition von Normalität und Anormalität, Vernünftigkeit und Unvernünftigkeit, die die Komödie, wie R. Warning annimmt, ausmacht. Die anderweitige Handlung, das heißt die Märchenhandlung, dient nicht der Schaffung einer Norm, auf deren Folie sich Unvernunft zeigen kann, vielmehr ist sie eben so weit von jeder Norm, von jeder »vernünftigen Weltordnung entfernt wie die komischen Masken auch. Zweifellos ist es die Märchenhandlung, die das Ausspielen der »ridicula « der Masken ermöglicht, wobei dieses häufig, wenn auch nicht immer, oberflächlich seinen Ausgang von der Märchenhandlung nimmt, doch stellt sie keine Ebene der Vernünftigkeit dar, auf der sich komischer Gegensinn erst manifestiert. Die Relation von Märchenhandlung und Maskenkomik in den Fiabe teatrali wäre wohl eher räumlich als flächenhaft zu beschreiben: Die beiden Konstituenten bilden zwei Rãume, die klar differenziert und relativ autonom sind. Sichtbare und hörbare, für den Zuschauer unmittelbar kenntliche Zeichen für diese Trennung sind Masken, Kostüme, Gestik und Sprache, die hinsichtlich der Maskenfiguren ein lustvolles Wiedererkennen von Bekanntem ermöglichen. Die Räume interagieren zwar auf der Figuren-

lafft auch deutlich werden, daß das Komische der Rede, der Gestik, der Bewegung in R. Warnings Ausfuhrungen kaum Beachrung findet.

197 Ebd., S. 290-291. 
ebene, aber dieses Interaktionsverhältnis zielt nicht auf die Restitution einer ursprünglich gegebenen, dann gestörten Ordnung oder auf die Reintegration eines Gescheiterten. Am Ende steht nicht eine sich schließlich durchsetzende Vernünftigkeit, sondern eine Märchenwelt und eine Maskenwelt, die gleichermaßen unvernünftig sind und sich kontrasthaft gegenüberstehen wie zu Anfang. Das märchenhaft gute Ende der Fiabe teatrali führt zwar in der Schlußszene komödientypisch alle Personen auf der Bühne zusammen, doch bleibt die Differenz zwischen Masken und nicht maskierten Figuren unaufgelöst bestehen.

Wenn normalerweise das Ausspielen komischer Handlungen der anderweitigen Handlung als norm- und regelhafter Ebene bedarf und die Ambivalenz von Normbefolgung und Normverletzung Bedingung der komischen Handlung ist, so stellen die Fiabe teatrali einen bemerkenswerten Sonderfall dar. Mit der Wahl des Märchens als anderweitiger Handlung verweigert sich Gozzi der Etablierung einer »vernünftigen* Folie für das »unvernünftige Treiben. Das Märchen ist kein allgemein anerkanntes oder anzuerkennendes, unproblematisches Sinnsystem, auf dem die komische Handlung operiert, sondern im Gegenteil ein höchst prekäres und spezielles, das in keiner Weise vernünftigen Maßstäben entspricht. Der bewußte Verzicht auf die Darstellung einer Norm oder Normalität in den Stücken eröffnet zum einen, wie wir gesehen haben, neue, unverbrauchte Spielräume, zum anderen wirft er, wie noch zu zeigen ist, ein Licht auf die Problematik der Sinnsysteme und ihrer Normativität selbst sowie auf die Transposition im Theater.

\section{Wirkungsintention Lachen und Weinen}

Die Fiabe teatrali zeichnen sich also dadurch aus, daß die Komik der Masken inhaltlich nicht der Ermöglichungsstruktur der Märchenhandlung bedarf und umgekehrt die Märchenhandlung nicht »bloße« Ermöglichungsstruktur komischer Handlungen ist, was eine Eigenwertigkeit und relative Unabhängigkeit der beiden Räume Masken- und Märchenwelt mit sich bringt, die auch Konsequenzen im Hinblick auf die Wirkungsintention der Fiabe teatrali haben. Werden im allgemeinen in der Komödie die komischen Handlungen von den Zuschauern lachend beantwortet, während die anderweitige Handlung ohne Antwort bleibt, zielt Gozzi mit seinen Stücken auf eine zweifache Reaktion des Publikums: auf Lachen und Weinen. In seinen Memoiren berichtet er mit Genugtuung über die Publikumsreaktion bei der Aufführung von Il corvo: „Il pubblico pianse e rise a modo mio, e corse in folla ad infinite repliche di 
questa fola * (Mem., 248) und konstatiert in Ragionamento ingenuo, daß der gewünschte Effekt seiner Stücke sil far ridere, il far piangere, e il tener fermo un'Uditorio $\left(\mathrm{Col} . \mathrm{I}, 4^{8}\right)$ sei. Daß es die Masken sind, die das Lachen auslösen, ist offensichtlich, wird doch bereits in L'amore delle tre melarance Truffaldino als *persona benemerita nel far ridere* (Col. I, 82 ) eingeführt, überraschend dagegen ist die beabsichtigte Wirkung des Weinens, die dann zwangsläufig der Märchenhandlung zukommt. Sind Lachen und Weinen die primär von Gozzi angestrebten Reaktionen der Zuschauer, liegt in Analogie zur Kontraststruktur der Fiabe teatrali auch in wirkungsästhetischer Perspektive ein Kontrast vor. ${ }^{200}$

Trifft es zu, daß das Komische nicht komisch aus sich selbst ist, sondern nur im Reflex einer verletzten Erwartungsnorm, ${ }^{201}$ diese aber in den Fiabe teatrali nicht in der anderweitigen Handlung anschaulich wird, ist anzunehmen, daß die *Erwartungsnorm $\propto$ so allgemein ist, daß sie einer besonderen Illustration nicht bedarf. Tatsächlich eignet der Komik der Masken eine Zeit-und Ortosigkeit, die das Gebundensein des Lächerlichen an sje individuelle Interpretationen und Anerkennungen des als normativ Vorausgesetzten * weitgehend aufhebt. Bezeichnend dafür ist eine Bemerkung über Truffaldino, die sich wiederum in L'amore delle tre melarance findet: saveva veduto quel Truffaldino, non era possibile il trattenere le risa al solo vederlo (Col. I, 84). Immer wieder weist Gozzi darauf hin, daß die Masken seit Jahrhunderten ihr Publikum zum Lachen bringen und sowohl hohe als auch niedere Schichten belustigen, ${ }^{202} \mathrm{daß}$ also die diachrone wie synchrone Gebundenheit des Komischen im Hinblick auf die Masken nicht relevant ist. Dagegen spielt die Begünstigung des Komischen durch seine Erwartung ${ }^{203}$ eine sicher nicht zu unterschätzende Rolle: schon das auffällige Äußere, die Maske, das Kostüm, die Haltung, die Gestik, sind

200 Ob die Zuschauer tatsachlich abwechslungsweise gelacht und geweint haben, wie Gozzi mehrfach berichtet, ist mangels zeitgenōssischer Zeugnisse nicht nachprüfbar. Angesichts des heute kaum noch verstandlichen großen Erfolgs der Tragikomódien v. a. im 17. Jahrhundert in Frankreich (s, o, ) oder der comédie larmoyante im 18. Jahrhundert in Frankreich und Italien muß allerdings von einer Zuschauerdisposition ausgegangen werden, die der heutigen nicht vergleichbar und uns fremd ist. Belegbar sind nur die Aufführungszahlen der Fiabe teatralt in der jeweils ersten Spielsaison, die fur ein reges Publikumsinteresse sprechen, worauf immer dieses auch zurückzuführen sei. Im Hinblick auf eine Analyse der Fiabe teatrali ist die tatsächliche Publikumsreaktion weniger relevant als die wirkungsästhetische Absichtserklärung.

201 Vgl. R. Warning, op, cit., S. 303.

202 Zur Faszinarion und dem Publikumserfolg der Commedia dell'arte und vor allem ihrer Masken vgl. Kap. 3.t und den Exkurs zur venezianischen Theaterszene.

203 R. Warning führt in diesem Zusammenhang Bemerkungen Freuds zur s. Isolierung des komischen Fallse in Der Wirz und seine Beziebung zum Unbewußten an, op. cit., S. 304 . 
Zeichen, die dem Entstehen einer solchen Erwartungshaltung entgegenkommen. Die äußerliche, sprachliche und *charakterliche* Stereotypie der Masken fördert und erfüllt diese Erwartung jedesmal von neuem. Das komisch Übertriebene - Unnormale - in Aussehen, Bewegung und Sprache wie das Komische »der Heraufsetzung des materiell Leiblichen der menschlichen Natur ${ }^{20+}$ das die Masken, vor allem Truffaldino und Brighella, kennzeichnet, sind von einer Allgemeinheit, daß sie einer normativen Folie im Text bzw. auf der Bühne nicht bedürfen, sondern unmittelbar ein Lachen hervorrufen, das sowohl ein Verlachen der Rolle als auch ein Belachen der gelungenen Darstellung ist, der allabendlich in der Improvisation zu leistenden sprachlichen und körperlichen Neuschöpfung. Nicht zuletzt kann die Betonung des Kreatürlichen vom Publikum auch als Emanzipation des Sinnlichen, der unterdrückten Natur, und momentane Überwindung gesellschaftlicher Zwänge erfahren werden und ein befreiendes Lachen auslösen.

Unbestritten in der theoretischen Reflexion über das Lachen ist, daß dieses durch eine stärkere Gefühlsbeteiligung gehemmt wird, daß also die Wirkung des Komischen einer Unbetroffenheit und gewissen distanzierten Haltung des Rezipienten bedarf, ${ }^{205}$ da andernfalls die Komik in Ernst, das Lachen in Mitleiden umzuschlagen droht. Diese Distanz des Betrachters ist bei den Maskenfiguren von vornherein sehr viel mehr gegeben als bei den komischen Charakteren einer Charakterkomödie, da die distanzschaffende Wirkung vor allem der Maske, aber auch des Kostüms und der Verweis auf Rollenhaftigkeit und Artifizialität unübersehbar sind; zudem wird das, was bereits beim Anblick der Masken in die Augen springt, noch durch ihre Rede verstärkt, in der regelmäßig Autoreflexivität, Selbstkommentierung und -ironie als verfremdende Verfahren wirken.

Umso überraschender mag es erscheinen, daß Gozzi diesem auf Distanzierung beruhenden Lachen über die Masken als zweite Publikumsreaktion das Weinen an die Seite stellt. Bemerkenswert ist dies nicht nur, weil das Weinen eine dem Lachen geradezu entgegengesetzte Disposi-

20. Hans Robert Jauss, - Über den Grund des Vergnügens am komischen Heldens, in: W. Preisendanz; R. Warning (Hgg.), Das Komische, op. cit., S. 103-132, hier S. 104.

205 So etwa bei Friedrich Schiller (* In der Comödie muß alles von dem moralischen Forum auf das physische gespielt werden, denn das moralische erlaubt keine Indifferenza, in: - Tragódie und Comödie- aus dem Nachlaß, in: Werke, Nationalausgabe Bd. 21/2, Hg. Benno von Wiese, Weimar, Böhlaus Nachfolger 1963, S. 92) oder Henri Bergson, der in Le rure von *insensibilités, sindifférence* und sanesthésie momentanće du cceur* spricht (Le rire, 7. Aufl., Paris, PUF 1993, S, 3). Bei R. Warning heißt es: = Während die komische Wirkung der Distanzierung des Publikums vom komischen Fall bedarf und sich folglich immer schon episodisch erfüllen kann, setzt die tragische Wirkung ein sympathetisches Mitleiden voraus [...] 6 , op. cit., S. 314. 
tion voraussetzt, sondern auch, weil es die Märchenhandlung ist, die die Zuschauer zum Weinen bringt. Im Gegensatz zum Lachen bedarf das Weinen nicht der Distanzierung, sondern einer Betroffenheit und einer sympathetischen Anteilnahme des Publikums am Geschehen wie an den Personen auf der Bühne. Soll, wie dies bei den Fiabe teatrali der Fall ist, im Verlauf der Aufführung das Publikum abwechselnd lachen und weinen, muß seine Haltung im Verhältnis zum Bühnengeschehen flexibel sein und rasch wechseln können. Um dies zu erwirken, sind die beiden Komponenten, die das Lachen und das Weinen generieren, stark voneinander geschieden und als Kontraststruktur gestaltet. ${ }^{206}$ Der Umschlag zwischen komischen Szenenfolgen, die auf das Lachen und pathetischen, die auf Sympathie hinzielen, ist, wie an La donna serpente sichtbar wurde, deutlich markiert, die Gegensätzlichkeit der Maskenszenen und der Szenen mit Märchenfiguren klar erkennbar: dem »faceto delle maschere stehen die sforti passioni* der Märchenfiguren gegenüber. Im Vorwort zu Il corvo legt Gozzi sein Vorgehen offen und fordert seine Kritiker wie so oft ironisch heraus:

L'Uditorio passava dalle risa al pianto con somma facilità, appagando quell'intenzione, ch'io aveva avuta, e quell'arte, ch'io m'era ingegnato di adoperare.

Per far piangere nel mezzo ad un'aperto ridicolo è necessaria una circostanza di fortissima passione; ma, se questa circostanza ha la sua base in un falso argomento, e per se ridicolo, com è quello del Corvo, senza colori rettorici, gradi di apparecchio, ed eloquenza pittrice artifiziosa, che ingannino coll'imitazione della natura, e del vero, si provino a trar delle lagrime i Signori Giornalisti, i Signori Vetturali Postiglioni Letterarj, e i Signori animaleschi Romanzieri, i quali si divertono a condannare senza facoltà, e senza ministri, che obbediscano alle loro condanne. (Col. I, 119-120)

Um inmitten des Lächerlichen Tränen hervorzurufen, sind nicht unerhebliche Eingriffe bei der Märchenkomponente erforderlich, denn das Märchen an sich zielt nicht auf moralische Betroffenheit, nicht auf Mitleiden, es will weder zum Lachen noch zum Weinen bringen. Die Betonung von Gefühlen ist dem Märchen fremd, innere Motivationen sind

206 Wie Erika Fischer-Lichte in =Grenzgange zwischen den Welten - Vachtangovs Inszenierung der Prinzessin Turandot (1922) ж, in: Franz Norbert Mennemeier; dies. (Hgg.), Drama und Theater der europaischen Avantgarde, Tübingen, Basel, Francke 1994, S. $317-340$, zeigt, zielte Vachtangovs Inszenierung insbesondere auf diesen $\approx$ dauernden Wechsel zwischen emotionaler Beteiligung und ästhetischer Distanz *, der den Zuschauer befahigte, „die auf der Bühne vorgeführte Welt als theatrale Wirklichkeit zu rezipieren, indem er selbst sie als theatrale Wirklichkeit konstruierte * (S. 333). Vachtangov verlangte von seinen Schauspielern starke Gefühlsintensität an den Stellen, an denen er Emotionen für nötig hielt* (S. 326), doch sollte noch im heftigsten Gefühlsausbruch die - Kunst des Vorführens $\approx$ (ebd.) deutlich werden. 
für die Handlung irrelevant. ${ }^{207}$ Wenn nun die Märchenkomponente in den Fiabe teatrali eine "circostanza di fortissima passione bilden soll, sind verschiedene, an La donna serpente verdeutlichte Maßnahmen notwendig, um der Intention Genūge zu tun, dem Publikum Tränen zu entlocken. Insbesondere könnte das Bewußtsein der Fiktionalität des Märchens, des »argomento falso «, wie es an anderer Stelle heißt, ${ }^{208}$ eine emotionale Wirkung verhindern, da ein entsprechender Gefühlsaufwand für rein Erfundenes und insofern lächerlich Unbedeutendes ${ }^{209}$ als nicht gerechtfertigt erscheinen mag. Um dem vorzubeugen, setzt Gozzi in bezug auf die Märchenhandlung und -figuren ncolori rettorici, gradi di apparecchio, ed eloquenza pittrice artifiziosa «, rhetorische Mittel, dramaturgische Verfahren ${ }^{210}$ und kunstvoll anschauliche Beredsamkeit ein. Die Märchenhandlung wird aufgeladen mit Sentiment, die Hauptfiguren werden in Extremsituationen und innere Konflikte geführt, die nicht nur rhetorischen Ausdruck finden, sondern auch in sprachloses Weinen münden, wie die häufige Anweisung spiange « deutlich macht. Diese emotional ausgerichtete Funktionalisierung der Märchenkonstituente kann nur dann erfolgreich im Sinne Gozzis sein, wenn der Zuschauer möglichst weitgehend am Bühnengeschehen partizipiert und sich mit den handlungstragenden Märchenfiguren identifiziert, was wiederum eine ungebrochene Illusion voraussetzt. ${ }^{211}$ In zahlreichen Vorworten und anderen

207 Vgl. M. Lüthi, op, cit., S. 29-32.

208 Vorwort zu Turandot, Col. I, 215.

2099 Die zweimalige Verwendung des Wortes -ridicolos im obigen Zitat sollte nicht daruber hinwegtäuschen, daß damit völlig Unterschiedliches gemeint ist: -un'aperto ridicoloist das Lacherliche der Masken, während das sridicolox des sfalso argomento a die Lacherlichkeit im Sinne einer Nichtigkeit meint.

210 Mit sapparecchio * meint Gozzi nicht etwa die Ausstattung, sondern den architektonisch-dramaturgischen Aufbau, wie auch Laura Riecò in ihrer eingehenden Untersuchung der heute nicht mehr unmittelbar verständlichen Terminologie Goldonis, Chiaris und Gozzis zeigt: "Infine, i concetti ricorrenti di smettere in apparecchio un'ossatura * e di -forza dell'apparecchio rimandano direttamente al problema architettonico dell'opera, indipendentemente dal genere, teatrale o meno, cui essa appartiener, in: "Goldoni, Chiari, Gozzi*, op, cit., S. 22.

211 Zu Identifikation, Distanzierung und der Doppelhaltung des Zuschauers 5. Kap. 3.4. Etwa 10 Jahre vor Carlo Gozzi, nämlich unmittelbar nach den ersten Aufführungen von Il corvo im Oktober 176r und Il re cervo im Januar 1762 aufert sich Gasparo Gozzi in ganz ähnlicher Weise wie sein Bruder zur Wirkung der Märchenkomponente. Auch er weist auf den Zusammenhang zwischen Illusion, starken Gefuhlen der Bühnenfiguren und emotionalen Reaktionen der Zuschauer hin. Zwar spricht Gasparo nicht explizit davon, daß das Publikum geweint habe, doch kehren mehrfach die Begriffe scommoziones, "compassionea, smuovere wieder. Wenn Gasparo auch der Bruder des Autors ist, kann sowohl angesichts seiner Wertschätzung Goldonis als auch des nicht ganz unproblematischen brüderliehen Verhältnisses davon ausgegangen werden, daß die Bemerkungen in der Zeitschrift L'osservatore veneto ( $\mathrm{Nr}, 77,28$. Oktober 1761 und $\mathrm{Nr} .98$, 
Texten kommt Gozzi darauf zu sprechen, wie essentiell die Illusion für die Märchenszenen ist, und nicht zuletzt mancher Nebentext in den Fiabe teatrali selbst macht deutlich, welche Wichtigkeit Gozzi der perfekten Täuschung der Zuschauer beispielsweise bei Verwandlungen von Personen in andere Personen oder Tiere beimilt. ${ }^{212}$ Spielt beim Märchen als narrativem Text die Frage nach der Wahrscheinlichkeit traditionell keine Rolle, sind für die Darstellung auf der Bühne gezielte Maßnahmen hinsichtlich der Geschehensdarstellung wie der Illusionierung notwendig, um das Geschehen wahr erscheinen zu lassen und das Publikum emotional zu involvieren. Damit steht die Märchen-Konstituente auch unter dieser Perspektive in extremem Gegensatz zur Masken-Konstituente, kann es doch als Grundtendenz der Komödie und des Komischen gelten, sich mittels illusionsstörender oder -durchbrechender Verfahren als Spiel zu zeigen. Masken und Märchen generieren mithin nicht nur auf der Ebene des dramatischen Textes Kontraststrukturen, sondern sind in den Fiabe teatrali auch Angelpunkte für die Gegensätzlichkeit von Komik und $\mathrm{Pa}$ thos, Verfremdung und Illusionierung, Distanzierung und Identifikation, Lachen und Weinen.

9. Januar $176 \mathrm{t}$ M.V.) nicht nur Gefalligkeitsbezeugungen an Carlo sind, sondern einen repräsentativen Eindruck vermitteln.

$\mathrm{Zu} / \mathrm{l}$ corvo stellt ein fiktiver Leser, der das Stück - una o due voltea gesehen hat, fest, - Comeeché in essa [la rappresentazione del Corvo] si veggano rappresentate molte cose le quali si sa che sono impossibili ad accadere, non posso negarvi che l'animo mio non ne sia rimasto ingannato a segno, che m'è convenuto a forza sentire que' movimenti che si provano al recitare d'una tragediae, und fragt, woher dies wohl rühre. Gasparo Gozzi antwortet am Beispiel der Verwandlung Jennaros: "La tramutazione del principe in statua è condotta con tale e tanto artifizio dall'autore che fa quel medesimo efferto che farebbe ogni altra orribilità tragica sul teatro. Non nasec la bellezza della commozione di tale scena, se notate bene, da quel cambiamento: nasce bensi dal costume e dalla forza d'una passione naturales, schildert die ausweglose Situation, in die Jennaro geraten ist, und schließt: - lo sono dunque più che certo che la passione naturale, la quale regna dall'un capo all'altro in essa rappresentazione, sia quella che abbia tanto potuto nell'animo di voi e degli altri spettatori, che non lasci campo di riflettere all' impossibilità delle tramutazioni; onde convien dire che vi sia dentro non picciolo artifizio. Quest'č quanto poss'io dirvi intorno all' industria della soprallegata rappresentazione, ch'io volontieri chiamerei tragedia per quell'effetto che fa di muovere a compassione e ad orrore, né mi so per tali ragioni maravigliare che piaccia, poiché sa cosi bene prendere a tener saldo l'animo da capo a fondo." Auch hinsichtlich $/ l$ re cervo spricht Gasparo Gozzi vom Wechsel zwischen emotionaler Betroffenheit und komischem Vergnügen der $\mathrm{Zu}$ schauer: "Ad ogni passo la maraviglia riesce di mezzo alla passione, onde non è punto da studiare in che consista la forza che lega gli ascoltatori. Oltre a quanto ho detto, vi ê la varietà delle scene, legate sempre all'azione principale, e la parte del piacevolissimo Zanni che interrompe di tempo in tempo la gravità, senza punto sturbare il filo; e vi sono le trasformazioni con molta prestezza eseguite. a (Gasparo Gozzi, L'osservatore veneto, Hg. Noris Raffaelli, 3 Bde., Milano, Rizzoli 1965 , hier Bd, 2, S. $148-152$ und $274-277$.) 212 Zur grundlegenden Bedeutung der Illusion für die Flabe teatralt vgl. Kap. 3.4. 



\section{DIE FIABE TEATRALI \\ IM ITALIENISCHEN THEATERKONTEXT}

Die Fiabe teatrali sind nicht nur Erwiderung auf Chiaris und Goldonis Komödien, lokal begrenzt auf die venezianische Theaterszene, sondern auch eine Reaktion auf die Jahrzehnte währende Auseinandersetzung um die Erneuerung des italienischen Theaters, ein Gegenentwurf zur zeitgenössischen Entwicklung insgesamt. Während die zehn neuartigen Märchentheaterstücke zwischen $176 \mathrm{r}$ und 1765 ohne Begleittexte, Manifeste oder Erklärungen zur Aufführung kommen und bis 1772 nicht in gedruckter Form vorliegen, ergreift Gozzi hauptsächlich in Zusammenhang mit den beiden Werk-Editionen ab 1772 bei Colombani und ab 1801 bei Zanardi in Venedig in ausführlichen Einleitungen und Vorworten Position in der Theaterdebatte. Weit entfernt davon, gelehrte Abhandlungen, tiefschürfende Traktate oder systematische Poetiken zu sein, führen diese Texte den polemischen Duktus der frühen Schriften fort, nehmen jedoch größere Zusammenhänge in den Blick und zeugen von einer umfassenden Vorstellung von Theater, einer engen Verbindung zwischen praktischer Theatererfahrung und literarischer Aktivität, zwischen der Welt der Bühne und theoretischer Reflexion, von einer Konzeption, die poetologische und āsthetische Aspekte genauso aufgreift wie Fragen der Aufführung, des Publikums, der Situation der Truppen, ökonomische Probleme und nationale Eigenheiten.

Dazu zihlen die im ersten und vierten Band $(1772)$ der Colombani-Edition als ausführliche Einleitungen verôffentlichten Texte $=$ Ragionamento ingenuo, $e$ Storia sincera dell'origine di dieci Fiabe sceniche^, wie es im Inhaltsverzeichnis, bzw. - [...] delle mie dieci Fiabe teatrali-, wie es im Titel beißt (im folgenden abgekurzt RI) und s Appendice al Ragionamento ingenuo del primo Volumee (Col. IV, 1772 ; im folgenden ARI), die Vorworte zu den einzelnen Stücken und = La più lunga lettera di risposta che sia stata scritta, inviata da Carlo Gozzi ad un Poeta teatrale italiano de' nostri giorni. Giuntivi nel fine alcuni frammenti tratti dalle stampe pubblicate da parecchi Autori, e de' commenti dallo stesso Gozzi fatti sopra i frammenti medesimi- (Zan. XIV, 1802; im folgenden LL) sowic einige kleinere, nicht in den Werkausgaben enthaltene Texte wie z. B. Manifesto del Co: Carlo Gozzi, dedicato a' magnifici Signon Giomalisti, Prefattori, Romanzieri, Pubblicatori di Manifesti, e Foglivolantisti dell'Adria, s.t.n., und ein Brief Carlo Gozzis an Giuseppe Baretti vom September 1776 (Ferdinando Galanti, - Scritti inediti di Carlo Gozzis, in: Atti del reale Istituto veneto di Scienze, Lettere ed Arti, $1885-86$, vol. 4, S. $1201-1215$ und $1319-1346$ ). Darüber hinaus geht Gozzi auch in seinen erstmals 1797 im Druck erschienenen Memoiren immer wieder auf die Theatersituation der letzten Jahrzehnte ein. 
Gozzis und Goldonis kritische Texte wie auch ihr Theaterschaffen sind auf dem Hintergrund der theoretischen Theaterdiskussion und der bühnenpraktischen Reformversuche in der ersten Hälfte des Settecento zu lesen, werden doch erst auf dieser Folie explizite und implizite Referenzen oder Distanznahmen deutlich. Dieser Kontext, der im folgenden näher beleuchtet werden soll, läßt das Charakteristische, Unkonventionelle der Fiabe teatrali umso stärker hervortreten, so daß sie immer weniger als "strapazzi $\alpha^{2}$ eines Autors erscheinen, der vor allem Goldoni beweisen wollte, sche un gran concorso di spettatori affollati ad un'opera teatrale, non faceva prova che quell'opera fosse buona « ( LL, 32), ${ }^{3}$ sondern als bewußt verfolgtes eigenständiges Projekt innerhalb der Vielfalt der dramatischen Produktion im I8. Jahrhundert.

\subsection{Vom Buch zur Bühne}

\section{Literarische Reformversuche in der ersten Hälfte des 18. Jahrbunderts}

Mit Ludovico Antonio Muratoris Della perfetta poesia italiana (1706) und Gian Vincenzo Gravinas Della ragion poetica (1708) erschienen Anfang des Jahrhunderts zwei ästhetisch-kritische Abhandlungen, die beide im Zusammenhang der Bemühungen der Arcadia um eine Erneuerung der italienischen Literatur stehen, jedoch unterschiedliche Akzente setzen. Während Gravina der Imitation der griechischen und römischen Antike sowie der italienischen Autoren des Trecento und in geringerem Maße auch des Cinquecento entscheidendes Gewicht beimißt und als Modellautoren Homer und Dante anführt, plädiert Muratori für eine unvoreingenommene Überprüfung der Tradition und verschließt sich

2 So wird Lamore delle tre melarance veráchtlich im *Addio* Goldonis zum Abschluß der Karneval-Saison 1761 bezeichnet, vgl. Kap, 2,2.

3 Diese oft wiederholte vorgebliche Motivation bezicht sich vor allem auf Goldonis Vorwort zur ersten Edition seiner Werke bei Bettinelli, in der Goldoni den Gang seiner Reformversuche idealiter nachzeichnet und es hinsichtlich der ersten, noch nicht ausgeschriebenen "commedia di carattere ", Momolo cortigiano, heißt: »Piacque essa estremamente, e fu tante volte replicata con estraordinario concorso, che fui allora tentato di crederla perfetta Commedia (Goldoni, I, 768), wobei Goldoni allerdings relativierend fortfährt, "Ma conobbi di poi quanto migliori Commedie si potessero scrivere«, was Gozzi in polemischer Absicht unterschlägt. Der Zusammenhang von Publikumserfolg und Qualität der Stücke ist jedoch, wie bereits im 1. Kapitel deutlich wurde, ein immer wiederkehrendes Element in Goldonis Vorworten. 
auch einem Blick auf die französische und spanische Literatur und Kultur nicht, ${ }^{4}$ Auf diese allgemeinen Überlegungen folgten spezifischere zur prestigeträchtigen Gattung der Tragödie, von Pier Jacopo Martello Del verso tragico (1709), und Della tragedia antica e moderna (1714), von Gravina Trattato della tragedia (1715), von Pietro Calepio Paragone della poesia tragica d'Italia con quella di Francia (1732), von Gian Rinaldo Carli Dell'indole del teatro tragico antico, e moderno (1745), um nur die für unseren Zusammenhang wichtigsten zu nennen. Daneben entstanden exemplarische Tragödientexte u.a. von Martello, Gravina und Scipione Maffei, der $1723 / 24$ unter dem Titel Teatro italiano $0^{5}$ auch eine vierbändige Sammlung von Tragödien des Cinquecento mit einem ausführlichen Vorwort, 1storia del teatro e difesa di esso, herausgab. Auffällig ist im gelehrten Kontext der Fokus auf die Tragödie, der sich aus ihrer traditionellen poetologischen Vorrangstellung erklärt, wohingegen die Komödie nur am Rand erwähnt wird und damit Freiräume für eine Komödienreform entstehen, die Goldoni nutzen wird. Die Diskussion um die Tragödie ist jedoch auch im Hinblick auf die Komödie von Interesse, da sich die Argumentationsstrategien teilweise decken. Die Bestrebungen, das italienische Theater zu erneuern, sind in allen Texten gleichermaßen sichtbar, die Überlegungen und Ratschläge gehen allerdings in unterschiedliche Richtungen. Während bei Gravina die Nachahmung des griechischen Theaters im Vordergrund steht, betont Martello in der dialogisch angelegten Abhandlung Della tragedia antica e moderna den Unterschied zwischen antiker und moderner Tragödie und empfiehlt in Del verso tragico die Nachahmung des französischen Alexandriners für die italienische Tragödie. ${ }^{6}$ Maffei veröffentlicht, um nicht auf das französische Theater angewiesen zu sein, Tragödientexte des Cinquecento im Hinblick auf ihre Spielbarkeit auf italienischen Bühnen, Calepios mehr auf die Tragödientheorie als auf Einzelwerke und Spielbarkeit gerichteter Vergleich wendet sich ebenfalls gegen die Vorrangstellung der Franzosen, unterstreicht jedoch im Unterschied zu Maffei die Notwendigkeit, daß die Stücke zeitgemäß und auf das entsprechende Publikum hin ausgerich-

4 Vgl. Mario Fubini, Dal Muratori al Baretti, 2 Bde., z. überarbeitete und erweiterte Auflage, Roma, Laterza 1975 , Kap. X, - Arcadia e illuminismo*.

3 Der vollstandige Titel, der auf die Bemühung Maffeis um Spielbarkeit hinweist, lautet: Teatro italiano o sia scelta di tragedie per uso della scena, premessa una Istona del teatro e difesa di essa, Verona, Vallardi 1723-25. Im folgenden wird Maffeis Vorwort als Istoria del teatro e difesa di essa zitiert.

- Zu den italienischen Tragödientheorien des 18 . Jh. siche A. Galletti, Le teorre drammatche ela tragedia in Italia nel secolo XVIII, Cremona, Fezzi I gor, und Enrico Mattioda, Terrie della tragedia nel Setrecento, Modena, Mucchi 1994. 
tet sein müssen, und Carlis 1744 in Venedig gehaltene und ein Jahr später gedruckte Rede ist zwar ein Plädoyer für ein zuschauernahes, modernes Theater, hebt aber Martellos Tragödien beispielhaft hervor, die nicht erst heute als unspielbar gelten. Bei aller Heterogenität der Textformen, die vom Dialog bei Martello über die systematisch in Kapitel und Artikel gefaßte Abhandlung Calepios bis zur akademischen Rede Carlis und dem Vorwort Maffeis reichen, und aller Uneinheitlichkeit der Intentionen und Inhalte lassen sich zwei Hauptgesichtspunkte in der literarischen Debatte um das Theater erkennen: die Frage nach dem zu imitierenden Modell und die Auseinandersetzung um die Vorrangstellung der französischen oder der italienischen Literatur. ${ }^{7}$ Die beiden Paradigmen des antiken griechischen, im Fall der Komödie auch des römischen, und des französischen Theaters sollten für die Reflexion über das Theater wie für die Produktion dramatischer Texte in der ersten Hälfte des Settecento bestimmend bleiben. Auf die praktische Theaterarbeit hatten allerdings weder die argumentativen Schriften noch die neu entstandenen Stücke einen wirksamen Einfluß, war die Kluft zwischen den theoretischen Überlegungen und ihrer literarischen Umsetzung einerseits und der konkreten Bühnenpraxis andererseits doch zu groß. Nicht zuletzt ist es die Konzentration der genannten Autoren auf die traditionell gewichtigere Gattung der Tragödie, die einer Auffrischung des Repertoires im Hinblick auf das Publikumsinteresse entgegenstand.

Parallel zu den theoretisch und literarisch geprägten Aktivitäten gab es jedoch auch Reformversuche von Seiten der Theatermacher selbst. ${ }^{8}$ Bereits Ende des 17. Jahrhunderts machte Pietro Cotta (genannt Celio), ein römischer Schauspieler und Spielleiter (*capocomico*) den Versuch, neben den Commedia dell'arte-Stücken auch Guarinis Pastor fido, Tassos Aminta und französische Tragödien in Übersetzung aufzuführen. Ein zweiter wichtiger Impuls ging von Luigi Riccoboni (genannt Lelio) aus, dessen $*$ Reform * sowohl künstlerische als auch moralische Aspekte des

7 Ein Kompendium der Schriften zur Diskussion um die Überlegenheit der französischen oder der italienischen Literatur bietet Gian Giuseppe Orsis Considerazioni del Marchese Giovan Gioseffo Orsz bolognese sopra la Maniera di Ben Pensare ne' Componimenti gia pubblicata dal Padre Domenico Bouhours della Compagnia di Gesù. S'aggiungono tutte le Scritture, che in occasione di questa letterara contesa, uscirono a favore e contro al detto Marchese Orsi, Modena, Sogliani 1735.

\& Zu diesen frühen Reformversuchen s. Giuseppe Ortolani, "Appunti per la storia della riforma del teatro nel ' $700 \%$, in: ders., La riforma del teatro nel Settecento e altri scriti. Venezia, Roma, Istituto per la collaborazione culturale 1962, S. 10-13, und Nicola Mangini, "Il teatro italiano fra Seicento e Settecento: primi tentativi di riforma ", in: Italia nistica $\mathrm{r}_{3}, \mathrm{I}-2$, 1984 , S. $11-20$. 
Theaters im Auge hatte und der Komödie ihren Platz einrãumte. ${ }^{9}$ Legendär ist seine Aufführung von Maffeis Tragödie La Merope ${ }^{10} 1713$ zuerst in Modena, dann in Venedig, die derart erfolgreich war, daß mehrere Aufführungstermine angesetzt werden mußten. ${ }^{11}$ Ermutigt durch diese positive Resonanz, präsentierte Riccoboni dem Publikum 1715 im Theater San Luca in Venedig Ariosts Scolastica, mußte jedoch einen Mißerfolg hinnehmen, ${ }^{12}$ so daß die Hoffnungen, das Publikum an die Tragödien und die literarischen Komödien des Cinquecento heranführen zu können, einen empfindlichen Rückschlag erlitten.

Auch das sogenannte Florentiner Dreigestirn ${ }^{13}$ Girolamo Gigli, Jacopo Nelli und Giovan Battista Fagiuoli, die als Komödienautoren allgemein als Vorläufer Goldonis zu Beginn des 18 . Jahrhunderts gelten, ${ }^{14}$ konnten auf der Bühne keine bleibenden Erfolge verbuchen. Als Verdienst im Hinblick auf Goldoni wird ihnen eine Wirklichkeitsnähe der Stücke angerechnet, die sich im zeitgenössischen Ambiente und an der sprachlichen Gestaltung manifestiert. Girolamo Giglis Komödien orientieren sich al-

7. Vgl. Salvatore Cappelletti, $=$ Dalla commedia dell'arte alla commedia borghese: Luigi Riccoboni e la sua riforma del teatroe, in: Foram Italicum 14, 1980, S. $175-194$. S. u. ausführlicher zu Riecobonis Reform in *Problematische Commedia dell'arte*.

10 Die fünfaktige Tragödic, die auf einem griechischen Stoff basiert, der in Italien bereits zuvor bearbeitet worden war, enthält keine Chorpartien, ist in endecasillabi geschrieben und endet glüeklich. Thre Wirkung war überwältigend, sowohl was die Bühnenaufführungen betrifft als auch als Referenztext - in lobender wie in kritischer Hinsicht - in der Theaterdiskussion des Settecento.

11 Nach E. Mattioda, Teorie della tragedia nel Settecento, op. cit., S. 8 und 200, steht Maffeis Merope exemplarisch für die Tragödie mit glücklichem Ausgang, die bis Ende der 70er Jahre in den literarischen Kreisen Italiens höchstes Ansehen genoß.

12 Vgl. Nicola Mangini, I teatri di Venezia, Milano, Mursia 1974, S. r1 2: $=11$ disastro fu inevitabile, anzi lo spettacolo fu addirittura interrotto alla fine del quarto atto. .

13 So bei Roberta Turchi, La commedia italiana del Settecento, Firenze, Sansoni 1985 , die den ersten Teil, der Fagiuoli, Nelli und Gigli gewidmet ist, mit *La triade toscana überschreibt; siche auch Mario Baratto, =La letteratura teatrale del Settecento in Italias, in: ders., La letteratura teatrale del Settecento in Italia (Studi e letture su Carlo Goldoni), Vicenza, Neri Pozza 1985 , S. $11-32$.

14. Dagegen zeigt sich N. Mangini in =Il teatro italiano tra Seicento e Setrecento*, op. cit, 5. 19-20, von einer venetisch-venezianischen Entwicklungslinie auf dramaturgischem wie auf szenischem Gebiet überzeugt: > Una continuità che dalla grande stagione cinquecentesca di Ruzante, Calmo, Giancarli e della mirabile Veniexiana si trasmette attraverso tutto il sec. XVII in una lunga serie di testi, che dall'Andreini, l'autore della Venetiana, ci rinvia agli scenari dell' Arte e alla cosidetta scommedia ridicolosar e quindi alla triade Balbi, Bonicelli, Mondini; una continuiti, d'altra parte, che ha il suo personaggio emblematico in Pantalone, la cui presenza drammaturgica e scenica risulta costante e quanto mai significante. - Diese Perspektive verfolgt P. Vescovo in verschiedenen Publikationen weiter: $>$ Per la storia della commedia cittadina veneziana pregoldonianae, in: Quaderni Veneti \{, 1987, S. 37-80; =Le riforme nella riforma. Preliminari goldoniania, in: Quddermi Veneti 16, 1992, S. 119-152 und -La riforma nella tradizione*, op, cit. 
lerdings größenteils so eng an französischen Modellen, daß sie mehr als Übertragungen oder Adaptionen hauptsächlich Molièrescher Stücke denn als aktuelle Eigenschöpfungen erscheinen, wenn auch Gigli beispielsweise im Vorwort zu Don Pilone ovvero Il bacchettone falso ausdrücklich auf die Unterschiede zu Molières Tartuffe hinweist. ${ }^{15}$ Dem Beispiel Molièrescher Ballettkomödien wie Le bourgeois gentilhomme oder Le malade imaginaire folgend, ist in Don Pilone - anders als in Tartuffe - nach den ${ }_{3}$ Akten jeweils ein Zwischenspiel mit Tanz, Pantomime und Gesang vorgesehen, sintermedj [...] allusivi alla falsa Bacchettoneria con balli, e gesti, all'uso de' Mimi antichi, e canti火, deren Handlung am Ende des Stückes skizziert ist. ${ }^{16}$ Diese Übernahme eines typisch höfischen Elements in einen ihm fremden Kontext zeugt zum einen vom eklektischen Umgang Giglis mit den französischen Modellen, wirft aber auch ein Licht auf den Publikumsgeschmack, der sich in der ersten Hälfte des Settecento in starkem Maße auf die Oper und musikalische Intermezzi richtete, während die Komödie nur geringes Interesse hervorrief, was sich erst mit Goldonis und Chiaris Aktivität in Venedig ändern sollte. Wie Don Pilone steht auch La sorellina di Don Pilone in Prosa, und in beiden Stücken wird nicht an derbem Witz und Flüchen gespart. Nach Angaben des Vorworts handelt es sich um eine autobiographisch motivierte Komödie, die von einer Farsetta Satirica* unversehens zu einer fünfaktigen Komödie angewachsen war, ${ }^{17}$ wobei die grobe Personenzeichnung dem offensichtlich satirischen Charakter der Stücke - bei Don Pilone ausdrücklich eine Personalsatire - entspricht. Auch Jacopo Angelo Nelli weist im Vorwort zu La dottoressa preziosa auf eine konkrete Person hin, die ihm als noriginale " für seine Komödie gedient habe, beruft sich aber zugleich auf Molière, der mit "les Precieuses, e les Femmes savantes « bezeugt habe, "che di queste Preziose, e di queste Dottoresse se ne trovino dapertutto ${ }^{18}$ so daß sich auch hier die literarische Referenz und der Bezug auf die Wirklichkeit - in Form des satirischen Verweises - in der Rechtfertigungsstrategie überlagern. In dramaturgischer wie inhaltlicher Hinsicht bemerkenswert ist in einigen Komödien Nellis (z. B. in L'amante per dis-

13 -Il soggetto di quest'Opera del D. Pilone é tirato dal celebre Tartufo del Molier; ma egli è cosi mutato nel passaggio, che ha fatto da un idioma all'altro, che il D. Pilone é oggidi un'altra cosa, che non è il Tartufo. Il dialogismo è tutto variato, l'idiotismo, la sentenza, il sale. (Don Pilone ovvero Il bacchettone falso, Commedia di Girolamo Gigli, Accademico della Crusca, s.n.t., S. VII; diese Ausgabe enthält auch die Komödie La sorellina di Don Pilone.)

16 Ebd., S. $127^{-1} 36$.

17 Ebd., S. XIV-XV.

36 Jacopo Angelo Nelli, La dottoressa preziosa, commedia, Milano, Angelli, s.t., "L'Autore a chi legge $\alpha$. 
prezzo oder La serva padrona) die Rolle der Diener bzw. Dienerinnen, die weitgehend an der Entwicklung der Handlung beteiligt sind. Selbst das desillusionierende Ende von La serva padrona kann die Lebendigkeit und Selbständigkeit der Dienerinnenfigur nicht zunichte machen. Giovan Battista Fagiuolis Komödien und vor allem Il cicisbeo sconsolato (1708) waren nicht nur in Florenz und anderen oberitalienischen Städten erfolgreich, sondern wurden auch am Hof in Wien aufgeführt. ${ }^{19}$ Mit Anselmo Traccagni, »Vecchio avaro Fiorentino* oder nur »Vecchio Fiorentino ${ }^{20}$ hat Fagiuoli eine immer wiederkehrende Figur geschaffen, die auf den Pantalone der improvisierten Komödien verweist, sich jedoch vom Lächerlichen, Lasterhaften emanzipiert und insofern als Modell für Goldonis Pantalone gelten könnte. Nicht nur diese Figur, sondern auch klassische Schemata sprachlicher Mißverständnisse, Wortspiele, Doppeldeutigkeiten zeigen einen Einfluß der »commedia all'improvviso* auf $\mathrm{Fa}$ giuolis Komödien, die sích gegenüber denjenigen Nellis zudem durch ein schnelleres Tempo der Handlung auszeichnen, insgesamt jedoch ebenso schematisch wirken.

Ein nicht zu unterschätzender Faktor für die Entwicklung der praktischen Theaterarbeit sowie die sie begleitende Diskussion ist auch der Aufführungsort: sowohl in geographischem Sinn, als auch im Hinblick auf die Art des Theaters. Wie beispielsweise Fagiuoli in seinen Memoiren hervorhebt, bestanden zwischen Florenz und Venedig beträchtliche Unterschiede, was die Organisation und Administration der Theater und damit auch das Repertoire betrifft, so daß sich ein regional stark divergierendes Bild ergibt. Während in Florenz das Musiktheater bei weitem überwog, fand in Venedig neben dem dominanten Publikumsgeschmack der Zeit für die Oper dank eines professionellen Theatermanagements mit Impresarien auch das Sprechtheater sein Recht. ${ }^{21}$ In bezug auf das Repertoire des Sprechtheaters lassen sich ebenfalls deutliche Unterschiede erkennen, wenn Fagiuoli berichtet, daß vor allem toskanische Autoren aufgeführt wurden und die Commedia dell'arte kaum eine Rolle spielte, wohingegen in Venedig in mehreren Theatern Commedia dell'arte-Truppen auftraten und daneben ein wichtiger Teil des Repertoires aus Übersetzungen aus

19 Vgl. Paolo Luechesini, -Rimettere in scena G. B. Fagiuoli: un granducato in erisi sotto gli occhi del vecchio poetar, in: Quaderni di teatro, II teatro dell'Illuminismo III, Ix, 1981 , S. $181-187$. Dezidiert lokal ausgerichtet waren dagegen die Komödien Fagiuolis, in denen toskanische Bauerntölpel als komische Figuren dienten.

20 Giovan Batista Fagiuoli, Commedie, 7 Bde., Venezia, Angelo Geremia 1753, Bd. 5, S. $131,279$.

21 Vgl. die Einführung zu Giovan Bartista Fagiuoli, La commedia che won si fa, Orictta Girardi; Maria Russo (Hgg.), Roma, Bulzoni 1994, S. 16. 
dem Französischen bestand. ${ }^{22}$ Solche örtlichen Eigenheiten waren zwar für die theoretische Diskussion um das Theater bedeutungslos, diejenigen jedoch, die auch die Theaterpraxis im Auge hatten, konnten kaum über solche Unterschiede hinwegsehen. Über diese regionalen Differenzen hinaus ist ein weiterer Aspekt in Betracht zu ziehen, nämlich die Trennung in private und öffentliche Theaterräume, die sowohl hinsichtlich der Verbreitung der Stücke als auch im Hinblick auf das Publikum, seine Größe, seine Zusammensetzung und seine Erwartungen Konsequenzen hat. Während Fagiuoli sowohl für öffentliche Theater als auch für private schrieb, wurden Giglis und Nellis Komödien nur im Rahmen der Akademien aufgeführt und blieben damit weitgehend wirkungslos, was ein breiteres Publikum betrifft, welches zum Beispiel in Venedig über Erfolg oder Mißerfolg einer Aufführung von Ariosts Scolastica entschied und damit letztlich über die gelehrten Theaterreformpläne befand. Bereits Ende des 18. Jahrhunderts waren Gigli, Fagiuoli wie auch Nelli in Vergessenheit geraten, wie Gherardo De Rossi 1794 in Del moderno teatro comico italiano feststellt: *Tutti caddero nella dimenticanza, e il dotto Apostolo Zeno può dirsi l'unico, che restò in qualche venerazione accanto al suo vincitore [d. h. Metastasio] $\propto .{ }^{23}$

\section{Problematische Commedia dell'arte}

Für die italienische Theaterdebatte spielte neben den zeitlich und örtlich entfernten Orientierungsgrößen des antiken und des französischen Theaters auch die Auseinandersetzung mit der heimischen Tradition der Commedia dell'arte eine wesentliche Rolle. In der theoretischen Diskussion diente sie seit langem als Negativfolie in moralischer und ästhetischer Hinsicht. Von kirchlicher Seite prägt der stereotype Vorwurf der Obszönität und Verderbtheit sowohl der Schauspieler als auch der Stücke die Polemik um die Commedia dell'arte. Allerdings ist diese laut Ferdinando Taviani mehr eine sstoria di parole che di fatti ${ }^{24}{ }^{24}$ in der der religiös-moralisch motivierten Verurteilung mit den immer gleichen Argumenten die Verteidigung von seiten der Schauspieler gegenübersteht, was auf dem Höhepunkt der Kontroverse im 17. Jahrhundert mit Nicolò Barbie-

22 Zu den einzelnen Theatern in Venedig vgl. N. Mangini, I teatri di Venezia, op. cit.

23 Gherardo De Rossi, Del moderno teatro comico italiano, e del suo restauratore Carlo Goldoni, Bassano 1794 , S. 73.

$24 \mathrm{Vgl}$. Ferdinando Taviani, La commedia dell'arte e la societa barocca. La fascinazione del teatro, Roma, Bulzoni 1969, S. XLIIIff. 
ris La supplica (2. definitive Fassung von 1636 ) und Giovan Domenico Ottonellis "Antworta Della christiana moderatione del theatro ( 1648 ) exemplarisch deutlich wird. ${ }^{25}$ Die Gefahr der Aushöhlung des kirchlich kontrollierten Festrhythmus durch die Professionalität der Truppen, die Zweckfreiheit des Spiels, die Kâuflichkeit des Theaters, kurz die Commedia dell'arte als eine Art früher Vergnügungsindustrie, als Phänomen außerhalb des Kreises der sanktionierten kulturellen Manifestationen weckte Mißtrauen und mündete in die Gleichsetzung von Theater und Teufelswerk. ${ }^{26}$ Eine solchermaßen rigoristische religiöse Argumentationslinie läßt sich bis in die Mitte des 18 . Jahrhunderts zu Daniele Concina, einem jesuitisch ausgebildeten Dominikaner, weiterverfolgen, der in De spectaculis theatralibus $(1752)$ und De' teatri antichi e moderni contrari alla professione cristiana (1755), einer unmittelbaren Reaktion auf Maffeis De' teatri antichi e moderni (1753), eine fundamentale Unvereinbarkeit von Glauben und Theaterpraxis nachweist. Dieser grundsätzlichen Verurteilung des Theaters stehen Texte gegenüber, die in topischer Weise die Dekadenz des italienischen Theaters beklagen und weitgehend die Commedia dell'arte dafür verantwortlich machen, jedoch auch Auswege aus der Misere aufzeigen. Für die einen liegen diese ausschließlich in der Imitation antiker oder französischer Modelle, für die anderen, die wie z. B. Riccoboni auch die Theaterpraxis im Auge haben, ist eine Veränderung und Moralisierung des bestehenden, auf der Commedia dell'arte basierenden Repertoires anzustreben. Werden, was allerdings selten der Fall

25 Ottonelli betont insbesondere die Obszónität des Theaters; zur negativen Bewertung des Theaters aus klerikaler Sicht s. Sylviane Léoni, Le poison et le reméde. Théâtre, morale et rhétorique en France et en Italie $1694^{-1758}$, Oxford, Voltaire Foundation 1998 , insbesondere den Abschnitt = Lieux et figures $\approx$, S. $156 \mathrm{ff}$.

$26 \mathrm{Vgl}$. die Ausführungen in F. Taviani, La commedia dell'are, op.cit, F. Taviani, M. Schino, op. cit. und R. Tessari, Commedia dell'arte, op. cit.

In diesem Zusammenhang ist die sogenannte scommedia ridicolosaa, später auch scommedia mimica๔, zu nennen, die gedruckt im 17. Jahrhundert vor allem in rōmischen Kreisen weite Verbreitung fand. -Scritte in tre giorni di vacanza da sconosciuti autori e gratuitamente rappresentate da attori dilettanti in luoghi che non sono edifici teatrali, e solo in tempi di festas, wie sie Luciano Mariti in Commedia ridicolosa. Comici di professione, dilettanti, editoria teatrale nel Seicenta Storia e testi, Roma, Bulzoni 1978, S. XIII, charakterisiert, weisen sie ähnliche Charakteristika wie die improvisierten Komodien auf, nämlich Masken, Dialekt, niedere Komik und Improvisationspassagen, haben jedoch eine bestimmte Funktion innerhalb der Festzeiten wie Hochzeiten oder Karneval und werden nicht von professionellen Schauspielern, sondern von Laien aufgeführt. Sie zeugen vom Bemuhen der Kirche, die Commedia dell'arte im Rahmen des Karnevals wieder in das Festprojekt zu integrieren und sie somit sunschädlich " zu machen, in der Gewilßheit, daß für die ncommedia ridicolosa * im Gegensatz zur Commedia dell'arte ein enger zeitlicher und örticher Rahmen besteht und sie keinen kommerziellen Interessen unterliegt. Damit ist sie. Teil des bewußt verfolgten gegenreformatorischen Kulturprojekts, das eine klare Trennung des Alltags von den Festzeiten und-räumen anstrebt. 
ist, das tatsächliche Publikumsinteresse und der -erfolg in Betracht gezogen, ist die Bedeutung der Commedia dell'arte - wie im übrigen auch der Oper - nicht zu übergehen. Während Martello in Della tragedia antica e moderna ( $\left.17 \mathrm{I}_{4}\right)$ lediglich gegen die Begeisterung der Italiener für die »opera in musica* polemisiert und die Librettisten mit ironischem Lob überschüttet, ${ }^{27}$ führt Maffei im Vorwort zu seiner Tragödiensammlung $(1723 / 24)$ die Dekadenz der italienischen Tragödie geradewegs auf den negativen Einfluß der Oper sowie auf die Einführung des Dialekts und der Masken in der Komödie - das heißt in anderen Worten auf die Commedia dell'arte - zurück:

Ma dell'essersi quasi affatto coll'andar del tempo dismesse in Italia le Tragedie ne' Teatri, due trovo essere state le cagioni, principiate già nell'anterior secolo. Fu la prima l'uso introdotto di recitare in musica e l'eccessivo compiacersi che fece il mondo de' Drami musicali. [...] Ma niente men di questa, altra ragione ci contribuì e fu che essendo già nel I 500 stati introdotti nella Comedia, non per verità senza molta grazia, i vari dialetti, e con questi le maschere ch'or sono in uso, la forza di tal ridicolo smoderato cominciò a rapire il popolo fuor di modo; e perché a sì fatte lingue riusciva disadatto il verso, si passò col tempo a dargli bando; ed a far le Comedie tutte in prosa. ${ }^{28}$

$\mathrm{Da}$ in beiden Texten die Tragödie im Vordergrund steht, findet eine ausführlichere Auseinandersetzung mit der Commedia dell'arte nicht statt, so daß es beim Vorwurf der derben Komik bleibt. Martello wie Maffei sehen in Luigi Riccoboni einen Hoffnungsträger für das Theater, der nicht nur das Commedia dell'arte-Repertoire durch gute geschriebene Stücke ergänzt, wie dies exemplarisch mit Merope geschah, sondern auch um eine Verbesserung, das heißt Verfeinerung der Schauspielkunst bemüht ist. Martellos und Maffeis Zuversicht bezieht sich über die Aufführung einzelner literarischer Theatertexte hinaus zum einen auf Riccobonis Bearbeitung von scenari, für die eine schriftliche Fassung der Dialoge und die anschließende Versifikation durch einen seiner Schriftstellerfreunde vorgesehen war, ${ }^{29}$ zum anderen auf die Bearbeitung französischer Stücke

27 -La professione del compor melodrammi, Martello mio, è una scuola per voi di morale che più di ogni altra insegna a' poeti il vincer se stessi, rinunciando al proprio desiderio*, in: Pier Jacopo Martello, Scritti critici e satirici, Hg. Hannibal S. Noce, Bari, Laterza 1963, S. 290.

28 In Istoria del teatro e difesa di esso, in: Scipione Maffei, De' teatri antichi e modemi e altri scritti teatrali, Hg. Laura Sannia Nowé, Modena, Mucchi 1988, S. 20 und 23.

29 Dies geht aus der Einführung Irene Mamezarzs zu ihrer Edition von Luigi Riccoboni, Discorso della commedia all'improvviso e scenari inediti, Milano, Il Polifilo 1973, S. XX, hervor. Teile des Discorso entstanden bereits Anfang, andere Ende der $1720 e r$ Jahre. 1743 fügte Riccoboni die Sammlung von scenari an, die zwischen 1713 und 1719 niedergeschrieben wurden. 
für seine Truppe mit Maskendarstellern. ${ }^{30}$ Riccoboni selbst stimmt in das allgemeine Klagelied über den Niedergang des italienischen Theaters ein, doch weist er unmißverständlich auf die Faszination des improvisierten Spiels hin, die zwischen den Zeilen auch in Maffeis eben zitierten Außerungen zu erkennen ist:

Depuis l'an 1600, jusqu'en 1700 , le Théâtre Italien perdit infiniment par les mauvaises Comedies \& les Tragi-Comedies Espagnoles, qui paroissoient sur la Scene avec afflucnce \& qui de plus en plus éloignoient l'esperance de revoir encore en Italie la bonne Tragedie \& la bonne Comedie; mais il gagna beaucoup du côté des habiles Acteurs qui les représentoient, ils porterent si loin l'excellence de leur Art qu'ils furent appellés à toutes les Cours de l'Europe. ${ }^{31}$

Aus diesem Passus geht klar hervor, daß das schlechte Image der Commedia dell'arte in der gelehrten Diskussion ihrem Publikumserfolg im In- und Ausland diametral entgegensteht, was fast zwangsläufig zu einer Ambiguität im Urteil über die Commedia dell'arte bei den Autoren führt, die sich überhaupt mit der Theaterrealität befassen. Merkwürdig erscheint in diesem Zusammenhang Riccobonis Feststellung in Discorso della commedia all'improvviso, die literarischen italienischen Komödien präsentierten samt und sonders schlechte Beispiele und führten Lasterhaftigkeit und verdorbene Sitten vor, ${ }^{32}$ seine scenari dagegen würden senza puerilità o dissolutezze $\propto$ zum Lachen bringen und seien einem »purgato teatro* angemessen. ${ }^{33}$ Diese Umkehrung der traditionellen Argumentation ist keineswegs ironisch zu verstehen, was die später (in den 4 oer Jahren) entstandenen Vorworte zu den einzelnen scenari bestätigen, sondern als Strategie eines Theaterpraktikers, der um die Attraktivität und die ökonomische Lukrativität der Commedia dell'arte weiß und sich im Kontext der zeitgenössischen Debatten um eine moralische Unbedenklichkeit bemüht, die die Commedia dell'arte - und damit auch die eigene Arbeit - der Kritik entziehen würde. ${ }^{3+}$

$30 \mathrm{VgL}$ L. Riccoboni, Histoire du theâtre italien, op. cit., S. $83-84:-$ Je me servis du Thèâtre François. Les Vieillards de ces Comedies devenoient le Pantalon \& le Docteur, \& les Valets l'A rlequin 8 le Scapin.*

31 Ebd., S. 57.

12 -Bibiena, Trissino, Ariosto, Machiavelli, Aretino, Cieco d'Adria, Firenzuola, Lorenzino de' Medici, Caro, Secchi, Parabosco, Bentivoglio, Cecchi, Porta, Domenichi, Lasca, Salviati, Castelletti, Calderari, Guarini, Salviano, e tanti altri Eccelentíssimi scrittori di Comedie in verso et in prosa, che sarebbe qui troppo noioso il descriverli, non mi presentavano che favole bellissime in vero, ma di cativo esempio, $\mathrm{c} \mathrm{la} \mathrm{di} \mathrm{cui} \mathrm{atione} \mathrm{et}$ il di cui nodo in turte quasi, solo dissolutezze, e corrotti costumi ci esponevanoa, in: L. Riccoboni, Discorso, op. cit., S. 3.

33 Ebd., S. 29 und 33.

$34 \mathrm{Vgl}$. Riccobonis - Procmio- zum scenario Il muto per spavento, op. cit., S. 84-85: -Sebbene prettendo di dar soggetti di Comedia riformata e migliore di quella che abbiamo 
Ein ebenso eindrucksvolles Beispiel für den schwierigen Umgang mit der Commedia dell'arte findet sich bei Martello im Vorwort zur Komödie Che bei pazzi. Zunächst bezieht sich Martello auf Ariost und Aristophanes, und weist dann ausführlich nach, daß sein Werk hinsichtlich der Charaktere und der Handlung den Auslegungen von Aristoteles' Poetik durch Antonio Riccoboni und Tarquinio Galluzzi genau entspricht sowie die bei Galluzzi aufgeführten rhetorischen Mittel des Komischen aus Ciceros De oratore ausschöpft. Derart abgesichert sieht er keinen Grund, seine Komödie nicht zum Druck zu geben, obwohl ihn der aktuelle Mißerfolg der Aufführung von Ariosts Scolastica in Venedig eigentlich davon abhalten müßte, eine Komödie in Versen zu veröffentlichen. ${ }^{35} \mathrm{Um}$ seinem Stück ein ähnliches Schicksal zu ersparen, trifft Martello konkrete Vorkehrungen: er untersagt den sistrioni «, den professionellen Schauspielern, die Aufführung in einem öffentlichen Theater (sbastandomi la sicurezza che da nessuno istrione sia eletta, ed al pubblico esperimento de' palchi venali esibita«) mit folgender Begründung:

Imperciocché conosco io [...] che quando cotesti artegianelli o barcaiuoli vanno al teatro per ridere, più tosto il Dottore, il Pantalone, ed Arlechino, e Finocchio, che la Lena, il Negromante, i Suppositi, la Casaria, e la Scolastica vorrebbero ritrovarvi: conciossiacosaché nessuna commedia ridevole, per savia, piccante, vivace, $e$ costumata che siesi, può alla commedia istrionica italiana resistere; né vi ha lingua al mondo, o nazione, appreso di cui si ritrovi un'invenzione di turpezza senza dolore che con questa osi paragonarsi. ${ }^{36}$

Das Lob der "commedia istrionica italiana* wird weiter ausgeführt und endet mit dem bemerkenswerten Satz: »così che confesso ch'io lascerei

presentemente, non mi sono già dato ad intendere di dar modelli di perfetta e regolata Comedia. Bisognava lusingare i proffessori Comici col presentarli una Comedia che non distrugesse la speranza del loro guadagno, ma col progresso del tempo li conducesse alla perfetta Comedia. [...] cosi la mediocremente buona cacciarà la cativa comedia, e quella dalla perfetta sarà cacciata.

Riccobonis Außerung macht deutlich, wie unterschiedlich, ja geradezu entgegengesetzt die Wahrnehmung und Beurteilung der Komödien im Hinblick auf moralische Kriterien ist. Solche Divergenzen, die selbst dann überraschend sind, wenn man die Funktionalisierung traditioneller Argumente im Hinblick auf das eigene CEuvre im Auge hat, bestehen nicht nur hinsichtlich des italienischen Theaters, wie das Urteil Maffeis über Molière zeigt, der Martello wie Goldoni als großes Vorbild gilt. In De' teatri antichn e moderni schreibt Maffei: *Che diremo delle celebrate Comedie del Moliere? Per la Morale sono mortali, e con ragione e con verità ne parlò í dottissimo Bossuet e le disapprovò.* (op. cit., S. 122).

35 Als Entstehungsdatum für Che bei pazzi ist aufgrund der Erwahnung dieser Aufführung das Jahr $17 \mathrm{r} 6$ anzunehmen, vgl. die Anmerkungen zum Stück in Pier Jacopo Martello, Teatro, Hg. Hannibal S. Noce, Bd. 1, Roma, Laterza 1980, S. 751.

36 Widmungstext zu Che bei pazzi in Pier Jacopo Martello, Teatro, op. cit, S. 235. 
l'Edipo di Sofocle, e l'Anfitrione di Plauto per una di queste favole da valenti istrioni rappresentata $\times{ }^{37}$ Auf dieses persönliche Bekenntnis zur improvisierten Komödie folgt die Feststellung, *Lontane dunque dal popolo le nostre commedie«, und die Einsicht in die Unvereinbarkeit von allgemeinem Vergnügen und literarisch-kulturellem Anspruch. Bezeichnend für das problematische Verhältnis zur scommedia istrionica italiana a ist der offensichtliche Widerspruch zwischen der Betonung ihres Erfolgs beim niederen Volk und dem Eingeständnis der eigenen Begeisterung sowie der Erwähnung der Faszination, die die "commedia italiana « auf Spanier wie auf Franzosen ausübt. In welchem Maße das niedere Volk als Legitimationsargument für die Commedia dell'arte herhalten muß, mag das Ende des Widmungstextes veranschaulichen: $\gg \mathrm{E}$, se dai governi, ancorché cattolici, si van tollerando [sc. le commedie istrioniche], egli è per lasciar uno sfogo il men novico che dar si possa al cattivo genio dei popolani, che almen per quel tanto che seggono e ridono alla commedia, non rubano le botteghe, non fan violenza alle vergini, non fanno ingiuria agli altari. ${ }^{38}$ Umgekehrt wird der Mißerfolg der Scolastica in Venedig allein dem *vulgo de' barcaiuoli $\alpha^{39}$ zugerechnet, denn, so versichert Martello seinem venezianischen Widmungsträger, dem Patrizier Giovanbatista Recanati, "se voi coi soli vostri sessanta patrizi aveste seduto, non calavasi senz'alcun dubbio la tenda $\times .{ }^{40}$ Aus dieser Sicht heraus ist es verständlich, daß Martello Che bei pazzi für die Aufführung »da un seminario, o da un'accademia ad un'udienza scelta e raccolta, la maggior parte di letterati $\alpha$ vorsieht und ausschließlich männliche Schauspieler vorschreibt. Trotz der Einsicht in die Lebendigkeit und Theatralität der Commedia dell'arte und ihren überwältigenden Erfolg nicht nur auf italienischen Bühnen entscheidet sich Martello für die Herrschaft des Textes auf der Bühne, zieht den geschlossenen Kreis privater Aufführungen vor und erhofft sich Lob von Seiten des literarisch gebildeten Publikums. Deutlicher kann die Kluft zwischen gelehrtem Anspruch und tatsächlicher Theaterpraxis kaum zum Ausdruck kommen. ${ }^{41}$

37 Ebd., S. 236.

38 Ebd., S. 239.

19 Ebd., S. 234.

*0 Ebd., S. 236. Warum Riccoboni mit Maffeis Tragödie Merope am selben Ort beim selben Publikum überaus erfolgreich war, wird konsequenterweise nicht gefragt. Eine ganz andere Position vertritt Martello in Della tragedia antica e moderna von 1714 , d. h. vor dem venezianischen Debakel der Scolastica: dort wird dem Urteil des Publikums im Theater großes Gewicht beigemessen, vorausgesetzt, das Publikum setzt sich aus allen Schichten und Altersgruppen zusammen und kann so als reprasentativ gelten.

* So verwundert es kaum, wenn Muratori in Della forza della fantasia umana urteile: -Felicissimo era l'ingegno di Pier-Jacopo Martelli; ma egli volea troppo mostrarlo nelle 
Die Diskrepanz zwischen Buch und Bühne, zwischen theoretischen wie dramatischen Texten und der Theaterpraxis bleibt bestehen bis zur Jahrhundertmitte. Davon legt noch Maffeis 1754 erschienene Abhandlung De'teatri antichi e moderni beredtes Zeugnis ab. Wenn er dort die Dekadenz des Theaters auf seinen formalen Verfall in der Commedia dell'arte und das Aufkommen der Oper zurückführt, nimmt er Gedanken auf, die bereits in den ersten beiden Jahrzehnten des 18. Jahrhundert die Diskussion bestimmten und ihren Niederschlag schon 1723 in Istoria del teatroe difesa di esso fanden. Wenn Maffei dann als Heilmittel nur die Entfernung der Frauen aus den Truppen und von der Bühne sowie die Einsetzung eines »dotto direttore e morigerato, il quale Tragedie in versi e Comedie di buon costume somministri« sieht, der den Truppen moralisch unbedenkliche Stücke liefert und darauf achtet, »discorsi o scherzi improprii e indecenti ${ }^{42}$ zu vermeiden, tritt die Distanz zur Wirklichkeit eklatant hervor. Wie weit ein solcher Text tatsächlich von der Theaterrealität entfernt ist, wird deutlich, wenn man bedenkt, daß Goldoni mit keinem Wort erwähnt wird. Zumindest seit 1750 setzte dieser mit der Aufführung von Il teatro comico im Theater Sant'Angelo und mit dem Vorwort zur ersten Ausgabe seiner Komödien bei Bettinelli in Venedig unübersehbare Zeichen für eine Veränderung der Theaterlandschaft. Daß gerade Venedig zum Schauplatz neuer Entwicklungen wurde, erscheint nur folgerichtig, zieht man das seit langem ausgeprägte Theaterleben in Betracht, das im folgenden Exkurs skizziert werden soll.

\section{Exkurs: Die venezianische Theaterszene}

1723 schreibt Maffei in Istoria del teatro e difesa di esso über die Wirkung von Riccobonis Reformbestrebungen:

Si cominciò dunque a gustare la bellezza e perfezione di si fatti componimenti, e quanto maggiore fosse il diletto del lagrimare istesso in si fatte rappresentazioni, che del ridere in altre; si cominciò da' Comici stessi a conoscere quanto maggiore fosse l'effetto del recitare in verso che in prosa, e quanto se ne nobilitasse la lor professione; passò questo sentimento ad altre Città, specialmente a Venezia, che con pace d'ogni altra in Italia, e fuori, è in ciò l'arbitra più autorevole e il più sicuro giudice; essendo indubitato che in nissun'altra s'intende tanto il Teatro: né

sue tragedie, molte delle quali perciò quantunque si belle da leggere, non possono già sperare gran fortuna poste in iscenar, was gleichermaßen für die Komodien gelten kann; Ludovico Antonio Muratori, Della forza della fantasia umana, $\mathrm{Hg}$. Claudio Pogliano, Firenze, Giunti 1995, S. 134.

42 Scipione Maffei, De' teatri antichi, op. cit., S. 226. 
potrebb'essere altrimenti, perché lasciando la singolar perspiçacia dell'ingegno e l'aggiustatezza del giudicio e del sentimento, che sono proprie di quel clima, in nissun altra fino a otto Teatri vedransi aperti nell' istesso tempo, e di numerosa udienza ripieni. Si aggiunge la confluenza de' forastieri d'ogni parte, per la quale il sentimento di tal Metropoli vien in certo modo ad acquistar faccia di sentimento comune. ${ }^{43}$

Bereits seit der ersten Hälfte des 17 . Jahrhunderts war Venedig eine Theaterstadt, in der es mehr öffentliche Spielstätten gab als an jedem anderen europäischen Ort. ${ }^{44}$ Die auf Privatinitiative hin gebauten Theater gehörten Patrizier-Familien, die sie auch leiteten und über das Repertoire entschieden. Im Laufe des Settecento traten zunehmend Änderungen in diesem lange stabilen System ein, und anstelle der Eigentümer übernahmen mehr und mehr Impresarien die Direktion der Häuser. In einigen Fällen gingen die Theater in andere patrizische Hände über oder wurden von Gesellschaften verwaltet. Unter diesen Bedingungen gewannen ökonomische Aspekte an Bedeutung, und die Konkurrenz zwischen den Theatern wurde härter. Bedingt durch die Vorliebe des Publikums für das Musiktheater, gab es in der ersten Hälfte des 18 . Jahrhunderts für die Sparte des Sprechtheaters im wesentlichen nur zwei Bühnen, das Teatro San Samuele, im Besitz der Familie Grimani, und das Teatro San Luca (auch San

4) Op. cit, 5, 26-27.

* Die Zahlenangaben varieren ie nach Zahlung (privat, offentlich; Größe; Bespielung). In der ausfuhrlichen Einleitung Ludovico Zorzis ( -1 teatri di Venezia (secoli XVIIXVIII) -) zum Ausstellungskatalog I teatri pubblici di Venezia (secoli XVII-XVIII). Venezia 1971, S.9-50, ist von 10 Theatern die Rede, die zwischen Ende des 16. und Mitre des 17. Jahrhunderts erôffnet werden, bis zum Jahrhundertende erhōht sich die Zahl auf etwa 20. $1 \mathrm{~m}$ Laufe des Settecento sinkt die Anzahl und stabilisiert sich bei $13-14$ Spielstätten, die zur Halfte gleichzeitig bespielt werden und in Konkurrenz zueinander stehen. N. Mangini widmet in seiner umfassenden Darstellung I teatri di Venezia, op. cit, acht offentichen Theatern des Settecento cingehende Untersuchungen und erwahnt zahlreiche weitere kleinere offentliche und private Theater. Die bedeutenderen Theater tragen meist die Namen der Gebiets, auf dem sie sich befinden, z B. Teatro di San Cassiano, Teatro di San Moisé, Teatro di San Luca ete.

Die Hinweise auf die Diskrepanz zwischen der abnehmenden ōkonomischen Prosperität Venedigs und dem bluhenden Theaterleben im 18. Jahrhundert sind dahingehend zu relativieren, daß erstens das Vermógen einzelner immer noch erlaubte, solche Institutionen zu fuhren, was auch an der regen Bautatigkeit der Zeit ablesbar ist, und zweitens die Theater auch von Gasten und Touristen besucht wurden, die in dieser Zeit nicht weriger zahlreich nach Venedig kamen. Drittens hat sich der Blick auf das Settecento und die Aufklarung in Italien in der neueren Forschung z. T. entschieden verändert, so daß auch der *Niedergang - Venedigs seritmythisiert * wird, s. Z. B. Franco Venturi, Settecento riformatore, 5 Bde., Torino, Einaudi 1969-1990, v, a. Bd. $5 / 2$ - La Repubblica di Venezia $176 \%-1797 \%$, und Volker Hunecke, Der venezianiscbe Adel am Ende der Republik 1646-1797. Demographie, Familie, Haushalt, Tubingen, Niemeyer 1995, der den Begriff -Dekadenz * als Leitfaden für die Betrachtung des i 8 . Jahrhundert ablehnt. 
Salvatore genannt), das der Familie Vendramin gehörte; in der zweiten Hälfte kam das Teatro Sant'Angelo dazu. Die venezianischen Theater unterlagen streng festgelegten Spielzeiten und konnten im Herbst, zum Karneval und eventuell um Himmelfahrt ${ }^{45}$ jeweils eine bestimmte Anzahl von Aufführungen ansetzen. Das Unternehmen Theater nahm in Venedig früh das Ausmaß einer Art *Unterhaltungsindustrie * an und wurde maßgeblich unter ökonomischen Kriterien geführt, wie L. Zorzi betont: -Sta di fatto che la rapida creazione a Venezia di una rete di sale di spettacolo quale nessuna città d'Europa poteva allora vantare fu anzitutto il risultato di una operazione di carattere economico, condotta con criteri di spiccata fisionomia proto-industriale. ${ }^{46}$ Das große Angebot schaffte Nachfrage, garantierte Variabilität und Qualität, Venedig zog die bekanntesten Künstler der Zeit, vor allem Sängerinnen und Sänger, aber auch berühmte Schauspieltruppen, an, so daß das Publikumsinteresse wachgehalten wurde. Es bildete sich eine »socialità teatrale $\alpha^{47}$ heraus, in deren Kontext "ridotti und "casini e entstanden, wo sich das Publikum nach der Aufführung traf und diskutierte. ${ }^{48}$ Dem Versuch, Schauspieltruppen

45 Die Spielzeiten variierten für die einzelnen Gattungen, so waren z. B. die Spieltage um Himmelfahrt für das Musiktheater reserviert, vgl. N. Mangini, I teatri di Venezia, op. cit., S. 92. P. Bosisio gibt in seiner Ausgabe der Frabe, op. cit., S. 392, für die Herbstspielzeit den Zeitraum 1. September bis 30. November, für die Karnevalsaison 26. Dezember bis 30. Marz, für die Himmelfahrtsaison die Zeit von Himmelfahrt bis is. Juni an, wobei allerdings das Ende der Karnevalssaison vom Datum der Karwoche abhing. In seinen Memoiren spricht Gozzi von Venedig als Winterquartier der Truppe Sacchi für die Zeit von Oktober bis zur Fastenzeit und von den sconsueti sei mesi $\alpha$ mit Aufführungen außerhalb Venedigs (Mem. I, 335 und 256).

t6 L. Zorzi, 1 teatri di Veneziae, op. cit., S. 16. So werden etwa auch Verträge zwischen den Häusern bzw. den Patrizierfamilien geschlossen, die die Spielstättenverteilung für Oper und Komödie im saisonalen Wechsel regeln, s. Nicola Mangini, *L'organizzazione teatrale a Venezia nel Settecento, in: Ariel 1, 1, 1986, S. 59-74, hier S. 62.

47 L. Zorzi, op. cit, S. 18.

18 Goldoni erwähnt diese Gewohnheit im Vorwort zu Il vecchio bizzarro (Goldoni, V. 354), einer Komödie, die ein großer Mißerfolg war: -Compatisco il popolo, che s'è annoiato; io medesimo non ebbi la tolleranza di vedere il fine della Commedia; partii dal Teatro per sollevarmi, e per mia mala sorte, andai a terminar la sera al Ridotto. Colà sogliono ragunarsi le Maschere, terminato il teatrale divertimento, ed ivi si sentono gli elogi o i biasimi delle rappresentazioni vedute, e specialmente la prima sera delle cose nuove rappresentate; là si pronunziano i giudizi, per lo più appassionati, e le sentenze barbare ed inumane. Fu per me un caro divertimento sentirmi strapazzare nella più sonora e caricata maniera che dar si possa; e la maschera che mi copriva, mi dava campo di penetrare nei circoli senza essere conosciuto, e di godermi le ingiurie delle quali mi caricavano.e

Ein Zeugnis für das Fortdauern dieses Brauchs liefert Leandro Fernández de Moratin in den Notizen zu seiner Italienreise in den Jahren 1793-1796: $n[\ldots$ ] dopo il teatro [i nobili] si riuniscono o nei circoli o in case private, e la conversazione o il giuoco continuano tutta la notte,* Zitiert in: A. Mariutti de Sanchez Rivero, Quattro spagnoli in Venezia, Venezia, Ongania 1957 , S. 185 . 
längerfristig an die Hâuser zu binden, stand die Tatsache entgegen, daß in der Sparte Sprechtheater im Vergleich zur Oper nur wenig Geld floß. Die Eintrittspreise für Schauspielaufführungen lagen weit unter denen der Oper, und Subventionen oder Sponsorengelder kamen fast ausschließlich dem Musiktheater zugute. Im Gegensatz zu den Sängern und dem Musiktheater waren die Schauspieler und der Kontext des Sprechtheaters im sozialen und kulturellen Wertekanon kaum vertreten, da die Wertschätzung vor allem dem literarischen Text galt. ${ }^{49}$

Gegen die Jahrhundertmitte ergibt sich folgendes Bild: Als Goldoni 1734 am Teatro San Samuele im Dienst der Grimani seine Karriere als Theaterautor (»poeta $\propto$ ) der Truppe Giuseppe Imers begann, übernahm er zunächst eine ganze Reihe dramaturgischer Aktivitäten, die zuvor durch Imer, den »direttore di compagnia *, oder Schriftsteller ausgeführt wurden, die in mehr oder weniger zufälligem Kontakt zur Truppe standen; dazu zählten vor allem die Einrichtung von Stücken, auch von scenari, 50 für die Truppe, das Verfassen von Intermezzi, Tragikomödien, komischen Opern etc. Nach Goldonis Verpflichtung an das Teatro Sant'Angelo $(1748)$, das unter der Leitung des Impresario und scapocomico* Girolamo Medebach stand, wurde Pietro Chiari 1749 als Nachfolger an San Samuele engagiert. 1753 fand erneut ein Wechsel statt, der Goldoni an das Teatro San Luca ${ }^{51}$ und Chiari an Sant'Angelo brachte. $175^{8}$ stellte Grimani San Samuele der berühmten, aus Portugal zurückgekehrten Truppe Antonio Sacchis zur Verfügung, die 1762 nach Sant'Angelo wechselte und ab 1770 an San Luca auftrat. Diese Revirements innerhalb ein und derselben Stadt werfen ein Licht auf die Konkurrenzsituation, die für das Theaterleben beherrschend war und Besitzer oder Impresarien dazu zwang, bei

4 VgL Gerardo Guccini, - Dall'innamorato all'autore. Strutture del teatro recitato a Venezia nel XVIII secolos, in: Teatro e storia 2, 1987, S. $251-293$, hice v.a. S. $252-254$.

Das Problem der Einbindung der Schauspieler bzw. des Sprechtheaters in ein soziokulturelles Gefüge ist auch gegen Ende des Settecento noch nicht gelöst, wie z. B. dem Vorwort zu Teatro tragico francese ad uso de' teatri d'Italia ovvero Raccolta di versioni libere di alcune tragedie francesi [Franceseo Gritti], Bd. 1, Venezia 1776, S. $6 \mathrm{ff}$, oder Gozzis La più langa lettera, op, cit, S. $104 \mathrm{ff}$., $132 \mathrm{ff}$, zu entnehmen ist.

\$ Vgl, Gozzi, der in seinen Memoiren über diese Art von Arbeit berichtet, Mem. I, 259.

si Wie Gozzi in seinen Memoiren festhäl, gab es eine > Rangliste* der drei Hauser, wobei das Teatro San Salvatore (=San Luca) als oteatro da commedia più comodo e più favorito- (Mem. II, 219) an erster Stelle stand. Diese Präferenz bezieht sich in erster Linie auf die Ràumlichkeiten, denen die Art der Stücke jew eils angepaßt werden mußte. Vgl. N. Mangini, I teatri di Venezia, op. cit., S. 115: „C'era poi il problema della sala, che essendo più vasta delle precendenti (S. Samuele, S. Angelo), imponeva al Goldoni nuove misure per le sue invenzioni. - Daneben waren selbstverständlich die Truppen für den Erfolg der Stücke ausschlaggebend, wobei im Falle Goldonis die Truppe Medebachs an Sant'Angelo, der vorigen Stelle Goldonis, über die besseren Schauspieler verfügte. 
Veränderungen sofort nach einkunftsträchtigen Alternativen zu suchen. So konzentrierte sich der Blick in den Jahren $1748-53$ auf die Theater San Samuele und Sant'Angelo, wo sich Chiari und Goldoni erbitterte Kämpfe um die Publikumsgunst lieferten und nicht zuletzt dadurch die »Präventivzensur « der Inquisitori di Stato für Theaterstücke provozierten..$^{52}$ In diesen Jahren, die sich durch ein Zurückdrängen der Commedia dell' arte auszeichnen, hing der Erfolg weitgehend von den spoeti scritturati , den fest angestellten Autoren einer Truppe, ab, die verpflichtet waren, eine bestimmte Anzahl von Stücken pro Jahr zu liefern. ${ }^{53}$ Damit war das System der spoeti prezzolatiø etabliert, das die venezianische Theaterlandschaft bis zum Jahrhundertende charakterisieren sollte. ${ }^{54}$ Die enge Anbindung eines Autors an eine Truppe führte im Idealfall dazu, den Schauspielern Rollen »auf den Leib « zu schreiben, wie Gozzi dies für Goldoni und für sich selbst schildert, ${ }^{55}$ und damit hervorragende Besetzungen zu erreichen, andererseits bestand die Gefahr, auf die immer wieder und in besonderem Maße von Gozzi hingewiesen wird, daß die angestellten Autoren nur erfolgsorientiert produzieren und die Qualität der Stücke darunter leidet. ${ }^{56}$

52 Die Stücke mußten den Inquisitori ungedruckt in Form des Aufführungsmaterials vorgelegt werden; vgl. N. Mangini, I teatri di Venezia, op. cit., S. 115 und 128 , und Gaetano Cozzi, *Note su Carlo Goldoni, la società veneziana e il suo dirittos, in: Attz dell'/stituto veneto di scienze, lettere ed arti, $137,1978-79$, S. 14 I-157, v. a. S. $150-52$.

53 Im Teatro San Luca war Goldoni per Vertrag zu 8 Komödien pro Jahr verpflichtet; $1750 / 51$ verfaßte Goldoni für Medebach die beruhmten 16 Komodien, von denen auch in Il teatro comico die Rede ist.

54. In den goer Jahren waren beispielsweise Camillo Federici bei der "compagnia " Battaglia, Anton Simon Sografi bei der Truppe Pellandis angestellt, vgl. Angela Paladini Volterra, -Verso una moderna produzione teatrales, in: Quaderni di teatro V, 20, 1983, S. 87-144, hier S, 90-91.

3) VgL. Gozzi, Mem. I, 249; angesichts der offensichtlichen Spezialisierung der Schauspieler auf bestimmte Rollen konnte es fur die Aufführung nur von Vorteil sein, wenn die Autoren beim Schreiben bereits die besonderen Fähigkeiten der Ausführenden vor Augen hatten. Aus Mem. II, s4 geht hervor, daß bei der Vorlage der Stücke bei den srevisori* die Rollenverteilung festgelegt war, so daß diese sich auch ein Bild von der Besetzung machen und eventuellen Andeutungen in Richtung einer persönlichen Satire entgegentreten konnten.

56. Die Polemik Gozzis gegen die *poeti prezzolati«, d.h. Goldoni und Chiari, die die Commedia dell'arte aus pekuniären Gründen durch ihre geschriebenen Stücke ersetzen wollen, für die sie etwa das Zehnfache einer Bearbeitung eines scenario erhalten ( $3 \circ \mathrm{Zec}$ chini anstelle von 3; u. a. ARI, 42 und Mem. Il, 5 ; vgl. G. B. Magrini, op. cit., S. 105, der auch andere Belege anführt, sowie die Anmerkungen zu La notte critica in Goldoni, XXII, 1136 ), zieht sich durch sämtliche Texte. Daß Gozzi mit seinen Bedenken gegenuber den mpoeti prezzolati* nicht allein steht, zeigen parallele Äußerungen Francesco Grittis und Camillo Federicis (s.u.). Das System der bezahlten Theaterautoren zeitigt ganz offensichtlich Mißstände, sind die Autoren doch in zweifacher Hinsicht abhängig: von den Truppen und vom Publikum. Dagegen betont Gozzi, daß er seine Fiabe teatrali wie auch die späteren Stücke gratis an die Truppe Sacchis gegeben habe: 1 miei 
Wie weit die Kompetenz beispielsweise Goldonis an S. Luca ging, macht das an die Schauspieler gerichtete Verbot deutlich, ${ }^{\text {[di] rappresentare }}$ azione, cioè opera o commedia d'altro poeta senza previo assenso del suddetto Goldoni ${ }^{5}$ ?

Das Repertoire des Sprechtheaters war weitgehend durch die Tradition der Commedia dell'arte geprägt, die Schauspieler waren dementsprechend ausgebildet. Die von Goldoni und Chiari angestrebte Verdrängung dieser Art von Theater war von mäßigem bzw, nur zeitweiligem Erfolg gekrönt, so daß noch am Ende des Jahrhunderts improvisierte Komödien auf dem Spielplan standen. ${ }^{58}$ Nachdem Goldoni und Chiari Venedig Anfang der 6 eer Jahre verlassen hatten und das Publikumsinteresse nicht mehr auf ihre direkte Konkurrenz gerichtet war, zogen Gozzis Fiabe teatrali die Aufmerksamkeit auf sich, und in den folgenden Jahren traten zunehmend Ubersetzungen des "genre sérieux * vor allem aus dem Französischen in den Vordergrund. Bedingt durch die starke Konkurrenzsituation und die Funktion des Theaters als gesellschaftliches Ereignis kam dem Publikums-

teatrali capricci erano da me donati. [...] Divenne una necessità e una specie di legge di consuetudine dettata dalla mia amicizia il dare ogn'anno una o due rappresentazioni della mia penna arrischiata, per sostenere la fortuna di que' comici che avevano sostenute con abilità le mie poetiche fantasie." (Mem. I, 264). Wenn Gozzi seine Stücke der Truppe Sacchi schenkt, scheint auch dies weniger darauf zurückzuführen zu sein, daß er vom Vermōgen lebt und das Schreiben als aristokratischen Zeitvertreib betrachtet, als vielmehr auf das Anliegen, eine Truppe, die die Tradition der Commedia dell'arte pflegt, finanziell zu unterstützen. Aus den Memoiren Gozzis spricht ein permanenter Kampf um das schwindende Vermögen der Familie, das Carlo verwaltet, wofür er, so kōnnte man vermuten, bezahlt wurde. Von Gasparo Gozzi, Carlos alterem Bruder, ist bekannt, daß er verschiedene Amter z. B. als Sekretär des Dogen Foscarini, Sopraintendente alle stampe etc, bekleidete, um Geld zu verdienen.

F. Gritti skizziert im erwähnten Vorwort zu Teatro tragico francese ad uso de' teatr d'Italia, op. cit., S. $7^{-8}$, die schwierige Situation der angestellten Autoren, die es in vielen Fällen nicht erlaubt, auf Qualitätsmerkmale zu achten, da der finanzielle Aspekt im Vordergrund steht. Er brandmarkt diese typisch italienische Einrichtung und spielt in diesem Zusammenhang auf Goldoni an, für dessen Weggang nach Paris er ökonomische Aspekte verantwortlich macht. In den =Notizie storico-critiche" zu Camillo Federicis Komödie L'avventuriere notturno, in der Reihe Teatro moderno applaudito, Bd, 2, Venezia 1796, S. 93, wird ebenfalls explizit auf die Problematik der mpoeti prezzolati* bzw. "stipendiati- hingewiesen: "Tranne però due soli difetti [d. i. - il romanzesco und der Titel] (cui un autore stipendiato, nell'odierna comune tendenza al meraviglioso, rade volte può sfuggire, poichè egli è costretto di contemplar più il vantaggio de' capocomici, che le regole de' gran maestri), noi non sappiamo scorgerne verun altro di essenziale in questo componimento. *

57 S. G. Guccini, op.cit., S, 287.

58 S. dazu neue Dokumentationen und Untersuchungen zum Repertoire, wie z. B. M. L. Pagnacco, s Squarzo degli utili del teatro per le recite relative degli Autunni e Car-

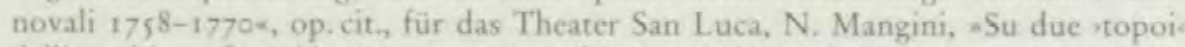
dell'autobiografia goldoniana*, op. cit., oder A. Paladini Volterra, op. cit., sowie zahlreiche verstreute Bemerkungen. 
erfolg eine entscheidende Bedeutung zu - blieb das Publikum aus, waren die Truppen finanziell gefährdet. ${ }^{59}$

Dieses Publikum war in Venedig seit langem ein gemischtes. Traditionell wurden die Logen an Adlige vermietet, was den Besitzern der Theater eine relative finanzielle Sicherheit bot, sie allerdings auch von deren Wohlwollen abhängig machte. Die Plätze im Parkett wurden verkauft oder kostenlos abgegeben, so daß sich folgender Publikumskreis zu den Aufführungen einfand: "L'alta borghesia delle aziende e degli uffici, la borghesia minore delle botteghe, qualche rappresentanza degli strati popolari (per lo più smanuali« e domestici), cui si aggiungevano gruppi sempre più numerosi di visitatori forestieri, attirati a Venezia dal credito delle sue istituzioni e dalla fama dei suoi divertimenti (che una accorta propaganda mirava a divulgare in tutta Europa), trovavano progressivamente il loro posto a teatro, accanto al rango dei patrizi, degli ambasciatori, degli ospiti ufficiali. ${ }^{60}$ Bei den Theaterbesuchen stand weniger der $*$ Kunstgenuß $*$ im Vordergrund als vielmehr die gesellschaftliche Begegnung und das Divertissement. Die Zeugnisse über das unziemliche Verhalten des Publikums - vor allem der Patrizier - im Theater sind zahlreich: in Goldonis Il teatro comico klagen die Schauspieler beispielsweise über das Desinteresse am Bühnengeschehen, den Lärm, die Unordnung, die vor allem in den Rängen herrschen, in Chiaris Commedie da camera äußert sich der Impresario folgendermaßen: "Che importa a noi, che in Teatro si mangi, si beva, si discorra, si fischj, o si dorma? Vengano dei soldi alla porta, e faccia ognuno che vuole, quando ha pagato $*{ }^{61}$ Das Theater in Venedig diente der Unterhaltung weiter Bevölkerungskreise und lebte von einer engen Verbindung zwischen Autoren, Impresarien, Schauspielern und Verlegern, die die gedruckten Ausgaben besorgten. ${ }^{62}$ In diesem Kontext spielte das Kriterium der Neuheit der Stücke eine große Rolle: Chiari, Goldoni,

59. So berichtet z. B. Gozzi von einer 22-tägigen Schließung des Theaters S. Salvatore wegen dringender Reparaturen, was für die Truppe Sacchis einen Verlust von 22 Auffuihrungen bedeutete und diese in große finanzielle Schwierigkeiten brachte; Mem. 1, 345.

60 L. Zorzi, sI teatri di Venezia «, op. cit., S. 17.

6) Pietro Chiari, Commedie da camera ossia Dialoghi familiari, Bd. 1, Venezia 1770, S. XIXII.

Auch Baretti mokiert sich in Les Italiens, ou Maeurs et coutumes d'Italie, op. cit, übet das ungezogene Publikumsverhalten, und in Antonio Piazzas Roman Giulietta ovvero seguito dell'Impresario in rovina, Venezia 1784 , ist ebenfalls davon die Rede, daßs das Publikum aus den Logen ins Parterre spuckt. Neben diesen literarischen Zeugnissen finden sich auch Belege in Reiseberichten $u$.ä. $\mathrm{Daß}$ das Phänomen nicht auf Venedig begrenzt war, geht aus G. Guccinis Einfuhrung zu Il teatro italiano nel Settecento, Bologna, Mulino 1988, S. 2 off. hervor.

6.2 Auf Goldonis Bemuhungen um möglichst zahlreiche gedruckte Editionen wurde bereits hingewiesen. 
Gozzi und andere weisen immer wieder darauf hin, daß der saspetto di novità « für den Publikumszulauf entscheidend sei. Nüchtern stellt Gozzi fest, $=$ Il successo fa buono il trattenimento* (RI, I6) und verweist damit auf die Praxisferne der Kontroverse, die in den theoretischen Schriften um die Relevanz des Publikumsurteils ausgetragen wird. Ob das Urteil der Gebildeten im Theater zählt oder das der Menge ausschlaggebend ist, spielt in einer vom Kommerz bestimmten Theaterlandschaft eben so wenig eine Rolle wie das Argument, die Commedia dell'arte richte sich an die niederen Volksschichten. Solange das Publikum kommt und bezahlt, wird dem Verlangen nach ständig Neuem und dem raschen Geschmackswandel Rechnung getragen, damit eben diesem Publikum »quel diletto sommo e quell'ultimo incanto che si genera da ciò che in Venezia si è sempre chiamato il Teatrale ${ }^{63}$ zuteil werde.

\subsection{Von alten und neuen Theaterformen auf der Bübne}

Mit Goldoni, so könnte man zugespitzt sagen, verlagert sich die Auseinandersetzung um das Theater vom Buch auf die Bühne. In der zweiten Hälfte des Settecento verliert die theoretische Debatte der Intellektuellen und Gelehrten über Reformen und Modelle an Gewicht, und es sind die Theateraufführungen selbst, von denen neue Impulse ausgehen, die dann in Begleittexten der gedruckten Editionen reflektiert werden, ${ }^{64}$ wobei sich der Schwerpunkt von der Tragödie auf die Komödie verlagert. Die autoritär-normativ bestimmte Theaterdiskussion findet nun ihre Fortsetzung in Form eines pragmatischen, oft pamphletären Diskurses, der seinen Ausgang meist von konkreten Aufführungen und einzelnen Stücken nimmt. ${ }^{65}$ Vielfach werden in den Texten Stereotype der vorausgehenden Debatte aufgegriffen, Argumente vereinfacht und - auf Gemeinplätze und Schlagwörter reduziert - neuen Zwecken dienlich gemacht.

Goldoni wie auch Chiari und später Gozzi schreiben nicht für Akademien und ein literarisch gebildetes Publikum, sondern in institutioneller Verankerung (Goldoni, Chiari) oder loser Verbindung (Gozzi) für Truppen öffentlicher Theater, sind somit auf Erfolg bedacht und bemüht, sowohl den Schauspielern als auch dem gemischten Publikum gerecht zu

6) S. Maffei, $=$ Risposta alla lettera del Signor di Voltaire*, in: ders., De' teatri antichi e moderni e altri scritu teatrali, op. cit., S. 92.

4 Sowohl Goldonis als auch Chiaris Stücke erschienen wenige Jahre bis unmittelbar nach ihrer Erstauffuhrung in Werkausgaben. Für die Aufführungen in Venedig lagen noch keine gedruckten Texte vor.

45 Vgl, Kap. 1 und Kap, 2.2. 
werden. Bei aller Praxisorientiertheit ist vor allem Goldoni bestrebt, mit seinen Komödien literarische Dignität zu erlangen und so endgültig und exemplarisch die Kluft zwischen literarischen Komödientexten und sowohl spielbaren als auch publikumswirksamen Stücken zu überwinden. Er konstruiert seine Reform $\propto$ in autobiographischen Texten und Vorworten teleologisch als Projekt, das in verschiedenen Etappen zum Ziel der "buona commedia " führt. ${ }^{66}$ Wichtige Bezugspunkte in der Theatergeschichte des 18. Jahrhunderts, wie zum Beispiel Luigi Riccoboni, der als einer der wenigen die Aufführungspraxis in seine Reformpläne einbezog, werden nicht genannt, so daß die Einmaligkeit und Originalitä $t^{67}$ der eigenen Leistung umso mehr hervorsticht. Im folgenden seien die Grundzüge von Goldonis Position anhand des Vorwortes zur ersten Komödien-Ausgabe bei Bettinelli und der metatheatralischen Komödie Il teatro comico, beide von 1750 , dargestellt. ${ }^{68}$

\section{Wegweiser zu einer neuen guten Komödie Goldonis "Prefazione"}

In demonstrativem Gegensatz zu gängigen Argumentationsstrategien wie etwa in Martellos Vorwort zu Che bei pazzi weist Goldoni im Vorwort gleich zu Anfang darauf hin, daß er die Leser enttäuschen müsse, wenn sie nuna Prefazione erudita e compiuta erwarteten, denn er wolle weder sin tuono pedantesco proferir per nuovi oracoli le cose tante volte dette e ridette da tanti ${ }^{69}$ noch seine eigenen Komödien loben, indem er ihre Übereinstimmung mit den Regeln belege. Stattdessen zeichnet er den von ihm bisher eingeschlagenen Weg nach, auf den ihn sein »Genio«, »quella interna forza, che mi voleva tutto alla Drammatica Poesia $x^{70}$ gerufen hat, um ein »risorgimento $\star^{71}$ der italienischen Komödie herbeizuführen. Auf diesem Weg zählen nicht Regeln, Autoritäten und anerkannte Vorbilder,

66 Goldoni, 1, 716. Zur bewußten Konstruktion des Reformprojekts vgl. z. B. die bereits angefuhrten Artikel von P. Vescovo, Le riforme nella riformar, op. cit., und $*$ La riforma nella tradizionee, op. cit., sowie Bartolo Anglani, $\rightarrow$ Dal genio al destino. Le prefazioni, le dediche e l'valtras autobiografia», in: Ariel 7, 3, 1992, S. 17-40, und Anna Scannapieco, "Alla ricerca di un Goldoni perduto: Osmano re di Tunisie, in: Quaderni Veneti 20, 1994, S. 9-53.

67 Bezeichnenderweise nennt Gozzi Goldoni in La tartana "Originale*.

68 Auf diese Texte, bis hin zu einzelnen Formulierungen, beziehen sich weite Teile von Gozzis Polemik gegen Goldonis Reform.

${ }^{69}$ s Prefazione dell'autore alla prima raccolta delle commediea, in: Goldoni, III, 761.

70 Ebd., S. 765 .

71 Ebd., S. 767. 
sondern die Beobachtung in allen möglichen Situationen, sei es auf Reisen, zu Hause, im Alltag, in der Freizeit, die einen reichen Vorrat an Material ergeben, das für das Theater bearbeitet werden kann. Damit läßt Goldoni die theoretischen Diskussionen hinter sich, die seit Anfang des Jahrhunderts keine unmittelbare praktische Umsetzung auf der Bühne erzielen konnten, und stellt sein Komödienschaffen unter die berühmt gewordene Dichotomie von $*$ Mondoe und $\times$ Teatro $*{ }^{72}$ Mit der Begründung seiner Reformbestrebungen steht er allerding ganz in der Tradition der Theaterdebatte, indem er den Topos der Dekadenz des italienischen Theaters als Anlaß für notwendige Reformen aufnimmt und den desolaten Zustand des komischen Theaters beklagt:

Ora fu in me questo Genio medesimo, che rendendomi osservator attentissimo delle Commedie, che su vari Teatri d'Ttalia già diciotto o venti anni in qua rappresentavansi, me ne fece conoscere e compiangere il gusto corrotto, comprendendo nel tempo stesso, che non poco utile ne sarebbe potuto derivare al Pubblico, e non iscarsa lode a chi vi riuscisse, se qualche talento animato dallo spirito comico tentasse di rialzare l'abbattuto Teatro Italiano. Questa lusinga di gloria finì di determinarmi all'impresa.

Era in farti corrotto a segno da più di un secolo nella nostra Italia il Comico Teatro, che si era reso abbominevole oggetto di disprezzo alle Oltramontane $\mathrm{Na}$ zioni. Non correvano sulle pubbliche Scene se non sconce Arlecchinate, laidi e scandalosi amoreggiamenti e motteggi; favole mal inventate, e peggio condotte, senza costume, senza ordine, le quali, anziché correggere il vizio, come pur è il primario, antico e più nobile oggetto della Commedia, lo fomentavano, e riscuotendo le risa dalla ignorante plebe, dalla gioventù scapestrata, e dalle genti più scostumate, noia poi facevano ed ira alle persone dotte e dabbene [... $]^{73}$

Diese Darstellung der Situation zeugt von der Vertrautheit Goldonis mit den Argumenten der bisherigen Debatte, die er hier konzentriert wiedergibt und zu seinen eigenen macht. Nicht nur die uneingeschränkte Verurteilung der "Arlecchinate , das heißt der improvisierten Komödien, die im Verlauf des Textes unterstrichen wird, ${ }^{74}$ sondern auch die Zuordnung des Lachens zum ungebildeten Volk wie die Auffassung, das höchste Ziel der Komödie sei es, die Laster zu korrigieren, sind topisch. Auf dieser längst legitimierten Negativfolie zeichnen sich die Bestrebungen Goldonis deutlich ab, zumal die unterschiedlichen Versuche, das Niveau des komischen 'Theaters zu heben, sei es durch spanische Komödien, sei es durch Übersetzungen aus dem Französischen, in einem kurzen Abschnitt als

72 In Goldonis Text sind beide Termini konsequent typographisch bervorgehoben.

7 Ebd., S. $764-765$.

74 Ebd., S. 773 : -sofferivano sul Teatro impropricta, inczie, Arlicchinate [sic] da mover nausea agli stomachi più grossolanie. 
erfolglos abgetan werden. Auch das Maschinentheater, aufwendige Ausstattungen und zuletzt die Mode der Intermezzi konnten das Publikum nicht auf Dauer binden. Dagegen wird der Bühnenerfolg von Tragödien etwa des Venezianers Antonio Conti, von Maffeis Merope oder Übersetzungen Gasparo Gozzis aus dem Französischen sowie der „Drammi composti per la musica von Zeno und Metastasio hervorgehoben und als * maggior vergogna della Commedia, come la più convincente prova della estrema sua decadenza e $^{75}$ gewertet. Dringlicher kann die Notwendigkeit eines Eingreifens in dieser trostlosen Situation kaum zutage treten, doch bedarf es noch etwas Geduld: »Io frattanto ne piangea fra me stesso, ma non avea ancora acquistati lumi sufficienti per tentarne il risorgimento «. Dann jedoch nehmen die Rettungsversuche Gestalt an, und auf der Basis der Erkenntnis, $»$ che, sopra del maraviglioso, la vince nel cuor dell'uomo il semplice e iI naturale ${ }^{7}{ }^{76}$ beginnt der langsame Reifungsprozeß $\beta$ des Reformvorhabens. Über erste Versuche mit Intrigenkomödien nach spanischem Vorbild und einer noch nicht vollständig ausgeschriebenen Charakterkomödie, Momolo cortigiano (Momolo cortesan), wird 1743 ein wichtiges Etappenziel erreicht: La donna di garbo, "la qual io chiamo mia prima Commedia, $[\ldots]$ giacché in fatti è la prima ch'io abbia interamente scritta«, ${ }^{7} \mathrm{Ab} 1748$ an Sant'Angelo als Theaterautor der Truppe Girolamo Medebachs engagiert, der malla testa di valorosi Comici va da' più celebri Teatri d'Italia spargendo ne' popoli, col mezzo di costumate Commedie, l'istruzione e il diletto «, sieht Goldoni seine Bemühungen »per ricondurre sul Teatro Italiano il buon costume e 'l buon gusto della Commedia $\alpha^{78}$ mehr und mehr von Erfolg gekrönt, und dies eben nicht mit Komödien, die sich an vorgängigen oder zeitgenössischen Texten orientieren, sondern primär am Studium der beiden Bücher Mondo und Teatro. Daß Goldoni in diesem Zusammenhang ständig auf die Buchmetapher zurückgreift, andererseits aber »esperienza « und »osservazione in den Mittelpunkt rückt, mag ein Indiz dafür sein, daß in der Theaterdiskussion die ideologische Aufwertung von Erfahrung und Beobachtung noch immer wenigstens

75. Ebd., S. 767. Interessant ist, daß Goldoni im Hinblick auf die Tragödic sehr venedigspezifisch argumentiert, sind doch Conti wie G. Gozzi Paduaner bzw. Venezianer und werden vor allem auf venezianischen Bühnen aufgeführt: Antonio Conti (1677-1749) war hauptsächlich durch seine rômischen Tragödien und die Dissertazion sopra la Ragion poetica di Gravina bekannt. Auch Merope steht insofern in diesem Kontext, als der Auffuhrungserfolg in Venedig als vil primo vero trionfo in Italia d'un'opera letteraria sulle pubbliche scenea gilt ( $G$. Ortolani, $>$ A ppunti per la storia della riforma-, op. cit., S. 13).

76. Goldoni, III, 767 .

77 Ebd, S, 768 .

78 Ebd., S. 769 . 
der metaphorischen Legitimation durch die Schrift bedurfte. Liefert das Studium des ersteren das Material für Personal und Handlung der Komödien, können dem Buch des Theaters Kriterien für die Auswahl und Gestaltung entnommen werden, so daß ograziose ed istruttive Commedie ${ }^{79}$ entstehen, die dem Publikum angemessen sind und dem nationalen Geschmack entsprechen. Die Abhängigkeit von der Tradition, von anderen Texten, seien es theoretische, seien es dramatische, wird in der Argumentation möglichst weit aus dem Blickfeld genommen, um die Unmittelbarkeit des Verhältnisses von Wirklichkeit und Bühnengeschehen ins Zentrum zu rücken. Diese Darstellung des Produktionsprozesses erweist sich jedenfalls im Hinblick auf die frühen Komödien Goldonis in zweierlei Hinsicht als fragwürdig, da zum einen zahlreiche Stücke entweder auf improvisierten Komödien oder auf literarischen Vorlagen beruhen und damit nicht der unmittelbaren Beobachtung der Umgebung entspringen, zum anderen gerade die Masken aus der Commedia dell'arte aufgrund ihres theatralischen Effekts nicht sofort eliminiert wurden, sondern die verpönten *Arlecchinate «, wenn auch domestiziert, weiterlebten. Letztlich verzichtet Goldoni denn auch nicht gänzlich auf eine Rückversicherung durch Autoritäten, stellt er doch fest, daß das, was ihn seine sgran libri, Mondo e Teatro « gelehrt hätten, mit den wichtigsten Vorschriften der ngran maestrix und den Ausführungen durch *eccellenti Poeti ${ }^{80}$ weitgehend übereinstimme.

\section{Wegweisendes Metatheater: "Il teatro comico"}

Die im selben Jahr entstandene Prosakomödie Il teatro comico ist das dramatische Gegenstück zum Vorwort der Bettinelli-Edition, von Goldoni als sprefazione [...] alle mie Commedie« und »une Poétique mise en action ${ }^{81}$ bezeichnet, ein metatheatralisches Drama par excellence, das im Theater spielt, in dem die Schauspieler Schauspieler darstellen, die sich über das Theater unterhalten und verschiedene Stücke probieren. Demonstrativ beendet der *capocomico* die Probe auf der Bühne mit einer Replik, die sich ebenso an seine Schauspieler wie an das Publikum richtet: scredo che ricavare si possa qual abbia ad essere, secondo l'idea nostra, il nostro Teatro Comico $(\mathrm{III}, 1 \mathrm{1})$. Deutlicher noch als im argumentativen Text treten hier die Unterschiede zwischen den $\nsim$ commedie antiche*

E Ebd., S. 769 .

${ }^{60}$ Ebd, S. 772. Namen nennt Goldoni nicht.

81 So in den Memoiren, Goldoni, I, 267. 
oder "commedie dell'arte « und dem "nuovo stile $(I, 2)$ hervor sowie die konkreten Schwierigkeiten, die die Umsetzung der Reform hinsichtlich der Schauspieler bereitet. Die in der Improvisation versierten Schauspicler müssen nun nicht nur vorgegebenen Text auswendig lernen - eine ganz neue, ungewohnte Aufgabe -, sondern auch ihre Art zu rezitieren den neuen Gegebenheiten anpassen. Nicht mehr schwülstig, übertrieben sollen sie sprechen, sondern natürlich, in einem "stile familiare, naturale e facile, per non distaccarsi dal verisimile« (II , 2). Die üblichen Sprachspiele, rhetorische Figuren und Vergleichsketten müssen einem »discorso regolato e naturale $\approx(\mathrm{III}, 2)$ weichen, und das s recitare naturalmente $(\mathrm{III}, 3)$ als eines der wichtigsten Gebote erlaubt die Verwendung von Versen in der Komödie nur noch unter der Bedingung, daß man sie als Zuhörer nicht als solche wahrnimmt. Unter diesen Umständen können die Schauspieler ihre *generici๔ verbrennen, wie es Placida bereits getan hat, denn sie gehört zu den "recitanti, che sono dal moderno gusto illuminate $(\mathrm{II}, 2)$, und sie vertraut dem Versprechen Orazios, für all diese Umstellungen und Mühen winke den Schauspielern ein größeres Ansehen. Gesangseinlagen wird es nicht mehr geben, Monologe nur noch, um sein Inneres auszudrücken, und keinesfalls, um narrativ den Handlungsgang zu erläutern oder voranzubringen. Unwahrscheinliche Ereignisse und unschickliche Situationen, wie sie in den "commedie all'improvviso * gang und gäbe sind, ${ }^{82}$ sind in den Charakterkomödien abgeschafft, die Einheit der Handlung wird gewahrt. Schlechte, böse Charaktere sollen auf der Bühne höchstens als Nebenfiguren auftreten, und dem "cattivo carattere $\propto$ ist ein "carattere virtuoso gegenüberzustellen, »perché maggiormente si esalti la virtù, e si deprima il vizio« $(\Pi, 3)$. Die Kritik hat sich auf das Allgemeine, nicht auf das Individuelle, Einzelne zu richten und darf nicht zur Satire werden. ${ }^{83}$ Wie anspruchsvoll das italienische Publikum ist, geht aus dem Vergleich mit dem französischen hervor, das sich bei den Charakterkomödien mit einer einzigen wirklichen Charakterfigur begnügt, während die Italiener sehr viel mehr fordern, wie Orazio Lelio erklärt:

I nostri Italiani vogliono molto più. Vogliono che il carattere principale sia forte, originale e conosciuto; che quasi tutte le persone, che formano gli episodi, siano altrettanti caratteri; che l'intreccio sia mediocremente fecondo d'accidenti e di novità. Vogliono la morale mescolata coi sali e colle facezie. Vogliono il fine ina-

82 Als Negativbeispiele werden Szenen erwahnt, in denen Frauen aus dem Haus auf die Straße gerufen werden oder Diener ihre Herren verprügeln $(\mathrm{I}, 1 \mathrm{x})$.

8 Damit kritisiert Goldoni indirekt Komödien in der Art Giglis und Nellis, die einen stark satirischen Charakter aufweisen, worauf die Autoren in den Vorworten selbst hinweisen. 
spettato, ma bene originato dalla condotta della commedia. Vogliono tante infinite cose, che troppo lungo sarebbe il dirle, e solamente coll'uso, colla pratica e col tempo si può arrivar a conoscerle e ad eseguirle. $(\mathrm{II}, 3$ )

Daß dem Publikum solch präzise Vorstellungen von einer idealen Komödie in den Mund gelegt werden, ist erstaunlich, hat es doch bisher vor allem mit »commedie all'improvviso* vorlieb nehmen müssen, an denen Kriterien dieser Art wohl kaum entwickelt werden konnten. Im Rahmen des Erzichungsprogramms zum wbuon gusto stellen derart ausgereifte Anforderungen an die Komödie freilich ein wichtiges Argument für die postulierte Wechselwirkung von sbuon costume und sbuon gusto auf der Bühne und beim Publikum dar.

Auch in Il teatro comico werden die Stationen des bisherigen Reformverlaufs aufgerufen, ausgehend von den inzwischen inakzeptablen *commedie a soggetto", wie sie der Dichter Lelio präsentiert, über eine "piccola farsa $\propto$ zu den $\nsim$ commedie di carattere $\propto$. Die »piccola farsa $\propto$ rechnet der Autor, der 16 Komödien in einem Jahr geschrieben hat (d. h. Goldoni) jedoch nicht zu seinen eigentlichen Komödien, da sie nur aufgrund der Besetzung der Truppe entstanden, der geeignete Darsteller für ernste Rollen fehlten. ${ }^{84}$ Auf die Frage Lelios, $"$ Ma presentemente che cosa si usa? $\propto$ antwortet Anselmo, der den Brighella spielt, kurz und bündig *Commedie di carattere « (II, 1) und begegnet dem Einwand Lelios, er habe nicht geglaubt, daß den Italienern solche Komödien gefallen könnten, folgendermaßen: ^Anzi l'Italia adesso corre drio unicamente a sta sorte de commedie; e ghe dirò de più, che in poco tempo ha tanto profittà el bon gusto nell'animo delle persone, che adesso anca la zente bassa decide francamente sui caratteri e sui difetti delle commedie $\alpha,{ }^{85}$ Die angestrebte Erziehung des Publikums zum ^buon gusto* ist also schon so weit gediehen, daß es nicht

14 Dieses Problem sollte noch Jahre spater aktuell sein, wie aus Äußerungen Gozzis über die Sacchi-Truppe hervorgeht. So klagr Gozzi beispielsweise im Vorwort zu Il re cervo: - [... tuttochè la Truppa Sacchi in quel tempo, affidando tutta la sua fortuna al caricato ridicolo delle valenti Maschere, fosse assai sfornita di Comici capaci a sostener colla necessaria compostezza, sentimento, e bravura, le parti serien (Col. I, 327).

ns Wie bei einigen anderen Passagen auch, besteht hier eine weitgehende Ubereinstimmung mit dem Bettinelli-Vorwort, in dem es bezüglich möglicher Kritik an den Komódien beißt: =Che se alle mie Commedie ne sono state fatte, o se ne faran tuttavia in avvenire, io trarrò quindi un sicuro argomento che degne sieno di osservazione, e però fornite di qualche merito. In fatti, se quelli che o due o tre anni fa sofferivano sul Teatro improprietà, inezie, Arliechinate da mover nausea agli stomachi più grossolani, son divenuti al presente cosi dilicati, che ogn'ombra d'inverisimile, ogni picciolo neo, ogni frase o parola men che toscana li turba e travaglia, io posso senza arroganza attribuirmi il merito d'aver il primo loro ispirata una tal dilicatezza col mezzo di quelle stesse Commedie che alcuni di essi indiscretamente, ingratamente, e fors'anche talvolta senza ragione si sono messi, o si metteranno a lacerare. “(Goldoni, I, 773 ). 
nur die Aufführungen der neuen Komödien mit Genuß besucht, sondern sich auch für fähig hält, über diese kennerhaft zu urteilen. In merkwürdiger Weise kontrastiert allerdings das Sozialverhalten des Publikums im Theater mit diesem reifen ästhetischen Urteil, denn wie die Schauspieler bemerken, wird von den Balkonen ins Parterre gespuckt, gesungen, gepfiffen, gegähnt und in den Rängen derart Lärm gemacht, daß ihnen das Rezitieren erheblich erschwert wird und noch viel Geduld erforderlich ist, um die gewünschte Ordnung herzustellen, sper perfezionare il buon ordine de' teatri ${ }^{\prime}(I I, I 0)$. Überhaupt bedarf das gesamte Projekt, das komische Theater zu erneuern, eines langsamen, schrittweisen Vorgehens, sowohl im Hinblick auf das Publikum als auch auf die Schauspieler, wie Orazio im Dialog mit Eugenio, dem zweiten Liebhaber, erläutert. Auf Eugenios Frage, ob nun die "commedie all'improvviso * vollständig abgeschafft würden, antwortet Orazio: „Intieramente no; anzi va bene che gl'Italiani si mantengano in possesso di far quello che non hanno avuto coraggio di far le altre nazioni $(\Pi, 10)$, und spricht den begabten Schauspielern für ein gekonntes "parlar a soggetto» höchstes Lob aus. Auch für die vollständige Entfernung der Masken in den Charakterkomödien hält Orazio den Zeitpunkt noch nicht gekommen. Wenn auch das Publikum nicht mehr ins Theater geht, um ausschließlich über die Masken zu lachen, sondern inzwischen bereit ist, den ernsten Rollen Gehör zu schenken, se godono le parole, e si compiaccono degli accidenti, e gustano la morale, e ridono dei sali e dei frizzi cavati dal serio medesimo* (II,10), sieht es doch noch immer gerne die Masken auf der Bühne, und es wäre unklug, dagegen anzugehen, sofern die Masken gut integriert und das Lächerliche mit dem Ernsten verbunden sind. Wenn Lelio gegen Ende der Komödie feststellt, II signor capo di compagnia mi va dicendo che il teatro si è riformato, che ora si osservano tutte le buone regole (III,8), scheinen die immer wieder angedeuteten oder ausgeführten Schwierigkeiten in den Augen Orazios überwunden und Stücke, Schauspieler und Publikum sich derart verändert zu haben, daß die Erfüllung des Wunsches, s[di] rendere un giorno la riputazione al Teatro Italiano * (III,11) nicht mehr lange auf sich warten lassen dürfte.

Eine so umfassende, praxisorientierte Theater- und Komödienreform, die nicht nur die Stücke, sondern auch die Darsteller und das Publikum öffentlicher Theater im Auge hat, war bislang weder angestrebt noch unternommen worden. Im Namen der Moral und im Hinblick auf Belehrung und Erziehung des Publikums wird die Commedia dell'arte als schauspielerische Tradition wie als Teil des Repertoires verabschiedet und durch die "commedia di carattere" ersetzt, die sich an der Wirklichkeit orientiert und den Kriterien der Einfachheit und Natürlichkeit entspricht. 
Die Berufung auf Mondo und Teatro als Grundlagen für die neuen Charakterkomödien zeigt, daß nun - im aufklärerischen Kontext ${ }^{86}$ - auch im Bereich des Theaters Beobachtung und Erfahrung einen neuen Stellenwert erhalten und es opportun erscheint, die Tradition samt den autoritativen Texten, seien es poetologisch-ästhetische, seien es dramatische, weit in den Hintergrund zu rücken. Dieses Reformprogramm und vor allem die von Goldoni in zahlreichen Vorworten und den Memoiren unternommene Darstellung und Verteidigung, die den Unterschied zur dekadenten Commedia dell' arte betont, die Nachahmung der Alltagswirklichkeit und den moralischen Anspruch in den Vordergrund rückt und die Perfektibilität der Komödie und des Publikumsgeschmacks und -verhaltens parallelisiert, blieb nicht unwidersprochen.

\section{Alternative Wege \\ Gozzis Pladoyer für die Commedia dell'arte}

Aus Carlo Gozzis Sicht stellt sich die Lage etwas anders dar. Im ausführlichen Vorwort zu seiner letzten, 1765 s uraufgeführten Fiaba teatrale, Il re de' genj, unterstreicht er, daß die Zeit der literarischen Komödien für ein auserwähltes Publikum längst vorüber sei, ${ }^{87}$ daß das Hauptanliegen eines Theaterschriftstellers darin bestehen müsse, ein Theater einige Abende lang mit einem Werk zu füllen ("far popolare un Teatro parecchie sere ad un'opera prodotta ; Col. III, I 28) und fährt dann fort: *Credo, che la condiscendenza de' Principi conceda le adunanze teatrali, per tenere i lor popoli divertiti con de' specchj morali, e gioviali di vicende umane rappresentate, nelle quali però la dimostrazione del bene premiato, e quella del male, e degli errori puniti, ammaestri, per quanto è possibile.« Diese kleine Einschränkung am Ende ist signifikant für Gozzis Skepsis gegenüber einem Programm, das Nützlichkeit, Belehrung und Besserung in den Mittelpunkt des Theaterereignisses stellt und aus dieser Perspektive gegen die »commedie all'improvviso $*$ und die Masken angeht. Gozzi stimmt

8t. S. dazu grundsätzlich Eirnst Cassirers erstes Kapitel =Die Denkform des Zeitalters der Aufklärung*, in: Die Philosophie der Aufklärung, Hamburg, Meiner 1998, v. a. S. 8-9. Es ist in diesem Zusammenhang bemerkenswert, daß Goldoni tatsächlich, dem aufklärerischen Diskurs folgend, *a forza di osservazioni e di sperienza $*$ zu seinem *particolare sistema* (-Prefazione*, Goldoni, III, 772 ) kommt.

87 -Se riguardiamo al Teatro, il dire: a me basta, che un'opera mia piaccia a pochi dotti, è un rifugio di molti infelici scrittori teatrali, che spesso hanno delle lusinghe fallaci, suggerite loro dall'amor proprio. Ciò sia detto senza offesa delle composizioni teatrali regolate ottime, c che l'universale approvazione, difficilissime, rarissime, e non mai bastevoli a sostenere i molti spettacoli di tutto l'anno de'nostri Teatri." (Col. III, 128-129). 
nicht in die topische Klage über die Dekadenz des italienischen Theaters ein, für die im wesentlichen die Commedia dell'arte als Verantwortliche ausgemacht wird, sondern geht zunächst von einer grundlegenden Differenzierung zwischen zwei verschiedenen Arten von Theater in zwei völlig unterschiedlichen Kontexten aus:

L'Autore della Storia critica de' Teatri antichie moderni [d. h. Maffei], che da valente, fedele italiano veridico sostiene, che l'Italia fu la prima a comporre una Drammatica sublime, e comica semplice famigliare, e regolare, ad imitazione de Greci, e de' Latini, deve anche sapere, che cotesta Drammatica regolare in Italia, fu composta, ed esposta soltanto ne' Teatrini privati delle sale de' gran Signori, o di alcune Accademie, alle occasioni di maritaggi illustri, o di nascite Principesche, o di incoronazioni, o di compleannos [sic], di Monarchi, o di simili festività. Si può vedere facilmente, che sempre ci fu in Italia un Teatro pubblico aperto all'universale, chiamato dal detto erudito storico: Teatro istrionico, buffonesco, di bassa comica non considerabile da' supposti abitanti del Parnaso, e si può vedere facilmente la immensa moltitudine de' Teatri pubblici che furono edificati, e aperti all'universale nel trascorrere degl'anni, e dopo i sopra accennati principi nell'Italia. (LL, 100)

Die Kritik an der traditionellen Darstellung der Theatergeschichte zielt vor allem auf die mangelnde Berücksichtigung des Zusammenhangs von Stückwahl, Aufführungsart und Aufführungskontext. ${ }^{88}$ Gozzi hingegen unterscheidet zwischen regelkonformen Stücken für kleine private Theater, die nur zu bestimmten Anlässen bespielt werden, und öffentlichen, jedem zugänglichen Aufführungen von Stücken, die, wie ihre Gegner sagen, durch eine niedere Komik charakterisiert sind. Da die Zahl der öffentlichen Theater in den letzten Jahrzehnten merklich zugenommen hat, ist davon auszugehen, daß der Erfolg dieses sogenannten steatro istrionico, buffonesco $\propto$ beträchtlich ist und die Kritik dem Publikumsinteresse entgegensteht. Trotz der klaren kontextuellen Trennung geht Gozzi von einer unvermeidlichen Konkurrenz zwischen den beiden "generi colto e popolare $(A R I, 30)$ aus, ohne einem der beiden den Vorzug zu geben, da sie sich in seinen Augen durch ihre Unterschiedlichkeit einem sinnvollen Vergleich entziehen. Wenn er die „Commedia Italiana improvvisa, detta dell'Arte als "genere popolare bezeichnet, bezieht sich "popolare " nicht

88. Wie ein fernes Echo (der Text datiert von 1801) auf Goldonis Reverenz an Zeno und Metastasio als Opernreformer und Vorbilder für die cigene Komödienreform im Vorwort zur Bettinelli-Edition von 1750 , die in den 1787 erschienenen Memoiren wiederholt wird ("L'Italie doit à ces deux illustres Auteurs la réforme de l'Opéra. On ne voyoit, avant eux, dans ces Spectacles harmonieux, que des Dieux, et des diables, et des machines, et du merveilleux ; Goldoni, 1, 187), klingt Gozzis abwertendes Urteil über sla Drammatica sublime composta per la musica, che a me parve sempre un'abbreviatura di metri poetici teatrali<, wobei er einschränkend hinzufügt, "e venero tuttavia Apostolo Zeno, Pietro Metastasion (LL, ror). 
auf untere soziale Schichten; "popolare « heißt „populär « im Sinn von allgemein beliebt, betont Gozzi doch immer wieder, daß das Publikum in öffentlichen Theatern alle Schichten umfaßt und dieses in gleicher Weise und Zusammensetzung Aufführungen improvisierter und geschriebener Stücke besucht. Polemisch rückt er die traditionelle Argumentation zurecht, nach der die scommedie dell'arte" nur vom Volk, die ausgeschriebenen, regelmäßigen Komödien dagegen vom gebildeten Publikum goutiert werden: "non appello con ebbra sfacciataggine ígnorante plebaglia quell'Uditorio nobile, che vedo con gli occhi miei proprj alla Commedia improvvisa, ed alla premeditata essere il medesimo $\left(\mathrm{RI},{ }_{3}\right.$ ). Im Hinblick auf eine regelkonforme Perfektion geschriebener Stücke einerseits und eine auf Publikumserfolg zielende Theaterpraxis andererseits, konstatiert Gozzi eine unüberwindliche Unvereinbarkeit: »O si desidera di comporre un'opera perfetta alle menti educate e durabile in un libro all'immortalità, o si vuol cercar la fortuna de' meschini Italiani Comici nell'opere, che si compongono, col divertimento morigerato della nostra nazione. (RI, I5). Unter diesem Aspekt kommt der Commedia dell'arte eine wesentliche Bedeutung zu, ist sie doch bis zum heutigen Tag $\gg$ la piú utile alle Comiche Italiane Compagnies (RI, i I). Die im ökonomischen Sinn verstandene Nützlichkeit oder besser Lukrativitât, auf die Gozzi immer wieder verweist, belegen konkrete Zahlen aus dem Jahr $1773^{89} \mathrm{Wäh}-$ rend die Truppe Sacchi mit der »commedia all'improvviso « Il convitato di pietra 657 Lire Eintrittsgelder einnahm, mußten sich die Schauspieler des Theaters Sant'Angelo bei der Aufführung von Merciers Disertore mit etwas mehr als 200 Lire zufriedengeben. ${ }^{90}$ Diese Tatsache bestätigt eine in Il teatro comico von Lelio gegen Orazios Überzeugung vorgetragene Vermutung, daß mit den neuen Komödien nie so viel zu verdienen sei wie mit den improvisierten. Interessanterweise zieht auch Lelio 23 Jahre vor dem Ragionamento ingenuo den Convitato di pietra als Beispiel heran: $" \mathrm{Si}$ danno ad intendere, per aver esposto al pubblico alcune commedie nuove, di cancellare tutte le vecchie? Non sarà mai vero; $e$ con le loro novità non arriveranno mai a far tanti danari, quanti ne ha fatti per tanti anni il gran Convitato di pietra. $\propto(\mathrm{I}, 1 \mathrm{I})$. So gesehen hat ein Schauspieler, der in der

Gozzi nennt diese Jahreszahl im $>$ Appendice al Ragionamento ingenuo del tomo primow, der im Band IV der Colombani-Edition abgedruckt ist. Als Erscheinungsdatum dieses $B$ andes ist auf der Titelseite allerdings 1772 angegeben.

$40-[\ldots]$ è ben da stupire riflettendo all'utilità teatrale, che il Convitato di pietra, replicato da più d'un secolo, abbia dato in quest'anno 1773 alla Truppa Sacchi seicento cinquantasette lire nella casetta alla porta, e che il Disertore del Signor Mercier, Dramma esposto tra noi da due soli anni, $e$ in così gran credito, abbia dato poco più di dugento lire a' colti Comici del Teatro S. Angelo.* (ARI, 33). 
Tradition der Commedia dell'arte aufgewachsen und ausgebildet ist ${ }^{91}$ sehr viel mehr Wert für eine Truppe als ein Theaterschriftsteller; während die geschriebenen Stücke der Mode unterliegen, sich durch häufiges Spielen abnutzen und bald wieder von der Bühne verschwinden, halten sich die improvisierten Stücke seit Jahrhunderten, ${ }^{92}$ da sie flexibel und offen sind für Modifikationen und das Publikum der Faszination des Theatralischen immer wieder aufs neue erliegt.

In Ragionamento ingenuo skizziert Gozzi eine kleine, polemisch durchsetzte Geschichte der Commedia dell'arte, die, wie er schreibt, seit 300 Jahren besteht, ${ }^{93}$ seitdem unablässig bekämpft wird, jedoch nie untergegangen ist, so daß die vehementen Invektiven der zeitgenössischen Autoren gegen einen Brighella, einen Pantalone, einen Dottore, einen Tartaglia und einen Truffaldino umso lächerlicher erscheinen. Vergeblich treten die Reformer gegen eine Komik an, die ihre Wirkung nie verfehlen wird, und umsonst wollen sie ein Lachen unterbinden, das nicht verboten werden kann:

Le persone perspicaci, spiritose ed argute, atte ad appagare anche i risvegliati talenti, le quali rappresentano le antiche maschere della nostra Commedia improvvisa, soccorse dagli scorcj naturali e dal loro caratterizzato vestiario faceto, hanno l'arma di un ridicolo tanto marcato, preciso, materiale ed efficace, che non potrà mai essere scemato nel suo effetto sul popolo, il quale averà sempre il diritto di godere di ciò che gli piace, di ridere a ciò che lo solletica, e di non badare a' mascherati Catoni, i quali non vogliono, ch'egli senta piacere di ciò, che gli piace. (RI, 12 )

Gozzi zeigt sich überzeugt davon, daß, sollten die Theater Italiens nicht überhaupt geschlossen werden, ${ }^{94}$ die ${ }^{*}$ commedia italiana improvvisa $*$ nie

91 Der Kern der Truppen bestand häufig aus ganzen Familien, die ihr Können und Wissen jeweils an die nächste Generation weitergaben.

$92 *$ Uno Scrittore Teatrale, per quanto fertile sia nelle sue produzioni, non sarà giammai per lungo tempo utile ad un Teatro, come lo sarà un Comico valente improvvisatore entrato nella grazia del popolo. Vedemmo tra noi decadere il Signor Goldoni fertilissimo, e veggiamo sussistere favorite ne' Teatri nostri le facete maschere improvvisatrici, che dominavano il pubblico genio prima di lui a, schreibt Gozzi mit direktem Bezug auf Goldoni (ARI, 25).

93 Nach heutigem Forschungsstand wird die Entstehung professioneller Schauspieltruppen als entscheidender Aspekt der Commedia dell'arte um die Mitte des 16. Jahrhunderts angesetzt; s. K. und L. Richards, op. cit., S. $35-37$.

94 Diese Drohung steht seit Jahren im Raum, und Gozzi selbst plädiert - allerdings wic meist mit ironischem Unterton - in mehreren Texten für eine zeitweise Schließung, wie z. B. im Vorwort zu Il re de' genj, um das Publikum in seinem Geschmack zu bekehren: - Converebbe far chiuder tutti i Teatri per un secolo, far abbruciare turte le Commedie in istampa, salve le poche ottime, semplici, regolate, e naturali, far invogliare per questo modo i posteri di veder delle rappresentazioni in iscena, e allora, perdute essendo le guaste idee delle gran cose vedute, godrebbero le semplici, e naturali.* (Col. III, r35). 
verschwinden noch die Masken ausgelöscht würden - eine Ansicht, die er in La più lunga lettera di risposta von 1801 angesichts der tatsächlichen Situation zu revidieren gezwungen ist. ${ }^{95}$

Ein wichtiges Kriterium bei der positiven Beurteilung der improvisierten Komödien ist ihr genuin italienischer Charakter. ${ }^{96}$ Die Empfehlungen, in Italien das französische Theater zu imitieren, konterkariert Gozzi mit dem Hinweis auf den Erfolg der italienischen improvisierten Komödie in Paris, die dort seit über einem Jahrhundert gespielt wird und es bis zu einem "privilegio della Corte Reale und einem eigenen Theater gebracht hat. Daß die Franzosen die genuin italienische improvisierte Komödie nach Paris holten, obwohl die französische Nation die Opéra comique hat, die der "commedia improvvisa « in ihrer Funktion als publikumswirksames Pendant zur Tragödie und Komödie gleicht, sollte in Gozzis Augen den Kritikern zu denken geben. Die Commedia dell'arte als spregio della nostra sola nazione $\propto(A R I, 4 \mathrm{I})$ entspricht nicht nur dem italienischen Charakter, sondern erfreut sich darüber hinaus der Attraktivität bei anderen Nationen, was sich auch in den Einladungen der Commedia dell'arte-Truppen an die europäischen Höfe manifestiert.

Neben der nationalen Komponente zählt die lange Tradition der scommedia improvvisa๔. Gozzi tritt gegen Versuche an, ihre Fortune aus dem Niedergang der Literatur im 17. Jahrhundert herzuleiten und als die eigentlich alte, das heißt altehrwürdige, die regelmäßige, geschriebene Komödie anzusetzten. ${ }^{97} \mathrm{Ob}$ der Ursprung der Komödie nun in der

7) Dort heißt es im Ton ciner Nănie: -Di fatto niente è piû insoffribile all'udito del creduto buon senso oggidi dell'antica Commedia italiana alla sprovveduta, considerata nella viltà, nella agghiacciata goffaggine, e nella miseria in cui la persecuzione dé Pocti scrittori I'hanno sospinta. [...] Gli Andreini, i Ricoboni [sic], i Garelli, [...] i Collalti, i Sacchi, i Zanoni, i Fiorilli, i Leandri, l'Eularie, le Victorie, le Rosaure, le Colombine, le Coralline, le Smeraldine, e cent'altri Comici studenti, educati, perspicaci, pronti, graziosi, naturali ed originali sostenitori della Commedia improvvisa dell'arte, rinovellatori di quella gradatamente di tempo in tempo a misura del cambiamento de' costumi, sono ora quasi turti negl'elisj a compiangere il loro genere di Commedia ridotta alla dejezione, e sostenuta soltanto per una necessità agonizzante da aleuni oggetti ignorantissimi, sguajati, senza carattere originale, scimie infelici di poche pantomimiche gesticolazioni de' trapassati.- (L.L, tr6).

\%. -Non v'e nessun'altra nazione che la sostenga. Gl'Italiani sono i soli arditi ingegni, che seppero per tanti secoli sostenere questo genere di spettacolo all'improvviso. [...] Contemplo nella commedia improvvisa un pregio dell'Italia [...] (RI, t3).

97. In diesem Abschnitt weist Gozzi den Passus sha avuto il suo principio nella decadenza delle belle lettere del secento als Zitat aus und merkt in einer Fußnote an: =Prefazione alla Collezione delle traduzioni Caminer, e Giornale Europa Letteraria* (RI, 17). In vielen Teilen ist der Text Ragionamento imgenuo tatsächlich eine Auseinandersetzung mit Außerungen Elisabetta Caminers und ihres Vaters Domenico Caminer, die sich zum einen in den Vorworten Elisabetta Caminers zu Obersetzungen bzw. Ubertragungen 
Improvisation oder tatsächlich bei den Dichtern liegt, muß offen bleiben, doch "stretto ad una naturale considerazione «, glaubt Gozzi, "ch'ell'abbia avuto il suo origine più dall'improvviso che dal premeditato, ma che, siccome l'improvviso non rimane in iscritto, e del premeditato ci restano gli esemplari, i nostri impostori fondino la loro opinione inopportuna e affettata sopra questa materialità. «(RI, I8). Diese Bemerkung zur Flüchtigkeit der improvisierten und zur Dauerhaftigkeit der aufgeschriebenen Komödie ist grundlegend für Gozzis Unterscheidung der »buone e immortali opere di Teatro scritte di tutte le nazioni $\alpha$ vom »divertimento teatrale all'improvviso de' nostri Comici Italiani a (ebd.), eine Überlegung, die nicht nur Dauer und Vergänglichkeit einander gegenüberstellt, sondern auch das Universale dem spezifisch Nationalen und der Qualität (in literarischem Sinn) die Unterhaltung. In seinem kleinen historischen Abriß bezeichnet Gozzi die "commedia italiana improvvisa* als *antichissima", also älter als die *commedia italiana regolata e scritta", und verlegt ihre Anfänge in die Lombardei, von wo sie sich über ganz Italien bis nach Frankreich verbreitete. Im Gegensatz zu Goldoni, der, den Blick ganz auf seine aktuellen Reformbestrebungen gerichtet, die Komödientradition so gut wie vollständig außer Acht läßt und in genereller Weise von den "commedie dell'arte" abwertend als alten, von den "commedie di carattere " dagegen positiv als neuen, zukunftsträchtigen Komödien spricht, versucht Gozzi, über eine, wenn auch sehr pauschale, historische Betrachtung das Wesentliche der Komödie als Theaterereignis zu fassen. Unter dieser Perspektive nobilitiert das Kriterium des Alters, der langen ungebrochenen Tradition die scommedia italiana improvvisa , denn sie zeugt vom anhaltenden Interesse des Publikums an dieser Form von

von Theaterstücken v. a. aus dem Französischen und Englischen finden, die 1772 in vier Bänden unter dem Titel Composizioni teatrali moderne erschienen (ab 1774 wurden weitere 6 Bände veröffentlicht: Nuova raccolta di composiziont teatrali), zum anderen in der von Domenico Caminer geleiteten Zeitschrift L'Europa letteraria. (S. u. wNachahmung und moralischer Anspruch «.) Vater und Tochter waren überzeugte Anhänger Goldonis ( $n[\ldots]$ il signor dottor Carlo Goldoni, il vero e solo riformatore del nostro teatro italiano, mio compatriota e mio buon amicoe, schreibt Domenico Caminer z. B. 1772 in einer Rezension zu Il burbero benefico in L'Europa letteraria, in: Giornali veneziani del Settecento, Hg. Marino Berengo, Milano, Feltrinelli 1962, S. 357). Elisabetta Caminer war zudem eine unermüdliche Verfechterin vor allem des französischen ngenre sérieux«, und beide polemisierten unverhohlen gegen Carlo Gozzi.

$\mathrm{Vgl}$. Alberto Beniscellis * Introduzione zu seiner Edition von Gozzis Il ragionamento ingenuo, Genova, Costa \& Nolan 1983, S. 18 -22, und Anna Scannapieco, Carlo Gozzi: la scena del libro, Venezia, Marsilio 2006, S. $29 \mathrm{ff}$.

Zu Elisabetta Caminer s. Elisabetta Caminer Turra (1751-1796). Una letterata veneta verso l'Europa, Hg. Rita Unfer Lukoschik, Verona, essedue edizioni 1998; zu L'Europa letteraria s. Giornali veneziani del Settecento, op-cit., S. LI-LIV. 
Theater. Mit dieser Sicht steht Gozzi nicht allein, hebt doch zum Beispiel auch Giuseppe Baretti neben dem Können der Maskendarsteller das Nationale und das Alter im Hinblick auf die Commedia dell'arte hervor:

Je ne puis réellement souhaiter l'extinction d'un genre de Spectacles, oủ les efforts, que sont forcés de faire les Acteurs pour plaire \&c captiver l'attention des Spectateurs, donnent bien plus souvent lieu à l'admiration qu'à la critique. D'ailleurs, ces Spectacles sont une des singularités de la Nation Italienne; \& ne fut-ce que par cette raison autant que pour l'antiquité de leur origine, je pense qu'on devroit les conserver aussi longtemps qu'il sera possible, \& que les Critiques, au lieu de chercher à les détruire, feroient mieux de s'exercer à les perfectionner. ${ }^{98}$

Den topischen Vorwurf gegen die improvisierte Komödie, sie sei unmoralisch, bestreitet oder widerlegt Gozzi nicht etwa, sondern weitet ihn als Feststellung auf die geschriebene Komödie aus ${ }^{99}$ und unterstreicht dies durch das Argument, daß konsequenterweise Frauen zu beiden Arten des Theaters der Zugang verboten war: * Tutti due questi spettacoli erano licenziosi. Nelle antiche Commedie Italiane scritte le oscenità si possono ancora leggere; di quelle delle improvvise non possiamo avere, che qualche tradizione." (RI, 18-19). Mit Verweis auf Grazzinis Canti carnascialeschi betont Gozzi noch einmal die Konkurrenz, die das Verhältnis der •commedia italiana, detta dell'arte und der regelmäßigen Komödie von Anfang an bestimmte, wobei ihnen als ganz unterschiedliche Arten von Theater jeweils spezifische Verdienste zukamen und bis in die Gegenwart zukommen, -Il guadagno di borsa fu ognora della Commedia improvvisa popolare, quello di decoro fu ognora di quella premeditata. « (RI, 19). Während im 17. Jahrhundert angesichts des schlechten Geschmacks der Schriftsteller die improvisierte Komödie die regelmäßige bei weitem übertraf, hat sich im 18. Jahrhundert aufgrund des zunehmenden Strebens nach Vergnügen und Luxus die Zahl der Theater und der Schauspieltruppen derart vermehrt, ${ }^{100}$ daß die Komödienschreiber ihre Stunde gekommen sahen und mit eigenen Produkten und Übersetzungen aus dem Französischen die Bühnen überschwemmten - doch ohne improvisierte Stücke

98 G. Baretti, Les Italiens, ou Maurs et coutumes d'Italie, op. cit., S. 79.

99 In diesem Punkt trifft sich Gozzis Urteil mit dem Riccobonis. Wahrend Riccobori jedoch die geschriebenen Komódien herabzusetzen versucht, um die eigenen scenari aufzuwerten, zielt Gozzis Bemerkung in eine ganz andere Richtung, nämlich auf die gattungsgemäßen Lizenzen, die die Obszönităten ete. der Kritik entziehen. Indirekt macht Gozzi auf diese Weise auf die Bedeutung von Gattungs- und Stiltraditionen aufmerksam.

100 Gozzi äußert sich konkret zu den venezianischen Verhältnissen: s In Venezia, dove non si aprivano che due Teatri di Commedia, nel giro di venticinqu'anni se ne sono aperti quattro, e spesso se ne aprono cinque, $*(R I, 21-22)$. Zeitweise wurde auch in den Theatern San Cassian und San Giovanni Grisostomo Sprechtheater angeboren. 
kommt keine Truppe aus, und so haben alle si loro Zanni, i loro Magnifici, $\mathrm{i}$ loro Dottori« (RI, 22). Allerdings nimmt deren Können rapide ab, denn ihnen fehlt die notwendige tägliche Übung in der Improvisation und im Zusammenspiel, da sie auch geschriebene Stücke auswendig lernen und aufführen müssen. Sacchi ist in dieser Situation einer der wenigen, die es verstehen, ihr Können zu bewahren und die Truppe in der Kunst der Improvisation zu unterrichten, wiewohl auch Sacchi geschriebene Stücke auf die Bühne bringt. ${ }^{101}$

Für die unablässigen Attacken seiner Zeitgenossen - damit meint er in erster Linie Goldoni und Chiari, aber auch Elisabetta Caminer - auf die Commedia dell'arte kann Gozzi angesichts der von ihm konstatierten Tatsachen nur einen Grund finden: das Geld. Stellt man sich das seit Jahren währende labile Gleichgewicht zwischen regelmäßiger und improvisierter Komödie vor Augen, die zur Tradition gewordene, aber über Jahrhunderte wirkungslose Bekämpfung der "commedia italiana improvvisa* durch die Geistlichen, die Literaten und Gelehrten, den seit Beginn ungeschmälerten Publikumserfolg sowie den für die Truppen lebensnotwendigen ökonomischen Nutzen, bleibt nur eine mögliche Erklärung: Die Angriffe »nascono da una rabbiosa venalità rispinta da una necessaria economia, e non dal zelo della letteratura Italiana, la quale non avrà mai nessun obbligo a' sgorbiatori e copisti. « (RI, 23 ). Unbestreitbar ist nämlich, daß es sich lohnt, als Autor Stücke für eine Kompanie zu schreiben, wird doch eines mit 30 Zecchini bezahlt, während beispielsweise die Bearbeitung von scenari oder das Verfassen von soggetti für improvisierte Komödien, was Goldoni anfangs viele Jahre lang besorgte, nur 3 Zecchini einbringt. ${ }^{102}$ So ist es für Gozzi nicht verwunderlich, daß Goldoni die Commedia dell'arte verfolgt und verschreit und sich vehement für ge-

101 In Appendice al Ragionamento ingenuo druckt Gozzi zur Veranschaulichung ein soggetto ab, das den Schauspielern als Grundlage für die Komódie I contratri rotri dient, und preist im Anschluß die erstaunlichen Fähigkeiten der Schauspieler mit Worten, aus denen jenseits aller strategisch-polemischen Intentionen echte Bewunderung spricht: „Si cambiano sul momento del cominciare la Commedia le parti agli Attori, secondo le circostanze, il peso, l'abilita proporzionata, con differenza di nome, di carattere, e tuttavia. si conduce la Commedia allegra al suo termine. Ogn'anno si troncano e si aggiungono delle scene agli argomenti, e un avviso alla Truppa basta per eseguirli con esatezza, $\mathrm{c}$ bravura. [...] Egli è ben vero che alcuni Attori serj di questo genere di spettacolo, e spezialmente le Attrici, hanno un'arsenale di materiali differenti premeditati alla memoria, che servono a preghiere, a rimproveri, a minaccie, a disperazioni, a sentimenti di gelosia, ma è pure cosa mirabile, che in faccia un Pubblico improvvisando delle scene con altri improvvisatori, possano aver pronti, e scegliere in quella massa, che hanno nel cervello, de' tratti, farli cadere al proposito, esprimerli con vigore, e guadagnarsi delle picchiate di palme dagli Spettatori. $=(A R I, 40)$.

$102 \mathrm{Vgl}$. ARI, 42. 
schriebene Stücke einsetzt, freilich ohne Rücksicht auf die Truppen, die dadurch arm werden, sind doch pro Jahr von den gelieferten zehn Komödien auf der Bühne hōchstens zwei erfolgreich. Als Folgerung bleibt: * Le sue Commedie scritte sono oggidì inutili capitali a' Comici, e i suoi sopra accennati soggetti all'improvviso sono ancora utilissimi capitali.\& (ARI, 43). Mag diese krasse Gegenüberstellung auch polemisch motiviert sein, birgt sie doch insofern sicher einen Kern Wahrheit, als die ökonomischen Aspekte der Theaterszene in der zweiten Hälfte des 18 . Jahrhunderts nicht zu vernachlässigen sind. ${ }^{103}$

Hinsichtlich des Publikums haben die improvisierten Komōdien für Gozzi einen weiteren entscheidenden Vorteil gegenüber den zeitgenössischen Stücken, denn sie entspringen der zweckfreien Lust am Spiel und dienen der reinen Unterhaltung. Unzählige Male ist von sdivertimento die Rede, von sintrattenere und zwar auf unschuldige, naive, nicht zweckgebundene Weise. Mit der ^Farsa dell'arte all'improvviso di materiale, popolare, caricato, allegro, e innocente divertimento scenico (LL, 137) gelingt es den Schauspielern, ihr Publikum zu fesseln, stenendo per tre ore un migliajo di persone attente, divertite, ed allegre $(\mathrm{LL}$, i 17 ). Die Betonung des »divertimento «, der Unterhaltungsfunktion, bezeichnenderweise meist in Verbindung mit dem Epitheton sinnocente «, das nicht in moralischem Sinn zu verstehen ist, sondern als nicht zielführend und keiner Nutzanwendung dienlich, ist eine für die Zeit ganz untypische $\mathrm{Va}$ riante wirkungsästhetischer Ziele der Komödie, steht doch die Orientierung an der Poetik Horaz' und insbesondere an dessen doppelter Funktionsbestimmung der Dichtung von ^prodesse* und ^delectare* im Zentrum der Diskussion, wobei der Akzent eindeutig auf der Nützlichkeit liegt und das Erfreuliche weit in den Hintergrund tritt. ${ }^{104}$ Auch Goldoni spricht im Vorwort zur Bettinelli-Edition davon, mit ^costumate Com-

103 Umfassendere Untersuchungen zu diesem Aspekt wic auch zum Wandel der Truppen stehen noch aus; zu Einzelaspekten siehe A. Paladini Volterra, op. cit., G. Guccini, -Dall'innamorato all'autore», op, cit., N. Mangini, =Lorganizzazione teatrale a Venezia nel Settecento*, op. cit.

Als Beleg für die Attraktivität der improvisierten Komödie führt Gozzi das Schicksal zweier Stucke von Chiari an, Il padre di famigla und I nimici del pane, che mangiano, die als ausgeschriebene und gedruckte höchstens noch 60 Zuschauer anlocken, während eine improvisierte Version der Truppe Sachi ein volles Haus einbringt.

104 Nicht nur die Komödie, sondern auch die Tragôdie soll nuttzlich sein, wie besonders Martello in Della tragedia antica e moderna hervorbebt. Dort wird der Tragödie ein pädagogisch-moralischer Auftrag zugeschrieben, dem nur die Darstellung exemplarischer Tugend und die demonstrative Bestrafung des Lasters und des Bösen auf der Bũhne gerecht werden kônnen. Zur Legitimation des Theaters mittels Nützlichkeit vgl. den Abschnitt =Plaire et instruire in S. Léoni, op. cit., S. $294 \mathrm{ff}$. 
medie, l'istruzione e il diletto ${ }^{105}$ zu verbreiten und verbindet mit seinem Projekt einer Komödienreform ein ganzes Erziehungsprogramm, sowohl im Hinblick auf das Publikum als auch auf die Schauspieler.

In kaum einem Traktat über das Theater wird versäumt, das Theater als *Schule zu charakterisieren, angefangen bei Muratori, der in Della perfetta poesia italiana seiner Hoffnung Ausdruck gibt, das Theater könne zu einer "dilettevole scuola de' buoni costumi e una soave cattedra di lezioni morali ${ }^{106}$ werden, über Maffei, der im Vorwort zu seiner Tragödien-Sammlung von 1723 von einem *programma di riforma complessivo s spricht, mittels dessen sil teatro diverebbe un efficace mezzo per educare piacevolmente la società «, ${ }^{107}$ und Carli, der Cicero als Gewährsmann dafür anführt, daß schon die griechischen Theater als "pubblica scuola « gegolten hätten, ${ }^{108}$ bis zu Chiari und Goldoni. Dieser scheut nicht davor zurück, im Gedicht "Visita delle sette chiese«, das in der Kontroverse zwischen Gozzi und Goldoni vor der Aufführung von L'amore delle tre melarance eine Rolle spielt, in der römischen Kirche San Giovanni Laterano folgendermaßen zu beten: $»$ Fa che l'opere mie, di zel ripiene, / Scuola dell'onestà rendan le Scene ${ }^{109}$ Auch Chiari weist in Traktaten, Vorworten und Theaterstücken mehrfach darauf hin, daß wi Teatri una Scuola piacevole del buon costume « sein sollten und führt zur Bestätigung nicht nur Platon, sondern auch die Kirchenväter an, »quali tra di noi li vuole Platone, che n'è l'Impressario; e quali pur vogliono i Santi Padri [...] nelle Provincie, e ne' Regni illuminati da' raggi dell'Evangelio $\alpha^{110}$ *Scuola migliore, e più confacevole al genio del pubblico non poteva oggidì aprirsi in Italia, che quella de' Teatria, stellt er wenige Jahre später fest und erklärt, daß er bereits früh den Entschluß gefaßt habe, $\bowtie$ di cangiare in cattedra di poesia comica le pubbliche scene, onde tutto ad un tratto illuminare i ciechi, convincere gli increduli, e dar l'armi in mano alle persone giudiziose, e discrete da sostenere le proprie opinioni, e combattere le altrui stravaganze«, was ihm nach eigenem Dafürhalten auch gelungen ist, "Il mio disegno riusci $\alpha$." Einem solchen oder ähnlichen Erziehungspro-

105 Goldoni, 1, 769 .

106 Muratori, Della perfetta poesia italiana, Hg. Anton Maria Salvini, Bd. III, 6, Milano, Società tipografica dei classici italiani $1821, \mathrm{~S}, 78$.

102 Maffei, Istoria del teatro e difesa di esso, op.cit., S. 42.

10k Gian Rinaldo Carli, Dell'indole del teatro tragico antico, e modemo, in: Opere, Bd. 17. Milano 1787 , S. 104 .

109 Goldoni, XIII, 517. Vgl. Kap. 1.3.

Ire Pietro Chiari, Lettere scelte di varie materie piacevoli, critiche, ed erudite, $\mathrm{Bd}$. III, $\mathrm{Ve}$ nezia 1752, S. 186.

(1) Pietro Chiari, Il genio ed i costumi del secolo corrente, op. cit., S. 69; =Osservazioni sopra il poeta comico a, in: Pietro Chiari, Commedie in verst, Bd. III, Venezia 1774, S. 6. 
grammen, die zum einen auf die Kultivierung des Publikumsgeschmacks im Sinne des vielbeschworenen obuon gusto* zielen, zum anderen aber auch auf die Verbesserung der Sitten und damit auf eine lebensweltliche Wirkung, steht Gozzi, wie bereits erwähnt, skeptisch gegenüber. Wenn er deshalb die Betonung auf die bloße Unterhaltung legt und zudem hartnäckig sutilità nicht in pädagogisch-moralischem Sinn, sondern als finanziellen Nutzen für die Truppe interpretiert, entlarvt er die stereotype Redeweise als fragwürdig. ${ }^{112}$ Die Unterscheidung zwischen einem unnützen, unmoralischen Theater und einem moralisch wie ästhetisch untadeligen, das allein den Anspruch erheben kann, in die kulturelle Ordnung integriert zu werden, macht Gozzi nicht mit. Allerdings versucht er auch nicht, in dieser strategisch motivierten Polarisierung zu vermitteln, sondern bedient sich desselben argumentativen Prinzips, indem er zum einen konsequent zwischen einem "genere colto und einem "genere popolare unterscheidet, und zum anderen die positiven Aspekte der Commedia dell'arte und die negativen der neuen Komödien in extremer Weise gegeneinander ausspielt. In einem weiten Kulturbegriff fänden das gelehrte wie das populäre Theater ihren Platz, doch zeigt die Polemik gegen die Commedia dell'arte, daß dieser Gedanke dem Jahrhundert Gozzis fremd war und sich in Goldonis Komödien vielmehr beispielhaft eine Nivellierung anbahnte, in der sowohl das Besondere der improvisierten Komödien als auch das Charakteristische der gelehrten verschwanden zugunsten einer in den Vorworten immer wieder hervorgehobenen Nähe zur Erfahrungswirklichkeit des Publikums. Gozzi dagegen gesteht beiden Arten des Theaters, dem improvisierten auf der Bühne und dem geschriebenen im Buch, ihre Daseinsberechtigung zu, verwahrt sich jedoch gegen alle Bestrebungen, die Komödien neuen Stils, seien es diejenigen Goldonis, seien es Úbersetzungen aus dem Französischen, als poetologisch und moralisch makellos zu deklarieren. ${ }^{113}$ Eine Äußerung wie diejenige Lelios in Goldonis Teatro comico, -Il signor capo di compagnia mi va dicendo che il teatro si è riformato, che ora si osservano tutte le buone regole $\propto$ (III, 8), oder diejenige Chiaris in bezug auf sein moralisches Programm, $i$ il mio disegno riusci $\nsim$, können angesichts der Diskrepanz zwischen selbstzufriedener Behauptung und Repertoiregegebenheiten nur den Spott Goz-

12 In besonders ironischer Weise spielt Gozzi im Vorwort zu La donna serpente auf die stereotype Berufung auf Horaz' sprodesse et delectare* an: $>$ S'ella [d. i. die Fiaba tedtrale] sia dilettevole, si chieda al popolo; s'ella sía utile, si chieda a' Comici, e si troverà, ch'ella è uniforme all'intenzione di Orazio.a (Col. II, 15 ).

13 Zur detaillierten Kritik an Goldonis sogenannten Reformkomödien und den Diskrepanzen, die zwischen den Vorworten und den Stücken bestehen, vgl. die Ausführungen zu II teatro comico all' Osteria del Pellegrino in Kap, 1.4. 
zis hervorrufen. ${ }^{114}$ Wenn Gozzi indessen die gut ausgeführte "commedia italiana alla sprovveduta « als "pubblica innocente ricreazione und die Masken als »nostri portenti di soccorrevole giovialità (Mem. I, 254 und 250) lobt, stellt er nicht nur getreu dem Prinzip der polemischen Kontrastierung der stereotypen negativen eine positive Bewertung gegenüber, sondern legitimiert die Commedia dell'arte als kulturelles Phänomen ${ }^{115}$ und entzieht sie zugleich bewußt jeder poetologischen oder moralischen Beurteilung, vor allem aber jedem Nützlichkeitsanspruch. Dem Konzept des Theaters als Schule und moralische Lehranstalt setzt er das Theater als Unterhaltung und Vergnügung entgegen. $* \mathrm{Dal}$ canto mio considero i Teatri recinti di divertimento * (ARI, I I), schreibt er gleich am Anfang des Appendice al Ragionamento ingenuo und macht sich lustig über *que' Poeti, che pretendono di cagionar ne' Teatri, puri recinti di passatempo e di passeggieri riflessi, gli effetti de' Pergami e de' Confessionali« (ARI, I8). Während die modischen Stücke dem Publikum auch noch ^quella picciola umana felicità che può dare un passeggiero teatrale divertimento* (RI, so) verwehren, sollen seine eigenen Theaterstücke dazu dienen, »di spassare e intrattenere con passione, interesse, e diletto i miei concittadini $(\mathrm{LL}, 43)$.

\subsection{Die Problematik der Nachabmung}

\section{Nachahmung und Kopie}

Neben der didaktischen Intention des Reformprojekts sieht Gozzi ein grundlegendes Problem in Goldonis ausdrücklichen Bestrebungen, sein Theater auf die Beobachtung zu gründen, aus den eigenen Erfahrungen Stoff für die Stücke zu gewinnen und die Wirklichkeit möglichst getreu abzubilden. ${ }^{116}$ Diese Äußerungen deutet Gozzi polemisch als ein Kopie-

114 Entgegen anderslautenden Behauptungen Goldonis setzte sich das Repertoire auf Venedigs Bühnen sowohl zu Zeiten seiner venezianischen Theateraktivität als auch danach aus geschriebenen und improvisierten Stücken zusammen, die vom Publikum offensichtlich gleichermaßen frequentiert wurden; vgl. N. Mangini, -Su due topoi dell'autobiografia goldonianax, op. cit., S. 29-39, und A. Paladini Volterra, *Verso una moderna produzione teatralea, op. cit., die v.a. das Sprechtheater-Repertoire der Jahre $1795-97$ untersucht.

115 Dies tut er ebenso, wenn er mit Bewunderung über die Kunst der improvisierenden Schauspieler spricht und damit den Aspekt der Beherrschung der sars unterstreicht.

116 Die Abbildung der Wirklichkeit wird in Il teatro comico all'Osteria del Pellegrino in drastisch-satirischer Weise vor Augen geführt; s. Kap. 1.4. 
ren der Wirklichkeit, das jede künstlerische Distanznahme vermissen läßt und dazu führt, daß auf der Bühne oft verwerfliche Verhaltensweisen die Oberhand gewinnen:

Espose sul Teatro tutte quelle verità, che gli si pararono dinanzi, ricopiate materialmente, e trivialmente, e non imitate dalla natura, nè coll'eleganza necessaria ad uno Scrittore.

Non seppe, o non volle separare le verità, che si devono, da quelle, che non si devono porre in vista sopra un Teatro; ma si è regolato con quel solo principio, che la verità piace sempre. Da ciò nasce, che le sue Commedie odorano per lo più d'un pernizioso costume. La lascivia, e il vizio gareggiano in esse colla modestia, e colla virtù, e bene spesso queste due ultime sono vinte da' primi. (RI, 55 )

Aufgrund der mangelnden Selektion der Beobachtungen enthalten die Theaterstücke Elemente, die zwar wahr sind, jedoch auf der Bühne keinen Platz haben, insbesondere sofern der Anspruch besteht, *costumate ", ${ }^{117}$ also moralisch einwandfreie Komödien zu schaffen. Zeigt Gozzi in Scrittura contestativa al taglio della Tartana und Il teatro comico all'Osteria del Pellegrino an einzelnen Komödien Punkt für Punkt auf, was als moralisch unangemessen erscheint, ist sein Urteil in Ragionamento ingenuo in größerem zeitlichen Abstand ein pauschales:

Moltissime delle sue Commedie non sono che un ammasso di scene, le quali contengono delle verità, ma delle verità tanto vili, goffe e fangose, che quantunque abbiano divertito anche me medesimo, animate dagli attori, non seppi giammai accomodare nella mia mente che uno Scrittore dovesse umiliarsi a ricopiarle nelle più basse pozzanghere del volgo, né come potesse aver l'ardire d'innalzarle alla decorazione d'un Teatro, e soprattutto come potesse aver fronte di porre alle stampe per esemplari delle vere pidoccherie. (RI, 56)

Zweierlei ist in diesem Abschnitt bemerkenswert: zum einem bezeugt Gozzi, daß die dummen, niederen Wahrheiten komisch und nicht etwa abstoßend wirken, und zwar auch auf Gebildete wie ihn selbst, zum anderen besteht er darauf, daß ein Schriftsteller diese in seinen Bühnenwerken und mehr noch im Hinblick auf deren Verbreitung im Druck vermeiden muß. Einmal mehr wird hier deutlich, daß sich seine Kritik nicht an den *verità vili, goffe e fangose* an sich entzündet - sonst erwähnte er sein eigenes Vergnügen nicht -, sondern an der Diskrepanz zwischen dem immer wieder geäußerten Anspruch Goldonis, die italienische Komödie reformiert, kurz ein exemplarisches Theater geschaffen zu haben, und den Stücken, die inhaltliche wie sprachliche Ambiguitäten aufweisen.

Diesen Vorwurf erhebt Gozzi nicht allein, Giuseppe Baretti schlägt in seinen Besprechungen von Il teatro comico, La bottega del caffe, Pamela

117 Goldoni, III, 769 . 
fanciulla und Pamela maritata in La frusta letteraria denselben Ton an. In noch direkterer Weise macht er sich über die Selbstgefälligkeit Goldonis lustig, das Eigenlob, das seine Vorworte und Widmungen durchzieht, über die Quantität seiner literarischen Produktion und die Fülle der gedruckten Ausgaben. Auch er entwickelt seine Kritik minutiös an den Stücken selbst, deckt sprachliche Zweideutigkeiten und Obszönitäten, gestische Handgreiflichkeiten und inhaltliche Inkonsistenzen auf, die dem Anspruch, die Komödien reformiert zu haben, nicht angemessen sind. ${ }^{118}$ Im Hinblick auf die Problematik des Verhältnisses von Tugend und Laster in den Komödien geht Baretti noch einen Schritt über Gozzi hinaus, ${ }^{119}$ wenn er geradezu eine Umkehrung der Werte konstatiert: „Ecco come gli autori del nuovo stile e delle moderne commedie di carattere sbagliano il vizio per virtù $\times .120$

Im Vorwort zu Le baruffe chiozzotte nimmt Goldoni Stellung zu einigen dieser Vorwürfe. Zunächst erklärt er den Titel mit seinen geographischen und soziologischen Implikationen,

Il termine Baruffa è lo stesso in linguaggio Chiozzotto Veneziano, e Toscano. Significa confusione, una mischia, un azzuffamento d'uomini, o di donne, che gridano, o si battono insieme. Queste baruffe sono comuni fra il popolo minuto, e abbondano a Chiozza più che altrove; poiché di sessanta mila abitanti di quel Paese ve ne sono almeno cinquanta mila di estrazione povera e bassa, tutti per lo più Pescatori o genti di marina, ${ }^{121}$

18 Vgl. dazu Verf., "Das Theater im Kreuzfeuer der Kritik in Il Caffe, La Frusta letteraria, La Gazzetta veneta und L'Osservatore venetoa, in: Helmut C. Jacobs u. a. (Hgg.), Die Zeitschrift $\mathrm{Il}$ Caffer, Frankfurt am Main, Lang 2003, S. 253-276.

119 Gozzi selbst hălt Barettis Kritik für zu hart ausgefallen, wie er z. B. in La più lunga lettera erklärt: "Fu nimico un po troppo acerrimo delle sceniche opere del Goldoni, che ci ha divertiti un lungo tempo ne' nostri Teatri, poco meno del Sacchi Truffaldino.e (L.L. 85). In der folgenden Schilderung einer zufälligen, kurzen persönlichen Begegnung mit Baretti antwortet Gozzi auf dessen Frage nach seiner Meinung zu La frusta letteraria, -che il modo con cui scriveva il suo foglio fosse troppo mordace e satirico «, was Baretti sehr verwundert, Gozzi fährt fort: =Egli mi guardò sorridente dicendomi: Non averei creduto giammai di sentirmi accusato di troppo satirico dalla sua voce. E' probabile che con questa sua risposta egli abbia inteso di trattar me da satirico, senza separare la satira cinica laceratrice, dalla satira urbana e scherzevole, $(\mathrm{LL}, 86)$. Wie im Zusammenhang der frühen polemischen Texte besteht Gozzi auch hier auf der Unterscheidung unterschiedlicher Arten von Satire.

Auch Diderot kritisiert z. B. in La locandiera die Titelfigur aus moralisch-dramaturgischen Gründen. Siehe dazu ausführlich Klaus Ley, *Neue Kontexte zu La Locandiera. Goldonis Reformkomödie und ihre Bedeutung für Diderots drame bourgeois", in: Franz Norbert Mennemeier ( $\mathrm{Hg}$.), Die großen Komödien Europas, Tübingen, Francke 2000, S. I21-151.

120 Giuseppe Baretti, La frasta letteraria, Bd. I, op. cit, S. 326.

121 . L'autore a chi legge 4 , in: Goldoni, VIII, $127-130$. 
erläutert dann die Eigenheiten des Dialekts von Chioggia, weist auf die Mühen der Schauspieler bei der möglichst perfekten Imitation und die Schwierigkeiten des nicht chiozzottischen oder venezianischen Publikums beim Verständnis hin, rechtfertigt den Gebrauch des Dialekts jedoch mit der exakten Nachahmung der Natur: «credo e sostengo, che sia un merito della Commedia l'esatta imitazione della natura ${ }^{122}$ In bezug auf die Kritik fährt er fort, "Diranno forse taluni, che gli Autori Comici devono bensi imitar la natura; ma la bella natura, e non la bassa e la difettosa. Io dico all'incontro, che tutto è suscettibile di commedia, fuorché i difetti che rattristano, ed i vizi che offendono.* Diese Einschränkung der Imitation auf sla bella natura weist Goldoni, wie Gozzi in Ragionamento ingenuo konstatiert, zurück, und zwar nicht nur im Hinblick auf sprachliche Aspekte, sondern auch auf inhaltliche: :Altri condanneranno, può essere, ch'io abbia troppo moltiplicato sopra le scene questa sorta di soggetti e di argomenti bassi e volgari. ${ }^{123} \mathrm{Als}$ Beispiele für solche "commedie popolari $\star^{124}$ nennt Goldoni I pettegolezzi delle donne, Le massere, Il campiello und eben Le barruffe chiozzotte, stratte da quanto vi è di più basso nel genere umano, le quali disgustano, o almeno non interessano le colte e delicate persone. ${ }^{125}$ Wenn die Natur derartige Sujets zur Nachahmung anbietet und zudem die Stücke erfolgreich sind, sieht sich Goldoni animiert, ungeachtet aller Kritik weitere zu schreiben. In diesem Zusammenhang verweist er auf die lateinischen *Tabernariae und die französischen „Poissardes «, führt das Vorwort einer Edition der Werke des französischen Autors Jean-Joseph Vadé an, der dort als »créateur du genre Poissard $\star$ vorgestellt wird, und zitiert den entscheidenden Satz, sTout ce qui est vrai, a droit de plaire, tout ce qui est plaisant, a droit de faire rire ${ }^{126} \mathrm{Am}$ Ende seines eigenen Vorworts nennt Goldoni einen weiteren entscheidenden Grund für die Darstellung niederer Themen und niederer Schichten im Rahmen seines Theaterreformprojekts,

Io aveva levato al popolo minuto la frequenza dell'Arlecchino; sentivano parlare della riforma delle Commedie, voleano gustarle; ma tutti i caratteri non erano adattati alla loro intelligenza: ed era ben giusto, che per piacere a quest'ordine di persone, che pagano come i Nobili e come i Ricchi, facessi delle Commedie, nelle quali riconoscessero i loro costumi e i loro difetti, e, mi sia permesso di dirlo, le loro virrù,

122 Ebd., S. 128 .

123 Ebd., S. 129.

124 Goldoni verwendet spopolare in einem ganz anderen Sinn als Gozzi, der mit sgenere popolare* ein allgemein beliebtes, gefragtes Theater meint, während Goldonis Gebrauch auf das in sozialem Sinn Niedere verweist.

125 Ebd.

126 Ebd, S. t30. 
und übersetzt abschließend den zentralen Gedanken aus dem Französischen ins Italienische: »tutto quello che è vero, ha il diritto di piacere, $\mathrm{e}$ tutto quello ch'è piacevole, ha il diritto di far ridere.«

Einer so formulierten Maxime hätte Gozzi wohl wenig entgegenzusetzen gehabt, doch trifft sie nicht den Kern der Auseinandersetzung, die komplexer ist, als sie zunächst scheinen mag, denn die einfache Gegenüberstellung zweier Positionen, von denen die eine für, die andere gegen eine uneingeschränkte Nachahmung der Natur steht, geht nicht auf. In Goldonis Argumentation für eine »esatta imitazione della natura s treten im Vorwort zu Le baruffe chiozzotte Ambivalenzen und Inkonsistenzen zutage, die andernorts kaum so deutlich werden. Einmal ergeben sich das Recht und die Pflicht, die Natur zu imitieren, und zwar die ganze Natur, auch was gemein und niedrig ist, aus dem Kriterium der Wahrheit, denn alles, was wahr ist, kann in der Komödie abgebildet werden - mit der kleinen Einschränkung, daß es nicht traurig machen oder Anstoß erregen darf. ${ }^{127}$ Goldoni bemüht aber auch einen anderen Faktor, nämlich das Publikum. In Anlehnung an stereotype Argumentationsstrategien wird suggeriert, daß der gebildete Teil des Publikums die \#commedie popolari« ablehnt, weil diese sich aus dem Untersten des Menschengeschlechts speisen, während das niedere Volk sich in derartigen Komödien wiedererkennt, sie deshalb goutiert und so besser über den Verlust der Harlekinaden hinwegkommt. Einmal mehr ist dies ein impliziter Hinweis auf das theatralische Erziehungsprogramm, das das Volk von den Masken über die "commedie popolari« zu den echten "commedie di carattere « leitet. Seine Kritiker verweist Goldoni im übrigen auf die guten alten und modernen Autoren, die die dramatische Gattung der *Tabernariae« und »Poissardes» pflegen und damit erfolgreich sind und waren; ein Gesichtspunkt, der die angeblich traditions- und autoritätsgläubigen Gegner überzeugen sollte. Wenn nun allerdings zum einen mit Nachdruck der Publikumserfolg der Baruffe chiozzotte wie auch der anderen Komödien hervorgehoben und zum anderen explizit erwähnt wird, daß sich das Publikum in venezianischen Theatern aus allen Schichten zusammensetzt, entsteht die Frage, ob allein der spopolo minuto * für den Erfolg verantwortlich ist oder etwa die geschilderten Vorbehalte der "colte e delicate persone $\propto$ im Theater nicht zum Tragen kommen. Und wenn einerseits die

127 Diese Einschränkung wird allerdings umgehend relativiert: :Un uomo che parla presto, e mangia le parole parlando, ha un difetto rídicolo, che diviene comico, quando è adoperato con parsimonia, come il balbuziente e il tartaglia. Lo stesso non sarebbe d'un zoppo, d'un cieco, d'un paralitico: questi sono difetti ch'esigono compassione, e non si deggiono esporre sulla scena, se non se il carattere particolare della persona difettosa valesse a render giocoso il suo difetto medesimo, « (ebd., S, 128-129). 
exakte Imitation der Natur, andererseits eine Gattung mit einer Tradition, die bis in die Antike reicht, als Rechtfertigungskriterien genannt werden, stellt sich das Problem ihres Verhältnisses zueinander und ihrer jeweiligen Rolle im Rahmen der *riforma delle Commedie $\alpha$. Der Rückgriff auf überkommene Argumentationsmuster und die Vermischung von ästhetischen, soziologischen und poetologischen Aspekten in Goldonis Vorwort wie auch in anderen Texten macht die Verteidigung der "commedie popolari* zu einer heterogenen Konstruktion, die für kritisch-polemische Einwände eines Gozzi oder eines Baretti anfällig ist. So verwundert es angesichts der Äußerungen zu den ncommedie popolari in ihrem Bezug zum niederen Volk nicht, wenn Gozzi den Verdacht äußert, Goldoni wolle sich bei diesem anbiedern, ${ }^{128}$ wobei die Anbiederung auf zweierlei zielt: einmal auf den Beifall im Theater, der ja für Goldoni als Qualitätskriterium gilt, zum anderen auf den ökonomischen Nutzen, der entsteht, wenn das Publikum zahlreich erscheint und solche Stücke verlangt.

In diesem Zusammenhang ist ein weiterer Aspekt von Interesse: Goldoni korreliert ausdrücklich die *Arlecchinate « und in ihrer Nachfolge die »commedie popolari « mit dem "minuto popolo* und weist explizit darauf hin, daß in den Reformkomödien nicht alles dem Verständnis des niederen Volkes zugänglich gewesen sei. Damit bewegt er sich ganz in den traditionellen Bahnen der literarischen Argumentation, in denen das Komische und das Lachen dem Volk und das Ernste dem gebildeten Publikum zugeordnet wird - eine Unterscheidung, die Gozzi in seiner Verteidigung der Commedia dell'arte als künstlich und wirklichkeitsfern entlarvt, muß er doch feststellen, daß bei Truffaldinos Späßen nnobiliø wie spopolani* gleichermaßen lachen. ${ }^{129}$ Wenn Goldoni der einmal gewählten Argumentationsstrategie gemäß suggeriert, seine Kritiker verurteilten generell alles Niedere und Gemeine (ssoggetti e [...] argomenti

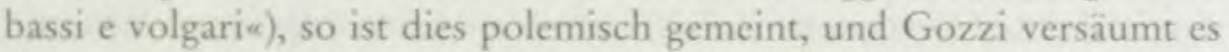
dementsprechend nicht, in mehreren Vorworten zu seinen Fiabe teatrali demonstrativ darauf hinzuweisen, daß diese sbassezze $\alpha$ und trivialità enthielten; allerdings, und hierin besteht der fundamentale Unterschied zu Goldoni, fügt er hinzu: „Una bassezza posta in un Teatro sviluppata, e

125 -Egli ha farto sovente de' veri Nobili lo specehio dell'iniquitá e il ridicolo; e della vera plebe l'esempio della virtù e il serio in confronto, in parecchie delle sue Commedie; io sospetto (e forse troppo maliziosamente) ch'egli abbia ciò fatto per guadagnarsi l'animo del minuto popolo, sempre sdegnoso col necessario giogo della subordinazione." (RI, 55).

129 Siebe oben Kap. 2.6 zur ironischen Szene zwischen Truffaldino und Brighella in La donna serpente, $\mathrm{II}, \mathrm{t}$. 
nel suo vero aspetto, che cagiona rivolta, e concorso, non è più bassezza. Ella è un colpo d'invenzion dilettevole, ed utile. ${ }^{130}$

\section{Nachahmung und Transformation}

Diese paradoxe Formulierung zielt darauf $\mathrm{ab}$, den Abstand zwischen einer "bassezza" in der Wirklichkeit und auf der Bühne zu markieren. Das Niedrige im Theater ist nicht eine Kopie der Wirklichkeit, sondern eine Um- und Ausformung, die den Anschein des Wahren erweckt; es ist nicht Imitation, sondern Invention. Damit wird die Distanz des Autors zum in der Wirklichkeit Vorgefundenen sowie seine Transformationsleistung unterstrichen. Zugespitzt bedeutet dies, daß eine Imitation der Natur, verstanden als bloße Kopie (»ricopiare $\propto$, wie Goldoni selbst schreibt ${ }^{131}$ ), die ohne Selektion erfolgt, keinerlei schriftstellerische Leistung impliziert. Diese setzt erst mit der Auswahl und Gestaltung ein.

In diesem Kontext gewinnt auch die Frage des Stils Gewicht; nicht oft genug kann Gozzi betonen, welche Wichtigkeit einem der Materie angemessenen Stil zukommt. Von den frühen Gedichten und den Fogli sopra alcune massime, in denen es heißt, »averò parecchi stili da trattare con distinzione le diverse materie $\propto,{ }^{132}$ bis zu den letzten Texten wie dem Vorwort zum letzten Band der Edition bei Zanardi und La piu lunga lettera zieht sich das Plädoyer für einen bewußten Stilgebrauch. Überzeugt, daß * le varietà degli stili proporzionate alle materie conformate dall'idioma medesimo* (LL, 94) für einen adäquaten Ausdruck der Gedanken unerläßlich sind, erscheint ihm eine Nivellierung nicht nur als literarischer Qualitätsverlust, sondern auch als Verarmung. Die Unterschiedlichkeit der Stile, wie übrigens auch der Gattungen, gewährleistet in Gozzis Augen sowohl eine reiche Variabilität als auch die Angemessenheit von Form und Inhalt. ${ }^{133}$ Dabei geht er keineswegs von einem unveränderba-

10 Vorwort zu La donna serpente, Col. II, 15.

13 S. im Vorwort zu La putta onorata: "[...] i Gondolieri di Venezia, i quali furono da me nella presente Commedia imitati con tanta attenzione che più volte mi posi ad ascoltarli, quando quistionavano, sollazzavansi o altre funzioni facevano, per poterli ricopiare nella mia Commedia naturalmente. \& (Goldoni, II, 42 I).

132 C. Gozzi, Fogli sopra alcune massime, op. cit., S. 118.

133 Unmittelbar deutlich wird dies in Gozzis Außerungen zur Satire, in denen er nicht müde wird darauf hinzuweisen, daß die Satire eine literarische Gattung ist und bestimmten - Gesetzen= unterliegt, daß darüber hinaus zwischen verschiedenen Arten der Sacire zu unterscheiden ist, der allgemeinen und der persönlichen ("satira urbana e scherzevole«, -satira cinica laceratrice", LL, 86), und er seine eigenen für »satire urbane * hält. Daß von den Zeitgenossen eine solchermaßen literarisch legitimierte Redeweise überwiegend 
ren kodifizierten Vorrat an Stilen und Gattungen aus, sondern hält sehr wohl Veränderungen und Neuerungen für sinnvoll und notwendig, wie dies die Fiabe teatrali als ganz neue dramatische Gattung belegen. Wenn seine Kritiker diese als "mostri teatrali^ bezeichnen, ist Gozzi zwar bereit, sich einem solchen Urteil zu unterwerfen, wio mi sommetto al di lui giudizio fondato però sulle Leggi delle antiche Poetiche da me benissimo conosciute, e riverite $(\mathrm{LL}, 102),{ }^{134}$ muß aber konstatieren, daß es auf der Basis einer traditionellen Regelpoetik gefällt wurde, die er im Rahmen seiner Differenzierung des "genere colto $*$ und des *genere popolare * explizit als Maßstab für die Fiabe teatrali ausschließt. ${ }^{135}$ In beredter Weise verleiht er seiner Verwunderung Ausdruck, daß in einer Zeit großer politischer, gesellschaftlicher und geistiger Umbrüche für die literarische Kritik immer noch die alten Gesetze gelten:

A me sembra tuttavia un portento, che in un secolo creduto filosofico rigeneratore, in cui si pretende di aver rovesciate tutte le leggi divine, ed umane; in cui tutte le immaginazioni dell'umano genere sono capivolte, e rivoluzionate; in cui la voluttà sguinzagliata cupida e insaziabile, è Regina e legislatrice; in cui tutti i freni posti da' saggi antenati alle passioni, sono atterrati, beffeggiati, e sputacchiati come ridicoli pregiudizi; in cui tutte le Città, le Castella, le Terre, e quasi i Villaggi dell'Italia sono forniti d'innumerabili Teatri aperti all'universale; in cui l'esercito di Xerse di Commedianti trae il vitto da que' ricinti specialmente in Italia; in cui tutto il premio dipende da pochi soldi all'entrata, esista ancora un picciolo drappelletto che sostenga in virga ferrea, a differenza di tutte le Leggi rovesciate, le Leggi delle antiche Poetiche come sacre, e intangibili nella Drammatica, e gridi, che ciò che non è Tragedia sublime, o Commedia semplice famigliare, composte in sul saggiuolo de' precetti delle Poetiche, è composizione spuria, mostro, spazzatura indegna di cntrare in un Teatro, e capitalmente sbandita dal Parnaso. (LL, 102-103)

Konsequenterweise müßten dann auch Aristophanes, Plautus, Shakespeare, Lope de Vega, Calderón etc. aus dem kulturellen Gedächtnis gestrichen werden, denn ihre Werke zeichnen sich ebenfalls durch stanta libertà, e lontananza da' precetti delle Poetiche legislatrici aus, daß sie nicht zu rechtfertigen sind. Mit dieser Polemik zielt Gozzi nicht nur auf

persönlich verstanden wurde, zeigen deren Reaktionen wie auch diejenigen nachfolgender Generationen, die Gozzi hauufig einen galligen Charakter attestieren.

${ }^{134}$ Gozzi bezicht sich hier direkt auf Pietro Napoli Signorellis Storia critica de' teatri antichi, e moderni, Napoli 1777, die er in La piu lunga lettera ausfuhrlich kommentiert.

13 In den Vorworten zu Il corvo und Il mastro turchino weist Gozzi deutlich auf die Unsinnigkeit eines Vergleichs seiner Fuabe teatrali zum Beispiel mit Maffeis Merope oder Corneilles $\mathrm{Cid}$ hin. $-[\ldots]$ così chiunque leggerà questo nuovo genere franco, audace, e smoderato con artifizio, coll'immagine (verbigrazia) della Merope del Sig. Marchese Maffei, che pur non potè andar esente dalle censure, o d'altri consimili componimenti, sarà buon critico facilmente, ma senza proposito, e senza merito* (Col. I, 125). 
einen einzelnen Kritiker, sondern auf die Heterogenität der Theaterdiskussion und -entwicklung des 18 . Jahrhunderts insgesamt, in denen sich die zunehmende Abwendung von der Regelpoetik, die Auflösung der Gattungsgrenzen, die Konkurrenz unterschiedlicher Auffassungen von Nachahmung sowie die Verschiebung der Akzente von einer Mimesispoetik zu einer Wirkungsästhetik und einer Autonomieästhetik abzeichnen und die Gültigkeit von Beurteilungskriterien unsicher wird.

\section{Nachahmung und moralischer Anspruch}

Unter dem Gesichtspunkt der angestrebten Wirklichkeitsnähe und des erzieherischen Anspruchs erscheinen Gozzi neben Goldonis Komödien auch die französischen »drammi $\alpha$, »drammi flebili $\propto$, „drammi flebili famigliari oder "tragedie urbani $\alpha$, kurz das "genre sérieux «, als fragwürdig. Während die Auseinandersetzung mit Goldonis Theater unmittelbar Ende der soer Jahre in den polemischen Texten, vor allem in Il teatro comico all'Osteria del Pellegrino stattfindet und 1772 in Ragionamento ingenuo, dem Vorwort zum ersten Band der Colombani-Edition, gewissermaßen im Rückblick erfolgt - Goldoni ist seit mehr als ro Jahren in Paris -, richtet sich dieser Text in aktueller Weise gegen das sgenre sérieux $\ltimes$, das in Úbersetzungen seit der Jahrhundertmitte mehr und mehr auf den venezianischen Bühnen zu sehen ist. ${ }^{136} \mathrm{Im}$ selben Jahr, 1772 erschien die vierbändige Sammlung Composizioni teatrali moderne, die Übersetzungen bzw. Übertragungen von Elisabetta Caminer enthielt und schon 1774 eine Neuauflage erlebte, $1774-76$ folgten weitere Stücke in Nuova raccolta di composizioni teatrali tradotte da Elisabetta Caminer Turra. Nicht zufällig wurden diese und weitere Übersetzungsbände in Venedig publiziert, war die Serenissima in dieser Zeit doch die Hauptstadt der Ubersetzungen, die reißenden Absatz fanden und sich als lukratives $\mathrm{Ge}$ schäft für die Verleger erwiesen. ${ }^{137}$ Gozzi wird denn auch nicht müde zu betonen, daß die neue Mode aus der Not der dauernden Forderung des Publikums nach Neuheiten geboren sei und die "romanzetti moderni metamorfosati in sceniche azioni, somigliantissima l'una all'altra, intitolate: Tragedie urbane, o Drammi flebili, o Commedie (la cui rigenerazione, e

136 Bereits 1754 veröffentlichte Gasparo Gozzi Übersetzungen aus dem Franzôsischen unter dem Titel Teatro comico francese.

137 Siche dazu die ausführliche, gut dokumentierte Arbeit von Giovanni Saverio Santangelo und Claudio Vinti, Le traduzioni italiane del teatro comico francese det secoli XVII e XVIII, indagine bibliografica diretta da Marcello Spaziani, Roma, Edizioni di storia e letteratura 1981 . 
originalità d'invenzione non è che nel frontispizio $) *(L L, 20)$, mit Sicherheit keinen Bestand haben werden. ${ }^{138}$ Die Überflutung der Bühnen mit hauptsächlich französischen Dramen gibt der latenten oder offenen Gallophobie italienischer Autoren neue Nahrung. ${ }^{139}$ Stand in der ersten Hälfte des Jahrhunderts die Frage nach dem Modellcharakter des französischen Theaters und der Überlegenheit des französischen über das italienische Theater im Zentrum der Theaterdebatten, rückt nun der französische Einfluß auf das tägliche Leben, die Mode, die Sprache, das Essen, die Literatur, den gesamten Geschmack ins Blickfeld. ${ }^{140}$ Die Skepsis, die Gozzi gegenüber den sinfranciosati๔ und allem Französischen zum Ausdruck

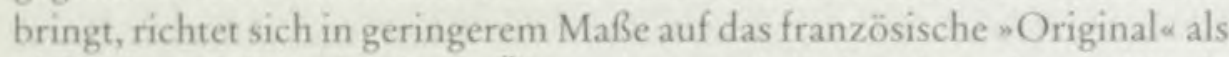
vielmehr auf die unkritische Übernahme und die in seinen Augen blinde Frankreichbegeisterung in Italien, die nationale Differenzen übersieht, italienische kulturelle Traditionen leichtfertig aufgibt ${ }^{141}$ und zu einer wimmaginaria coltura (RI, $50, \varsigma$ I etc.), einer nur eingebildeten Bildung führt, "che non sarà mai confacente agli stati, e a' genj nostri universali๔ (ARI, 54). Gozzi ist überzeugt von der nationalen Unterschiedlichkeit des Geschmacksempfindens und hält einen universalen $»$ buon gusto $\alpha$ und $»$ buon senso für eine Illusion. ${ }^{142}$ Gerade in bezug auf das Theater sind für ihn die nationalen Eigenheiten entscheidend, und mit Blick auf Shakespeare schreibt er: "Tutti i Poeti teatrali delle diverse nazioni cercarono di far popolare i teatri con delle opere sensate in proporzione al talento ch'ebbero, e principalmente studiarono l'indole, $e$ il gusto delle nazioni loro per avere l'intento « (LL, 9). Am Beispiel des Gastspiels einer französischen Truppe

138 In La piü lsnga lettera (180r) stellt Gozzi denn auch fest: stal moda non è più moda, ma è divenuta anticaglia stucchevolen (LL, ${ }_{4}$ o), mit der die Theater nicht mehr zu füllen sind. Stattdessen werden nun wieder Metastasio-Opern und -le Farse più buffonesche del Goldonis ausgegraben. In Ragionamento ingenuo (1772) reagiert Gozzi auf hóchst aktuelle Auffuhrungen und Editionen, zum Teil desselben Jahres.

$139 \mathrm{Zu}$ den vielfältigen Aspekten dieses Phänomens v. a. in Venedig vgl. Ginetta Auzzas, -Gallomania e anglomania =, in: Storia della cultura veneta, $5 /$, op. cit., S. 579-606, und das erste Kapitel -Gallomania e gallofobia - in Arturo Graf, L'anglomania e l'influsso inglese in Itatia nel secolo XVIII, Torino, Loescher $191 \mathrm{I}$.

10 Gozzis Marfisa bizzama bietet ein umfassendes Bild des franzôsischen Einflusses unter satirischer Perspektive.

$141 \mathrm{~V}_{\mathrm{g}}$. z. B. ARI, 53, >Misera Italia, i tuoi ben disposti talenti non averanno da te giammai questi stimoli, e confessandoti sommessa, e avvilita imitatrice della Francia, tu non sei, che una bertuccia, che imita le invenzioni delle insalate di quella Nazione, per farti ridicola.*

162 - Erra di gran lunga chi considera le Nazioni tutte eguali nel genio, ed è infallibile, che quelle Nazioni, che si vorranno riformare collo specchio d'alcune alure senza bilanciar l'indole de' loro nazionali, il genio, le circostanze e il sistema de' propri stati, diverranno ridicole, piene di dissonanze, di confusioni, di cervelli sconvolti, inquieti, insaziabili. (ARI, $5 \circ-51)$. 
in Venedig im Herbst 1772 veranschaulicht Gozzi die Unterschiede, die zwischen dem französischen und dem italienischen Theater im Hinblick auf die Darstellungsweise bestehen. Die »decenza teatrale francese $\alpha$ und die "esatezza in den Auftritten der Schauspieler erscheinen den Italienern als ×ridicole, e affettate caricature $\approx$ (ARI, 63), so daß die Nachahmung der Franzosen durch die Italiener nur lächerlich wirkt. Die Polemik Gozzis gegen die »drammi flebili« zielt daher nicht nur auf die neue Gattung an sich, sondern auch auf den sich damit deutlich manifestierenden französischen Einfluß auf die italienische Theaterlandschaft.

Wie bei Goldonis »commedie di carattere dient auch bei den »drammi flebili famigliari* (RI, 30) nicht wie etwa in Frankreich eine neue Sensibilität, sondern die topische Negativbewertung der Commedia dell'arte als Rechtfertigung für das neue Genre. ${ }^{143} \mathrm{Im}$ Gegenzug hebt Gozzi zum einen darauf $a b$, daß sich diese neuen Stücke untereinander nicht weniger ähnlich sind als die improvisierten Komödien, zum anderen - und dies mit Vehemenz - auf die verdorbene und verderbliche Moral:

lo mi guarderò sempre dal lordare le morigerate scene dell'Adria col turpe specchio de' scellerati famigliari seri argomenti, novità che potria dare dovizia di teatrali soggetti, non da animare, ma da far arrossire qualunque veneto tragico o comico scrittore.

Alla umanità, per lo più inclinata ad appagare le proprie sfrenate passioni, sono perniziosissimi maestri gli empi caratteri posti in scena da un'insidia raffinata, spezialmente se questi tali empi non hanno un castigo adequato a' misfatti loro, il qual castigo, proporzionato che sia, riesce uno spettacolo insofferibile agli sguardi de' nostri umani spettatori. $(\mathrm{RI}, 24)^{144}$

Dem Argument der Gegner der Commedia dell'arte, ${ }^{145}$ diese müsse aus moralischen Gründen von den italienischen Bühnen verbannt werden,

[4] Im Vorwort $*$ Prefazione della tradutrice [sic] $\times$ des ersten Bandes der Composizioni teatralt moderne tradotte da Elisabetta Caminer, 2. Auflage, Venezia 1774, S. 3-4, heißt es dementsprechend: $=$ Le Scene d'Italia erano ingombre di mostruosità strampalate, $e$ d'insipidi contorni, a' quali fu dato il nome di Commedie dell'Arte. Tutte le stravaganze lasciate in Ispagna dagli Arabi, e cresciutevi felicemente, passarono cogli Spagnuoli fra noi. Il falso meraviglioso invase i diritti della sensata Commedia; [...] La ragione, il buon senso, il maneggio delle passioni, la delicatezza, la forza della Poesia Teatrale si stabili sul Teatro di Francia, e vi si mantiene tuttora.

144 Diese Passage ist ein Selbstzitat Gozzis aus dem Vorwort zu seiner Ubersetzung von François Baculard d'Arnaulds Tragödie Fayel unter dem Titel Il Fajel, ntragedia del Sig. D'Arnaud, tradotta in versi sciolti $\alpha$, erschienen 1772 bei Colombani in Venedig und nicht in die Gesamtausgaben aufgenommen (entgegen anderslautenden Angaben in P. Bosisios Ausgabe der Fiabe, op, cit., S, 101). Gozzi zitiert dieses etwa zeitgleich entstandene Vorwort mehrfach in Ragionamento ingenuo.

145 Hier hat Gozzi besonders Elisabetta Caminer im Auge, deren Vorwort zu ihrer Ausgabe von Übersetzungen französischer Theaterstücke er die Argumente zum Teil als wörtliche Zitate (im Text meist durch Kursivierung kenntlich gemacht) entnimmt. 
stellt Gozzi nicht nur kontrastiv die genuine Harmlosigkeit der »commedia italiana all'improvviso « und ihren reinen Unterhaltungscharakter entgegen, sondern er greift deren Stücke mit demselben Argument an. Die Gefahr einer Vermischung, wenn nicht einer Umkehrung von Tugend und Laster, die Gozzi bereits in Goldonis Charakterkomödien sieht, ist in den übersetzten Dramen eklatant, und dies wirkt sich umso negativer aus, als die Theater ja nicht mehr dem Vergnügen, sondern der Erziehung dienen sollen. ${ }^{146}$ Doch es ist nicht nur das problematische Verhältnis von Tugend und Laster, das Gozzi angreift, sondern auch und vor allem die Art der Darstellung und Vermittlung der Inhalte, eine "pericolosa sublimità (RI, 30), die unmittelbaren Einfluß nimmt auf die Zuschauer und in einer Weise wirkt, die ihm unverantwortlich erscheint:

L'aspide sta in quel sublime insidioso, che colla commozione degl'animi introducono alcuni de' novelli Drammi flebili famigliari dalle nobili passioni, tradotti, $e^{1+7}$ difesi ne' nostri 'Teatri degl'impostori per cecità, per venalità, o per malizia come strumenti d'una sana morale educazione.

Il sostenere con efficacia, ed industria continuamente il jus di natura; il dipingere $\mathrm{co}^{\prime}$ più vivi tratti della eloquenza i superiori da mal consiglio ingannati, fallaci, e tiranni; pregiudizj le ben fondate regole delle famiglie, e le leggi; ingiustamente divise le facoltà; inumano despotismo de' padri; l'incitare ognuno alla liberta di pensare, $\mathrm{e}$ di operare; lo spargere delle palliate, $\mathrm{e}$ ingegnose empietà nel mezzo alla commozione degl'animi, e alle nobili passioni, è quella sublimità, ch' io abborrisco, e quell'educazione popolare, ch'io non vorrei. (RI, 30-31)

In dieser polemischen Zuspitzung kommt deutlich zum Ausdruck, daß die Übermittlung konkreter und aktueller gesellschaftlich-politischer Inhalte in Verbindung mit der Erweckung von Gefühlen wie Rührung und Mitleid für Gozzi inakzeptabel ist; inakzeptabel zum einen, weil die unbewußt eindringenden Vorstellungen und neuen Ideale bei den $\mathrm{Zu}$ schauern Unzufriedenheit schüren, da sie nicht zu realisieren sind, zum anderen, weil die Gefühle funktionalisiert werden. Rührung und Mitleid sind nicht mehr selbstlos, vielmehr werden die Emotionen mißbraucht für ideologische Intentionen und das Theater degradiert zur Schule der

146 nSe da' nostri impostori si vuole la Drammatica inserviente all'educazione de' popoli, e non inserviente ad un lecito trattenimento, concediamolo; ma non ci scordiamo giammai che il recinto de' Teatri diviene una scuola universale. Non difendo la barbarie, ma disprezzo la falsa sublimità della scienza, che d'oltremonti giugne a farsi adottare da noi.e (RI, 30; Kursivierungen im Originaltext).

167 An dieser Stelle fügt Gozzi maliziös eine Fußnote ein: > Supplico gli Italiani infranciosati a non prendere quel difesi per protbiti.- Die Kursivierungen in Gozzis Text markieren Zitate aus E. Caminers Vorwort. 
selbsternannten Weltverbesserer. ${ }^{148}$ Hinsichtlich gesellschaftlich-politischer Entwicklungen ist Gozzis Position - wie bei vielen Aufklärungsgegnern - von einem tiefen Pessimismus geprägt; er zieht Verbesserungsmöglichkeiten grundsätzlich in Zweifel, hält ein Fortschrittsdenken für unrealistisch und sieht im Status quo einen der bestmöglichen Zustände. Aus dieser Perspektive heraus spottet er über den Glauben der "filosofi “ an Freiheit und Gleichheit und sieht in der Propagierung dieser Ideale auf der Bühne eine Irreführung des Volkes, da dieses aufgrund der unumgänglichen Stratifikation der Gesellschaft nie in den Genuß wahrer Freiheit und Gleichheit kommen wird. ${ }^{149}$ Daraus ergibt sich die Verteidigung von Religion, Obrigkeit und Gesetzen als Garanten einer gewissen Stabilität, die im Hinblick auf das Volk bisher gute Dienste geleistet haben. ${ }^{150}$ Bei aller vehementen Polemik gegen die aktuellen Tendenzen, für die der französische Einfluß nicht nur in literarischer Hinsicht verantwortlich gemacht wird, schließt Gozzi Änderungen von Gesetzen und sozialen Reglementierungen nicht aus; allerdings sind diese, und das ist essentiell, von Spezialisten vorzunehmen und nicht von den Schriftstellern im Theater zu initiieren. ${ }^{151}$ Das Theater ist in Gozzis Augen nicht der Ort für propagandistische Maßnahmen zur Einleitung gesellschaftspolitischer Veränderungen.

${ }_{148}$ Die Kontamination von Literatur und sphilosophie nimmt auch in der franzôsischen Diskussion breiten Raum ein, wie die Polemik Palissots und Frérons gegen die sphilosophes deutlich macht; vgl. Didier Masseau, Les ennemis des philasophes. L'antiphilosophie an temps des Lumieres, Paris, Albin Michel 2000, S. 14 I-149.

${ }^{149} \mathrm{Daß}$ ein solcher Gedanke nicht pauschal als antiaufklärerisch gewertet werden kann, geht aus Werner Schneiders Feststellung hervor, daß sdie Aufklärung als ganze [...] nicht primär und bewußt auf gesellschaftliche Freiheit, etwa gar Freiheit für alle, ausgerichtet [war], da sie fast bis zuletzt politisch zurückhaltend und zumindest offiziell monarchistisch war*; W. Schneiders, Aufklarung und Vorurteilskritik. Studien zur Geschichte der Vorurteilstheorie, Stuttgart-Bad Cannstatt, frommann-holzboog $198_{3}$, S. 26 .

150. Che un minuto popolo Cattolico educato nella semplicita, in una immagine grande della Religione, nel timore verso il Principato, e le leggi, nell'assiduita delle arti; divertito in Teatro con delle parodie facete, del mirabile, della forte, ma onesta passione, sia un minuto popolo più suscettibile d'una virtù comoda alla società, che un minuto popolo Cattolico, a cui s 'intuoni sempre il jus di natura, ingiusto il vincolo delle leggi, tranna la preminenza, si decanti sempre la dolcezza de' protestanti, e la rigidezza del Cattolicismo, ciò sarà un problema facile a sciogliersi, e sembra impossibile, che quella, che si chiama sublimità del secolo, abbia fatto cadere il proposito d'un tal problema sul proposito de' Teatri.* (RI, 44).

$15 i$-Spetta a' saggi scelti dall'umanità mallevadori dell'esecuzione delle leggi stabilite, it riformare, o l'aggiungere de' decreti a norma delle circostanze, onde gli effetti della equità, e della giustizia tengano equilibrato il jus di natura dipendente dalle leggi volute; nè spetta a' maligni, e torbidi scrittori il suscitare separatamente tutti gli uomini a farsi giudici di loro medesimi, per guadagnare un partito di malcontenti, che gl'ingrassi, e mantenga i piaceri loro.* (RI, 33). 
Im Laufe der Besprechung einiger Übersetzungen Elisabetta Caminers (v. a. Il disertore, Il Jenneval ovvero il Barnevelt francese ${ }^{152}$ ) führt Gozzi die ganze Fragwürdigkeit der angeblich moralischen Stücke vor Augen und dies besonders im Hinblick auf die Veränderungen, die die Übersetzerin gegenüber den Originalen vorgenommen hat. Im Gegensatz zu Merciers Le déserteur endet beispielsweise die italienische Version nicht mit dem Tod des Protagonisten, sondern mit der glücklichen Wiedervereinigung von Vater und Sohn und der Aussetzung des Todesurteils. Wenn Gozzi sich schon bei Merciers Version fragt, "Quanto fu sempre la dannosa diserzione inevitabile, tanto si accrebbe la necessità della pena di morte per evitarla, e se, con tutta la punizione di morte reale, de' soldati disertano, come terrà stretto il soldato al proprio dovere l'esempio d'una scenica morte? « $(\mathrm{RI}, 34)$, wieviel unangemessener muß dann die Werbung für die Abschaffung der bei Desertion vorgesehenen Strafe erscheinen, die nur von einer "fanciulla di buon' animo (RI, 35) kommen kann. Auch in Jenneval endet der von der Kurtisane Rosalia verführte und sich immer tiefer in Laster und Schuld verstrickende Jenneval nicht auf dem Schafott, sondern in den Armen der tugendhaften Lucilla. In ihrem Vorwort weist die Übersetzerin darauf hin, daß sie die Mängel des englischen Theaters beheben und das Stück dem italienischen Geschmack habe angleichen müssen, da der Charakter Rosalias zu drastisch, der Mord Barnevelts an seinem Onkel unmöglich und der zweifache Tod auf dem Schafott zu grausam seien. ${ }^{153}$ Das quasi neue Stück gehöre zum "genere utile che espone con tanta forza le disgrazie e i doveri della vita civile«, trage zur Verbesserung der Sitten bei und weise s un nuovo grado di verità e di vita ${ }^{154}$ auf. Mit einem Seitenhieb auf Gozzis Theaterverständnis en-

132 Louis-Sébasticn Mercier, Le déserteur; George Lillo, The London Merchant bzw. Mercier, Jenneval ou le Barnevelt franpois. G. S. Santangelo und C. Vinti weisen darauf hin, daß Elisabetta Caminer französische Versionen für ihre Übersetzungen von englischen, deutschen, dänischen, russischen Texten benutzte (op, cit., S, t2). Dies bedeutet eine weitgehende Abhàngigkeit der italienischen von der franzôsischen literarischen Szene, die gewissermaßen die Stücke durch Übersetzungen bzw, Übertragungen selektioniert und sanktioniert hatte, bevor sie nach Italien gelangten.

153. -Questo Dramma inglese di Lillo è in una grande e meritata riputazione; regna in esso la verità e il patetico commovente, anima del genere Drammatico [...]; ma la confusione delle scene, I'interesse tronco $\mathrm{c}$ diviso, il bizzarro accanto al sublime, tutti insomma i difetti del Teatro Inglese impediranno che Barnevelt venga mai rappresentato, nello stato in cui si ritrova, sul nostro. [...] lo ho procurato di superare gli ostacoli, $e$ di addattare questo argomento al nostro 'Teatro, vale a dire a' nostri costumi*, in: Composizioni teatrali modeme, Bd. 4 , op. cit., S. 75 .

${ }^{154}$ Ebd., S. 78 und 81. Tatsächlich erscheint es heute schwer verständlich, wie angesichts der schematischen Figurenzeichnung, der klaren Trennung in Gute und Böse und der vôllig unwahrscheinlichen Schlußwendung von = Wahrheit * und =Lebensnähe* gesprochen werden kann. 
det das Vorwort: $\bowtie$ Quanta energia, qual trionfo non avrebbe nel medesimo tempo il nostro Teatro se invece di riguardarlo come il rifugio degli oziosi, si considerasse come la scuola delle virtù e de' doveri del Cittadino! ${ }^{155}$ In höchst ironisch-polemischer Weise analysiert Gozzi das Drama und führt dabei die Behauptung ad absurdum, es diene der Erziehung des Publikums und führe zur Tugend. Die tugendhaften Personen machen in seinen Augen den Eindruck einer $*$ ridicola, e caricata austerità o di scioccherella inutilex, die verschlagenen Dienerfiguren dagegen erwecken bei den Zuschauern »immagini di nobili passioni «, die Kurtisane Rosalia als handlungstragende Figur, auf die Gozzi sein Hauptaugenmerk richtet, ist «uno specchio di educazione mirabile in sul Teatro». Dem vierten Akt dieses $*$ Dramma educatore $\alpha$, in dem Rosalia von Jenneval absolute Liebe fordert und ihn vor die Alternative stellt, seinen Onkel entweder selbst umzubringen oder ihn mit seinem Einverständnis von ihr umbringen zu lassen, attestiert Gozzi, Caminers Vorwort zitierend, stutta la quintessenza d'una scuola sublime alle fanciulle, alle mogli, ed a' servi $\alpha$, und er wird nicht müde, ironisch von *utilissimo liceo $*$ und vernichtend von "scuola di seduzione« zu sprechen. Das Endergebnis ist eindeutig:

Lo schifo specchio di quest'opera, non può, che lasciare un'impressione perniziosa. La lorda lascivia, la scelleraggine, $\mathrm{e}$ la seduzione, che dimostrativamente, $\mathrm{e}$ con acutezza maneggiate occupano la parte spirituale di [sic] spettatori, e divengono lo scopo principale in essa; o scandalezzano, o ammaestrano al male l'umanita per lo più inclinata ad appagare le proprie sfrenate passioni. ${ }^{156}$

Nicht zufällig wählt Gozzi als Paradebeispiel für seine Demontage eines angeblich auf Tugend zielenden Stückes das »dramma flebile « Jenneval, stehen doch hier die negativen, lasterhaften Charaktere einerseits ganz im Vordergrund des Geschehens, während andererseits die "gerechte* Bestrafung in der italienischen Übertragung ausbleibt. ${ }^{157}$ I77I erstmals in Venedig am Theater Sant'Angelo aufgeführt und ein Jahr später in die Composizioni teatrali moderne aufgenommen und mit einem Vorwort versehen, ist Jenneval höchst aktuell und den Lesern des Ragionamento ingenuo wohl präsent. Gozzis Kritik kann ähnlich wie in Il teatro comico all'Osteria del Pellegrino in bezug auf Goldonis Komödien bei den Wi-

155 Ebd., S. 8 t.

156 Zitate RI, 38-41. Die Kursivierung im Text Gozzis markiert ein Selbstzitat aus dem Vorwort zu II Fajel, das bereits in RI, 24 zitiert wurde.

157 Diese Ambiguität scheint auch im Vorwort Elisabetta Caminers auf, wenn sie sich fragt, -Come esporre tutta l'energia della passione e non mancare allo scopo morale, far raccapricciare e non ispirar orrore? $\times$ (op. cit., S. 77), wird jedoch nicht weiter verfolgt. 
dersprüchen innerhalb des Vorworts sowie zwischen den Beteuerungen dort und dem Stück selbst ansetzen.

Die in der Diskussion um das Theater immer wieder bemühte Spiegelmetapher, die auf die Nähe des Dargestellten zur Erfahrungswelt der Zuschauer und den Effekt des Wiedererkennens zielt, ${ }^{158}$ erfährt durch Gozzi eine kritische Interpretation, die zweifach begründet ist. Zum einen läßt sein Pessimismus und das von Skepsis geprägte Menschenbild eine Spiegelung auf der Bühne zweifelhaft erscheinen, und dies umso mehr, als in seinen Augen das Theater dem Vergnügen dient, zum anderen enthüllt er eine Inkonsistenz in der Argumentation der Anhänger des Theaters als Schule, die die Spiegelmetapher unterminiert. Wenn das auf der Bühne Dargestellte den Zuschauern möglichst nah sein soll und also die Wirklichkeit weitestgehend abgebildet bzw. gespiegelt wird, andererseits aber der Anspruch auf eine erzieherische Funktion des Theaters besteht, ergibt sich die Schwierigkeit, wie ein Lerneffekt entstehen soll, wenn das Publikum auf der Bühne dasselbe sieht wie außerhalb des Theaters und erfahrungsgemäß die nicht-theatrale Wirklichkeit die Tugendhaftigkeit der Menschheit nicht gerade befördert. ${ }^{159} \mathrm{Da}$ unausgesprochen die Wahl der Sujets für die Darstellung auf der Bühne im Hinblick auf die Wirksamkeit immer eher auf Problematisches, Laster- und Schuldhaftes fallen wird, da das "Normale " Langeweile und Desinteresse erzeugt, ist das Problem umso virulenter, denn eine direkte Abbildung der schlechten

158 Die Metapher taucht z. B. bei Goldoni im Vorwort zu La casa nova auf, in Chiaris Komödie Il poeta comico, in Verris La vera commedia, bei Gasparo Gozzis etc. Vgl. E. Caminer, $=\mathrm{E}$; , oserò dirlo, desiderio generale della nazione di veder finalmente Drammi che ci appartengano, e lo scopo morale de' quali sia più effettivo, come più vicino a noi. [...] Quanto piú dice Gravina, la favola si avvicina agli avvenimenti famigliari, tanto più apre nell'anima un libero ingresso alle massime cui contiene,e (op. cit., S. 80).

159 Interessanterweise bestätigen neuere theatersemiotische Untersuchungen Gozzis mehr indirekt als direkt zum Ausdruck gebrachte Überlegungen zur Problematik einer »naturalistischen = Theaterkonzeption mit padagogischen Implikationen. In Lire le théâtre I beschreibt A. Ubersfeld das illusionistische Theater wie folgt: * Le théàtre d'illusion. est un accomplissement pervers de la dénégation [d. h. - tout ce qui passe sur la scène est frappé d'irrealité<]: il s'agit de pousser sí loin la ressemblance avec la réalitér de l'univers socio-ćconomique du spectateur, que ce soit l'ensemble de cet univers qui bascule dans la dénégation; l'illusion se reverse sur la réalité elle-même, ou plus précisément, le spectateur, devant une réalité qui tente de mimer parfaitement ce monde, avec la plus grande vraisemblance, se trouve contraint à la passivité. Le spectacle lui dit: se monde, qui se trouve ici reproduit avec tant de minutie, ressemble à s'y méprendre au monde où tu vis (où vivent d'autres que toi, plus chanceux); pas plus que tu ne peux intervenir dans le monde scénique enclos dans son cercle magique, tu ne peux intervenir dans l'univers réel où tu visヶ, (A. Ubersfeld, Lire le theâtre I, op. cit., S. 36). Mimesis als Kopie verhindert demnach eine Re-Aktion, also auch ein Lernen, und verurteilt den Zuschauer zur Passivitat. 
Realität kann in Gozzis Augen nicht positiv auf den Zuschauer wirken. Tatsächlich wird diese komplexe Frage nach dem Verhältnis von Wirklichkeitsnachahmung, Sujetwahl, Erziehungsanspruch und Wirkungsweise von italienischen Autoren und Übersetzern in den Vorworten und Hinweisen an die Leser kaum reflektiert, ${ }^{160}$ sondern in stereotyp-doktrinärer Weise zum einen die Wirklichkeitsnähe der Stoffe und Charaktere betont, zum andern die Nützlichkeit des Theaters aufgrund seines Erziehungsauftrags. Ein weiteres Schlaglicht wirft Gozzis Kritik auf den latenten Widerspruch, der zwischen der Konzeption des Theater als Schule und der angestrebten Wirkung der Rührung besteht. Eine derartige emotionale Wirkungsintention, die auf »commozione « und »piangere» basiert und in Elisabetta Caminers Vorworten vielfach zu finden ist, ${ }^{161}$ will nicht zur fortwährenden Verwendung des Begriffs »scuola « passen, zielt der Unterricht in der Schule doch auf den Intellekt und nicht auf Emotionen. Wäre das Theater tatsächlich eine Schule, so dürfte es in Gozzis Augen nicht Rührung und Mitleid verursachen, hingegen müßte es vernünftig demonstrieren und glaubhaft vor Augen führen. Unter diesem Blickwinkel und unter der momentanen Aneignung des utilitaristischen Theaterverständnisses liest Gozzi polemisch die übersetzten weinerlichen Lust- und bürgerlichen Trauerspiele, wobei er konsequenterweise zum

160 Im französischen Kontext konstatiert z. B. Beaumarchais in -Essai sur le genre dramatique sérieux « : "à la honte de la morale, le spectateur se surprend trop souvent à s'intéresser pour le fripon contre l'honnête homme, parce que celui-ci est toujours le moins plaisant des deux a. Diese Feststellung bezieht sich allerdings auf die Komodie, das ngenre plaisant *, dessen moralische Wirkung damit zunichte ist. Dagegen bewirkt das sgenre sérieux* bzw, "genre touchant «, wie der Begriff schon sagt, ein stilles Mitfühlen und -leiden, das eine moralische Besserung bewirkt: -Le tableau du malheur d'un honnête homme frappe au cœur, l'ouvre doucement, s'en empare, et le force bientôt à s'examiner soi-même. [...] comme je ne m' intéresse qu'au malheureux qui souffre injustement, j'examine si par légèreté de caractère, défaut de conduite, ambition démesurée, ou concurrence malhonnête, je me suis attiré la haine qui me poursuit, et ma conclusion est sûrement de chercher à me corriger. Ainsi je sors du spectacle meilleur que je n'y suis entré, par cela seul que j'ai été attendri. « (Pierre-Augustin Caron de Beaumarchais, Euvres, Hg. Pierre Larthomas unter Mitarbeit von Jacqueline Larthomas, Paris, Gallimard 1988, S. 127-128.). Trotz seiner hellsichtigen Beurteilung des Zuschauerinteresses und -vergnügens am A-Normalen, Ausgegrenzten, geht Beaumarchais beim ernsten Drama a priori vom Interesse am Unglücklichen, am Opfer aus und konstruiert auf dieser Basis eine individuelle heilsame moralische Wirkung, während Gozzi umgekehrt die fatale Wirkung der Verführer, der Bösewichte, der Täter akzentuiert.

161 Beispielhaft seien die "Prefazione della tradutrice* angeführt, in der mit Blick auf das Publikum »fargli piangere per commozione (op. cit., Bd. I, S. 2) als Hauptzweck angegeben wird, und das Vorwort zu Jenneval, in dem es in genuin empfindsamer Diktion uber die neue Dramengattung heißt: *che più dell'orgogliosa Tragedia parla alla moltitudine, ove riposano moltissime anime semplici e sensibili, le quali per commoversi altro non attendono che le grida della naturae (op. cit., Bd. 4, S. 78 ). 
Ergebnis kommt, daß das, was hier vorgeführt wird, keineswegs lernenswert ist, sondern im Gegenteil das Publikum zu unmoralischem Handeln verführt.

In der Auseinandersetzung Gozzis mit den zeitgenössischen Tendenzen werden sowohl die Koexistenz unterschiedlichster Formen von Theater (wie Commedia dell'arte, Goldonische Charakter- und Volkskomödien, bürgerliche Trauerspiele, weinerliche Lustspiele, Theatermärchen) als auch fundamentale Differenzen in der Konzeption des Theaters sichtbar. Diese Vielfalt oder - je nach Standpunkt - Heterogenität ist in Gozzis Augen typisch für sein Jahrhundert, »un secolo vacillante, immerso in un caos di confusione, e senza nessun gusto determinato, spezialmente sulle belle lettere $\propto$ (RI, I6). Nicht, daß Gozzi nun für normative Geschmacksrichtlinien oder eine Regelpoetik einträte, die das Chaos ordnen könnten, im Gegenteil weist er - in einer Art Selbstrechtfertigung bezüglich der Fiabe teatrali - auf die unglücklichen Effekte zu streng befolgter Regeln hin,

L.a rispettabile antichità pensava sopra le parti d'una composizion teatrale con quelle stesse ristrette, ed austere massime, colle quali il Petrarca, ed il Bembo pensavano sulle parti, che deve avere un sonetto, e nulla risparmiava per istringere gl'ingegni entro ad un'angusta circonferenza, che non gli lasciasse uscire dalla perfezione, e dalla semplicità.

La noja ne popoli fu una conseguenza di queste ristrette regole, e molti Scrittori teatrali, ostinatisi in queste, empierono le opere loro di maggiori assurdi, che non le avrieno empiute, se se ne fossero dispensati. (RI, 47)

Sein entschiedener Widerspruch entzündet sich am missionarischen Ernst, mit dem die sogenannten Neuerungen vertreten werden, an der bewußten Mißachtung literarischer und kultureller Traditionen und dem omnipräsenten Nützlichkeitsgedanken, der von den binomischen horazischen Formeln nur noch das »prodesse $\propto$ und das »utile « übrigläßt, während die Komponente des $\nsim$ delectare $\star$ wie des $\nsim$ dulcis $\approx$ zu verschwinden drohen. Dagegen setzt Gozzi bewußt die Konzeption eines Theaters, das dem Zeitvertreib und dem Vergnügen dient. Es will nicht Schule sein, will kein Erziehungsprogramm bieten, will sich keinen gesellschaftlichen und politischen Ideologien dienstbar machen lassen, und sein einziger nützlicher Effekt ist der, eine Schauspielertruppe zu unterstützen: nscrissi per il Teatro per ispassare la mia Patria, per mio passatempo, e per soccorrere una Truppa comica morigerata, ed esperta ${ }^{162}$ Sowohl hinsichtlich

162 Manifesto del Co: Carlo Gozzi, dedicato a' magnifici Signori Giomalisti, Prefattori, Romanzier, Pubblicatori di manifesti, e Foglivolantisti dell'Adria, s.t.n., S. 8; in diesem Manifest kündigt Gozzi die unmittelbar bevorstehende Edition seiner Werke bei 
des Autors als auch des Publikums wird die unterhaltende Funktion in den Vordergrund gerückt, und anders als die «poeti prezzolati setzt sich Gozzi weder einem Produktionszwang aus, noch ist er daran interessiert, mit seinen Stücken Geld zu verdienen. ${ }^{163}$ Dies sind die Rahmenbedingungen für ein Theater bzw. eine Literatur, die sich nicht einem vorgeblichen oder wirklichen Nützlichkeitsanspruch verschreiben, sondern als autonom verstehen. ${ }^{164}$

\subsection{Von der Wabrheit der Illusion in den, Fiabe teatralic}

\section{Distanz zur Wirklichkeit}

Mit der Wahl des Märchens und der Masken als Hauptkonstituenten der Fiabe teatrali legt Gozzi in mehrfacher Hinsicht einen radikalen Gegenentwurf zu den zeitgenössischen dramatischen Formen vor. Märchen und Masken stehen bei seinen Zeitgenossen im Verdacht, der Irrationalität entsprungen zu sein und einer vernünftigen Weltsicht nicht zu entsprechen, sie werden abgetan als kindisch bzw. unmoralisch, als nutzlos, wirklichkeitsfern und überlebt. Diese negativ konnotierten Charakteristika kehrt Gozzi mit den Fiabe teatrali ins Positive - zum einen in expliziter Weise, indem er die unbestreitbare Wirkung des Wunderbaren und des maskenhaft Komischen hervorhebt und den Unterhaltungswert der "capricci scenici« mit den harmlos-kindlichen Titeln betont, zum andern unausgesprochen, indem er der Nachahmung der Erfahrungswirklichkeit die artifizielle Kombination von in der kulturellen Tradition verankerten Materialien entgegenstellt, sehr wohl im Bewußtsein, damit etwas Neues zu schaffen. ${ }^{165}$ Ganz im Geist seiner Zeit fehlt auch bei Gozzi der moralische Anspruch nicht, doch ist die Vermittlung der Moral eine ganz andere, nämlich allegorisch-indirekt: ${ }^{166}$

Colombani an, so daß es auf $1771 / 72$ datiert werden kann. Inhaltlich steht es in engem Zusammenhang mit Ragionamento ingenuo.

$163 \mathrm{Vgl}$. oben Anm. 56 im Exkurs zur venezianischen Theaterszene.

$164 \mathrm{Vgl}$. Roberto Tessari, der in Teatro e spettacolo nel Settecento, 2. Auflage, Roma, Laterza 1997, S. 87, in allgemeiner Weise auf die Bedeutung der Autonomie des Theaters bei Gozzi hinweist: - Per lui, l'insegnamento di fondo che si deve ricavare dalle ragioni autonome della pratica scenica è proprio l'autonoma capacitá della scena di essere, a un tempo, forma e contenuto d'una savia dottrina di risposta alla ricerca del piacere.

165 Siehe z. B. RI, 48, - le mie Fiabe, quali si sieno, sono più originali, e più nuove nell'indole de' Drammi flebili.e

166 Siche Kap. 3.5. 
Io non ho, che divertito i miei nazionali in Teatro con delle opere innocenti, sostenendo il mirabile, passione indivisibile dall'umanità, colla forte, e modesta passione di circostanza, vestita di quella eloquenza pittrice, che a me fu possibile, ma nulla certamente dannosa; colla imitazione della natura, tuttochè ciò non si voglia; con de' voli faceti di fantasia, e con un'austera morale spesso allegorica. (RI, 24-25)

Wenn Gozzi hier von ^mirabile und ^imitazione della natura « spricht, gebraucht er in der Zeit geläufige Begriffe der Ästhetik, ohne diese auch nur näher zu bestimmen oder gar in eine argumentative Auseinandersetzung einzutreten. Er geht weder auf Theorien und Überlegungen zur imitatio naturae, zum Wunderbaren oder Erhabenen ein, ${ }^{167}$ noch entwickelt er in systematischer Weise Gedanken zu diesen Problemkreisen, sondern operiert im Hinblick auf eine pragmatische Funktion mit Schlagwörtern - analog zu denjenigen, gegen die sich seine Art von Theater richtet, ${ }^{168}$ und ganz offensichtlich im Bewußtsein, daß es sich dabei um ein eingespieltes Verfahren in den literarischen Debatten der Zeit handelt: $*$ Non ci corbelliamo; cotesto difendere un genere, e sprezzare un'altro genere è una battaglia dell'impostura de' nostri tempi ${ }^{169}$ ' In diesem kodifizierten Schlagabtausch verfährt Gozzi in zweierlei Weise, indem er einmal antithetisch Schlagwörter oder zentrale Aussagen einander (meist implizit) gegenüberstellt, ein andermal dieselben Begriffe mit subtilen Bedeutungsunterschieden versieht. Beidesmal muß er davon ausgehen, daß seine Leser die Referenztexte gut genug kennen, um die Anspielungen verstehen und goutieren zu können. So steht in der zitierten Passage etwa »innocente $\propto$ für die Unschuld nicht in moralischem Sinn wie häufig in den Erklärungen zu »drammi flebili «, in denen die gequälte Unschuld letztendlich doch über die Widrigkeiten triumphiert, sondern in ideologischem Sinn, für nicht zielführend und daher ohne Nutzen, nutz-los also im Gegensatz zum nützlichen Erziehungsanspruch. Und die entscheidende

167 Zur Diskussion um die Nachahmung im französischen Kontext s. Herbert Dieckmann, -Die Wandlung des Nachahmungsbegriffes in der französischen Ästhetik des 18. Jahrhunderts", in: Hans Robert Jauss (Hg.), Nachabmang und Illusion (Poetik und Hermeutik I), 2. Auflage, München, Fink r969, S. 29-59; zum Erhabenen s. Winfried Wehle, -Vom Erhabenen oder über die Kreativität des Kreatürlichen*, in: S. Neumeister, Frubasfklärung, op. cit, S. 195-240, der Muratoris Ausführungen in Della perfetta poesta erwähnt. Ausfuhrliche Untersuchungen zum italienischen Bereich liegen nicht vor.

168 Zur Praxisorientiertheit von Goldonis Reformpoetik und der unzutreffenden und anachronistischen Anwendung von Diderots Theorien auf Goldoni 5. a. Wolfgang Theile, "-La buona Commedia. Goldonis Reformpoetik als Ausdruck von Geschichtlichkeit ", in: Romanische Forschungen 98, 1986, S. 96-119; jetzt in: W. Theile, Carlo Goldoni, op. cit., S. $119^{-1} 3^{8}$.

169 Aus dem Vorwort zu II re de' gen, Col. III, 135. 
Aussage "sostenendo il mirabile, passione indivisibile dall'umanità \& kontrastiert sicher nicht zufällig mit Goldonis apodiktischer Feststellung zum Wunderbaren im Vorwort zur Bettinelli-Edition 1750, die lautet, npiù di tutto mi accertai che, sopra del maraviglioso, la vince nel cuor dell'uomo il semplice e il naturale $\propto .{ }^{170}$ Der Nachahmung der Alltagswirklichkeit, die auf genauer Beobachtung und Erfahrung basiert, wie Goldoni immer wieder betont, von Gozzi polemisch gedeutet als buchstäbliches Kopieren (sricopiare «) von Banalitäten, ${ }^{177}$ steht die Wirklichkeitsferne gegenüber, die sich inhaltlich im Märchen, dramaturgisch in Form der Masken, emotional in den starken Leidenschaften und sprachlich in Versen und rhetorischer Ausgestaltung manifestiert. Überraschenderweise werden jedoch auch die Nachahmung der Natur und eine strenge Moral als Merkmal der Fiabe teatrali genannt - erkennbar im Bewußtsein, mit diesen Feststellungen zu provozieren und gängige Auffassungen in Frage zu stellen. Bei Masken und Märchen von »imitazione della natura $\alpha$ und »austera morale« zu sprechen, muß diejenigen brüskieren, die die Nachahmung der täglichen Wirklichkeit und direkten Umgebung des Publikums propagieren, die Masken in topischer Manier der Unmoral bezichtigen und das Märchenhafte für kindisch halten. Präzisierend bezeichnet Gozzi die Moral seiner Stücke denn auch als »allegorisch «, ein Begriff und eine Vorstellung, die nichts mit der Direktheit eines prononcierten moralischen Besserungsanspruchs zu tun haben und im Kontext der zeitgenössischen Theaterdiskussion fremd wirken.

Der Abstand zur alltäglichen Wirklichkeit könnte kaum stärker markiert werden als in der Kombination von Märchenstoffen und -figuren mit den Masken aus der Tradition der Commedia dell'arte, sowohl was das Material selbst betrifft, als auch was seine Gestaltung angeht. Das Material ist nicht aktuell, sondern Jahrhunderte alt, steht in einer langen ungebrochenen Tradition und verweist auf eine wandere Wirklichkeit, sei es die geschlossene der Märchenwelt, sei es die doppelgesichtige der Masken. ${ }^{172}$ Der Gestaltung liegt, wie gezeigt, eine bewußte Auswahl aus dem komplexen Material zugrunde, die Ausarbeitung erfolgt in einer Art ars combinatoria. Im Unterschied zu einem erfahrungswelt lichen Kontinuum ist die Form bestimmt von Fragmentarisierung und Kontrasten, die

170 Goldoni, 1, 767.

$171 \mathrm{Vgl}$. Anm. 131.

172 Vgl. Erika Fischer-Lichte, Semiotik des Theaters. Eine Einführung, Bd. I, Das System der theatralischen Zeichen, Tübingen, Narr 1983, S. 108-109, die ebenfalls darauf hinweist, daß die Maske *stets auf zwei Subjekte [verweist], nämlich auf dasjenige, das sie bedeutet, und auf dasjenige, das sie verhullt * und die Maske *als cines der Theater allererst konstituierenden Zeichen - begreift. 
den gestaltenden Zu- und Eingriff deutlich vor Augen führen, der neben den Grundkonstituenten des Märchens und der Masken auch wunderbare Elemente aus dem Epos, einer gleichermaßen amimetischen Gattung, cinbezieht. ${ }^{173}$ Subtile Unterscheidungen zwischen Wahrscheinlichem und Wahrem als Gegenstand der Nachahmung, zwischen Nachahmenswertem und Tabuisiertem, zwischen Naturwahrem und Kunstwahrem ${ }^{174}$ sind nicht angemessen, die Priorität des Erfundenen vor dem Erfahrenen und des Konstruierens vor dem Imitieren ist eindeutig. Damit wird der Imagination des Autors als Gestaltendem, wenn auch nicht im Hinblick auf die Erfindung des Stoffes, so doch hinsichtlich der Auswahl und Zusammenstellung eine Bedeutung eingeräumt, die im zeitgenössischen Kontext außerordentlich erscheint. Sind nvero", s naturale $*$ und ssemplice die Schlagwörter, die im Zusammenhang der »commedie di carattere* wie der »drammi flebili $\propto$ und der »tragedie urbane* sowohl für das Dargestellte als auch für die Darstellungsweise herhalten müssen, sollte das entsprechende Schlagwort für die Fiabe teatrali wohl sartificiale a lauten - ein Begriff, der bei Gozzi allerdings nicht fällt.

17) So etwa bei den Abenteuern, die Farruscad in La donna serpente zu bestehen hat. In den Vorworten zu // corvo und /l re de' genj führt Gozzi Boiardo, Ariost und Tasso als Vorbilder fur eine gelungene Verwendung von unwahrscheinlichen, wunderbaren Elementen in der Literatur an: *Que' tre rari, immortali talenti del Bojardo, dell'Ariosto, e del Tasso, che colle rettoriche tinte di verità, date agl'impossibili, e mirabili avvenimenti, ebbero tanto vigore ne" cuori umani, mi persuasero al mio cimento. (Il corvo, Col. I, r20),

I. Calvino weist in Salla fiaba, op. cit., S. 7o, darauf hin, daß die Einflüsse auf das Märchen und seine Beziehungen etwa zu religiösen Traditionen oder dem Ritterepos noch nicht erforscht sind.

174 Solche Differenzierungen sind v, a. in der gelehrten Diskussion zu finden, während sie in der praxisorientierten Auseinandersetzung keine Rolle spielen. Z. B. stellt Martello in Della tragedia antica e modema klar, daß sich die Imitation zwangsläufig vom Wahren

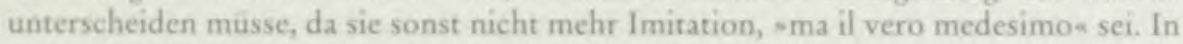
seiner Perfektion sei das Kunstwahre dem Naturwahren überlegen und wecke deshalb Bewunderung und Vergnügen: * Ma tutti questi disinganni operano poi che l'imitazion del costume, delle passioni, de' riti di quella nazione, di cui si parla, e la condotta naturale e fervida dell'azione appunto piacciano perché nel finto cotanto lontano dal vero si ravvisa un non so che più perfetto e più pulito de' veri medesimi; è il vero anzi ridotto ad un'ideal dal vero, ché tale è il rappresentarlo nelle sue perfezioni qual è, e fuori delle sue imperfezioni qual esser dovrebbe. E questo è per isvegliare la maraviglia e il diletto convenientissimo.* (op. cit, S. 257). Zur angestrebten Übereinstimmung von Naturwahrem und Kunstschonem/-wahrem bei Diderot vgl. u. a. Abschnitt V. in Hans Robert Jauss, "Diderots Paradox uber das Schauspiel *, in: GRM 11, 1961, S. 380-413. 


\section{Bühnen-Capriccio}

Stattdessen spielen "capriccio und «capriccioso» eine wichtige Rolle, sowohl hinsichtlich der Charakterisierung der Stücke als auch in bezug auf die inventio. In Vorworten und Widmungen zu den Fiabe teatrali liest man von squesto nuovo, e capriccioso genere teatrale» (Col. II, 5) und »una libera, capricciosa scenica opera fiabesca (Col. II, 303), wie auch von «quelle Fiabe, che uscirono poscia dal mio capriccio* (Col. I, 119), "la mia capricciosa poetica opinione (Col. I, 125) und von der stemerità d'un cervello capriccioso «(Col. I, 326). ${ }^{175}$ Damit sind das Originelle, Scherzhafte der Werke sowie das Eigenwillige, Launenhafte ihrer Entstehung bezeichnet, in deutlichem Kontrast zur betonten Ernsthaftigkeit anderer Autoren und Theaterstücke. Der Begriff »capriccio» und seine Ableitungen verweisen auf die freie Erfindung, das Phantastische, das Spielerische, das Irrationale und sind besonders in bezug auf die Commedia dell'arte hinsichtlich der Improvisation, des Erfindungsreichtums und des Burlesken der Masken sowie im Bereich der Musik zur Bezeichnung von Stücken in imitierender oder freier Schreibweise seit langem gebräuchlich, ${ }^{176}$ wobei in der italienischen Musik eines Locatelli oder eines Tartini um 1730/40 das Bizarre, Virtuose an Gewicht gewinnt. Im Settecento tritt das Capriccio mit Luca Carlevarijs, Marco Ricci, Giovan Battista Piranesi, Canaletto und Giambattista Tiepolo gerade in der venezianischen Malerei in den Vordergrund, analog zur Musik nun als Terminus für ein Genre, das eine eigene Formsprache entwickelt. So erhält das eigentlich Freie, Erfundene, Phantastisch-Bizarre des Capriccio seine Normen und wird zu einer "irregolarità regolata ${ }^{177}$ Gozzis Gebrauch von "capriccio und "capriccioso" im Kontext der Fiabe teatrali ist insofern bemerkenswert, als der Begriff im literarischen Zusammenhang keine Tradition hat, aber einmal mehr eine Verbindung zur Commedia dell'arte konnotiert und überdies geeignet ist, einen Bogen zur zeitgenössischen Malerei zu schlagen. ${ }^{178}$ Sowohl im Hinblick auf seine allgemeine Bedeu-

175 Eine Fülle von Belegen findet sich auch in La piu lunga lettera.

$176 \mathrm{Vgl}$. Dario Succi, = L'arte dell'arte: i capricci veneziani del Settecento $\%$, in: ders. ( $\mathrm{Hg}$.), Capricci veneziani del Settecento, Ausstellungskatalog, Torino, Allemandi 1988, S. 13-38. In Zusammenhang der Commedia dell'arte spricht Gozzi zwar nicht direkt von •capriccio*, charakterisiert aber die Schauspieler z. B. als *spiriti bizzarri* $\left(R I, 1_{3}\right)$ und ruft so einen wichtigen Bedeutungsaspekt von =capriccio a auf, der auch in der Bezeichnung seiner eigenen Werke wieder auftaucht: "poetiche bizzarric in sul teatro (Mem. 1, 190); -le sceniche mic bizzarre rappresentazioni* (Mem. 1, 263) etc.

177 Ebd., S. 16.

178 Gozzi erwàhnt die venezianische Malerei allerdings an keiner Stelle. Im Gegensatz zu einer umfassenden ästhetischen Diskussion, wie sie etwa in Frankreich und Deutschland 
tung als auch in direktem Bezug zum landschaftlichen und architektonischen Capriccio der venezianischen Malerei des 18 . Jahrhunderts vermag die Verwendung gerade dieses Begriffs ein Licht auf Gozzis Theater zu werfen. Generell stehen sich, wie gezeigt, die semantischen Felder von Laune, Scherz, Phantasie und Beobachtung, Erfahrung, Ernsthaftigkeit, Wirklichkeit in der Verteidigung der unterschiedlichen dramatischen ogeneri« gegenüber, darüber hinaus lassen sich aber noch weitere Parallelen zum Capriccio in der Malerei erkennen. Dazu sei Dario Succis Charakterisierung von Carlevarjis' svedute ideate « zitiert, die im Katalog zu einer umfassenden Ausstellung venezianischer Capricci des 18. Jahrhunderts unter dem Titel $\approx$ Il capriccio paesaggistico e rovinistico $* \mathrm{zu}$ finden ist: - L'assemblaggio di citazioni, interpolate per lo più da prototipi barocchi berniniani, di monumenti equestri e di fontane ed il ricorso ad una serie di immagini, non letterali ma sufficientemente riconoscibili, codificate nei dipinti e nelle incisioni di precedenti generazioni di artisti, vengono rielaborate da Carlevarijs con "pittoresca licenza\&, cioè a capriccio.e ${ }^{179} \mathrm{Der}$ Zugriff auf vorhandenes Material, das Zusammenfügen von Elementen unterschiedlicher Provenienz, deren Transformation im neuen Kontext in einer Weise, die die Möglichkeit des Wiedererkennens im Auge behält, all dies sind Aspekte, die auch für die Fiabe teatrali charakteristisch sind und Werke kennzeichnen, die nicht auf eine direkte Nachahmung oder Abbildung der Wirklichkeit zielen oder eine solche vorgeben. In La piu lunga lettera beschreibt Gozzi dieses Vorgehen mit "rifabbricare degli edifizj di nuova architettura a mio senno $(\mathrm{LL}, 35)$ in einer Weise, die geradezu postmodern anmutet. ${ }^{180}$ Entscheidend ist die Verankerung des Materials in der Tradition, die zitathafte Verwendung und Neukombination

geführt wird, spielen Bezüge zwischen Literatur, Malerei und Musik in der praxisorientierten italienischen bzw. venezianischen Theaterdebatte keine Rolle, Wenn Gozzi den Begriff scapriccio verwendet, zeugt dies jedoch zumindest von einer bewußten Wahrnehmung aktueller Tendenzen in der Malerei.

179 Ebd., S. 16-17.

1Ko Vgl. Niklas Luhmann, Die Kunst der Gesellschaft, 2. Aufl, Frankfurt am Main, Suhrkamp r998, S. 205 , der im Zusammenhang der Betonung der Unwahrscheinlichkeit des Kunstwerks feststellt: $=$ Dekontextierte historische Referenzen mógen, wie in der Postmoderne, aufgenommen werden, wobei dann die Unwahrscheinlichkeit in eben dieser Dekontextierung, also im wahlfreien Zugriff auf den geschichtlichen Formenvorrat besteht. Was gebunden war, kann nun frei verwendet werden, sofern die Wiedererkennbarkeit gesichert ist. « Wenn N. Luhmann dann konstatiert, daß in der Romantik die Erkenntnis beginnt, daß - cin für Kunstformen geeignetes Medium [...] gesucht und gefunden, schließlich konstruiert werden [muß] durch Abbau von Interpretationshilfen, die dem tăglichen Leben entnommen werden können= (S. 206), kōnnten Gozzis Fabe teatrali als fruhe Zeugnisse dieser Tendenz gelten, was u.a. die intensive Rezeption Gozzis in der deutschen Romantik erklaren könnte. 
des Vorhandenen. Wenn es sich auch beim Capriccio in der Malerei wie bei Gozzi nicht um eine völlig freie Erfindung der Phantasie handelt, ${ }^{181}$ verweist das Capriccio doch unübersehbar auf die Einbildungskraft, sei es die seines Schöpfers, sei es die seines Betrachters im Theater oder vor dem Bild. Diese Einbildungskraft ermöglicht Verwandlungen, Umbildungen, neue Zusammensetzungen, so daß die Konstruktion gegenüber der Imitation ein weitgehendes Übergewicht erhält. ${ }^{182}$ Der Akzent liegt auf der artifiziellen Herstellung einer neuen, anderen Realität, die sich allerdings nicht unmittelbar als konstruierte zu erkennen gibt, sondern auf den ersten Blick täuschend wahr erscheint. Dies fordert vom Betrachter zuvorderst die Fähigkeit, den Abstand zwischen dieser anderen und der tatsächlichen Wirklichkeit zu erkennen und zu ermessen. ${ }^{183} \mathrm{Im}$ Unterschied zu den gemalten Capricci enthalten die Fiabe teatrali deutliche Signale für einen solchen Rezeptionsprozeß, da nur die märchenhaften Szenen auf eine derartige Illusionierung zielen, während die Auftritte der Masken diese jäh unterbrechen und damit die Des-Illusionierung der Zuschauer entscheidend befördern.

Neben der Neukombination präexistenter Elemente ist der Aspekt des spielerischen, freien, nicht zweckgerichteten, utilitaristischen Schaffens wesentlich für das Capriccio. Analog zum Antagonismus von Theater als Vergnügen und Unterhaltung und Theater als Schule, ist "capriccioso $\alpha^{184}$ als Gegenbegriff zum allgegenwärtigen »utile ${ }^{185} \mathrm{zu}$ verstehen, das vor allem zur Legitimation für die wachsende Bedeutung des Theater als öffentlicher Institution herangezogen wird, denn nur unter der Bedingung, daß das Theater einen Erziehungsauftrag erfüllt, kann es als gesellschaft-

181 So nimmt bei Gozzi der Begriff *fantastico * im Gegensatz zu wcapriccioso * des ófteren cine negative Konnotation an und steht für Traditionsvergessenheit und reine Erfindung ohne Verbindung zur Realitãt, sei damit dic kulturelle Tradition oder die Alltagswelt gemeint; vgl. z. B. wfantastiche novelle metafisiche di un formicajo di Romanzetti francesi $(\mathrm{LL}, 5-6)$, sun semplice fantastico disegno dell'opulenza* (Mem. I, 75).

182 In der Malerei stehen sich die beiden Konzeptionen, die mimetische und die konstruktive, nicht so unversöhnlich gegenüber wie dies im Theater der Fall ist. Die Maler der Capricci schaffen auch exakte Veduten, wie das wohl berühmteste Beispiel Canalettos zeigt, und demonstrieren damit die Kontiguität und Komplementarität der Genres; D. Succi spricht von einem $\nsim$ disinvolto passaggio di tutti i grandi vedutisti dalla veduta esatta al capriccio dimostrando la contiguità e la complementarità - non l'opposizione - dei generix, ebd. S. I7.

$183 \mathrm{Vgl}$. D. Succi, op. cit., S. 23 : * Leggere un capriccio è soprattutto misurare uno scarto.*

184 Da die deutsche Ubersetzung des Adjektivs mit "kapriziös * negativ konnotiert ist, wird sie hier vermieden.

185 Nicht umsonst betitelt Gozzi seine Memoiren mit Memoric inutili. Vgl, dazu Stefano Calabrese, *Carlo Gozzi e l'ingenuita dei moderniк, in: Rivista di letterature modeme e comparate $38,3,1985$, S. $241-261$, v. a. $247 \mathrm{ff}$. 
lich nützlich gelten und damit Teil des offiziellen kulturellen Lebens werden. ${ }^{186}$ Gozzi konterkariert auch diese argumentative Strategie, indem er darauf insistiert, daß seine ncapricci teatrali ${ }^{187}$ nur dem Zeitvertreib dienen und nützlich allein im Hinblick auf die Einnahmen der Truppe Sacchi sind. Sinn- und nutzlos sind sie deshalb jedoch keinesweg. In ihnen manifestiert sich die für das Capriccio so maßgebliche Fähigkeit zur Imagination, die angesichts der zunehmenden Instabilităt traditioneller Wertvorstellungen und konsensueller Wahrnehmungsmodi die Möglichkeit eröffnet, sich der Wirklichkeit in anderer Weise als mimetisch zu nähern. Wie beispielsweise die kontroverse Beurteilung italienischer Komödien des Cinquecento oder der Komödien Molières, der Dissens zwischen Goldoni und Gozzi oder Baretti über die Charakterkomödien Goldonis oder zwischen Elisabetta Caminer und Gozzi über die Übersetzungen bürgerlicher Trauerspiele und weinerlicher Lustspiele ${ }^{188}$ deutlich macht, ist nicht nur die Bedeutung von »verità $\alpha$ und virtù $\propto$ hinsichtlich der Abbildung der Umgebungswirklichkeit auf dem Theater unsicher geworden, ein und dasselbe Stück kann auch völlig konträre Interpretationen und Meinungen zu seiner Publikumswirksamkeit hervorrufen. Mit seinen *capricci scenici« versucht Gozzi deshalb einen ganz anderen Weg zu beschreiten, auf dem die Imagination einen Markstein bildet.

\section{Kraft der Einbildung}

Überzeugt davon, daß die Einbildungskraft ein wichtiges Element menschlicher Selbstbestimmung darstellt und "la passione del mirabile* immer sla regina di tutte le umane passioni $($ Col. III, 131) sein wird, rücken in den Fiabe teatrali das Wunderbare, Märchenhafte und deren Wirkung auf das Publikum in den Vordergrund. Bereits in der narrativen Darstellung der Aufführung von L'amore delle tre melarance weist Gozzi darauf hin, daß die Zuschauer gebannt dem märchenhaften Geschehen

is Zur Situation in Venedig s.o. Da in Venedig seit langem öffentliche Theater existieren, trifft diese aus Frankreich simportierte - Argumentation für die besondere venezianische Situation weniger zu, worauf Gozzi polemisch verweist, wenn er unbeirrt darauf besteht, daß das Theater gestern wie heute und in Zukunft dem Vergnûgen und nicht der Belehrung dient.

18. Mem. I, 190.

136 Wahrend die Obersetzerin mittels der sverità*, die Jenneval enthàlt, das Ziel verfolgt, -[di] combattere i vizj che disturbano l'ordine sociale* (E. Caminer Turra, Composizioni teatrali moderne, Bd. 4, op. cit., S. 78 ), bewertet Gozzi das Stück als Demonstration der smorale al rovescio* und sscuola di seduzione- (RI, 38 und 41 ). 
folgten ${ }^{189}$ und er selbst nicht minder: "L'Uditorio era contentissimo di quella mirabile novità puerile, ed io confesso, che rideva di me medesimo, sentendo l'animo a forza umiliato a godere di quelle immagini fanciullesche, che mi rimettevano nel tempo della mia infanzia. « (Col. I, 100). Sei sie nun wahr oder erfunden, aus dieser Beschreibung der Überwältigung des Geistes durch die wundersamen Ereignisse auf der Bühne spricht die Faszination, die das Wunderbare, Unwahrscheinliche auf das menschliche Gemüt ausübt. Die am eigenen Leib gemachte Erfahrung, daß der Verstand eine Zeitlang quasi außer Kraft gesetzt und der verständige Erwachsene für Momente wieder zu einem Kind wird, nötigt Gozzi ein Lächeln $\mathrm{ab}$ - wohl nicht nur über die eigene *Schwäche«, sondern auch über die Behauptung seiner Zeitgenossen, das Wunderbare sei nicht mehr zeitgemäß und habe beim Publikum seine Wirkung verloren. ${ }^{190}$ Immer wieder betont Gozzi, daß es ein Hauptanliegen ist, die Zuschauer zu fesseln, ein Publikum von 800 oder 900 Menschen unterschiedlichster Art drei Stunden lang zu unterhalten, ${ }^{191}$ und weist darauf hin, daß dies insbesondere im Hinblick auf die erfundene Märchenhandlung, "falsa base e [...] argomento fanciullesco « (Col. II, 99), eine besondere Art der Darstellung erfordere: das Unwahre, Unmögliche, Unwahrscheinliche muß den Anschein der Wahrheit erwecken. Die Aufgabe des Autors besteht darin, eine sillusione ingannevole zu erzeugen, die geeignet ist »di far comparire all'animo e alle menti de' spettatori verità l'impossibilità $\alpha^{192}$ Eine solche Ästhetik ist zeitgenössischen Auffassungen, die Mimesis als

189 "Ebbi occasione di conoscere, all' apritura di questa scena con degli oggetti affatto ridicoli, la gran forza, che ha 'I mirabile sull'umanità. Un portone fatto a cancello di ferro nel fondo, un cane affamato, che ululava, e passeggiava, un pozzo con un viluppo di corda appresso, una Fornaja, che spazzava il forno con due lunghissime poppe, tenevano tutto il Teatro in un silenzio, e in un'attenzione nulla minor di quella, ch'ebbero le migliori scene dell'Opere de' nostri due Poeti. $($ Col. I, 97-98). Mit den letztgenannten *Poeti* meint Gozzi Goldoni und Chiari.

196 Dies dementieren die Fiabe teatrali ganz offensichtlich durch ihren Publikumserfolg, der je nach Stück zwischen 7 und 19 Wiederholungen zeitigte. In den Vorworten zu den einzelnen Fiabe teatrali gibt Gozzi die Anzahl der Aufführungen in Venedig im ersten Jahr an. L'augellino belverde führt mit tg Wiederholungen die Liste an, Turandot erreichte als Schlußlicht nur 7. Il corvo, Il re cervo und La donna serpente waren ebenfalls sehr erfolgreich (16, 16, 17 -repliche 4$)$. Im Ensuite-Theater der Zeit können bereits; Wiederholungen als zufriedenstellend gelten (vgl. N. Mangini, $*$ Su due rtopoik dell'autobiografia goldoniana «, op. cit., S. 32). Als größter Erfolg des 18. Jahrhunderts auf den venezianischen Bühnen gilt Goldonis La sposa persiana mit 34 Aufführungen; vgl. L. Zorzi, I teatri pubblici di Venezia, op. cit., S. 94 und Carmelo Alberti, La scena veneziana nell'età di Goldoni, Roma, Bulzoni 1990, S. 146.

19. Vgl. im Vorwort zu Il re cervo: -tener ferme in un Teatro con piacere per tre ore otto, o novecento persone di colta, e d'incolta maniera di pensaren (Col. I, 328).

$192 \mathrm{Mem}$. I, 267. 
Abbildung oder Kopie verstehen, diametral entgegengesetzt, geht aber auch weit über jene hinaus, die eine perfekte Illusion für unmöglich halten und daher von der Forderung nach Wahrscheinlichkeit abrücken. ${ }^{195}$ Nicht eine wie auch immer konzipierte Nachahmung der Wirklichkeit ist angestrebt, sondern das Ziel ist, das Imaginäre so zu gestalten, daß es in

193 Wie unterschiedlich die Positionen allein im venezianischen Umkreis zu Zeiten Gozzis sind, mögen einige repräsentative Beispiele verdeutlichen, in denen das Problem der Illusion aberwiegend im Kontext der Tragödie angesprochen, jedoch kaum ausgefürt wird. Im Vorwort zu seinen Ubersetzungen Voltairescher Tragodien erwähnt Cesarotti kritisch Gravinas Forderung nach einer durchgängigen Illusion in der Tragödie, die er nicht fur notwendig erachtet: $\rightarrow$ Io non ardirei d'asserire, come il Gravina ed altri, che la rappresentazione faccia un'illusione completa, e continua all'animo degli spettatori, ma non mi par nemmeno che possa assolutamente stabilirsi, ch'ella non abbia luogo almeno per qualche spazio di tempo. * (Melchiorre Cesarotti, Il Cesare e Il Maometto. Tragedie del Signor di Voltaire trasportate in versi italiani con alcuni ragionamenti del traduttore, Venezia 1762 , S. 193). Dagegen balt Franceseo Gritti mehr als to Jahre danach im Vorwort zu seiner Sammlung französischer Tragödien eine nicht unterbrochene Illusion in der Tragodie fur unabdingbar, sollen die Tragödien für die Zeitgenossen ebenso inreressant sein wie für die Griechen: -In fatti la situazione di Merope, quella di Oreste, di Edipo, o di Fedra ec. è tuttavia quasi tanto interessante per noi (supposta per altro una non interrotta, ma troppo rara, illusione) quanto lo fu gia a quegli Ateniesi medesimi, che furono la prima volta convocati a vederla.* (Teatro tragico francese ad uso de' teatri d'Italia ovvero Raccolta di versioni libere di alcune tragedic francesi [Francesco Gritti), op. cit., 5. 4) Im bereits erwähnten Vortrag Dell'indole del teatro tragico antico, e moderno (Venezia, 1744) geht Carli das Thema im Kontext der Frage der Einheiten ganz pragmatisch an, indem er darauf verweist, daß im Epos die Phantasie den Leser ja auch an die unterschiedlichsten Orte trage, und die Frage stellt, warum das im Theater nicht auch môglich sein solle: „Che se una storia puồ trasportarmi in più luoghi senza ch'io me ne risenta, e se à tanta forza d'ingannarmi non avendo io avanti gli occhi niente altro che il libro, qual maggior facilità avrebbe l'inganno, se le cose si facessero vedere rappresentate da varie persone che sembrano interessate da dovvero in que' fatti che si espongono, e che indi per trattarsi d'un qualche secreto maneggio, io fossí chiamato da una sala, a un gabinetto, non solo col pensiere, ma con l'occhio stesso, innanzi a cui con un'indicibile prestezza si fa un cambiamento d'oggetti, che sembrano veri? Se adunque naturali sono i passaggi in un libro di storia in cui si leggono le azioni morte; quanto più lo saranno in un Teatro, in cui si veggono le azioni vive? - (op. cit., S. 178-179). In sehr ironischer Weise bringt Baretti die Imagination ins Spiel, wenn er in Discours sur Shakespeare et sur Monsieur de Voltaire im Rahmen seiner Voltaire-Schelte konstatiert, daß die Zuschauer ihre Stücke in Paris nur mit Hilfe der Imagination für wahrscheinlich balten können und dies ja dann in ähnlicher Weise auch fur London (d. h. Shakespeares Theater) gelten könne: - Ils [d. h. das französische Publikum] ne les trouvent que probables, que vraisemblables, à l'aide de leur imagination! Je veux de tout mon cour que cela soit: Mais si a Paris on peut trouver des choses si éloignées du vrai, probables et vraisemblables à l'aide de l'imagination, pourquoi à la même aide ne trouvera-t-on pas à Londres probables et vraisemblables d'autres choses pas un pas plus éloignées du vrai que celles-là? - Wie Gozzi stellt er darauf nüchtern fest, daß das Publikum sowieso nicht wegen der geglückten Illusion ins Theater gehe, sondern: „Chacun y va pour s'amuser d'une Représentation. (Giuseppe Baretti, Discours sur Shakespeare et sur Monsieur de Voltaire, 1. Nachdruck des Originals ( 1777 ), Hg. Francesco Biondolillo, Lanciano, Carabba rost, S. 49-51). 
der theatralischen Illusion als wahr erlebt wird. ${ }^{194}$ Die Transformation des Märchenhaften in Wahrhaftes und die Wahrnehmung des Märchenhaften als Wahrheit impliziert die Einbildungskraft des Autors wie die der Rezipienten. Nicht umsonst wird das Publikum im Prolog zu L'amore delle tre melarance aufgefordert, sich zurückzudenken in die Zeiten, als es mit der Großmutter am häuslichen Ofen saß, ${ }^{195}$ sind doch im Kindesalter die Phantasie wie die Bereitschaft, das Wunderbare wahr zu heißen, groß und ein unbedingtes Einlassen auf die Märchenwelt als andere Wirklichkeit mit eigenen Gesetzen unproblematisch. Noch nicht domestiziert und vom Verstand dominiert, tritt die Einbildungskraft beim Kind am deutlichsten zutage. ${ }^{196}$ Auf diesen Sachverhalt zielt auch Gozzis oben zitierte Äuße-

194 Die detaillierten Angaben Gozzis zur Ausführung von Verwandlungsszenen u. a. in Il re cervo und La donna serpente machen deutlich, wie sehr Gozzi darauf bedacht ist, in der Bühnenpraxis die Tauschung möglichst -echt* erscheinen zu lassen. So lauten die Anweisungen zur Verwandlung Tartaglias in Deramo in $I l$ re cervo: * Anderà verso il corpo del Re, e mentre vorrà dire il verso, udirassi strepito di corni, e di cacciatori, che usciranno inseguendo un' orso. Tartaglia spaventato si ritirerà. I cacciatori entreranno inseguendo l'orso. Uscirà un' uomo nella forma di 'Tartaglia a tale, che s'assomigli a segno d'ingannare, si farà sopra 'l corpo del Re. Tartaglia dirà in poca distanza il verso cra cra ec. quel suo simile accompagnerà le parole col gesto, caderà morto, risusciterà i) Re. Nuovamente di ritorno usciranno i cacciatori inseguendo l'orso, il Re si ritirerà. Partito l'orso, e i cacciatori, uscirà nuovamente Tartaglia in forma di Deramo. Avvertasi, che sin dal principio Deramo dovrà avere una maschera, per poter con altra simil maschera accomodar al possibile la simiglianza [sic] di questi due personaggi. * (II, 7). Auch in La donna serpente $(1,7)$ wird Pantalones Auftritt als Priester Checsaja durch doppelte Maskierung so gestaltet, daß das Publikum einerseits Pantalone nicht als solchen erkennt, andererseits aber die zauberhafte Rückverwandlung problemlos möglich ist. "Pantalone uscirà senza la solita sua maschera, ma ingombrato il viso da gran basette, e gran barba bianca. Sotto questa avrà nascosta la consueta sua barba. Abbia una gran mitra sacerdotale. Sotto a questa sia nascosta la sua maschera di Pantalone, a tale che possa cadergli sul viso allo sparir della mitra. Abbia una veste sacerdotale; sotto a questa la sua sottana, e le brache di Pantalone. Sia accomodato in modo, che possa trasformarsi dalla figura di sacerdote in quella di Pantalone. Si avverte, che 'I Pantalone accomodato da sacerdote non dovrà avere nessun segno, per cui gli spettatori possano riconoscerlo. Dovrà egli accompagnar con gesti proporzionati ciò, che un' altro di dentro dirà per lui, sino al punto della trasformazione, e 'I gesto dovrà esser grave, e decente ad un vecchio sacerdote. $\alpha$

195 "Fate conto, mie vite, mie colonne, / D'essere al foco colle vostre Nonne.* (Col. I, 79 ).

196. In bezug auf die Phantasie ergeben sich interessante Bezüge zwischen Gozzi und Muratoris Abhandlung Della forza della fantasia umana (op. cit.; die folgenden Zitate sind den Seiten 58-67 entnommen). Für Muratori manifestiert sich die Phantasie besonders in den Träumen, scherzi e divertimenti vani della nostra fantasia «, in denen der Verstand ("intelletto oder $m$ mente-) keinen Gebrauch von seinen Fähigkeiten, »cioè del volere, del discernere, $\mathrm{e}$ del giudicare*, macht. Muratori bezeichnet die Träume als scommedie della fantasia sognante* und $»$ sregolate commedie $\alpha$, die uns jedoch im Traum als wahr erscheinen, ja manchmal sogar darüber hinaus: * anzi talvolta ci sembrano cosi vere le cose sognate, che anche svegliati stiamo un pezzo a deporre quella vana credenza, e a riconoscere la falsità di quei fantasmi.* Da die Urteilsfăhigkeit im Traum aussetzt, 
rung, squelle immagini fanciullesche, che mi rimettevano nel tempo della mia infanzia , ein Zustand, der allerdings nicht lange anhält und danach ein wissendes Lächeln über sich selbst provoziert. Der oft geforderten Abbildung der Wirklichkeit in den »commedie di carattere*, »tragedie urbane und *commedie flebili* steht also in den Fiabe teatrali die Darstellung des Nicht-Wirklichen als Wahres gegenüber, und anstelle eines unmittelbaren Wiedererkennens fordern sie die Reflexion über das Verhältnis von Bühnengeschehen und Erfahrungswirklichkeit heraus.

\section{Theatrale Wirklichkeit und Imagination}

Diese Konzeption der Fiabe teatrali ist in dreifacher Hinsicht bemerkenswert: in bezug auf die Einbildungskraft, das Theaterverständnis und den Zuschaueraspekt. Wic den angeführten Außerungen Gozzis zu entnehmen ist, sicht er in der Einbildungskraft eine anthropologische Konstante, von Alter und Bildung ${ }^{197}$ unabhängig, weshalb das Wunderbare seinen Effekt auf die Menschen nicht verfehlen kann. Wenn sie auch in den zeitgenōssischen Diskussionen zugunsten des Verstandes und der Vernunft verdrängt und verachtet wird, ist sie doch keineswegs verschwunden, sondern wartet vielmehr darauf, stimuliert zu werden - auch bei einem aufgeklärten Publikum. Explizit erklärt Gozzi dies im Vorwort zu I pitocchi fortunati: "Credei di essere in necessità di riconfermare al Pubblico con questa [Fiaba teatrale], che un'apparecchio di circostanze ben maneggiate, benchè sieno piantate sopr'una falsa base, può divertire, e intrattenere un'Uditorio, tuttochè illuminato.* (Col. II, 30r). So sind die Fiabe teatrali unter anderem im Hinblick darauf konzipiert, die Vorstellungskraft der Zuschauer durch das Wunderbar-Märchenhafte zugleich anzuregen und unter Beweis zu stellen. Darüber hinaus wird mit der Vorstellungs- und Einbildungskraft eine genuin theatralische Kategorie aufgerufen. Theater operiert grundsätzlich auf der Basis von Imagination und Illusion und

erscheint das Unwahrscheinliche (sazioni incredibili e ridicolea) fraglos als wahr, und erst wenn der Verstand wieder eine dominante Rolle cinnimmt, setzt die Unterscheidung zwischen Wahrheit und Falschheir (sverità o falsitaे) wieder ein. Gozzis Fiabe teatrali erscheinen wie eine szenische Umsetzung dieser Uberlegungen, bestehen doch Ubereinstimmungen bis in Formulierungen hinein. Zeugnisse für eine intensivere Beschäftigung Gozzis mit Muratoris Schrift existicren jedoch nicht.

1971720 geboren, ist Gozzi zum Zeitpunkt der Aufführung von L'amore delle tre melarance bereits $4 \mathrm{I}$ Jahre alt, bei der Veröffentlichung der $=$ Analisi riflessiva = 52 . Daß gemäß seiner Darstellung in der * Analisi riflessiva e selbst er als Autor dieses Stucks der Faszination der Marchenszene unterliegt, unterstreicht die Wirkungsmacht des märchenhaft Wunderbaren. 
ist, wie auch der Begriff „Capriccio» impliziert, ein artifizielles System, nach Patrice Pavis ein "système artistique et non [...] un succédané de réalitée. ${ }^{198}$ Ausgehend von dieser theoretischen Feststellung kann eine Konzeption des Theaters als Wirklichkeit oder selbst als Abbildung der Wirklichkeit nur als Mißverständnis gedeutet werden. Ein Theater, das direkte didaktische oder moralische Ziele verfolgt, ist ein Widerspruch in sich selbst, beruht doch die theatralische Kommunikation auf dem Bewußtsein, daß es sich bei dem, was auf der Bühne geschieht, nicht um die Alltagswirklichkeit handelt, so daß eine derartige Appellfunktion ebenfalls unter den Status des Nicht-Wirklichen fallen muß und damit ihre Wirksamkeit verliert. ${ }^{199}$ Ganz in diese Richtung weist Gozzis Polemik gegen das zeitgenössische "realistische «, wirklichkeitsnahe Theater mit Erziehungsanspruch: "nessuno potrà levarmi la facoltà di ridere di que' Poeti, che pretendono di cagionar ne' Teatri, puri recinti di passatempo, e di passaggieri riflessi, gli effetti de' Pergami e de' Confessionali« (ARI, 18). In diesem Kontext erscheint "dare aspetto di verità ad una fola" (RI, ro86) als treffende Beschreibung des Produktionsprozesses von Theater, des schriftlichen wie des darstellerischen, beinhaltet sie doch den Aspekt des Künstlichen und Künstlerischen (dare aspetto di verità), markiert die Distanz zur Wirklichkeit (fola) und verweist auf die Relation von Wahrheit und Imagination.

Auch im Hinblick auf die Zuschauer kommt Gozzis Theaterkonzeption modernen Standpunkten erstaunlich nahe. Wie Gozzi in der "Analisi riflessiva * an sich selbst demonstriert, wird der Zustand des Gebanntseins durch das Märchenhafte abgelöst durch ein selbstreflexives Lachen, zu dem in den Fiabe teatrali noch ein anderes Lachen hinzukommt, das die Masken auslösen. Damit sind in recht präziser Weise zwei Zustände erfaßt, die sich als Identifikation und Distanzierung bezeichnen lassen und in enger Verquickung dialektisch ihre Wirkung entfalten. ${ }^{200}$ Hinsichtlich dieser Doppelhaltung des Zuschauers im Theaterbereich sind zwei Ebenen zu unterscheiden, für die Uri Rapp die Begriffe *Illusion* und *Inlusion « vorschlägt. Einerseits identifiziert sich der Zuschauer »mit den ihm vorgespielten Rollen, lebt sich ein, erlebt mit [...] Er steht in der Illusion, ist von ihr ergriffen und mitgerissen. * Auf einer anderen Ebene aber *ist der Zuschauer sich selbst jederzeit der Illusionshaftigkeit des Geschehens

198 Patrice Pavis, Problèmes de sémiologie théatrale, Montréal, Presses de l'université de Québec 1976, S. 99-100.

199 Vgl. A. Ubersfeld, op. cit, S. 35: * La caractéristique de la communication thếtrale, c'est que le spectateur considère le message comme non réel ou plus exactement non vrai.e

$200 \mathrm{Vgl}$. A. Ubersfeld, op, cit., S. 42 ; - identification et distanciation jouant en symbiose leur rôle dialectique.* 
bewußt, steht in Distanz nicht nur zum Schauspiel und zur Bühne, sondern auch zu sich als Miterlebendem (eine neue Quelle der Ironie) $\alpha_{*}^{201}$ Für diese Meta-Ebene wählt U. Rapp den Begriff "In-lusion «. Es ist frappant, wie Gozzis Reaktion in L'amore delle tre melarance geradezu als Illustration dieser theoretischen Uberlegungen erscheint, nicht zuletzt auch im Hinblick auf die Ironie, die in Gozzis Selbstbeschreibung mitschwingt. Das Ergriffensein von der Märchenhandlung auf der einen Ebene, auf der anderen die Distanzierung, die sich sowohl auf sich selbst als Miterlebenden als auch auf die miterfahrene Handlung und ihre "Rolle als theatralische Scheinhandlung * bezieht, überlagern und überkreuzen sich. Wie U. Rapp weiter ausführt, wird die Inlusion "unterstützt von den Stil- und Werkkonventionen der Bühne, und nimmt institutionalisierte Formen an. Ihr Ursprung liegt jedoch in der Distanzierung als grundlegende anthropologische Fähigkeit. ${ }^{202}$ Solche Konventionen sind in Gozzis Fiabe teatrali in Form der Masken besonders offensichtlich. Indem die Märchenund die Maskenkonstituenten kontrastive Strukturen bilden und sich in der zeitlichen Sukzession auf der Bühne abwechseln, findet gewissermaBen eine Dissoziierung der Doppelhaltung des Zuschauers statt, Illusion und Inlusion manifestieren sich an den unterschiedlichen Bestandteilen des Ganzen. Identifikation und Distanzierung als s grundlegende anthropologische Fähigkeit[en]\& spielen für die Fiabe teatrali eine essentielle Rolle. Sie sind die Basis für die angestrebten gegensätzlichen Wirkungen des Weinens und des Lachens, ${ }^{203}$ als echte Grundmöglichkeiten des allgemein Menschlichen ${ }^{204}$ Folgt man H. Plessners Ausführungen, stellt sich •das Genus von Lachen und Weinen [im Gegensatz zur mimischen Ausdrucksgebärde] als eine Äußerungsweise dar, bei welcher der Verlust der Beherrschung im Ganzen Ausdruckswert hat. « Es zeigt »ein Zerbrechen der Ausgewogenheit zwischen Mensch und physischer Existenz\& angesichts von "Situationen, denen gegenüber keine wie immer geartete sinnvolle Antwort durch Gebärde, Geste, Sprache und Handlung noch

201 Uni Rapp, Handeln and Zuschauen, Untersuchungen über den theatersoziologischen Aspekt in der menschlichen Interaktion, Darmstadt, Neuwied, Luchterhand 1973,5 . 75. 76.

202 Ebd., S. $76-77$.

20) Siche Kap, 2.7.

$20+$ Helmuth Plessner, - Lachen und Weinen. Eine Untersuchung der Grenzen menschlichen Verhaltense, in: ders., Ausdruck und menschliche Natur, Frankfurt a. M., Suhrkamp 2003, S. $201-387$, hier S. 211 .

Wahrend in den zeitgenôssischen Âußerungen das Lachen (über die Masken) fast ausnahmslos dem Volk zugeordnet wird, ist es fur Gozzi keine sozial bestimmte Reaktion, sondern eine anthropologische Konstante. Das Weinen dagegen wird auch von Gozzis Zeitgenossen als universale Reaktion angesehen. 
möglich ist $*{ }^{205}$ Nimmt man Gozzis Außerungen zum Lachen über das Komische der Masken und zum Weinen über die Geschehnisse der Märchenhandlung zusammen, zeigt sich, daß er eben die Unmittelbarkeit und Willkürlichkeit der Reaktion, diesen Verlust der Beherrschung im Auge hat. Wird beim Lachen und Weinen der Verlust der Herrschaft über den Körper deutlich, ${ }^{206}$ manifestiert sich bei der geglückten Illusionierung der Verlust der Herrschaft des Verstandes über die Einbildungskraft - beides Phänomene, die die Beherrschbarkeit menschlichen Verhaltens grundlegend in Frage stellen und auf seine Komplexität hindeuten.

Somit liegt den Fiabe teatrali ein anthropologisches Verständnis zugrunde, das die Möglichkeiten der Einbildungskraft wie der Reflexion, der Identifikation wie der Distanzierung, des Weinens wie des Lachens umfaßt und dezidiert Vereinseitigungen entgegensteht, sei es bezüglich des Stellenwertes der Vernunft im pointiert rationalistischen Denken, sei es hinsichtlich der Dominanz des Gefühls in empfindsamen Strömungen. Zieht man die subversiven Möglichkeiten des Theaters in Betracht, ${ }^{207}$ kann die kontrastive Struktur der Fiabe teatrali als Hinweis auf die Problematiken der Komplexität, der Vereinbarkeit, der Gleichzeitigkeit und der Überlagerung solch gegensätzlicher Charakteristika interpretiert werden, die in der zeitgenössischen Debatte, vor allem in ihrer vulgarisierten Form, zugunsten apodiktischer Behauptungen vernachlässigt werden.

205 Ebd., S. 274 (Kursivierung im Text), 273, 275.

206 Ebd., S. 274: *Genau das Ümgekehrte findet bei Lachen und Weinen statt. Die leibseelische Transparenz des Körpers erreicht in ihnen ihren Tiefpunkt. Körperliche Vorgänge emanzipieren sich. Der Mensch wird von ihnen geschüttelt, gestoßen, außer Atem gebracht.*

Nicht zufällig zielt Gozzi auf die gegensäzzlichen und doch zusammengehörigen Reaktionen des Weinens und des Lachens und nicht auf die =sensations composées*, die die isthetische Diskussion zunehmend bestimmen. Zum einen haben sie als echte anthropologische Grundmöglichkeiten einen anderen Stellenwert als die gemischten Empfindungen, zum anderen entsprechen sie der kontrastiven Struktur der Ftabe teatrali, der als solcher eine bedeutungstragende Funktion zukommt.

$207 \mathrm{Vgl}$. A. Ubersfeld, op, cit., S. 4r: -Le théâtre, on le sait depuis longtemps, apporte la possibilité de dire ce qui n'est pas conforme au code culturel ou à la logique sociale: ce qui est impensable logiquement, moralement, socialement scandaleux, ce qui devrait être récupéré selon des procédures strictes est dans le théâtre à l'état de liberté, de juxtaposition contradictoire. C'est par là que le théâtre peut désigner le lieu des contradictions non résolues.* Siche auch Jacques Scherer, der in Théatre et anti-tbéâtre au XVIIIe siècle, Oxford, Clarendon 1975, die Bedeutung von Form und Struktur für das "anti-théâtre- hervorhebt: - Lorsque le théâtre se fait anti-théâtre, il se dissimule sous le masque trompeur de l'amusant et peut égratiner au passage tous les usages ( $\mathbf{S}$. 10 ). 


\subsection{Indirektheit und Allegorie}

Mit den Grundkonstituenten Märchen und Masken umgeht Gozzi in den Fiabe teatrali die Aporien einer mimetischen Theaterkonzeption und eröffnet neue Spielräume, in denen das Spiel als Spiel und als solches wahr, als theatrale Wirklichkeit erscheint. Damit entkommt die neue Gattung nicht nur der ästhetischen und ideologischen Fragwürdigkeit einer abbildenden Nachahmung auf der Bühne, sondern ist auch geeignet, Dimensionen zu erschließen, die dem beschränkten Blick auf die Alltagswirklichkeit entgehen. Einer Beobachtung, die in die Reproduktion der Wirklichkeit auf der Bühne mündet, steht bei Gozzi eine Beobachtung gegenüber, die zur Erkenntnis unterschiedlicher Möglichkeiten der Wahrnehmung von Wirklichkeit führt und die Vergeblichkeit bzw. das Ungenügen eines Abbildungsversuchs impliziert. ${ }^{208}$ Diese Einsicht in die Relativität von Wahrnehmung und Wahrheit schlägt sich in einem amimetischen Theaterverständnis nieder. Um sich jedoch nicht in der reinen Evasion zu erschöpfen, ist ein wie auch immer gearteter Bezug zur Wirklichkeit unumgänglich. Ganz eindeutig ist dieser in den ironischen und satirisch-polemischen Anspielungen und Aussagen der Masken gegeben, die sich auf Venezianisches, auf Theater, auf Literatur oder andere Realien beziehen. Zu diesen punktuellen, direkten Verweisen treten andere $\mathrm{Ar}$ ten der Relation zur Wirklichkeit, sowohl was die Masken- als auch die Märchenkonstituente betrifft. Die Eigengesetzlichkeit der Märchenwelt, in der das Wunderbare *nicht wunderbar, sondern selbstverständlich $\star^{209}$ ist, und die Masken, die zugleich verbergen und entlarven, unterstreichen zwar die Distanz zur Wirklichkeit, werfen aber in indirekter Weise ein Licht auf sie, das auch Schattenseiten, Verborgenes, Problematisches beleuchtet, Aspekte, die sich direkter Darstellung entziehen. Aus dieser

208 Insbesondere in den Memorie izutili spielt der Begriff mosservazione* eine wichtige Rolle, wobei Gozzi deutlich macht, daß diese Beobachtung mit einer bestimmten slente ottica* erfolgt. So heißt es im -Proemio*: - Abbiamo tutti una spezic di lente ottica nell'intelletto, che col suo riverbero ci presenta gli oggetti di questo mondo. Se ho qualche particella di filosofia, inclino più a Democrito che ad Eraclito a' riverberi di questa lente. (Mem. 1, 22). In einem fruhen satirischen Gedicht ist ebenfalls von socchialia und =lente mia die Rede, wobei Gozzi auch den Namen eines *valentissimo artefice d'ottica in Venezias nennt (-Per la Vestizione della Signora Marina Licini*, Col, VIII, 306-310) und so deutlich wird, daß̉ derartige Oberlegungen durch die zeitgenóssische Entwicklung der Optik stimuliert wurden. Interessant ist, daß auch Baretti, der in wichtigen Punkten mit Gozzis Beurteilung der zeitgenôssischen Literatur- und Theaterszene übereinstimmt, in La frusta letteraria von =occhiali d'Inghilterra* (op. cit., Bd. I, S. 314 ) spricht, damit auf seinen spezifischen Blickwinkel hinweist und wie Gozzi universalistischen Tendenzen eine Absage erteilt.

200 A. Jolles, op. cit., S. 243. 
offensichtlichen Wirklichkeitsferne der Grundkonstituenten einerseits und ihrem latenten Wirklichkeitsbezug andererseits ergibt sich eine Ambivalenz, die vom Zuschauer aufzulösen ist. Die sandere Wahrheit, die Märchen und Masken innewohnt, enthüllt sich nicht unmittelbar in der Anschauung, sondern erst in der Reflexion und in der Kontrastierung mit der Realität. Insofern sind die Fiabe teatrali mehr als ein oberflächlichvergnügliches Divertissement, und die harmlos-märchenhaften Titel sollten, wie Gozzi seine Kritiker warnt, nicht dazu verleiten, die Stücke selbst als s frivolezze * (LL, 4) zu beurteilen. In Ragionamento ingenuo erklärt er unzweideutig: $»$ Protesto tuttavia che la scelta de' titoli e degli argomenti fanciulleschi non fu che un'arte insidiosa * (RI, 66) - hinterlistig nicht nur im Hinblick auf das Publikum, dessen Neugier durch die Märchentitel auf den Theaterplakaten geweckt wird, sondern auch auf die Stücke selbst, die weniger kindisch und harmlos sind, als sie zunächst erscheinen mögen. Insbesondere die Märchenhandlung ist in ein Verhältnis zur Erfahrungswirklichkeit zu setzen, will sie sich nicht dem Vorwurf aussetzen, Kinderei oder Ausgeburt der Phantasie zu sein; ist sie auch "una base fantastica, e falsa , so ist sie doch $*$ sempre allegorica, e significatrice* (LL, 26). Um diese allegorische Intention evident zu machen, hat Gozzi nach eigenen Angaben einen Kunstgriff angewandt: we perchè la allegoria fosse più chiara, ed intesa, ho lasciato talora correre ad arte degli anacronismi accennando oggetti de' giorni nostri« (LL, 26). Die direkten Referenzen der Masken auf die Wirklichkeit fungieren also als Indikatoren für eine generelle allegorische Interpretierbarkeit. ${ }^{210}$ Wenn Gozzi den indirekten Bezug zur Wirklichkeit als *allegorico * ${ }^{211}$ bezeichnet, meint dies nicht die Auslegung eines sensus litteralis in Hinblick auf einen übergeordneten Sinngehalt, " allegorisch $*$ ist vielmehrim allgemeinen Sinne einer uneigent-

$2 \pi$ Vgl. dazu Klaus W. Hempfer, $=$ Allegorie als interpretatives Verfahren in der Renaissance: Dichterallegorese im 16. Jahrhundert und die allegorischen Rezeptionen von Ariosts Orlando furiosos, in: ders, Enrico Straub ( $\mathrm{Hgg}$ ), Italien und die Romania in Humanismus und Renaissance, Wiesbaden, Steiner $\mathrm{I}_{98} 3$, S. $5 \mathrm{I}_{-75}$. Wie K. W. Hempfer feststellt, -wurden [...] Unverstandlichkeit und moralische Fragwürdigkeit des Literalsinns traditionell als Textsignale für die Notwendigkeit einer allegorischen Lektüre aufgefaßt. (S. 54), wobei diese in der Renaissance zunehmend beliebig wird, da ses keine verbindlichen :Quellen mehr gibte (S. 74). Dies trifft sehr viel mehr noch auf das 18. Jahrhundert zu, in dem die Allegorese als interpretatorisches Verfahren unüblich geworden war und daher umso mehr eines unverkennbaren $\rightarrow$ Signals* bedarf. Vom hermeneutischen Ansatz der Allegorese bleibr nur noch die Übertragbarkeit auf eine andere Ebene.

211 Vgl. oben sun'austera morale spesso allegorica* (RI, 25) und in den Vorworten zu den Fiabe teatrali, den Memorie inutili und vor allem in La piü lunga lettera, wo Gozzi mehrfach von sle mie allegoriche rappresentazioni", "genere allegoricos, -favole morali allegoriches, "generi miei innocenti, morali, allegri, e per lo piü allegorici- (LL, t2, 5, 79) spricht. 
lichen Redeweise zu verstehen, die die Möglichkeit der Herstellung einer Referenz zwischen wirklichkeitsfernem dargestellten Geschehen und der Wirklichkeit impliziert. ${ }^{212}$ Dieser Bezug ergibt sich nicht unwillkürlich und spontan, sondern erfordert eine intellektuelle Leistung des Zuschauers, so daß die im allgemeinen mit der Allegorie verbundene gewollte Anregung zur Reflexion auch für die Fiabe teatrali gilt. Im Vorwort zu Il corvo schreibt Gozzi bezüglich der Reaktion der Kritiker auf die Aufführung von L'amore delle tre melarance: „Oltre alle parodie, ch'io intesi di porre in questa, eglino scopersero delle profonde allegorie, e molte di quelle, ch'io non m'era nè meno sognate " $\left(\mathrm{Col}\right.$. I, 117 ); ${ }^{213}$ dies ist nicht nur eine Verflechtung von topischer Selbstbescheidenheit und indirekter Legitimation eines vorgeblich bloß unterhaltenden Genres, sondern gleichsam eine Anleitung zur Rezeption der Fiabe teatrali. ${ }^{214}$

212 In einigen Fallen bezeichnet Gozzi auch einzelne Figuren in den Fiabe teatrali als sallegoria $=$, so z. B. den Konig Sinadabbo in La Zobeide ( $\cdot \mathrm{Ne}^{\prime}$ costumi, e nel carattere del Re Moro, Sinadabbo, io vorrei, che fosse falsa allegoria, ch'è pur troppo allusiva a' nostri tempi, colla sciagura di molte fanciulle infelici, le quali poco ascoltano i Calenderi Abdalac...., Col. II, roo) oder Tartaglia in L'augellino belverde.

211 Die Bemerkung bezicht sich auf Gasparo Gozzis Kritik in La gazzetta veneta vom 27. Januar 1761 , in der es heißt: $>$ Io avea fatto proposito di non parlare di commedie fatte all'improvviso, e durerei nel parer mio, se questa non fosse d'un genere particolare e della condizione di quelle che anticamente si chiamavano allegoriche, [...] Siasi chiunque si voglia il tessitor di essa, egli ha avuta l'intenzione di coprire sotto il velo allegorico certi doppi sentimenti e significati che hanno una spiegazione diversa dalle cose che vi sono espresse", (op, cit., S. 467). Dies verdeutlicht Gasparo Gozzi im folgenden an zwei Beispielen, nämlich dem Blasebalg, der Truffaldino und Tartaglia in einem Augenblick 1500 Meilen weit zu den Orangen bläst, was er als Hinweis des Autors auf die Unwahrscheinlichkeit von großen Ortswechseln in Tragödien und Komödien interpretiert, und der Szene bei Creontas Schloß, die er als Apologie der - commedia improvvisa* wertet. Mit dieser punktuellen sallegorischen Deutung weist Gasparo Gozzi zwar auf einen stieferen* $\operatorname{Sinn}$ hin, der sich unter der spektakulären Oberflāche verbirgt, verstellt jedoch den Weg zu einer umfassenden sallegorisehen « Interpretation, die allerdings für L'amore delle tre melarance aufgrund des stark parodistischen Charakters problematisch ist und erst fü die folgenden Fabe teatrali relevant wird, wie auch aus den Besprechungen Gasparo Gozzis von $I l$ corvo und $I l$ re cervo in L'osservatore veneto ersichtlich ist. Dort weist er ebenfalls auf den allegorischen Aspekt hin und stellt die Fiabe teatrali in einen Zusammenhang mit Aristophanes' Komôdien, dem es gelungen sei, ,di tassare i costumi col mezzo della maraviglia- (L'osservatore veneto, op. cit., S. 274).

Gasparo Gozzi selbst, der in La gazzetta veneta (1760/61) der Beobachtung und Beschreibung auch des Alltäglichen viel Platz einräumt, tendiert dagegen in L'osservatore veneto $(1761 / 62)$ wie sein Bruder Carlo zu einer indirekten Darstellung in Form von allegorischen Erzählungen.

214 Jean Starobinski operiert in sIronie et mélancolic (I): Le théatre de Carlo Gozzi", op. cit., und -Ironie et mélancolie: Gozzi, Hoffmann, Kierkegaard", in: Vittore Branca $(\mathrm{Hg}$.). Sensibilità e razionalita nel Settecento, Venezia, Sansoni 1967, S. 423-462 (in weiten Teilen identisch mit =Ironic et mélancolie (I) und (II)-), unter Hinweis auf Batteux mit den Termini sallégorèse ascendante* und sallégorie oratoire" bzw, sallégorie descendantee, wobei im ersten Fall die allegorische Erzählung nicht auf eine bekannte 
Das Märchen als eine Grundkonstituente der Fiabe teatrali eröffnet mit seiner langen Tradition und weiten Verbreitung, seiner Universalität und Volksnähe die Möglíchkeit, auf größere Zusammenhänge, auf gesellschaftliche oder ideologische Mechanismen und Strukturen zu verweisen, ohne diese selbst darstellen zu müssen und damit notwendig eine bestimmte Perspektive zu privilegieren. Die Indirektheit des Wirklichkeitsbezugs bürgt für eine Offenheit und Vielfalt möglicher Interpretationen, wird doch, was auf der Bühne als wahr erscheint, von jedem einzelnen an seiner individuellen Wirklichkeitserfahrung gemessen, wobei bereits die pure Andersartigkeit des Märchenhaften Anlaß zu einem veränderten Realitätsbewußtsein geben kann. Angesichts der grundlegenden Zweifel an der Reproduzierbarkeit von Wirklichkeit auf dem Theater und einer generellen Unsicherheit über den Status der Realität, die sich aus der Divergenz unterschiedlicher Wahrnehmungsmodi ergibt, kommen der Imagination bei der Konzeption der Stücke wie bei ihrer Rezeption im Theater und der Allegorie als Möglichkeit der Rückbindung an die Wirklichkeit essentielle Bedeutung zu.

Ein mittelbares Wirklichkeitsverhältnis kennzeichnet nicht nur die Märchenkonstituente, sondern auch die Maskenfiguren. ${ }^{215}$ Darauf wird der Zuschauer schon durch das Äußere der Masken hingewiesen: er sieht nicht das wirkliche Gesicht des Schauspielers und das seiner Rolle entsprechende Kostüm, sondern die immer gleiche Gesichtsmaske und das

Realitàt verweist, sondern vil se rapporte à une vérité encore inconnue, à une maxime

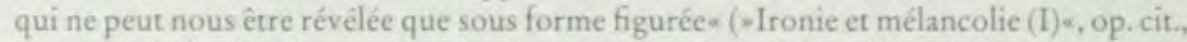
S. 295 , und identisch im zweiten Artikel, S. 428 ), während die *allégorie oratoire direkt auf die Wirklichkeit zielt. L'amore delle tre melarance wäre demnach eine sallégoric oratoirex, dagegen näherten sich $I l$ corvo und alle späteren Fiabe teatrali der Kategorie nallégorèse ascendante $\kappa$, da sie dazu dienten, $\cdots[$ de] symboliser une leçon smorales* (ebd., S. 297 bzw. S. 430). Problematisch erscheint an dieser Darstellung zunächst, daß der Begriff der nallégorie oratoire* dem parodistisch-satirischen Charakter von L'amore delle tre melarance kaum angemessen scheint bzw, alle parodistischen Texte mit diesem Terminus zu belegen wären. Wenn J. Starobinski dann für Il corvo feststellt, >Elle devenait le véhicule d'une sagesse assez simple concernant les vices et les vertuse und damit den *Aufstieg * in die Kategorie der *allegorèse ascendante * gewissermaßen nicht verdient hat, stellt sich zum einen die Frage der Nützlichkeit dieser Terminologie für Gozzis Fiabe teatrali, zum anderen greift eine einfache moralische Interpretation der Fiabe teatrali zu kurz, wie J. Starobinski mit seiner Untersuchung v. a. an der Maske Truffaldino selbst deutlich macht.

215 Zur Bedeutung der Masken in Venedig im r8. Jahrhundert s. Michael L. Quinn, "The Comedy of Reference: The Semiotics of Commedia Figures in Eighteenth-Century Venicex, in: Theatre Journal 43, 1991, S. 70-92, dessen Untersuchung interessante allgemeine Beobachtungen zu Masken in Theater, bildender Kunst und Wirklichkeit enthält. In Venedig ist die Situation insofern eine ganz besondere, als Masken im gesellschaftlichen Leben einen festen Platz haben und die Zuschauer, die die Masken auf der Bühne sehen, größtenteils ebenfalls Masken tragen. Dazu ausführlicher in Kap. 4,I. 
unveränderliche Gewand. Insbesondere bei der Gesichtsmaske ist das Verhältnis zur Wirklichkeit unverkennbar durch Verzerrung und Starrheit charakterisiert, aber auch die Verhaltensweisen sind typisiert und übertrieben. Da die Masken zur Zeit Gozzis ihre sozialen und lokalen Referenzen weitgehend eingebüßt haben, ist ihre Zeichenhaftigkeit offener und ihre De-formationen sind geeignet, auf allgemeine, generelle Formationen zu verweisen. Im Unterschied zum Märchen und seiner in sich geschlossenen Welt, deren Bezug zur Wirklichkeit erst in einer bewußten *allegorischen « Deutung herzustellen ist, lenken die Masken die Aufmerksamkeit der Zuschauer unmittelbar auf die Thematik des Verund Enthüllens, da sie nicht den Anschein des Wahren erwecken, sondern demonstrativ die Abweichung von der Wirklichkeit vor Augen führen. So macht Gozzi für die Fiabe teatrali unterschiedliche Möglichkeiten eines indirekten Wirklichkeitsbezugs des Bühnengeschehens fruchtbar, lenkt die Aufmerksamkeit auf Täuschung, Selbsttäuschung und Enttäuschung und erreicht einen Grad an Autonomie des Theaters, der eine direkte moralische Deutung konterkariert und die unmittelbare, nützliche Anwendung in der Lebenswelt vereitelt. 

Die Indirektheit des Wirklichkeitsbezugs, die sich maßgeblich in den Grundkonstituenten Märchen und Masken sowie dem kontrastiven Strukturprinzip zeigt, und die allegorische Lesbarkeit als Charakteristika der Fiabe teatrali wirken einer einfachen moralischen Interpretation entgegen. Analog zum Märchen ist die Moral eine implizite und nicht unmittelbar relevant für das Verhalten der Zuschauer im Alltag, wie es eine utilitaristische Theaterkonzeption will. Ausgehend von der Prämisse, daß Wahres und Wesentliches nicht durch ein Aufzeigen beziehungsweise eine direkte Referenz zu vermitteln sind, ist die dargestellte Wirklichkeit in den Fiabe teatrali eine sandere ${ }^{2}$, eine wahre Illusion: Titel, ${ }^{2}$ Geschehen, Personen, Zeit und Raum markieren die Distanz zur Erfahrungswirklichkeit und müssen in ihrem Verweischarakter durchschaut werden, um der Deutung im Sinne einer Evasion zu entgehen.

Die Märchen als Konstituenten der Fiabe teatrali bergen bereits Grundwahrheiten in sich, ${ }^{3}$ die in ihrer Allgemeinheit in die Stücke einge-

1 Vgl. I. Calvino, op. eit., S. 75: - La morale della fiaba è sempre implicita, nella vittoria della semplice virtù dei personaggi buoni e nel castigo delle altrettanto semplici e assolute perversita dei malvagi; quasi mai s'insiste in forma sentenziosa o pedagogica*, und A. Jolles, op. cit, S. 240, der konstatiert, daß das Märchen nicht auf die Frage * was muß ich tune antworter, sondern auf die Frage swie muß es in der Welt zugehen? a, wobei sich das ethische Urteil nicht auf das Handeln, sondern auf das Geschehen richtet. Diese Ethik des Marchens nennt Jolles =Ethik des Geschehens oder [...] naive Morale.

z Zum Vergleich seien einige Titel von Komôdien Fagiuolis genannt: La nobiltà vuol ricchezza, Non bisogna in amor correre a furia, La virtì vince l'avarizia, Il sordo fatto sentir per forza, Cio che pare e non è ovvero Il cicisbeo sconsolato etc. (Titel aus G. B. Fagiuoli, Commedie, op.cit.), in denen der Inhalt und zum Teil die Moral sentenzartig zusammengefaßt sind. Goldoni, der sich in Il teatro comico gegen derartige lange, erzahlende Titel wendet, nennt in seinen Titeln meist den Hauptcharakter bzw. die Haupteharaktere des Stücks, z. B. La donna vendicativa, Il vecchio bizzarro, Le donne de casa soa, I rusteghi, La buona madre etc.

3. Vgl. 1. Calvino, op. cit., S. 38-39: $>[$... io credo questo: le fiabe sono vere. Sono, prese tutte insieme, nella loro sempre ripetuta e sempre varia casistica di vicende umane, una spicgazione generale della vita, nata in tempi remoti e serbata nel lento ruminio delle coscienze contadine fino a noi; sono il catalogo dei destini che possono darsi a un uomo e a una donna, soprattutto per la parte di vita che appunto è il farsi d'un destino: la giovineaza, dalla nascita che sovente porta in sé un auspicio o una condanna, al distacco dalla casa, alle prove per diventare adulto e poi maturo, per confermarsi come essere umano. $\mathrm{E}$ in questo sommario disegno, turto; la drastica divisione dei viventi in re e poveri, ma 
hen, doch werden bestimmte Aspekte hervorgehoben, modifiziert oder hinzugefügt, so daß eine neue Akzentuierung entsteht, die das Theatermärchen vom Märchen hinsichtlich der $\gg$ Moral ${ }^{4}$ unterscheidet. Meist ist es diese Differenz, die die Möglichkeit eines Wirklichkeitsbezuges signalisiert, der über das Allgemeine, Zeit- und Ortsunabhängige hinausgeht und auf Aktuelles zielt. Im Unterschied zu den Masken, die in ihren Äußerungen auf Singuläres, Punktuelles aus der venezianischen Realität anspielen, verweist die Märchenkomponente auf eine Aktualität anderer Art, nämlich auf grundsätzliche Fragestellungen der Zeit. So werden durch das ganze Jahrhundert der Aufklärung hindurch relevante Themen wie das der Wahrheitsfindung, des Stellenwertes von Vernunft und Verstand, der Selbstbestimmung und der Identität des Menschen, und Debatten um Vorurteile, Fanatismus und Irrationalismus in den Fiabe teatrali aufgenommen und, wie die folgenden Kapitel zeigen, in indirekter Weise zur Sprache gebracht.

\subsection{Identität und Metamorphose, Wabrbeit und Täuschung}

"Non son chi sono und snon sarò più chi sono $*^{5}$ sind wohl die deutlichsten Äußerungen von Personen der Märchenstücke, die auf eine Identitätsproblematik verweisen. Cherestanì, die in La donna serpente Farruscad als Hirschkuh erscheint, sich als Prinzessin zeigt und zu seiner Frau wird, verbindet die Feststellung "non son chi sono « mit der Warnung, nach ihrer wahren Identität zu forschen, die sie zu gegebener Zeit selbst enthüllen wolle: "Non ricercar chi sia. Verrà '1 momento, / Che saprai tutto.« $(\mathrm{I}, 2)$. In $I l$ re de' genj kündigt die Prinzessin Zelica der Sklavin

la loro parità sostanziale; la persecuzione dell' innocente e il suo riscatto come termini d'una dialettica interna da ogni vita; l'amore incontrato prima di conoscerlo e poi subito sofferto come bene perduto; la comune sorte di soggiacere a incantesimi, cioè d'essere determinato da forze complesse e sconoseiute, e lo sforzo per liberarsi e autodeterminarsi inteso come un dovere elementare, insieme a quello di liberare gli altri, anzi il non potersi liberare da soli, il liberarsi liberando; la fedeltà a un impegno e la purezza di cuore come virtù basilari che portano alla salvezza e al trionfo; la bellezza come segno di grazia, ma che può essere nascosta sotto spoglie d'umile bruttezza come un corpo di rana; e soprattutto la sostanza unitaria del tutto, uomini bestie piante cose, l'infinita possibilità di metamorfosi di ciò che esiste. - Die Auswahl der Märchen, die Gozzi für die Fiabe teatrali trifft, ist geeignet, die vielfältigen, von Calvino genannten Aspekte sichtbar zu machen, so daß die Stücke im Hinblick auf diese allgemeine Erklärung des Lebens gelesen werden können.

+ Moral hier in Anführungszeichen, um dem Mißverständnis einer Moral als lehrreiche Nutzanwendung vorzubeugen.

5 Cherestanì in La donna serpente, I, 3; Zelica in Il re de' genj, IV, 8. 
Zirma mit den Worten »non sarò più chi sono « ihre Metamorphose in einen Tiger an. Verwandlungen von Feen und Menschen in Tiere, Steine und andere Menschen tauchen in fast allen Fiabe teatrali auf, und wo man wie in Turandot und I pitocchi fortunati nicht von smaraviglie magiche di trasformazioni $(\mathrm{LL}, 33)$ sprechen kann, geht es für die Protagonisten Calaf und Usbec darum, ihre wahre Identität geheimzuhalten. Offensichtlich stehen die Metamorphosen und Verwandlungen in den Fiabe teatrali nicht nur für die märchentypische substantielle Einheit von Menschen, Tieren, Pflanzen und Dingen, ${ }^{6}$ sondern gehen darüber hinaus, indem sie zum einen die Labilität der Identität als Einheit der Person andeuten, zum anderen die Legitimität der zweckgerichteten Vortäuschung einer falschen Identität problematisieren und nicht zuletzt die Wahrnehmung als Täuschung und Ent-täuschung in den Blickpunkt rücken. Das Märchenmotiv der Metamorphose wird auf vielfältige Art variiert, wobei die fremdbestimmten oder selbst inszenierten Identitätswechsel häufig auch die Frage nach Authentizität und Wahrheit hervorrufen, wie im folgenden an einigen Beispielen sichtbar wird.

\section{Verwandlung als Identitätsverlust}

Eine märchenhafte, fremdbestimmte Verwandlung verbunden mit dem Verbot, die wirkliche Identität preiszugeben, liegt neben La donna serpente auch der *fiaba tragicomica Il mostro turchino zugrunde, die im Dezember 1764 erstmals aufgeführt wurde? Allerdings sind in Il mostro turchino gleich drei dramatis personae von den Metamorphosen betroffen: Zelou, «Genio, Mostro Turchino «, Dardanè, Prinzessin von Georgien, und Taer, Prinz von Nanking. In knapper Form sei dieser Handlungsstrang skizziert: Zelou, das blaue Ungeheuer, verwandelt das vorbildlich treue Paar Dardanè und Taer, um sich selbst seines häßlichen Äußeren zu entledigen und in seine ursprüngliche Form zurückzukehren. Dardanè nimmt die Gestalt eines Mannes an, Taer die des blauen Ungeheuers, wobei Dardanè über Taers Schicksal im Ungewissen ist, während Taer von Dardanès Verwandlung weiß. Zelou fordert von beiden das

6. S. Anm. 3, I. Calvino, - [...] e soprattutto la sostanza unitaria del tutto, uomini bestie piante cose, l'infinita possibilità di metamorfosi di ciò che esiste, «

7 Vgl. Gozzis Vorwort in Col. II, 199.

$\mathrm{Zu} I l$ mostro turchino hat Letterio Di Francia unter dem Titel sIl mostro turchino*, in: Giomale storico della letteratura italiana 103, 1934, S. 27-54, eine ausführliche Quellenstudie vorgelegt, die nicht nur die Mārehenvorlagen beachtet, sondern auch auf die zahlreichen intertextuellen Bezüge zu epischen Texten und Novellen verweist. 
Versprechen, ihre wahre Identität nicht zu verraten, und droht Dardanê, daß Taer andernfalls sterben müsse. Dardanè wird unter Ankündigung schwerster Prüfungen an den Hof in Nanking geschickt, Taer wird durch Zelou über unhaltbare Zustände am väterlichen Hof unterrichtet, von drei Plagen, die als Strafe verhängt wurden - wovon eine das blaue Ungeheuer selbst ist -, und davon, daß er auf die verwandelte Dardanè treffen werde und sich so verhalten müsse, daß diese ihn als blaues Ungeheuer liebe. In fremder Gestalt in fremder, widriger Umgebung sieht sich Dardanè gezwungen, gegen das blaue Ungeheuer, gegen einen verzauberten Ritter und eine Hydra anzutreten. Taer als blaues Ungeheuer läßt sich von ihr gefangennehmen, an den Hof führen und gibt ihr zu verstehen, daß sie ihren Abscheu gegen sein häßliches Aussehen überwinden müsse, wolle sie ihren geliebten Taer nicht verlieren. Er hilft ihr, die beiden anderen Plagen auszuschalten, kann aber nicht verhindern, daß aufgrund von Verleumdung über Dardanè das Todesurteil gesprochen wird. In dieser Situation droht Dardanè, sich dem König von Nanking zu erkennen zu geben, »egli saprà chi io sono $(\mathrm{V}, 4)$, fügt sich jedoch dem Todesurteil, als das Ungeheuer sie daran erinnert, daß Taer dann sterben müsse. In letzter Sekunde enthüllt das Ungeheuer selbst die Identität Dardanès, worauf diese in ihrer ursprünglichen Gestalt erscheint und aus Mitleid und Dankbarkeit das blaue Ungeheuer an der Hand nimmt, das sich unter Donner und Blitz in Taer verwandelt.

Aus der ausgeglichenen, glücklichen Situation eines liebenden Paares werden Dardanè und Taer unvermittelt herausgerissen und radikalen Veränderungen unterworfen. Der erzwungene Geschlechtertausch Dardanès und die Verwandlung Taers in ein abscheuliches Tier sind verbunden mit härtesten Prüfungen: Als vermeintlichem Mann werden Dardanè Kämpfe zugemutet, die männlichen Mut und männliche Kraft erfordern, als abstoBendes Tier muß Taer die Zuneigung Dardanès gewinnen. Diese Prüfungen führen beide in Extremsituationen, da der äußerlichen Verwandlung keine wesensmäßige entspricht, sondern Dardanè sich entsprechend ihrer wahren Identität als Frau schwach und den Aufgaben nicht gewachsen fühlt und Taer als menschliches Wesen um die Unmöglichkeit weiß, in dieser Form die Liebe Dardanès erwecken zu können. Die Divergenz zwischen Äußerem und Innerem, Aussehen und Wesen führt in letzter Konsequenz zur existentiellen Bedrohung: Das Ungeheuer wie auch Acmed alias Dardanè sind des Todes, und erst im Angesicht des Henkers wird die verlorene Einheit der Person zurückerstattet. In der Zeit des Verlusts ihrer wahren Identität deutet für die Umgebung nichts darauf hin, daß Dardanè und Taer nicht das sein könnten, was sie zu sein scheinen, ja nicht einmal Dardanè kann unter der Tiergestalt ihren geliebten 
Taer erkennen. Zwar wundert sie sich bei der ersten Begegnung mit dem blauen Ungeheuer, "Qual linguaggio è mai / questo! e qual mai trovo / Uman costume nella fera orrenda! « (III,6), doch ist sie bis zum Schluß überzeugt, daß das Ungeheuer Zelou ist. Allerdings nimmt sie in zunehmendem Maß die Diskrepanz zwischen widerwärtiger äußerer Form und gewinnendem Verhalten wahr, so daß sie am Ende aus Mitleid angesichts dieser Diskrepanz und aus Dankbarkeit für das freundliche Wesen die Rückverwandlung ermöglicht:

Il mostruoso aspetto più non odio;

Commossa sono il cor. Di me medesma

Più che sia non lo so .... Confusione...

Speranza ... agitazion... La tua bell'alma

Ad amar sono sforzata, e nasca amore

Dalla compassion, da gratitudine,

$\mathrm{Da}$ vivi dubbj miei, Zelou, t'adoro. $(\mathrm{V}, \mathrm{s})$

Zelou selbst verschafft sich durch die Verwandlung Taers und Dardanès eine neue Identität, beziehungsweise er erhält seine alte, die er verloren hat, wieder zuruick. Wie er Taer erklärt, hat er vor hundert Jahren die Weisen des heiligen Berges von China beleidigt und war daraufhin in das häßliche Ungeheuer verwandelt worden. ${ }^{8}$ Die Verwandlung Zelous in ein Tier als Strafe für ein Vergehen ist, wenn man so will, ein selbstverschuldeter Identitätsverlust, der eine Aussonderung aus der Gemeinschaft der Geister und eine Zeichnung durch Häßlichkeit bedeutet, während Taers und Dardanès Verwandlung in keiner Weise durch eine Schuld motiviert ist - sie entspringt vielmehr den eigennützigen Interessen Zelous, der - gemäß einer Vorhersage ${ }^{9}$ - gerade ein vorbildliches Paar als *Opfer « wählt. Diesen egoistischen Aspekt unterstreicht der Prolog Zelous, in dem er zugleich auf die allegorische Deutbarkeit des Geschehens hinweist:

Tempo verrà, che le trasformazioni,

Ch'io son per cagionar, servir potranno

D'allegorici casi, e i sprezzatori

Mostri saranno, com'io son, cercando

Di trasformar se stessi in nuovo aspetto,

Grato nel mondo, trasformando altrui,

Se mai potranno, in abborriti mostri. $(1,1)$

* - Io son Zelou, famoso Genio, un giorno / Di stupenda bellezza. Offesi i Saggi / Del monte sacro della China, e quelli / In questa deplorabile orridezza / $\mathrm{M}$ ' han trasformato, oggi saran eent'anni. * (I, s).

9 Zur Abhängigkeit der natürlichen wie der übernaturlichen Wesen von anderen Mächten s.u. Kap. 4-3. 
Die Motive des Identitätsverlustes, sei er selbst verschuldet oder unverschuldet, der Übertragbarkeit der körperlichen Hülle auf andere, ${ }^{10}$ der fatalen Divergenz zwischen Erscheinung und Wesen, der beschränkten Wahrnehmung, die sich im Äußeren erschöpft und somit täuscht, machen die Gefährdung der Einheit der Person deutlich - eine Gefährdung, die nicht einmalig und mit der Restitution der wahren Identität der drei Protagonisten am Ende der Fiaba teatrale behoben ist, sondern angesichts der Vorgeschichte Zelous sowie Taers und Dardanès" eine permanente zu sein scheint.

In für die Fiabe teatrali charakteristischem Kontrast steht der an den Märchenfiguren aufgezeigten Problematik eine Maskenszene gegenüber, in der die Anagnorisis als dramatisches Element der Komödien und Tragikomödien parodiert wird. Als neues Opfer für die Hydra, die täglich eine Jungfrau fordert, wurde Smeraldina ausgelost, die eben ahnungslos in Nanking eingetroffen ist. Brighella, ihr Bruder, hat als Hauptmann der königlichen Wache die Jungfrau festzunehmen und der Hydra zum Fraß zu bereiten. Schon beim ersten Anblick Smeraldinas, die er mehr als 12 Jahre nicht gesehen hat, ahnt Brighella, daß er seine Schwester vor sich hat, und die Fragen nach Herkunft, Namen, unveränderlichen Kennzeichen bestätigen dies. Zug um Zug wird die Identität Smeraldinas geklärt, doch führt das problemlose Wiedererkennen paradoxerweise nicht zu einem glücklichen Ende, sondern geradewegs ins Verderben, da sich Brighella seiner Pflicht als königlicher Hauptmann besinnt, heroisch seine Geschwisterliebe verleugnet und Smeraldina abführen läßt. ${ }^{12}$ Diese an autoreferentiellen und metatheatralischen Anspielungen reiche Szene geht einem Monolog Taers als blaues Ungeheuer voraus, in dem er sich über die schiere Unmöglichkeit klar wird, von Dardanè geliebt zu werden, ohne ihr seine wahre Identität zu enthüllen: „Ch'altro mai / Portria far, che tu amassi questo mostro, / Fuor che 'l saper chi sono, e la mia cruda / Me-

10. Die Übertragbarkeit des Äußeren auf andere und die Diskrepanz zwischen äußerer Erscheinung und innerem Wesen sind bercits in $/ l$ re cervo ein entscheidendes Motiv, das im Zusammenhang der Identitâtsfrage hinsichtlich der Masken noch einmal aufgegriffen wird.

11 In der zweiten Szene des 1. Aktes, einer Improvisationsszene zwischen Truffaldino und Smeraldina, werden Taers heroische Kämpfe zur Befreiung Dardanès aus der Macht des Zauberers Bizeghel erwähnt. Dardanè selbst wurde von Bizeghel ein Zauberschleier umgelegt, sche mette furor nelle Donne, e desiderio di aver tutti gli uomini, che vedono.* Diesen Versuch, in die Identität Dardanès einzugreifen und ihr Wesen zu verändern, vereitelt jedoch ihre unübertreffliche Standhaftigkeit.

12 Vgl. Giorgio Barberi Squarotti, $>$ Le Fiabe di Carlo Gozzi๔, in: Egidio Del Boca $(\mathrm{Hg}$ ), Scritti in onore di Franco Falletti, Vercelli, Collegio Dal Pozzo 1983, S. 69-99, hier S. 87 ff., der die Szene als Parodie auf die aufklärerische Maxime vernunftbestimmten Handelns und der Affektkontrolle interpretiert. 
tamorfosi atroce? * (III, 3). Die Kontrastierung eines unproblematischen, komischen und eines problematischen, pathetisch-tragischen Wiedererkennens könnte kaum drastischer ausfallen und ist dazu angetan, die polarisierende Stilisierung beider Konstellationen zu unterstreichen.

\section{Verwandlung und Verstellung als Täuschung}

Einen anderen Akzent setzen La Zobeide und I pitocchi fortunati, in denen die Identitätsproblematik mit der Suche nach Wahrheit verbunden ist. Allerdings unterscheiden sich die beiden Fiabe teatrali insofern, als La Zobeide märchenhaft geprägt ist, während I pitocchi fortunati zum ngenere fiabesco, spoglio di mirabile magico ${ }^{13}$ zählt. Zunächst sei ein Blick auf La Zobeide geworfen, die als einzige Fiaba teatrale die Bezeichnung -tragedia fiabesca* trägt, was Gozzi im Vorwort selbstkritisch kommentiert: "Sussiste sul Teatro tuttavia, quantunque il suo tragico sia un po" troppo fiero, e ch'ella sia scarsa di quel ridicolo delle nostre Maschere, che suol rendere queste tali Opere più generali, e più popolari.* (Col. II, IOI). Daß trotz der extrem wirklichkeitsfernen Gestaltung ein überraschend deutlicher Wirklichkeitsbezug besteht, geht aus dem Vorwort hervor, in dem Sinadab, die männliche Hauptperson, »Re di Samandal, Negromante, sposo di Zobeide, Moro* (Col. II, IO2), als wallegoria - eines niederträchtigen Verführers, so ist zu ergänzen - bezeichnet wird. ${ }^{14}$ Sinadab hat Zobeide wie bereits ihre Schwester Salè und ihre Schwägerin Dilara auf sein Schloß entführt und ist seit 39 Tagen mit ihr verheiratet. Zobeide, die ihren schwarzen Gatten liebt, will dem weisen Abdalac keinen Glauben schenken, als er sie vor Sinadabs Zauberkünsten warnt und ihr für den 40. Tag gleich hundert königlichen Damen vor ihr die Verwandlung in ein Kalb ankündigt. Angesichts des liebenswürdigen Verhaltens Sinadabs fragt Zobeide Abdalac: sChe mai ti move/ A narrarmi tai fole? $\propto$, worauf dieser antwortet: $* \mathrm{Ah}$ 'l so, che fole / Ti den parer la verità, che troppo / Sembrano inverisimili $(1,4)$. Damit sind die Stichworte sfole* und $» v e-$

1) So Gozzi im Vorwort zu I pitocchi fortunati, Col. II, 301. Diese Art von Märchen ist den novellenartigen zuzurechnen, vgl. Kap. 2,4.

14 Vgl. Kap. 3.5. Den Wirklichkeitsbezug präzisiert Gozzi in den Mernoiren im Zusammenhang des Berichts über seine Militärzeit in Dalmatien: sQuel tale colonnello ch"ella m'aveva nominato era in fatti un famoso stupratore di ragazze e un di presso il -Sinadato - [sic] della mia favola allegorica teatrale: La Zobeide, che godute alquanti giorni le giovinette, le trasformava in giuvenche e le mandava alla pastura. Il gran potere che quel colonnello aveva sui popoli della Dalmazia lo salvava da' rigori della giustizia.* (Mem. II, 167). 
rità * gefallen, die den Handlungsgang motivieren: In einem schmerzhaften Prozeß erweist sich für Zobeide nach und nach das Märchen als Wahrheit. In diesem Prozeß spielen Verstellungen und Verwandlungen eine bedeutende Rolle, bis zuletzt Sinadab seinem bösen Wesen gemäß als »centauro orrido« die Bühne verläßt. Sinadab wird dem Publikum bereits im 1. Akt als heuchlerisch vorgestellt, was Zobeide jedoch verborgen bleibt, so daß aus dem Informationsvorsprung der Zuschauer die Spannung erwächst, ob und wann endlich Zobeide die Falschheit ihres Gatten durchschaut. Nach Abdalacs Charakterisierung von Sinadab als Zauberer tritt dieser auf und stellt sich im Gespräch mit Pantalone und Tartaglia als guter, moralischer, gläubiger Herrscher dar, was jedoch von den Masken in zahlreichen a parte-Äußerungen ironisch dementiert wird und sich durch den folgenden Monolog Sinadabs tatsächlich als scheinheilige Verstellung erweist. Während seiner Umgebung die Diskrepanz zwischen Sein und Schein längst deutlich ist, sie das falsche Spiel jedoch entweder aus Angst vor der eigenen Verwandlung in ein Tier (Pantalone, Tartaglia) oder aufgrund der Unterlegenheit der magischen Kräfte (Abdalac) mitspielt, lassen sich Zobeide sowie die zu ihrer Rettung angereisten Verwandten, Vater (Beder), Bruder (Schemsedin) und Geliebter Salès (Masud), von Sinadabs Hypokrisie täuschen. Um an sein Ziel, das heißt die Verwandlung Zobeides in ein Kalb und die Vernichtung des Heeres Beders, zu kommen, bedient sich Sinadab zweier identitätsfälschender Maßnahmen. Zobeide gegenüber macht er von der Verstellung - einer »menschlichen « Möglichkeit der Täuschung - Gebrauch, während er seine magischen Kräfte in der Konfrontation mit Beder für Verwandlungen in andere Personen nutzt: So erscheint Sinadab einmal Schemsedin als der Priester Abdalac, ein andermal gibt er Beder und Schemsedin zugleich seine eigene Gestalt. Diese erste Szene des letzten Aktes ist ein Höhepunkt im bösen Spiel mit verschiedenen Identitäten: Sinadab hat Beder zum Duell herausgefordert und Schemsedin heimtückisch in Gestalt Abdalacs um Hilfe für den Vater gebeten. Beder und Schemsedin betreten beide, ohne sich dessen bewußt zu sein, die Bühne in Gestalt Sinadabs; dabei glaubt Beder, sein Duell mit Sinadab auszutragen und Schemsedin, dem Vater zuvorgekommen zu sein und den Duellanten Sinadab vor sich zu haben. Schemsedin trifft Beder tödlich, worauf Sinadab zur Verzweiflung Schemsedins den Sachverhalt aufklärt: »quello è tuo Figlio. (mostra Schemsedino) / Quello è tuo Padre, da te stesso ucciso. (addita Beder) / S'impari a molestarmi. * (V, I). ${ }^{15}$ Inter-

15 Der blasphemische Anklang an die Jesusworte am Kreuz (*Mulier, ecce filius tuus * und - Ecce mater tua / / donna ecco tuo figlio*, secco tua madre*, Joh. 19, 26-27) ist sicher kein Zufall, führt doch Sinadab ohne Unterlaß heuchlerisch den Himmel im Mund. 
essant ist diese Szene auch im Hinblick auf die Zuschauerillusionierung, sehen diese doch die Personen in der Gestalt, wie sie sich gegenseitig auf der Bühne wahrnehmen: Beder wie Schemsedin glauben, Sinadab vor sich zu haben, und merken nicht, daß sie selbst in dessen Gestalt erscheinen, ${ }^{16}$ so daß auch für das Publikum in diesem Moment unklar bleibt, wer gegen wen kämpft. In perfider Weise verwandelt sich Sinadab also nicht nur in andere Personen, sondern läßt auch andere als Sinadab erscheinen. Während die wechselnden Identitäten Sinadabs der Suche nach der Wahrheit entgegenstehen, wird diese durch seine Verzauberungen anderer Personen befördert. Der direkte Anblick der tierischen und bedauernswerten menschlichen Gestalten, die Zobeide wider den Willen Sinadabs mit Hilfe Abdalacs entdeckt, öffnet ihr die Augen. Brighella und Truffaldino als Tiger und Löwe werden durch Abdalac rückverwandelt, um Zobeide von ihrer wahren Identität zu überzeugen, für Dilara und Salè dagegen kann Abdalac nichts tun. ${ }^{17}$ Sie haben sich Sinadab verweigert und müssen zur Strafe mit anderen Frauen in einer dunklen Höhle hausen, wo Zobeide sie verstümmelt, in Ketten findet: Dilara "che sotto è cambiata in animale, o cagna, o capra (II, II), Salè *al seno attaccata una serpe, che la divora, e 'I sangue, che gronda giù per una veste bianca, che avrà di sotto* (II, I 2). ${ }^{18}$ Angesichts dieses Elends willigt Zobeide ein, Sinadab mit Hilfe Abdalacs zu entlarven. Sinadabs unlauteres Spiel mit Identitäten, das - wie bei Beder - tödliche Folgen haben kann, wird nun konterkariert durch Zobeide, die zum Schein auf Sinadabs Ansinnen eingeht und so der Arglist des Zauberers mit der menschen-möglichen Verstellung begegnet. Noch einmal wird die Dichotomie von sfola und »verità $\propto$ aufgerufen, wenn Zobeide scheinheilig über Abdalacs Erzählung von den Verwandlungen der

16. Wie in La donna serpente bei Pantalones Auftritt als Priester Checsaja und Togruls als Vater Farruscads, gibt Gozzi genaue Anweisungen zur Ausführung der Szene, und wie im Fall Pantalones, der seiner Rückverwandlung nicht gewahr wird, setzt auch bei Beder und Schemsedin angesichts der Konzentration auf das Gegenüber die Eigenwahmehmung aus.

17. Trotz der im Vorwort angesprochenen reduzierten Präsenz der Masken nutzt Gozzi diese auch in La Zobeide zur Schaffung von Kontrasten wie dem zwischen der *komischen * und leicht behebbaren Verwandlung der Masken in Tiere und der ernsten, mitleiderregenden Dilaras und Salès. Während Truffaldino und Brighella in einer Improvisationsszene auf Vor-und Nachteile ihres ehemaligen Tierdaseins eingehen, haben sich Dilara und Salè ihrem Schicksal ergeben.

16. Daß3 Gozzi über das handlungsfundierende Märchen hinaus (hier König Blaubart) wie in allen anderen Fiabe teatrali auch andere intertextuclle Bezüge schafft, macht diese Szene deutlich, in der die Referenz zu Dantes Inferno offensichtich ist, wobei im Nebentext ausdrücklich darauf hingewiesen wird, daß die Gestalt Dilaras und Salès Mitleid erwecken und nichr lächerlich wirken sollen, "la figura deve far compassione, e non rideres (II, It). 
Frauen durch Sinadab sagt, »Saran fole $«(V, 6)$, und eine Bestãtigung sucht, *Deh scusa ... / Fole son, non è ver?...*, um Sinadabs Falschheit bloßzustellen. Erwartungsgemäß antwortet dieser, »Fole, il confesso $\propto$. Die beiderseitige bewußte Täuschung, Zobeides fingierte Ahnungslosigkeit und Sinadabs bösartige Verstellung, mündet in die Enthüllung der Wahrheit über Sinadab vor Zobeides Augen und in seine unmittelbare Bestrafung. Das Zauberbrot, das sie zu sich nehmen, verwandelt nicht Zobeide in ein Kalb, sondern Sinadab - mit Hilfe Abdalacs - in einen Zentaur. Mit dieser letzten Szene hat sich das, was Zobeide ein Märchen dünkte, als wahr erwiesen. Was Worte nicht vermochten, macht erst die eigene Anschauung möglich: ${ }^{19}$ sie von Sinadabs Hypokrisie zu überzeugen, sein Erscheinen als Täuschung zu erkennen, der sie aus Liebe erlegen war. ${ }^{20}$

\section{Verstellung zur Wabrheitsfindung}

Die 1764 im Abstand eines Jahres auf La Zobeide folgende "fiaba tragicomica I pitocchi fortunati kann unter dem Aspekt der Identitätsproblematik als komplementärer Entwurf gelten. Der Täuschung, Verstellung, Verwandlung in böser Absicht steht in I pitocchi fortunati die Annahme fremder Identitäten zur Wahrheitsfindung entgegen. Ohne die Intervention magischer Kräfte bleibt der Identitätswechsel auf die Verkleidung beschränkt. Nach dem Tod seines königlichen Vaters, "che nel Regno / Mal scopria 'l ver $(I, 2)$, täuschte Usbec seinen Abschied von Samarkand vor, um in unterschiedlicher Gestalt sein Reich, seine Untertanen und Minister besser kennenzulernen:

[...] forse in venti forme

Cambiato in Samarcanda, ebbi a mio senno

Intrinsichezze, pratiche, e conobbi

Nel Popol mio, ne' Sudditi, nel Regno

E ne' Ministri ciò, che in Real seggio

Non s'intende giammai. Troppo ha possanza

Educazion in noi. Mal si comprende

Fra le idee di ricchezze, e fasti, ed agi

La miseria de' Sudditi meschini,

E troppo abbaglia adulazione, ed arte

De' rei Ministri, ingordi, e saggi, e accorti

19 Hier ergibt sich ein nicht weiter ausgeführter Bezug zum Theater Gozzis, das den $\mathrm{Zu}$ schauern die Wahrheit des Märchenhaften, unwahrscheinlich Anmutenden vor Augen führen will.

20 Zu positiven und negativen Konnotationen der Liebe s. Kap. 4.2. 
Sol per se stessi, che 'I Monarca fanno

Macchina stolta spesso, ma a' tesori,

Alle lor passioni, alle vendette,

Alle ingiustizie valido strumento. ( $\mathrm{I}, 2)$

Nach Usbecs Überzeugung ist ein Monarch zu weit von der Realität entfernt, um die Wahrheit zu erkennen. Die königliche Erziehung, der ökonomische Überfluß und von Eigeninteressen geleitete Minister stellen sich als Hindernis in den Weg und trüben den Blick für die Wahrheit. Als guter, offensichtlich aufgeklärter Herrscher ${ }^{21}$ sucht er die Nähe zu seinen Untertanen, um ihre Nöte und Bedürfnisse selbst in Erfahrung zu bringen und ordnend eingreifen zu kônnen. Der Zeitpunkt ist gekommen, an dem er gemäß seinen Beobachtungen handeln und auf den Thron Samarkands zurückkehren will. Sein Vorhaben bedarf noch eine Weile seines Unerkanntseins, so daß Usbec im Verlauf der Fiaba teatrale in verschiedenen Verkleidungen auftritt. Hauptsāchlich geht es Usbec um die Bestrafung des verruchten Großwesirs Muzaffer und die Entschädigung des gepeinigten Pantalone, wobei ein Eigeninteresse Usbecs mit im Spiel ist: Er liebt das schönste, tugendhafteste Mädchen Samarkands und will dieses zu seiner Frau machen, obwohl es in Armut und Elend lebt. Verkleidet als Imam, den er ins Vertrauen gezogen hat, erfährt Usbec, daß die Geliebte Angela die Tochter Pantalones ist, was sich gut in seine Pläne fügt, Pantalone für die Schikanen Muzaffers zu entschädigen. Dieser hat im Sinn, Pantalones Wertvollstes, eben seine Tochter, unter Vortäuschung einer falschen Identität mit einem elenden Bettler zu verheiraten, den er getroffen hat. Nicht ahnend, daß sich hinter der Maske des Bettlers Us-

It Unüberhörbar ist die Kritik Usbecs an der Wirklichkeitsferne der Regenten und müßte die Interpreten eines Besseren belehren, die sich daran aufhalten, daß angeblich in Gozzis Fiabe teatrali immer dasselbe Muster nguter König / böser Minister* wiederkehre, was als typisch für einen reaktionären Aristokraten gewertet wird. Zum einen ist festzuhalten, daß die Kōnige in den Fiabe teatrali keineswegs immer gut und souveràn, sondern schwach und melancholisch wie Millo in $I l$ corvo, gutgläubig wie Deramo in Il re cervo oder gar senil, dumm und böse wie Fanfur in $1 /$ mostro turchino sind. Was den -bösen- Minister Tartaglia betrifft, steht diesem in den typischen Kontraststrukturen der Fiabe teatrali immer ein gutes Pendant, meist Pantalone, gegenüber. Daß in Gozzis Stücken Könige auftreten, kann - abgesehen von der märchenbedingten Vorgabe - in politischer Hinsicht nicht als antiaufklärerisch gelten, denn der Bezugspunkt der Aufklarung ist nicht etwa das republikanische System, sondern das monarchische, dem die größte Wirksamkeit zugesprochen wird, wie Michel Vovelle im Vorwort zu Der Mensch der Aufklärung, Frankfurt, New York, Campus; Paris, Editions de la Fondation Maison des Sciences de l'Homme 1996, S. 15, betont. Außerdem ist die besondere Situation Venedigs in Betracht zu ziehen, in der eine monarchische Struktur in der theatralen Wirklichkeit nicht als systemstabilisierend angesehen werden kann, da die Stadt als Republik oligarchisch regiert wurde. 
bec verbirgt, gaukelt er Pantalone vor, der Sultan von Charism wolle seine Tochter heiraten, und inszeniert eine erste Begegnung, in der der Bettler in königlichen Gewändern vor Pantalone und Angela erscheint, und eine zweite, in der Usbec entkleidet wird und als Bettler dasteht. Nachdem Muzaffer zufrieden mit dieser äußersten Demütigung Pantalones die Bühne verlassen hat, enthüllt Usbec seine wahre Identität und kündigt Vergeltung an Muzaffer an. Diese bedarf der Mithilfe Angelas, die sich, mit einem Schleier verhüllt, als Omega ausgibt und beklagt, von ihrem Vater Brighella wegen ihrer angeblichen Häßlichkeit und Dummheit vor der Öffentlichkeit verborgen zu werden. Angela stellt ihre Anmut und Schönheit vor Muzaffer unerkannt zur Schau, so daß dieser ihrem Wunsch nach einem Gatten selbst nachkommen will und bei Brighella zu dessen großer Verwunderung um Omegas Hand anhält. Die wirkliche Omega, eine Ausgeburt an Häßlichkeit, wird verschleiert vor Muzaffer gebracht und mit ihm vermählt. Usbec kehrt mit Angela auf den Thron zurück, während Muzaffer seiner Wesirkleider entledigt wird.

Der gesamte erste Akt, in dem Usbec als Imam von den Sorgen und Nöten der Bettler erfährt, die gekommen sind, um Almosen zu erhalten, steht im Zeichen der Wahrheit, die einem König nur in falschem Gewand zugänglich ist. In kontrastiven Szenen wird sichtbar, daß der Umgang mit der Wahrheit sehr unterschiedlich sein kann, daß sie widerwillig oder bereitwillig, vollständig oder nur teilweise enthüllt wird, daß sie einmal auf der Hand liegt, ein andermal überrascht. In diesem Spektrum ist Truffaldinos Verhältnis zur Wahrheit ein besonderes, maskenhaftes: Auf Usbecs Mahnung, "la verità non cela «, antwortet dieser, "che ha sempre sentito dire, la verità esser una sola, e che per ciò dal canto suo ha voluto risparmiarla, perchè non si consumi. « (I, 10$)$. Im zweiten und dritten Akt dient die Verkleidung nicht mehr der Wahrheitssuche, sondern der Herstellung von Gerechtigkeit, die zunächst in den Augen der Betroffenen immer wieder zu mißlingen scheint. Höhepunkt des "travestimento" ist Usbecs Auftritt als Sultan von Charism - eine Verkleidung, die nicht Usbec selbst, sondern Muzaffer veranlaßt, ohne die geringste Ahnung, daß damit Täuschung und Wirklichkeit nahezu zusammenfallen. Die Verwunderung Muzaffers angesichts des professionellen Auftretens des Bettlers als Sul$\tan$ ist durchsetzt von Verweisen auf das Theaterspiel: "Questo pitocco mi sorprende. Oh come / Ben finge la persona d'un Monarca! «, oder * Non fu Comico mai, che sulla scena / Questo Pitocco a far da Re avanzasse* (II, 3 ), und so ist es nur konsequent, wenn sich die Fiktion wieder auflöst und der Sultan zum Bettler wird. Wie sich Pantalone von diesem überzeugenden Auftritt täuschen läßt, hat sich allerdings auch Muzaffer zuvor von Usbecs Auftritt als Bettler täuschen lassen. 


\section{Identitätswechsel und Rollenspiel}

Offensichtlich ist es also nicht nur das (zufällige) Zusammenfallen von gespielter Rolle und wirklicher Identität, das die Illusion hervorruft, sondern die Kunst der Verstellung überhaupt, die zeitweilige Anverwandlung fremder Identitäten. Usbecs Identitätswechsel zeichnen sich im Unterschied zu Verstellungen und Verwandlungen in anderen Fiabe teatrali dadurch aus, daß sie bei allem ernsten Hintergrund spielerischen Charakter haben - sie sind selbstbestimmt, über Anfang und Ende und Art und Weise entscheidet niemand als Usbec selbst. Ein schauspieltechnisches Indiz für diese Andersartigkeit ist der Umgang mit der Stimme. Wenn Pantalone in La donna serpente als Checsaja erscheint und Togrul als Vater Farruscads oder Sinadab in La Zobeide anstelle Beders und Schemsedins, ertönt laut Gozzis Anweisung jeweils die Stimme des Dargestellten, den Zuschauern auf der Bühne Sichtbaren, während Usbec als Bettler wie als Sultan mit seiner eigenen Stimme spricht, ja diese sogar für seine Wahrhaftigkeit bürgt. Zu Pantalone, dem er als Imam das Ende der Mühsal und Sorgen prophezeit, sagt er: $\bowtie$ Se mai tu senti / Il suon della mia voce in altr'oggetto, / Quello il segno sarà, ch'ogni tuo affanno / In gioja è per cambiarsi. ( $(\mathrm{I}, 6)$. Bei Usbecs Verkleidungen ist beidesmal die Wahrheit im Spiel - als Bettler tut sich ihm die Wahrheit auf, als Sultan stellt er quasi das dar, was er wirklich ist -, was im Zusammenhang mit Gozzis Theaterkonzeption wiederum als Hinweis auf die in der Illusion aufscheinende Wahrheit gelesen werden mag. ${ }^{22}$ Daß das Fingieren allerdings nicht unproblematisch ist und ein Ende haben muß, macht der Imam unmißverständlich deutlich, „Io stupido [sic] rimango a sì bizzarro / Modo d'oprar a (I, 2), und fordert die Rückkehr zur Realität, - Io vi priego, Signor, troncate il filo / Alle bizzarrie vostre, e nella Reggia / Entrate, come Re. Punite l'empio / Muzaffer, gran Visir. Questa Cittade / Sconvolta da disordini, e ingiustizie / Pensate a sollevar.* (I, I2). Auch dieser Aspekt der zeitlichen Beschränkung des Fingierens ist für das Theater von Bedeutung, da gerade die Zeitbegrenzung Voraussetzung für die Inlusion als Sich-Selbst-Aufgeben des Zuschauers ist. ${ }^{23}$ Damit stellt $I$ pitocchi fortunati im Hinblick auf einen unproblematischen Wechsel der Identitäten nicht nur ein Gegenstück zu Il mostro turchino und $\mathrm{La} \mathrm{Zo-}$

VgL. oben Anm. 18.

23 Vgl. Kap. 3.4 und U. Rapp, op. cit, S. 77 zur Inlusion: - [... / ein Sich-Selbst-Aufgeben, wenn auch mit noch so großem Enthusiasmus, aber auf bestimmte und vor-bedingte Zeit, ist kein Sich-Selbst-Verlieren; es behalt sich von vornherein die Selbstbeherrschung vor. Zeitbegrenzung ist Voraussetzung der Selbstbestimmung, * 
beide dar, sondern deutet mit der spielerischen Variante der Verkleidung auch auf das Theater selbst hin.

Die Thematik der Identität ist in besonderer Weise für die Masken virulent, die in den Fiabe teatrali nicht nur als Masken auftreten, sondern auch Rollen im Märchengeschehen einnchmen und so eine doppelte Rollenhaftigkeit aufweisen: als Pantalone, Tartaglia, Brighella, Truffaldino und als Admiral, Bettler, Minister, Jäger, Vogler etc. ${ }^{24}$ War es in der Commedia dell'arte ursprünglich üblich, daß ein und dieselben Schauspieler nicht nur Masken-, sondern auch andere Rollen darstellten, verwandelt Gozzi diesen sukzessiven Rollenwechsel gewissermaßen in eine simultane Überlagerung, in der Maske und Märchenfigur zusammenfallen. Diese Doppelung erzeugt unterschiedliche Effekte, die vom Grotesken über das Komische bis zum relativ Unauffälligen reichen - unübersehbar bleibt die Doppelrolle in jedem Fall durch die immer gleiche Maske, die dem Publikum bekannt und mit vorgeprägten Erwartungen verbunden ist. Insofern wird die Aufmerksamkeit der Zuschauer, die sich bei den Masken normalerweise auf die mehr oder minder glanzvolle Erfüllung der weitgehend festgelegten Verhaltensmerkmale richtet, auf das Verhältnis von Maskencharakteristika und der Rolle im Märchengeschehen gelenkt. Die stark stilisierte Maske unterstreicht den Unterschied zwischen Rollenträger und Rolle, führt vor Augen, daß sich hinter dem sichtbaren ein verdecktes, unsichtbares Gesicht befindet. Diese Gesichter sind nicht identisch und nicht deckungsgleich, vielmehr verweist ihre Unterschiedlichkeit auf das Spiel als zeitweilige Übernahme einer Rolle in einer Wirklichkeit anderer Art. Steht damit die Maske an sich einem mimetischen Verständnis von Theater entgegen, verdoppelt sich der distanzierende, verfremdende Effekt, wenn beispielsweise in L'amore delle tre melarance der Märchenprinz und in L'augellino belverde der -könig oder in Il re cervo der Minister des Märchenkōnigs durch sein Äußeres als Tartaglia zu erkennen sind: Der Schauspieler stellt Tartaglia dar, der den König bzw. den Minister spielt. Bei den Masken stellt sich demnach nicht wie bei den Märchenfiguren die Frage nach Gefährdung, Verlust, Restitution der Identität, sondern die nach der Ambivalenz der körperlichen Erscheinung als Zeichen für die Identität einer Rolle.

Diese Ambivalenz wird in einigen Fiabe teatrali bereits beim ersten Anblick der Masken deutlich, wenn ihre Kostüme denen der Märchenfiguren, d. h. dem Ort der Handlung, entsprechen. In aller Regel steht die Einheit des Maskengesichts und des entsprechenden Kostüms für die Glaubwürdigkeit einer Gestalt, und im Falle der Commedia dell'arte-

$24 \mathrm{Vgl}$. Kap. 2.5, wo die einzelnen Rollen im Märchengeschehen aufgeführt sind. 
Masken ist dies nicht anders. In $\mathrm{Il}$ re cervo treten aber nach ausdrücklicher Anweisung des Autors im Personenverzeichnis alle Personen außer $\mathrm{Ci}$ golotti, das heißt auch die Masken, $\diamond$ vestiti all'orientale (Col. I, 330) auf, in Turandot und Il mostro turchino ebenfalls, in I pitocchi fortunati als Bettler. ${ }^{25}$ Offensichtlich wird also die traditionelle Einheit von Maske und Kostüm aufgelöst und die typische Maske mit einem Kostüm kombiniert, das die Zugehōrigkeit zur Märchenwelt und den übrigen Märchenfiguren signalisiert. So bilden Pantalone, Tartaglia, Brighella und Truffaldino einerseits durch ihre Masken einen Kontrast zu den anderen Personen der Märchenwelt, andererseits wird ihre Integration in das Märchengeschehen am Kostüm deutlich. Sobald die Masken zu reden anfangen, verstärkt sich die Ambivalenz durch Art und Inhalt des Gesagten - je nach Stück und Maske in unterschiedlichem Maß. Bei Truffaldino und Brighella ist in ihren meist untergeordneten Rollen als Diener, Jäger, Aufseher etc. die Diskrepanz zwischen typischen Maskencharakteristika und Rollenerwartung geringer als bei Pantalone und vor allem Tartaglia. ${ }^{26}$ Vor allem bleibt ihnen ein typisches Merkmal der Commedia dell'arte erhalten: die Improvisation, wenn auch auf der Grundlage einer von Gozzi vorgegebenen Skizze. Die lose Einbindung Truffaldinos und Brighellas in das Märchengeschehen ist die Voraussetzung dafür, daß im typisch Maskenhaften weniger die Ambivalenz von Maske und Rolle zutagetritt als vielmehr der Kontrast zwischen der Maskenfigur und den Märchenfiguren. Sobald die Masken tiefer in das Märchengeschehen involviert sind und sich den *ernsten « Rollen der Märchenfiguren nähern, stehen sich die jeweiligen Charakteristika sichtbar entgegen.

Dies wird vor allem an Tartaglia deutlich, dessen Auftritt als Prinz in L'amore delle tre melarance groteske Züge trägt und in $I l$ re cervo als metatheatralische Demonstration der Rollenproblematik gelesen

25. In den übrigen Fiabe teatrali fehlen explizite Angaben zu den Kostumen oder sind nur vereinzelt vorhanden, so daß sich kein Gesamtbild der Kostümierung ergibe. In La donna serpente geht aus den Angaben zur Verwandlung Pantalones in den Priester Checsaja klar hervor, daß unter den Priestergewändern die traditionelle Maske wie auch das dazugehôrige traditionelle Kostüm verborgen sind: * Pantalone uscirà senza la solita sua maschera, ma ingombrato il viso da gran basette, e gran barba bianca. Sotto questa avrà nascosta la consueta sua barba. Abbia una gran mitra sacerdotale. Sotto a questa sia nascosta la sua maschera di Pantalone, [...] Abbia una veste sacerdotale; sotto a questa la sua sottana, e le brache da Pantalone. $<(1,7)$.

35 Sobald Brighella wie in L'augellino belverde nicht mehr eine Dienerrolle, sondern die eines Poeten einnimmt, tritt die Diskrepanz zwischen Maske und Rolle hervor. Wie schr bei Gozzi formale Aspekte die Gestaltung der Figuren bestimmen, belegt die Szene in Il mostro turchino, in der Brighella auf seine Schwester Smeraldina trifft und diese in unterschiedlichen Sprachen reden: Brighella als Maske venezianisch, Smeraldina dagegen italienisch. 
werden kann. ${ }^{27}$ Gleich zu Beginn des Stücks wird die Frage nach Rolle und Authentizität aufgeworfen, wenn die verschiedenen Heiratskandidatinnen vor König Deramo erscheinen und ihr Verhalten - bis auf das Angelas - von der Zauberbüste als Verstellung enthüllt wird. Tartaglia als erster Minister und Vertrauter des Königs Deramo steht insofern in Zusammenhang mit dieser Präsentation, als er seine Tochter Clarice ins Rennen schickt und diese dazu zwingt, ihre wahre Liebe zu Leandro zu verleugnen. Die Szene zwischen Vater und Tochter läßt die Diskrepanz von derb-komischer Masken- und seriöser Ministerrolle deutlich werden, wenn Tartaglia z. B. seine Tochter mehrfach fragt, "non avresti già qualche taccherella secreta, ch'egli potesse scoprire eh ?* $(I, 2)$ und ihr droht, sie zu vergiften, wenn sie den Wettbewerb nicht gewinne, dem König ihre Liebe zu Leandro verrate oder ihm von seinen väterlichen Mahnungen berichte, wun veleno è pronto; la morte per te è preparata; cadrai vittima del mio furore $\propto$. Nach der Wahl Angelas geht es Tartaglia nicht nur darum, sich an Deramo für den entgangenen Machtzuwachs als Schwiegervater zu rächen, sondern auch für die vereitelte Heirat Angelas, die er "per amore, o per forza zu seiner Gattin machen wollte. Er erschleicht sich das von Deramo gehütete Geheimnis eines Zauberspruchs, der es erlaubt, den eigenen Körper abzustreifen und in den eines toten Tieres oder Menschen zu schlüpfen und sich danach wieder seines eigenen Körpers zu bemächtigen, ${ }^{28}$ In zwei Etappen verwandelt sich daraufhin Deramo in einen getö-

27 Vgl. F. Vazzoler, -Ruoli e recitazione nel Settecento: P'impossibile metamorfosi di Tartaglia a, in: Carlo Gozzi, Re cervo, Collana del Teatro di Genova 68, Genova, Marietti 1991, S. 37-50, und „Un napoletano a Venezia «, op. cit., der Tartaglia vor allem im Hinblick auf die Veränderungen der Rezitation im 18 . Jahrhundert deutet, das heißt auf den Wechsel des sprachlichen Registers von der Commedia dell'arte zur ausgeschriebenen Komödie.

28 - Ecco un verso infernale. Udite, amico, / La portentosa facoltà di questo. / A qualunque animale, od uomo morto / Recitandolo sopra, voi morrete, / E per magica forza il vostro spirto / Passerà nel cadavere di quello, / E in quello entrato lo farete vivo, / Lasciando il vostro corpo in terra morto.... (II, s).

Die Möglichkeit, sich einer anderen außeren Hulle zu bedienen, hat Deramo, wie er Tartaglia erklärt, vielfach dazu genutzt, in Form eines Hundes, eines Vogels, anderer Tiere oder auch Menschen seine Untertanen besser kennenzulernen, Lügner zu entlarven und Unrecht zu entdecken und zu bestrafen und so sein Reich von Übeltàtern frei zu halten. Dieses Motiv fürt Gozzi in I pitocchi fortunati aus, jedoch unter Vermeidung magischer Mittel.

Interessant ist, daß die Thematik der Verwandlung in verschiedene körperliche Hüllen auch in einem Text Gasparo Gozzis auftritt, der am 11 . April 1761 in L'osservatore veneto erschien und von Baretti in La frusta letteraria (Nr. 21 vom 1.8.1764, op. cit., Bd. 2 , S. 166-170) ausführlich zitiert wird, um seinen Lesern einen Eindruck di quel bel libro dell'Osservatore veneto* zu vermitteln. Gasparo Gozzi berichtet von einem gewissen verrückten Naldo, der Schuhmacher war, sein Metier aufgegeben hat und sich nun der Bildung widmet. Unter Berufung auf den letzten Dialog in Platons Politeta und den 
teten Hirsch und Tartaglia in Deramo, ${ }^{29}$ später Deramo als Hirsch in einen alten Mann. Zwar erscheint nun Tartaglia seiner Umgebung in Deramos Gestalt, doch erwecken sein Verhalten und vor allem das maskentypische Stottern ein Mißtrauen, das er nicht entkräften kann. Explizite Äußerungen vor allem Pantalones, aber auch von Tartaglia selbst, machen auf das Problem der mangelnden Übereinstimmung von Verhalten und Rolle aufmerksam. ${ }^{30}$ Damit wird auf der Bühne eine Problematik angesprochen, die unausgesprochen bereits für die primäre Rollendoppelung Tartaglia-Minister zutrifft, so daß eine Art des Theaters im Theater entsteht - was die Personen des Stücks an der Usurpation der Rolle des Königs durch Tartaglia-Minister irritiert, gilt im Hinblick auf die $*$ Usurpation $\propto$ der Rolle des ersten Ministers durch die Maske Tartaglia analog für das Publikum im Saal, wobei die Ambiguität dieser Doppelung durch die Diskrepanz von Maske und orientalischem Kostüm zeichenhaft vermittel wird, während die äußerliche Übereinstimmung zwischen dem »echten * und dem "falschen $\propto$ Deramo laut Nebentext möglichst perfekt sein soll. Der metatheatralische Hinweis kann in zweierlei Weise verstanden werden: Zum einen wird die Nicht-Identität von Darsteller und Rolle generell ins Blickfeld gerückt, zum andern die aktuelle Problematik, die Maskenschauspieler in vorgegebenen, ausgeschriebenen, zum Teil ernsten Rollen auftreten zu lassen. Tartaglia als erster Minister läßt durch seine Sprache wie durch sein Verhalten eine Unangemessenheit in der Darstellungsweise der Rolle erkennen, die einen komischen Effekt hervorruft, während sein Auftritt als Deramo, der als möglichst vollkommene Illusion inszeniert ist, Irritation und Argwohn erzeugt, da er sich selbst, das heißt sein Stottern, nicht verleugnen kann. Analog zur indirekten Darstellung der Wirklichkeit in den

Schlußmythos über das Schicksal der Seele nach dem Tod erzählt Naldo unglaubliche Geschichten über Verwandlungen in verschiedenste Körper. Die erste dieser Geschichten gleicht in weiten Teilen dem zweiten Handlungsstrang von $1 l$ re cervo, d.h. der Verwandlung des Kónigs in ein Tier und des Höflings in den König. Diese Geschichte könnte neben - Histoire du Prince Fadlallah fils de Bin-Ortoc, Roy de Mouzele aus Les mille et an jours (vgl. Kap. 2.3) als Hintergrund für die Fuaba teatrale gedient haben, die im Januar 1762 aufgefuhrt wurde.

27) Zur Sicherheit schlägt Tartaglia in Gestalt Deramos dem toten Tartaglia-Körper den Kopf ab und verbirgt den Körper im Gestrüpp, damit Deramo sich nicht in Gestalt Tartaglias an den Hof begeben und dort seine Pläne durchkreuzen kann. Diese Verwandlungsszene wird yon Gozzi genau beschrieben bis hin zur Anweisung, daß Deramo von Anfang an eine Maske tragen muß, die zusammen mit einer zweiten eine möglichst weitgehende Ähnlichkeit von Deramo und Tartaglia als Deramo ermōglicht.

so Vgl. Kap. 2.5, z. B. Tartaglia: $=$ Resti Deramo nella sua miseria. (tartaglierá) Oh malederta imperfezione di lingua, ancora mi perseguiti? = $(11,8)$ und Pantalone a parte: - Mi son sbasio! l'è deventà un can. No lo conosso più. L'ha cambià infin la ose, e el se intartagia, che el fa stomego* und -Tolè! Che schienze de tartagiac! * (II, ro). 
Fiabe teatrali scheint also auch eine distanzierende, verfremdende Darstellungsweise eher zu glücken als die angestrebte Identität von Darsteller und Dargestelltem. Hinsichtlich der vor allem von Goldoni betriebenen "Umschulung « der Maskenschauspieler zu Darstellern ausgeschriebener Rollen, deren Vor- und Nachteile in Il teatro comico zur Sprache kommen, ${ }^{31}$ wird an Tartaglia als Deramo deutlich, daß sich das typisch Maskenhafte nicht einfach eliminieren läßt und die Absicht, in ernste Rollen zu schlüpfen, zum Scheitern verurteilt sein kann. ${ }^{32}$

Ein besonderer Aspekt im Kontext der Frage nach Identität und Rolle ist die Tatsache, daß das zeitgenössische venezianische Publikum nicht nur die Masken auf der Bühne sah, sondern selbst Masken trug. ${ }^{33}$ Die Zeit, in der die Theater geöffnet waren, war auch die Zeit des Maskentragens: von Anfang Oktober bis zur Fastenzeit, um Himmelfahrt und bei offiziellen Anlässen der Republik wie der Wahl eines Dogen, eines Prokuratos etc. ${ }^{34}$ Die Undurchsichtigkeit der äußeren Erscheinung, der zeitweilige Rollenwechsel im gesellschaftlichen Leben haben also ihr Pendant im Theater, wenn auch nicht zu übersehen ist, daß sich Art und Funktion der Masken unterscheiden. Während Tabarro und Bauta die Individualität in einer Uniformität aufheben, die nicht nur geeignet ist, schichtenspezifische Merkmale, sondern auch geschlechtsspezifische Unterschiede aufzuheben, ${ }^{35}$ betonen die Masken auf der Bühne gerade das Typische,

31 Vgl. Kap. 3.3.

12 Zum Mangel an guten Darstellern für ernste Rollen äußern sich Goldoni indirekt in II teatro comico und Gozzi direkt im Vorwort zu Il re cervo. Dagegen konstatiert Gozzi in seinen Memoiren, daß die Truppe Sacchi um 1770 über geeignete, begabte Schauspieler auch für die ernsten Rollen verfügte; Mem. I, 275.

13 Wie aus einer Bemerkung in L'osservatore veneto vom 17 . Februar 1762 hervorgeht, waren in den Theatern selbst die Türsteher, die den Eintritt kassierten, maskiert.

4 Vgl. Samuele Romanin, Storia documentata di Venezia, 3. Aufl., Bd. 9, Venezia, Filippi 1975, S. 14: "Dalla prima domenica di ottobre alla Quaresima e nei quindici giorni della Sensa (fiera dell' Ascensione) nonché nelle occasioni solenni dell'elezione di un doge o Procuratore di s. Marco, costumavasi la foggia del tabarro e bauta. Era la bauta una sorta di mantellina di seta nera di cui coprivasi il capo, fornita di pizzi, e sopra alla quale con singolare bizzarria e uomini e donne portazano [sic] un cappello tripuntato. Costituiva, sebbene di sovente a viso scoperto, una specie di maschera, o piuttosto di abito di convenzione, che veniva assunto anche da' più gravi magistrati, perfino dagl'Inquisitori di Stato, e dallo stesso doge, non ché da' principi stranieri e dagli ambasciatori, per quei liberi da ogni etichetta, più non salutandosi che col nome di maschera, potevano intervenire da per tutto, frammischiavansi tra il popolo, sicuri da qualunque insulto od offesa, essendo l'individuo in tabarro e banta considerato come sotto la speciale tutela delle leggi e della doverosa urbanità. [...] Nei tempí in cui, come abbiam detto, era regolarmente permesso l'uso del tabarro e bauta, s'aprivano altresì i teatri, e quello in particolare dis. Benedetto*.

15. Vgl den Reisebericht des Abbé Coyer, der über die Fiera dell'Ascenzione von 1764 berichtet (zitiert in Paul Bédarida, sQuelques écrivains français à Venise au XVIIle 
stilisieren einzelne Charakteristika ins Extreme. Gemeinsam ist ihnen jedoch die Verhüllung eines Darunter-Liegenden, die Fixierung und die Täuschung, umgekehrt gesagt: die Schaffung einer anderen Wirklichkeit eigener Logik und eigener Gesetze. Diese Wirklichkeit eigenen Rechts gilt es zu durchschauen und zu durchdringen, den Schleier zu entfernen, um zu erfahren, was sich dahinter verbirgt. Ob ein Publikum, das maskiert die Ambiguität der Erscheinung ins Theater trägt, für das Spiel von Dissimulation und Transparenz auf der Bühne in höherem Maße sensibilisiert ist, muß dahingestellt bleiben. ${ }^{36}$

Die Problematik von wirklicher und vorgegebener, von selbstbestimmter und aufgezwungener Identität, von äußerer Erscheinung und wahrem Wesen, von Rollenerwartung und authentischem Verhalten durchzieht alle Fiabe teatrali und ist mit Sicherheit nicht nur auf ein venezianisches Phänomen zurückzuführen, sondern vielmehr auf die generelle, das Denken der Aufklärung bestimmende Suche nach Wahrheit, Eindeutigkeit, Allgemeingültigkeit, die in der Inszenierung der existentiellen Unsicherheit und Gefährdung von Identität und Authentizität in den Fiabe teatrali in Frage gestellt wird. Mit Cherestanis *non son chi sono und »non ricercar chi sia ${ }^{37}$ wird emblematisch zum einen auf eine problematische Identität verwiesen, zum anderen auf das Geheimnis der wahren Identität.

\subsection{Liebe als Passion mit Variationen}

Mit Betonung der Passion ist zunächst ausgesagt, daß die Liebe sich außerhalb des Bereichs rationaler Kontrolle abspielt «, stellt N. Luhmann fest. ${ }^{38}$ Eine solche Liebe, die den Anspruch auf Absolutheit stellt und

siècle», in: Studi in onore di Vittore Lugli e Diego Valeri, Bd. 1 , Venezia, Neri Pozza $1961,5.53-82$, hier 5.73 ): $>$ Comme on est actuellement sous le masque dans ce temps de foire, espèce de carnaval d'été, qui dure six semaines, je ne sçaurais vous dire si les femmes sont magnifiques dans leur parure. L'habit de masque qu'on porte jour et nuit, n'est autre chose qu'un tabaro avec la babute (mantelet de gaze) et un chapeau, le tout en noir: cet uniforme, qui n'a rien de réjouissant pour les yeux, est fort commode pour la liberté qu'il donne; il confond les états et le sexes $\alpha$.

3t Theatersoziologische Untersuchungen, die dies belegen und eventuell auch die Theaterbegeisterung in Venedig u.a. auf das gesellschaftliche Phänomen der Maskierung zurückführen könnten, liegen nicht vor.

37 S. o., La donna serpente, I, 2. Im Gegensatz zum snon son chi sono in den Fiabe teatrali findet sich in Goldonis Komödien häufig die affirmative Aussage sson chi sono* (besonders auffällig in La locandiera), die von einer unproblematischen Identität zeugt; diese wird höchstens durch ein sfingere * bzw, =dissimulare - kurzzeitig und willentlich verändert, doch nie in existentieller Weise unsicher oder in Frage gestellt.

36 Niklas Luhmann, Liebe als Passion. Zur Codierung von Intimität, 6. Aufl., Frankfurt am Main, Suhrkamp 1992, S. 76. Das Titelzitat zielt hauptsächlich auf diesen Aspekt der 
den Verstand außer Kraft setzt, wird in Gozzis Theater mehrfach deutlich. Wie die Metamorphosen ist auch diese Unbedingtheit der Liebe ein typisch märchenhaftes Element, das in den Fiabe teatrali in verschiedenen Varianten ins Spiel gebracht wird, einen eigenen Akzent erhält und mit anderen Arten der Liebe kontrastiert. Die Liebe bildet in den Fiabe teatrali ein zentrales Handlungsmovens, wobei unübersehbar ist, daß die Darstellungsweise allen Psychologisierungs- und Moralisierungstendenzen in der zeitgenössischen Literatur entgegensteht. Vielmehr wird in indirekter Weise sichtbar, wie wenig dieses Phänomen vernünftig zu erfassen und zu reglementieren ist.

Zwei im selben Jahr, 1762 , erstmals aufgeführte Fiabe teatrali, Turandot und La donna serpente, zeigen, daß die Liebe als Passion Prinzen und Feen in gleicher Weise erfaßt. In Turandot erklärt sich Calaf selbst zum *cieco d'amor « $(\mathrm{II}, 3)$, in La donna serpente begründet Cherestani ihr Verhalten mit einem »eccesso d'amor per Farruscad $\propto$ (I, IO). An Calaf wird der Wechsel vom vernünftig Denkenden zum blind Liebenden geradezu demonstrativ vorgeführt: Die Erzählungen von Turandots Schönheit und Grausamkeit quittiert Calaf mit dem überlegenen Lachen des Vernünftigen ( $»$ chi ha buon senno, ride $\propto$; I, I), beim Anblick der aufgespießten Köpfe derjenigen, die vergeblich versuchten, Turandots Rätsel zu lösen, fragt er sich, wie ein Mann so dumm sein könne, seinen Kopf für ein so grausames Mädchen aufs Spicl zu setzen ( $*$ Come può darsi tal sciocchezza in uomo / D'espor la testa per aver consorte / Si barbara fanciulla? $; I, I$ ), und Barachs Warnung vor der Verführungskraft von Turandots Portrait schlägt er mit der Bemerkung in den Wind, nur ein Verrückter könne ihr erliegen ( Un qualque folle«; I, 1). Beim Anblick des Portraits allerdings ist Calaf überwältigt, das Paradox der "crude bellezze« erscheint ihm plötzlich als »armonia animata, e parlante $(I, 3)$, und es gibt für ihn nur noch die Alternative zwischen dem Tod und Turandot ( Morte pretendo, o Turandotte in sposa $;$ II, 3 ). Die Schönheit, die aus dem Portrait spricht, ${ }^{39}$ läßt die Vernunft verstummen, und jeder Versuch, Calaf von der Gefährlichkeit seines Vorhaben zu überzeugen, ist vergeblich, wie er selbst bemerkt: pinvan t'affatichi, invan ragioni.« (II, 3$)$. Calaf ist angesichts einer Schönheit, " che trae l'uom da se stesso* (II, 3 ), einem

Liebe als Passion und nicht auf den gesamten "Code amour passion «, der vor allem an französischen Texten des 17. Jahrhunderts aufgezeigt wird. Einzelne Aspekte des Code wie z. B. das Exzeßhafte sind jedoch auch in den Fiabe teatrali zu finden.

39 Zu unterschiedlichen Formen der Präsentation und Repräsentation in Turandot vgl. Barbara Kuhn, - Reflexion und Repräsentation: Bilder, Körper, Namen in Gozzis Turandot *, in: Elisabeth und Joachim Leeker (Hgg.), Text - Interpretation - Vergleich. Festschrift für Manfred Lentzen, Berlin, Erich Schmidt 2005, S. 378-394. 
Selbstverlust erlegen, hat die Klarheit des Verstandes eingebüßt und ist zum blind Liebenden geworden. Was bei seinen Vorgängern die Vorstufe zum Tod war, führt bei ihm, dem auserwählten Märchenhelden, zwar zu einem glücklichen Ende, doch bringen die drei Rätsel Turandots Calaf drei Mal in Todesgefahr, auf die er nur stereotyp mit "Morte pretendo, o Turandotte in sposa $\approx$ zu antworten weiß ${ }^{40}$ Der Selbstverlust Calafs ist nicht eine Selbstaufgabe und ein Aufgehen im anderen, sondern eine sonderbare, exklusive Fixierung auf den Besitz des begehrten Objekts, der unter Ausschaltung allen vernünftigen Bedenkens verfolgt wird.

\section{Exzessive und vernünftige Liebe}

Cherestanis weccesso d'amor per Farruscad « zeitigt dagegen ganz andere Folgen: Durch ihre leidenschaftliche Liebe ist sie dazu verurteilt, Farruscad als tyrannisch und der übrigen Umgebung als Hexe und Betrügerin zu erscheinen. ${ }^{41}$ Aus Liebe will sie auf die Unsterblichkeit als Fee verzichten, nimmt die Gefahr auf sich, 200 Jahre lang als Schlange vegetieren zu müssen und gerät in Situationen, in denen sie zu grausamen Handlungen wider Willen gezwungen ist. ${ }^{42}$ In paradoxer Weise wird sie durch ihre Liebe Farruscad zur Qual und sich selbst ungeheuer: sPer troppo amore / Sono a te di tormento, a me d'angoscia.« $(\mathrm{I}, \mathrm{I}(\mathrm{O})$. Wie weit eine solch exzessive Liebe von der Wirklichkeit entfernt ist, zeigt sich darin, daß Gozzi die entscheidende Szene, in der Cherestani Farruscad ihre leidenschaftliche Liebe erklärt und die widersinnig scheinenden Konsequenzen andeutet, über das für die Fiabe teatrali typisch Märchenhafte hinaus als Traumszene gestaltet, so daß gewissermaßen eine doppelte Distanz zur Wirk-

$40 \mathrm{Daß}$ der Verstand allerdings nicht gänzlich ausgeschaltet ist, wird an den zutreffenden Antworten auf die Rätsel deutlich. Zur Ambivalenz von Vernunft und Gefühl bei Calat und Turandot in vergleichender Perspektive bei Gozzi und Schiller s. Verf., "Tra ragione e passione. Turandot di Carlo Gozzi e di Friedrich Sehillere, in: Problemi di critica goldoniana VIII, 200I, S. 223-25I.

4 -Sforzata sono a comparir tiranna / Per eccesso d'amor. Son condannata / A farmi sospettar maga, deforme, / Sotto a finte bellezze, e tutto c̀ amore, / E 'I più fervido amor, che a te mi stringe- $(1,10)$.

42 Bevor Cherestani ihre Kinder ins Feuer wirft, wird ihre Zerrissenheit zwischen dem Wissen um die Unausweichlichkeit ihres Handelns und dem *menschlichen Entsetzen über die schreckliche Handlung in kunstvollen, durch Antithesen, Paradoxa, Parallelismen, Alliterationen auffallenden Versen deutlich. Die fragmentarische Sprechweise zeugt von der Erregung Cherestanìs, die im Weinen (gli abbraccia, e bacia piangendo) ihren körperlichen Ausdruck findet: *Anime mie ... ciỏ, che non voglio ...v voglio.... Deggio voler ... ció, che voler non posso .... / Piango per voi ... per me ... pel padre vostro, $=(\mathrm{II}, 5)$. 
lichkeit geschaffen wird. Wenn Cherestani in der folgenden Szene nach dem Tod ihres Vaters in ihr Reich zurückgerufen wird, unterstreichen ihre Worte, $\bowtie \hat{\mathrm{E}}$ ignoto al mondo / Il regno mio (II, $\mathrm{It}$ ) die Un-Wirklichkeit noch einmal - nur in einem den Sterblichen unbekannten Reich kann eine Liebe dieser Art ihre Wurzeln haben. Wird an Cherestani die Absolutheit der Liebe sichtbar, die zu ihrer Erfüllung der Unterwerfung unter übernatürliche Gesetze bedarf, nimmt Farruscad als Geliebter eine eher passive Rolle ein. Narrativ werden zunächst zum einen die Anziehungskraft Cherestanis durch die Verfolgung der Hirschkuh bis in den Fluß, zum andern die Exklusivität der Liebe zwischen Cherestanì und Farruscad in einem märchenhaften Palast bildhaft vor Augen geführt. Diese Phase unbedingter, erfüllter Liebe wird jedoch durch Farruscads Neugier jäh beendet, und bei seinem ersten Auftritt erscheint er wie gelähmt vom Verlust der Gemahlin und der Kinder. Sein Verlangen ist erstarrt in Versen petrarkistischer Manier, sein Lamentieren erschöpft sich in konventioneller Rhetorik. Pantalones und Togruls Appelle, in die "Wirklichkeit « zurückzukehren, verhallen ungehört. Eine Liebe, die so exzessiv und absolut ist, kann nur außerhalb der Wirklichkeit gelebt werden und bedeutet den Ausschluß aus der Gesellschaft. So stehen sich der Palast Cherestanis und der Hof in Tiflis zeichenhaft als Ort der Liebe und als Ort gesellschaftlichpolitischen Handelns gegenüber. Eine Vermittlung zwischen diesen Polen ist offensichtlich nicht möglich, denn selbst als Cherestani Farruscad an den väterlichen Hof zurückschickt, erweist sich dieser als handlungsunfähig, ist er doch zu Beginn der entscheidenden Schlacht bereits wieder verschwunden. Gefangen von Liebe und Verlangen nach Cherestanì, ist Farruscad zu "normalen* Verhaltens- und Handlungsweisen außerstande, und konsequenterweise führt die Wiedervereinigung von Farruscad und Cherestani die beiden nicht als Regenten nach Tiflis, sondern in Cherestanis Reich zurück, nach Eldorado: "Tu meco co' miei figli / Del vasto Regno d'Eldorado, occulto / Al mondo tutto, e mio, regnar potrai.e (III, I5). Der Liebe Cherestanis und Farruscads steht kontrastiv die zwischen Canzade und Togrul gegenüber. Die Schwester Farruscads und der treue Wesir Togrul übernehmen in Farruscads Abwesenheit die Verantwortung im darniederliegenden Reich. Sie kämpfen gegen den Aggressor Morgone, sorgen für Lebensmittelnachschub für die belagerte Stadt, kurz: sie nehmen die Aufgaben einer guten Regierung wahr. Ihre Liebe ist nicht exklusiv, sondern integriert in das gesellschaftspolitische Geschehen, sie erhebt keinen Anspruch auf Alleinherrschaft über die Liebenden, im Gegenteil, sie setzt auf Ausgleich und nützt dem Gemeinwesen. Wenn Canzade und Togrul von Cherestani am Ende als Herrscher in Tiflis eingesetzt werden, ist die Harmonie von privatem Glück und öffentlichem Wohlergehen 
endgültig hergestellt. Mag diese Variante auch weitgehend dem *Traditionsideal der vernünftig-geordneten Liebe $\alpha^{43}$ entsprechen und insofern eine Deutung als >realistisch $\times$ naheliegen, ${ }^{44}$ ist doch zum einen ihre Mârchenhaftigkeit, zum andern die Kontrastfunktion nicht zu übersehen. Canzade und Togrul sind Märchenfiguren im Märchengeschehen, die eine steigt durch den Olymp in eine ferne Wüste ab, die andere kämpft gegen Riesen, und ihre Bemühungen um das öffentliche Wohl sind nur durch Cherestanis Eingreifen und nicht aus eigener Kraft erfolgreich, ${ }^{45}$ so daß cin Wirklichkeitsbezug in Form von Wahrscheinlichkeit analog zu allen anderen Fiabe teatrali nicht gegeben ist. Aussagekräftig wird ihre Welt vor allem im Kontrast mit der Cherestanis und Farruscads. Eldorado ist der Ort, an dem der seccesso d'amor *, eine unbedingte, absolute Liebe, fern von aller Öfentlichkeit ihre Erfüllung findet, in Tiflis dagegen ist die Liebe in einen sozialen und politischen Kontext integriert. Wer wie Farruscad einmal der exzessiven Liebe anheimgefallen ist, hat den Weltbezug verloren, ${ }^{46}$ wer sie nicht kennt, steht ihr verständnislos gegenüber. Was die Welt sieht, oder anders gesagt, was auf der Bühne darstellbar und dem Publikum erkennbar ist, ist die Gefährdung der leidenschaftlichen Liebe, ihre Erfüllung in Eldorado muß als Utopie unsichtbar bleiben.

\section{Varianten der Liebe}

In I pitocchi fortunati wird das Thema Liebe an vier Paaren enggeführt. Im Zentrum stehen Usbec und Angela, umgeben von den Paaren Tartaglia-Zemrude, Saed-Zemrude, Truffaldino-Smeraldina. Usbec hat sich als Bettler in Angela verliebt, "La più bella fanciulla, la più saggia, / E la più virtuosa, che vivesse $\propto(I, 2)$, die allerdings *in un'abisso / D'inedia, di miseria * lebt. Den Standesunterschied, der die Erwiderung von Usbecs Liebe durch Angela verhindert, löscht Usbec durch seine Verkleidung als Bettler aus und hofft, sie so »noch heute« zu seiner Gemahlin zu machen.

4 N. Luhmann, Liebe als Passion, op, cit., S. trg.

+4 A. Beniscelli macht in =La finzione del fiabesco ne La Donna serpentes, op. cit, S. 37 eine *divaricazione tra mondo della realtà e mondo degli ideali- geltend, die bei Gozzi nicht in eine ssintesi di vero e di mitico* überführt, sondern in ihrer Unvereinbarkeit akzentuiert werde.

4s Cherestani selbst schickt Farrusead in sein Reich zurück, vernichtet die vergifteten Lebensmittel des Verräters Badur und greift im Kampf gegen Morgone hilfreich ein.

th Eine andere Variante des *eccesso d'amor* wird in Zobeide vorgeführt, in der die Liebe nicht gegenseitig ist und Zobeide, die Sinadab anfangs wie sich selbst und leidenschaftlich liebt (-Quanto me stessa๔; *L'amo all'eccesso*; I, 4), von Abdalac langsam zur Einsicht gebracht wird, daß ibre Liebe auf Tauschung beruht. 
Damit sind gleich mehrere Topoi aufgerufen: Schönheit und Moral als auslösende Momente der Liebe, der Kontrast zwischen äußerem Elend und exemplarischen Qualitäten der Geliebten sowie die Aufhebung von Standesgrenzen in der Liebe. Gerade dieser letzte Aspekt erscheint bemerkenswert bei einem Autor, dem sein aristokratischer Hintergrund oft zum interpretatorischen Verhängnis wurde. ${ }^{47} \mathrm{Nicht}$ nur in 1 pitocchi fortunati schließt ein Monarch eine durch einen großen Standesunterschied charakterisierte Ehe, auch in $I l$ re cervo und Il re de' genj ist dies der Fall, wobei die Auserwählte jeweils Pantalones Tochter ist, in Il re cervo und I pitocchi fortunati Angela und in Il re de' genj Sarchè heißt. Dies kann nicht allein als Hommage an Venedig gedeutet werden, sondern wirft zum einen ein Licht auf die Liebe als eine Kraft, die Standesgrenzen überwin$\mathrm{det}^{48}{ }^{48}$ zum anderen wird deutlich, daß sich die in der Tradition verankerten Kriterien für die Wahl einer königlichen Gattin, nämlich moralische Integrität und Schönheit, offensichtlich eher oder zumindest ebenso in

77 Daß Gozzis Adelstitel von der Terraferma stammt und die Familie nicht dem venezianischen Patriziat angehört, wurde bereits erwähnt. Zum stereotypen Kurzschluß von einer Zugehörigkeit zur Aristokratie zu einer reaktionären Ideologie und einer Frauenfeindlichkeit siche z. B. Jacques Joly, - La Turandot de Carlo Gozzie, in: E. Konigson ( $\mathrm{Hg}$.$) , Les voies de la création théâtrale 8, Paris, CNRS 1980$, S. 317-346, hier S. $342-$ 346 , der Gozzi im Hinblick auf Turandot eine vvision réactionnaire des femmes*, eine -vision aristocratique et pessimiste und eine sidéologie réactionnaire * bescheinigt, was B. Kuhn, op. cit., in ihrer Analyse klar widerlegt. In P. Bosisios Ausgabe der Fiabe ist dic angebliche Misogynie Gozzis ebenfalls ein Tenor der Kommentare. Deutlich zeigt sich diese laut P. Bosisio in Il re cervo, wenn Deramo überlegt, ob Angela anders sei als die anderen Frauen; *Ella è pur donna / E più bel corpo con iniquo spirto, / Che gentil spirto in orridezza chiuso / Vorrà, seguendo il femminil costume. / Stanche membra, coraggio. Angela forse / Non è, com'altre son. « (II, 12). Aus der Tatsache, daß Angela zu perfekt sei, um als wahrscheinlich gelten zu kônnen, zieht P. Bosisio den Schluß, daß Angela die Regel bestätige. Eine solche Deutung kann nur zustande kommen, wenn sowohl die gattungsmäßig bedingte, bewußte und generelle Unwahrscheinlichkeit der Figuren und des Geschehens ignoriert werden als auch die grundlegende kontrastive, polarisierende Darstellungsweise, die beides, die ssupposta regola wie die neccezione di Angela (op. cit., S. 217) gleichermaßen wirklichkeitsfern erscheinen laßt. Im Unterschied zu Interpretationen, die von Gozzis konservativer sozialpolitischer Disposition ausgehen und diese in den Stücken wiederzufinden glauben, trennt Mead Kinsella Hunter in ihrer Arbeit Carlo Gozzi and his * Ten Tales for the Theatrer, Ph. D. Thesis, University of California, Los Angeles, 1994, die Interpretationen aller ro Fiabe teatrah enthält, zwischen *Leben * und $*$ Werk * und stellt fest, daß insbesondere in Turandot, La donna serpente, La Zobeide und $I /$ mostro turchino Frauenbilder entworfen werden, die sie als *strong woman* (S. 192) bezeichnet und die keinesfalls einem patriarchalischen System entsprechen.

43. Im Hinblick auf das venezianische Publikum gewinnt die Heirat eines Kônigs mit einer nicht standesgemäßen Frau in einer *allegorischen * Deutung an sozialkritischer Relevanz, da in Venedig die Heirat eines Patriziers mit einer nicht dem Patriziat angehörenden Frau mit dem Verlust patrizischer Rechte wie z. B. der Mitgliedschaft im *Maggior Consiglio* verbunden war. 
den unteren sozialen Rängen finden. Daß vor allem die moralische Integrität, Tugendhaftigkeit, Treue, Ehrlichkeit bürgerliche Qualitätsmerkmale und Ideale sind, bedarf kaum der Erwähnung. Alle drei, die beiden Angelas wie Sarchè, lassen keinen Zweifel daran aufkommen, daß sie der Wahl ihrer königlichen Gatten würdig sind. Damit wird deutlich, daß der indirekte Wirklichkeitsbezug der Fiabe teatrali etwas ermöglicht, was Goldoni im Kontext einer mimetischen Theaterkonzeption unmöglich scheint: die Darstellung einer Liebe, die Standesgrenzen nichtig macht. Im Vorwort zu La Pamela weist Goldoni ausdrücklich auf eine entsprechende Veränderung hin, die er gegenüber dem englischen Roman vorgenommen hat:

Piacque a me immaginare una peripezia avvantaggiosa per li due amanti, e cambiando la condizion di Pamela, premiar la virtù, senza oltraggiare il puro sangue di un Cavaliere, che al pari degli stimoli dell'amore, quelli ascolta eziandio dell'onore.

Sembra che ciò in Italia stato sia dall'unanime consenso degli ascoltatori approvato, e certamente fra noi sconvenevole troppo riuscito sulle nostre scene sarebbe il matrimonio di un Cavaliere colla virtuosa sua Cameriera. (Goldoni, III, 331)

So erweist sich die Fiaba teatrale in dieser Hinsicht als subversives Medium, in dem soziale Konventionen aufgerufen und in Frage gestellt werden können, während Goldoni diese in seiner Komödie bewußt bestätigt. ${ }^{49}$ Der geglückten Liebe Usbecs und Angelas über Standesgrenzen hinweg stehen drei weitere, problematische Beziehungen gegenüber, die in verschiedenen dramatischen Codes jeweils unterschiedliche Aspekte des Phänomens Liebe in den Vordergrund rücken. Im Dreierverhältnis zwischen Saed, Zemrude und Tartaglia treten kaleidoskopisch die unterschiedlichsten Ausprägungen von Liebe zutage: Saed, ehemaliger Wesir von Caracoran, wurde vom dortigen Hof verbannt, weil seine Geliebte Zemrude unvorsichtigerweise in Anwesenheit des Königs im Scherz vortrug, Saed liebe Gulendan, die Geliebte des Königs. Seit sechs Monaten schlägt sich Saed als Bettler durch, und seine Geliebte, deren Namen und Identität er nicht kennt, ${ }^{50}$ geht ihm nicht aus dem Sinn. Zemrude wurde von ihrem Vater, der als Botschafter des Königs von Caracoran nach Tiflis reiste, dem außergewöhnlich reichen Tartaglia als Frau versprochen. Seit einem Monat ist Zemrude gegen ihren Willen in Tiflis, verabscheut Tar-

49 La Pamela mache durch die Verinderung der Vorlage Goldonis konventionelle Lösung besonders deutlich, doch finder sie sich in ähnlicher Weise auch in anderen Komödien wie z. B. La vedova scaltra und La locandiera.

so Zemrude laßt Saed nachts mit verbundenen Augen von sechs bewaffneten Soldaten zu sich in einen prächtigen Palast führen, wo sie ihn bewirtet und mit Musik unterhält. 
taglia und hat ihn bisher zurückgewiesen. Nun hat dieser die Geduld verloren und "la legge Tartara angewandt: "Le sono andato dinanzi, l'ho guardata con un zeffo infernale, ho gridato tre volte: ti ripudio, ti ripudio, ti ripudio: e pu, e pu, e pu, le ho sputato tre volte in faccia, el'ho ripudiata. ( $(\mathrm{I}, \mathrm{II})$. Dies bereut Tartaglia inzwischen, will Zemrude wieder heiraten und benötigt dazu jemanden, der sie kurzfristig heiratet und ebenfalls verstößt, worauf gemäß der slegge Tartara« eine erneute Heirat mit Tartaglia möglich ist. Diese Aufgabe übernimmt Saed, um mit dem Lohn die weitere Suche nach Zemrude antreten zu können. Daraus ergibt sich eine pathetische Wiedererkennungsszene zwischen Saed und Zemrude und eine groteske Szene, in der der höchst eifersüchtige Tartaglia Saed auffordert, Zemrude endlich zu verstoßen, worauf er ihn abführen läßt. Zu spät erkennt Zemrude, daß sie mit ihrer Aufforderung an Saed, um der Liebe willen alles zu ertragen und ihre Treue zu belohnen, ${ }^{51}$ wohl zu weit gegangen ist: »Ahi, mi facesti / Troppo tiranna, Amor ... Numi, assistetelo.* (II, Iо). Durch Usbecs Eingreifen werden die beiden endlich vereint, während Tartaglia verlassen zurückbleibt.

Im Unterschied zur Beziehung zwischen Usbec und Angela stehen dem Gelingen der Verbindung zwischen Saed und Zemrude sowie zwischen Tartaglia und Zemrude gravierende äußere beziehungsweise innere Hindernisse entgegen. Einen grundlegenden Kontrast bilden die galante, im höfischen Bereich angesiedelte gegenseitige Liebe zwischen Saed und Zemrude, die sich durch geheimnisvolle Umstände auszeichnet und durch einen übermütigen Scherz jäh zu Ende ist, und die erzwungene, auf ökonomischen Überlegungen des Vaters beruhende Zwangsvermählung von Tartaglia und Zemrude, die auf der Seite Tartaglias durch eine auf den körperlichen Besitz ausgerichtete Begier und eine ins Groteske gesteigerte Eifersucht gekennzeichnet ist, auf Seiten Zemrudes durch die Abscheu vor dem unfeinen, zudringlichen Tartaglia. Auch im Hinblick auf den körperlichen Aspekt der Liebe bietet die Fiaba teatrale mit der Maskenfigur Tartaglia die Möglichkeit, auf ein Thema zu verweisen, das auf der Bühne normalerweise tabuisiert ist. Typisch maskenhafte, komisch übertriebene Züge weist Tartaglias Bemühen auch da auf, wo er den Rivalen mit Hilfe der Bestechung Muzaffers aus der Welt zu schaffen versucht. Die lächerliche Liebe und Eifersucht Tartaglias verhindern jede vernünftige Beurteilung der Situation, was sich unter anderem daran zeigt, daß er nicht nur lange der Überzeugung ist, Zemrude sei ihm für die *Befreiung * von Saed

31 *Si, Saed, ti rinforza, ed i piû acerbi / Colpi di tirannia soffri; io ben merto / Un com penso d'amore, e di costanza.* (II, 7$)$. 
dankbar und komme gern zu ihm zurück, sondern auch an der unmäßigen Bestechungssumme, die er für die Beseitigung Saeds zu zahlen bereit ist. Zemrude, die ihre Beständigkeit in der Liebe zu Saed mit dessen heroischer Haltung belohnt sehen will, fällt angesichts des blutverschmierten Hemdes, in dem er vorgeführt wird, in Ohnmacht, und Saed bedient sich vor Muzaffer einer Lüge, um Zemrude nicht wieder an Tartaglia zu verlieren. Nicht zu vergessen in diesem Panorama sind Truffaldinos Situation, die eine weitere traditionelle Variante zum Thema liefert, nämlich der Vater als Hindernis für eine jugendliche Liebe, ${ }^{52}$ sowie die Heirat von Muzaffer und Omega, die als grotesk-komische Parallel- und Kontrastszene zur Heirat von Usbec und Angela gestaltet ist.

Dieses Spektrum von Spielarten der Liebe, ${ }^{53}$ dargestellt in unterschiedlichsten dramatischen Formen, in ernster, pathetischer, komischer und grotesker Weise, dokumentiert ganz offensichtlich die Vielfalt des Phänomens und in indirekter Weise auch seine Unfaßbarkeit. Die Kontraste zwischen exklusiver, absoluter und weltfähiger Liebe, zwischen erfüllter und unerfüllter, zwischen keuscher Liebe und körperlicher Begier markieren Extreme, die zeichenhaft zu verstehen sind. Eldorado als Ort der Liebe zwischen Cherestani und Farruscad und die Grube, in die Truffaldino absteigt, um Smeraldina seine Liebe sagen zu können, stecken den weiten Raum ab, in dem die Liebe sich abspielt. Sie wird in den Fiabe teatrali nicht in ihrer Prozeßhaftigkeit dargestellt - in keinem Stück wird ausgeführt, wie die Liebe entsteht -, sie ist vielmehr gegeben, die Personen sind von ihr ergriffen, besessen, überwälrigt; als Gründe werden höchstens die Topoi Schönheit und Tugend genannt. Auf der Bühne zu sehen sind die Gefährdungen, die der Liebe drohen, sei es durch das Eingreifen übernatürlicher Kräfte wie etwa in Il mostro turchino oder La Zobeide, sei es durch die Liebenden selbst wie in La donna serpente oder I pitocchi fortunati. Der Zeitraum der Gefährdung ist märchenhaft durch schwerste Prüfungen gekennzeichnet, die oft nur mit Hilfe übernatürlicher Kräfte zu meistern sind. Wenn dann am Ende, den Gesetzen der Komödie und

32 Truffaldino liebt Smeraldina, die Tochter des Großwesirs Muzaffers, der die Liebe entdeckt und Truffaldino daraufhin 100 Streiche auf den Bauch verpaßt, bevor er ihn verjagt. Truffaldino muß nun als Bettler verkleidet dahinvegetieren, um wenigstens auf ungewöhnliche Weise unerkannt mit Smeraldina reden zu können: An Smeraldinas Zimmer lauft ein Rohr entlang, das in einer Grube endet, in die Truffaldino von Zeit zu Zeit absteigt, um von dort mit Smeraldina durch das Rohr Liebesschwure zu tauschen.

53 Die Liebe, die keine Gegenliebe findet und in $\mathrm{Haß}$ mündet, ist in I pitocchi fortunati nicht vertreten. Ein extremes Beispiel dafür findet sich in $/ 1$ mostro turchino in der Person Gulindis, deren nicht erwiderte Liebe zu Acmed alias Dardanè sich in Haß verwandelt und zum Verrat an Acmed führt. 
des Märchens folgend, die Paare reihenweise ${ }^{54}$ in prächtigen Gewandern auf der Bühne wieder zusammenfinden, wird die Distanz zur Wirklichkeit noch einmal und sehr deutlich sichtbar. Die Fiabe teatrali dienen in keiner Weise als "Lern- und Orientierungsfaktor in Liebesangelegenheiten $\propto, 55$ sondern deuten auf das paradoxe Miteinander von Normalität und Unwahrscheinlichkeit der Liebe, die sich weder lernen noch dauerhaft festhalten läßt.

\subsection{Die Macht des Schicksals}

In den Personenverzeichnissen aller Fiabe teatrali, die nicht auf novellenartigen Märchen basieren, findet sich jeweils mindestens eine Person, die ersichtlich mit übernatürlichen Kräften ausgestattet ist: ${ }^{56} \mathrm{In} / \mathrm{l}$ corvo ist es Norando, Negromante, in Il re cervo Durandarte, Mago, in La donna serpente sind es die Feen Cherestani, Farzana, Zemina, in La Zobeide Sinadab, Negromante und Abdalac, Sacerdote Calender, in Il mostro turchino ist es Zelou, Genio, in L'angellino belverde Brighella, Indovino, und in Il re de' genj Zeim, Re de' Genj sotto varie forme. Zu diesen auf der Bühne sichtbaren Wesen treten nicht sichtbare, die entweder durch ihre Stimme präsent sind wie etwa Geonca in La donna serpente oder nur Erwähnung finden wie Demogorgone im selben Stück. Die Zauberer, Magier, Geister, Feen sind bereits in den Märchen vorhanden, die als Grundlage für die Fiabe teatrali dienen, doch erhält auch dieses Märchenelement eine neue Bedeutung, ${ }^{57}$ die sich im Kontext der aufklärerischen Überzeugung von der Selbstbestimmung des Menschen und der rationalen Erfaßbarkeit der Phänomene verorten läßt. Wie im folgenden zu zeigen ist, werden das Geschehen und die Personen der Fiabe teatrali weitgehend von diesen märchenhaften Wesen bestimmt, wobei immer wieder eine Abhängigkeit

54 In La donna serpente, La Zobeide, I pitocchi fortunati, Laugellino belverde und Il re de' genj sind es jeweils mehrere Paare, die Wirrungen und Gefahren überstanden haben.

s5 N. Luhmann, Liebe als Passion, op. cit, S, 12.

56 Novellenartige Marchen liegen Turandot und I pitocchi fortunati zugrunde. In der Colombani-Ausgabe von $I l$ corvo fehlt versehentlich Norando, was in der Zanardi-Ausgabe korrigiert ist.

57. Uber den Unterschied zwischen den übernatürlichen Wesen der Märchen und denen der Fiabe teatrali liegen keine Außerungen Gozzis vor, während er im Vorwort zu Il corvo darauf aufmerksam macht, daß die übernatürlichen Wesen der Fiabe teatrali nichts mit den Zauberern der Commedia dell'arte zu tun haben: $>$ In Norando, negromante di questa Fola, scorgerà il mio Lettore in qual'aspetto nobile, e differente da tutti gli altri goffi Maghi delle consuete Commedie dell'arte, io abbia voluto porre i negromanti, ch'entrano nelle mie Fiabe.* (Col. II, t2o-121). Zu den Zauberergestalten in improvisierten Komodien s. Kap. 2.5. 
der auf der Bühne sichtbaren Zauberer, Magier, Feen von anderen übernatürlichen Wesen zum Vorschein kommt, aus der ein Rückverweis ins Unbestimmte resultiert.

\section{Fremdbestimmung und Schicksalsabbängigkeit}

Die letzte Fiaba teatrale Gozzis führt das übernatürliche Wesen bereits im Titel: Il re de' genj o sia La serva fedele. Diese s fiaba seriofaceta\&, die noch einmal in auffälliger Weise den Kontrast zwischen pathosgeladenen ernsten und grotesk-komischen Szenen vor Augen stellt, zeichnet sich auch in anderer Hinsicht durch Extreme aus, beim Titel angefangen, der das betont Märchenhafte mit dem ausgesprochen Komödientypischen vereint; unter dramaturgischer Perspektive ist die große Anzahl improvisierter Passagen Truffaldinos bemerkenswert, unter sprachlicher die ausgeprägte Rhetorik der Dialoge. Im Hinblick auf die Charakterisierung der „ernsten $\approx$ Personen fällt die polarisierende Stilisierung ${ }^{58}$ auf, hinsichtlich des übernatürlichen Geisterkönigs namens Zeim macht allein seine Bühnenpräsen $z^{59}$ den Einfluß auf das verwobene Geschehen sichtbar, das kurz skizziert werden soll: ${ }^{60}$

Zeim, dem König Farue von Balsora wohlgesonnen, hat diesen mit Reichtümern und in hohem Alter noch mit Zwillingen und einem Erben gesegnet. Über die Kinder wurde jedoch namenloses Unheil verhängt: Suffar, der Prinz, wurde schon in der Wiege der schrecklichen Mohrenkönigin Canzema versprochen, die jetzt Balsora belagert, weil Suffar sich weigert, sie zu heiraten; die Prinzessin Dugmè wurde der Mutter von der Brust weg geraubt und ist verschwunden, der Prinzessin Zelica hat die Mutter ein furchtbares Schicksal prophezeit, sollte sie heiraten. Pantalone,

58 Z.B. steht dem verwerflichen jugendlichen Verhalten Suffars die vorbildlich-ubertriebene Schicksalsergebenheit Dugmès gegenuber, dem Verzicht Zelicas auf den geliebten Alcouz die Belagerung Balsoras durch Canzema zur Durchsetzung ihrer Ansprüche auf Suffar.

59 Zeim betritt die Bühne in 8 Szenen in unterschiedlicher Gestalt. In keiner anderen Fiaba teatrale erscheint das übernaturliche Wesen so oft vor dem Publikum.

to In Il re de' genj zeigt sich auch noch einmal die *ars combinatoria , die den Fube teatrali zugrunde liegt und sich zum einen in der Kombination von Märchen- und Maskenelementen manifestiert, zum anderen in der Kombination zahlreicher intertextueller Bezüge, von denen für $I l$ re de' genj die * Histoire du Prince Zeyn Alesnam * aus Les mille et une nuits und Sarnellis Postlecheata die wichtigsten sind (5. G. Luciani, Carlo Gozzi, op. cit., S. 512-513). Weitere Verweise ergeben sich z. B. durch das Spiegelmotiv, das an Il re cervo erinnert, das Motiv des Rückzugs aus der höfischen Welt und der Isolierung eines Kindes, das sich u. a. im Novellino (Nov, 5 ) finder, sowie durch Canzemas Belagerung der Stadt, die sich aus dem epischen Bereich speist. 
der sich mit seiner Tochter Sarchè in einen Wald zurückgezogen hat, um diese fern von allem Bösen aufzuziehen, versichert Zeim, daß er für die Königskinder alles tun und opfern würde, um diese wieder glücklich zu machen. Damit ist Pantalone in Zeims Falle getappt, und seine Tochter wird in Suffars Schicksal verwickelt. Von Zeim zum Grab seines Vaters geschickt, findet Suffar einen reichen Schatz, fünf Statuen, ein leeres Piedestal und eine Nachricht, bei der Suche nach der sechsten, wertvollsten Statue könne ihm Pantalone behilflich sein. Dort angekommen, vernimmt Suffar von Zeim, daß er die sechste Statue erhalte, wenn er ihm, Zeim, mit Hilfe eines * Tugendspiegels« ein tugendhaftes Mädchen zuführen könne. Dieses Mädchen ist Sarchè, die Pantalone eingedenk seines Versprechens dem grausamen Zeim überlassen muß. Zelica, im Unsicheren über ihr Schicksal, wird von Zeim mehrfach in Gestalt der Mutter heimgesucht, die ihr bisher eine Heirat untersagt hat, sie nun jedoch auffordert, Alcouz, der sie liebt und den sie ebenfalls liebt, zu heiraten und ihr im selben Atemzug ein schreckliches Schicksal prophezeit. In der Hochzeitsnacht muß Zirma, Zelicas treue Dienerin, als Gattin Alcouz' und Königin an ihre Stelle treten, während Zelica selbst in ein häßliches Tier verwandelt wird. Zirma, die als Dienerin von Zelica auf Geheiß der Mutter bis aufs äußerste erniedrigt und tyrannisiert wurde, um ihre Treue auf die Probe zu stellen, vertritt Zelica vier Jahre und einen Tag, verpflichtet Alcouz, sie nicht zu berühren und hält sich meist bei dem häßlichen Tier auf. In einem abrupten Ende überreicht Zeim Suffar die sechste Statue, unter deren Verhüllung sich Sarchè verbirgt, führt Zelica in Menschengestalt dem glücklichen Alcouz zu und gibt bekannt, daß sich hinter Zirma die verschwundene Schwester Dugmè verbirgt.

Das völlige Ausgeliefertsein von Suffar, Zelica und Dugmè an Zeims Vorgaben ist offensichtlich, manifestiert sich jedoch in unterschiedlicher Weise. Während Suffar in persönlichen Begegnungen direkte Anweisungen von Zeim erhält, erscheint dieser Zelica nur in Gestalt der verstorbenen Mutter und gibt ihr dunkle Hinweise auf ein fürchterliches Schicksal. Dugmè dagegen begegnet Zeim in keiner Form, er hat sie vielmehr in einen ihrer königlichen Abstammung entgegengesetzten Stand versetzt, in dem sie in völlig unwahrscheinlicher, geradezu grotesk übertriebener Ergebenheit ihre unerschütterliche Treue zu Zelica beweist, die die Voraussetzung für die ebenso unwahrscheinliche Stellvertreterrolle ist. ${ }^{61}$ So-

44 Hinsichtlich der kontrastierenden Figurenzeichnung in Il re de' genj steht Dugmè Sarchè gegenüber, die im Gegensatz zu Dugmè, die Sklavin aus kōniglichem Geblüt ist, aus ihrem niederen Stand als Tochter Pantalones zur Frau Suffars erhoben wird; gemeinsam ist den beiden ihre exemplarische Tugendhaftigkeit. Diese Durchlāssigkeit der sozialen 
mit unterliegt Dugmè den Handlungsanweisungen Zelicas, die wiederum von den Vorhersagen der Mutter bestimmt sind, die ihrerseits sowohl als Lebende wie als Tote mit Zeim in Verbindung steht. Zelica selbst wird durch die Prophezeiungen der Mutter dazu gezwungen, gegen ihren eigenen Willen und ihre Überzeugung zu handeln und gerät daher in größte Gewissensnöte. ${ }^{62}$ Wenn überhaupt, dann scheint bei Suffar eine Art von Gerechtigkeit im Spiel zu sein, da er für sein ausschweifendes Verhalten in der Jugend büßen muß. Die Massierung des Unheils auf der einen Seite und die extreme Tugendhaftigkeit - vor allem Dugmès, aber auch Zelicas und Sarchès - auf der anderen stellen, wie das Publikum bereits in der zweiten Szene erfährt, gewissermaßen Komprimierungen ${ }^{63}$ dar, die auf einen Eingriff Zeims in den normalen Ablauf des Schicksals zurückzuführen sind. Zeim verweist Pantalone in diesem Zusammenhang auf die »memorie, / Dagli antichi lasciate, e da te lette $(I, 2)$, in denen doch vom Glücksrad die Rede sei:

Hierarchie in beide Richrungen spricht gegen C. Albertis Bemerkung, si profila $[\ldots]$ l'esaltazione di una gerarchia sociale talmente solida da potersi permettere di assorbire senza seosse qualche elemento proveniente dai livelli inferiori-, in: $\rightarrow$ Il declino delle maschere. Drammi flebili e commedie serio-facete oltre le favole teatralia, in: Carlo Gozzi, scrittore di teatro, op. cit., S. 215-271, hier S. 224. Zwar erwähnt Dugme squesto bell'ordine, dal Ciel posto fra noi- (II, 4), doch weist sie auch darauf hin, daß vor den Augen des Himmels das gerechte, tugendhafte Verhalten eines Königs gleichviel zähle wie das eines sfiglio della pleben. Insofern scheint mir das Augenmerk mehr auf dem Kriterium der Tugendhaftigkeit zu liegen, die vom sozialen Stand unabhängig ist. In bezug auf Dugmè, an der Gozzis *affermazione del principio di sortomissione* (ebd.) festgemacht wird, sollte nicht übersehen werden, daß zum einen diese Unterwürfigkeit so weit geht, daß sie selbst das Mitleid eines Truffaldino erregt, so daß dieser Dugmè einen Fluchtplan unterbreitet, das heißt, daß sie geradezu ins Groteske tendiert, und zum anderen, daß Dugmè am Ende der Fiaba teatrale weder einen Partner noch Reichtümer erhalt wie die anderen, sondern leer ausgeht mit der ironischen Begrûndung, solche Tugend könne man gar niche belohnen, da bleibe nur der Applaus als Zeichen der Anerkennung.

22. In einem Dialog mit Suffar, der ihr von Alcouz' Liebe berichtet und dessen taktisches Verhalten gegenüber Canzema lobt, das diese davon abhalten soll, die Stadt vollends zu zerstốren, gibı Zelima ihrer Verzweiflung Ausdruck (I, 3):

-Fratel, ti ferma ... A me Alcouz! qual punto, / Cieli, è mai questo! Udirlo come posso, / Per disprezzarlo? Ah Madre, a che non dirmi, / In qual miseria cader deggio, quando / Mi doni ad uno Sposo? e perchè mai / Voler, ch'io tenga un'infelice schiava / Ócculta in questa Reggia, e che per forza / Di tirannie la fedeltà in lei scopra? / Un'assediato Regno, a cui soccorso / Io non posso donar. Un'amor caldo, / Che mi distrugge il cor, nè appagar posso. / Tiranna sono a forza all'infelice / Zirma, mia schiava, a palesar non deggio, / Perchè cruda le son. Quanti funesti / Arcani deggio chiusi in questo seno / Sempre tener? Ma qui Alcouz s'appressa / Io non potrei la sua dolce favella, / Senza donarmi a lui, più sofferire. / Fuggiam l'incontro, il minor mal s'elegga.*

as Besonders augenfallig ist dies bei Sarchè, die in ihrer Tugendhaftigkeit förmlich erstarnt und folgerichtig zur Statue wird. 
E non t'cे noto,

Che la felicità sulla miseria

Pianta i primi lavori, indi s'innalza,

E giunta al sommo della sua grandezza,

Gira la ruota, e quel, ch'era felice,

Nell'infelicità cade primiera?

Tal sempre fu l'irreparabil corso

Delle umane vicende, e tale è 'l giro

Di tutto ciò, che agli uman sensi è noto. (I, 2)

Nun hat Zeim das Glücksrad angestoßen, um die lange Phase des Elends, die auf die königliche Familie zukommt, zu verkürzen und die Rückkehr des Glücks zu beschleunigen: *Tutto io procuro, / Che 'l peso lungo di miserie acerbe / Di dieci etadi, abbia il suo corso, e sfogo / Sui figli di Faruc.* In drastischen Worten beschreibt er sein Vorgehen: „Io tento / L'unico mezzo d'una sferza acerba, / Per destar virtù, ch'è 'l perno vero / Della felicità, perchè dal Cielo / Premio suole ottener; nè son tiranno.“ Pantalone allerdings meldet Zweifel an dieser Methode an und pariert Zeims Warnung, »Vecchio, non ti fidar de' tuoi giudizj« mit der Feststellung, wxe delle cose recondite, che nu altri miseri mortali no podemo capir, perchè pensemo materialmente, e i Filosofi po dise, che le xe fiabe. « Die Anspielungen auf die Debatten der Zeit über das Glück, die Tugend, das Irrationale sind unüberhörbar, werden aber im Dialog nicht weiter ausgeführt, sondern im Spiel allegorisch in Szene gesetzt. Suffar, Zelica und Dugmè können außer ihrer Tugendhaftigkeit nichts zur glücklichen Wendung beitragen; ihr Schicksal selbst in die Hand zu nehmen, ist ihnen nicht möglich. Genau so unvermittelt wie in frühester Kindheit das Unheil über sie hereinbrach, tritt am Ende der Fiaba teatrale das Glück hervor. Die Macht Zeims ist in $I l$ re de' genj ungebrochen, als Repräsentant des Wunderbaren, Übernatürlichen erhält er eine Autonomie, die im Märchen undenkbar ist. Dennoch wird immer wieder deutlich, daß es nicht Zeim allein ist, der die Geschicke lenkt, sondern die Personen diffusen Mächten ausgeliefert sind: So ist vom Glücksrad die Rede, von einem »occulto destin, barbaro, atroce $*(I, 3)$, von den Sternen, von fato crudele $\alpha(I, 5)$ und »sacra, non intesa providenza (II, 4), und Zeim selbst bezeichnet sich als •Genio [...] / Diletto al Cielo $(\mathrm{I}, 2)$. Hierarchien und Verhältnisse dieser Instanzen untereinander werden nicht geklärt, vielmehr entsteht der Eindruck eines ganzen Arsenals von verborgenen Mächten, in deren Hand die Personen stehen. Zeim tritt quasi als Spielleiter aus der Verborgenheit ans Licht und schafft die Konstellationen, die die Betroffenen als Unglück oder Glück erleben ${ }^{64}$ Das Unglück trifft alle gleichermaßen, seien sie wie

if In $I l$ corvo, $I l$ mostro surchino und $I /$ re de' genj erfullen die Zauberer und Geister die 
Suffar tugendlos oder tugendhaft wie Dugmè, doch um das verlorene Glück wiederzugewinnen, bedarf es in jedem Fall eines tugendhaften Verhaltens. So ist tatsächlich die Tugend der Grundpfeiler des individuellen Glücks, wie Zeim anfangs sagt, aber sie ist keineswegs ihr Garant. Gerade an Pantalone, der sein Schicksal und vor allem das seiner Tochter selbst in die Hand nimmt und das Glück entfernt vom Luxus und den Frivolitäten des Hofes sucht und findet, wird offensichtlich, daß dieser Zustand nicht von Dauer ist. Die Forderung nach dem Glück, die in der Aufklärung allenthalben laut wird, ${ }^{65}$ sowie die moralphilosophische Prämisse, nach der Tugend und Glück koinzidieren, erfahren in Il re de' genj eine Problematisierung, die zum einen erkennen läßt, daßs sich die Identifikation von Tugend und Glück als unangemessen erweist, zum anderen, daß Glück nicht gefordert noch erworben noch festgehalten werden kann, daß es sich vielmehr nach unerfindlichen Gesetzen einstellt und auflöst.

Nicht in allen Fiabe teatrali ist die Abhängigkeit der Personen von übernatürlichen Kräften in so extremer Weise gestaltet wie in Il re de' genj. Überall wird jedoch deutlich, daß eine Selbstbestimmung und ein freier Wille nur in begrenztem Rahmen möglich sind. Häufig geht wie in $I l$ re cervo, La donna serpente und $I l$ mostro turchino bereits aus dem Pro$\log$ oder der ersten Szene hervor, daß das Geschehen, das auf der Bühne zu sehen ist, in Zusammenhang steht mit der Erfüllung einer Prophezeiung oder der Auflösung eines Fluchs, die nach Ablauf einer bestimmten Frist eintreten. Explizite Hinweise auf ein Datum, auf Zeitspannen und Fristen sind in den Fiabe teatrali gang und gäbe und signalisieren dem Zuschauer einerseits, daß er dem entscheidenden Moment einer märchenhaft lange währenden Geschichte beiwohnt, erzielen aber andererseits einen komischen Effekt aufgrund der Diskrepanz zwischen der exakten numerischen Angabe und der offensichtlichen Unwahrscheinlichkeit des Geschehens. In Il re cervo kündigt Cigolotti, eine Figur, die dem Geschichtenerzähler desselben Namens auf der Piazza San Marco nachgebildet ist, ${ }^{66}$ an, daß er am 5 . Januar 1762 - dies ist der Tag der Uraufführung

dramaturgische Funktion von Spielleitern. Was in der traditionellen Komödie meist die Aufgabe der Diener, in der Commedia dell'arte der zanni ist, übernehmen in den Fiabe teatrali die übernatürlichen Kräfte.

${ }^{45} \mathrm{Vgl}$. Michel Delons Artikel *Bonheur* in: ders. $(\mathrm{Hg})$, Dictionnaire européen des $\mathrm{Lu}$ mières, Paris, PUF 1997, S. 165-167; - La revendication du bonheur marque une rupture par rapport à une tradition qui plaçait les valeurs supérieures dans le salut de l'àme ou dans la gloire du prince e; als typisches Beispiel für einen glũcklichen Menschen nennt er =le campagnard qui sait se tenir à distance des tentations du libertinage et du luxee, eine Situation also, wie sie Pantalone ausdrücklich anstrebt.

4* Im Vorwort zu II re cervo erläutert Gozzi: =La Fiaba del Re Cervo cominciava, come si vedrì, colla disinvoltura d'un Prologo assai ridicolo. Questo era d'un vecchio, appel- 
von $I l$ re cervo - den von Demogorgone in einen Papagei verwandelten Zauberer Durandarte im nahen Wald von Roncislappe freilassen müsse. An diesem Tag sei ein Vergehen zu rächen, das mit Hilfe eines der beiden magischen Geschenke an den König Deramo begangen worden sei, die er diesem vor fünf Jahren überlassen habe. Im Prolog wird nicht nur das aktuelle Aufführungsdatum genannt (das ohne Zweifel jeweils angepaßt wurde) und in Verbindung mit dem Bühnengeschehen gebracht, es wird auch darauf hingewiesen, daß an diesem Tag das Geheimnis der beiden Geschenke, »de' due secreti^, gelüftet wird, das Cigolotti bis ins Jahr 1762 wahren mußte. Auch in La donna serpente warten die Feen Farzana und Zemina mit einer Reihe Zahlen auf, die teils geheimnisvoll verklausuliert sind wie der Tag, den Demogorgone für den Ablauf der Frist festsetzt, innerhalb derer Farruscad Cherestanì nicht verwünschen darf, um ihre Verwandlung von einer Fee in ein menschliches, sterbliches Wesen nicht zu gefährden, ${ }^{67}$ teils durchsichtig wie der Zeitraum von acht Jahren und einem Tag, innerhalb dessen Cherestani ihre wahre Identität verborgen halten muß, oder die 200 Jahre, die ihr als Schlange drohen, wenn Farruscad sein Versprechen nicht hält, sie unter keinen Umständen zu verfluchen. ${ }^{68}$ Bereits in der ersten Szene wird so die Verflechtung verschiedener magischer zeitlicher Grenzen in La donna serpente offensichtlich, die das Handeln Cherestanis bestimmen. In La Zobeide ist es der 40. Tag, der über Zobeides Schicksal entscheidet, in Il mostro turchino wird Zelou, wenn er ein treu liebendes Paar findet, nach roo Jahren von seiner häßlichen äußeren Hülle erlöst. Während das Publikum über diese entscheidenden Zeitpunkte informiert wird, wissen die Personen der Bühnenhandlung meist nichts davon, es sei denn, sie sind selbst übernatürlicher Natur wie Cherestani oder werden wie Zobeide von anderen vor dem bevorstehenden Unheil gewarnt. Unwissentlich oder wissentlich stehen die Personen also unter Vorgaben übernatürlicher Provenienz, die den Ablauf des Geschehens maßgeblich bestimmen und für die Betroffenen undurchschaubar bleiben.

lato Cigolotti, notissimo in Venezia, d'una grottesca figura, solito formare de' rigoletti nella Piazza di S. Marco, e a narrare al popolo le maraviglie degli antichi Romanzi, $e$ de' Negromanti, con una voce molto grossa, una goffa gravità, e un miscuglio di spropositi infiniti, nel suo linguaggio, ch'egli affettava toscano.e (CoL. I, 327).

a) -So, che giurò Demogorgon, che, s'ella / Passa il canicolar secondo giorno / Sin che tramonta il sol del corrente anno, / Senz'esser maladetta dal suo sposo, / Che mortal diverrà, come il marito* $(I, 1)$.

68. Che condannata l'ha a tener occulto / L'esser suo per ott'anni, e 'I fatal giorno, / E a non scoprir dell'opre sue gli arcani? a; *Nè ti sovvien dell'orrida condanna, / Alla qual per due secoli è ristretta? / Che cambierà la sua bella presenza / In schifo, abbominevole serpente, / Se lo sposo in diman la maledice? = $(\mathrm{I}, \mathrm{1})$. 


\section{Aspekte des Übernatürlichen}

Gegen die Entzauberung der Welt durch die Naturwissenschaften und den aufklärerischen Glauben an die rationale Erklärbarkeit der Phänomene, die bislang dem Bereich des Übernatürlichen zugehörten, sind die letzten Worte des Zauberers Durandarte in Il re cervo gerichtet. Dieser verkündet nicht nur das Ende der magischen Geheimnisse, sondern überraschenderweise auch das Ende seiner eigenen Zaubertätigkeit, "Durandarte / [...] sol vi dice / Ch'oggi i segreti magici hanno fine; / Ch'io più mago non son $\approx$ (III, II), ${ }^{69}$ und macht statt des Zaubers nun die Physik für die Erklärung der Metamorphosen verantwortlich: „Resti l'incarco / Alla Fisica industre di far guerra / Sugli organi, e le voci, che passando / Di corpo in corpo le medesme sono. / Tolga questo mio fine a'dotti spirti / Cagion di disputar. Eine ähnliche Polemik ist in der letzten Fiaba teatrale, Il re de' genj, aus dem Mund Pantalones zu vernehmen: $\gg x$ delle cose recondite, che nu altri miseri mortali no podemo capir, perchè pensemo materialmente, e i Filosofi po dise, che le xe fiabe.. $(\mathrm{I}, 2)$. Wenn die Physik an die Stelle des Magiers tritt, hat das Erstaunen vor dem Unerklärlichen ein Ende, und die Sphäre des Wunderbaren löst sich auf. In Gozzis Augen allerdings ist dieses Wunderbare, Irrationale nicht aus der Welt zu schaffen, da es zum einen nicht möglich ist, alles zu klären und zu erklären, zum anderen die Einbildungskraft als anthropologische Konstante ein Garant für die Permanenz des nicht rational Faßbaren ist.

69 Im 10. Gesang der Marfisa bizzarra (Col. VII) geht der Zauberer Malagigi ausfürlich auf die neuen Būcher ein, in denen das Ende der Magie verkündet und sein Berufsstand aufgelost wird: -Non vi sono più streghe, o Negromanti, / Un'impostura è oggi l'arte mia. / I moderni scrittor spregiudicati / I Negromanti al sole hanno mandati. * (X, 66). In einer Art Umschulung hat Malagigi sich glūcklicherweise andere Fahigkeiten aneignen können, so daß er trotz der Abschaffung der Magie nicht arbeitslos geworden ist: = Grazie a Salomone, / Ed a Rutilio, in altro sono dotto; / Ed ho sempre concorso di persone, / Sapendo trar la cabala pel Lotto. / Servo mille persone del Paese / Con la mia Fiorentina, e Bolognese. $(\mathrm{X}, 71)$. So wird überdeutlich, daß das Wunderbare oder Irrationale keineswegs aus der Welt verschwunden ist, sondern nur eine okkulte Macht die andere und ein Aberglaube den anderen ersetzen.

$\mathrm{Da}$ es vor, während und nach der Aufklarung einen > besoin de merveilleux * gibt und der Rationalismus nur ein, wenn auch wichtiger, Aspekt der AufkJärung ist, macht Michel Delon am Beispiel des Mesmerismus und des animalischen Magnetismus deutlich, der eine beträchtliche Anziehungskraft ausübte; vgl. M. Delon, - Crise ou tournant des Lumières? -, in: Werner Schneiders ( $\mathrm{Hg}$.), Aufkelärung als Mission/La mission des Lumières. Akzeptanzprobleme und Kommunikationsdefizite/Accueil réciproque et difficultés de communication, Marburg, Hitzeroth 1993, S. 83-90, hier S, 84 . Insofern läßt sich Gozzis Polemik als Einwand gegen cine Vereinseitigung lesen, die einem anthropologischen Grundbedürfnis entgegensteht. 
Hinsichtlich der Konstellation der wunderbaren Kräfte werden in den Fiabe teatrali verschiedene Varianten ausgespielt, die sich unter dem Kriterium der Zahl und des Status der Zauberer, Magier, Geister etc. ergeben. In $I l$ re de' genj wie auch in $I l$ corvo, Il re cervo und $I l$ mostro turchino ist es ein Geist oder Zauberer, der auf die Personen und das Geschehen direkten Einfluß nimmt, während sich in La donna serpente und $\mathrm{La}_{\mathrm{Zo}} \mathrm{O}$ beide jeweils zwei mit wunderbaren Kräften ausgestattete Wesen Macht und Einfluß gegenseitig streitig machen. In La donna serpente bestimmen zunächst Cherestanì und die Sphäre der Feen über Farruscads Handeln, doch geht bereits aus Brighellas Reiseerzählung hervor, daß es eine Gegenkraft gibt, den Zauberer Geonca, der in Tiflis mit Rat und Tat den Zurückgebliebenen zur Seite steht und beim abenteuerlichen Transfer in die Wüste behilflich war. Zur direkten Konfrontation der beiden Einflußsphären kommt es bei Farruscads Prüfungen. Auf der Suche nach einer Möglichkeit, Cherestani zurückzugewinnen, begibt sich Farruscad in Farzanas vermeintlich hilfreiche Hände, die ihn jedoch ins Verderben schicken will, um ihre Schwester Cherestani für das Feenreich zu retten. Hier greift Geonca nicht sichtbar, sondern nur mit seiner Stimme ein und konterkariert das Ansinnen Farzanas, indem er Farruscad konkrete Anweisungen zuruft, wie er seine übernatürlichen Gegner besiegen kann. So gewinnt Farruscad Cherestani zurück und das Feenreich verliert sie. Da Farzana zwar Farruscad in den Tod führen will, dies aber aus Liebe zu ihrer Feenschwester Cherestanì tut, wirkt ihr Handeln ambivalent, und es ist schwer zu entscheiden, ob es sich in La donna serpente um den Kampf einer guten gegen eine böse Macht handelt, während dies in La Zobeide unübersehbar der Fall ist, stehen sich doch von Anfang bis Ende der böse Zauberer Sinadab und der gute, mit magischen Kräften ausgestattete Abdalac gegenüber, die beide gleichermaßen auf Zobeide einwirken. Abdalac will Sinadab unschädlich machen und Zobeide selbst sowie Dilara und Salè retten, doch sind ihm die Hände gebunden, solange Sinadab als Mensch existiert und ein Vergehen Beders aus früheren Zeiten nicht gesühnt ist. ${ }^{70}$ Sinadab wird vom Schicksal noch benötigt, um mittels Täuschung Beders Tod durch den eigenen Sohn Schemsedin herbeizuführen, und Zobeide muß Sinadabs böses Ansinnen, sie wie alle Frauen vor ihr nach 40 Tagen in ein Tier zu verwandeln, erkennen und entdecken, bevor Abdalac die vielen Unschuldigen erlösen kann. In La Zobeide sind

70 .Zobeide, il Padre / fu iniquo un tempo, e sopra se, ed i Figli/ Attiró le sciagure. Ei de purgare / col sangue suo per inaudita forma / I suoi misfatti, ed io, s'ei non li purga, / E sin che Sinadabbo in uomo esiste, / La tua famiglia sollevar non posso. / Cosi sta scritto; c più dirti non deggio.* (I, 9) Diese Verse spricht Abdalac märchentypisch drei Mal. 
also die gute wie die böse Macht von einer anderen Instanz oder Ebene gewollt, und es liegt an Zobeide, der einen oder der anderen zu vertrauen - eine Entscheidung, die aufgrund der Undurchschaubarkeit der Verflechtungen und Abhängigkeiten nur mühsam zu treffen ist.

Aus Abdalacs Äußerungen zu seinem begrenzten Handlungsspielraum ( $\circ$ Cosi sta scritto $\alpha)$ und seiner Schlußreplik, $»$ da' Numi prima / Fu l'opra disegnata, e da Zobeide / Poscia eseguita fu $\alpha(V, 8)$, geht ein weiteres Charakteristikum hervor, das zahlreiche Fiabe teatrali in bezug auf die übernatürlichen Kräfte kennzeichnet: die auf der Bühne sichtbaren übernatürlichen Wesen hängen ihrerseits von anderen übernatürlichen Kräften ab. ${ }^{71}$ In La Zobeide werden diese mit "Numi benannt, und offensichtlich gibt es auch ein Buch, in dem alles aufgezeichnet ist, ${ }^{72}$ in $I l$ re cervo und La donna serpente stellt Demogorgone seine Bedingungen, in $I l$ mostro turchino sind es die "Saggi / Del monte sacro dela China $(I, 5)$, die die Strafe über Zelou verhängt haben. Besonderes Gewicht hat diese Konstellation bereits in der ersten ausgeschriebenen Fiaba teatrale, Il corvo. Selbst der Zauberer Norando, der von seiner Tochter Armilla als allmächtig beschrieben wird, ${ }^{73}$ ist Spielball whöherer « Mächte. Von Weisen wurde ihm bei der Geburt seiner Tochter prophezeit, daß der Abschuß eines schwarzen Vogels »miserie, e strazj, e morte « (IV, 4 ) und die Entführung seiner Tochter hervorrufen werde und er selbst »diverria inumano, / Cieco ministro delle più tiranne / Occasion d'angosce. . Auch die strenge Bewachung seiner Tochter konnte das drohende Unheil nicht verhindern, ${ }^{74}$ so daß Norando tatsächlich zum unerbittlichen Rächer wird. Mit Prophezeiungen, Verwünschungen, Drohungen tyrannisiert er den unschuldigen Jennaro, der in die ausweglose Situation gerät, entweder dem geliebten Bruder die Wahrheit zu sagen und zur Statue zu werden oder zu schweigen und den Bruder ins Verderben zu stürzen. Nachdem sich Jennaro in ein simulacro della innocenza $(\mathrm{V}, 2)$ verwandelt hat und Millo sein Mißtrauen bitter bereut, enthüllt sich Norando diesem, „Crudo è 'l destino; / Io di quel son ministro $(\mathrm{V}, 4)$, und verweist auf eine Abhängig-

7 Zeim in $/ l$ re de' genj ist der einzige, der nicht direkt von einer anderen Macht abhängt, sondern eher in einem Umfeld ubernaturlicher Kräfte steht.

72 In Il mostro turchmo liest Taer sein Schicksal und das Dardanès ebenfalls in einem Buch, das ihm Zelou überlassen hat.

n -Norando, il padre mio, / Implacabile, fier, di regia stirpe, / Insuperabil negromante, a tale, / Che ferma il sol, rovescia i monti alpestri, / Cambia gli uomini in piante, e ció, che brama, / tutto avvien* $(1,4)$.

74 Dies kommentiert Smeraldina, Armillas Kammerfrau, die als einzige um die Prophezeiung wußte, folgendermaßen: - Ma che! cede al destino, ed alle stelle / L'umano ingegno, ed avverato è alfine / II vaticinio * (IV, 4), und macht damit die Machtlosigkeit gegenuber dem Sehicksal deutlich. 
keit, die ihn zum Handeln wider seinen Willen zwingt. ${ }^{75}$ Die insistierende, viermalige Wiederholung von scritta fu $\ll / »$ scritto è $\star$ unterstreicht die Unmöglichkeit der Abweichung vom einmal Festgelegten. Unter diesen Vorzeichen steht auch das letzte Mittel, das Norando nennt, um Jennaro zu retten: der Tod Armillas, der eigenen Tochter und Frau Millos. Erst als diese sich umgebracht hat und die Versteinerung Jennaros sich auflöst, ist der Punkt erreicht, an dem Norando wieder sein eigener Herr ist, $»$ Or solamente in libertà rimango / Di non esser più crudo. E' già compiuto / Il grand'arcano, nè ragion si chieda $(\mathrm{V}, 8)$, menschlich handeln (»al mio poter / Nulla s'oppone. Or posso esser umano.*) und Armilla zum Leben erwecken kann. Damit ist die Rolle des Zauberers Norando eine ambivalente, tritt er doch zugleich als Gegner und Helfer auf, der die Personen in ausweglos scheinende Situationen führt, aus denen er ihnen selbst wieder heraushilft. ${ }^{76}$ Die Dialektik von vorherbestimmtem Schicksal und Handlungs- oder Entscheidungsfreiheit, von zeitweise fremdbestimmtem und autonomem Agieren prägt das Geschehen in $I l$ corvo in entscheidender Weise. Dabei werden allenthalben Unsicherheiten über die Verantwortung für Taten und Worte sichtbar. Millo deutet Jennaros Verhalten als Verrat und verurteilt ihn zum Tode, während Jennaro sich wider Willen durch Norandos Drohungen zu diesem Verhalten gezwungen sieht. Jennaro hält Norando deshalb für unerbittlich und grausam, während dieser wiederum gemäß den Prophezeiungen der Weisen handelt. So ergibt sich eine immer weiter ins Unbestimmte reichende Abhängigkeit von Vorgaben, deren Ursprung sich in einem nicht näher definierten Schicksal oder in den Sternen 77 verliert. Die terminologische Variationsbreite zur Bezeichnung der letztlich entscheidenden Instanz (»destino «, »stelle «, »ruota *libro $\alpha$, sielo $\alpha$, Numi $\alpha$ ) ist ein Zeichen für die ideologische Offenheit wie auch ein Hinweis auf die Persistenz der Problematik von Freiheit und Bestimmtheit menschlichen Handelns, für die jede Zeit ihre Bilder und Begrifflichkeiten schafft. Die Vervielfachung der Abhängigkeitsverhältnisse und der quasi endlose Rückverweis machen die Komplexität einer Situation sichtbar, die eine sichere Orientierung ausschließt, da eine Vielzahl von Instanzen den Lauf der Dinge beeinflußt. Ein selbstbestimmtes

75 * Scritta ne' fati / Fu d'un Corvo la morte, indi fu scritta / La maladizion, che ti fu data. / Scritto è 'l ratto d'Armilla, e scritto è ancora, / Ch'esser debba crudele alla tua stirpe, / A me stesso crudel per mia vendetta, $*(\mathrm{~V}, 4)$.

76 Das offensichtlichste Beispiel für diese Ambivalenz bietet Zelou in Il mostro turchino.

$\pi 7$-Destino* und wstella/stelle* werden ohne Bedeutungsdifferenzierung in etwa gleicher Hāufigkeit aufgerufen; vgl. Smeraldina: scede al destino, ed alle stelle / L'umano ingegno, ed avverato è alfine / Il vaticinio* (IV, 4$)$. 
Handeln ist nur in engen Grenzen möglich, denn die Personen sind der Macht eines diffusen, undurchschaubaren Schicksals ausgeliefert.

\subsection{Ein philosophisches Märchen}

„Fiaba filosofica nennt Gozzi seine vorletzte Fiaba teatrale, die eigentlich die letzte hätte sein sollen. ${ }^{78}$ Tatsächlich erscheint L'augellino belverde wie ein Kompendium der vorausgegangenen Stücke und führt zugleich das eminent Theatralisch-Spielerische der Fiabe teatrali vor Augen. L'augellino belverde ist die Fortsetzung der Geschichte von L'amore delle tre melarance nach etwa 20 Jahren und nimmt auch den polemischen Duktus des ersten Stücks wieder auf; ${ }^{79}$ Zielscheibe ist nun allerdings nicht mehr das zeitgenössische Theater, sondern, wie die ungewöhnliche Gattungsbezeichnung deutlich macht, die Philosophie beziehungsweise die Philosophen. ${ }^{80}$ In einem turbulenten Bühnengeschehen wird das Konzept des »amor proprio «, wie es die Zwillinge Renzo und Barbarina vertreten, einer betont märchenhaften Erfahrungswirklichkeit $\propto$ ausgesetzt, die seine Unangemessenheit enthüllt.

Wie L'amore delle tre melarance basiert L'augellino belverde nicht auf einem orientalischen Märchen, sondern hauptsächlich auf Sarnellis Posilecheata sowie Basiles Pentamerone ${ }^{81}$ und spielt nicht im fernen

78 Im Vorwort zu L'angellino belverde heißt es $*$ Io m'era determinato a tentar con uno sforzo di fantasia uno strepito grande teatrale popolare, e a troncare il corso delle composizioni sceniche, dalle quali non voleva utilitá nessuna, ma nè meno quel peso disturbatore, che incominciavo a darmi; massime sembrandomi già di aver abbastanza ottentuo quell'intento, che m'era proposto per un purissimo, capriccioso, poetico puntiglio.* (Col. 111, 9). Der in der Karneval-Saison 1765 mit großem Erfolg (allein 19 Aufführungen im Karneval) aufgeführten neunten Fiaba teatrale folgte im Herbst eine zehnte, Il re de' gen). Siehe auch im Vorwort zu Il re de' genj: = Doveva essere I'Augel belverde l'ultima delle mie Fiabe* (Col. 111, 125 ). Laut Gozzi entstand die zehnte Fiaba teatrale dann noch auf Bitten der Truppe Sacchi und um diejenigen Lügen zu strafen, die verbreiteten, seine Ideen seien erschöpft.

79 Vgl. Verf., =La polémique déguisée en conte de fées dramatisé. L'amore delle tré melarance et L'augellino belverde de Carlo Gozzi ", in: Elisabeth Décultot; Mark Ledbury ( $\mathrm{Hgg}$.), Théories et débats esthétiques au dix-buitiéme siècle / Debates on Aesthetics in the Eighteenth Century, Paris, Champion 2001, S. $155-183$.

80 Ein entscheidender Vers aus dem Mund Calmons lautet: =Filosofia v'è ben, ma non Filosofi.e $(1,10)$.

8) Auf mögliche volkstümliche, venetische Quellen weist Marinella Pregliasco hin in *Il modello popolare nelle Fiabe di C. Gozzi: L'augellino belverde a, in: Atti dell'Istituto veneto di scienze, lettere ed arti, Bd. $\mathrm{t}_{42}, \mathrm{I}_{9} 8_{3}-84, \mathrm{~S}, 427-446$, hier S. $442 \mathrm{ff}$. Wahrend zwei dieser Volksmärchen nur sehr allgemeine Ubercinstimmungen mit der Geschichte der Fiaba teatrale aufweisen, bietet das dritte uberzeugende Aspekte cines direkten intertextuellen Bezugs. 
Orient, sondern in Monterotondo. Die Masken nehmen entscheidende Rollen ein - Tartaglia ist König von Monterotondo, Brighella ist Hofpoet und Wahrsager - und sind in weit mehr als der Hälfte der Szenen auf der Bühne präsent. ${ }^{82}$ Bemerkenswert sind viele lange $a$-soggetto-Szenen, die nicht nur, wie in den Fiabe teatrali nach L'amore delle tre melarance üblich, von Truffaldino und Brighella bestritten werden, sondern von allen vier Masken, also auch von Tartaglia und Pantalone. Darüber hinaus treten im Dialog mit den improvisierenden Masken auch Smeraldina und sogar der als Prinz geborene Renzo mehrfach in die Improvisation ein. Die sprachliche und stilistische Variationsbreite der einzelnen Figuren wie des gesamten Stücks ist groß, was sich gerade an Smeraldina zeigt, die je nach Gesprächspartner und Situation improvisiert oder in Versen spricht, ${ }^{83}$ oder an Tartaglia, der im zweiten Akt in drei langen aufeinanderfolgenden asoggetto-Szenen auftritt, sich mit der Königinmutter Tartagliona zwar in Versen, doch in einem derb-ordinären Stil unterhält und bei Pantalone für sein Liebeswerben um Barbarina "due parole graziose di quelle tue veneziane* $(\mathrm{III}, 7)$ lernen will. Im Blick auf das gesamte Stück stehen sich die grundverschiedenen Improvisationsarten der Masken (wie auch Smeraldinas und Renzos) einerseits und des Poeten Brighella andererseits gegenüber, dessen poetisches Genie sich in extemporierten, gekünstelten Versen ausdrückt; es kontrastieren Improvisation und ausgeschriebene Passagen, Dialekt und Hochsprache, Prosa und Vers, wobei Gozzi in L'augellino belverde abwechslungsreich unterschiedliche Versarten verwendet, ${ }^{84}$ sowie ein hoher und niederer Stil, der allerdings aufgrund der «hohen « Rollen der Masken und maskennaher Personen (Tartagliona) nicht dem üblichen Schema ernste Personen/hoher Stil, Masken/niederer Stil gehorcht.

82 In 29 von 47 Szenen sind Masken zu sehen.

83 Im direkten Gespräch mit Truffaldino, ihrem Mann, improvisiert Smeraldina, während sie im Dialog mit Renzo und Barbarina (auch in Gegenwart Truffaldinos) in Versen spricht.

\$t Neben der Grundversart des endecasillabo finden sich die Verse der singenden Äpfel und des klingenden, tanzenden Wassers in Sechs--, Sieben- und Elfsilblern sowie die -kunstvollen* Gebilde des Poeten Brighella, in denen Gozzi in bunter Reihenfolge Strophen aus Sieben- und Elfsilblern oder Sechs: und Elfsilblern, aus Fünfsilblern und aus Achtsilblern vorführt.

Brighella, spoeta ed indovino «, ist eine beifende Satire auf den poeta vates, dessen $\mathrm{Er}$ habenheit mit den maskenhaften Zügen der Figur heftig kontrastiert. Die hermetischen Verse Brighellas sind durchsetzt mit Anspielungen auf die Mode der raccolte, auf das Schlagwort von *cose e non parole $\alpha$, auf die Sprachthematik, und einer Fülle von Zitaten v. a. Bernis, aber auch Petrarcas. Seine hellseherischen Gaben setzt er vor allem dazu ein, die Koniginmutter Tartagliona, die er zu lieben vorgibt, zu einem Testament zu veranlassen, in dem er als Haupterbe eingesetzt wird. Zur Strafe für seine schmeichlerische Heuchelei - und sicher auch als Zeichen der Geringschätzung Gozzis für so manchen Dichterkollegen - wird er am Ende der - fiaba filosofica e in einen Esel verwandelt. 
In groben Zügen sei die Handlung skizziert: Vor I8 Jahren hat die Orangenprinzessin Ninetta als Königin und Frau Tartaglias Zwillinge zur Welt gebracht, die von der bösen Schwiegermutter Tartagliona an Pantalone übergeben wurden, der sie umbringen sollte, sie stattdessen aber aussetzte. Von Smeraldina gefunden, wachsen Renzo und Barbarina beim Wurstmacher Truffaldino und seiner Frau Smeraldina auf. Als sie Zeugen eines Gesprächs werden, in dem Truffaldino Smeraldina Vorwürfe macht, daß sie die beiden Bastarde jahrelang durchfüttern mußten, beschließen diese kurzerhand, ihr »Elternhaus « zu verlassen, schätzen sich glücklich, daß sie aus philosophischen Büchlein gelernt haben und so Smeraldinas Verhalten zweifelsfrei auf den »amor proprio « zurückführen können. An einem verlassenen Strand treffen sie auf Calmon in Form einer alten Statue, der ihnen Schreckliches und Wunderbares prophezeit und einen Zauberstein überreicht. Als sie diesen in der Nähe des königlichen Palastes auf den Boden werfen, entsteht vor ihren Augen ein herrlicher Palast, in den sie sogleich reich gekleidet einziehen. Tartaglia, der König von Monterotondo, ist nach langer Abwesenheit an den Hof zurückgekehrt und trauert um Ninetta, die von Tartagliona in ein unterirdisches Grab gesperrt wurde, wo sie schon lange verhungert wäre, brächte ihr nicht Tag für Tag ein grünes Vögelchen zu essen. Beim Anblick Barbarinas auf dem gegenüberliegenden Balkon verliebt sich Tartaglia sofort in diese, doch lenken zwei Sprüchlein Tartaglionas, die Barbarina aus dem Weg schaffen will, deren Aufmerksamkeit auf ganz anderes: auf die Äpfel, die singen und das Wasser, das klingt und tanzt. Trotz tödlicher Gefahren schickt Barbarina ihren Bruder Renzo, der sich inzwischen unsterblich in eine Statue verliebt hat, auf die Suche, die dank Calmons Hilfe erfolgreich endet. Beim Versuch, noch ein Drittes, nämlich das grüne Vögelchen zu beschaffen, wird Renzo allerdings zu Stein. Ein blutendes Messer ist für Barbarina das Zeichen, daß ihrem Bruder Leid zugestoßen ist, und sie bereut ihre Versessenheit bitter. Wiederum mit Calmons Hilfe bemächtigt sie sich selbst des Vogels und befreit Renzo von seiner steinernen Hülle. Das grüne Vögelchen verwandelt sich in einen König, der nicht nur Barbarina heiratet und so den Inzest zwischen Tartaglia und seiner Tochter verhindert, sondern auch Ninetta aus ihrem Grab befreit, so daß die königliche Familie am Ende auf der Bühne glücklich vereint ist. 


\section{Ein philosophisches Prinzip und seine Erprobung}

L'augellino belverde führt das problematische Verhältnis von philosophischem System und Erfahrungswirklichkeit ${ }^{85}$ in polemischer Zuspitzung vor Augen, indem einerseits das Prinzip des wamor proprio* in extremer Weise vereinfacht und übertrieben erscheint, andererseits die Wirklichkeit, in der sich zum einen seine Gültigkeit, zum anderen die Standhaftigkeit der *filosofi « zu beweisen hat, eine ganz märchenhaft-unwahrscheinliche ist. Wenn sich bereits im ersten Akt herausstellt, daß die Zwillinge Renzo und Barbarina ihre philosophische Bildung aus * libriccini filosofici« $(I, 4)$ gewinnen, die Smeraldina und Truffaldino zum Kilopreis als Einpackpapier für die Wurst kaufen, und sich das so erworbene Wissen über die menschliche Natur und die Vernunft im Begriff des "amor proprio « kondensiert und zugleich erschöpft, erübrigt sich die Frage, auf welche konkreten Texte oder Philosophen sich die Polemik bezieht. ${ }^{86}$ Gozzi greift zwar einen im moralistischen Denken des 18 . Jahrhunderts vieldiskutierten Begriff auf und situiert die Fiaba teatrale damit in einer aktuellen

85 Auf diese Problematik weist Barbarina am Ende des zweiten Aktes unter Verwendung des Terminus *sistema explizit hin: $\approx$ Ah, Renzo, io temo assai, ch'ogni Filosofo / Sia mosso a ragionar da fame, e freddo, / Dagl'incentivi di natura usati. / Bella cosa è l regnar sopra icervelli / Dei deboli seguaci, e co' sistemi / Farsi Monarchi delle genti stolte, I Che adoran gl'impostori. (II, 8).

86 Insofern ist die Suche nach direkten Quellen wie sie G. Luciani in Carlo Gozzi, op. cit., S. 406-4 4, oder Norbert Jonard in s Les structures idéologiques de L'augellino belverde de C. Gozzia, in: Romanistische Zeitscbrift für Literaturgeschichte/Cahiers d'Histoire des Littératures Romanes 1 , 1978 , S. 1-20, vornehmen, nicht ertragreich.

Im Vorwort zu L'augellino belverde legt Gozzi selbst eine Spur, die sich allerdings als unsicher erweist: =I due moderni Filosofi, Renzo, e Barbarina, principali personaggi in quest'azione, imbevuti delle massime de' perniziosi Signori Elvezio, Russò, e Voltere; (Col. III, I0). Wohl am ehesten in Helvétius' 1758 erschienenem Werk mit dem Titel De l'esprit läßt sich hinsichtlich des *amour-propres eine ähnlich radikale Position finden wie bei den Zwillingen. Daß Gozzi die Schrift bekannt war, kann aufgrund des Skandals, den sie bei ihrem Erscheinen verursacht hatte, als wahrscheinlich gelten; s. dazu D Masseau, op. cit., S. 131-141. Im Hinblick auf Gozzi erweisen sich E. Cassirers Bemerkungen zu Helvétius in Die Pbilosophie der Aufklarung, op, cit., S. 33 ff., als interessant. Über De l'esprit schreibt er, „daß̊ die Epoche hier einen Grundzug ihres Denkens in prägnanter Bestimmtheit, und freilich auch in einer fast-parodistischen Übertreibung ausgeprägt fand. In dieser Übertreibung tritt die methodische Schranke und die methodische Gefahr dieser Denkweise deutlich hervor. Sie besteht in der Nivellierung, die dem Bewußtsein dadurch droht, daß seine lebendige Fülle im Grunde geleugnet und als bloße Maske, als Verkleidung genommen wird, [...] Die Differenz der Gestalten wie die der Werte verschwinder; sie erweist sich als eine trügerische Illusion.* Gegen eine solche Nivellierung in der zeitgenössischen Denkweise polemisiert Gozzi auch in anderen Bereichen wie etwa dem der Gattungen oder des Stils, so daß es plausibel erscheint, daß Gozzi mit Helvétius einen Autor nennt, der dieses Denken in sfast-parodistischer Übertreibung « repräsentiert und damit zum Objekt einer Parodie wird. 
Debatte, doch dient der allegorisch-indirekten Darstellungsweise keine differenzierte, sondern eine plakative, ironisch-distanzierte Interpretation des zur Diskussion stehenden Prinzips. Für Renzo und Barbarina erkärt der *amor proprio* sämtliche Verhaltensweisen, und sei es um den Preis eines Paradoxes: saverete / Ricompensa a quel danno, che vi siete / Fatto per amor proprio. $\propto(I, 4)$. Ihrer Stiefmutter Smeraldina erläutern sie, daß sich ihr *amor proprio * im sfanatismo d'un'azion eroica* und der "idea di guadagnarvi/Dominio sopra noi « $(\mathrm{I}, 4)$ zeige, aufgrund derer sie sie gerettet, aufgezogen und ernährt hat. Das universelle Erklärungsmuster des samor proprio $\alpha$, das Renzo und Barbarina auf die Handlungen der anderen anwenden, nimmt diesen sowohl das Undurchschaubare als auch ihre ethische Qualität und macht sie alle gleichwertig. Eine Vergeltung für gute Taten ergibt sich demnach nicht aus Dankbarkeit, sondern höchstens aus den gesetzlichen Regelungen der gesellschaftlichen Verhältnisse ( leggi di società $; \mathrm{I}, 4$ ). In der Tat versucht Barbarina, als sie reich geworden im Palast von Smeraldina aufgesucht wird, die Unerwünschte für ihre Mutterliebe mit Geld zu entlohnen und so loszuwerden. Die Überzeugung der sfilosofi* - wie sich die Zwillinge selbst bezeichnen - von der Allgemeingültigkeit des Prinzips hat zur Folge, daß sie sich über nichts mehr wundern und der Welt mit Gleichgültigkeit begegnen. ${ }^{87}$ Auf der Basis des samor proprio* entsteht die Maxime, sche in generale / Tutti i mortali sien superbi, avari, / Vani, vendicativi, impraticabilia (I, 5), und es gibt für Renzo und Barbarina nur einen Weg, dem Prinzip der Selbstliebe zu entrinnen: Freundschaft und Liebe zu vermeiden ( $*$ Mai / Non converrà prender affetto alcuno, / amicizia nessuna a questo mondo ; $\mathrm{I}, 5$ ) und sich am besten ganz von den Mitmenschen zu entfernen ("Lungi da tutti andiamo, e fuor di questa / Città pericolosa ; I, s). Diese extreme, fanatische ${ }^{88}$ Position wird zum einen von Smeraldina in der ironischen Adaption der Denkweise der *filosofi « unterminiert : "Io maledico / Il punto, in cui per troppo amar me stessa / Tanto ho penato ad allevar due ingrati, / Due matti da legar, che m'abbandonano / Con tanta indifferenza, $e$ ingratitudine.« $(I, 4)$, zum anderen tritt ihr Calmon deutlich entgegen: Er führt Renzo vor Augen, daß er durch das alleingültige Prinzip des samor proprio* nichts gewinne, sondern nur alle allen verdächtig werden, bringt die Diskrepanz zwischen Eigen- und Fremdwahrnehmung ins Spiel, appelliert an die Überlegenheit der Vernunft, die nicht Sklavin der Sinne sei, sondern sehr wohl entscheiden könne, was gut und böse sei,

\footnotetext{
67 -E conosciamo a fondo ogni sorgente / Dí tutte quante son le azioni umane, / Nê ci facciam di nulla maraviglia. $[. .$.$] Noi con somma indifferenza andiamo via.e (1,4)$.

is Barbarina selbst bezeichnet ihren Bruder als sfanatico* $(I, 9)$.
} 
und stellt schlieflich dem *amor proprio $\propto$ ein $*$ Ama te stesso / Amando gli altri« ( $\mathrm{I}, \mathrm{I0})$ gegenüber. Calmon leugnet nicht etwa die Existenz der Selbstliebe, sondern sieht sie als eine Kraft, die den Menschen neben anderen wie Mitleid, Streben nach Tugend, Furcht vor dem Tod beherrscht. ${ }^{89}$ Wenn er schließt, sLeva il grugno da terra, animal sozzo, / Mira il cielo, e le stelle, e il tuo pensiero / Non allacciar qua giù tra i sensi, e il nulla«, wird deutlich, daß die Versteifung auf das Prinzip des »amor proprio * vor allem zweierlei bedeutet: den Verlust der eigenen Denkfähigkeit und das Aufgeben einer transzendenten Dimension.

Wie schnell sich die phílosophischen Überzeugungen und Schlußfolgerungen angesichts der $*$ Wirklichkeit $*$ der eigenen Erfahrung in Nichts auflösen, demonstrieren die folgenden vier Akte. ${ }^{90}$ Barbarina und Renzo sehen sich mit dem Wunderbaren konfrontiert, verfallen in eine jeder Vernunft spottende Liebe zu einem Vogel beziehungsweise einer Statue und sind auf Hilfe und Rat anderer angewiesen. Daß der Vorsatz der Zwillinge, »spogliamci d'amor proprio affatto, affatto $\propto(I, 5)$, der Realität nicht standhält, sondern sie im Gegenteil dem »amor proprio « in besonderer Weise verfallen sind, wird schnell sichtbar. Barbarina erweist sich in der neuen Umgebung als höchst eitel, selbstsüchtig - eine Selbstsucht, die nicht einmal davor zurückschreckt, den Bruder tödlichen Gefahren auszusetzen - und machthungrig, während bei Renzo eine andere Variante des »amor proprio» zutage tritt, wenn er in völliger Selbstüberschätzung die drei magischen Dinge, Äpfel, Wasser und Vogel, in seinen Besitz zu bringen sucht und kläglich scheitert. Während die vermeintlich vor dem *amor proprio" gefeiten "filosofi* sich als höchst kontaminiert entpuppen, erweist sich der von ihnen als mamor proprio * diagnostizierte "materno amor $\propto$ (III, 3 ) Smeraldinas als dauerhaft und resistent. Im Kontrast zu Smeraldina vertritt Truffaldino eine eigene, maskenhaft verzerrte Spielart des *amor proprio, einen »amor proprio illecito* (II,

89 Zum Begriff des * amor proprios, der Begriffs- und Bedeutungsgeschichte im Uberblick s. den Eintrag *Amour-proprea, in: Joachim Ritter ( $\mathrm{Hg}$.), Historisches Worterbuch der Philosophie, Bd. 1, Darmstadt, Wissenschaftliche Buchgesellschaft 1971.

90 Fine erste Aufweichung der starren Haltung Renzos zeichnet sich bereits in der 9. Szene des 1 . Aktes ab. Angesichts der Käte, des Hungers, der Müdigkeit, die die Zwillinge fernab der Menschbeit erleiden, und dem Wunsch nach Abhilfe, gesteht Barbarina: -Renzo, / Ti dico il ver; la fame, il freddo, il sonno / Mi farieno parer quella persona / Adorabile affatto, e d'amor piena / Più per noi, che per se๔, und sie wirft ihrem Bruder Fanatismus vor, - Renzo, la fame, il freddo, e la stanchezza/ Hanno in me tal vigor, che agli occhi miei / Ti dipingono un pazzo, ed un fanatico, / $\mathrm{E}$ pieno d'amor proprio più degli altrik. Darauf antwortet Renzo: $>$ Aspetta un poco. Temo, che tu dica / La verità. Se 'l vero tu dicessi, / Nol so negar, m'increscerebbe assai. « (I, 9). Diese versöhnliche Position verhärtet sich jedoch in der darauffolgenden Begegnung mit Calmon wieder. 
3), wie Tartaglia feststellt. Truffaldinos Maxime lautet, oche il saper conoscere il mondo, e l'avere il proprio intento o per dritto, o per torto, è la vera felicità filosofica moderna* (IV, 9), womit der Egoismus zur Norm allen Tuns erhoben wird. In zwei Parallelszenen mit Tartaglia und Renzo meldet er in unverschämter Weise Anspruch auf Geld, Essen, Trinken an und bedient sich schmeichlerischer Heuchelei, als die unverblümte Art zu fordern bei Renzo auf Unverständnis stößt. Entsprechend dieser extrem materialistischen Weltauffassung ist Dankbarkeit für erwiesene Hilfe überflüssig. ${ }^{91}$

\section{Erstarrung und Verwandlung}

In diesem allegorischen Experimentierfeld spielen wie in allen anderen Fiabe teatrali auch übernatürliche Kräfte eine Rolle, wobei im Hinblick auf die charakteristischen Metamorphosen die Vielzahl an Statuen in Laugellino belverde auffällt. Calmon, Pompea, Renzo, Truffaldino sind oder werden Statuen, und in zwei spektakulären Szenen betreten zudem bekannte Statuen aus Treviso und Venedig die Bühne. ${ }^{92}$ Abgesehen von diesen, die um des Effekts willen eingesetzt werden, unterscheiden sich vor allem die Versteinerungen Calmons und Pompeas von den märchenhaften Transformationen, die wie im Falle Jennaros in $\mathrm{Il}$ corvo durch die Übertretung eines Gebotes ausgelöst werden. ${ }^{93}$ Calmon, der mit allen

9) Calmons Bitte an Renzo, als Dank für die Hilfe seine Nase zu ersetzen, kommentiert

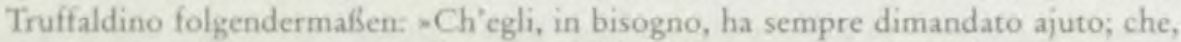
appena avuto il soccorso, non s'cे curato del benefattore, come se non fosse. Che, tornato il bisogno, con franchezza, e senza menomo rimorso ha ridomandato ajuto, e che, quanto a' rimproveri, in caso di bisogno, gli ha sempre ascoltati col collo torto, con gli occhi lagrimosi, e con apparente dolore, e dando pienissima ragione al rimproveratore; che, avuto il servigio, era quello di prima ec. $\approx$ (IV, 9).

$92 \mathrm{Zu}$ diesem dramaturgischen Kunstgriff außert sich Gozzi im Vorwort: -Paleserò, che, oltre $a^{*}$ dati di serietà, ch'io posi in questa rappresentazione, nulla ho risparmiato per farla faceta, e popolare. Per dar movimento a tutta la città, mi sono insino immaginato di porre in iscena delle mostruose statue notissime, ch'esistono ne' luoghi più lontani, e popolati di questa Metropoli, col solo fine di attraere, e d'invogliare il minuto popolo di quelle contrade a venir a vedere, se le statue, rese ambulanti, e favellatrici, somigliavano a' loro simulacri; e trovandole somigliantissime, ritornavano furiosamente al Teatro, per veder i loro vicini di marmo animati, e parlanti. = (Col. III, $12-13$ ). Die Statuen, die auf der Bühne auftreten, befinden sich auf dem Campo de' Mori.

Neben der visuellen Reverenz an die Serenissima enthält L'augellino belverde auch zahlreiche verbale Venedigbezūge, vor allem in Form von Eigennamen stadtbekannter Personen und Ortsbezeichnungen.

4) P. Vescovo weist in *Per una lettura non evasiva delle Fiabe - op. cit, S, 207-2 ro, ebenfalls auf diesen Unterschied hin, nimmt ihn jedoch nur für Calmon und nicht für Pompea in Anspruch. 
Attributen eines Zauberers ausgestattet ist, unter stremuoto, prodigi, oscurità « auftritt, den Zwillingen ein Zaubermittel, den Stein, überreicht, war einstmals sre d'uomini* und herrscht nun als König über »tutti i simulacri× (I, IO). Gleich Renzo war er überzeugt, menschliches Handeln durch das Prinzip des »amor proprio « erklären zu können, glaubte an die Priorität der Sinne vor der Vernunft, den Egoismus der Menschheit und hielt gute Werke für »fanatismo, [...] follia, figlia del proprio amor * (I, 10). ${ }^{94}$ Gleich Renzo wollte er erzwingen, daß seine eigenen Werke nicht von der Selbstliebe abhingen, worauf er vor 400 Jahren zu Stein wurde:

Allor m'avvenne

Che pietra si fe' 'l cor, le membra tutte

Mi si cambiaro in marmo, e sul terreno

Caddi, ivi giacqui molti anni fra l'erba

Sepolto, e 'l sucidume. Inutil corpo,

Berzaglio fui de' passeggier, che 'l peso

Di natura sgravar. ( 1, ro)

Diese Verwandlung als Bestrafung der ideologischen Versteifung durch eine Versteinerung trägt den Charakter eines contrappasso, der keine Rückverwandlung vorsieht. Die malträtierte Statue wurde jedoch von den Vorfahren der Zwillinge aus dem Schlamm geborgen und in einem Garten der Stadt aufgestellt; diese gute Tat will Calmon, der inzwischen längst seinen Irrtum erkannt hat, nun an Renzo und Barbarina vergelten. Die sich in tätiger Hilfe äußernde Dankbarkeit, an die Renzo und Barbarina nicht glauben, rettet Renzo im weiteren Verlauf des Geschehens das Leben. Renzo, der den $*$ libretti moderni $*(I, 4)$ folgt und sich als Vertreter einer modernen Philosophie sieht, hält Calmon für einen *moralista / Rancido, marcio * $(I, 10)$. Durch den Gegensatz modern/veraltet wird ein zeitliches Verhältnis der philosophischen Positionen etabliert, das durch Calmons Geschichte allerdings ironisch in sein Gegenteil verkehrt wird, hat doch Calmon vor 400 Jahren Renzos Position geteilt, ist aber inzwischen über dieses Stadium hinaus, so daß seine jetzige Überzeugung als die moderne und die Renzos als diejenige erscheint, die sich überlebt hat. Calmon ist also gewissermaßen ein Denkmal, das an philosophische Irrtümer und ihre mögliche Revision gemahnt.

Pompeas, Renzos und Truffaldinos Verwandlungen in Statuen sind im Vergleich zu Calmon ideologisch leichtgewichtiger. Zwar steht auch Pompeas Statuendasein im Kontext des »amor proprio « und entspricht einem

94 Die Formulierung Calmons macht deutlich, daß die subjektive Wahrnehmung unter dem Diktat der ideologischen Prämisse eine Täuschung war: „Vidi, o mi parve / Farneticando di veder $*$, und .di veder mi parve- (I, 10). 
contrappasso, wird sich Pompea doch angesichts der Schmeicheleien und Lobreden ihrer Verehrer selbst zum Idol, sun idol di me stessa / A me stessa facendo (IV, r), aber es genügt die Reue über ihren Hochmut und ihre Eitelkeit, damit die steinerne Schöne am Ende der Fiaba teatrale wieder zum Leben erweckt wird. Auch Renzos und Truffaldinos Metamorphosen stehen in losem Zusammenhang mit dem Thema der Selbstliebe, denn der ungesunde Mut ( insano coraggio «; IV; 9), mit dem sie sich dem grünen Vögelchen nähern, resultiert aus einem übersteigerten Selbstwertgefühl, das ebenfalls einen Aspekt des *amor proprio* darstellt. Insofern ist ihre Verwandlung sowohl eine Folge des samor proprio* als auch die Strafe für die Übertretung des Verbotes, sich dem magischen Gegenstand zu nähern. Wenn dagegen die Königinmutter Tartagliona und der heuchlerische Hofpoet Brighella in der Schlußszene als Schildkröte und als Esel die Bühne verlassen, folgt diese Metamorphose dem Schema der märchenhaft-gerechten Bestrafung der $\approx$ Bösen $\alpha$, wie sie auch Tartaglia in Il re cervo oder Sinadab in La Zobeide trifft.

\section{Konfrontation mit dem Wunderbaren}

In der betont märchenhaften Sphäre des zweiten bis fünften Aktes begegnen Renzo und Barbarina dem Wunderbaren nicht nur in Form der Statue Calmon, sondern auch in Gestalt des saugellino belverde $\alpha$. In frühester Kindheit wurde der Königssohn von einem Menschenfresser in das grüne Vögelchen verwandelt und lebt seitdem angekettet auf dem $*$ Colle dell'Orco", den er nur verlassen kann, um der bei lebendigem Leib begrabenen Ninetta Wasser und Brot zu bringen. Calmon wie das Vögelchen prophezeien einzelnen Personen bereits im ersten Akt Ereignisse, die dem Publikum dann im folgenden vor Augen geführt werden. ${ }^{95}$ Damit erhalten die Zuschauer einen Informationsvorsprung - darauf verweist das Vögelchen am Ende der Fiaba teatrale explizit ( in Augello fatato, / Come sa l'Uditorio, fui dall'Orco cambiato $\propto ;$ V; 2 ) -, der die Spannung auf das Wie der Lösung der verflochtenen Handlung richtet. Der Verlauf der Ereignisse hängt im wesentlichen von wunderbaren Elementen ab:

95 Als wahrsagender Dichter eröffnet Brighella das Stück mit der Prophezeiung, daß $>$ cose tremende* $(1,1)$ gesehehen werden, Tartaglia an den Hof zurückkehre und Ninetta sowie die königlichen Sprößlinge noch nicht verloren seien. Diese Andeutungen geben Pantalone die Gelegenheit, die Vorgeschichte, die sich in L'amore delle tre melarance zugetragen hat, zu resumieren und das Publikum in den Stand der Dinge einzuweihen. Im Unterschied zu Calmon und dem grünen Vögelehen verfügt Brighella nicht über magische Kräfte, sondern nur uber seherische Gaben. 
dem Stein, den Calmon den Zwillingen überreicht, dem Messer, das der Vogel ihnen zukommen läßt, den Zauberäpfeln und dem Zauberwasser sowie dem Augellino belverde selbst. Hinzu kommen Pompea als Statue sowie die übrigen *wirklichen $*$ Statuen aus Treviso und Venedig, die Calmon, der König der Statuen, Renzo als Helfer bei der Bewältigung der beiden ersten $\star$ Aufgaben $*$ zur Verfügung stellt. Angesichts dieser Vielfalt wunderbarer Einflüsse muß Barbarina ganz im Gegensatz zu Renzos anfänglicher überzeugter Feststellung *nè ci facciam di nulla maraviglia* $(\mathrm{I}, 4)$ am Ende des Stücks eingestehen: $\mathrm{E}$ questo il punto / Di sciorre il nodo a mille cose ignote, / Ch'io non potei capir *; ein schwerwiegendes Eingeständnis der Undurchschaubarkeit und Unerklärlichkeit des am eigenen Leib Erfahrenen, das jedoch sogleich ironisch aufgehoben wird, "Son curiosa / Estremamente anch'io di saper, come / Deve finir questa Tragedia greca. $\propto(\mathrm{V}, \mathrm{i}){ }^{96}$

Wie in den anderen Fiabe teatrali sind die mit übernatürlichen Kräften ausgestatteten Wesen nicht autonom, sondern in ihrem Handlungsspielraum begrenzt. Der grüne Vogel steht in einem nicht näher ausgeführten Abhängigkeitsverhältnis zum Menschenfresser und erklärt selbst, daß er, obwohl er Barbarina heiraten wolle, gezwungen sei, wider seinen Willen gegen die Zwillinge zu handeln. ${ }^{97}$ Und selbst Calmon, ein $*$ Sonderfall $\propto$ unter den Zauberern und Magiern, verweist hinsichtlich des Schicksals der Zwillinge auf das grüne Vögelchen, von dem alles abhänge. So läßt sich auch in L'augellino belverde die Handlungsmotivation der Agierenden nicht kausal erschließen, und die Verantwortlichkeit für den Lauf der Dinge verliert sich im fortgesetzten Rückverweis auf andere Mächte. Die transzendente Dimension, deren Verlust Calmon beklagt, bleibt auch in dieser Fiaba teatrale unbestimmt und offen. Calmon selbst spricht von *il cielo, e le stelle $*(I, 10)$, und »cielo* sowie »Numi werden von anderen Personen häufig bemüht, wenn sie sich aus dem Diesseits keine Hilfe mehr versprechen. Wie konventionalisiert und säkularisiert diese Anrufe sind, wird offensichtlich, wenn sich auch Barbarina in ihrem eitlen, ego-

96. -Tragedia greca - insofern, als es fast zu einem Inzest zwischen dem König Tartaglia und seiner Tochter Barbarina gekommen wäre. Schon im 4. Akt spielt Pantalone auf Ödipus an: sperchè, se nasce un matrimonio d'un pare, e d'una fia, le xe po de quelle tragedie da orbarse, come Edipo, da impiccarse per la gola al rampegon della crane, come una dindietta de grassa. $=($ IV, $s)$.

97 Ninetta prophezeit das Vögelchen: Se i tuoi Gemelli vincono i perigli tremendi, / Tu dall'immonda fossa l'usato trono ascendi; / Perisce Tartagliona; io lascio queste spoglie, / Se Barbarina è forte, e la prendo per moglie. / $\mathrm{Ma}$, oh Dio, ch'io son forzato ad esserle avversario.e $(1,7)$.

$\mathrm{Vgl}$. Cherestanis Klage uber das ihr auferlegte und aufgezwungene Handeln in La donna serpente, II, 5 . 
istischen Streben nach dem singenden Apfel und dem tanzenden Wasser an Himmel und Götter wendet:

Ho vinto, Smeraldina. Al Ciel si mandino

Preci divote. Ricchi sacrifizj

Faremo ai Numi. I Numi la mia brama

Appagheranno, e non vorran, ch'io resti

Mortificata, e i di meni funesti. (III, IO)

Als entscheidend erweist sich in den Fiabe teatrali die Erfahrung, daß das Dasein wissens- und verstandesmäßig allein nicht zu bewältigen ist, daß in ihm vielmehr undurchschaubare, übernatürliche Kräfte wirken, wo auch immer deren Ursprünge liegen mögen, bei den Göttern, im Himmel, bei den Sternen oder im Schicksalsbuch. Das Märchenhaft-Wunderbare fordert neben dem rational Erfaßbaren unmißverständlich Raum und Respekt und stellt damit nicht die Vernunft an sich, sondern ihre Alleinherrschaft in Frage.

Unter einer ganz anderen Perspektive macht L'augellino belverde auch deutlich, welche Bedeutung Verstand und Vernunft im gesellschaftlichen Kontext zukommt, und wie sehr sie innerweltlich gefährdet sind. So setzen etwa die Fixierung Renzos und Barbarinas auf das Prinzip des - amor proprio* und seine Verabsolutierung den gesunden Menschenverstand außer Kraft und lassen alles Handeln unterschiedslos und a priori als Folge der Selbstliebe erscheinen. Neben der Gefährdung der Vernunft durch den blinden Glauben an ein Prinzip oder System weist Calmon auf die Bedrohung des Verstandes durch die Vorrangigkeit der sinnlichen Wahrnehmung hin, wie sie im Sensualismus vorliegt (•ragione/Schiava de'sensiø; 1,10 ). In einer Art Vorahnung der Dialektik der Aufklärung nimmt Gozzi eine polemische Umkehrung des aufklärerischen Fanatismus-Urteils vor. Bekämpft die Aufklärung im Namen der Vernunft die Unvernunft, wobei nalles, was man nicht versteht oder nicht anerkennt $\alpha$, mit den Begriffen des Vorurteils oder des Fanatismus gedeutet und bekämpft wird, ${ }^{98}$ stellt Gozzi in der *fiaba filosofica a aufklärerische Positionen in ihrer Einseitigkeit als Unvernunft beziehungsweise Fanatismus bloß und weist damit auf die Relativität der Perspektiven hin. Über diese »philosophischen« Angriffe auf die Souveränität der menschlichen Ratio

\footnotetext{
Vgl. Werner Schneiders, Anfklarung und Vorurteilskritik, op, cit, S. i7: *Der Begriff -Vorurteila wird zu einem Schlüsselbegriff, zu einem universal brauchbaren Erklarungsmittel, mit dessen Hilfe man alles, was man nicht versteht oder nicht anerkennt, disqualifizierend deuten und bekämpfen kann. - Zur Umkehrung des Fanatismus-Vorwurfs im Hinblick auf das Theater, s. C. Alberti, $\rightarrow$ Il grano e la zizania. Carlo Gozzi giudica la scena europea di fine Settecentos, in: Carlo Gozzz. Letteratura e musica, op. cit., S. $91-118$, hier S, $98 \mathrm{ff}$.
} 
hinaus wird die verheerende Wirkung der nicht-vernūnftigen Liebe augenfällig. Renzo, der als Konsequenz aus dem «amor proprio « auf jede Art von Liebe und Freundschaft verzichten wollte, entbrennt in heißer Liebe zu einer Statue und ließe am liebsten Zauberer vom Ende der Welt kommen, um diese zum Leben zu erwecken. ${ }^{99}$ Damit durchbricht Renzo seinen eigenen Vorsatz auf eine Art, die jeder Vernunft spottet; er ist sich selbst der *Unmöglichkeit « der Situation bewußt und ist ihr doch machtlos ausgeliefert. ${ }^{100} \%$ Qual forza ha mai ragione / Sull'alme innamorate? * (III, I4) singt einer der Zauberäpfel, als Renzo sich mit Gewalt eines Zauberapfels und des Zauberwasser bemächtigen will. Wie das Prinzip des samor proprio wird auch Renzos Liebe zur Statue Pompea und Barbarinas Begehren nach den Zauberdingen zur Obsession, die die Vernunft bedroht. Allerdings zeichnet sich die "philosophische $\mathrm{Obsession}$ dadurch aus, daß sie unter dem Vorzeichen der Vernünftigkeit und Rationalität propagiert wird und ihre Unvernünftigkeit erst enthüllt werden muß.

Im Zentrum der »fiaba filosofica* steht weniger die Auseinandersetzung mit einem philosophischen Konzept als vielmehr mit dem Fanatismus der modernen, selbsternannten * filosofi «, was Calmon deutlich zum Ausdruck bringt: "Filosofia v'è ben, ma non Filosofo.« (I, ro). Die Kontraste auf der Figurenebene - zwischen den Zwillingen und Smeraldina, zwischen Renzo und Calmon, zwischen Smeraldina und Truffaldino - werfen ein grelles Licht auf die unbeugsame Haltung Renzos und Barbarinas und machen zugleich mögliche Alternativen sichtbar. ${ }^{101}$ Auf der Geschehensebene manifestiert sich der erhellende Kontrast zwischen dem ersten Akt, in dem die Zwillinge als arme Stiefkinder auftreten, und den weiteren, in denen sie märchenhaft reich geworden sind und einen Palast bewohnen. In dieser betont wirklichkeitsfernen Sphäre erweist sich das, was anfangs zwingende, unumstößliche Wahrheit schien, als null und nichtig, ja verkehrt sich ins Gegenteil. An sich selbst erfahren Renzo und Barbarina, daß ihre Überzeugungen der * Wirklichkeit « nicht standhalten können.

99 „Or chi direbbe, / Che 'l sprezzator sdegnoso d'ogni Donna / Caduto fosse in un'amor si ardente / Per una Donna da scarpello industre / D'una pietra formata? Ah, tu 'I dicesti / Calmon, che debolezza in uman core / $\overrightarrow{\mathrm{E}}$ grande troppo, e che fra pochi istanti / Io proverei, qual forza abbia una Statua. / Vaglia questi tesori. Io da' confini / Farò venir del mondo Negromanti, / Che diano vita al Simulacro amato. / L'oro puó tutto; disperar non deggio.* (III, 4).

100 Fast grotesk wirkt die Szene, in der Pompea als Statue mit Kleidern versehen ist, die Renzo ihr aus Eifersucht angezogen hat: Q Quelle ricehe vesti, / Donde le belle membra ricopersi, / Effetto son di gelosia crudele, / Ch'altri, mirando tua bellezza intera, / Nella felicitade a me s'uguagli.a (IV, 1 ).

101 Calmon repräsentiert unter diesem Blickwinkel die philosophisch-ideologische Alternative, Smeraldina die des gesunden Menschenverstandes, und Truffaldino führt eine konsequent zu Ende gedachte, ins Groteske gehende Variante des samor proprio vor. 
Indem gerade die märchenhafte, mit allen Attributen des Nicht-Wirklichen versehene Sphäre die Wahrheit, das heißt die Labilität beziehungsweise Hinfalligkeit der vermeintlichen Gewißheit enthüllt, bedient sich Gozzi in seiner "fiaba filosofica* eines Verfahrens, das dem einer narrativen Gattung der Aufklärung ähnlich ist: dem *conte philosophique «. Die "fiaba filosofica wie der "conte philosophique stehen im Zeichen des $»$ Dilemmas von System und Erfahrungswirklichkeit «, in beiden wird -eine philosophische Lehre nicht etwa popularisiert und propagiert, sondern problematisiert « ${ }^{102}$ so daß die ungewöhnliche Bezeichnung des Stücks als * fiaba filosofica a sicher nicht zufällig ist, sondern bewußt, mit leiser Ironie gewählt für ein neinmaliges « dramatisches Pendant zur narrativen Gattung. Erzählung wie Theaterstück liegen eine Belehrung fern, vielmehr zeigen sie in indirekter Weise und auf vergnügliche Art Wesentliches auf, was weltanschauliche Systeme aufgrund ihrer Geschlossenheit und Einsinnigkeit ausklammern oder an den Rand drängen, führen Problematisches vor Augen, das in direkter Weise nicht zur Sprache kommt.

Nicht zuletzt illustriert L'angellino belverde Gozzis auf einer indirekten, amimetischen Darstellungweise beruhende Theaterkonzeption, die in der Illusion, im Märchenhaften die Wahrheit und das Wesentliche aufscheinen läßt. In der s fiaba filosofica* ist die theatrale Wirklichkeit gedoppelt; was die normale, "wirkliche" Umgebung im ersten Akt nicht vermag, nämlich die Zwillinge von der Unsinnigkeit ihrer Ansicht zu überzeugen, gelingt in der dezidiert wirklichkeitsfernen Märchensphäre. In L'augellino belverde ist diese allerdings so unwahrscheinlich und tendiert derart ins Extreme, daß auch die Wahrheit, die sie enthüllt, als wenig wahrscheinlich erscheint. So wird in einer doppelten Reflexion die Problematik der Erkenntnis von Wahrheit theatralisch in Szene gesetzt. Die betont artifizielle Gestalt der Bühnenwirklichkeit, die in Raum und Dauer auf das Theaterereignis begrenzt ist und im üblichen beifallheischenden *commiato « verabschiedet wird, wirft auch ein Licht auf den KonstruktCharakter der vermeintlich vorgegebenen Wirklichkeit außerhalb des Theaters. Unterwirft sich die Vernunft diesem unmittelbar Vorfindlichen, gehen andere Dimensionen von Wirklichkeit verloren, und es siegt das "Programm der Aufklärung [...], die Entzauberung der Welt $\times .{ }^{103}$ Dagegen spielen Gozzis Fiabe teatrali mit Märchen und Masken an.

10: R. Warning, -Diderot. Jacques le fataliste et son maîtreø, in: Klaus Heirmann (Hg.), Der französische Roman. Vom Mittelalter bis zur Gegenwart, Bd. 1, Düsseldorf, August Bagel 1975, S. $210-233$, hier S. 232.

103 Max Horkheimer, Theodor W. Adorno, Dialektik der Aufkläung. Philosophische Fragmente, Frankfurt am Main, Fischer 1988, S. 9. 



\section{LITERATURVERZEICHNIS}

\section{Primärtexte}

Anon., Riflessioni critiche sopr'alcune proposizioni trovate nel libro intitolato Il genio ed i costumi del secolo corrente, Venezia, Bassanese 1762.

Atti degli Accademici Granelleschi, Dezember 1760, Januar 1761.

Baretti, Giuseppe, Discours sur Shakespeare et sur Monsieur de Voltaire. Nachdruck des Originals (1777), Hg. Francesco Biondolillo, Lanciano, Carabba I911.

- La frusta letteraria, Hg. Luigi Piccioni, 2 Bde., Bari, Laterza 1932.

- Les Ttaliens, ou Maurs et coutumes d'Italie. Ouvrage traduit de l'Anglais de M. Baretty, Genève 1773 [Account of the Manners and Customs of Italy, London 1768 ].

Basile, Giambattista, Lo cunto de li cunti, Hg. Michele Rak, Milano, Garzanti I986.

Beaumarchais, Pierre-Augustin Caron de, Euvres, Hg. Pierre Larthomas unter Mitarbeit von Jacqueline Larthomas, Paris, Gallimard 1988.

Bettinelli, Saverio, Le Raccolte, con il Parere dei Granelleschi e la Risposta di C. Gozzi, Hg. Pietro Tommasini-Mattiucci, Città di Castello, Lapi 1912.

- Lettere virgiliane, Hg. Pietro Tommasini-Mattiucci, Città di Castello, Lapi 1913.

- Lettere virgitiane e inglesi e altri scritti critici, Hg. Vittorio Enzo Alfieri, Bari, Laterza 1930.

Bordoni, Placido, Nuovo segreto per farsi immortale un poeta nelle gazzette, Venezia 1760.

Calepio, Pietro de' Conti di, Paragone della poesia tragica d'Italia con quella di Francia, e sua difesa, con l'apologia di Sofocle, Venezia, Zatta 1770.

Caminer, Domenico, Rezension zu $1 /$ burbero benefico in L'Europa letteraria, in: Giomali veneziani del Settecento, Hg. Marino Berengo, Milano, Feltrinelli 1962, S. $357-361$.

Caminer, Elisabetta, Composizioni teatrali moderne tradotte, 2. Aufl., 4 Bde., Venezia, Savioli 1774.

- Nuova raccolta di composizioni teatrali tradotte, 6 Bde., Venezia, Savioni $1774^{-1776}$

Carli, Gian Rinaldo, Dell'indole del teatro tragico antico, e moderno, in: Opere, Bd. 17, Milano 1787 .

Cesarotti, Melchiorre, Il Cesare e Il Maometto. Tragedie del Signor di Voltaire trasportate in versi italiani con alcuni ragionamenti del traduttore, Venezia, Pasquali 1762.

Chiari, Pietro, Commedie da camera ossia Dialoghi familiari, 2 Bde., Venezia, Battifoco $1770-1771$.

- Commedie in versi, 10 Bde., Venezia, Bettinelli 1756-1762. 
- Il festino d'Amore. Per le solenni nozze di S. E. la N.D. Maria Venier, con S. E. il N. H. Pietro Contarini. Ottave dell'abate Pietro Chiari, Poeta di S. A. il Sig. Duca di Modena, s.n.t.

- Il genio ed i costumi del secolo corrente. Riflessioni critiche e filosofiche tradotte dal francese, ed accresciute, Venezia, Novelli $176 \mathrm{r}$.

- La filosofia per tutti, Venezia, Pasinelli 1756.

- La mascherata degli dei, Venezia, Coleti 1759.

- Lettere scelte di varie materie piacevoli, critiche, ed erudite, 3 Bde., Venezia, Pasinelli $1750-52$.

- Nuova raccolta di commedie in versi, 2 Bde., Venezia, Pasinelli 1763.

- Poesie e prose italiane e latine, 3 Bde., Venezia, Pasinelli 1761.

- Raccolta di prologhi in versi alle sue commedie recitate in Venezia e altrove, cominciando dall'anno 1753 , Venezia, Pasinelli 1754.

De Rossi, Gherardo, Del moderno teatro comico italiano, e del suo restauratore Carlo Goldoni, Bassano 1774.

Della vera poesia teatrale. Epistole poetiche di alcuni letterati modanesi dirette al Signor Abate Pietro Chiari colle risposte del medesimo, Modana 1754.

Fagiuoli, Giovan Battista, Commedie, 7 Bde., Venezia, Geremia 1753.

- La commedia che non si fa, Hgg. Orietta Girardi, Maria Russo, Roma, Bulzoni 1994.

Farsetti, Daniele, Memorie dell'Accademia Granellesca, in: Nuova raccolta di operette italiane in prosa ed in verso inedite o rare, Bd. 14 , Treviso 1795.

Federici, Camillo, L'avventuriere notturno, Venezia 1796.

Gigli, Girolamo, Don Pilone ovvero Il bacchettone falso, s.n.t.

Gli scenari Correr. La commedia dell'arte a Venezia, $\mathrm{Hg}$. Carmelo Alberti, Roma, Bulzoni r996.

Goethe, Johann Wolfgang, "Campagne in Frankreich «, in: Werke. Hamburger Ausgabe, Bd. 10, München, Deutscher Taschenbuch Verlag 1982.

Goldoni, Carlo, Mémoires, Hg. Norbert Jonard, Paris, Aubier 1992.

- Tutte le opere, Hg. Giuseppe Ortolani, 14 Bde., Milano, Mondadori 1935 56.

Gozzi, Carlo, Fiabe teatrali, Hg. Alberto Beniscelli, Milano, Garzanti 1994.

- Fiabe teatrali, Hg. Paolo Bosisio, Roma, Bulzoni 1984.

- Fiabe, Hg. Ernesto Masi, 2 Bde., Bologna, Zanichelli 1884.

- Fogli sopra alcune massime del genio e costume del secolo dell'abate Pietro Chiari e contro a' Poeti Nugnez de' nostri tempi, Venezia, Colombani 1761.

- I sudori d'Imeneo, Venezia, Zatta 1759.

- Il Fajel, tragedia del Sig. D'Arnaud tradotta in versi sciolti, Venezia, Colombaní 1772 .

- Il ragionamento ingenuo, $\mathrm{Hg}$. Alberto Beniscelli, Genova, Costa \& Nolan 1983 .

- Le spose riacquistate. Poema giocoso di Carlo Gozzi, Daniele Farsetti e Sebastiano Crotta con gli argomenti di Gasparo Gozzi, accademici Granelleschi, Hg. D. Pietro Bettio, Venezia, Alvisopoli 18 I9.

- Lettere, Hg. Fabio Soldini, Venezia, Regione del Veneto, Marsilio 2004.

- Manifesto del Cittadino Carlo Gozzi, Venezia, Palese 1797.

- Manifesto del Co: Carlo Gozzi, dedicato a' magnifici Signori Giomalisti, Pre- 
fattori, Romanzieri, Pubblicatori di manifesti, e Foglivolantisti dell'Adria, s.t.n.

- Memorie inutili della vita di Carlo Gozzi scritte da lui medesimo e pubblicate per umiltà, Hg. Giuseppe Prezzolini, z Bde., Bari, Laterza 1910.

- Opere, ro Bde., Bd. 1-8, Venezia, Colombani $1772-1774$; Bd. 9, Venezia, Foglierini 1787 ; Bd. 10, Venezia, Curti e Vitto 1792.

- Opere, Teatro e polemiche teatrali, Hg. Giuseppe Petronio, Milano, Rizzoli 1962.

- Opere edite ed inedite, 14 Bde., Venezia, Zanardi 1801-1803.

- Opere edite ed inedite non teatrali, Bd. 1, Venezia, Zanardi 1805.

- Parere o sia lettera scritta da un'amico del Friuli, ad un'amico di Venezia, sopra il poemetto intitolato Le raccolte, con la risposta dell'amico di Venezia all'amico del Friuli, Venezia $175^{8}$.

- Scritti inediti di Carlo Gozzi, $\mathrm{Hg}$. Ferdinando Galanti, in: Atti del reale Istituto veneto di scienze, lettere ed arti $4,188,-86$, S. I $20 \mathrm{I}-1215$ und $\mathrm{r}_{3} 19-$ 1346.

Gozzi, Gasparo, La gazzetta veneta, Hg. Antonio Zardo, Firenze, Sansoni 1915.

- Lettere, Hg. Fabio Soldini, Parma, Ugo Guando 1999.

- L'osservatore veneto, $\mathrm{Hg}$. Noris Raffaelli, 3 Bde., Milano, Rizzoli 1965.

Gravina, Gian Vincenzo, Opere italiane: Della ragion poetica e Della tragedia, unverànderter Nachdruck der Ausgabe Venezia 173 I, Roggiano Gravina, Cosenza 1992.

Griselini, Francesco, Il marito dissoluto, Venezia, Bassaglia 1752.

Gritti, Francesco, Teatro tragico francese ad uso de' teatri d'Italia ovvero Raccolta di versioni libere di alcune tragedie francesi, Venezia 1776.

Maffei, Scipione, De' teatri antichi e moderni e altri scritti teatrali, $\mathrm{Hg}$. Laura Sannia Nowé, Modena, Mucchi 1988.

- Teatro italiano o sia scelta di tragedie per uso della scena, premessa una Istoria del teatro e difesa di essa, Verona, Vallardi $1723-1725$.

Martello, Pier Jacopo, Scritti critici e satirici, Hg. Hannibal S. Noce, Bari, Laterza 1963.

- Teatro, Hg. Hannibal S. Noce, 3 Bde., Roma, Laterza r980-1982.

Milizia, Francesco, Trattato completo, formale e materiale del teatro, unveränderter Nachdruck der Ausgabe Venezia, Pasquali 1794, Bologna, Forni 1969.

Muratori, Ludovico Antonio, Della forza della fantasia umana, $\mathrm{Hg}$. Claudio Pogliano, Firenze, Giunti 1995.

- Della perfetta poesia italiana spiegata e dimostrata con varie osservazioni, $\mathrm{Hg}$. Anton Maria Salivini, 4 Bde., Milano, Società tipografica dei classici italiani 1821 .

Nelli, Jacopo Angelo, La dottoressa preziosa, commedia, Milano, Angelli, s.t.

Orsi, Gian Giuseppe, Considerazioni del Marchese Giovan Gioseffo Orsi bolognese sopra la, Maniera di Ben Pensare ne' Componimenti già pubblicata dal Padre Domenico Bouhours della Compagnia di Gesú, Modena, Sogliani 1735 .

Perrucci, Andrea, Dell'arte rappresentativa premeditata ed all'improvviso, $\mathrm{Hg}$. Anton Giulio Bragaglia, Firenze, Sansoni antiquariato 1961. 
Pétis de la Croix, François, Les mille et un jour. Contes persans, s Bde., Paris, Vve Riccur $1710-1712$.

- Les mille et un jours, contes persans, Hg. Paul Sebag, Paris, Christian Bourgois Editeur 1980.

Piazza, Antonio, Giulietta ovvero il seguito dell'Impresario in rovina, Venezia, Gatti 1784 .

Riccoboni, Luigi, Discorso della commedia all'improvviso e scenari inediti, $\mathrm{Hg}$. Irene Mamczarzs, Milano, Il Polifilo r 973.

- Histoire du théâtre italien, 2 Bde., Paris $1730-1731$.

Sanguineti, Edoardo, L'amore delle tre melarance, un travestimento fiabesco dal canovaccio di Carlo Gozzi, Teatro di Genova, Genova, il melangolo 200r.

Scala, Flaminio, Il teatro delle favole rappresentative, $\mathrm{Hg}$. Ferruccio Marotti, 2 Bde., Milano, Il Polifilo 1976.

Schiller, Friedrich, * Tragödie und Comödie «, in: Werke, Nationalausgabe Bd. 21 / 2, Hg. Benno von Wiese, Weimar, Böhlaus Nachfolger 1963, S. $91-93$.

Schlegel, August Wilhelm, *Vorlesungen über dramatische Kunst und Literatur. Erster Teilø, in: ders., Kritische Schriften und Briefe, Bd. 5, Hg. Edgar Lohner, Stuttgart u, a., Kohlhammer 1966.

Soffolto Planomaco, Arte senza regole per rendere immortale un poeta fuori delle gazzette, e nelle gazzette, s.n.t.

Tieck, Ludwig, Der gestiefelte Kater. Ein Kindermärchen in drei Akten mit Zwischenspielen, einem Prologe und Epiloge, Stuttgart, Reclam 1984.

Tutti $i$ Trionfi, Mascherate, o Canti carnascialeschi andati per Firenze dal tempo del Magnifico Lorenzo de' Medici fino all'anno I559, 2 Bde., 2. Aufl., Cosmopoli, Passerio 1750.

Valaresso, Zaccaria, Rutzvanscad il Giovine, Venezia, Rossetti 1724.

Verri, Pietro, La vera commedia, [Midonte Priamideo], s.n.t.

\section{Forschungsliteratur}

Alberti, Carmelo (Hg.), Carlo Gozzi, scrittore di teatro, Roma, Bulzoni 1996.

- Gare e contrasti tra due spoeti comicis negli anni 1753-1756", in: Carmelo Alberti; Ginette Herry (Hgg.), Tra libro e scena. Carlo Goldoni, Venezia, Il Cardo 1996, S. 61-Ior.

- Goldoni, Roma, Salerno 2005 .

- Il declino delle maschere. Drammi flebili e commedie serio-facete oltre le favole teatrali\&, in: Carlo Gozzi, scrittore di teatro, $\mathrm{Hg}$. Carlo Alberti, Roma, Bulzoni 1996, S. $215-271$.

- -Il grano e la zizaniac. Carlo Gozzi giudica la scena europea di fine Settecento“, in: Bodo Guthmüller; Wolfgang Osthoff (Hgg.), Carlo Gozzi. Letteratura e musica, Roma, Bulzoni 1997, S. 91-1 18.

- Introduzionee, in: ders. (Hg.), Pietro Chiarie il teatro europeo del Settecento, Vicenza, Neri Pozza 1986, S. 1 i -36 .

- La scena veneziana nell'età di Goldoni, Roma, Bulzoni 1990. 
- (Hg.), Pietro Chiari e il teatro europeo del Settecento, Vicenza, Neri Pozza 1986.

-; Pizzamiglio, Gilberto (Hgg.), Carlo Goldoni 1793-1993. Atti del Convegno del Bicentenario, Venezia, Regione del Veneto 1995.

Anglani, Bartolo, -Dal genio al destino. Le prefazioni, le dediche e l', altrar autobiografia e, in: Ariel 7, 3, 1992, S, 17-40.

Auzza, Ginetta, =Gallomania e anglomania, in: Girolamo Arnaldi; Manlio Pastore Stocchi (Hgg.), Storia della cultura veneta $5 / 1$, Il Settecento, Vicenza, Neri Pozza 1985, S. 579-606.

Baratto, Mario, $=$ La letteratura teatrale del Settecento in Italia*, in: ders., Studie letture su Carlo Goldoni, Vicenza, Neri Pozza 1985 , S. 11 -32.

Barberi Squarotti, Giorgio, =Le Fiabe di Carlo Gozzia, in: Egidio Del Boca $(\mathrm{Hg})$, Scritti in onore di Franco Falletti, Vercelli, Collegio Dal Pozzo I983, S. $69-99$.

Battagia, Michele, Delle Accademie veneziane, Venezia, Picotti r 826.

Bauer-Funke, Cerstin, =Dramaturgische Kreativität. Theaterdichter des 18 . Jahrhunderts dramatisieren scontes moraux von Jean-Francois Marmontele, in: Perry Reisewitz ( $\mathrm{Hg}$.), Kreativität, Bonn, Romanistischer Verlag 1997, S. 23-34.

Bédarida, Paul, »Quelques écrivains français à Venise au XVIIIe siècle «, in: Studi in onore di Vittore Lugli e Diego Valeri, Bd. I, Venezia, Neri Pozza 1961, S. $53-82$.

Beniscelli, Alberto, „Goldoni nello specchio di Gozzi: divergenze e incontri tra drammaturgia e scena , in: Elena Sala Di Felice; Laura Sannia Nowé (Hgg.), La cultura fra Sei e Settecento, Modena, Mucchi 1994, S. 197-2 ro.

- Introduzione a Carlo Gozzi: La Marfisa bizzarra, tra pamphlet e teatroe, in: La rassegna della letteratura italiana 83,1979, S. $225^{-244}$.

- La dilogia di Bettina nelle pagine critiche di Carlo Gozzi*, in: Carlo Goldoni, La buona moglie, Genova, Edizioni del Teatro di Genova r987, S. $4^{8-68}$.

- La finzione del fiabesco. Studi sul teatro di Carlo Gozzi, Casale Monferrato, Marietti 1986.

- (Hg.), Naturale e artificiale in scena nel secondo Settecento, Roma, Bulzoni I997.

Berengo, Marino ( $\mathrm{Hg}$.$) , Giomali veneziani del Settecento, Milano, Feltrinelli$ 1962.

Bergson, Henri, Le rire, 7. Aufl., Paris, PUF 1993.

Bosisio, Paolo, Carlo Gozzi e Goldoni. Una polemica letteraria con versi inediti e rari, Firenze, Olschki 1979.

- "Gli autografi di Re Cervo a, in: $A C M E$, Annali della Facoltà di lettere e Filosofia dell'Università degli Studi di Milano 36, 1,1983, S. $61-146$.

Brocchi, Virgilio, $" \mathrm{La}$ polemica a teatrox, in: Rivista d'Italia, Mai 1907, S. 723742 .

Bruni, Arnaldo, $\rightarrow$ La polemica antiilluministica del Sognatore italiano $\alpha$, in: Studi e problemi di critica testuale 14,1977, S. 61-1 10.

Brusatin, Manlio (Hg.), Venezia e lo spazio scenico, Venezia, Edizioni $*$ La Biennale di Venezia * 1980.

Calvino, Italo, Sulla fiaba, Milano, Mondadori 1996.

Cambiaghi, Mariagabriella (Hg.), Studi gozziani, Milano, CUEM 2006. 
Campra, Rosalba, -Il fantastico: una isotopia della trasgressione «, in: Strumenti critici 45,1981, S. 199-231.

Cappelletti, Salvatore, $\times$ Dalla commedia dell'arte alla commedia borghese: Luigi Riccoboni e la sua riforma del teatro*, in: Forum Italicum 14, 1980, S. $175^{-}$ 194 .

Cassirer, Ernst, Die Philosophie der Aufklärung, Hamburg, Meiner 1998.

Cecchi, Emilio; Sapegno, Natalino (Hgg.), Storia della letteratura italiana, Bd. 3: Il Quattrocento e l'A riosto, Milano, Garzanti 1966.

Colagrosso, Francesco, Un'usanza letteraria in gran voga nel Settecento, Firenze, Le Monnier 1908.

Cozzi, Gaetano, *Note su Carlo Goldoni, la società veneziana e il suo diritto «, in: Atti dell'Istituto veneto di scienze, lettere ed arti $137,1978-79$, S. $141-157$.

Crotti, Ilaria, $\gg$ Bettinelli e Goldoni, da Venezia alla luna , in: Ilaria Crotti; Ricciarda Ricorda (Hgg.), Saverio Bettinelli: un gesuita alla scuola del mondo, Roma, Bulzoni 1998 , S. $217-245$.

-; Ricorda, Ricciarda (Hgg.), Gasparo Gozzi. Il lavoro di un intellettuale nel Settecento veneziano, Padova, Antenore 1989.

-; Ricorda, Ricciarda (Hgg.), Saverio Bettinelli: un gesuita alla scuola del mondo, Roma, Bulzoni 1998.

Delon, Michel, Artikel »Bonheur*, in: ders. (Hg.), Dictionnaire européen des Lumières, Paris, PUF 1997, S. I65-167.

- Crise ou tournant des Lumières? ?a, in: Werner Schneiders ( $\mathrm{Hg}$.), Aufklarung als Mission/La mission des Lumières. Akzeptanzprobleme und Kommunikationsdefizite/Accueil réciproque et difficultés de communication, Marburg, Hitzeroth 1993, S. $83 \rightarrow 90$.

De Michelis, Cesare, "La scoperta del pubblico*, in: ders., Letterati e lettori nel Settecento veneziano, Firenze, Olschki 1979, S. 7-35.

Deupmann, Christoph, Furor satiricusc. Verhandlungen über literalische Aggression im 17. und I8. Jahrhundert, Tübingen, Niemeyer 2002.

Di Francia, Letterio, - Il mostro turchinos, in: Giornale storico della letteratura italiana 103,1934, S. 27-54.

Dieckmann, Herbert, Die Wandlung des Nachahmungsbegriffes in der französischen Ästhetik des 18. Jahrhunderts a, in: Hans Robert Jauss (Hg.), Nachahmung und Illusion, 2. Aufl., München, Fink 1969, S. 29-59.

Dooley, Brendan, Le accademiec, in: Girolamo Arnaldi; Manlio Pastore Stocchi (Hgg.), Storia della cultura veneta $5 / 1$, Il Settecento, Vicenza, Neri Pozza 1985, S. $77-90$.

Elwert, W. Theodor, $*$ Venedigs historische Bedeutung. Ein bibliographischer Versuch ", in: Archiv für Kulturgeschichte 36, 3, 1954, S. 261-300.

Fabrizi, Angelo, "Carlo Gozzi e la tradizione popolare: a proposito dell'Amore delle tre melarance «, in: Italianistica 7, 1978, S. 336-345.

Fasano, Pino, L'utile e il bello. Le transizioni delle forme letterarie alle soglie dell'era borghese, 2. Aufl., Napoli, Liguori 1996.

Feldmann, Helmut, Die Fiabe Carlo Gozzis. Die Entstehung einer Gattung und ihre Transposition in das System der deutschen Romantik, Köln, Wien, Böhlau 1971 . 
Fido, Franco, Guida a Goldoni, Teatro e società nel Settecento, Torino, Einaudi 1977.

Fischer-Lichte, Erika, *Grenzgänge zwischen den Welten - Vachtangovs Inszenierung der Prinzessin Turandot (1922)*, in: Franz Norbert Mennemeier; Erika Fischer-Lichte (Hgg.), Drama und Theater der europätschen Avantgarde, Tübingen, Basel, Francke 1994, S. 317-340.

- Semiotik des Theaters. Eine Einführung, Bd. 1, Das System der theatralischen Zeichen, Tübingen, Narr 1983 .

Finné, Jacques, La littérature fantastique. Essai sur l'organisation surnaturelle, Bruxelles, Edition de l'Université de Bruxelles 1980.

Fubini, Mario, Dal Muratori al Baretti, 2 Bde., 2. uberarbeitete und erweiterte Auflage, Roma, Bari, Laterza r975.

Galletti, A., Le teorie drammatiche e la tragedia in Italia nel Secolo XVIII, Cremona, Fezzi i 90 r.

Garbero Zorzi, Elvira, =Intorno ai manoscritti di Carlo Gozzi $\alpha$, in: Chigiana 31 , 1976, S, $233-246$.

Gozzi, Carlo, La donna serpente, Genova, Edizioni del Teatro di Genova 1979.

Gozzi, Carlo, Re cervo, Teatro di Genova, Genova, Marietti 199r.

Graf, Arturo, L'anglomania e I'influsso inglese in Italia nel secolo XVIII, Torino, Loescher 1911.

Greimas, Algirdas Julien, Sémantique structurale, Paris, Larousse 1966.

Greiner, Bernhard, Die Komódie, Tübingen, Francke 1992.

Grewe, Andrea, Monde renversé - Théâtre renversé. Lesage und das Théâtre de la Foire, Bonn, Romanistischer Verlag r989.

Guagnini, Elvio, "Sul Bettinelli singleser", in: Ilaria Crotti; Ricciarda Ricorda (Hgg.), Saverio Bettinelli: un gesuita alla scuola del mondo, Roma, Bulzoni 1998, S. $149-163$.

Guccini, Gerardo, =Dall'innamorato all'autore. Strutture del teatro recitato a Venezia nel XVIII secolo«, in: Teatro e Storia 2, 1987, S. $251-293$.

- (Hg.), Il teatro italiano nel Settecento, Bologna, Mulino 1988.

Guichemerre, Roger, La tragi-comédie, Paris, PUF $198 \mathrm{I}$.

Guthmüller, Bodo; Osthoff, Wolfgang (Hgg.), Carlo Gozzi. Letteratura e musica, Roma, Bulzoni r997.

Gutiérrez Carou, Javier, Carlo Gozzi. La vita. Le Opere. La critica. Con un inedito componimento in veneziano, Venezia, Supernova 2006.

Habermas, Jürgen, Strukturwandel der Offentlichkeit, mit einem Vorwort zur Neuauflage 1990, Frankfurt am Main, Suhrkamp 2001.

Hempfer, Klaus W., $*$ Allegorie als interpretatives Verfahren in der Renaissance: Dichterallegorese im 16. Jahrhundert und die allegorischen Rezeptionen von Ariosts Orlando furioso*, in: Klaus W. Hempfer; Enrico Straub (Hgg.), Italien und die Romania in Humanismus und Renaissance, Wiesbaden, Steiner 1983 , S. $51-75$.

- Textkonstitution und Rezeption: Zum dominant komisch-parodistischen Charakter von Pulcis Morgante, Boiardos Orlando Innamorato und Ariosts Orlando Furioso *, in: Romanistisches Jabrbuch 27, 1976, S. 77-99.

Herry, Ginette, $>1756-1758$ : Venezia a teatro ossia Carlo Gozzi prima di Carlo 
Gozzia, in: Carmelo Alberti (Hg.), Carlo Gozzi, scrittore di teatro, Roma, Bulzoni 1996, S. $33-82$.

Horkheimer, Max; Adorno, Theodor W., Dialektik der Aufklärung. Philosophische Fragmente, Frankfurt am Main, Fischer 1988.

Hunecke, Volker, Der venezianische Adel am Ende der Republik 1646-1797. Demographie, Familie, Haushalt, Tübingen, Niemeyer i995.

Jauss, Hans Robert, "Diderots Paradox über das Schauspiel", in: GRM 11, 1961, S. $380-413$.

Jolles, André, Einfache Formen. Legende, Sage, Mythe, Rätsel, Spruch, Kasus, Memorabilie, Märchen, Witz, 6. unveränderte Aufl., Tübingen, Niemeyer 1982 .

Joly, Jacques, * La Turandot de Carlo Gozzi<, in: E. Konigson (Hg.), Les voies de la création théâtrale 8, Paris, CNRS 1980, S. 317-346.

Jonard, Norbert, La vie quotidienne à Venise au XVIII siècle, Paris, Hachette 1965 .

- "Les structures idéologiques de L'angellino belverde de C. Gozzia, in: Romanistische Zeitschrift für Literaturgeschichte /Cabiers d'Histoire des Littératures Romanes I, 1978, S. I-20.

Kinsella Hunter, Mead, Carlo Gozzi and his sTen Tales for the Theatre «, Ph.D. Thesis, University of California, Los Angeles, 1994.

Korthals, Holger, Zwischen Drama und Erzählung. Ein Beitrag zur Theorie geschehensdarstellender Literatur, Berlin, Erich Schmidt 2003.

Krômer, Wolfram, Die italienische Commedia dell'Arte, Darmstadt, WBG 1976.

Kuhn, Barbara, "Reflexion und Reprāsentation: Bilder, Körper, Namen in Gozzis Turandot *, in: Elisabeth und Joachim Leeker (Hgg.), Text - Interpretation - Vergleich. Festschrift für Manfred Lentzen, Berlin, Erich Schmidt 2005 , S. 378-394.

Léoni, Sylviane, Le poison et le remède. Théâtre, morale et rhétorique en France et en Italie 1694-1758, Oxford, Voltaire Foundation 1998.

Ley, Klaus, sNeue Kontexte zu La Locandiera. Goldonis Reformkomödie und ihre Bedeutung für Diderots drame bourgeois «, in: Franz Norbert Mennemeier (Hg.), Die großen Komödien Europas, Tübingen, Franke 2000, S. 121 -151.

Lucchesini, Paolo, $»$ Rimettere in scena G. B. Fagiuoli: un granducato in crisi sotto gli occhi del vecchio poeta", in: Quaderni di teatro, Il Teatro dell'Illuminismo III, 11 , 1981, S. $181-187$.

Luciani, Gérard, Carlo Gozzi (1720-1806). L’homme et l'auvre, 2 Bde., Lille, Atelier reproduction des thèses; Paris, Champion 1977.

- Carlo Gozzi o la ricerca di un rinnovamento del teatro comico a, in: Carmelo Alberti (Hg.), Carlo Gozzi, scrittore di teatro, Roma, Bulzoni 1996, S. 1332.

Luhmann, Niklas, Die Kunst der Gesellschaft, 2. Aufl., Frankfurt am Main, Suhrkamp 1998.

- Liebe als Passion. Zur Codierung von Intimität, 6. Aufl., Frankfurt am Main, Suhrkamp 1992.

Lüthi, Max, Märchen, bearbeitet von Heinz Rölleke, 9. durchgesehene und ergãnzte Aufl., Stuttgart, Metzler 1996. 
Magrini, Giovanni Battista, I tempi, la vita e gli scritti di Carlo Gozzi, aggiuntevi le sue annotazioni inedite alla Marfisa bizzarra, Benevento, De Gennaro 1883.

Malamani, Vittorio, La satira del costume a Venezia nel secolo XVIII, Torino, Napoli, Roux e Favale i 886.

Mangini, Nicola, $=$ Il teatro italiano fra Seicento e Settecento: primi tentativi di riforma , in: Italianistica 13, 1-2, 1984, S. $11-20$.

- Iteatri di Venezia, Milano, Mursia 1974.

- L'organizzazione teatrale a Venezia nel Settecento a, in: Ariel 1, 1, 1986, S. 5974.

- -Su due stopoi dell'autobiografia goldoniana Memorie di Goldoni e memoria del teatro, Roma, Bulzoni 1996, S. 23-34.

Marchi, Armando, sIl mercato dell'immaginario , in: Carmelo Alberti ( $\mathrm{Hg}$.), Pietro Chiari e il teatro europeo del Settecento, Vicenza, Neri Pozza 1986, S. $77^{-113}$.

Mariti, Luciano, Commedia ridicolosa. Comici di professione, dilettanti, editoria teatrale nel Seicento. Storia e testi, Roma, Bulzoni 1978.

Mariutti de Sanchez Rivero, A., Quattro spagnoli in Venezia, Venezia, Ongania 1957 .

Masi, Ernesto, Sulla storia del teatro italiano nel secolo XVIII, unveränderter Nachdruck der Edition Florenz 1891, Sala Bolognese, Forni 1989.

Massa, Jean-Michel, "Un canevas inédit de Carlo Gozziк, in: Revue des études italiennes 4 , 1957, S. 219-229.

Masseau, Didier, Les ennemis des philosophes. Lantiphilosophie au temps des lumières, Paris, Albin Michel 2000.

Mattioda, Enrico, Teorie della tragedia nel Settecento, Modena, Mucchi 1994.

Mazzucchelli, Giovanni Maria, Gli scrittori d'Italia, Brescia, Bossini 1753-63.

Momo, Arnaldo, La carriera delle maschere nel teatro di Goldoni, Chiari, Gozzi, Venezia, Marsilio 1992.

Moschini, Giannantonio, Della letteratura veneziana del secolo XVIII fino $a^{x}$ nostri giomi, Venezia, Palese 1806.

Napoli Signorelli, Pietro, Storia critica de' teatri antichi, e moderni, Napoli 1777.

Natali, Giulio, Il Settecento. Storia letteraria d'Italia, z Bde., 6. Aufl., Milano, Vallardi 1964 .

Neri, Ferdinando, Scenari delle maschere in Arcadia, Città di Castello, Lapi 1913.

Nolting-Hauff, Ilse, märchen und Märchenroman 4 , in: Poetica 6, 1974, S. 129179.

Ortolani, Giuseppe, La riforma del teatro nel Settecento e altri scritti, VeneziaRoma, Istituto per la collaborazione culturale I 962.

- Settecento. Per una lettura dell'abate Chiari. Studi e note, Venezia, Fondazione Cini 1905.

Padoan, Giorgio, *L'esordio di Goldoni: la conquista della moralità «, in: Lettere italiane $35,1,1983$, S. $29-60$.

- L'impegno civile di Carlo Goldoni ${ }^{-}$, in: Lettere Italiane 35, 1983 , S. 421 456. 
- "Venezia: Mondo e Teatro \&, in: Manlio Brusatin (Hg.), Venezia e lo spazio scenico, Venezia, Edizioni "La Biennale di Venezia* 1980, S. 37-42.

Pagnacco, Maria Luisa, *Squarzo degli utili del teatro per le recite relative degli Autunni e Carnovali 1758-1770\%, in: Carmelo Alberti; Ginette Herry (Hgg.), Tra libro e scena. Carlo Goldoni, Venezia, Il Cardo 1996, S. 103-119.

Paladini Volterra, Angela, *Verso una moderna produzione teatrale «, in: Quaderni di teatro V, 20, 1983 , S. $87^{-1} 44$.

Pandolfi, Vito, La commedia della'arte. Storia e testi, 6 Bde., Firenze, Sansoni 1957-1961.

Pavis, Patrice, Problèmes de sémiologie théâtrale, Montréal, Presses de l'Université du Québec 1976.

Pedrina, Francesco, L'Accademia Gozziana, Milano u.a., Albrichi, Segati \& C. 1925.

Peruzzi, Bianca, La polemica teatrale tra Carlo Goldoni e Carlo Gozzi. Unveröffentl. Tesi di laurea, Padova, anno accademico $1969 / 70$.

Plessner, Helmut, "Lachen und Weinen. Eine Untersuchung der Grenzen menschlichen Verhaltens«, in: ders., Ausdruck und menschliche Natur, Frankfurt am Main, Suhrkamp 2003, S. $201-387$.

Pregliasco, Marinella, "Il modello popolare nelle Fiabe di C. Gozzi: L'augellino belverde $\propto$, in: Atti dell'Istituto veneto di scienze, lettere ed arti $142,1983-84$. S. $427-446$.

Propp, Vladimir, Morphologie du conte, Paris, Seuil 1970.

Quinn, Michael L., sThe Comedy of Reference: The Semiotics of Commedia Figures in Eighteenth-Century Venices, in: Theatre Journal 43, 1, March 1991, S. $70-92$.

Rapp, Uri, Handeln und Zuschauen. Untersuchungen über den theatersoziologischen Aspekt in der menschlichen Interaktion, Darmstadt, Neuwied, Luchterhand 1973 .

Riccó, Laura, „Goldoni, Chiari, Gozzi fra scritto e non scritto , in: Problemi di critica goldoniana VI, Ravenna, Longo 1999, S. 7-67.

- Parrebbe un romanzoc. Polemiche editoriali e linguaggi teatrali ai tempi di Goldoni, Chiari, Gozzi, Roma, Bulzoni 2000.

Richards, Kenneth; Richards, Laura, The Commedia dell'Arte. A Documentary History, Oxford, Blackwell r990.

Ricorda, Ricciarda, "La Gazzetta Veneta di Pietro Chiari๔, in: Elena Sala Di Felice; Laura Sannia Nowé (Hgg.), La cultura fra Sei e Settecento, Modena, Mucchi 1994, S. $85-114$.

Romanin, Samuele, Storia documentata di Venezia, 3. Aufl., Bd.9, Venezia, Filippi 1975 .

Sanguineti, Edoardo, $*$ La donna serpente come fiaba $\propto$, in: Carlo Gozzi, La donna serpente, Genova, Edizioni del Teatro di Genova 1979, S. 13-24.

Santangelo, Giovanni Saverio; Vinti, Claudio, Le traduzioni italiane del teatro comico francese dei secoli XVII e XVIII, indagine bibliografica diretta da Marcello Spaziani, Roma, Edizioni di Storia e Letteratura $198 \mathrm{I}$.

Scannapieco, Anna, "Alla ricerca di un Goldoni perduto: Osmano re di Tunisia, in: Quaderni veneti 20, 1994, S. 9-53.

- Carlo Gozzi: la scena del libro, Venezia, Marsilio 2006. 
- -Su Goldoni e Gozzi: cantieri aperti, tra ieri e domani*, in: Susanne Winter ( $\mathrm{Hg}_{\mathrm{g}}$ ), Il mondo e le sue favole. Sviluppi europei del teatro di Goldoni e di Gozzi, Roma, Edizioni di storia e letteratura 2006, S. 259-275.

Scherer, Jacques, Théâtre et anti-théâtre au XVIIIle siècle, Oxford, Clarendon 1975 .

Schneiders, Werner, Aufkläung und Vorurteilskritik. Studien zur Geschichte der Vorurteilstheorie, Stuttgart-Bad Cannstatt, frommann-holzboog 1983 .

Schulz-Buschhaus, Ulrich, "Parinis Giorno und das Epos im Settecento", in: Susanne Knaller, Edith Mara (Hgg.), Das Epos in der Romania, Tübingen, Narr 1986, S. 357-372.

Semsch, Klaus, Abstand von der Rhetorik. Strukturen und Funktionen ästhetischer Distanznahme von der sars rhetoricac bei den französischen Enzyklopädisten, Hamburg, Meiner 1999.

Soldini, Fabio ( $\mathrm{Hg}$ ), Carlo Gozzi 1720-1806. Stravaganze sceniche, letterarie battaglie, Venezia, Marsilio 2006.

Souriau, Etienne, Les deux cent mille situations dramatiques, Paris, Flammarion t950.

Starobinski, Jean, sIronie et mélancolie (I): Le théâtre de Carlo Gozzi«, in: Critique 22,1966, S. 29i-308.

- Ironie et mélancolie (II): La Princesse Brambilla de E.T.A. Hoffmann «, in: Critique 22, 1966, S. $43^{8-457 .}$

- Ironie et mélancolie: Gozzi, Hoffmann, Kierkegaard «, in: Vittore Branca $(\mathrm{Hg})$, Sensibilità e razionalità nel Settecento, Venezia, Sansoni 1967, S. 423462.

Steinmetz, Jean-Luc, La littérature fantastique, Paris, PUF I990.

Stierle, Karlheinz, • Komik der Handlung, Komik der Sprachhandlung, Komik der Komödie, in: Wolfgang Preisendanz; Rainer Warning (Hgg.), Das Komische (Poetik und Hermeneutik VII), München, Fink 1976, S. 237-268.

Succi, Dario, =Larte dell'arte: i capricci veneziani del Settecento a, in: Dario Succi $(\mathrm{Hg})$, Capricci veneziani del Settecento, Ausstellungskatalog, Torino, Allemandi 1988, S. 13-38.

Taviani, Ferdinando, La Commedia dell'arte e la società barocca. La fascinazione del teatro, Roma, Bulzoni 1969.

-; Schino, Mirella, Il segreto della Commedia dell'arte, Firenze, Usher 1982.

Tessari, Roberto, Commedia dell'arte: la maschera e l'ombra, Milano, Mursia r981.

- Il testo e l'assenza. Carlo Gozzi e la Commedia dell'artea, in: Carlo Gozzi, La donna serpente, Genova, Edizioni del Teatro di Genova 1979, S. 42-69.

- Teatro e spettacolo nel Settecento, 2. Aufl., Roma, Laterza 1997.

Theile, Wolfgang, Carlo Goldoni. Gesammelte Aufsätze 1972-2002, Kritik - AnaIyse - Kontext, Hg. Irmgard Scharold, Essen, Die Blaue Eule 2002.

Todorov, Tzvetan, Introduction à la littérature fantastique, Paris, Seuil 1970.

Turchi, Roberta, La commedia italiana del Settecento, Firenze, Sansoni 1985.

Ubersfeld, Anne, Lire le théâtre I, durchgesehene Neuauflage, Paris, Belin 1996.

Ueding, Gert, >Rhetorik des Lächerlichen«, in: Lothar Fietz; Joerg O. Fichte; Hans-Werner Ludwig (Hgg.), Semiotik, Rhetorik und Soziologie des Lachens. 
Vergleichende Studien zum Funktionswandel des Lachens vom Mittelalter zur Gegenwart, Tübingen, Niemeyer 1996, S. 21-36.

Unfer Lukoschik, Rita, Der erste deutsche Gozzi. Untersuchungen zu der Rezeption Carlo Gozzis in der deutschen Spätaufklärung, Frankfurt am Main, Lang 1993.

- (Hg.), Elisabetta Caminer Turra (1751-1796). Una letterata veneta verso l'Europa, Verona, Essedue Edizioni 1998.

Vanore, Marta, ^Per l'edizione critica de La Marfisa Bizzarra di Carlo Gozzi«, in: Quaderni veneti 39, 2004, S. 29-63.

Vazzoler, Franco, sRuoli e recitazione nel Settecento: l'impossibile metamorfosi di Tartagliae, in: Carlo Gozzi, Re cervo, Teatro di Genova, Genova, Marietri 1991, S. 37-50.

- .Un napoletano a Venezia: Agostino Fiorilli (Tartaglia) fra Sacchi e Gozzix, in: Carmelo Alberti (Hg.), Carlo Gozzi, scrittore di teatro, Roma, Bulzoni 1996, S. $151-169$.

Venturi, Franco, Settecento riformatore, s Bde., Torino, Einaudi 1969-1990.

Vescovo, Piermario, $\approx \mathrm{L}$ a più lunga lettera di risposta che sia stata scritta .... Riflessioni sull'ultimo Gozzi๔, in: Bodo Guthmüller; Wolfgang Osthoff (Hgg.), Carlo Gozzi. Letteratura e musica, Roma, Bulzoni 1997, S. 119-140.

- La riforma nella tradizionea, in: Carlo Goldoni 1793-1993. Atti del Convegno del Bicentenario, Hgg. Carmelo Alberti, Gilberto Pizzamiglio, Venezia, Regione del Veneto I995, S. $137^{-1} 55$.

- Le riforme nella riforma. Preliminari goldoniani, in: Quaderni veneti 16, 1992, S, 119-152.

- Lo specchio e la lente. Il mondo dello spettatore ( $1760-62)$ a, in: Ilaria Crotti; Ricciarda Ricorda (Hgg.), Gasparo Gozzi. Il lavoro di un intellettuale nel Settecento veneziano, Padova, Antenore 1989 , S. $388-412$.

- Per la storia della commedia cittadina veneziana pregoldoniana «, in: Quadermi veneti 5 , 1987 , S. $37-80$.

- Per una lettura non evasiva delle Fiabe. Preliminaria, in: Carmelo Alberti (Hg.), Carlo Gozzi, scrittore di teatro, Roma, Bulzoni 1986, S. 171-213.

Vovelle, Michel (Hg.), Der Mensch der Aufklärung, Frankfurt, New York, Campus; Paris, Editions de la Fondation Maison des Sciences de l'Homme 1996.

Warning, Rainer, ×Diderot. Jacques le fataliste et son maitre", in: Klaus Heitmann (Hg.), Der französische Roman, Bd. 1 , Vom Mittelalter bis zur Gegenwart, Düsseldorf, August Bagel 1975, S. $210-233$.

- Elemente einer Pragmasemiotik der Komödie , in: Wolfgang Preisendanz; Rainer Warning (Hgg.), Das Komische (Poetik und Hermeneutik VII), München, Fink 1976, S. 279-333.

Wehle, Winfried, ^Vom Erhabenen oder über die Kreativität des Kreatürlichen«, in: Sebastian Neumeister (Hg.), Frühaufklärung, München, Fink 1994, S. 195240.

Winter, Susanne, "Das Theater im Kreuzfeuer der Kritik in Il Caffe, La Frusta letteraria, La Gazzetta veneta und L'Osservatore venetoa, in: Helmut Jacobs u. a. (Hgg.), Die Zeitschrift ,Il Caffè̀, Frankfurt am Main, Lang 2003, S. $253-276$.

- (Hg.), Il mondo e le sue favole. Sviluppi europei del teatro di Goldoni e di 
Gozzi / Inszenierte Wirklichkeit und Illusion. Zur europäischen Rezeption von Goldonis und Gozzis Theater, Roma, Edizioni di storia e letteratura 2006.

- "La polémique déguisée en conte de fées dramatisé. L'amore delle tre melarance et L'augellino belverde de Carlo Gozzic, in: Elisabeth Décultot; Mark Ledbury (Hgg.), Théories et débats esthétiques au dix-huitième siècle/Debates on Aesthetics in the Eighteenth Century, Paris, Champion 2001, S. 155-183.

- Tra ragione e passione. Turandot di Carlo Gozzi e di Friedrich Schiller«, in: Problemi di critica goldoniana VIII, 2001, S. 223-251.

- "Un cosi frivolo principio: L'amore delle tre melarance di Carlo Gozzi๔, in: Edoardo Sanguineti, L'amore delle tre melarance, un travestimento fiabesco dal canovaccio di Carlo Gozzi, Teatro di Genova, Genova, il melangolo 200 r, S. $15-28$.

Wolfzettel, Friedrich, „Der verzerrte Spiegel der höfischen Welt: Überlegungen zum historischen Standort des französischen Feenmärchens am Ende des 17. Jahrhunderts und im frühen 18 . Jahrhundert *, in: Sebastian Neumeister ( $\left.\mathrm{Hg}_{\mathrm{g}}\right)$, Frühaufklärung, München, Fink 1994, S. $241-286$.

Zorzi, Ludovico u. a. (Hgg.), I teatri pubblici di Venezia (secoli XVII-XVIII), Venezia 1971 .

- Il teatro e la città. Saggi sulla scena italiana, Torino, Einaudi 1977.

- I teatri di Venezia (secoli XVII-XVIII) «, in: ders. u. a. (Hgg.), I teatri pubblici di Venezia (secoli XVII-XVIII), Venezia r 971, S. 9-50.

- Struttura $\rightarrow$ Fortuna della fiaba gozziana «, in: Chigiana 31, 11, 1976, S. $25-$ 40. 



\section{VERZEICHNIS DER WERKE CARLO GOLDONIS}

Enea nel Lazio tos

I malcontenti $4^{8}$

I pettegolezzi delle Donne 253

Il bugiardo 157

Il campiello 86, 253

Il cavaliere di buon gusto 40

Il filosofo inglese $35 \mathrm{ff}$.

Il giuocatore 90

Il Moliere 35, 59

Il teatro comico $9,32,35,59 f$., 63 , $97,{ }_{44}$ f., $148,224,228,230$,

$232,235-239,241,249,251$, 289,306

Il vecchio bizzarro $89,226,289$

L'impresario delle Smirne 54,111

L'avventuriere onorato 36

L'incognita $32 \mathrm{f}$, 36

La birba 164
La bottega del caffè $87,90,25 \mathrm{I}$

La buona moglie $54,59 \mathrm{f}$.

La putta onorata 59,256

La sposa persiana $35 \mathrm{f}$., 101,276

La vedova scaltra $27,31 \mathrm{f} ., 85,313$

La villeggiatura 25, II 6

Le baruffe chiozzotte 76,86, I I6, 252,254

Le massere 86,253

Mémoires 20, 32, 40, 90, 101, 235, 240

Momolo cortigiano 65, 21 2, 234

La Pamela 35, 87, 197

Pamela maritata 36, 197, 25 If ., 313

Prefazione Bettinelli 28, 32, 34, 54, $63,65 f$., $71,212,224,232-235,237$, $239 f$., 247,270

Sior Todero Brontolon 116

Terenzio 35, 59 


\section{VERZEICHNIS DER WERKE CARLO GOZZIS}

Appendice al Ragionamento $\mathrm{I}_{4} 6, \mathrm{I}_{4} 8$, $211,241,246,250$

Canti due del ratto delle fanciulle castellane 19

Discorso, notizie, verità, e riflessi 39 , $45,47,114$

Fogli sopra alcune massime $67-72$, $106,108,110,114,160,256$

I pitocchi fortunati $73,117,132,140$, $154,157 f$., 160f., 279, 291, 295, $298-301,303$ f., $311-316$

I sudori d'Imeneo $19,4^{8-50,67}$

Il corvo $73,93,116-128,131 \mathrm{ff}, \mathrm{I}_{3} 8-$ 141,143 , $150 f$., 154,157 f., $160 \mathrm{ff}$., $165,204,207 \mathrm{ff}, 257,271,276$, $285 f$., 299, $316,320,324$ ff., 333

Il Fajel 260,264

Il mostro turchino $73,117,132,140$, $154,159,257,291-295,299,301$, 303, 312, 315f., 32 If., $324 \mathrm{ff}$.

Il re cervo $73,93,116-120,124$, I $26 \mathrm{ff}$., 13 Iff., 149 , I 54 f., $159 \mathrm{ff}$., $163,179,208 \mathrm{f}, 237,276,278,28 \mathrm{~s}$, $294,299,302-306,312,316 f ., 32$ I325,335

Il re de' genj (Zeim, Re dei genj) 73, $117,132,154,159,162,167,239$, $242,269,271,290,312,316-321$, $323 \mathrm{ff}, 327$

Il teatro comico all'Osteria del Pellegrino $19,44,54 \mathrm{f} ., 57-61,66 \mathrm{f} ., 71$, $249 \mathrm{ff}, 258,264$

L'amore delle tre melarance (Analisi riflessiva) $10,54,72-102,105,108$, III, II I - I19, I2I, I24, I26, I28, $133,135,137,149,152,154 f ., 160$,
$165 f ., 172,205,212,248,275,278-$ $28 \mathrm{I}, 285 \mathrm{f}$., $302,327 \mathrm{f}$., 335

L'augellino belverde $11,73,117,127$, $140,154,159,163 f$., $166 f$., 276,285 , $302 f ., 316,327-339$

La donna serpente $73,117,121,131$, $132,133,154,158,168-194,207 f$. , $249,255 f$., $271,276,278,290 f .$, 297, 301, 303, 307-312, 31 5f., 321f., 324 f., 336

La Marfisa bizzarra 87, 99, $105-111$, $173,259,323$

La più lunga lettera $117,211,227,243$, $256 f$., $259,272 f$., 284

La tartana $17,19-31,34,36,39 \mathrm{ff}, 44^{-}$ 48,53 ff., 58,62 ff., $67-70,74,84,89$, $10 \mathrm{I}, 103,107, \mathrm{III}_{1} \mathrm{II}_{4} \mathrm{f} ., 232$

La Zobeide $73,117,132,154,285,295-$ $298,301,311 \mathrm{f} ., 315 \mathrm{f} ., 322,324 \mathrm{f} ., 335$

Le spose riacquistate $19,52-55,99 \mathrm{f}$, 103

Manifesto del Co: Carlo Gozzi 211, 267

Memorie inutili $27,50,56,61,75,115$, I47, 149, 151, 204, 21 1, 226f., 229, 274,283 f., 295,306

Parere o sia lettera scritta da un'amico del Friuli $19,49 \mathrm{ff}$., 55

Ragionamento ingenuo $77,205,211$, $24 \mathrm{I}-244,25 \mathrm{I}, 253,25^{8-260,264}$, 268,284

Scrittura contestativa $19,44-48,54 \mathrm{f}$, $64,66 f ., 71,112,251$

Turandot 73, I16f., I26, $132 \mathrm{f}$, I54, Is $8 \mathrm{ff}$., 191, 207f., 276, 291, 303, $308 \mathrm{f} ., 312,316$ 


\section{NAMENREGISTER}

Albergati Capacelli, Francesco $\mathrm{Ir}$, 197

Ariosto, Ludovico 30, $50 \mathrm{f}$, $56,106 \mathrm{ff}$., $112,179,194,215,218,222,271$, 284

Arrighi Landini, Orazio $23 \mathrm{ff}, 30,107$

Baffo, Giorgio 37, 39

Baretti, Giuseppe $81,87,144$ f., 230 , 245,25 Iff., $275,277,283,304$

Basile, Giovan Battista $79 f ., 119 f$. , $123,126 f ., 129,131,160,327$

Beaumarchais, Pierre-Augustin Caron

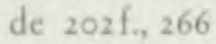

Becelli, Giulio Cesare $30,89,113$

Berni, Francesco $42,107,112,167$, 328

Bettinelli, Saverio $30,39,49-52,71$

Boiardo, Matteo Maria 80, 107 f., 171, 191, 194, 271

Boileau, Nicolas 30, sof. 114

Bordoni, Placido $39,67,69$

Bresciani, Caterina totff.

Burchiello $21 \mathrm{ff}, 29,4 \mathrm{If}, 46,64,70$, 101, 112

Calderón de la Barca, Pedro 15, 257

Calepio, Pietro $18,213 \mathrm{f}$.

Caminer Turra, Elisabetta 243 f., 246 , $258,260-266,275$

Caminer, Domenico $243 \mathrm{f}$.

Carli, Gian Rinaldo 213 f, 248,277

Cecchini, Pier Maria I53, 155

Cesarotti, Melchiorre 277

Chiari, Pietro 19, 21-40, 42f, 45, 47$50,52,54,57,6$ Iff., $65-71,73-76$, $79 f ., 83-91,93-106,109-116,149-$ $152,159 f ., 163,165,196 f ., 208,211$, $216,227-231,246-249,265,276$

Concina, Daniele 18,219

Cotta, Pietro 89, $2 \mathrm{I}_{4}$

Crotta, Sebastiano 19, $52 \mathrm{f}, 100$

Dante, Alighieri 42, 51 f., 56f., 60,64 , $70,80,114,119,160,212,297$
De Rossi, Gherardo 218

Delle Laste, Natale so

Diderot, Denis 252, 269, 271

Fagiuoli, Giovan Battista 151, 215218,289

Farsetti, Daniele 19f., $52 \mathrm{ff} ., 56,58$, 100

Federici, Camillo $228 \mathrm{f}$.

Forcellini, Marco so

Galland, Jean Antoine 127, 129, 131, 317

Gigli, Girolamo 215f., 218,236

Goldoni, Carlo s. Titelliste

Gozzi, Carlo s. Titelliste

Gozzi, Gasparo 37, 40, 52 f., 57, $67,73 \mathrm{f} ., 76,79,102,208 \mathrm{f}$., 229, 234,258 ,

$265,289,304$

Gravina, Gian Vincenzo 18, 212f., 277

Grazzini, Anton Francesco (gen. Il Lasca) $77,101,245$

Griselini, Francesco 30, 33, 112

Gritti, Francesco $227 \mathrm{ff}, 277$

Gueullette, Thomas-Simon 129 , $13 \mathrm{I}$

Imer, Giuseppe 27, 151, 153,227 Lesage, Alain-René $68,129,197$ Maffei, Scipione $18,50,213 \mathrm{ff}$., 219-224, 231, 234, 248, 257

Marcello, Benedetto 30,113

Martello, Pier Jacopo $18,21,30$, $113,213 f$, $220,222 \mathrm{f}, 232,247$, 271

Medebach, Girolamo 27, 32, 227f., 234

Mercier, Louis-Sebastien 241,263

Metastasio, Pietro $218,234,240$, 259

Molière 34, 202f., 216, 222, 275

Muratori, Ludovico Antonio 18 , $212,223 f, 248,269,278 f$. 
Nelli, Jacopo $215-218,236$

Parini, Giuseppe 90, 106, 113

Perrucci, Andrea 147, I53, I55, I58, 201

Pétis de la Croix, François I 29, I 3 If., I 92

Petrarca, Francesco 42, $56,64,167$, 328

Pulci, Luigi 21, 56, 70, 80, $106 \mathrm{ff} .$, I 12 , I94

Riccoboni, Luigi 89, $148,214 \mathrm{f} ., 219$ $224,232,245$
Sacchi, Antonio 28, 40, 53 f., 72, 74 f., $81,93,100-103,115,147-152$, 178f., 226-230, 237, 241, $246 \mathrm{f}$., 252 , $275,306,327$

Sarnelli, Pompeo 129, I3 1, 317, 327

Scala, Flaminio I3 I, I53, $197 \mathrm{ff}$.

Shakespeare, William I5, 92, 257, 259, 277

Sografi, Anton Simon 228

Valaresso, Zaccaria 190

Verri, Pietro 38, 265

Zeno, Apostolo $56,218,234,240$ 



\begin{tabular}{l}
$\begin{array}{l}\text { FWF-BIBLIOTHEK } \\
\text { InventarNr: } \\
\text { Standort: }\end{array}$ \\
\hline
\end{tabular}



Venedig war im 18 . Jahrhundert nicht nur ein Zentrum des Theatergeschehens, sondern zugleich Mittelpunkt lebendiger Theaterdiskussionen. Der sogenannte venezianische Theaterstreit mit den Protagonisten Carlo Goldoni und Carlo Gozzi erscheint in der Literatur- und Theatergeschichtsschreibung vielfach in Form einer vereinfachenden Reproduktion der Polemik. Wo Goldoni und die von ihm propagierte Theaterreform einseitig hoch geschätzt werden, überwiegt ein kritisch-negatives Gozzi-Bild, wo Gozzi als Retter der Commedia dell'arte verehrt wird, gilt Goldoni als ihr Totengräber.

Diese Studie versucht, derartige Vorurteile aufzubrechen und Carlo Gozzis Fiabe teatrali als veritablen Gegenentwurf zu Goldonis Komödien und zum aufklärerischen Drama zu verstehen. Vor dem Hintergrund des italienischen Theaterkontexts im 18. Jahrhundert und der venezianischen Theaterszene der Zeit treten die Besonderheit der Märchenstücke und die Modernität der Konzeption Gozzis deutlich zutage. In einer Art ars combinatoria setzen die Fiabe teatrali die Problematik der Erkenntnis von Wahrheit in Szene und eröffnen einen Blick auf den Konstruktcharakter von Wirklichkeit. So ist es nicht verwunderlich, daß Gozzi zum Bezugspunkt für eine (Re-)Theatralisierung des Theaters im I9. und 20. Jahrhundert wurde. 